\title{
C-H Activation for Sustainable Synthesis: Base Metal- and Electro-Catalysis
}

\author{
Dissertation \\ for the award of the degree \\ "Doctor rerum naturalium" \\ of the Georg-August-University of Göttingen

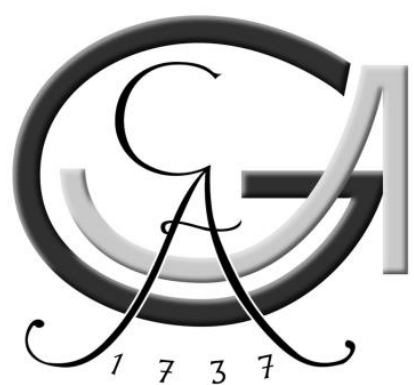

within the doctoral program

„Catalysis for Sustainable Synthesis” (CaSuS)

of the Georg-August-University School of Science (GAUSS)

submitted by

Nicolas Sauermann

from Lindlar

Göttingen, 2018 



\section{Thesis Committee}

Prof. Dr. Lutz Ackermann, Institute of Organic and Biomolecular Chemistry, Göttingen

Prof. Dr. Konrad Koszinowski, Institute of Organic and Biomolecular Chemistry, Göttingen

Prof. Dr. Matthias Tamm, Institute for Inorganic and Analytical Chemistry, Braunschweig

\section{Examination Board}

Reviewer: Prof. Dr. Lutz Ackermann, Institute of Organic and Biomolecular Chemistry Second Reviewer: Prof. Dr. Konrad Koszinowski, Institute of Organic and Biomolecular Chemistry

\section{Further Members of the Examination Board}

Prof. Dr. Dietmar Stalke, Institute of Inorganic Chemistry

PD Dr. Alexander Breder, Institute of Organic and Biomolecular Chemistry

Dr. Shoubhik Das, Institute of Organic and Biomolecular Chemistry

Dr. Franziska Thomas, Institute of Organic and Biomolecular Chemistry

Date of the Oral Examination: $03.07 .2018,10.30$. 



\section{Acknowledgement}

Zuallererst gebührt an dieser Stelle Dank meinem Doktorvater Professor Lutz Ackermann für die Möglichkeit die vorliegende Arbeit unter seiner Anleitung anzufertigen. Neben der stets freundlichen und fachlich exzellenten Beratung sowie der Sicherstellung einer optimalen Ausstattung, ist es vor allem seine Art und Weise eine große, internationale Gruppe zu einem Team zu formen die erwähnt werden sollte.

Weiterhin danke ich Prof. Konrad Koszinowski und Prof. Matthias Tamm für die Bereitschaft die Betreuung dieser Arbeit im Rahmen des CaSuS Promotionsprogramms zu übernehmen sowie Prof. Dietmar Stalke, Dr. Alexander Breder, Dr. Shoubhik Das und Dr. Franziska Thomas für ihre Teilnahme im Rahmen der Prüfungskommission.

Auch bei den analytischen Abteilungen hier im Haus möchte ich mich für die gewissenhafte Bearbeitung aller Messaufträge bedanken, ebenso wie für die kompetente Beratung bei analytischen Problemen jeder Art.

Ich danke dem gesamten AK Ackermann für die überrragende Arbeitsatmosphäre und die vielen kleinen Dinge, die die letzten Jahre bereichert haben.

Vor allem Gabi, für die Hilfe bei allen bürokratischen Herausforderungen, Karsten für die zuverlässige Bereitstellung von Chemikalien und Glasgeräten sowie Stefan für die kleineren und größeren Reparaturen, die alles am Laufen halten.

Ein ganz besonderer Dank gebührt allen Kollegen, mit denen ich die letzten Jahre verbringen durfte, allen voran Marc, Svenja, Ralf, Torben, Julian, Thomas, Alan und Tjark. Auch ein herzlicher Dank geht an Maria und Elisabetta, für die gemeinsamen Projekte. Leo, Julian, Valentin, Torben und Tjark danke ich für die äußerst gewissenhafte Korrektur dieser Arbeit.

Mein größter Dank gebührt jedoch meiner Familie, die mich während der Studienzeit und auch in der Promotion immer bedingungslos unterstützt hat und ohne die dies alles nie möglich gewesen wäre. Zum Schluss danke ich noch meiner liebsten Jasmin, für die stete Unterstützung, Geduld und ihre Liebe 



\section{Contents}

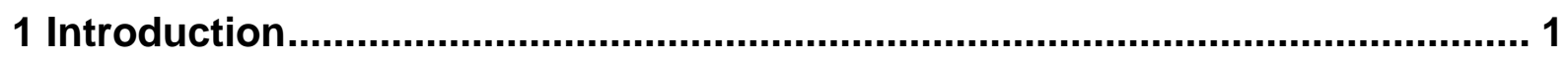

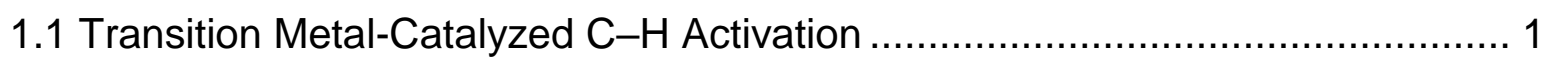

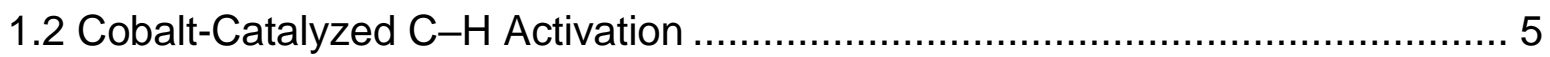

1.2.1 C-H Activation with Well-Defined Cobalt Complexes ............................... 6

1.2.2 C-H Activation using Low-Valent Cobalt Catalysis ................................. 8

1.2.3 C-H Activation using High-Valent Cobalt Catalysis ................................. 15

1.2.4 Oxidative C-H Activation using Cobalt Salts......................................... 21

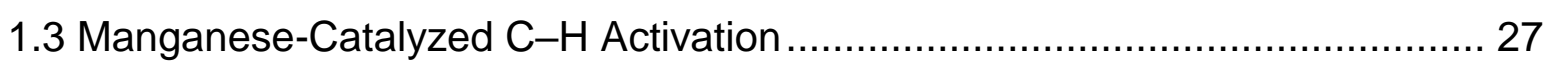

1.4 Electrochemical Transition Metal-Catalyzed C-H Activation .......................... 31

1.4.1 Palladium-Catalyzed Transformations ............................................... 33

1.4.2 Transformations Catalyzed by other Transition Metals ........................... 37

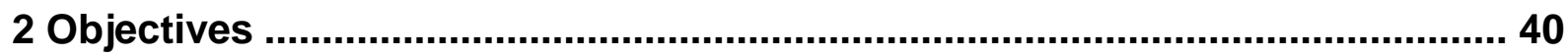

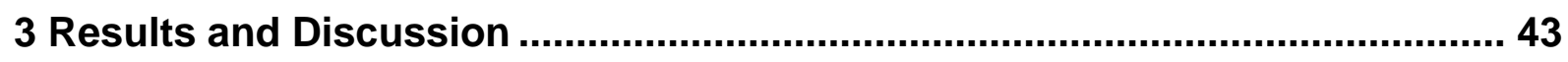

3.1 Cobalt-Catalyzed Alkenylation under Triazolylidene-Assistance by $\mathrm{C}-\mathrm{H} / \mathrm{C}-\mathrm{O}$

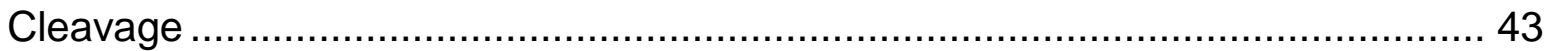

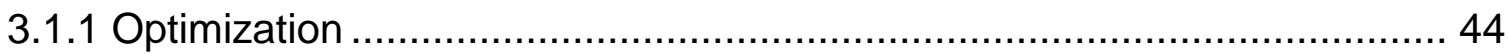

3.1.2 Scope of the Cobalt-Catalyzed Alkenylation using Alkenyl Phosphates ... 46

3.1.3 Scope of the Cobalt-Catalyzed Alkenylation using Alkenyl Acetates ........ 49

3.1.4 Mechanism of the Cobalt-Catalyzed Alkenylation .................................. 54

3.2 Cobalt-Catalyzed Allylation using Allyl Acetates......................................... 55

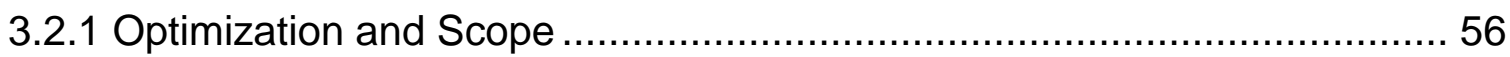

3.3 Base Metal-Catalyzed C-H Alkynylation ………..................................... 58

3.3.1 Optimization of the Cobalt-Catalyzed C-H Alkynylation.......................... 58

3.3.2 Scope of the Cobalt-Catalyzed C-H Alkynylation .................................. 60

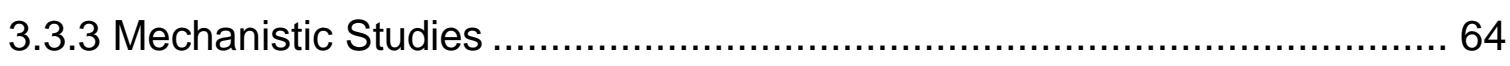

3.3.4 Proposed Catalytic Cycle .................................................................. 65

3.3.5 Diversification of the Alkynylated Indoles …...........................................6 66

3.3.6 Optimization of the Manganese-Catalyzed C-H Alkynylation .................. 67

3.3.7 Scope of the Manganese-Catalyzed C-H Alkynylation ........................... 70

3.3.8 Mechanistic Studies for the Manganese-Catalyzed Alkynylation .............. 75

3.4 Electrochemical Cobalt-Catalyzed C-H Oxygenation ................................ 79

3.4.1 Optimization of the Cobalt-Catalyzed Electrochemical C-H Oxygentation 79

3.4.2 Scope of the Cobalt-Catalyzed Electrochemical C-H Oxygentation 
3.4.3 Mechanistic Studies and Proposed Mechanism.................................... 92

3.5 Electrochemical Cobalt-Catalyzed C-H Amination...................................... 97

3.5.1 Optimization of the Cobalt-Catalyzed Electrochemical C-H Amination.... 97

3.5.2 Scope of the Electrochemical Cobalt-Catalyzed C-H Amination ............ 102

3.5.3 Mechanistic Studies and Proposed Mechanism ................................... 109

3.6 Mechanistic Studies on Transititon Metal-Catalyzed Electrochemical C-H Activation.

3.6.1 Cobalt-Catalyzed Electrochemical Annulation of Terminal and Internal Alkynes using an Electrocleavable Directing Group...................................... 115

3.6.2 Rhodium-Catalyzed C-H/O-H Annulation of Benzoic Acids .................. 119

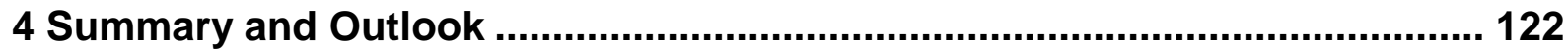

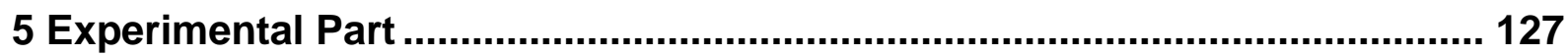

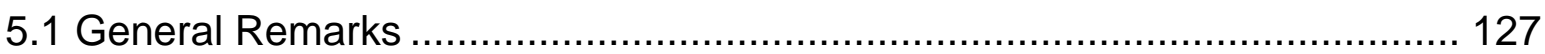

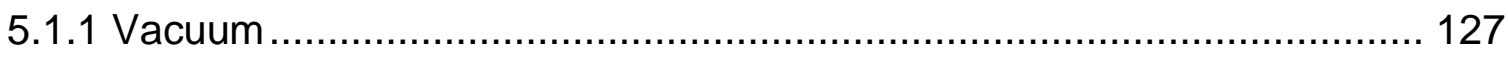

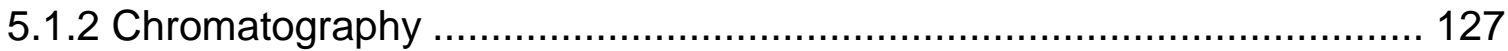

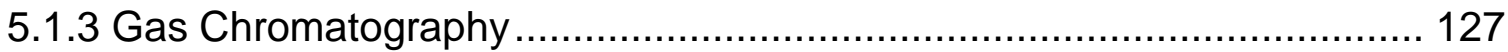

5.1.4 Nuclear Magnetic Resonance ....................................................... 128

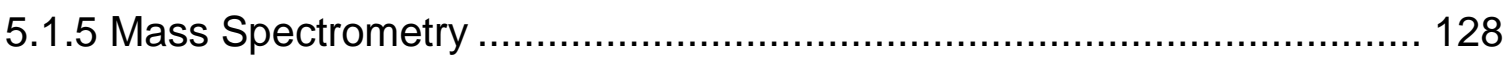

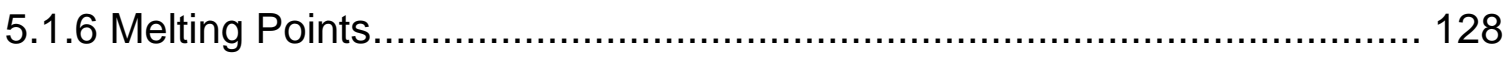

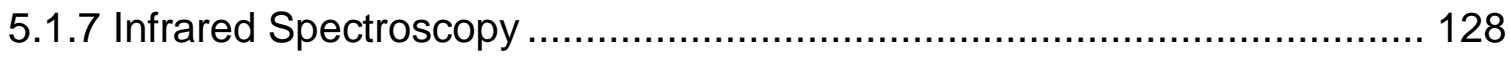

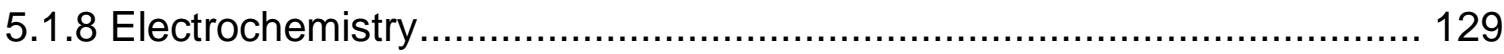

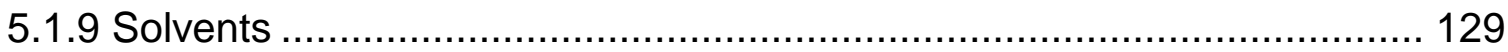

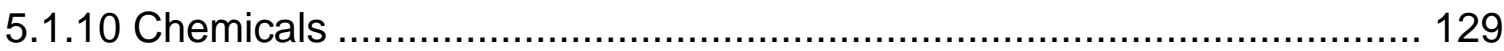

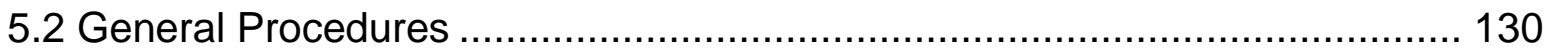

5.3 Cobalt-Catalyzed C-H Alkenylation under Triazole Assistance ................... 133

5.3.1 Analytical Data and Experimental Procedures .................................... 133

5.4 Cobalt-Catalyzed Allylation of Indoles .................................................. 146

5.4.1 Analytical Data and Experimental Procedures ................................... 146

5.5 Base-Metal Catalyzed C-H Alkynyaltion .................................................. 149

5.5.1 Analytical Data and Experimental Procedures .................................... 149

5.5.2 Mechanistic Experiments for the Cobalt Catalysis .............................. 165

5.5.3 Mechanistic Experiments for the Manganese Catalysis .......................... 167

5.6 Electrochemical Cobalt-Catalyzed C-H Oxygenation ................................. 177

5.6.1 Analytical Data and Experimental Procedures .................................... 177

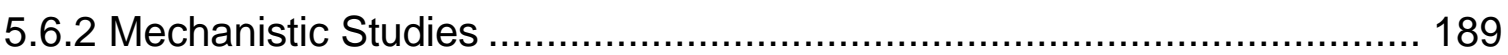


5.7 Electrochemical Cobalt-catalyzed C-H Amination ....................................... 199

5.7.1 Analytical Data and Experimental Procedures .................................... 199

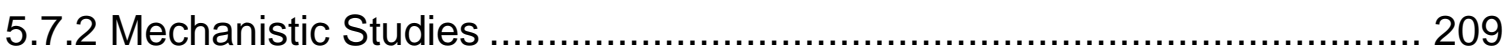

5.8 Mechanistic Experiments for Electrochemical C-H Activation...................... 215

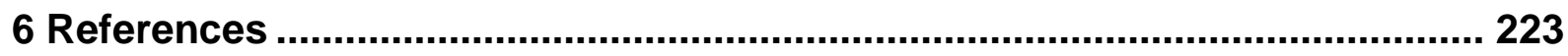




\section{List of Abbreviations}

\begin{tabular}{ll} 
Ac & acetyl \\
acac & acetylacetonate \\
Alk & alkyl \\
AMLA & ambiphillic metal-ligand activation \\
aq & aqueous \\
Ar & aryl \\
atm & atmospheric pressure \\
BIES & base-assisted internal electrophilic substitution \\
Bn & benzyl \\
Boc & tert-butyloxycarbonyl \\
Bu & butyl \\
calc. & calculated \\
cat. & catalytic \\
CCE & constant current electrolysis \\
CMD & concerted metalation deprotonation \\
Cp & cyclopentadienyl \\
Cp* & pentamethylcyclopentadienyl \\
CV & cyclic voltammetry \\
Cy & chemical shift \\
d & doublet \\
DCE & i,dichloroethane \\
\hline
\end{tabular}


doublet of doublets

DG

directing group

DMF

$N, N$-dimethylformamide

DMSO dimethylsulfoxide

$d t$

doublet of triplets

ee

enantiomeric excess

El

electron ionization

equiv

equivalent

ESI

electrospray ionization

Et

ethyl

g

gram

GC

gas chromatography

$\mathrm{h}$

hour

HFIP

1,1,1,3,3,3-hexafluoro-2-propanol

HRMS

high resolution mass spectrometry

$\mathrm{Hz}$

Hertz

i

iso

IMes

1,3-bis(2,4,6-trimethylphenyl)imidazole-2-ylidene

$\mathrm{IPr}$

1,3-bis(2,6-iso-propylphenyl)imidazole-2-ylidene

IR

infrared spectroscopy

$J$

coupling constant

KIE

kinetic isotope effect

L

ligand

$m$

meta

m

multiplet 


\begin{tabular}{|c|c|}
\hline M & molar \\
\hline$[\mathrm{M}]^{+}$ & molecular ion peak \\
\hline $\mathrm{mA}$ & milliampere \\
\hline Me & methyl \\
\hline Mes & mesityl \\
\hline $\mathrm{mg}$ & milligram \\
\hline $\mathrm{MHz}$ & megahertz \\
\hline $\min$ & minute \\
\hline $\mathrm{mL}$ & milliliter \\
\hline $\mathrm{mmol}$ & millimole \\
\hline M. p. & melting point \\
\hline MS & mass spectrometry \\
\hline$m / z$ & mass to charge ratio \\
\hline napht & naphthenate \\
\hline NCTS & $N$-cyano-4-methyl- $N$-phenyl-benzenesulfonamide \\
\hline $\mathrm{NHC}$ & $\mathrm{N}$-heterocyclic carbene \\
\hline NMR & nuclear magnetic resonance \\
\hline 0 & ortho \\
\hline ox & oxalate \\
\hline$p$ & para \\
\hline $\mathrm{Ph}$ & phenyl \\
\hline PIP & (2-pyridin-2-yl)isopropylamine \\
\hline Piv & pivaloyl \\
\hline ppm & parts per million \\
\hline $\mathrm{Pr}$ & propyl \\
\hline
\end{tabular}




$\begin{array}{ll}\text { Py } & \text { pyridyl } \\ \text { PyO } & \text { pyridine- } N \text {-oxide } \\ \text { q } & \text { quartet } \\ \text { Q } & \text { 8-aminoquinoline } \\ \text { RT } & \text { room temperature } \\ \text { RVC } & \text { Reticulated vitreous carbon } \\ \text { S } & \text { singlet and second } \\ \text { SET } & \text { single electron transfer } \\ \text { SPS } & \text { solvent purification system } \\ t & \text { tert } \\ \text { t } & \text { triplet } \\ T & \text { temperature } \\ \text { TEMPO } & 2,2,6,6 \text {-tetramethylpiperidine- } N \text {-oxide } \\ \text { TFE } & 2,2,2-\text { trifluoroethanol } \\ \text { THF } & \text { tetrahydrofuran } \\ \text { TIPS } & \text { tri-iso-propylsilyl } \\ \text { TLC } & \text { thin layer chromatography } \\ \text { TM } & \text { transition metal } \\ \text { TMS } & \text { trimethylsilyl } \\ \text { TS } & \text { Volt } \\ \text { X } & \text { pseudo-)halide } \\ & \end{array}$




\section{Introduction}

In the last century, organic synthesis has made tremendous progress, which has affected the daily lives of billions of people. Valuable products of organic synthesis are used for a wide range of applications ranging from pharmaceuticals and cropprotection agents to functional materials, such as OLEDs, coloring agents and polymers. ${ }^{[1]}$ Although these products unarguably present a huge benefit in their diverse applications, their synthesis is associated with a number of drawbacks, for example a huge amount of toxic waste, the depletion of limited natural resources and overall high energy consumption. ${ }^{[2]}$

Therefore, in 1998, Anastas and Warner proposed their 12 Principles of green chemistry, ${ }^{[3]}$ which outlined ways to reduce the ecological footprint of organic synthesis and minimize the amounts of byproducts and waste. Among them are the use of catalytic transformations, avoidance of unnecessary prefunctionalization and auxiliaries to increase the atom economy, use of mild reaction conditions (e.g. ambient temperature) and renewable sources for chemicals and the use of nontoxic reagents and solvents.

\subsection{Transition Metal-Catalyzed C-H Activation}

Although the beginnings of transition metal-catalyzed coupling chemistry ${ }^{[4]}$ can be traced back to inter alia the early copper-catalyzed reactions by Glaser ${ }^{[5]}$ and Ullmann, ${ }^{[6]}$ it was not until the discovery of palladium-catalyzed cross-couplings that these transformations found considerable use in organic synthesis. ${ }^{[7]}$ However, once established, palladium-catalyzed cross-coupling chemistry soon became the benchmark process for the formation of $\mathrm{C}-\mathrm{C}$ and $\mathrm{C}-\mathrm{Het}$ bonds. In time, a wide range of methods using different organometallic coupling partners were realized, resulting in a range of well-known named reactions, such as Suzuki-Miyaura, ${ }^{[8]}$ Negishi, ${ }^{[9]}$ Kumada-Corriu, ${ }^{[10]}$ Hiyama, ${ }^{[11]}$ Stille ${ }^{[12]}$ and Sonogashira-Hagihara ${ }^{[13]}$ cross coupling reactions. Furthermore, although not a cross coupling reaction its traditional sense, the Mizoroki-Heck ${ }^{[14]}$ reaction and the Buchwald-Hartwig amination ${ }^{[15]}$ should be mentioned as milestones in palladium-catalyzed chemistry. These important 
contributions were recognized with the award of the Chemistry Nobel Prize to Heck, Negishi and Suzuki in 2010. ${ }^{[16]}$

Despite recent efforts to render cross-coupling chemistry more environmentally benign and cost effective by the use of earth-abundant metals, such as iron ${ }^{[17]}$ or nickel, ${ }^{[18]}$ and the use of renewable solvents, ${ }^{[19]}$ the major drawback of cross-coupling chemistry remains, namely the need for prefunctionalized starting materials. Moreover, these materials are in most cases either not stable under ambient conditions (Grignard reagents, organolithium and organozinc compounds) or toxic (organotin compounds). Therefore, the direct functionalizations of $\mathrm{C}-\mathrm{H}$ bonds is extremely desirable in terms of the step- and atom-economy of organic syntheses (Scheme 1.1).[20]

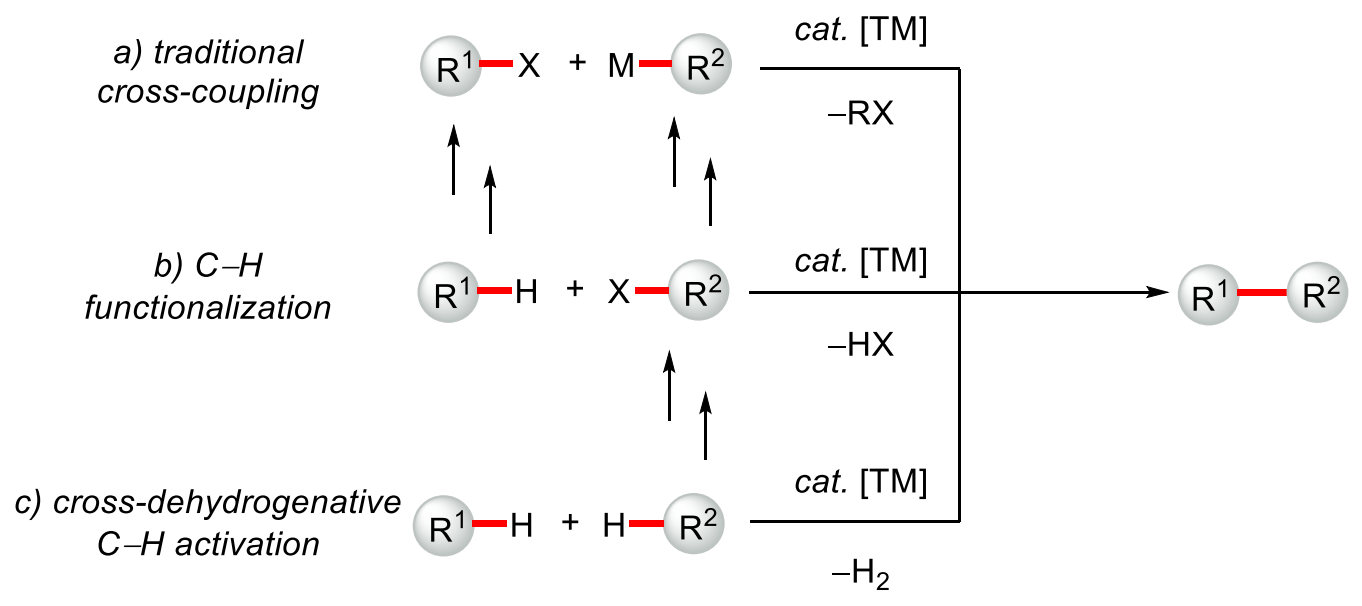

Scheme 1.1. Comparison of traditional cross-coupling chemistry versus $\mathrm{C}-\mathrm{H}$ activation.

While the most atom efficient reaction is in principle the cross-dehydrogenative $\mathrm{C}-\mathrm{H}$ activation, which formally only generates hydrogen as a byproduct, these reactions suffer from the need for a stoichiometric oxidant, resulting in additional waste (Scheme 1.1c). Moreover, common oxidants include expensive and toxic silver(I) and copper(II) salts. While direct $\mathrm{C}-\mathrm{H}$ functionalization using organic electrophiles requires a degree of prefunctionalization in one coupling partner (Scheme 1.1b), the substance classes most often employed, organic halides and phenol derivatives are accessible within a reasonable number of steps and largely stable under ambient conditions. ${ }^{[21]}$ Traditional cross-coupling meanwhile (Scheme 1.1a) does not only require an electrophilic coupling partner, but also an additional nucleophilic organometalic reagent.

In contrast to traditional cross-coupling reactions, $\mathrm{C}-\mathrm{H}$ functionalization faces an additional challenge besides the activation of otherwise inert $\mathrm{C}-\mathrm{H}$ bonds. While the new connection in cross-coupling chemistry is clearly defined by the substitution 
pattern of the electrophile and nucleophile, organic molecules contain a large number of $\mathrm{C}-\mathrm{H}$ bonds with similar bond dissociation energies $\left(113.5 \mathrm{kcal} / \mathrm{mol}\right.$ for $\mathrm{C}\left(\mathrm{sp}^{2}\right)-\mathrm{H}$ bonds in benzene). ${ }^{[22]}$ This problem can be overcome in mainly three ways: ( $I$ ) the use of electronically activated substrates, where one $\mathrm{C}-\mathrm{H}$ bond has a higher kinetic acidity than the others, (ii) steric shielding of $\mathrm{C}-\mathrm{H}$ bonds where the reaction is undesired and (iii) the use of lewis-basic directing groups (DG) to coordinate to the transition metal catalyst in close proximity to the $\mathrm{C}-\mathrm{H}$ bond to be functionalized (Scheme 1.2). ${ }^{[23]}$

a) Differentiation of $\mathrm{C}-\mathrm{H}$ bonds

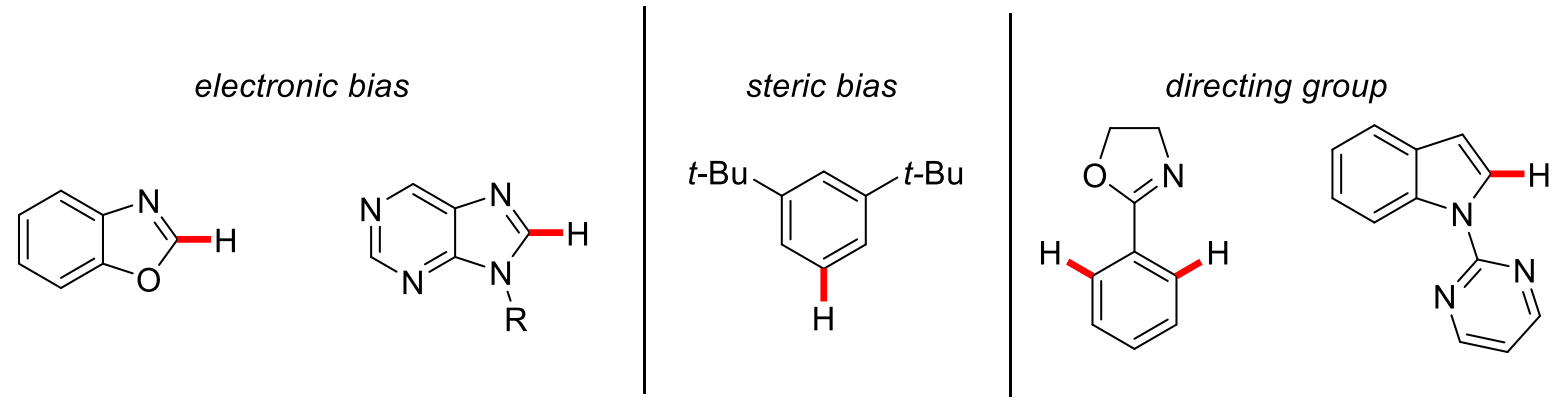

b) Influence of the directing group (DG)

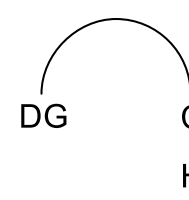

Scheme 1.2. a) Differentiation of $\mathrm{C}-\mathrm{H}$ bonds.

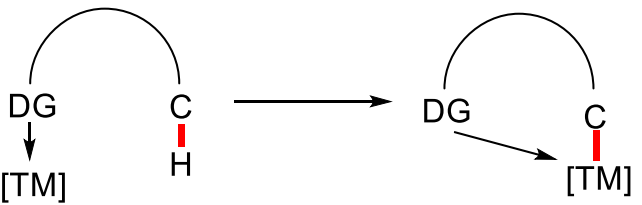

While the first two options are severely limited in substrate scope, the directing group approach shows tremendous potential. This holds especially true if the directing group is an important building block of the target molecule or is easily removed or modified. [24] The key step for $\mathrm{C}-\mathrm{H}$ functionalization reactions is often the cleavage of the $\mathrm{C}-\mathrm{H}$ bond itself. Therefore, $\mathrm{C}-\mathrm{H}$ bond cleavage was and still is studied in close detail, resulting in different modes of action being identified (Scheme 1.3). ${ }^{[25]}$ 


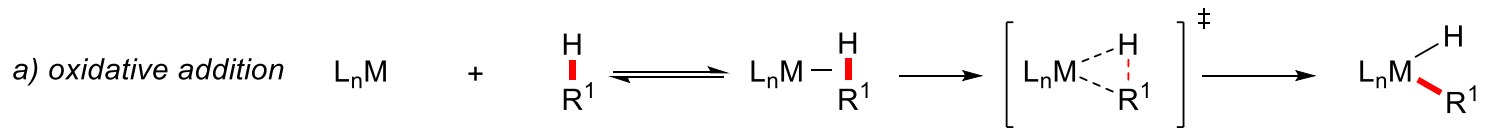

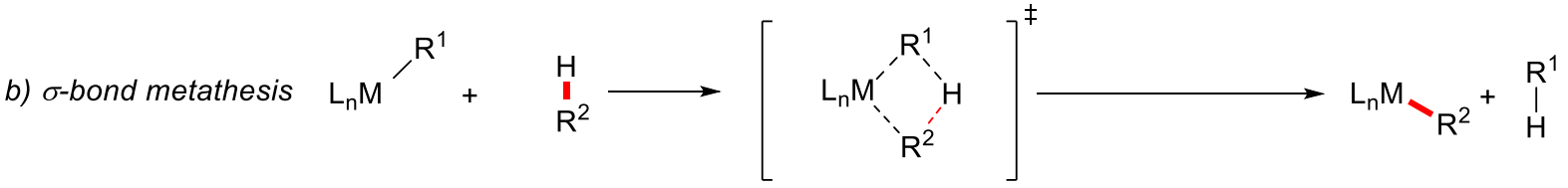

c) 1,2-addition<smiles>[Y][Y10]#[W]</smiles>

d) electrophilic

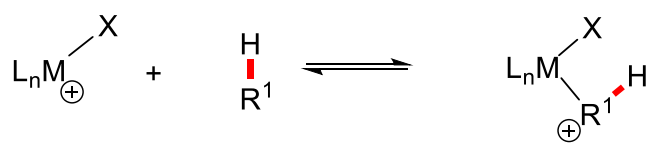

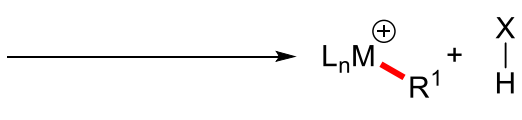

e) base-assisted

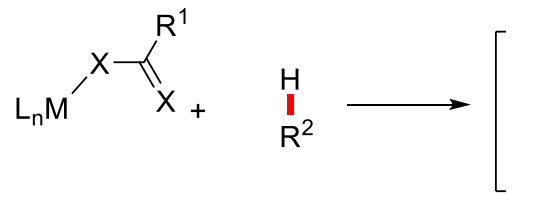

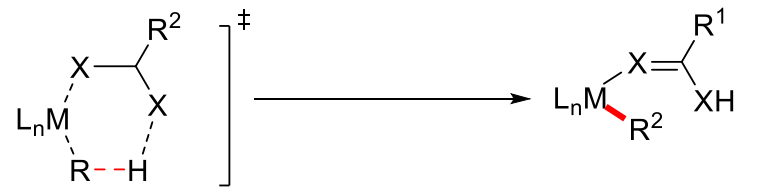

Scheme 1.3. Modes of action for various $\mathrm{C}-\mathrm{H}$ cleavage mechanisms under transition metal assistance.

Oxidative addition to cleave $\mathrm{C}-\mathrm{H}$ bonds was mostly observed with electron-rich complexes of late transition metals. ${ }^{[25 a]}$ For early transition metals with $\mathrm{d}^{0}$-configuration, this mode of action is obviously not feasible. In contrast, $\sigma$-bond metathesis and 1,2addition are possible ways to achieve $\mathrm{C}-\mathrm{H}$ activation with early transition metals, ${ }^{[25 b]}$ while electrophilic substitution was proposed for cationic complexes of late transition metals. ${ }^{[25 c]}$ In recent years, base-assisted $\mathrm{C}-\mathrm{H}$ activation has gained traction as a model for $\mathrm{C}-\mathrm{H}$ cleavage in $\mathrm{C}-\mathrm{H}$ functionalizations using basic additives. ${ }^{[25 a]}$

This base-assisted $\mathrm{C}-\mathrm{H}$ cleavage was the object of further research, resulting in the proposal of several transition states (Scheme 1.4).<smiles>[R]O[M]1CCCC1[R]</smiles>

IES

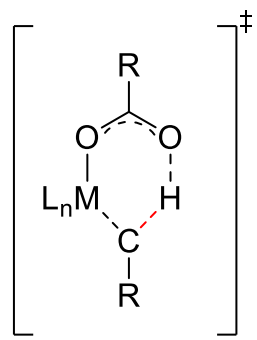

CMD

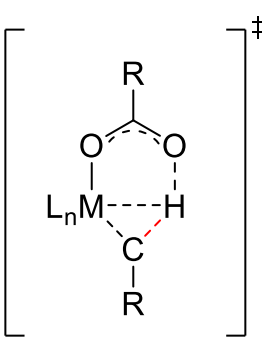

AMLA

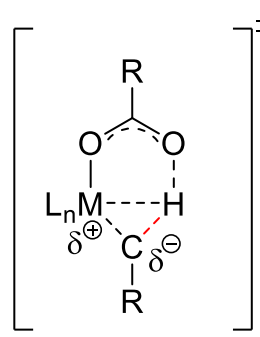

BIES

Scheme 1.4. Transition state models for base-assisted $\mathrm{C}-\mathrm{H}$ metalation.

Intramolecular electrophilic substitution (IES), ${ }^{[26]}$ the mechanism for alkoxide bases relies on a highly strained, thus high-energy four-membered ring transition state. 
Concerted metalation-deprotonation (CMD) ${ }^{[27]}$ and ambiphillic metal-ligand activation $(A M L A)^{[28]}$ were disclosed independently and describe the interaction of metal, carboxylate-ligand and $\mathrm{C}-\mathrm{H}$ bond especially for electron-deficient substrates. In contrast, base-assisted internal substitution (BIES) ${ }^{[29]}$ was proposed to explain the preferred reactivity of electron-rich substrates in several transformations.

Despite tremendous progress in the recent decades regarding $\mathrm{C}-\mathrm{H}$ activation, $\left.{ }^{44}, 30\right]$ most of these advances were realized using cost-intensive and toxic $4 d$ and $5 d$ transition metals, such as rhodium, ${ }^{[31]}$ iridium, ${ }^{[32]}$ palladium ${ }^{[33]}$ and ruthenium. ${ }^{[34]}$ Here, new opportunities remain for the development of $3 \mathrm{~d}$ transition metal-catalyzed $\mathrm{C}-\mathrm{H}$ activation with possible benefits due to the significantly lower toxicity, abundance and lower price of the employed metal catalysts.

\subsection{Cobalt-Catalyzed C-H Activation}

Cobalt is one of the more abundant elements in the earth crust, with a concentration of approximately $25 \mathrm{ppm}$, compared to $1 \mathrm{ppb}$ for noble metals, such as iridium and rhodium. ${ }^{[35]}$ The result is a relatively low price for cobalt salts, which makes the use of cobalt as a catalyst quite attractive. ${ }^{[36]}$

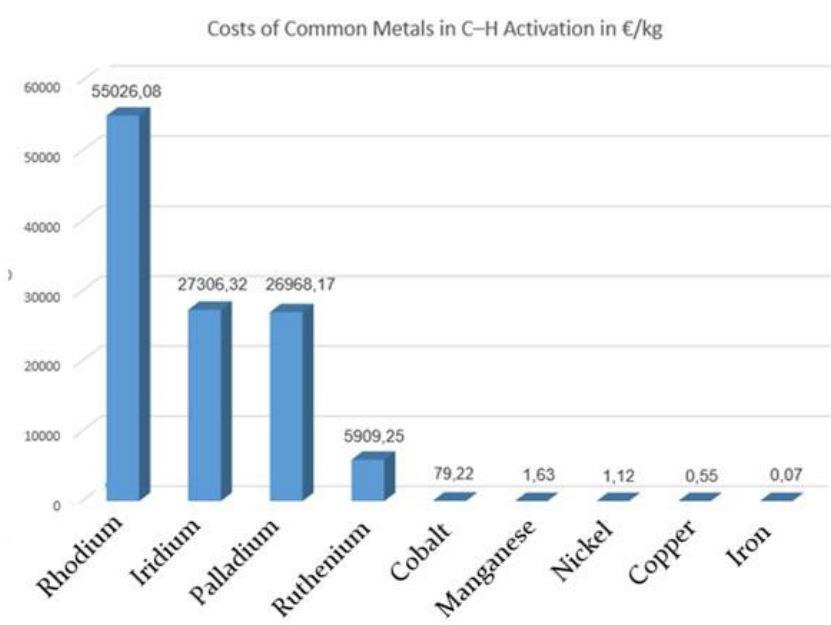

Figure 1.1. Prices of metals in $\mathrm{C}-\mathrm{H}$ activation.

Therefore, a wide range of transformations are known employing cobalt catalysis, such as hydroformylation, ${ }^{[37]}$ the Bönnemann pyridine synthesis, ${ }^{[38]}$ the Pauson-Khand reaction, ${ }^{[39]}$ the Jacobsen kinetic resolution of epoxides ${ }^{[40]}$ and the coupling of Grignard reagents in the Kharash-coupling, ${ }^{[41]}$ to name a few examples. 
Indeed, even cobalt-catalyzed $\mathrm{C}-\mathrm{H}$ activation is not a new concept, and the groundbreaking work published by Murahashi in 1955 is not only the first catalytic $\mathrm{C}-\mathrm{H}$ activation with cobalt, but among the first examples of $\mathrm{C}-\mathrm{H}$ activation in general (Scheme 1.5). ${ }^{[42]}$ Although the reaction proceeded under harsh conditions and the scope was severely limited, it highlighted the use of simple and stable cobalt complexes as catalysts.
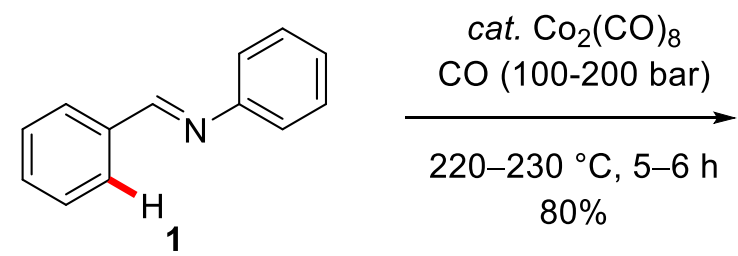<smiles>O=C1c2ccccc2CN1c1ccccc1</smiles>
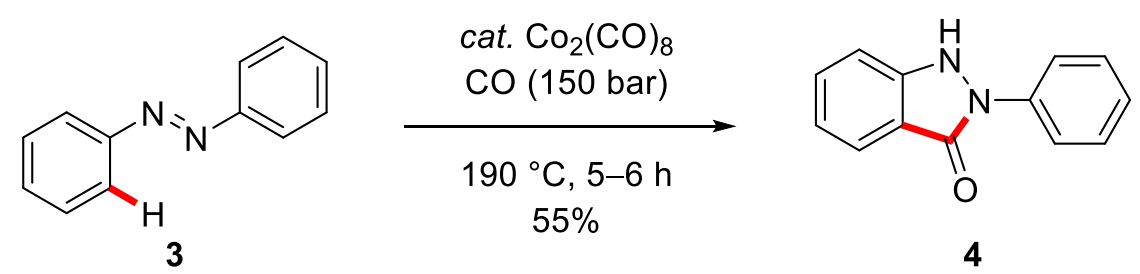

Scheme 1.5. Murahashis cobalt-catalyzed carbonalytion of benzaldimine 1 and azobenzene $3 .{ }^{[42]}$

Despite these early advances, cobalt-catalyzed $\mathrm{C}-\mathrm{H}$ activation did not receive much attention for the next decades. The recent progress in the field will be discussed in the next chapters. For this thesis, cobalt-catalyzed $\mathrm{C}-\mathrm{H}$ activation will be divided into four parts: (i) C-H activation with well-defined complexes, (ii) low-valent cobalt-catalyzed $\mathrm{C}-\mathrm{H}$ activation, (iii) $\mathrm{Cp}^{*} \mathrm{Co}(\mathrm{III})$-catalyzed $\mathrm{C}-\mathrm{H}$ activation and (iv) oxidative $\mathrm{C}-\mathrm{H}$ activation using simple cobalt salts.

\subsubsection{C-H Activation with Well-Defined Cobalt Complexes}

In the early 1990s, Klein showed in a stoichiometric reaction that the cobalt phosphine complex 5 was able to metalate $\mathrm{C}-\mathrm{H}$ bonds of several substrates (Scheme 1.6). ${ }^{[43]}$ Besides the depicted five-membered species, ${ }^{[43 a-d, 43 f]}$ four-[ ${ }^{[3 e]}$ and six-membered ${ }^{[43 d]}$ rings could also be obtained. 


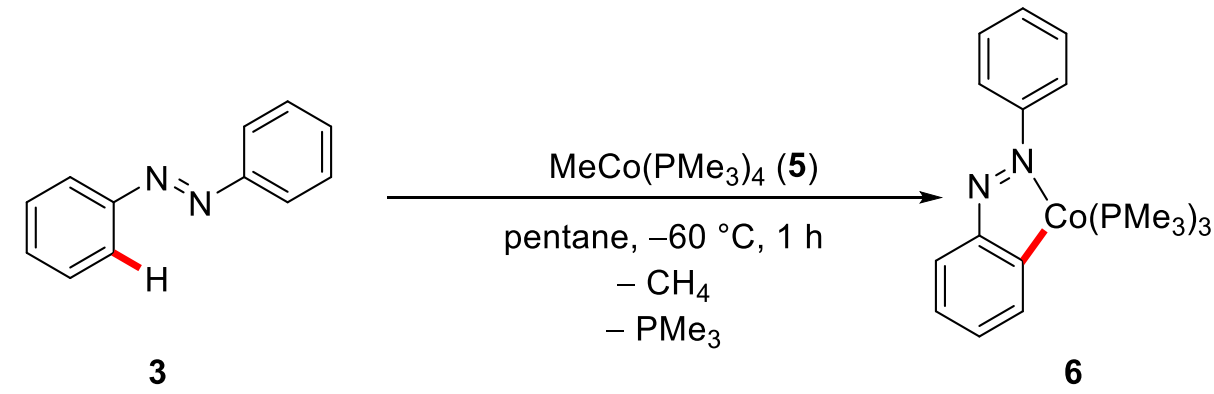

Scheme 1.6. Stoichiometric $\mathrm{C}-\mathrm{H}$ metalation using complex 5. ${ }^{[43 f]}$

Furthermore, Brookhart disclosed that well-defined cobalt ethylene complex 7 enabled deuterium scrambling if heated in benzene- $d 6$. Through various steps of insertion and elimination, the completely deuterated complex $[\mathrm{D}]_{8}-7$ was thereby available (Scheme 1.7). ${ }^{[44]}$

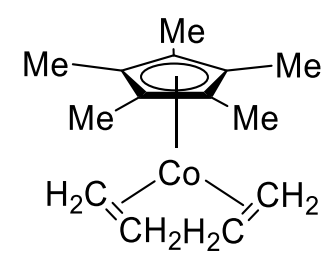

7

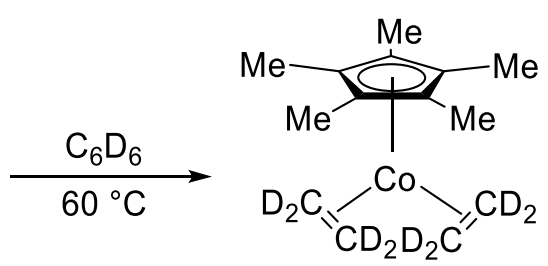

$[\mathrm{D}]_{8}-7$

Scheme 1.7: $\mathrm{H} / \mathrm{D}$ scrambling in Brookhart's complex 7. ${ }^{[44]}$

In a groundbreaking contribution, Kisch reported on the hydroarylation of alkynes $\mathbf{8}$ with catalytic amounts of cobalt-hydride complex $9 .{ }^{[45]}$ Although limited in scope and practicability, this work presented the first substoichiometric use of a well-defined cobalt(I) complex in $\mathrm{C}-\mathrm{H}$ activation (Scheme 1.8).<smiles>C(#Cc1ccccc1)c1ccccc1</smiles>

3

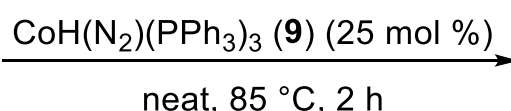
neat, $85^{\circ} \mathrm{C}, 2 \mathrm{~h}$<smiles>C(=C(c1ccccc1)c1cccc(/C(=C\c2ccccc2)c2ccccc2)c1N=Nc1ccccc1)c1ccccc1</smiles>

10

Scheme 1.8: Hydroarylation of tolane 8 using Kisch's complex 9.[45]

Subsequently, similar work in this field was performed in the 2010s by Petit. However so far, these systems remain limited to the addition of $\mathrm{C}-\mathrm{H}$ bonds to $\mathrm{C}-\mathrm{C}$ double or triple bonds. ${ }^{[46]}$ 


\subsubsection{C-H Activation using Low-Valent Cobalt Catalysis}

While the early work by Kisch highlighted the potential of low-valent complexes for C-H activation, ${ }^{[45]}$ their instability towards air and moisture makes their handling rather difficult. In reference to the Kharash coupling, ${ }^{[41]}$ Nakamura and coworkers proposed the generation of a low-valent cobalt species in situ from a cobalt salt and a Grignard reagent (Scheme 1.9). ${ }^{[47]}$ Hence, a combination of $\mathrm{Co}(\mathrm{acac})_{3}$ and cyclohexylmagnesiumchloride was able to catalyze the hydroarylation as well as the direct alkylation of benzamides 11 .

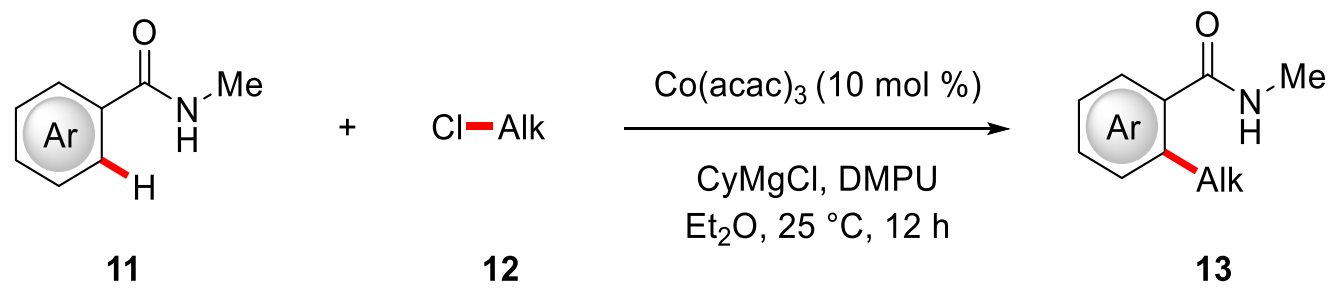

Scheme 1.9. Alkylation of benzamides 11 by Nakamura. ${ }^{[47]}$

Besides the fact that this method is more user-friendly than the direct use of cobalt(I) or cobalt(0) species, its biggest benefit may be the highly modular approach to optimizing the reaction conditions. After Nakamuras initial report, this flexibility was shown in subsequent reports by Ackermann and Yoshikai, among others. ${ }^{[48]} \mathrm{A}$ List of ligands commonly employed in low-valent cobalt catalysis is shown below (Figure 1.2). It should be noted, that most reactions are highly specific to the substitution pattern of the ligand, and even small changes can shut down the observed reactivity.

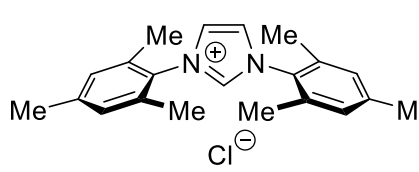

IMesHCl (14)

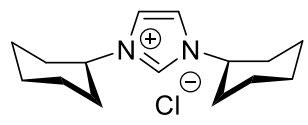

ICyHCl (18)

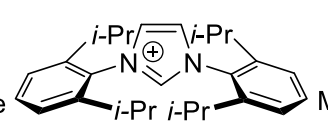

$\mathrm{Cl}^{\ominus}$

$\mathrm{IPrHCl}(\mathbf{1 5})$

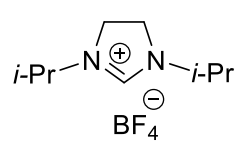

19

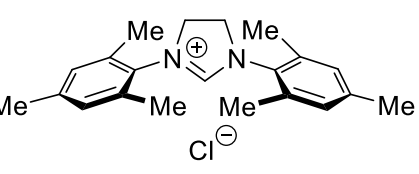

SIMesHCl (16)

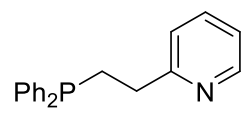

pyphos (20)

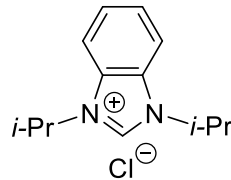

17

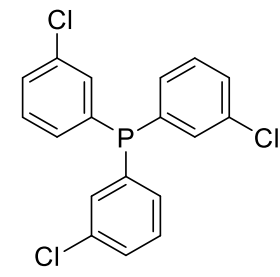

21

Figure 1.2. Common (pre)ligands in cobalt-catalyzed C-H activation.

In contrast to the reactions published using well-defined complexes, ${ }^{[45-46]}$ this approach also enables coupling-type chemistry besides simple hydrofunctionalization. 
Ackermann ${ }^{[49]}$ disclosed the alkylation of 2-arylpyridines $\mathbf{2 2}$ and pyrimidylindoles $\mathbf{2 3}$, with a report from Yoshikai[50] broadening the scope of directing groups to ketimines 26 (Scheme 1.10).

a) $\mathrm{C}-H$ Benzylation

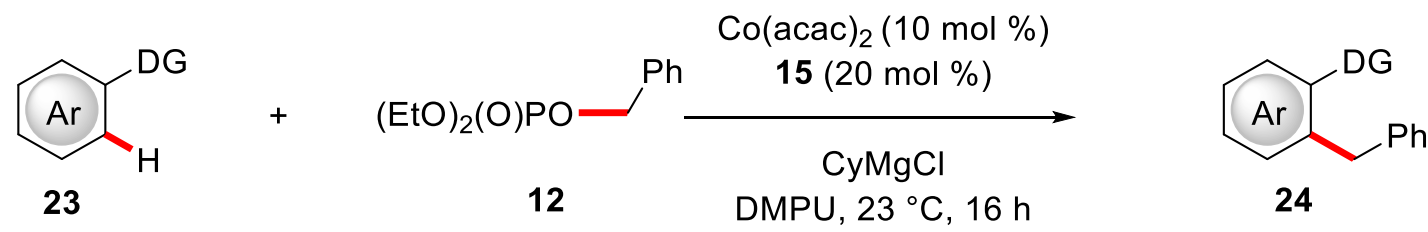

b) $\mathrm{C}-\mathrm{H}$ Alkylation of Arylpyridines $\mathbf{2 2}$ and Pyrimidines $\mathbf{2 3}$

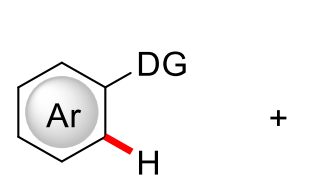

22 or 23

c) C-H Alkylation of Ketimines 26

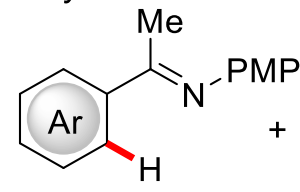

26

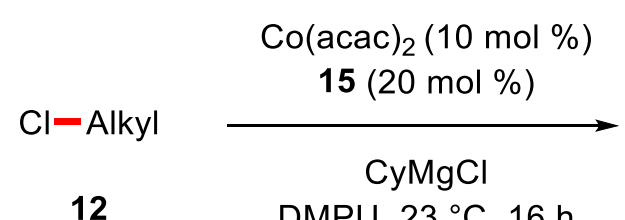

DMPU, $23^{\circ} \mathrm{C}, 16 \mathrm{~h}$

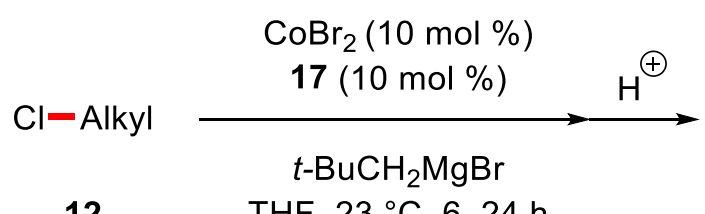

12

THF, $23^{\circ} \mathrm{C}, 6-24 \mathrm{~h}$

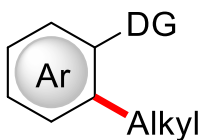

24 or 25

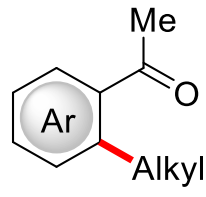

27

Scheme 1.10. Cobalt-catalyzed primary and secondary C-H alkylations. ${ }^{[49-50]}$

Both reports showed the possibility to utilize primary as well as secondary alkyl chlorides 12. Although the reaction conditions are somewhat similar, it should be noted, that $\mathrm{CyMgCl}$ is more cost effective than the corresponding neopentylmagnesiumbromide. ${ }^{[51]}$ Along the same lines, an unprecedented benzylation was published by Ackermann (Scheme 1.10a). ${ }^{[52]}$

Based on mechanistic experiments performed to gain insight into the mode of action of the low-valent cobalt-catalyzed alkylation, a plausible catalytic cycle was proposed (Scheme 1.11). ${ }^{[48 d]}$ The reaction is initiated by the formation of the ill-defined active species 28 from the cobalt salt, NHC (pre-)ligand and the Grignard reagent. This species can perform $\mathrm{C}-\mathrm{H}$ metalation, either by oxidative addition of the $\mathrm{C}-\mathrm{H}$ bond due to the electron-rich cobalt species or by ligand to ligand hydrogen transfer (LLHT).[48a] Subsequently, the alkyl halide $\mathbf{1 2}$ is activated by single electron transfer, ${ }^{[48 \mathrm{~d}]}$ followed by radical recombination to generate intermediate $\mathbf{3 0}$. Reductive elimination of the product 24 and transmetalation with another equivalent of the Grignard reagent regenerates the catalytically active species 28 . 
Besides alkylations, also $\mathrm{C}-\mathrm{H}$ arylation reactions have been reported using this approach, beginning with Ackermann in 2012 ${ }^{[49,52]}$ (Scheme 1.12). A variety of substrates, such as ketimines 26 , $^{[50]}$ benzamides 12 and tetrazoles $31^{[53]}$ as well as oxazolines $32^{[54]}$ have here been utilized, highlighting the versatility of this strategy.

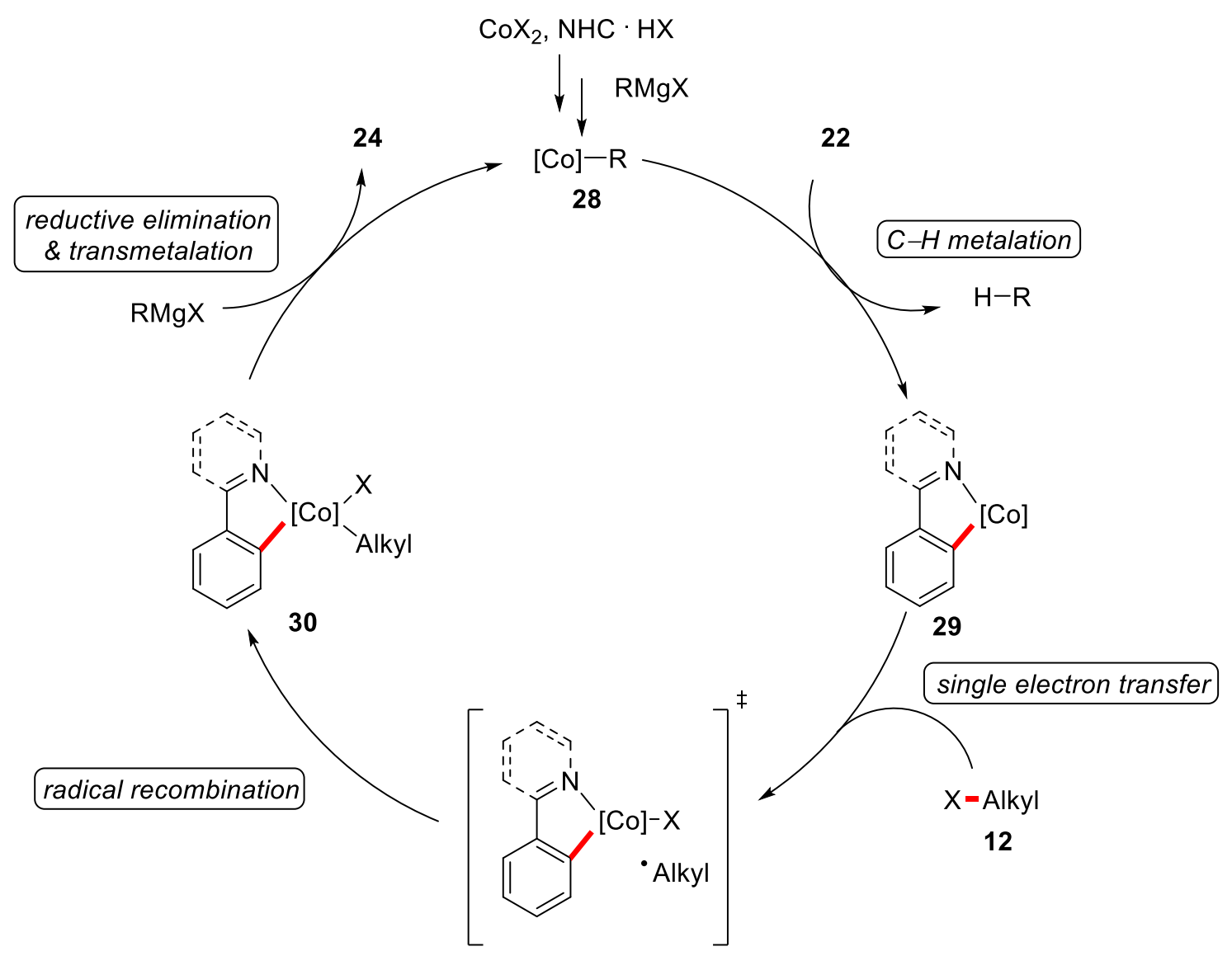

Scheme 1.11. Plausible catalytic cycle for the cobalt-catalyzed $\mathrm{C}-\mathrm{H}$ alkylation. ${ }^{[48 \mathrm{~d}]}$

The mechanism of low-valent cobalt-catalyzed $\mathrm{C}-\mathrm{H}$ arylations is rationalized to be similar to the related alkylations. ${ }^{[48 d]}$ Additionally, besides halides 33, phenol derivatives $\mathbf{3 4}$ and $\mathbf{3 5}$ also proved to efficiently yield the desired products 36-38. 
a) Ackermann<smiles>[O-]c1ccccc1</smiles>

$12,31,32$

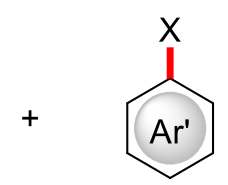

$\mathrm{X}=\mathrm{Cl}(\mathbf{3 3})$

OC(O) $\mathrm{NMe}_{2}(34)$

$=\mathrm{OSO}_{2} \mathrm{NMe}_{2}(\mathbf{3 5})$

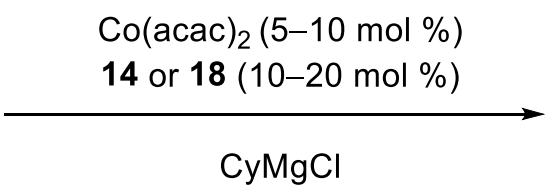

DMPU, $23-60{ }^{\circ} \mathrm{C}, 16 \mathrm{~h}$

b) Yoshikai<smiles>CC(=N[PH3+])c1ccccc1</smiles>

26

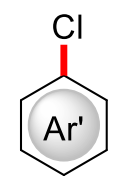

33

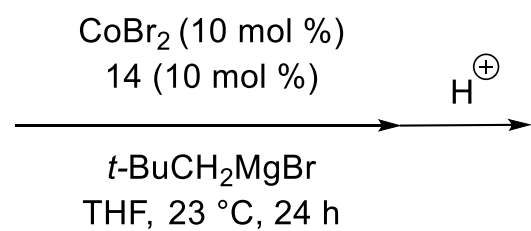

THF, $23^{\circ} \mathrm{C}, 24 \mathrm{~h}$

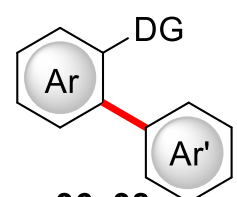

36-38

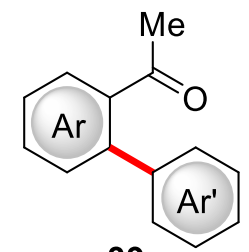

39

Scheme 1.12. Cobalt-catalyzed C-H arylations. ${ }^{[49-50,52-54]}$

Related electrophiles, enol acetates 40, phosphates 41, carbamates 42 and carbonates 43 , which are easily accessible from the related ketones, ${ }^{[55]}$ were shown by Ackermann to be viable substrates in cobalt-catalyzed direct $\mathrm{C}-\mathrm{H}$ alkenylations (Scheme 1.13). ${ }^{[56]}$

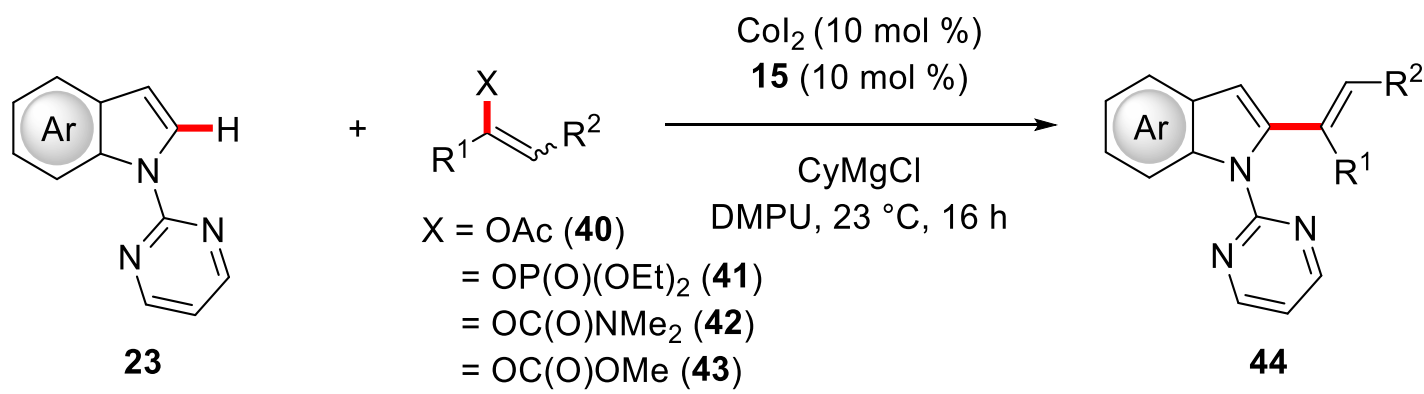

Scheme 1.13. Cobalt-catalyzed C-H alkenylation of indoles $23 .{ }^{[56]}$

Advantages of this method are the excellent regioselectivity in cases of unsymmetrical substrates $\mathbf{4 0}$ and the possibility to use cyclic enol electrophiles $\mathbf{4 0 - 4 3}$, both of which are usually not achieved in alkyne hydroarylation. ${ }^{[48 a]}$ Indeed, for low-valent cobaltcatalyzed $\mathrm{C}-\mathrm{H}$ activation, several hydroarylation reactions are known. For alkynes $\mathbf{8}$, Yoshikai disclosed examples using simple phosphines as ligands and various directing groups, such as phenylpyridines $22,{ }^{[57]}$ indoles 23 and imidazoles $45^{[58]}$ as well as aldimines 46 and ketimines 26 (Scheme 1.14). ${ }^{[59]}$ Additionally, when alkenes 47 were used instead of arenes, heterocycle synthesis by hydro-functionalization proved possible. ${ }^{[60]}$ Furthermore, Yoshikai also developed hydroarylations of alkynes 8 using the inherent kinetic acidity of heterocycles. ${ }^{[61]} \mathrm{A}$ catalytic cycle was rationalized to 
include the generation of the active cobalt species 56 , followed by precoordination of alkyne 8 to the metal center (Scheme 1.15). ${ }^{[48 c]}$ Then, $\mathrm{C}-\mathrm{H}$ activation takes place, most probably by oxidative addition of the $\mathrm{C}-\mathrm{H}$ bond. After cyclometallation, migratory insertion of alkyne 8 into the $\mathrm{Co}-\mathrm{H}$ bond yields vinylic cobalt species 59 , furnishing the desired product 49 via reductive elimination.

Besides alkynes $\mathbf{8}$, also alkenes $\mathbf{6 0}$ were identified as viable substrates. Here, the possibility of branched or linear selectivity offers a further challenge. Beginning with work from Nakamura, who explored hydroarylation of unactivated alkenes $\mathbf{6 0},{ }^{[47]}$ Yoshikai broadened the field of cobalt-catalyzed alkene hydroarylation by the use of phenylpyridines $2^{[62]}$ and imines 26 and 46 $^{[63]}$ using activated alkenes 60 (Scheme 1.16). It is noteworthy, that linear/branched products 61 and 62 could be selectively accessed using different combinations of ligand and Grignard reagents.

a) Phenylpyridines, Aldimines, Ketimines

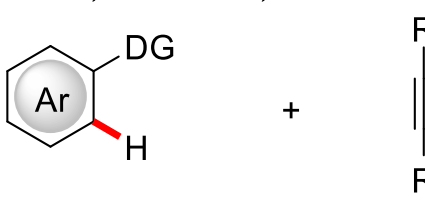

22, 26, 46

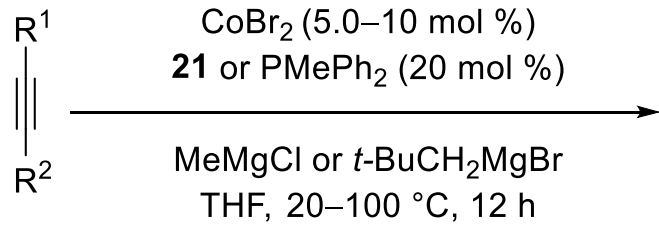

8<smiles>[R]C=C([R])c1ccccc1[O+]</smiles>

48-50

b) $\mathrm{C}-\mathrm{H}$ activation of Alkenes<smiles>[R]C=C([R])C([R])=N[R16]</smiles>

47

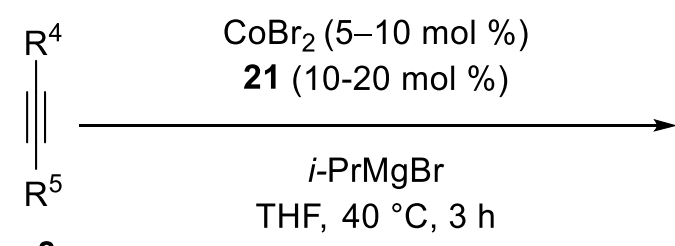

8<smiles>[R]C1=C([R])C([R8])N([R16])C([R])=C1[R]</smiles>

51

c) Hydroarylation of Azoles<smiles>[R]c1[X]cnc1[R]</smiles>$$
X=O(52)
$$$$
=S(53)
$$

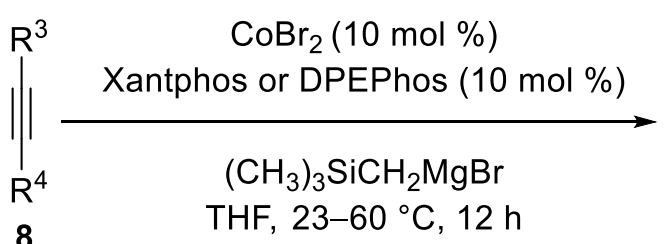

8<smiles>[R4]C=C([R])c1[X]c([R])c([R])n1</smiles>

54 or 55

Scheme 1.14. Hydroarylation of alkynes 8. ${ }^{[57-61]}$ 


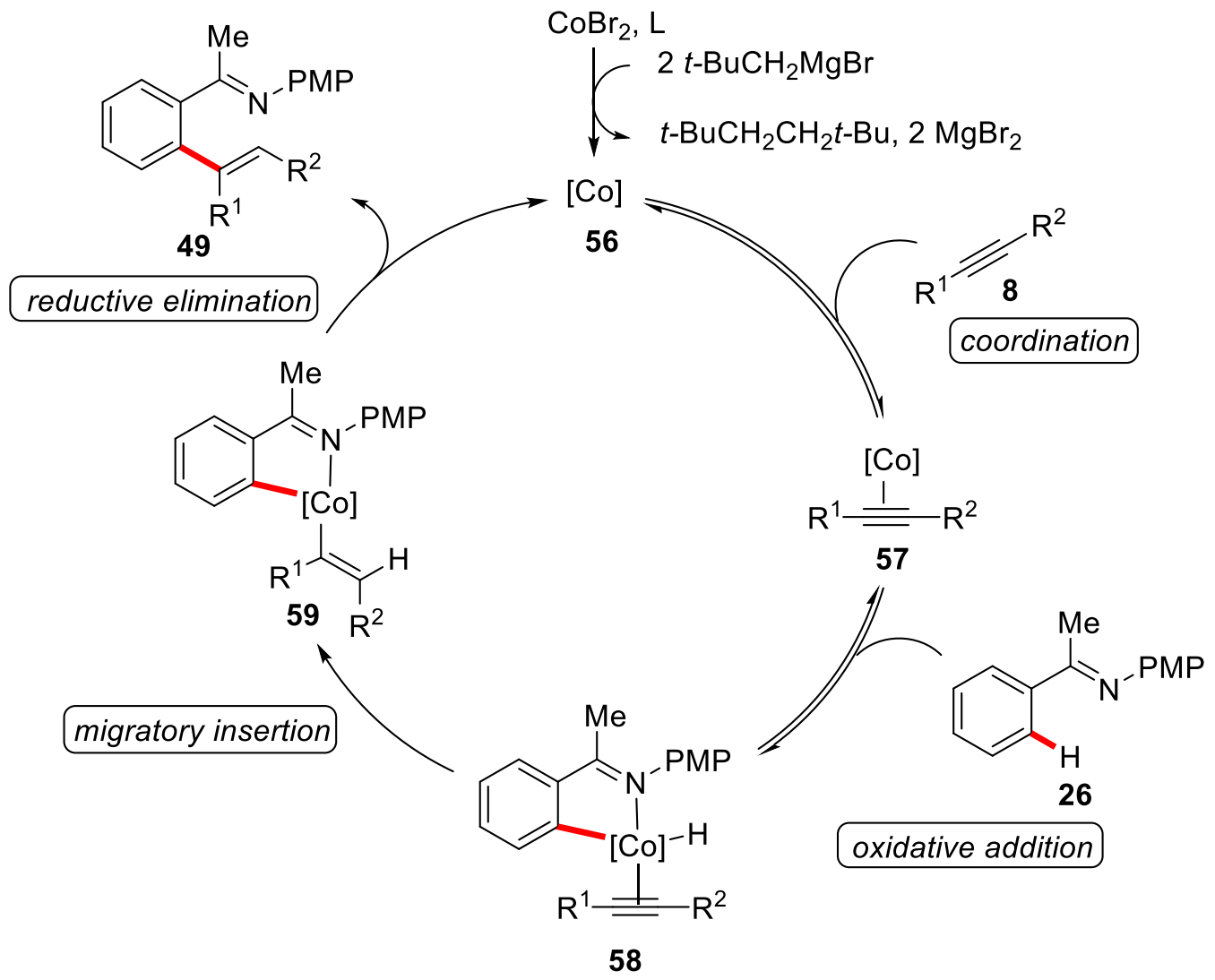

Scheme 1.15. Proposed catalytic cycle for alkyne hydroarylation. ${ }^{48 c]}$

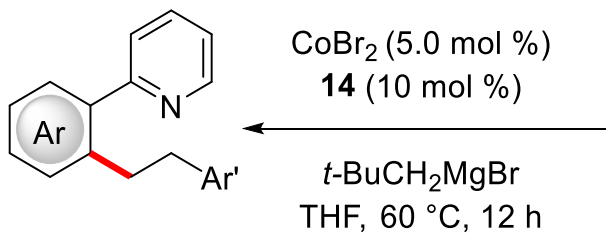

61

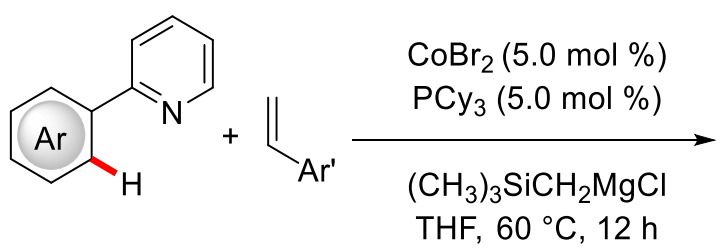

22

60<smiles>CC(Br)c1ccccc1-c1ccccn1</smiles>

62

Scheme 1.16. Hydroarylation of alkenes 60 with switchable selectivity. [62]

The proposed mechanism was generally comparable to the mechanism proposed for the hydroarylation of alkynes $\mathbf{8} .{ }^{[48 c]}$

The branched-selective hydroarylation of alkenes $\mathbf{6 0}$ offers the potential to conduct these reactions in an enantioselective fashion. Indeed, Yoshikai disclosed a cobaltcatalyzed asymmetric $\mathrm{C}-\mathrm{H}$ alkylation by the use of $\mathrm{Co}(\mathrm{acac})_{2}$ and ligand 65 (Scheme 1.17). ${ }^{[64]}$ 


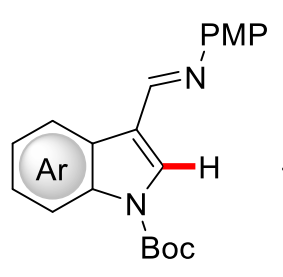

63

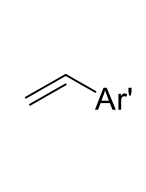

60

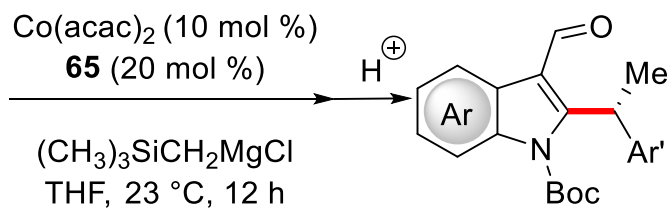

64<smiles>CCCCc1c2ccc(OP(N(C)CCC)N(I)C(C)C)c1-c1c(ccc3c1CCCC3)O2</smiles>

65

$58-87 \%$ ee

Scheme 1.17. Enantioselective hydroarylation of styrenes $60 .[64]$

While the majority of low-valent cobalt-catalyzed $\mathrm{C}-\mathrm{H}$ functionalizations are based on the use of Grignard reagents, there are inherent drawbacks associated; for instance, limited tolerance for electrophilic functional groups, such as cyano groups and aldehydes. Therefore, the substitution of the Grignard reagent with another reductant would be beneficial. To this end, magnesium, zinc or indium were identified as viable reductants, however these reactions remain limited to simple hydrofunctionalizations. ${ }^{[65]}$ Thus, hydroacylations were achieved in an intramolecular, enantioselective fashion by assistance of a chiral phosphines 71 and 72 (Scheme 1.18). Although the first contributions using a metal reductant were reported in 2014 , progress in this field has been limited, and the diversity of the disclosed reactions cannot be compared to that of low-valent cobalt catalysis employing Grignardreagents.

60

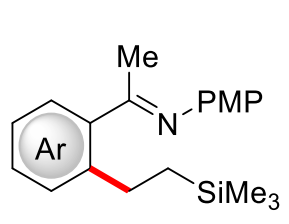

66

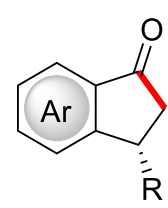

$\mathrm{X}=\mathrm{CH}_{2}(69)$
$\mathrm{CoBr}_{2}(10 \mathrm{~mol} \%)$

Phen (10 mol \%)

$\mathrm{Mg}(50 \mathrm{~mol} \%)$

THF, $80^{\circ} \mathrm{C}, 12 \mathrm{~h}$

$\mathrm{CoBr}_{2}(10 \mathrm{~mol} \%)$

$71(10 \mathrm{~mol} \%)$

$\mathrm{Zn}(20 \mathrm{~mol} \%)$

$\operatorname{MeCN}, 25^{\circ} \mathrm{C}, 12 \mathrm{~h}$

$90-97 \%$ ee
60

$\mathrm{CoBr}_{2}(10 \mathrm{~mol} \%)$

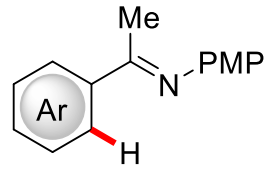

26

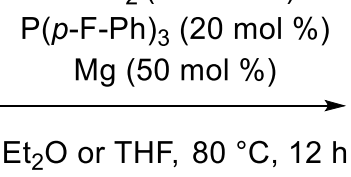

$\mathrm{Et}_{2} \mathrm{O}$ or $\mathrm{THF}, 80^{\circ} \mathrm{C}, 12 \mathrm{~h}$
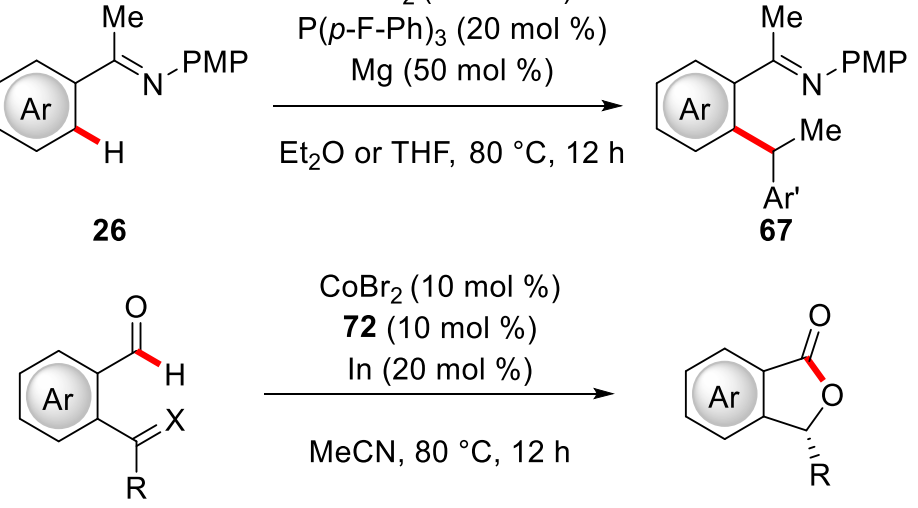

68

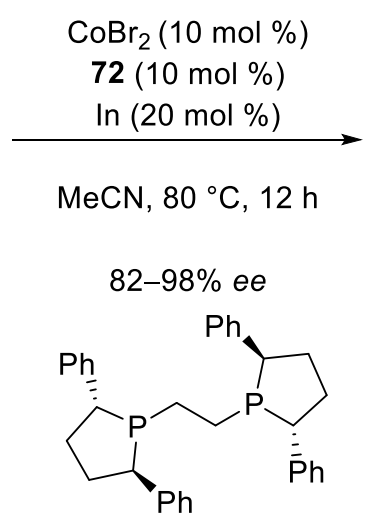

72

Scheme 1.18. Low-valent cobalt-catalyzed $\mathrm{C}-\mathrm{H}$ activation using metal reductants. ${ }^{[65]}$ 


\subsubsection{C-H Activation using High-Valent Cobalt Catalysis}

Despite tremendous progress by low-valent cobalt catalysis under rather mild conditions, ${ }^{[48 b, 48 d]}$ these transformations suffer from a lack of functional group tolerance. Especially the functionalization of molecules containing sensitive or protic functional groups, such as aldehydes, ketones, esters, nitro- and hydroxyl-groups are difficult or impossible. Therefore, demand for an air-stable, easy to handle and robust cobalt catalyst grew. Inspired by the Brookhart contributions, ${ }^{[44]}$ this demand was met in a important work from Matsunaga and Kanai, establishing the known $\mathrm{Cp}^{*} \mathrm{Co}$ (III)complex $73^{[66]}$ as a competent catalyst in the hydroarylation of imines $\mathbf{7 4}$ with phenylpyridines 22 ${ }^{[67]}$ (Scheme 1.19) and later pyrimidylindoles 23. [68]

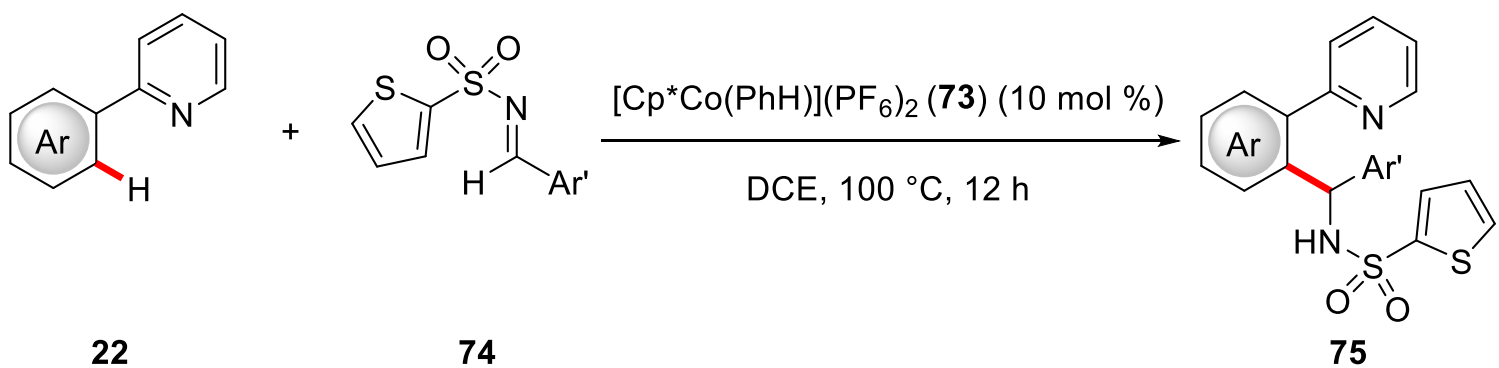

Scheme 1.19. Hydroarylation of imines 74 using $\mathrm{Cp}^{\star} \mathrm{Co}(\mathrm{III}) .{ }^{[67]}$

While the reaction temperatures were mostly higher than in the low-valent cobalt catalysis, the catalyst is generally more stable and robust and therefore offers a larger functional group tolerance. Furthermore, the $\mathrm{Cp}^{*} \mathrm{Co}(\mathrm{III})$-catalysis generally offers a wide range of $\mathrm{C}-\mathrm{X}$ bond formations, ${ }^{[48 \mathrm{a}, 69]}$ being somewhat orthogonal in reactivity to the low-valent systems. Over time, a variety of $\mathrm{Cp}^{*}$-derived $\mathrm{Co}$ (III)-complexes have been synthesized, the structures of which are summarized below (Figure 1.3).[48a] However, simple $\mathrm{Cp}^{*} \mathrm{Co}(\mathrm{CO}) \mathrm{I}_{2}(\mathbf{8 1})$ is by far the most commonly employed complex in Co(III)-catalysis. 


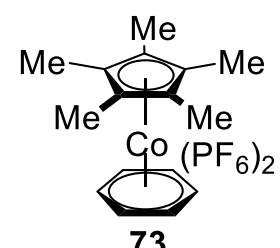

73

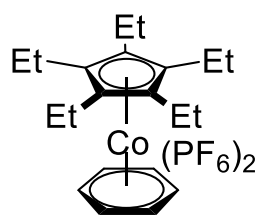

79

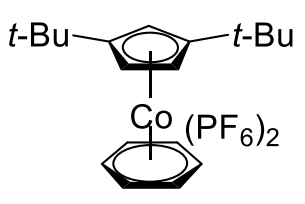

76

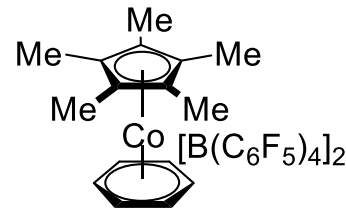

80

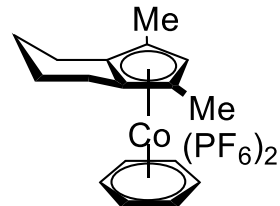

77

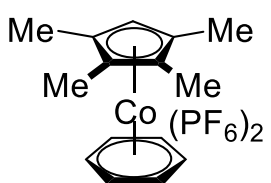

78

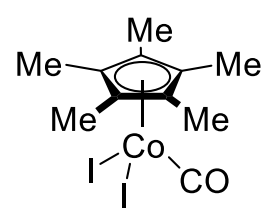

81

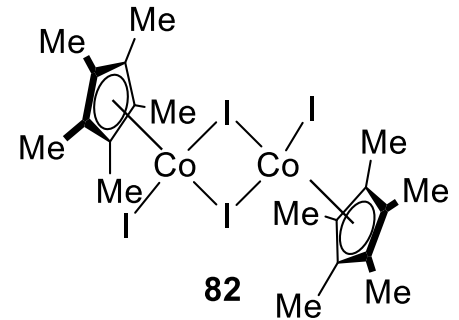

Figure 1.3. Common complexes in $\mathrm{Cp}^{\star} \mathrm{Co}(\mathrm{III})$-catalyzed $\mathrm{C}-\mathrm{H}$ activation.[48a]

$\mathrm{Cp}^{\star} \mathrm{Co}(\mathrm{III})$-catalyzed hydroarylation was not limited to imines $\mathbf{7 4}$, as also a variety of other $\mathrm{C}-\mathrm{C}$ and $\mathrm{C}-\mathrm{X}$ multiple bonds reacted readily. Matsunaga established two protocols for alkyne hydroarylation of indoles $\mathbf{8 3}$ using carbamates as the directing group (Scheme 1.20). Simple dimethylcarbamates yielded the hydroarylation product $\mathbf{8 5},{ }^{, 70]}$ whereas morpholine substituted carbamates underwent directing group migration to yield the $\alpha, \beta$-unsaturated compound 84. ${ }^{[71]}$ The former protocol was later extended to include the mono-functionalization of 3-substituted pyrroles using the same directing group. ${ }^{[72]}$

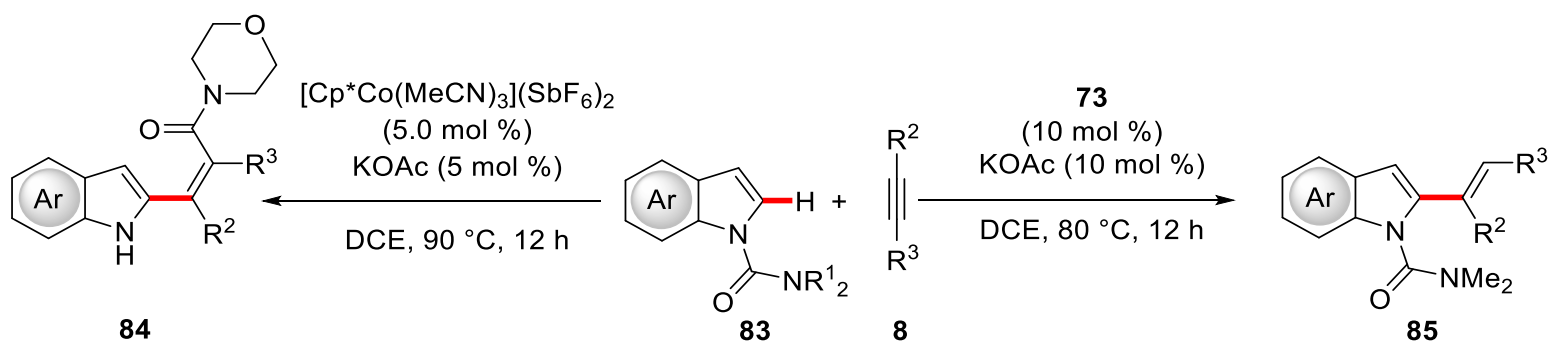

Scheme 1.20. Hydroarylation of alkynes 8 using 2-carbamoylindoles $83 .{ }^{[70-71]}$

Besides alkynes 8, also alkenes 60 were employed in hydroarylation reactions. Ackermann reported on a switchable Markovnikov/anti-Markovnikov hydroarylation of alkenes 60, dependent on the nature of the additive (Scheme 1.21). ${ }^{[29 b]}$ Extensive mechanistic studies and theoretical calculations revealed that the change in selectivity is based on an underlying change in the reaction mechanism. While the use of bulky adamantanecarboxylic acid promoted the BIES-type ${ }^{[29]}$ mechanism, resulting in the branched product, the linear was furnished in the absence of further additives by ligand to ligand hydrogen transfer (LLHT, Scheme 1.21). ${ }^{[29 b]}$ 


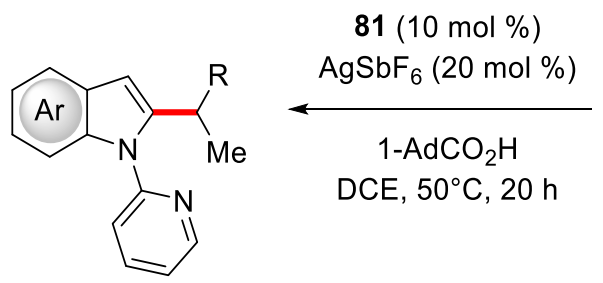

86

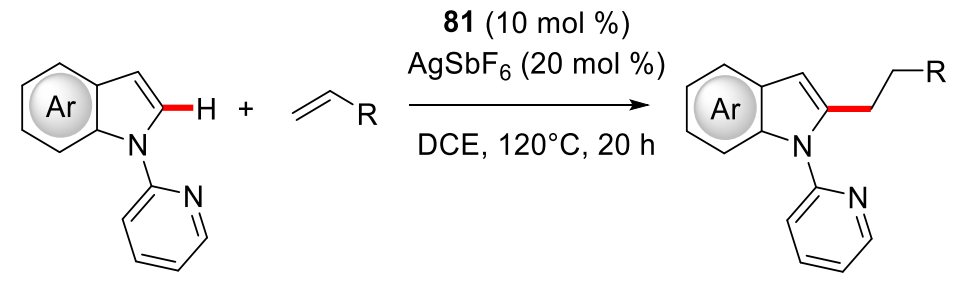

60

87

Scheme 1.21. Switchable selectivity in $\mathrm{C}-\mathrm{H}$ hydroarylation of alkenes $60 .{ }^{[29 b]}$

Further progress in $\mathrm{Cp}^{*} \mathrm{Co}$ (III)-catalysis for hydroarylation reactions was witnessed by Ackermann using challenging allenes, ${ }^{[73]}$ as well as $\mathrm{Li}$ and coworkers using activated alkenes and maleimides. ${ }^{[74]}$

Additionally, protocols for the synthesis of heterocycles were developed for $\mathrm{Cp}^{*} \mathrm{Co}$ (III)catalysts, ranging from indazoles and furanes, ${ }^{[75]}$ isoquinolines ${ }^{[76]}$ to indoles, ${ }^{[29 c]}$ and isoquinolines. ${ }^{[77]}$

Further $\mathrm{C}-\mathrm{C}$ forming reactions besides hydroarylations are also known for $\mathrm{Cp}^{*} \mathrm{Co}$ (III) complexes. A cobalt(III)-catalyzed alkynylation was published by Shi employing pyrimidylindoles 23 and hypervalent iodine based reagent TIPS-EBX (88) (Scheme 22). ${ }^{[78]}$ This method for cobalt-catalyzed $\mathrm{C}-\mathrm{H}$ alkynylation suffers from poor functional group tolerance and harsh reaction conditions, that is the use of a strong alcoholate base, resulting in a limited scope.

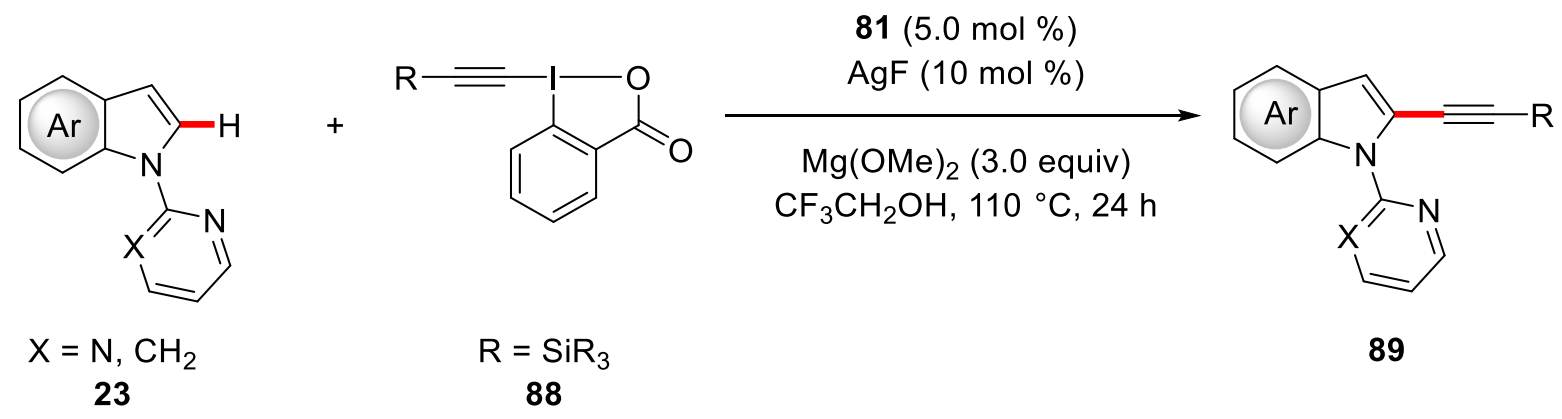

Scheme 1.22. Alkynylation using hypervalent iodine reagent $88 .{ }^{[78]}$

Moreover, allylations have been established with different allylating reagents (Scheme 1.23). Beginning with work from Glorius and Ackermann using pyrimidylindoles 23 and allylic electrophiles $90,{ }^{[79]}$ this field was extended among others ${ }^{[80]}$ by Ackermann using cyclic carbonates $93^{\left[{ }^{[1]}\right.}$ and Matsunaga who was able to directly utilize allylic alcohols 95 as a coupling agent ${ }^{[82]}$ and thus increased atom efficiency. 
a) Ackermann, Glorius

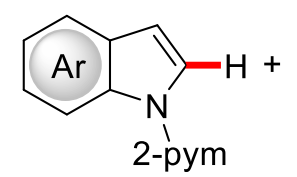

23

b) Ackermann<smiles>[R1]OC(=N[NH3+])c1ccccc1</smiles>

92

c) Matsunaga

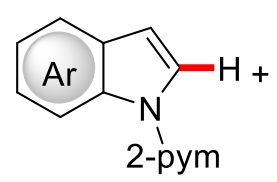

23

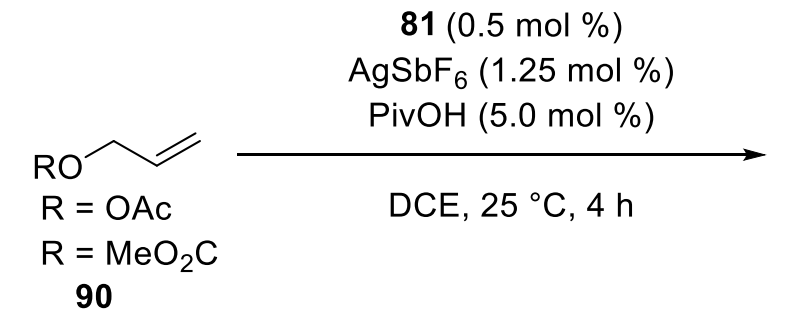

$\left[\mathrm{Cp}{ }^{*} \mathrm{Co}(\mathrm{MeCN})_{3}\right]\left(\mathrm{PF}_{6}\right)_{2}(5.0 \mathrm{~mol} \%)$ $\mathrm{NaOAc}(40 \mathrm{~mol} \%)$<smiles>[R2]C1OC(=O)O[C@@H]1C=C</smiles>

93

HFIP, $55^{\circ} \mathrm{C}, 16 \mathrm{~h}$

$81(5.0 \mathrm{~mol} \%)$ AgOTf (10 mol \%) AgOAc (10 mol \%)

DCE, $60^{\circ} \mathrm{C}, 8 \mathrm{~h}$

95

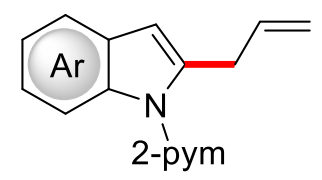

91

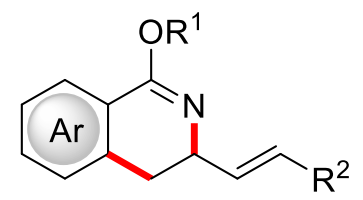

94

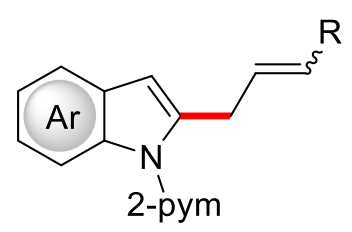

91

Scheme 1.23. $\mathrm{Cp}{ }^{*} \mathrm{Co}(\mathrm{III})$-catalyzed $\mathrm{C}-\mathrm{H}$ allylations. ${ }^{[78,79 b, 81-83]}$

Besides $\mathrm{C}-\mathrm{C}$ forming transformations, the strength of $\mathrm{Cp}{ }^{*} \mathrm{Co}(\mathrm{III})$ catalysts lies in the formation of $\mathrm{C}-\mathrm{X}$ bonds, and here in in particular (pseudo-)halogenations and $\mathrm{C}-\mathrm{N}$ forming reactions. Beginning with reports on the cyanation of (hetero)aromatic $\mathrm{C}-\mathrm{H}$ bonds by Ackermann (Scheme 1.24) ${ }^{[84]}$ and a publication by Glorius using NCTS $(96)^{[79 b]}$ the field was extended by Chang to include arylpurines 97 and $N$ cyanosuccinimide (98) as cyanating reagent. ${ }^{[85]}$

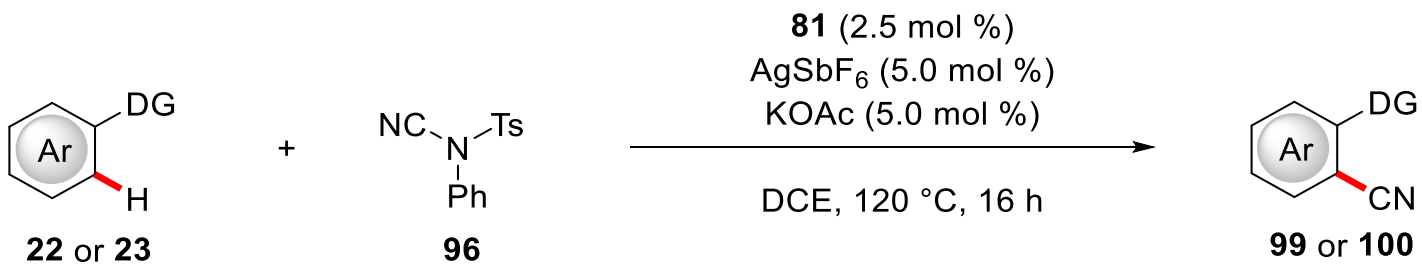

Scheme 1.24. $\mathrm{Cp}{ }^{*} \mathrm{Co}(\mathrm{III})$-catalyzed $\mathrm{C}-\mathrm{H}$ cyanation by Ackermann. ${ }^{[84]}$

In his report, Ackermann also rationalized a catalytic cycle to explain the product formation (Scheme 1.25). ${ }^{[84]}$ After the in-situ generation of the cationic cobalt complex 101, a BIES-type C-H metalation ${ }^{[29]}$ results in the formation of cobaltacycle 102, which can coordinate the cyanating reagent 96. ${ }^{[84]}$ The key intermediate, seven-membered cobaltacycle 104 is generated by insertion of the $\mathrm{C}-\mathrm{N}$ triple bond into the Co-C bond. 
Subsequently, a $\beta$-elimination releases the product 100 and regenerates the active catalyst 101.

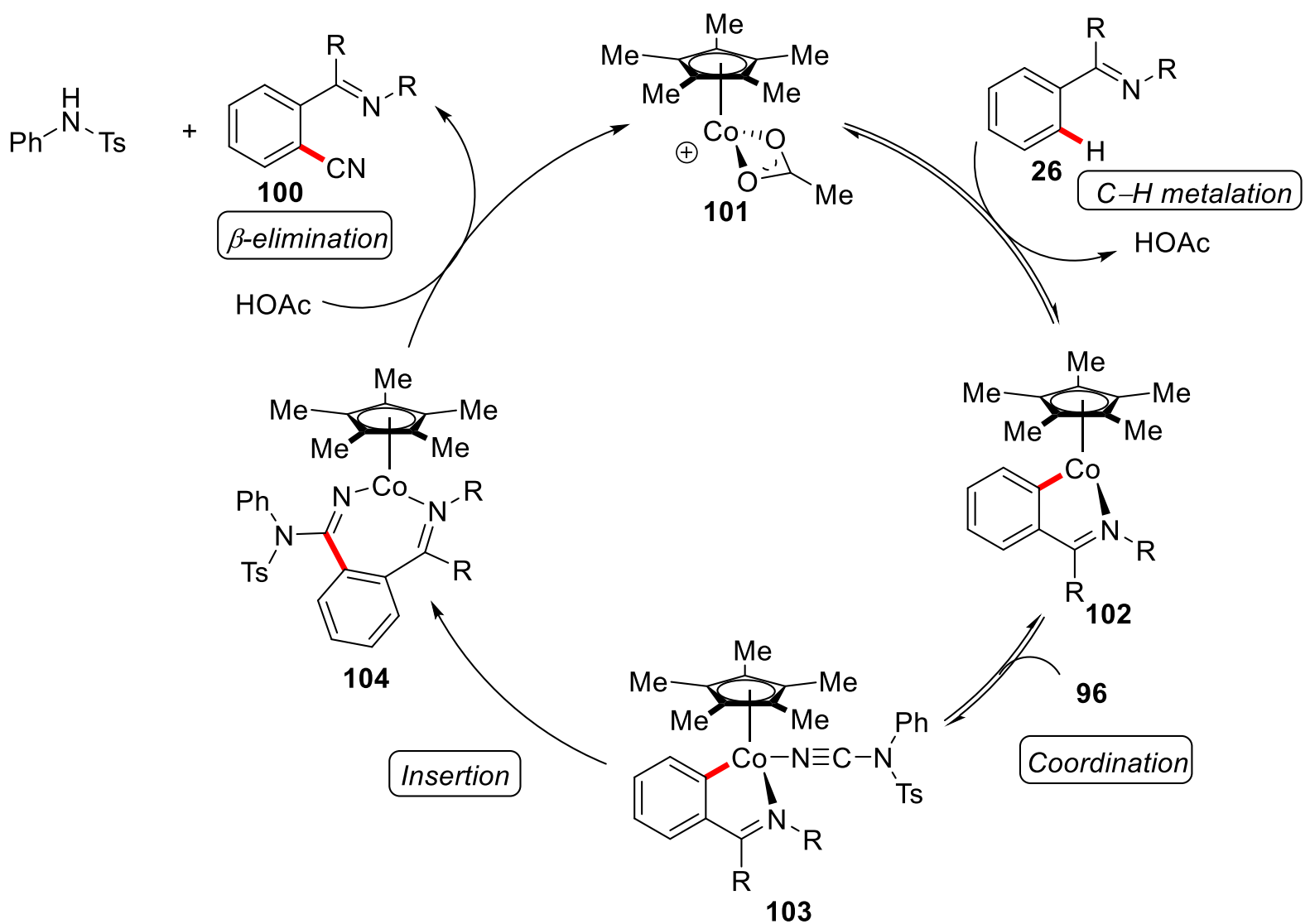

Scheme 1.25. Plausible mechanism for the cobalt-catalyzed C-H cyanation. ${ }^{[84]}$

Along the same lines, $\mathrm{C}-\mathrm{H}$ halogenations were reported using $\mathrm{Cp}{ }^{*} \mathrm{Co}(\mathrm{III})$ complexes by Glorius, ${ }^{[79 b]}$ and Pawar. ${ }^{[86]}$

Beginning with a report by Matsunaga using sulfonylazides 105 as amidating reagents in $2014,{ }^{[87]}$ also $\mathrm{C}-\mathrm{N}$ formation by cobalt(III) catalysis has seen significant advances. Ackermann ${ }^{[29 e]}$ and Jiao $^{[88]}$ reported that cyclic carbamates 108 were viable amidating reagents, while Chang disclosed a protocol using acetoxycarbamates 110 (Scheme 1.26). ${ }^{[89]}$ Plausible mechanisms have been proposed, and the reaction is explained using as an example the reaction shown in 1.26b (Scheme 1.27). After generation of the active catalyst 101, a BIES-type $\mathrm{C}-\mathrm{H}$ metalation ${ }^{[29]}$ affords the five membered cobaltacycle 112. Coordination of the dioxazolone 108 is followed by extrusion of $\mathrm{CO}_{2}$, which yields intermediate $114,{ }^{[29 e]}$ which itself can release the final product 109 upon proto-demetalation by acetic acid, thus regenerating the active catalyst 101. 
a) Matsunaga<smiles>[Z6][R9]([H])n1c([CH2+])cc2ccccc21</smiles>

23

b) Ackermann<smiles>c1ccc(C2=NCCO2)cc1</smiles>

c) Chang 10<smiles>[R1]n1c[Y]c2c(-c3ccccc3)ncnc21</smiles>

96<smiles>[R]c1noc(=O)o1</smiles>

108
$81(2.5 \mathrm{~mol} \%)$

$\mathrm{AgSbF}_{6}(5.0 \mathrm{~mol} \%)$ KOAc (5.0 mol \%)

DCE, $100{ }^{\circ} \mathrm{C}, 12 \mathrm{~h}$

105

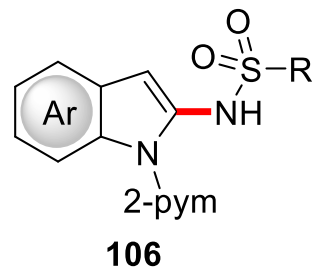

DCE, $100^{\circ} \mathrm{C}, 16 \mathrm{~h}$<smiles>[R]C(=O)Nc1ccccc1C1=NCCO1</smiles><smiles>[R17]n1c[X]c2c(-c3ccccc3NC(=O)OCc3ccccc3)ncnc21</smiles>

111

Scheme 1.26. $\mathrm{Cp}^{\star} \mathrm{Co}(\mathrm{III})$-catalyzed amidations. ${ }^{29 \mathrm{e}, 87,89]}$

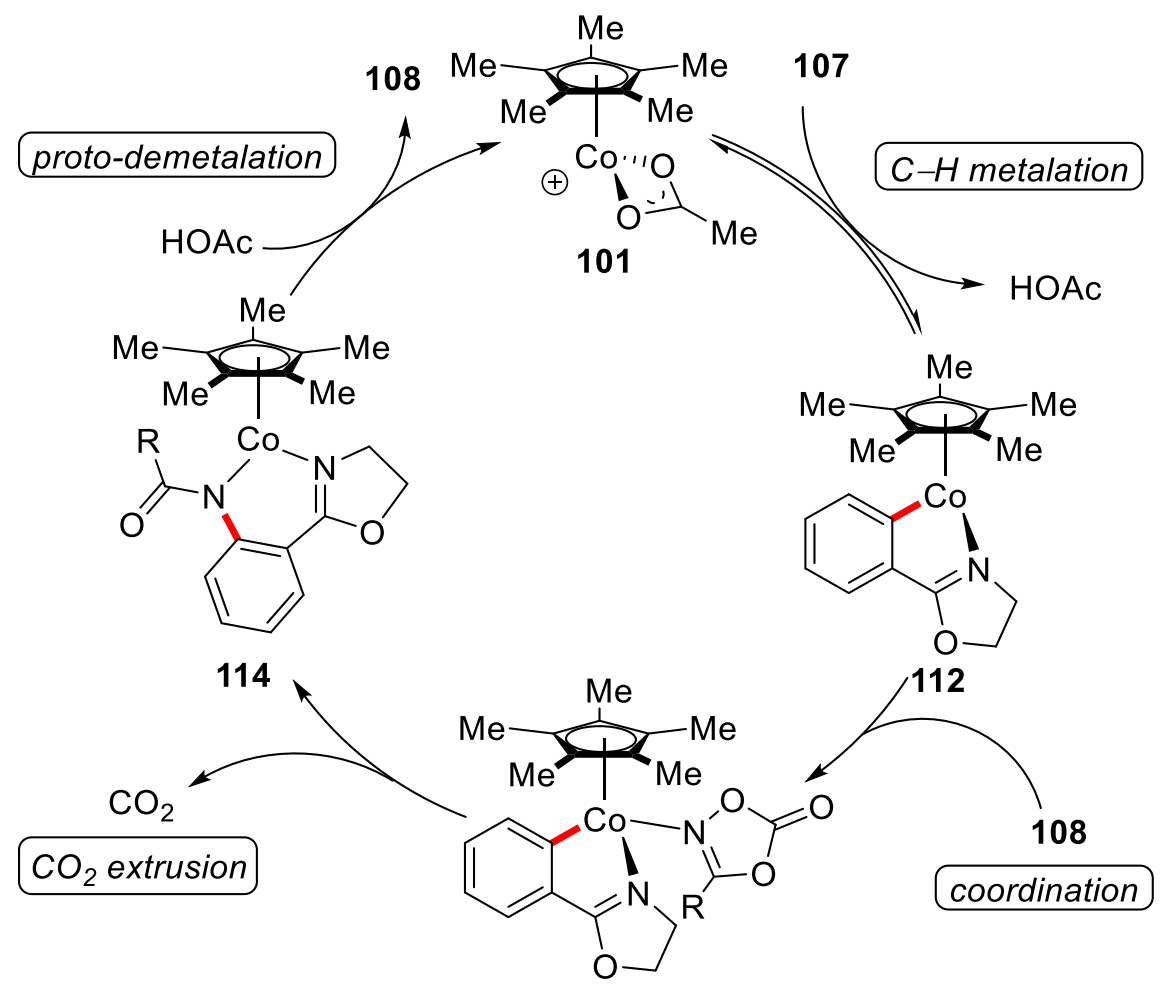

113

Scheme 1.27. Plausible catalytic cycle for the $\mathrm{C}-\mathrm{H}$ amidation. $\left.{ }^{29 e}\right]$ 


\subsubsection{Oxidative C-H Activation using Cobalt Salts}

As mentioned before, the use of high valent cobalt catalysts in $\mathrm{C}-\mathrm{H}$ activation greatly enhances the simplicity of the experimental setup and user-friendliness. However, the most simple setup would be the direct use of air-stable cobalt(II) salts as the (pre)catalyst. In 2005, Daugulis popularized the use of bidentate, monoanionic directing groups in the form of 8-aminoquinoline $(Q)$ benzamides for palladiumcatalyzed $\mathrm{C}-\mathrm{H}$ activation. ${ }^{[90]}$ This concept was applied to include other metals and directing groups, such as TAM, ${ }^{[91]} \mathrm{PIP}^{\left[{ }^{[2]}\right]}$ and PyO ${ }^{[93]}$ (Figure 1.3).<smiles>CC(=O)Nc1cccc2cccnc12</smiles>

8-Aminoquinoline (Q)

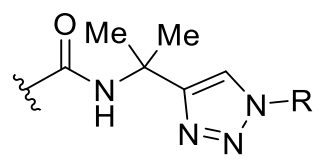

Triazolyldimethylmethanamine (TAM)

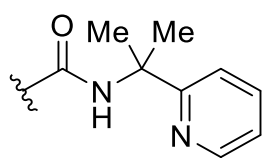

(2-pyridin-2-yl)isopropylamine (PIP)

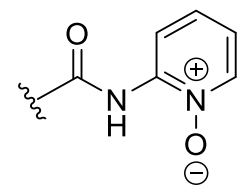

2-Aminopyridine- $N$-oxide (PyO)

Figure 1.4 Common bidentate directing groups in catalyzed $\mathrm{C}-\mathrm{H}$ activation.

However, it took nearly 10 years, before the 8-aminoquinoline directing group was applied to cobalt catalysis. Daugulis disclosed a cobalt-catalyzed $\mathrm{C}-\mathrm{H} / \mathrm{N}-\mathrm{H}$ annulation of quinolinebenzamides 115 and alkynes 8 to generate isoquinolones 118 (Scheme 1.28a). ${ }^{\left[{ }^{[9]}\right]}$ It soon became apparent, that heterocycle formation by $\mathrm{C}-\mathrm{H} / \mathrm{X}-\mathrm{H}$ annulation was one strength of oxidative cobalt-catalyzed $\mathrm{C}-\mathrm{H}$ activation. Further heterocycle syntheses followed soon by the same group regarding tetrahydroisoquinolones 119, ${ }^{\text {[95] }}$ cyclic phosphoramides 120[96] and isocoumarines 121 from benzoic acids 116 (Scheme 1.28e, 1.28h, 1.28c). ${ }^{[97]}$ Important contributions were also disclosed by Ackermann, establishing the formation of isoindolones 122 (Scheme 1.28d), ${ }^{[98]}$ and furthermore the first use of molecular oxygen as a competent terminal oxidant for this reaction employing PyO substituted benzamide 117 (Scheme 1.28b). ${ }^{[99]}$ Besides alkenes $\mathbf{6 0}$ and alkynes 8, also allenes 124 were shown to be reactive by Volla and Maiti. ${ }^{[100]}$ Finally, the synthesis of sultam motifs 126 by cobalt catalysis was disclosed independently by Ribas and Sundararaju under identical conditions (Scheme $1.28 \mathrm{~g}) \cdot{ }^{[101]}$ 


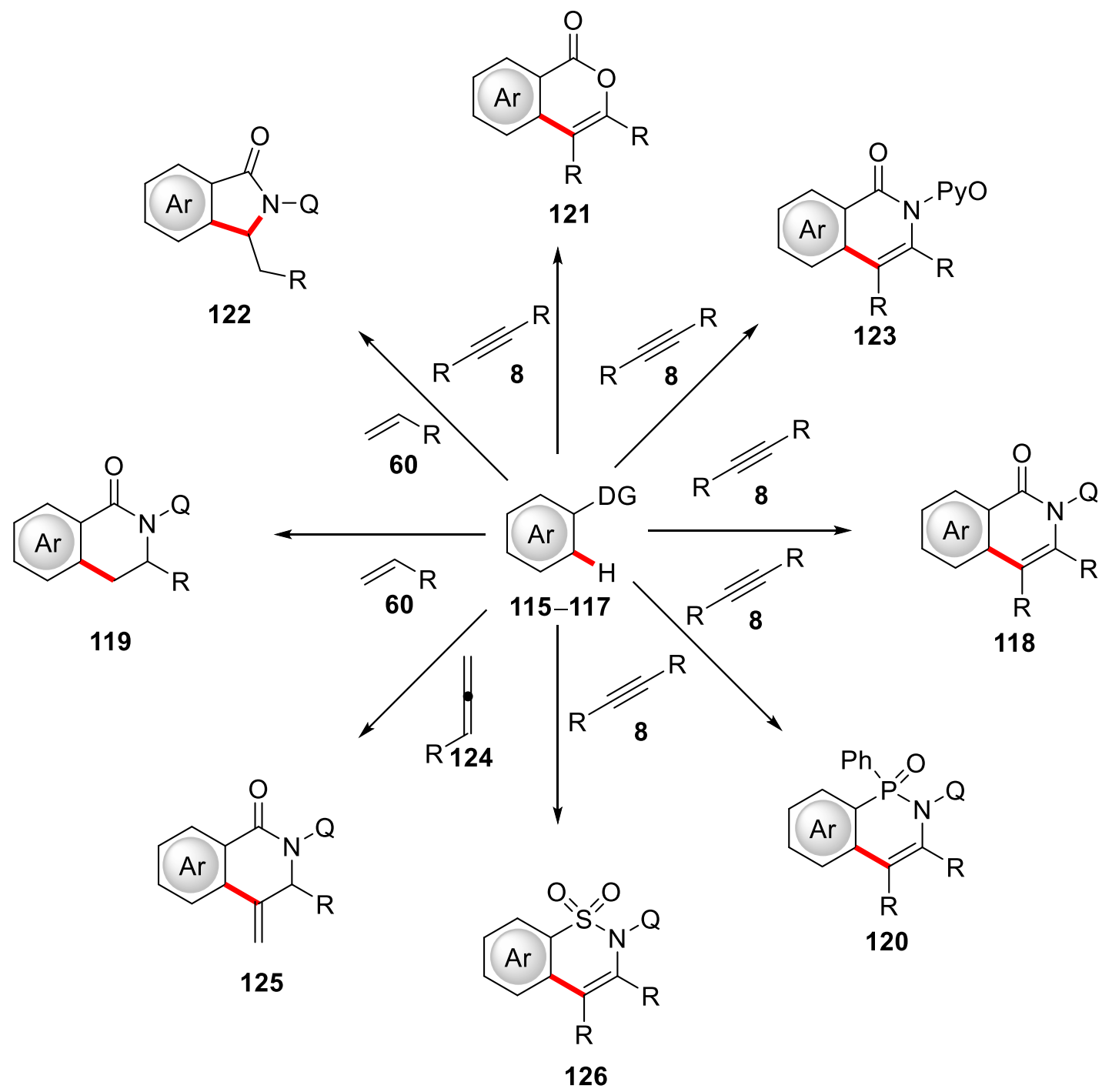

Scheme 1.28 Heterocycle formation by $\mathrm{C}-\mathrm{H} / \mathrm{X}-\mathrm{H}$ annulation.

All the above-mentioned $\mathrm{C}-\mathrm{H} / \mathrm{X}-\mathrm{H}$ annulation protocols generally follow similar mechanistic pathways, which should be explained with the example of the cobalt catalyzed isoindolone synthesis (Scheme 1.29). ${ }^{[98]}$ The initial step of the mechanism is proposed to be the base-assisted $\mathrm{C}-\mathrm{H}$ activation of the chelating substrate-catalyst complex to form five membered cobaltacycle 128. This intermediate is reactive towards unsaturated multiple bonds and can undergo migratory insertion. The resulting sevenmembered intermediate 129 reacts by $\beta$-hydride elimination to yield the final product 122. Subsequently, the cobalt species $\mathbf{1 3 1}$ is reoxidized to regenerate the active species 127. 


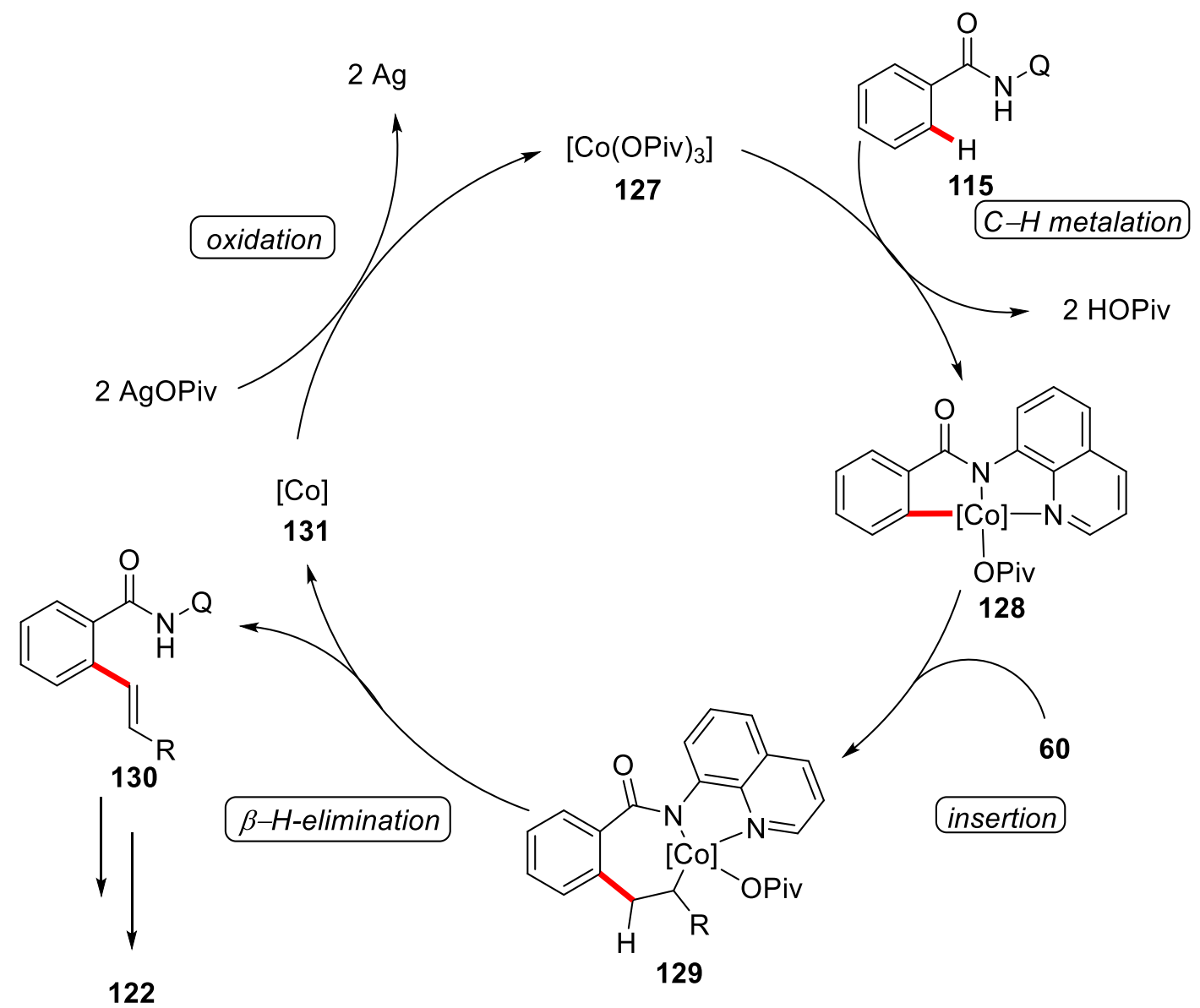

Scheme 1.29. Proposed catalytic cycle for the cobalt-catalyzed isoindolone formation. ${ }^{[98]}$

Furthermore, carbonylations have been reported as a method for heterocycle formation, for example by Daugulis in 2014. ${ }^{[102]}$

Besides $\mathrm{C}-\mathrm{H} / \mathrm{X}-\mathrm{H}$ annulations, $\mathrm{C}-\mathrm{C}$ forming reactions have been reported. In 2016 , Balaraman disclosed a cobalt-catalyzed oxidative alkynylation of benzamides $\mathbf{1 1 5}$ (Scheme 1.30a). ${ }^{[103]}$ Although the functional group tolerance on the benzamide moiety is generally good, the reaction suffers from a limited alkyne scope. In the same year, Lu and coworkers achieved a methylation under assistance of the PIP directing group in an elegant protocol using highly reactive dicumylperoxide 135 as the methylating reagent as well as the oxidant, avoiding the use of costly silver(I) salts (Scheme 1.30b). ${ }^{[104]}$ Although ortho-substituted benzamides 115 were used preferentially, other substitution patterns led to bis methylation. Further, Chatani reported on a cobaltcatalyzed allylation protocol using terminal alkenes 137 (Scheme 1.30c). ${ }^{[105]}$ 
a) Alkynylations<smiles>O=C(NO)c1ccccc1</smiles>

115<smiles>[R]C#CBr</smiles>

132

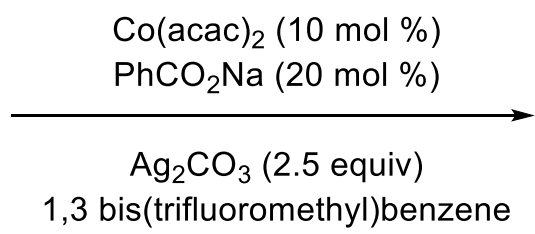

$150{ }^{\circ} \mathrm{C}, 18 \mathrm{~h}$

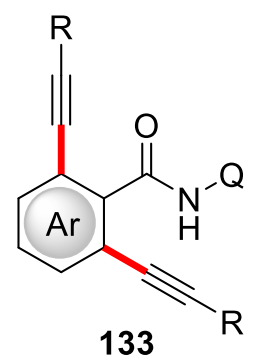

133

b) Methylation<smiles>O=C(N[In])c1ccccc1</smiles>

134<smiles>CC(C)(OOC(C)(C)c1ccccc1)c1ccccc1</smiles>
135

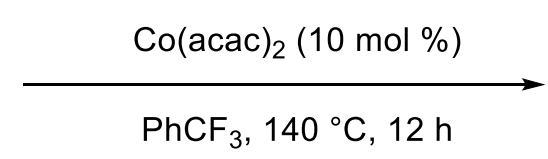

$\mathrm{PhCF}_{3}, 140{ }^{\circ} \mathrm{C}, 12 \mathrm{~h}$<smiles>Cc1ccccc1C(=O)NC(C)C</smiles>

136

c) Allylation<smiles>O=C(NO)c1ccccc1</smiles>

115<smiles>[R]CC=C</smiles>

137

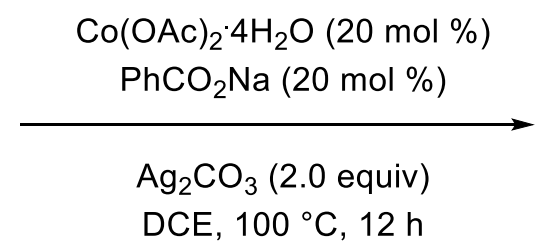

DCE, $100{ }^{\circ} \mathrm{C}, 12 \mathrm{~h}$

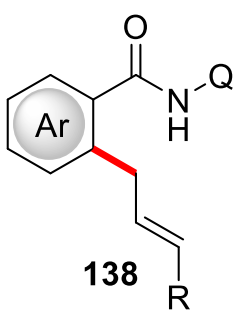

Scheme 1.30. Cobalt-catalyzed C-H activation for the formation of $\mathrm{C}-\mathrm{C}$ bonds. ${ }^{[103-105]}$

Without a doubt, the formation of biaryls is one of the most important applications of $\mathrm{C}-\mathrm{H}$ activation, due to the abundance of biaryls in biologically active motifs and the deficits regarding sustainability and atom economy associated with cross coupling chemistry. ${ }^{[4]}$ In oxidative cobalt-catalyzed C-H activation, biaryl formations have been established beginning with the dimerization of quinoline benzamides 115. ${ }^{[106]}$ This approach was elaborated by the use of different directing groups to achieve selective $\mathrm{C}-\mathrm{H} / \mathrm{C}-\mathrm{H}$ cross-activation, ${ }^{[107]}$ while other methods used boronic acids 139 or activated heterocycles 52 or 53 (Scheme 1.31a). ${ }^{[108]}$ A noteworthy example for an oxidative cobalt-catalyzed $\mathrm{C}-\mathrm{H}$ arylation was published by Song, employing indoles 23 and boronic acids 139. While arylations of this substrate have also been achieved using low valent cobalt catalysis, ${ }^{[49,52]}$ (vide supra) this example remains one of the very rare oxidative-cobalt catalyzed transformations not dependent on a bidentate directing group (Scheme 1.31b). ${ }^{[109]}$ 
a) Arylations under Bidentate Assistance

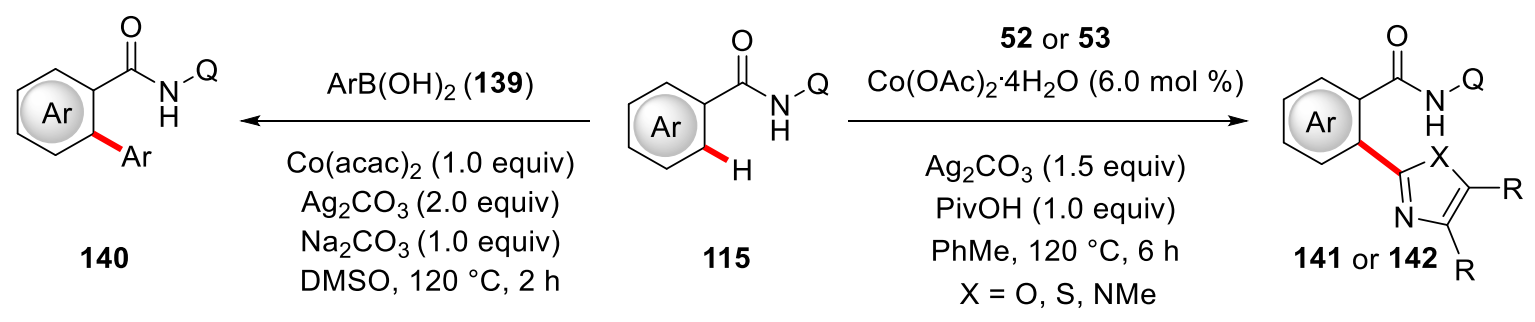

b) Arylation of Pyri(mi)dylindole

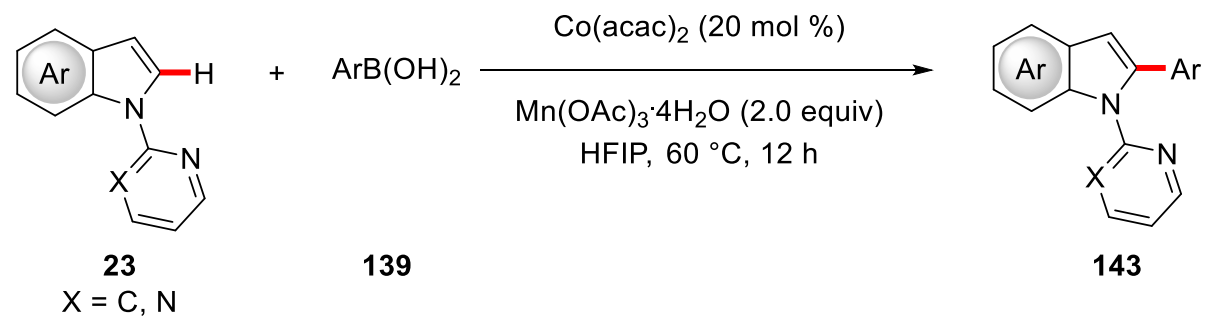

Scheme 1.31. Arylations using oxidative cobalt-catalyzed C-H activation. ${ }^{[108-109]}$

Oxidative cobalt-catalyzed $\mathrm{C}-\mathrm{H}$ activation is not limited to $\mathrm{C}-\mathrm{C}$ forming reactions, as also several $\mathrm{C}-\mathrm{X}$ formations have been disclosed. $\mathrm{C}-\mathrm{N}$ forming transformations have been realized using 8-aminoquinoline as well as pyridine- $N$-oxide directing groups using (cyclic) secondary alkyl amines 146 as well as arylamines 144 (Scheme 1.32a). ${ }^{[110]}$ With regard to $\mathrm{C}-\mathrm{O}$ bond forming reactions, both alkoxygenations and acyloxylations have been reported, by Song and recently by Chatani (Scheme 1.32b). ${ }^{[111]}$ Both reactions proceeded with good to excellent functional group tolerance and good yields. Furthermore, also alkenes were viable substrates in the presented alkoxylation protocol.[111b] Moreover, an oxidative cobalt-catalyzed $\mathrm{C}-\mathrm{H}$ halogenation was recently achieved by Chatani using molecular iodine 154 as the iodination reagent (Scheme 1.32c). ${ }^{[12]}$ While the reaction showed good functional group tolerance, the directing group had to be modified to exclude undesired side reactions. The mechanism of these transformations shall be discussed with the example of the cobaltcatalyzed $\mathrm{C}-\mathrm{H}$ acyloxylation (Scheme 1.33).[111a] After coordination of the cobalt catalyst to the deprotonated amide 115, oxidation from cobalt(II) to cobalt(III) followed by $\mathrm{C}-\mathrm{H}$ bond cleavage generates the five-membered intermediate 158 . This species can then undergo ligand exchange with the present acid to form intermediate 159. From this complex, the product 152 can be released by reductive elimination, followed by reoxidation of the cobalt catalyst. 
a) $C-N$ formations

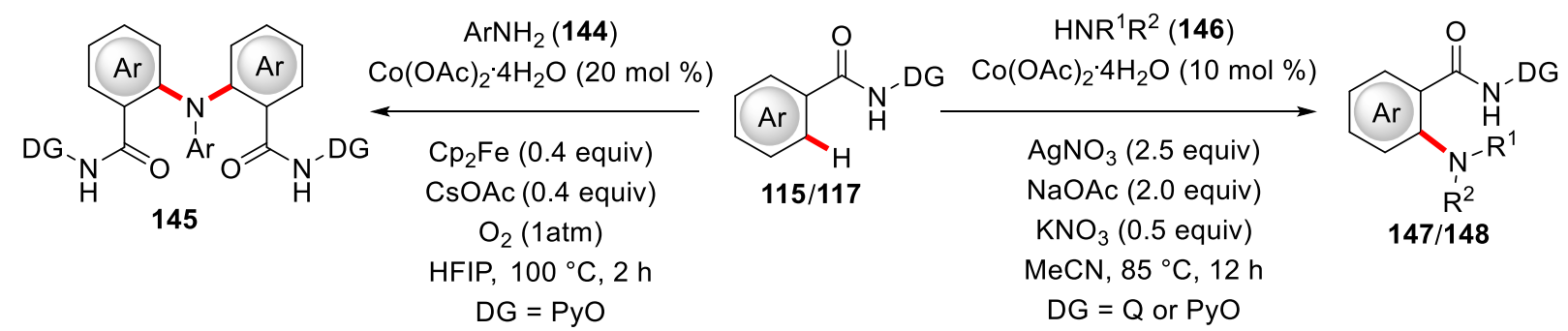

b) C-O formations

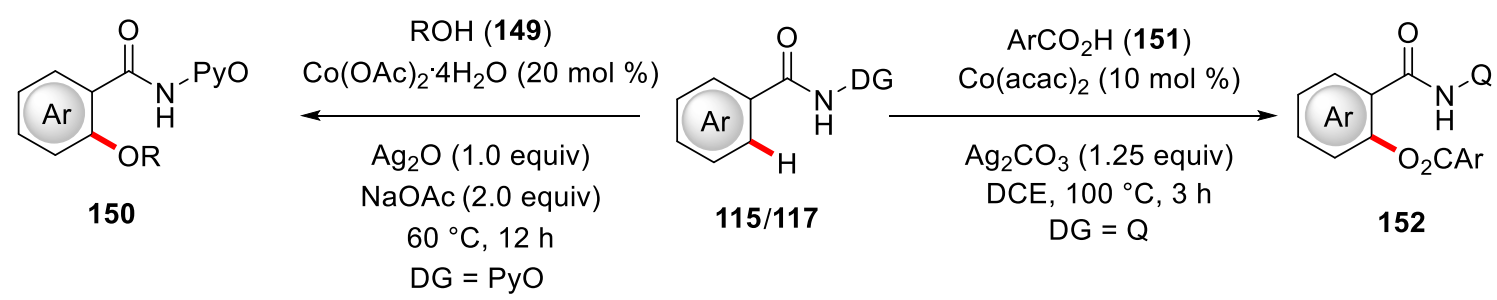

c) $\mathrm{C}-\mathrm{H}$ lodination

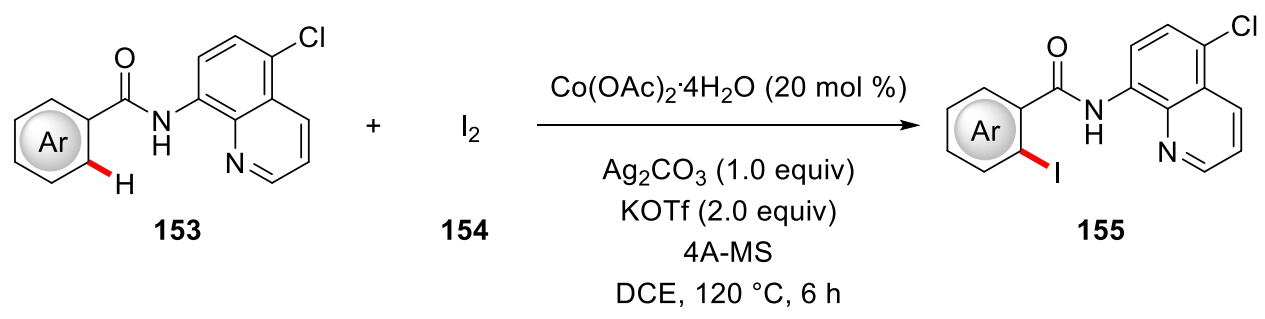

Scheme 1.32. Oxidative cobalt-catalyzed C-X formations. ${ }^{[109-112]}$

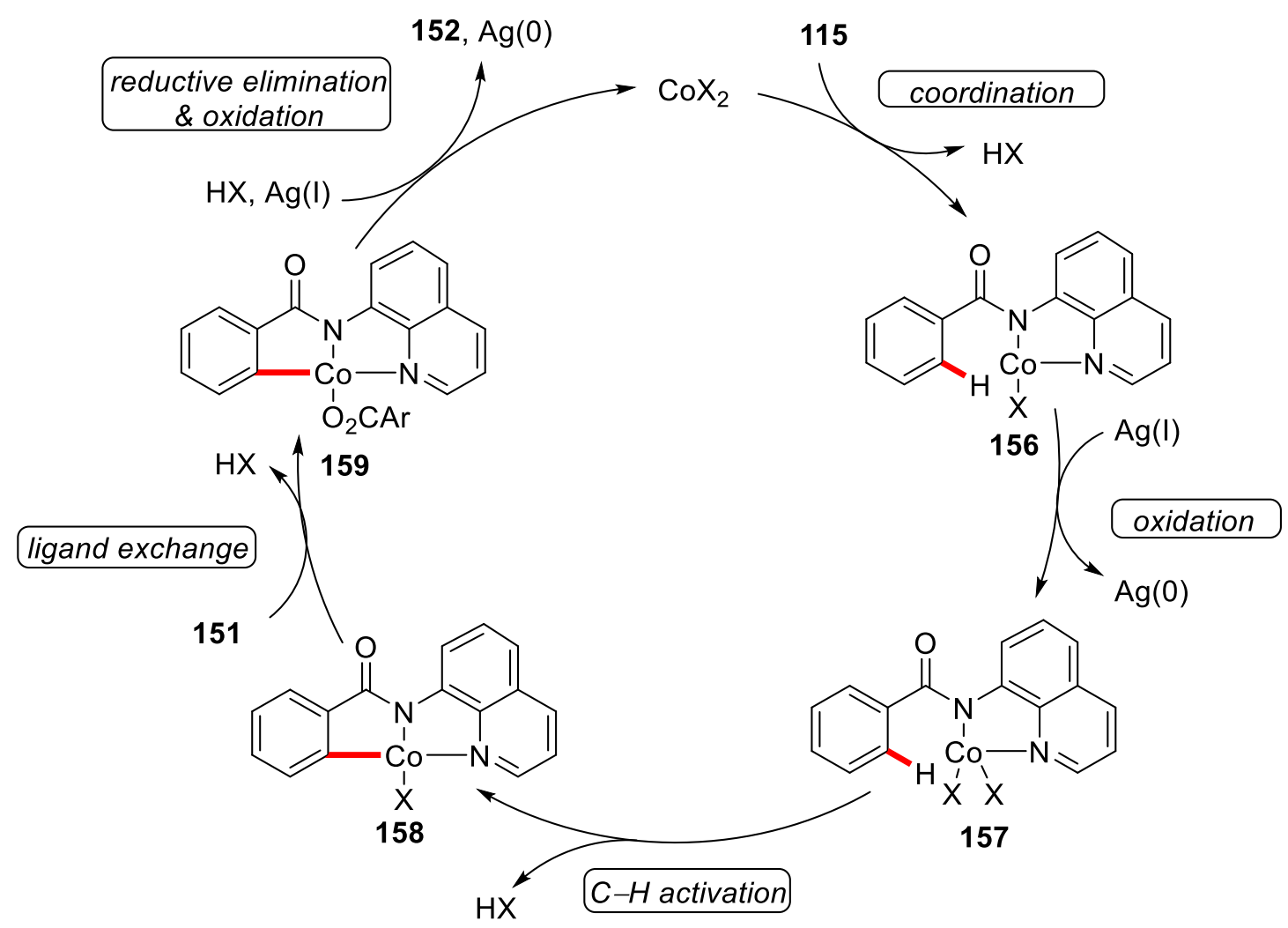

Scheme 1.33. Plausible mechanism for the cobalt-catalyzed $\mathrm{C}-\mathrm{H}$ acyloxylation.[111a] 
Finally, besides the oxidative $\mathrm{C}-\mathrm{H}$ activation of $\mathrm{C}\left(\mathrm{sp}^{2}\right)-\mathrm{H}$ bonds, a few reports have highlighted the ability of cobalt to activate $\mathrm{C}\left(\mathrm{sp}^{3}\right)-\mathrm{H}$ bonds. An intramolecular cyclizytion to generate small ring lactams was reported by He in 2015 (Scheme 1.34a). [113] Intermolecular transformations using either terminal alkynes ${ }^{[114]}$ or carbonmonooxide, (Scheme 1.34c) ${ }^{[115]}$ as coupling partners were disclosed recently likewise.

a) Intramolecular Cyclization<smiles>[R]C([R])(C[14CH3])C(=O)N[O-]</smiles>

b) Coupling with Terminal Alkynes

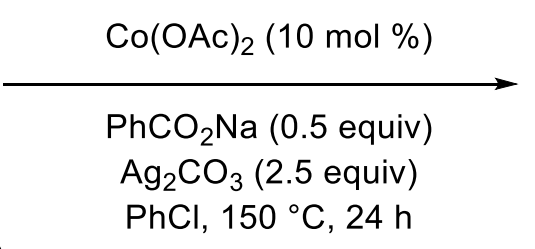

$\mathrm{PhCl}, 150{ }^{\circ} \mathrm{C}, 24 \mathrm{~h}$<smiles>[R]C1([R])CN(O)C1=O</smiles>

161

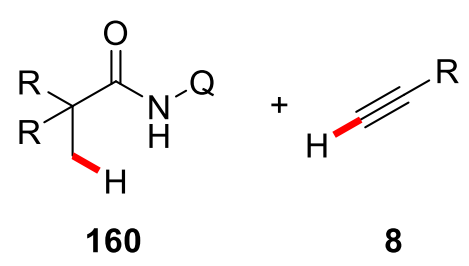

c) Coupling under CO Atmosphere

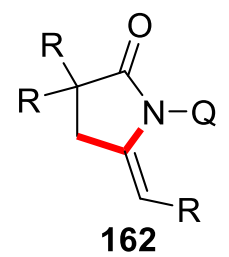

162

$$
\text { TBAI (4.0 equiv) }
$$$$
\text { pyridine (2.0equiv) }
$$

$\mathrm{PhCF}_{3}, 150^{\circ} \mathrm{C}, 24 \mathrm{~h}$<smiles>[R]C([R])(C[2H])C(=O)NO</smiles>

160

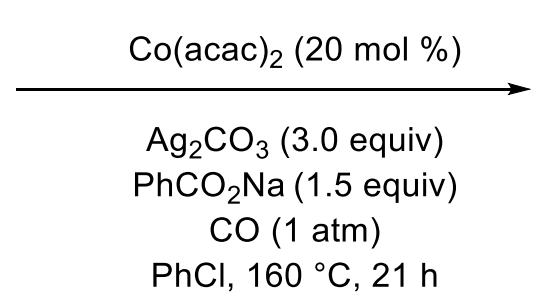

$\mathrm{PhCl}, 160^{\circ} \mathrm{C}, 21 \mathrm{~h}$

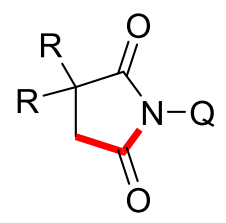

163

Scheme 1.34. Oxidative cobalt-catalyzed $\mathrm{C}\left(\mathrm{sp}^{3)}-\mathrm{H}\right.$ activation. ${ }^{[113-115]}$

\subsection{Manganese-Catalyzed C-H Activation}

After iron and titanium, manganese is the third most abundant transition metal in the earth's crust. ${ }^{[35]}$ Hence, it represents an essential trace element for life, with manganese cores being essential for a number of enzymes in human metabolism, such as arginases and manganese-superoxide dismutases.[116] Therefore, it is attractive as a catalyst, due to its availability, low price and low toxicity. The presence of manganese in many enzymes, led to the investigation of similar chemistry in laboratory model systems, ${ }^{[116 c, 117]}$ in due course realizing $\mathrm{C}-\mathrm{H}$ functionalizations by an 
outer-sphere mechanism for a number of transformations. ${ }^{[118]}$ However, the focus of this chapter shall be manganese(I)-catalyzed organometallic $\mathrm{C}-\mathrm{H}$ activation, ${ }^{[119]}$ so outer-sphere transformations and recent advances in low valent manganese chemistry ${ }^{[120]}$ will not be discussed.

An early stoichiometric $\mathrm{C}-\mathrm{H}$ activation by manganese was reported by Bruce and Stone, cyclometalating azobenzene 3 with $\mathrm{MeMn}(\mathrm{CO})_{5}(\mathbf{1 6 4})$ (Scheme 1.35). ${ }^{[121]}$ While the same complex $\mathbf{1 6 5}$ had been prepared two years earlier by Heck, ${ }^{[122]}$ his synthesis involved the transmetalation from palladium to manganese, and not $\mathrm{C}-\mathrm{H}$ activation by manganese itself. In the following years, several cyclometalated manganese complexes were synthesized using various substrates and manganese precursors. ${ }^{[123]}$

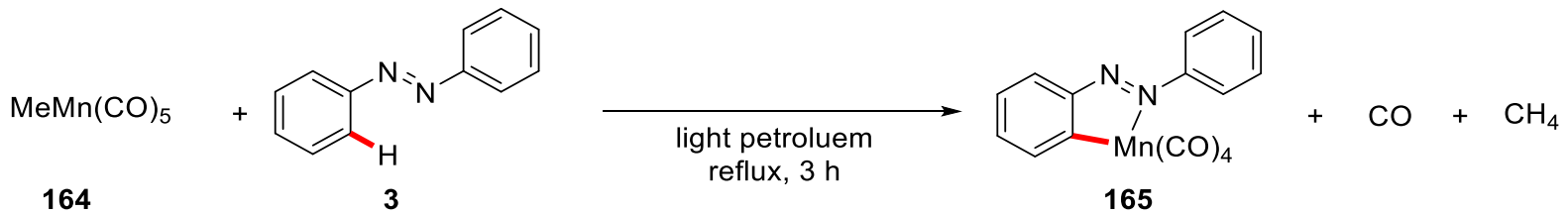

Scheme 1.35. Stoichiometric C-H activation with $\mathrm{MeMn}(\mathrm{CO})_{5}(164) .{ }^{[121]}$

Groundbreaking progress in catalytic $\mathrm{C}-\mathrm{H}$ activation by manganese(I) was achieved by Kuninobu and Takai in 2007 (Scheme 1.36). Using simple and stable $\operatorname{MnBr}(\mathrm{CO})_{5}$ (169) as the catalyst, ortho functionalization of phenylimidazoles 166 was achieved in the presence of triethylsilane 168 , albeit requiring stoichiometric silanes to ensure catalytic turnover . ${ }^{[124]}$

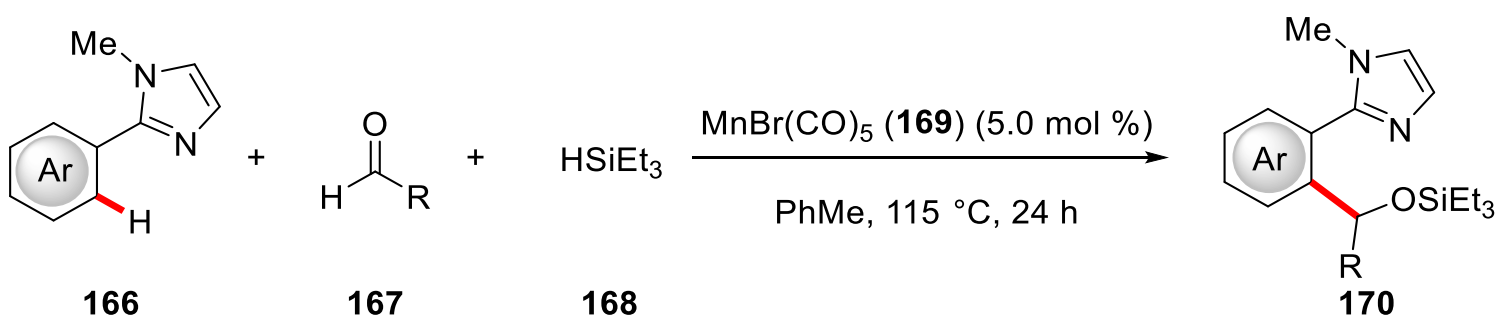

Scheme 1.36. Manganese(I)-catalyzed hydroarylation/silylation of aldehydes $167 .{ }^{[124]}$

In due course, hydroarylation of $\mathrm{C}-\mathrm{C}$ and $\mathrm{C}-\mathrm{X}$ bonds has become a broad field of application for manganese catalysis, with notable contributions by Wang ${ }^{[125]}$ and Ackermann ${ }^{[126]}$ among others. ${ }^{[127]}$ Over time, hydroarylations have been reported by these groups for aldehydes, nitriles, imines, alkynes and activated alkenes. In addition to hydroarylations, also $\mathrm{C}-\mathrm{H} / \mathrm{X}-\mathrm{H}$ annulations have been disclosed with diverse coupling partners to efficiently synthesize heterocycles. ${ }^{[128]}$ 
Besides these addition-based reactions, a significantly smaller number of substitutive protocols in manganese (I)-catalysis is known, although these reactions offer more synthetic diversity as they are not limited to $\mathrm{C}-\mathrm{C}$ or $\mathrm{C}-\mathrm{X}$ multiple bonds. Ackermann disclosed the substitutive allylation of indoles 23 and ketimines 26 by the use of allylcarbonates 90 as easily accessible allylating reagents (Scheme 1.37a). ${ }^{[129]} \mathrm{A}$ protocol for the $\mathrm{C}-\mathrm{H}$ cyanation of similar substrates was reported by the same group, relying on NCTS (96) as a mild and safe cyanating reagent (Scheme 1.37b). ${ }^{[130]}$ Finally, Glorius applied manganese catalysis to allenylation reactions by the use of similar alkynes 172 with an ester as the leaving group (Scheme 1.37c). ${ }^{[131]}$

a) Substitutive Allylation

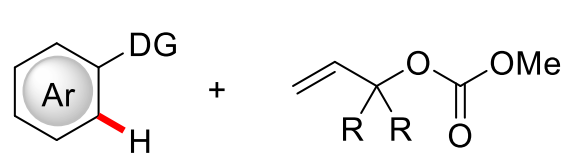

23 or 26

b) Cyanation<smiles>[R]c1c([2H])n([13CH3])c2ccccc12</smiles>

23

c) Substitutive Allenylation

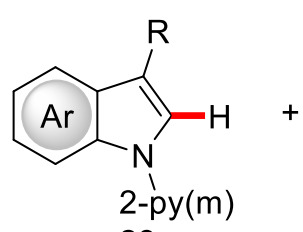

23

90

$$
\begin{gathered}
\mathrm{Ph}_{-}-\mathrm{CN} \\
\frac{1}{\mathrm{Ts}} \\
96
\end{gathered}
$$
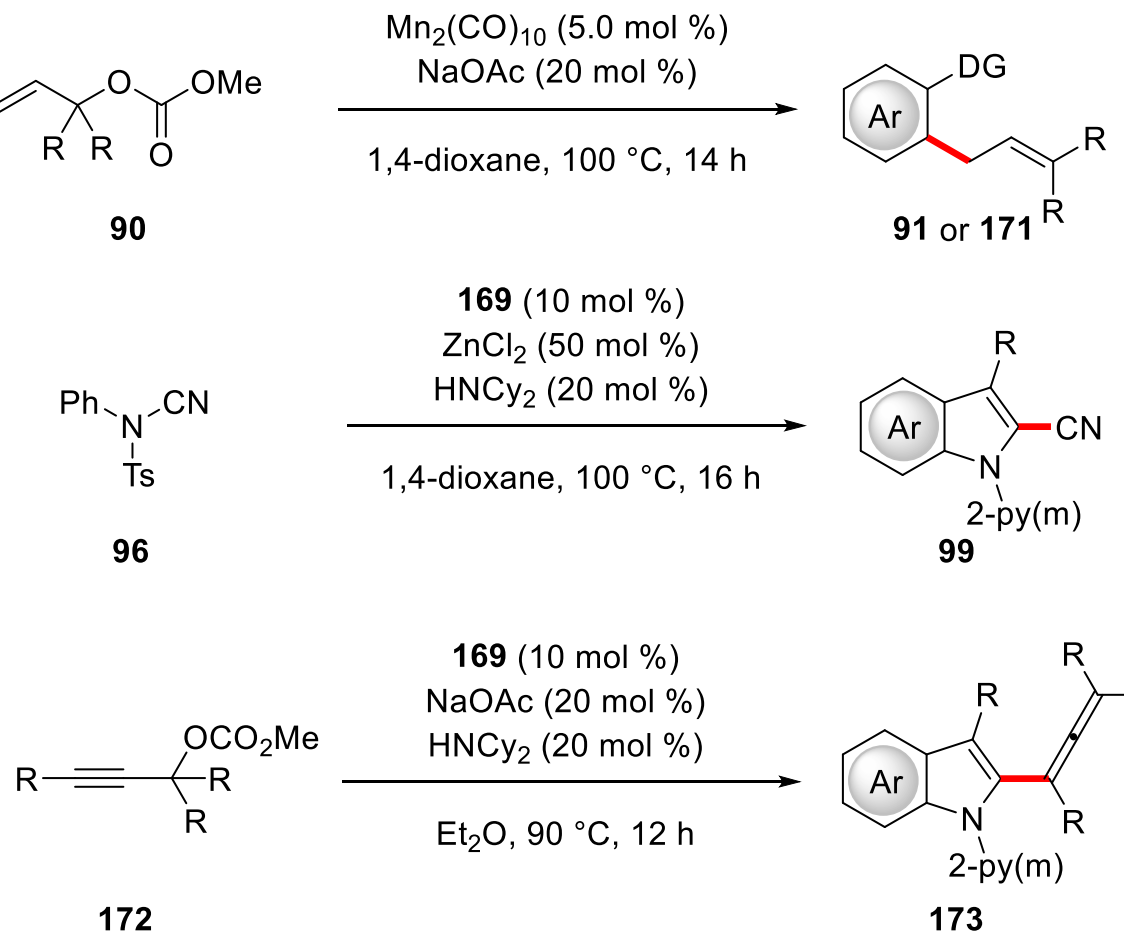

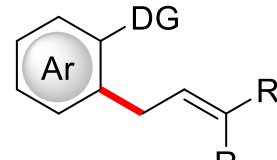

91 or $^{171^{\mathrm{R}}}$

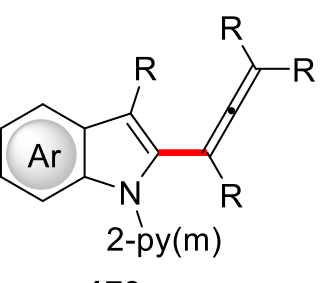

173

Scheme 1.37. Substitutive manganese(I)-catalyzed transformations. ${ }^{[129-131]}$

Mechanistic proposals for these transformations were rationalized, which are discussed here with the example of the manganese-catalyzed $\mathrm{C}-\mathrm{H}$ allylation (Scheme 38). ${ }^{[129]}$ The key intermediate, the five-membered manganacycle 176 is generated by a base-assisted $\mathrm{C}-\mathrm{H}$ metalation. Coordination of allylcarbonate 90 in a chelating fashion sets the stage for a facile insertion of the double bond into the $\mathrm{Mn}-\mathrm{C}$ bond. Subsequent $\beta$-elimination of the carbonate releases the final product 171 and regenerates the catalytically active species 174 (Scheme 1.38). ${ }^{[129]}$ 


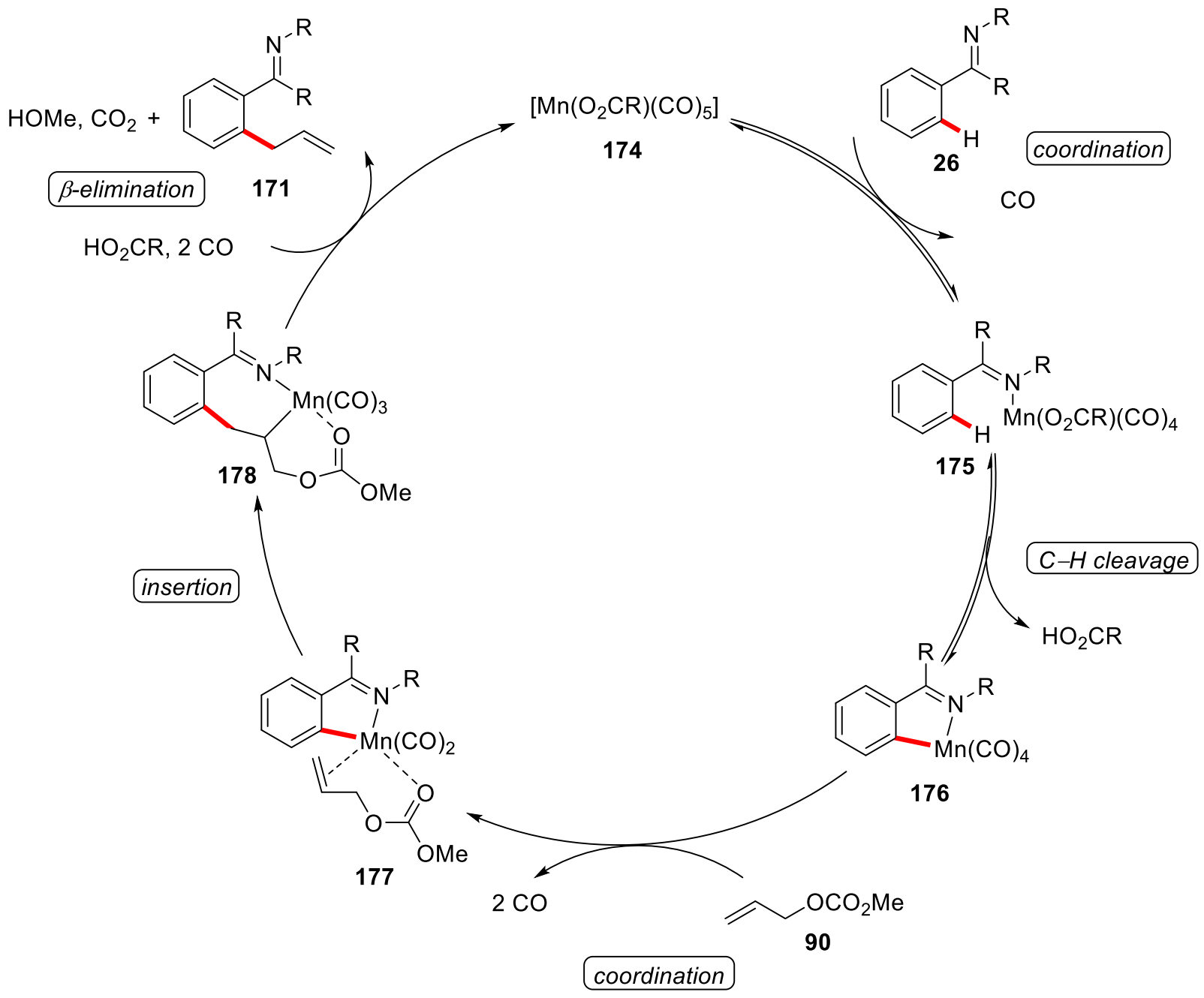

Scheme 1.38. Proposed mechanism for the manganese(I)-catalyzed $\mathrm{C}-\mathrm{H}$ allylation. [129]

Lastly, manganese $(\mathrm{I})$ catalysis has been exploited to catalyze challenging $\mathrm{C}-\mathrm{H} / \mathrm{C}-\mathrm{F}$ activation reactions. This is noteworthy, as $\mathrm{C}-\mathrm{F}$ bonds are generally relatively inert due to the high bond strength and the reluctance of organofluorine compounds to coordinate to metal centers. ${ }^{[132]}$ Despite these challenges, $\mathrm{C}-\mathrm{H} / \mathrm{C}-\mathrm{F}$ activation has been successfully employed in the manganese-catalyzed perfluoroallylation by Ackermann (Scheme 1.39) ${ }^{[133]}$ and in the monofluoroalkenylation by Ackermann ${ }^{[133]}$ and Loh $^{[134]}$ in independent reports.

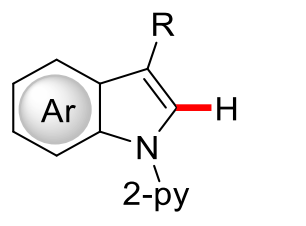

23

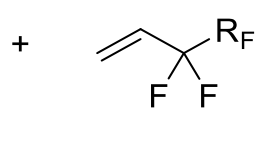

179

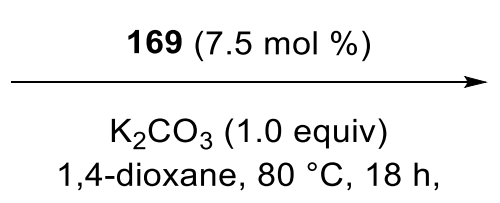

1,4-dioxane, $80^{\circ} \mathrm{C}, 18 \mathrm{~h}$

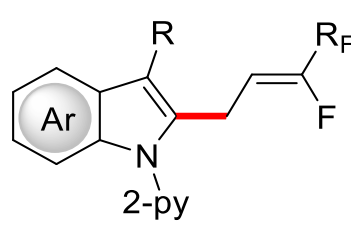

180

Scheme 1.39. C-H/C-F activation by manganese(I)-catalysis. ${ }^{[133]}$ 


\subsection{Electrochemical Transition Metal-Catalyzed C-H Activation}

The growing demands for renewable power sources, including solar energy, hydropower and wind energy (Figure 1.5), ${ }^{[135]}$ makes the utilization of electricity to drive chemical transformations increasingly desirable.

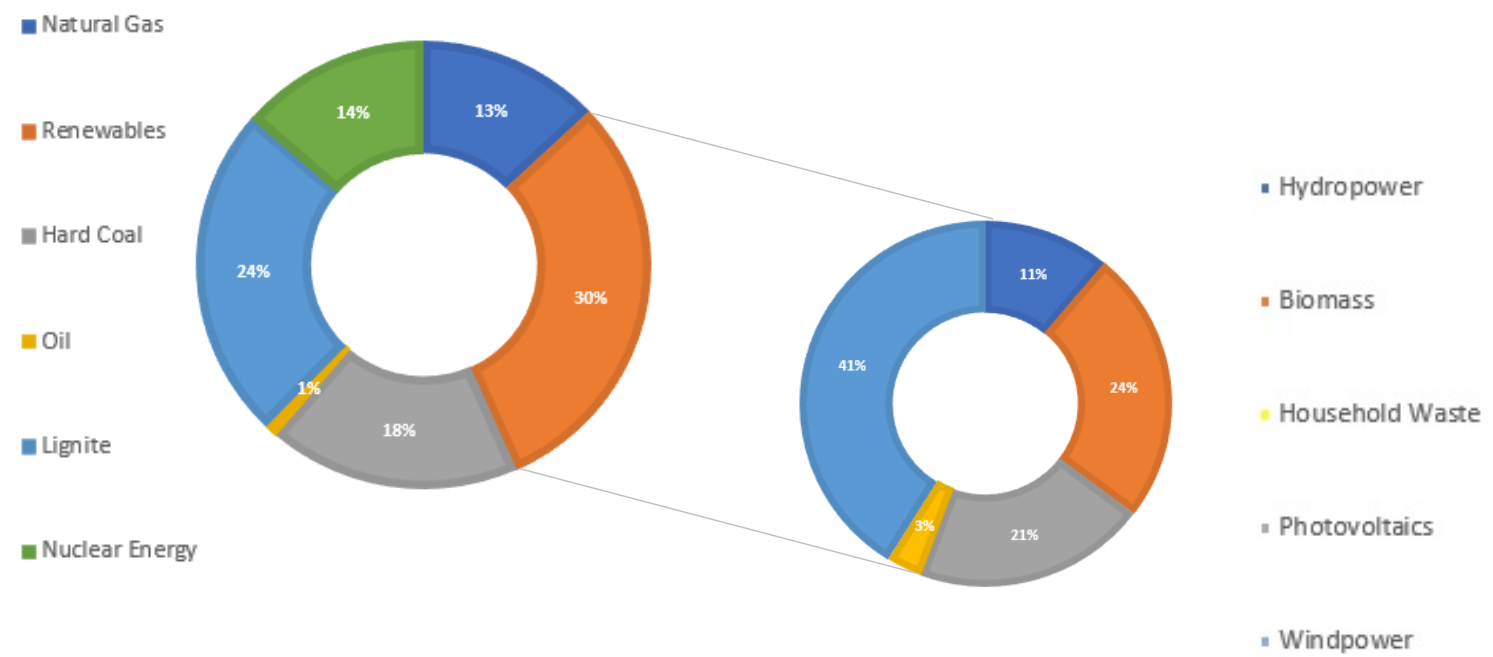

Figure 1.5. Share of energy sources of gross electricity production in Germany 2016. ${ }^{[135]}$

Due to the increasingly sustainable energy production, the use of electricity in chemical synthesis would therefore significantly reduce the environmental footprint of molecular sciences. ${ }^{[136]}$ Furthermore, if electricity is employed to substitute costly and potentially toxic stoichiometric oxidants and reductants the cost efficiency of organic synthesis is drastically improved (Figure 1.6). ${ }^{[137]}$ Moreover, the use of electricity allows to tune the applied potential and current to a transformation, thus enabling milder conditions and potentially better selectivities. In case of chemical oxidation/reduction, the potential of the employed redox-reagent and the metal may not always overlap and thus leave room for more efficient reaction conditions by electrocatalysis (Table 1.1). ${ }^{[35]}$ 


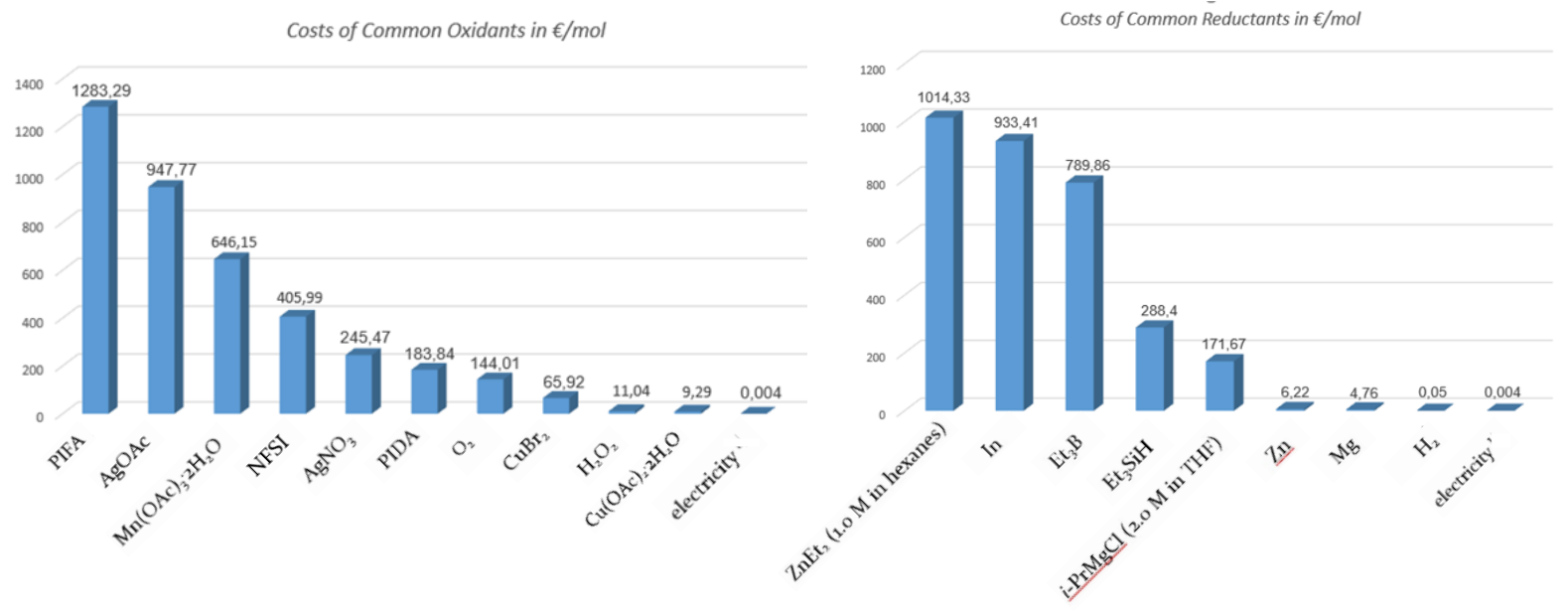

Figure 1.6. Costs of common oxidants and reductants. ${ }^{[137]}$

Table 1.1. Standard potentials of selected redoxreagents and transition metals. ${ }^{[35]}$

Reaction

Potential $\mathrm{E}^{0}[\mathrm{~V}]$

\section{Oxidants}

$\mathrm{H}_{2} \mathrm{O}_{2}+2 \mathrm{H}^{+}+2 \mathrm{e}^{-} \rightarrow 2 \mathrm{H}_{2} \mathrm{O}$

$\mathrm{Mn}(\mathrm{III})+\mathrm{e}^{-} \rightarrow \mathrm{Mn}(\mathrm{II})$

$\mathrm{Ag}(\mathrm{l})+\mathrm{e}^{-} \rightarrow \mathrm{Ag}(0)$

0.79

$\mathrm{Cu}(\mathrm{II})+\mathrm{e}^{-} \rightarrow \mathrm{Cu}(\mathrm{I})$

0.15

\section{Reductants}

$\ln ^{3+}+3 \mathrm{e}^{-} \rightarrow \ln$

$\mathrm{Zn}^{2+}+2 \mathrm{e}^{-} \rightarrow \mathrm{Zn}$

$\mathrm{Mg}^{2+}+2 \mathrm{e}^{-} \rightarrow \mathrm{Mg}$

\section{Transition Metals}

$\mathrm{Co}^{3+}+\mathrm{e}^{-} \rightarrow \mathrm{Co}^{2+}$

$\mathrm{Pd}^{2+}+2 \mathrm{e}^{-} \rightarrow \mathrm{Pd}$

0.95

$\mathrm{Ru}^{2+}+2 \mathrm{e}^{-} \rightarrow \mathrm{Ru}$

0.46

Electro-organic synthesis has been discussed in science, since the first reports by Volta, Faraday and Kolbe. ${ }^{[138]}$ Oxidation reactions of activated substrates have been studied since the 1960s, ${ }^{[139]}$ with recent progress broadening the applicability towards a range of activated substrates, ${ }^{[140]}$ with key contributions from Waldvogel, ${ }^{[141]}$ Baran, ${ }^{[142]}$ Yoshida ${ }^{[143]}$ and $X u,{ }^{[144]}$ among others. ${ }^{[145]}$ In contrast, the focus of this 
introduction is on $\mathrm{C}-\mathrm{H}$ activations catalyzed by transition metals under the assistance of electricity. Moreover, outer-sphere transformations with early reports using noble metals ${ }^{[146]}$ and recent advances towards $3 d$-metals ${ }^{[147]}$ will also not be discussed in detail.

\subsubsection{Palladium-Catalyzed Transformations}

An elegant early example of palladium-catalyzed electrochemical $\mathrm{C}-\mathrm{H}$ activation was achieved by Amatore and Jutand in 2007 (Scheme 1.40). ${ }^{[148]}$ They reported on a Fujiwara-Moritani-type reaction, ${ }^{[149]}$ using co-catalytic amounts of benzoquinone (182). While the reaction scope was severely limited, the authors provide a detailed mechanistic concept. The reaction is proposed to be initiated by base-assisted $\mathrm{C}-\mathrm{H}$ activation, followed by an insertion of the double bond into the $\mathrm{Pd}-\mathrm{C}$ bond (Scheme 1.41). A subsequent $\beta$-elimination liberates the product 183 and a reductive elimination of acetic acid generates palladium(0). Intermediate 188 is then reoxidized by benzoquinone (182) and the thus formed hydroquinone 189 is then oxidized again at the anode.
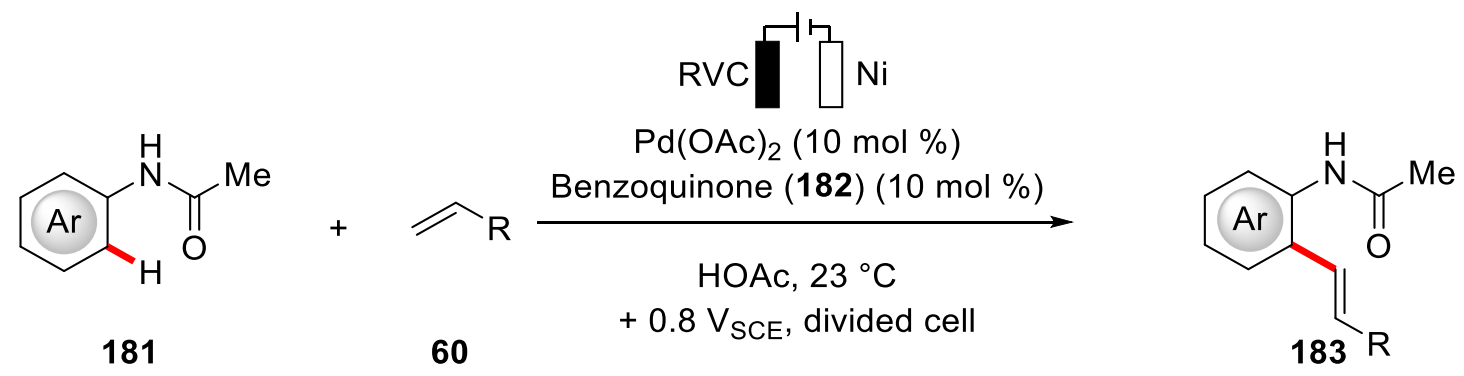

Scheme 1.40. Electrocatalytic palladium-catalyzed C-H alkenylation. ${ }^{[148]}$

In 2009, Kakiuchi reported on a palladium-catalyzed $\mathrm{C}-\mathrm{H}$ halogenation using electrochemistry (Scheme 1.42). ${ }^{[150]}$ Here, electricity was essential to generate the electrophilic halonium cation from mineral acids, which presents an elegant and costeffective alternative to other halogenation reactions. This approach was extended to include $\mathrm{C}-\mathrm{H}$ iodinations using molecular iodine (154) or potassium iodide.[151] Additionally, $\mathrm{C}-\mathrm{H}$ chlorinations of benzamides 153 , including the synthesis of marketed drug vismodegib, ${ }^{[152]}$ were disclosed. ${ }^{[153]}$ 


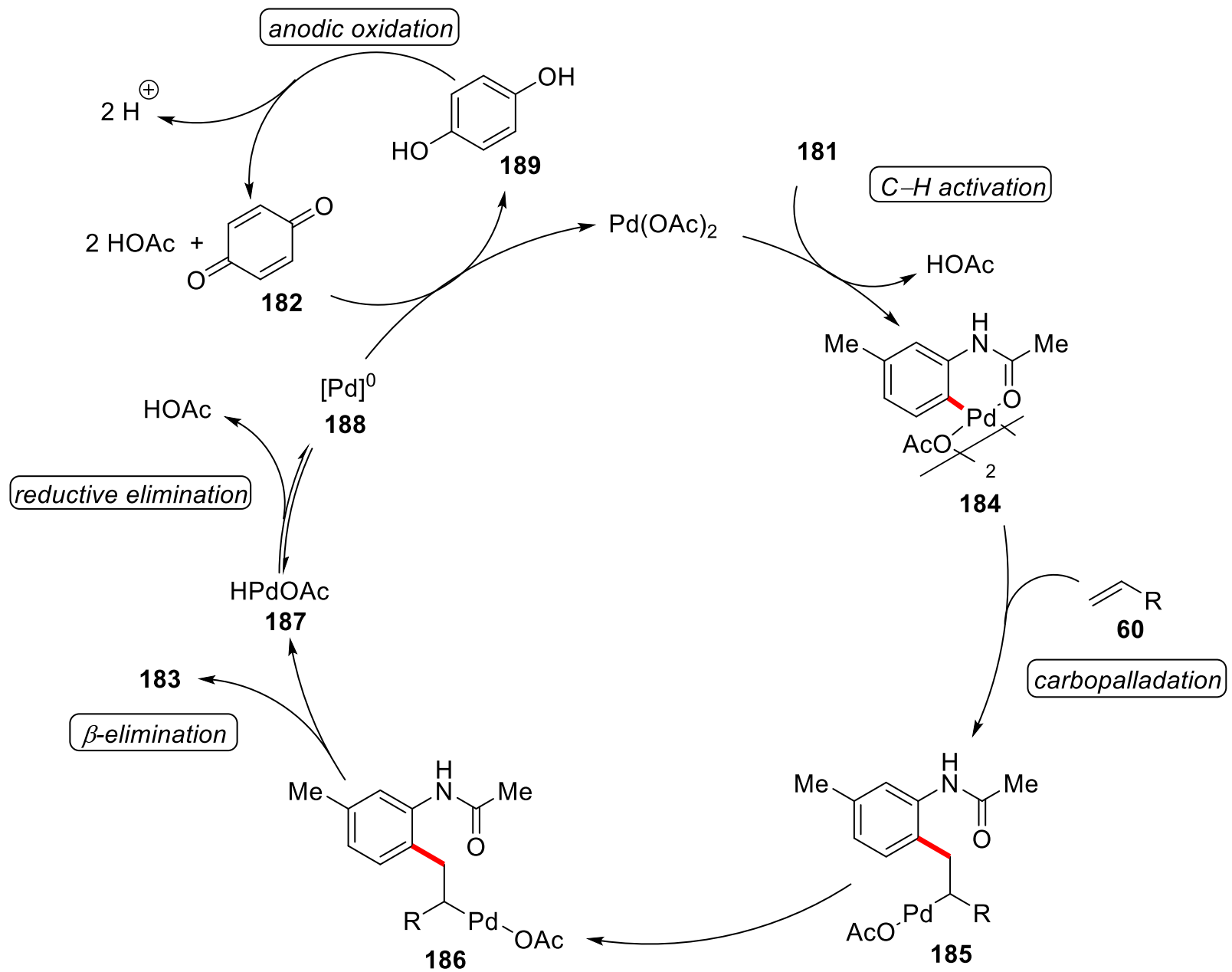

Scheme 1.41. Electrocatalytic Fujiwara-Moritani reaction. ${ }^{[148]}$<smiles>c1ccc(-c2ccccn2)cc1</smiles>

23

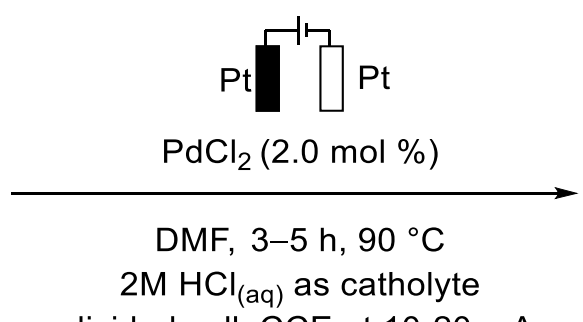

divided cell, CCE at 10-20 mA

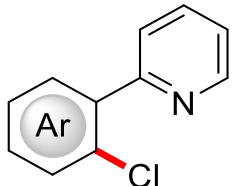

190

Scheme 1.42. Electrochemical C-H halogenation of phenylpyridines $23 .{ }^{150]}$

Along the same lines, Kakiuchi reported on the homodimerization of phenylpyridines 23 in the presence of stoichiometric or co-catalytic amounts of iodine (154). ${ }^{[154]}$ 
$\mathrm{C}-\mathrm{H}$ oxygenations were achieved by electrochemical transition metal-catalyzed $\mathrm{C}-\mathrm{H}$ bond activation by Budnikova using palladium complexes in the coupling of perfluoroacids and phenylpyridines 23.[155] While the scope was limited, the authors supported their mechanistic proposal by detailed studies, including the isolation of key intermediates as well as cyclovoltammetric (CV) studies. ${ }^{[156]}$ Moreover, besides the desired perfluoroalkoxylation, at higher current also significant amounts of perfluoroalkylated product were observed. This transformation was subsequently improved to yields of more than $80 \% .{ }^{[157]}$ Related transformations were also proposed in comparable yields by nicke[ ${ }^{[158]}$ and iron ${ }^{[157 a]}$ catalysis. Recently, Mei disclosed C-H oxygenations using electrochemical palladium-catalysis. ${ }^{[159]}$ This work constitutes the first $\mathrm{C}-\mathrm{H}$ activation on $\mathrm{C}\left(\mathrm{sp}^{3}\right)-\mathrm{H}$ bonds using transition metal-catalysis and electrochemistry. The desired reaction was achieved using palladium acetate as the catalyst in a divided cell setup using carboxylic acids 192 as the solvent and the corresponding sodium salt 193 as base (Scheme 1.43).

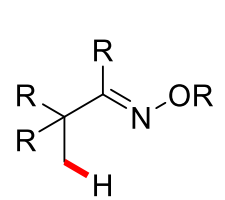

191

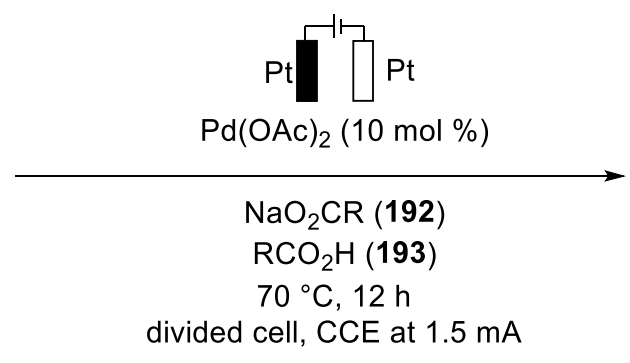

divided cell, CCE at $1.5 \mathrm{~mA}$

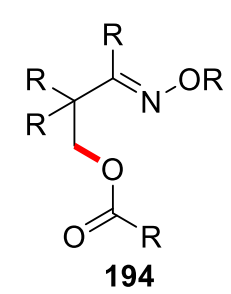

194

Scheme 1.43. Palladium-catalyzed Oxygenation of $\mathrm{C}\left(\mathrm{sp}^{3}\right)-\mathrm{H}$ bonds. ${ }^{[159]}$

The mechanism was proposed to proceed by a proximity-induced base-assisted $\mathrm{C}-\mathrm{H}$ metalation at the primary $\mathrm{C}-\mathrm{H}$ bond (Scheme 1.44). ${ }^{[159]}$ The thus formed intermediate 196 is oxidized to a palladium(III) or palladium(IV) complex 197, which then undergoes reductive elimination to form the $\mathrm{C}-\mathrm{O}$ bond, followed by a ligand exchange to furnish product 194 (Scheme 1.44). In a follow-up work, Mei could show that also the oxygenation of aromatic $\mathrm{C}-\mathrm{H}$ bonds was feasable with a similar catalytic system. ${ }^{[160]}$ Thereafter, Sanford disclosed a similar transformation, broadening the applicability to include quinoline and pyrazine as directing groups. ${ }^{[161]}$ 
<smiles>[R]ON=C(C)C(C)(C)COC(C)(C)C(C)C(C)C(C)(C)C(C)=NO[R]</smiles>

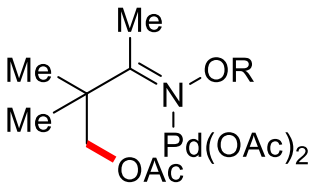

198

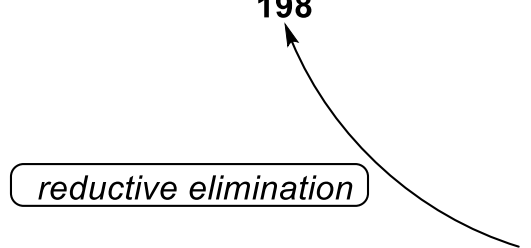

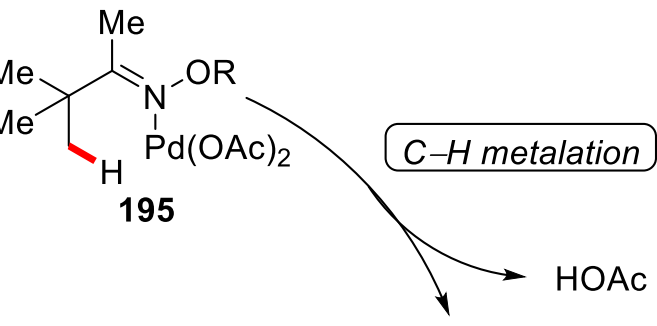<smiles>[R]N1C(=C(C)C)C(C)(C)C[P+]1[O-]</smiles>

196

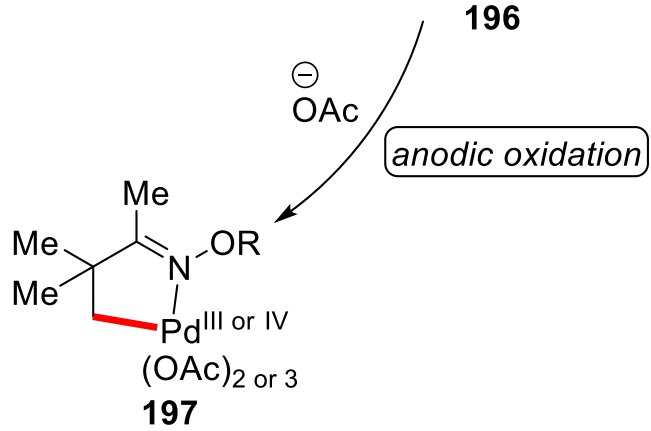

Scheme 1.44. Plausible mechanism for the palladium-catalyzed $\mathrm{C}-\mathrm{H}$ oxygenation. ${ }^{[159]}$

Additionally, Mei discovered an oxidative alkylation by palladium catalysis using alkyltrifluoroborates 200 (Scheme 1.45a). ${ }^{[162]}$ In the same report, Mei also disclosed a palladium-catalyzed benzoylation of oximes 199 (Scheme 1.45b).

a) Electrocatalytic palladium-catalyzed methylation
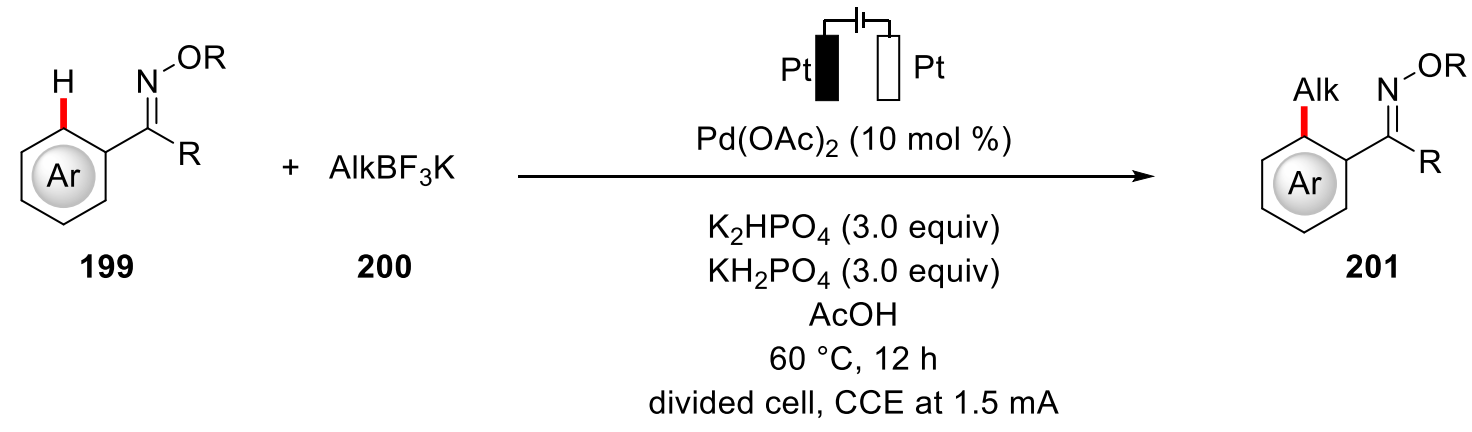

201

at $1.5 \mathrm{~mA}$

b) Electrocatalytic palladium-catalyzed acylation
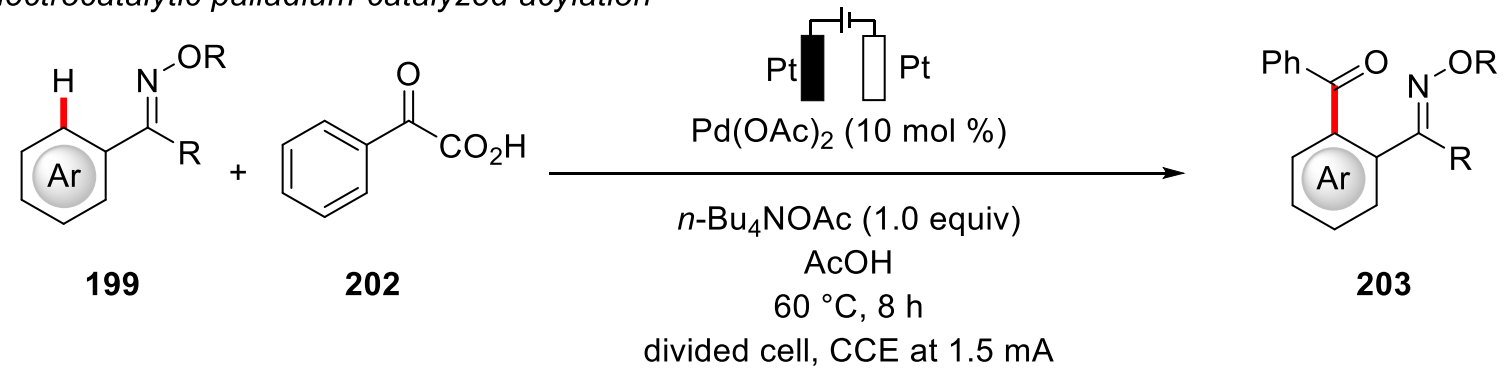

Scheme 1.45. Palladium-catalyzed alkylation and acylation. ${ }^{[162]}$ 


\subsubsection{Transformations Catalyzed by other Transition Metals}

At the outset of this thesis, no electrocatalytic $\mathrm{C}-\mathrm{H}$ activation was known employing metals other than palladium. However, during the course of this thesis, other reports were published, which shall be discussed in this following chapter.

Ruthenium-catalyzed $\mathrm{C}-\mathrm{H}$ activation under assistance of electricity was only recently realized by Xu based on a previously reported ${ }^{[163]}$ oxidative indole synthesis (Scheme 1.46). ${ }^{[164]}$ Preliminary results also indicated that ruthenium-catalyzed [4+2] annulation of benzylamine to isoquinolines are viable. ${ }^{[164]}$

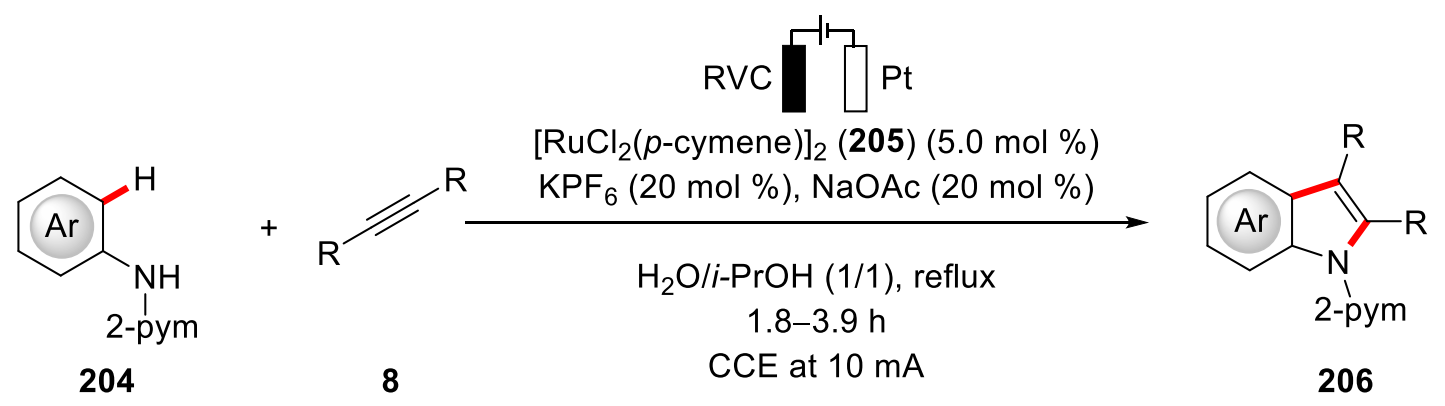

Scheme 1.46. Ruthenium-catalyzed electrochemical indole synthesis. ${ }^{[164]}$

Concurrently, Ackermann developed a ruthenium-catalyzed synthesis of isocoumarines 121 by $\mathrm{C}-\mathrm{H} / \mathrm{O}-\mathrm{H}$ annulation (Scheme 1.47). ${ }^{[165]}$ Noteworthy is the use of weakly coordinating benzoic acids $\mathbf{1 1 6}^{[166]}$ as substrates, showing for the first time electrochemical $\mathrm{C}-\mathrm{H}$ activation by transition metals without the use of strongly coordinating nitrogen atoms.<smiles>O=C(O)c1ccccc1</smiles>

116<smiles>[R]C#[R]</smiles>

8

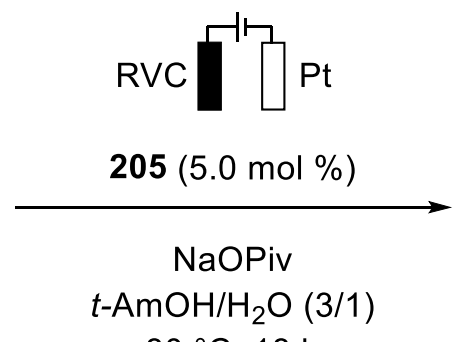

$80^{\circ} \mathrm{C}, 18 \mathrm{~h}$

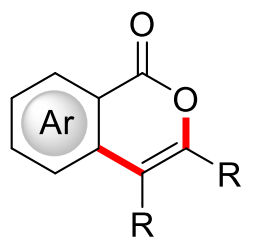

121 undivided cell, CCE at $4.0 \mathrm{~mA}$

Scheme 1.47. Ruthenium-catalyzed electrochemical $\mathrm{C}-\mathrm{H} / \mathrm{O}-\mathrm{H}$ annulation. ${ }^{[165]}$

Moreover, besides benzoic acids 116, also benzamides 11 were found to be viable substrates. ${ }^{[165]} \mathrm{A}$ plausible catalytic cycle was proposed, which includes the formation of five-membered ruthenacycle $\mathbf{2 0 8}$, followed by coordination and migratory insertion of alkyne 8 (Scheme 1.48). ${ }^{[165]}$ From the resulting seven-membered species 210, reductive elimination generates the product, which is still attached to the ruthenium( 0 ) 
center in sandwich complex 211. Upon anodic oxidation to regenerate ruthenium(II)carboxylate species 207, the desired product 121 is liberated (Scheme 1.48).

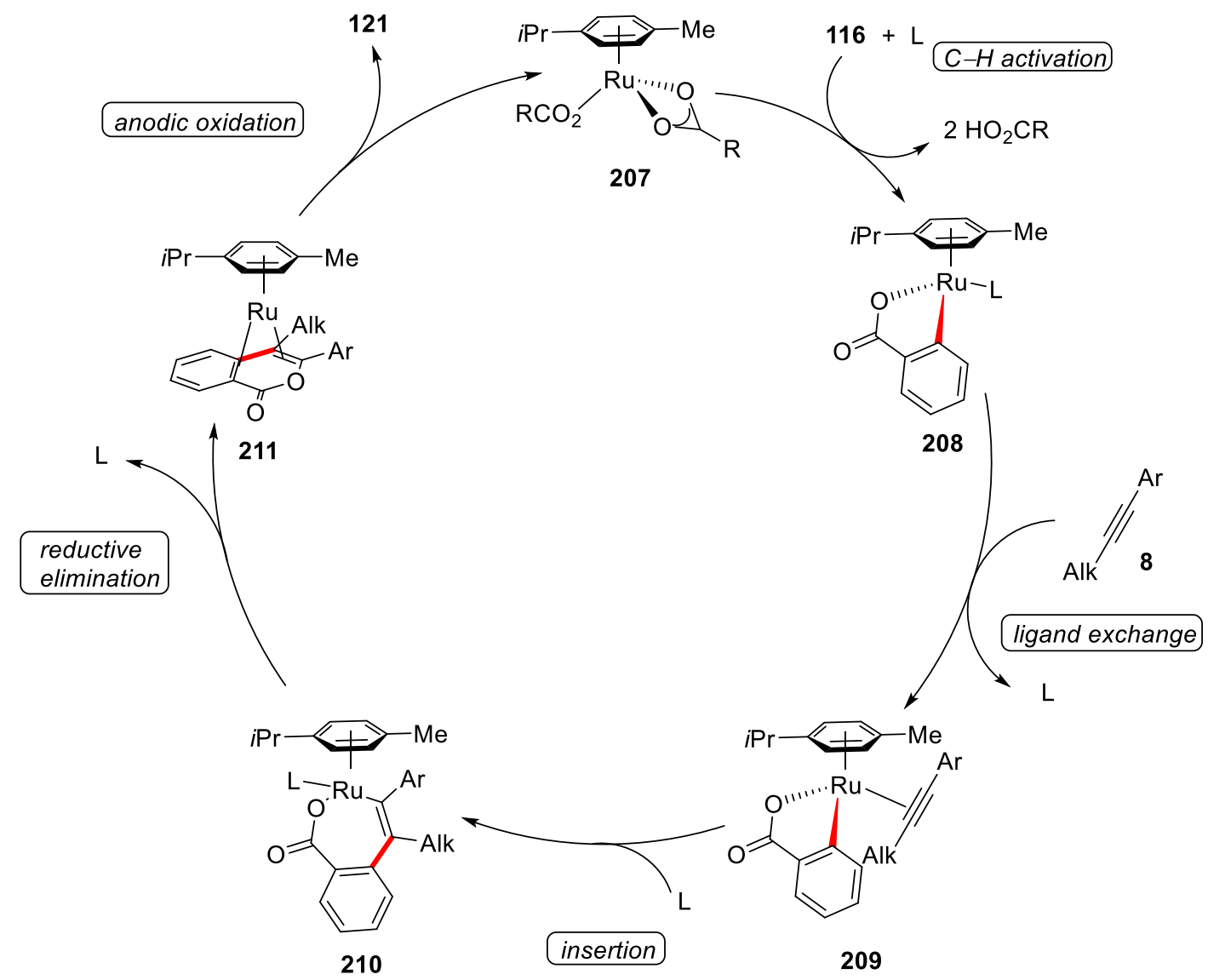

Scheme 1.48. Plausible mechanism for the ruthenium-catalyzed $\mathrm{C}-\mathrm{H} / \mathrm{O}-\mathrm{H}$ annulation. ${ }^{165]}$

Cobalt-catalyzed electrochemical cross-couplings have been known for over a decade through the pioneering work from Gosmini. ${ }^{[167]}$ However, cobalt-catalyzed electrochemical $\mathrm{C}-\mathrm{H}$ activation remained elusive. Although this thesis presents substantial contributions to the field of electrochemical cobalt-catalyzed $\mathrm{C}-\mathrm{H}$ activation later, concurrently published contributions shall be discussed here shortly.

Recently, Ackermann reported on the electrochemical cobalt-catalyzed isoquinolone formation by assistance of the pyridine-N-oxide directing group (Scheme 1.49). ${ }^{[168]}$ This approach was later extended by Lei to also include the functionalization using gaseous ethylene and ethyne. ${ }^{[169]}$ 


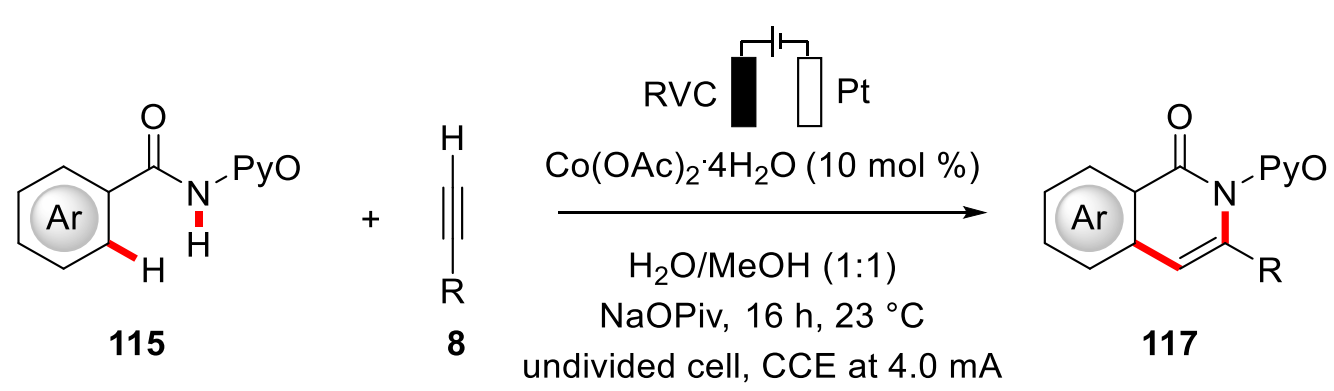

Scheme 1.49. Electrochemical cobalt-catalyzed $\mathrm{C}-\mathrm{H}$ activation/annulation. ${ }^{168]}$ 


\section{Objectives}

In the last decades, C-H activation exerted a significant influence on organic synthesis, as it became more efficient, cost-effective and generally applicable. $[4,30]$ Also, considerable advances have been made in the use of earth-abundant $3 \mathrm{~d}$ metals, ${ }^{[18 a}$, 119, 170] rendering these methods more suitable for sustainable organic synthesis. Especially in the field of cobalt-catalyzed reactions, ${ }^{[48,69,171]}$ with the use of low-valent cobalt, $\mathrm{Cp}{ }^{\star} \mathrm{Co}(\mathrm{III})$-complexes and simple cobalt salts, three independent and to some degree complementary regimes of catalytic action are available.

Direct alkenylations using low-valent cobalt catalysis are known, ${ }^{[66]}$ however, these transformations are highly dependent of the ligand, as even small changes in the substitution pattern can dramatically alter the outcome. Triazolium salts were rarely used in $\mathrm{C}-\mathrm{H}$ activation, but a large number of triazolium salts are available due to their prominence in organo-catalysis. ${ }^{[172]}$ Therefore, triazolium salts 212 were tested as (pre)ligands in cobalt-catalyzed alkenylations (Scheme 2.1).

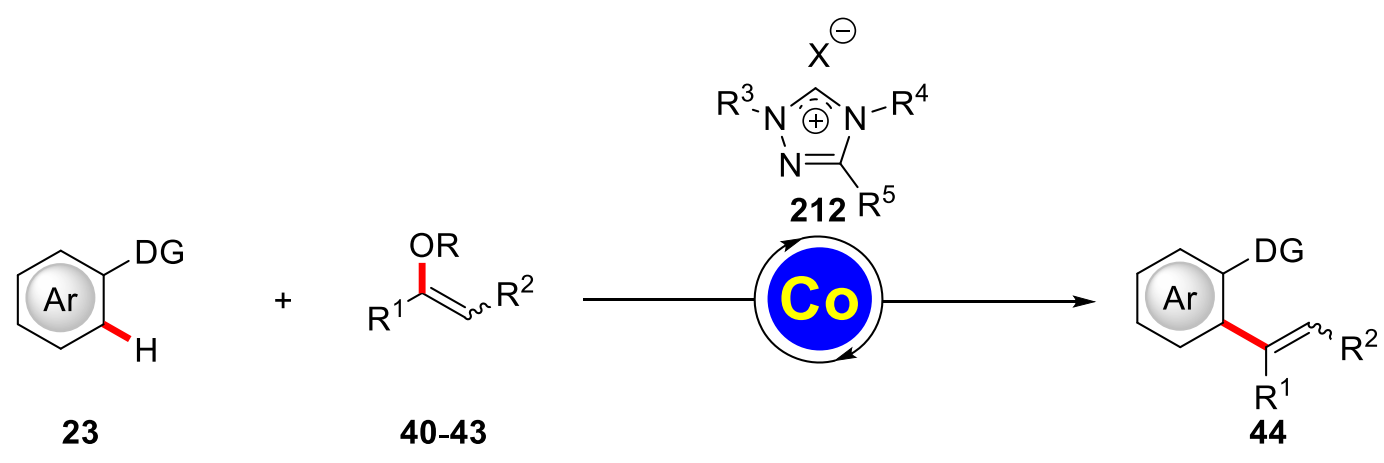

Scheme 2.1. Cobalt-catalyzed C-H alkenylation with triazolium salts 212 as (pre)ligands.

Cobalt-catalysis by $\mathrm{Cp}{ }^{\star} \mathrm{Co}(\mathrm{III})$-complexes does not feature the highly modular approach of low-valent cobalt catalysis. However, the functional group tolerance is considerably higher. [48a, 69] Allyl groups are important building blocks and offer the possibility to be functionalized in post-synthetic transformations, which makes the introduction of allyl groups by $\mathrm{Cp}^{\star} \mathrm{Co}(\mathrm{III})$-catalysis highly desirable (Scheme 2.2).

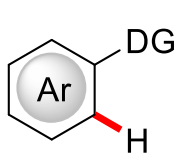

22 or 23

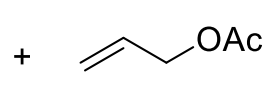

213

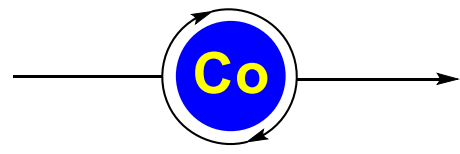

Scheme 2.2. Cobalt-catalyzed C-H allylation.

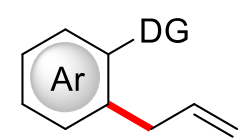

91 or 214 
Likewise, alkynes offer huge possibilities for post-synthetic functionalizations. This is especially important given the biorthogonal nature of the alkyne moiety and possible applications in late-stage peptide ligation.[173] Base metal-catalyzed protocols for alkynylations were at the outset of this thesis only known for cobalt using hypervalent iodine reagents $\mathbf{8 8}$ under harsh reaction conditions. ${ }^{[78]}$ Therefore, a cobalt-catalyzed protocol at mild conditions using bromoalkynes 132 should be developed for the alkynylation of heteroarenes. Additionally, this transformation is interesting also for manganese-catalyzed processes, as substitutive transformations for this metal are scarce (Scheme 2.3). ${ }^{[119]}$

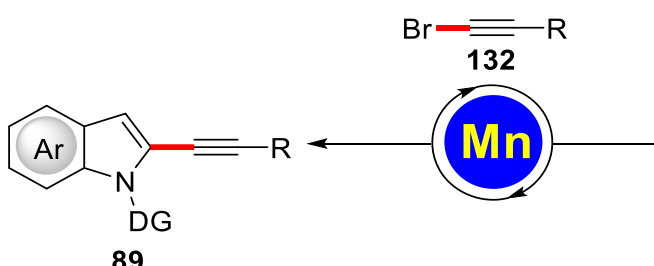

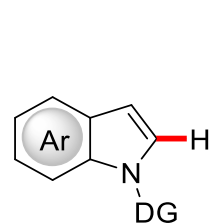

23

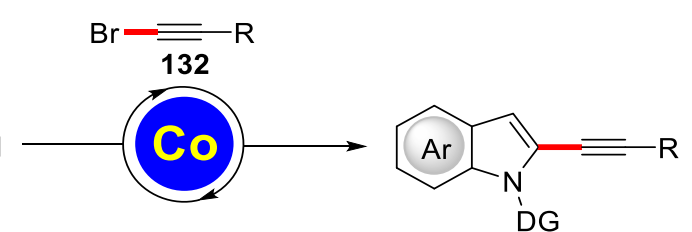

89

Scheme 2.3. Base metal-catalyzed $\mathrm{C}-\mathrm{H}$ akynylation.

Cross-dehydrogenative couplings present the most atom-economical transformation in $\mathrm{C}-\mathrm{H}$ activation, as the formal byproduct is solely $\mathrm{H}_{2 .}{ }^{[174]}$ However, to achieve these transformations sacrificial oxidants are needed, which greatly reduces the atom economy of $\mathrm{C}-\mathrm{H}$ activation. Furthermore, most transformations rely on expensive silver salts as oxidants, which drive the cost of the overall reaction (see Figure 1.6). ${ }^{[137]}$ Additionally, these chemical oxidants offer a specific potential associated with the redox couple, which can hardly be modified. In light of these facts, the use of electricity as the terminal oxidant would greatly increase the atom economy and reduce the associated costs of the reaction. Moreover, a modification of the potential to finely tune the reaction is possible, when needed. Here, a combination of cobalt-catalyzed $\mathrm{C}-\mathrm{H}$ activation and electrocatalysis would be highly desirable in the formation of $\mathrm{C}-\mathrm{O}$ and C-N bonds (Scheme 2.4).
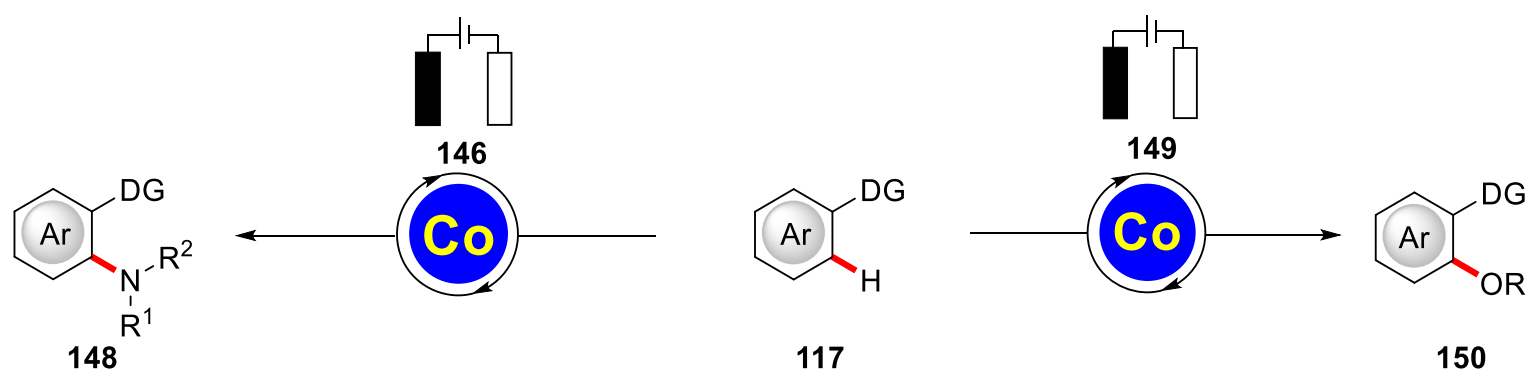

Scheme 2.4. Electrocatalytic cobalt-catalyzed $\mathrm{C}-\mathrm{H}$ oxygenations and aminations. 
Finally, electro-oxidative cobalt-catalyzed $\mathrm{C}-\mathrm{H} / \mathrm{N}-\mathrm{H}$ annulations with alkynes 8 were realized following the same principles, and the mechanism should be investigated using different methods (Scheme 2.5).<smiles>CN([Pb])NC(=O)c1ccccc1</smiles>

215<smiles>[R]C#[R]</smiles>

8

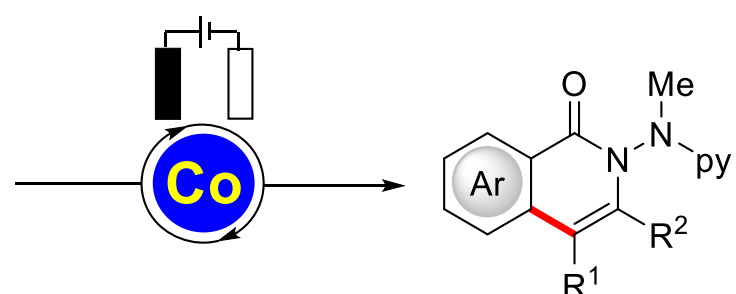

216

Scheme 2.5. Electro-oxidative cobalt-catalyzed $\mathrm{C}-\mathrm{H} / \mathrm{N}-\mathrm{H}$ annulation. 


\section{Results and Discussion}

\subsection{Cobalt-Catalyzed Alkenylation under Triazolylidene-Assistance by $\mathrm{C}-\mathrm{H} / \mathrm{C}-\mathrm{O}$ Cleavage}

Based on the initial work from Yoshikai, ${ }^{[57]}$ several cobalt-catalyzed $\mathrm{C}-\mathrm{H}$ alkylations, ${ }^{[49-}$ ${ }^{50,52]}$ arylations ${ }^{[49,52-54,175]}$ and alkenylations ${ }^{[56-61]}$ were reported. However, the majority of $\mathrm{C}-\mathrm{H}$ alkenylations are based on the hydroarylation of alkynes $8 .^{[57-61]}$ This presents a major limitation, due to the poor selectivity in the conversion of unsymmetrical alkynes 8 and the absence of cyclic alkynes 8 in small and medium ring sizes. ${ }^{[176]}$

Low-valent cobalt-catalyzed $\mathrm{C}-\mathrm{H}$ functionalization reactions mainly feature two classes of ligands (see Figure 1.1), namely phosphines and NHC ligands. For NHCs, imidazole-derived IMesHCl (14) and $\mathrm{IPHCl}(15)$ are the most common preligands.

In cooperation with the group of Prof. A. Berkessel from the University of Cologne, a small library of triazole derived NHCs 212 were synthesized (Figure 3.1) ${ }^{[177]}$ and tested towards their performance in cobalt-catalyzed $\mathrm{C}-\mathrm{H}$ alkenylation.
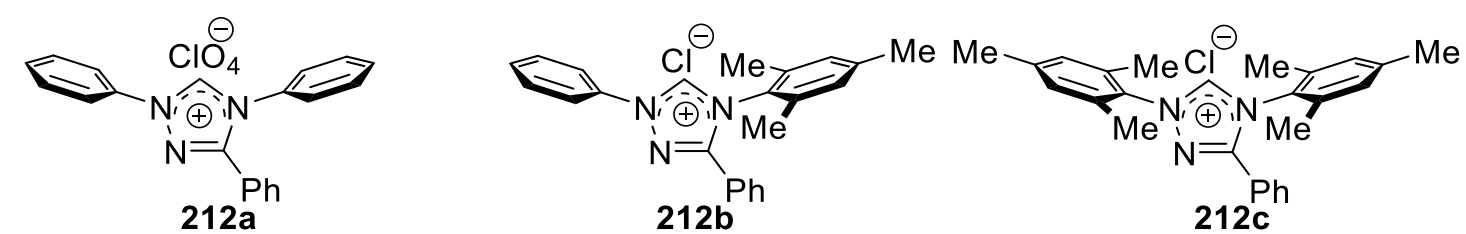

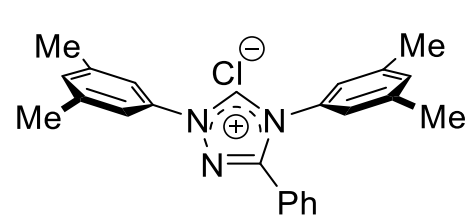

212d

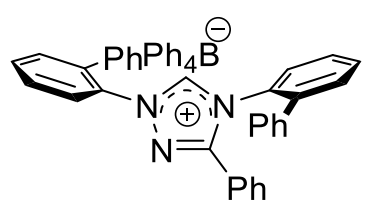

$212 e$

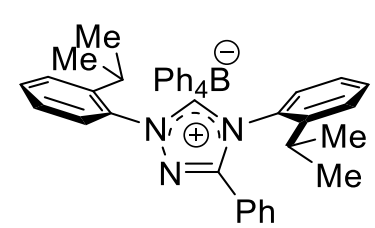

$212 f$
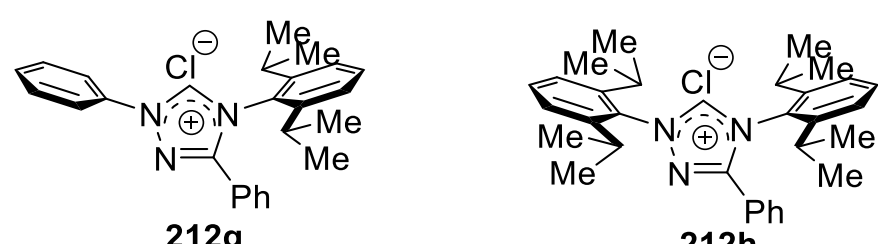

212h

Figure 3.1. Triazolium salts 212 for the cobalt-catalyzed $\mathrm{C}-\mathrm{H}$ alkenylation.

While generally employed as organocatalysts, ${ }^{[172 a, 178]}$ these triazolium salts were especially interesting in terms of their lower donating abilities ${ }^{[172 b]}$ and possible dispersion interactions ${ }^{[179]}$ enabled by the distal phenyl group. Moreover, their application in cobalt-catalyzed $\mathrm{C}-\mathrm{H}$ activation is without precedence. 


\subsubsection{Optimization}

Based on previous studies, ${ }^{[56]}$ initially $\mathrm{Col}_{2}, \mathrm{DMPU}$ and $\mathrm{CyMgCl}$ were chosen as components of the ternary catalytic system. With these conditions, the preligands 212a-h were evaluated on their ability to promote the desired reaction (Table 3.1)

Table 3.1 Ligand screening for the cobalt catalyzed $\mathrm{C}-\mathrm{H}$ alkenylation under triazole assistance. ${ }^{\mathrm{a}}$

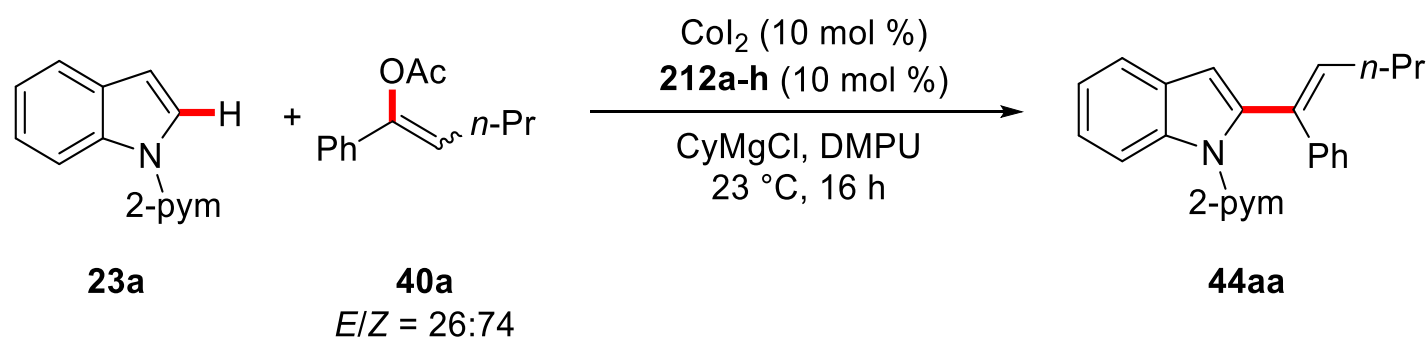

\begin{tabular}{ccc}
\hline Entry & $\mathrm{L}$ & Yield [\%] \\
\hline 1 & --- & $<5$ \\
2 & $\mathbf{2 1 2 a}$ & --- \\
3 & $\mathbf{2 1 2 b}$ & --- \\
4 & $\mathbf{2 1 2 c}$ & 14 \\
5 & $\mathbf{2 1 2 d}$ & $<5^{\mathrm{b}}$ \\
6 & $\mathbf{2 1 2 e}$ & 19 \\
7 & $\mathbf{2 1 2 f}$ & $<5$ \\
8 & $\mathbf{2 1 2 g}$ & 21 \\
$\mathbf{9}$ & $\mathbf{2 1 2 h}$ & $\mathbf{5 2}$
\end{tabular}

${ }^{a}$ Reaction conditions: 23a $(0.25 \mathrm{mmol}), 40 \mathrm{a}(0.38 \mathrm{mmol}), \mathrm{Col}_{2}(10 \mathrm{~mol} \%), 212 \mathrm{a}-\mathrm{h}$ (10 mol \%), CyMgCl (0.50 mmol), DMPU (1.5 mL), $23^{\circ} \mathrm{C}, 16 \mathrm{~h}$. b Performed by J. Loup.

The reaction was not effective in absence of a preligand (entry 1). Ligand 212a, as well as the $\mathrm{N}$-phenyl- $\mathrm{N}$-mesityl substituted triazole $\mathbf{2 1 2 b}$ did not lead to improvements in efficacy (entries 2 and 3 ), while 212c facilitated product formation to some extent (entry 4). meta-Xylene derived ligand $\mathbf{2 1 2 d}$ was not effective (entry 5) while biphenylsubstituted ligand $\mathbf{2 1 2} \mathrm{e}$ as well as 2-isopropylphenyl-substituted triazole $\mathbf{2 1 2} \mathrm{g}$ showed improved reactivities (entries 6 and 8). Triazolium salt 212f was not suitable (entry 7), while the best results were achieved using 2,6-diisopropylphenyl substituted triazolium salt $212 \mathrm{~h}$ (entry 9 ), which is in good agreement with the observations from our previous studies. ${ }^{[56]}$ 
After the best preligand $\mathbf{2 1 2} \mathrm{h}$ was identified, further optimization studies were performed with a focus on the cobalt source, Grignard reagent and solvent (Table 3.2).

Table 3.2 Optimization of the reaction conditions for the cobalt-catalyzed C-H alkenylation. ${ }^{a}$

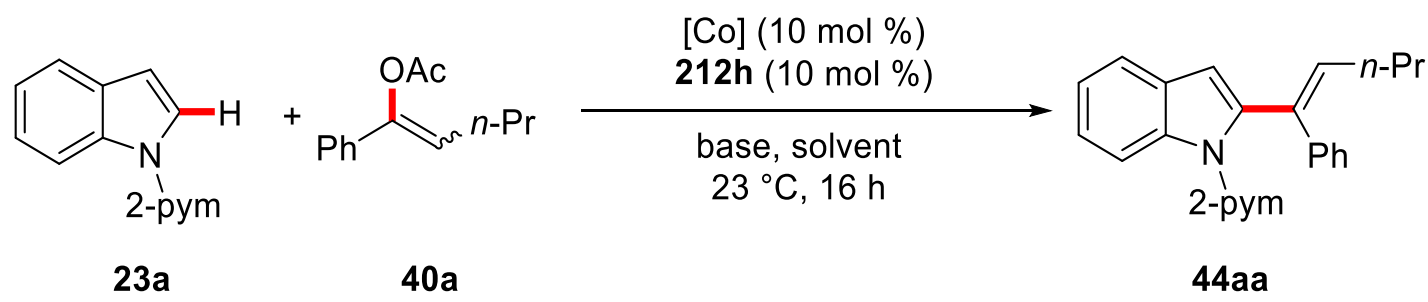

$E / Z=26: 74$

\begin{tabular}{ccccc}
\hline Entry & {$[\mathrm{Co}]$} & Base & Solvent & Yield [\%] \\
\hline 1 & $\mathrm{Col}_{2}$ & CyMgCl & DMPU & 52 \\
2 & $\mathrm{CoBr}_{2}$ & $\mathrm{CyMgCl}$ & DMPU & 48 \\
3 & $\mathrm{CoCl}_{2}$ & $\mathrm{CyMgCl}$ & DMPU & 33 \\
4 & $\mathrm{Co}(\mathrm{OAc})_{2}$ & $\mathrm{CyMgCl}$ & DMPU & --- \\
5 & $\mathrm{Co}(\mathrm{acac})_{2}$ & $\mathrm{CyMgCl}$ & DMPU & $<5$ \\
6 & $\mathrm{Col}_{2}$ & $\mathrm{CyMgCl}$ & THF & 33 \\
7 & $\mathrm{Col}_{2}$ & $\mathrm{CyMgCl}$ & Et2O & $<5$ \\
8 & $\mathrm{Col}_{2}$ & $\mathrm{CyMgBr}$ & DMPU & 51 \\
9 & $\mathrm{Col}_{2}$ & $\mathrm{PhMgBr}$ & DMPU & $<5$ \\
10 & $\mathrm{Col}_{2}$ & $\mathrm{EtMgCl}$ & DMPU & $<5$ \\
11 & $\mathrm{Col}_{2}$ & $\mathrm{Me} S \mathrm{SiCH}{ }_{2} \mathrm{MgCl}$ & DMPU & --- \\
12 & $\mathrm{Col}_{2}$ & $t-\mathrm{BuCH}{ }_{2} \mathrm{MgCl}$ & DMPU & $<5$ \\
13 & $\mathrm{Col}_{2}$ & --- & DMPU & --- \\
14 & --- & $\mathrm{CyMgCl}$ & DMPU & --- \\
\hline
\end{tabular}

a Reaction conditions: $23 a(0.25 \mathrm{mmol}), 40 \mathrm{a}(0.38 \mathrm{mmol}),[\mathrm{Co}$ ] $(10 \mathrm{~mol} \%), 212 \mathrm{~h}(10 \mathrm{~mol} \%)$, base $(0.50$ $\mathrm{mmol})$, solvent $(1.5 \mathrm{~mL}), 23^{\circ} \mathrm{C}, 16 \mathrm{~h}$.

The optimization commenced with a screening of various cobalt prescoursors. While cobalt(II) halides generally promoted the $\mathrm{C}-\mathrm{H}$ alkenylation with similar efficacy (entries 1-3), cobalt(II) acetate (entry 4) and cobalt(II) acetylacetonate (entry 5) only provided trace amounts of the desired product. Besides DMPU, THF proved amenable (entry 6 ), while $\mathrm{Et}_{2} \mathrm{O}$ was not a suitable reaction medium (entry 7). Regarding the Grignard reagent, a comparison between $\mathrm{CyMgCl}$ and $\mathrm{CyMgBr}$ (entry 8) revealed no significant influence of the halide, while other alkyl and phenyl derived Grignard reagents (entries 
9-12) proved not suitable. This is especially noteworthy, since $\mathrm{Me}_{3} \mathrm{SiCH}_{2} \mathrm{MgCl}$ and $t-\mathrm{BuCH}_{2} \mathrm{MgCl}$, which were shown to be active in cobalt catalysis before, ${ }^{[57,61-62]}$ are quite costly compared to $\mathrm{CyMgCl}$, which presents an advantage of this method. The essential nature of the base and the cobalt salt was confirmed by control experiments (entries 13 and 14).

Next, different leaving groups on the alkenyl moiety were investigated on their ability to promote the cobalt-catalyzed $\mathrm{C}-\mathrm{H}$ alkenylation (Table 3.3).

Tabel 3.3 Leaving group performance in cobalt-catalyzed C-H alkenylation. ${ }^{a}$

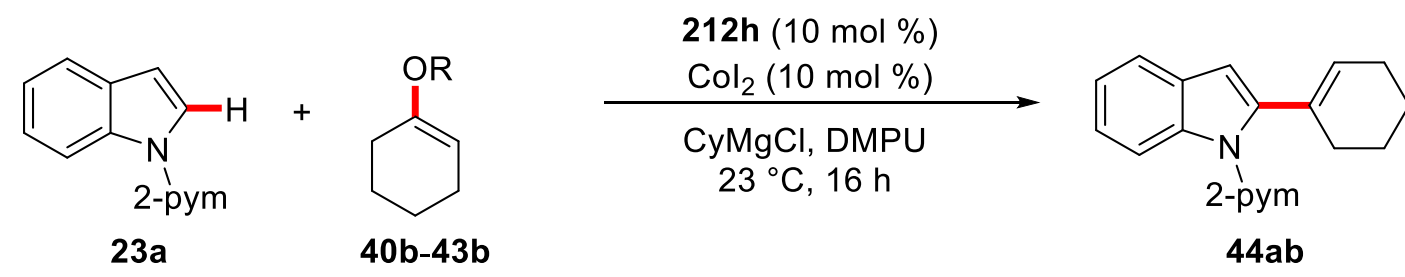

\begin{tabular}{ccc}
\hline Entry & $\mathrm{R}$ & Yield [\%] \\
\hline 1 & $\mathrm{Ac}(\mathbf{4 0 b})$ & 80 \\
2 & $\mathrm{P}(\mathrm{O})(\mathrm{OEt})_{2}(\mathbf{4 1} \mathbf{b})$ & 84 \\
3 & $\mathrm{C}(\mathrm{O}) \mathrm{OEt}(\mathbf{4 2 b})$ & 52 \\
4 & $\mathrm{C}(\mathrm{O}) \mathrm{NMe}_{2}(\mathbf{4 3} \mathbf{b})$ & 72
\end{tabular}

a Reaction conditions: 23a $(0.25 \mathrm{mmol}), 40 \mathrm{~b}-43 \mathrm{~b}(0.38 \mathrm{mmol})$, Col2 $(10 \mathrm{~mol} \%), 212 \mathrm{~h}(10 \mathrm{~mol} \%)$, CyMgCl (0.50 mmol), DMPU ( $1.5 \mathrm{~mL}), 23^{\circ} \mathrm{C}, 16 \mathrm{~h}$.

This evaluation established alkenyl acetate $40 \mathrm{~b}$ and alkenyl phosphate $41 \mathrm{~b}$ as competent alkenylating agents (entries 1 and 2). Carbonate 42b only showed moderate efficacy, while carbamate 43b performed somewhat better than carbonate 42b. Based on these results, the scope of the cobalt-catalyzed alkenylation under triazole assistance was investigated using alkenyl acetates $\mathbf{4 0}$ and phosphates $\mathbf{4 1}$ with an optimized catalytic system comprising of $\mathrm{Col}_{2}$, ligand $212 \mathrm{~h}$ and $\mathrm{CyMgCl}$ in DMPU as the solvent.

\subsubsection{Scope of the Cobalt-Catalyzed Alkenylation using Alkenyl Phosphates}

With the optimized conditions in hand, the scope of the reaction was examined with different alkenyl phosphates $\mathbf{4 1}$ (Table 3.4). 
Table 3.4 Scope of the cobalt-catalyzed $\mathrm{C}-\mathrm{H}$ alkenylation using alkenyl phosphates $41{ }^{\mathrm{a}}$

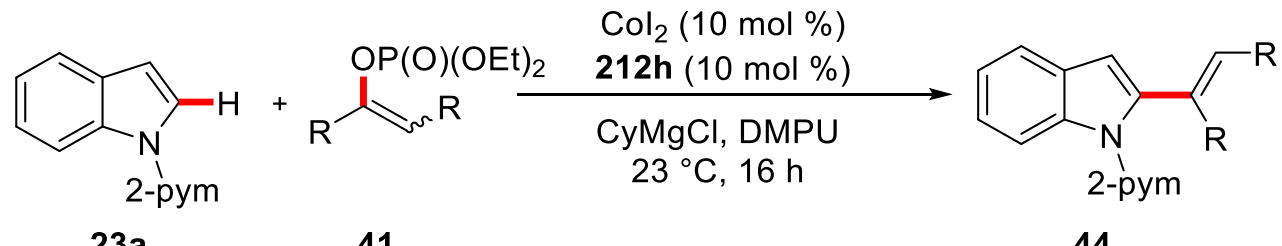

23a

41

44

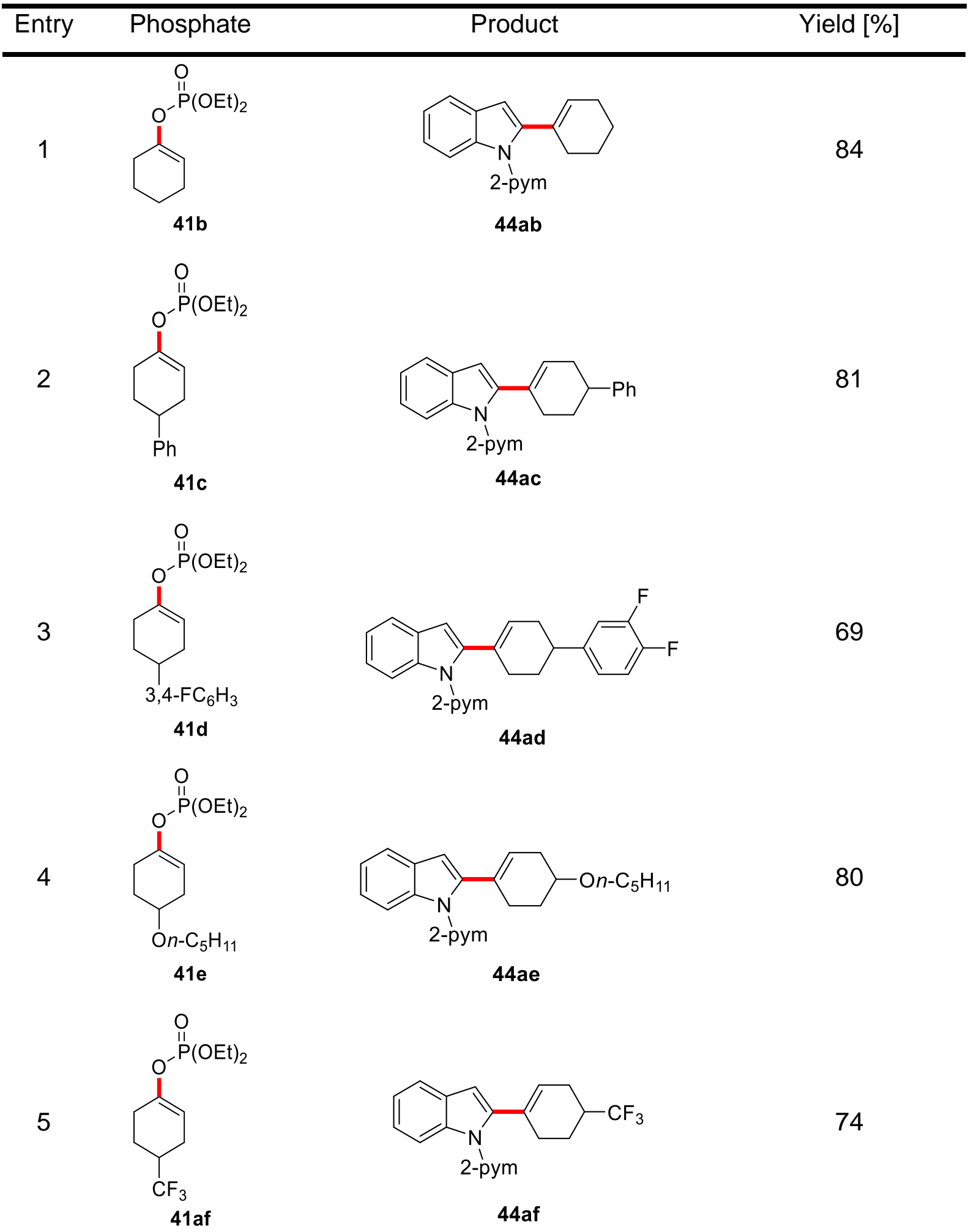


6<smiles>CCO[PH](=O)OC1=CCC(C)CC1</smiles>

$41 \mathrm{~g}$

7<smiles>CCC=C(O[PH](=O)OCCC)PCC</smiles>

$41 \mathrm{~h}$

$$
E / Z=30 / 70
$$

8

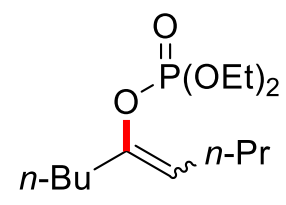

$41 \mathbf{i}$

$E / Z=30 / 70$

9<smiles>C/C=C(\OP(=O)=O)O[PH](=O)OCC</smiles>

41j

$$
E / Z=25 / 75
$$<smiles>CC1CC=C(c2cc3ccccc3n2[PbH2])CC1</smiles>

a Reaction conditions: 23a $(0.25 \mathrm{mmol}), 41(0.38 \mathrm{mmol}), \mathrm{Col}_{2}(10 \mathrm{~mol} \%), \mathbf{2 1 2 h}(10 \mathrm{~mol} \%), \mathrm{CyMgCl}$ (0.50 mmol), DMPU $(1.5 \mathrm{~mL}), 23^{\circ} \mathrm{C}, 16 \mathrm{~h}$.

The reaction proceeded with moderate to excellent yields for all substrates. Comparable efficacy was achieved for cyclohexenylphosphate (41b) as well as 4substituted cyclohexenylphosphates 41c-g (entries 2-6). This is indicative of only a minor influence of the substituent in C-4 position of the alkenyl phosphate. Good yields could be observed for acyclic bisalkyl alkenyl phosphates 41h and 41i (entries 7 and 8), while alkenyl phosphate 41j with mixed aryl and alkyl substituents was converted with moderate yield (entry 9 ). It is noteworthy, that although a mixture of $E / Z$-isomers was employed in this reaction (30/70 for entries $41 \mathrm{~h}$ and $41 \mathrm{i}, 25 / 75$ for $41 \mathrm{j}$ ), the $E$ product was observed exclusively, indicating a stereoconvergent process being operative here. ${ }^{[56]}$ 
Furthermore, different indoles $\mathbf{2 3}$ were employed in the reaction using cyclohexenylphosphate (41b) as the alkenylating reagent (Table 3.5).

Table 3.5. Scope of the cobalt-catalyzed C-H alkenylation of indoles 23. ${ }^{\text {a }}$
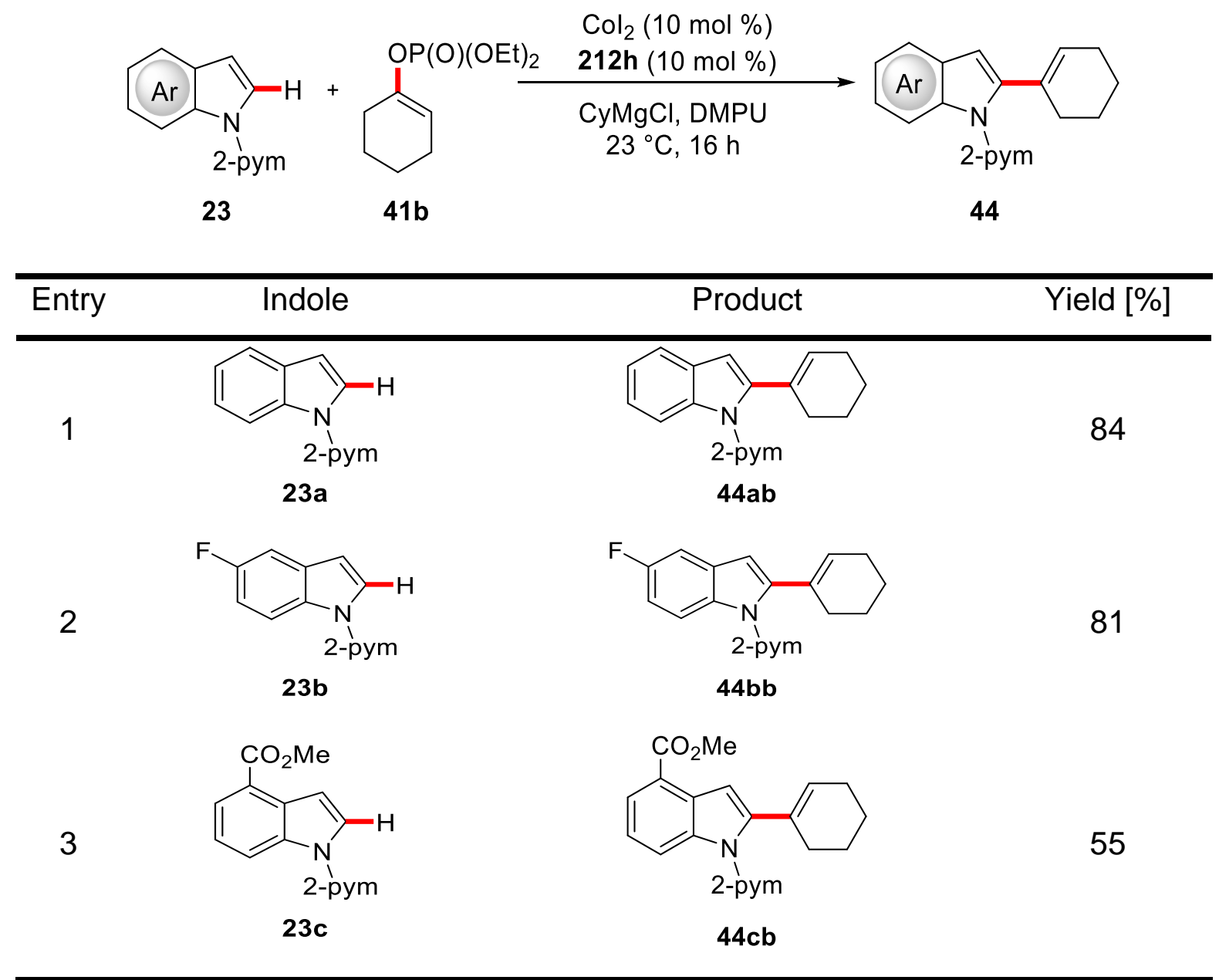

a Reaction conditions: 23 (0.25 mmol), 41b (0.38 mmol), Col 2 (10 mol \%), 212h (10 mol \%), CyMgCl (0.50 mmol), DMPU (1.5 mL), $23^{\circ} \mathrm{C}, 16 \mathrm{~h}$.

Unsubstituted 2-pyrimidylindole (23a) and 5-fluoroindole 23b were identified as excellent substrates for the $\mathrm{C}-\mathrm{H}$ alkenylation (entries 1 and 2). Remarkable was the smooth conversion of indole $\mathbf{2 3 c}$, because the ester group proved to be stable. ${ }^{[180]}$

\subsubsection{Scope of the Cobalt-Catalyzed Alkenylation using Alkenyl Acetates}

After establishing the scope of alkenyl phosphates 41 , more atom-economical acetates 40 were investigated for their use in the cobalt-catalyzed $\mathrm{C}-\mathrm{H}$ alkenylation (Table 3.6). 
Table 3.6. Cobalt-catalyzed C-H alkenylation with alkenyl acetates $\mathbf{4 0}$.

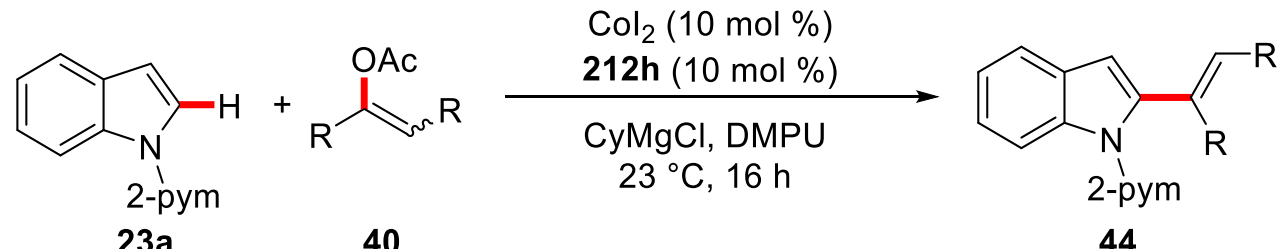

23a

40

44

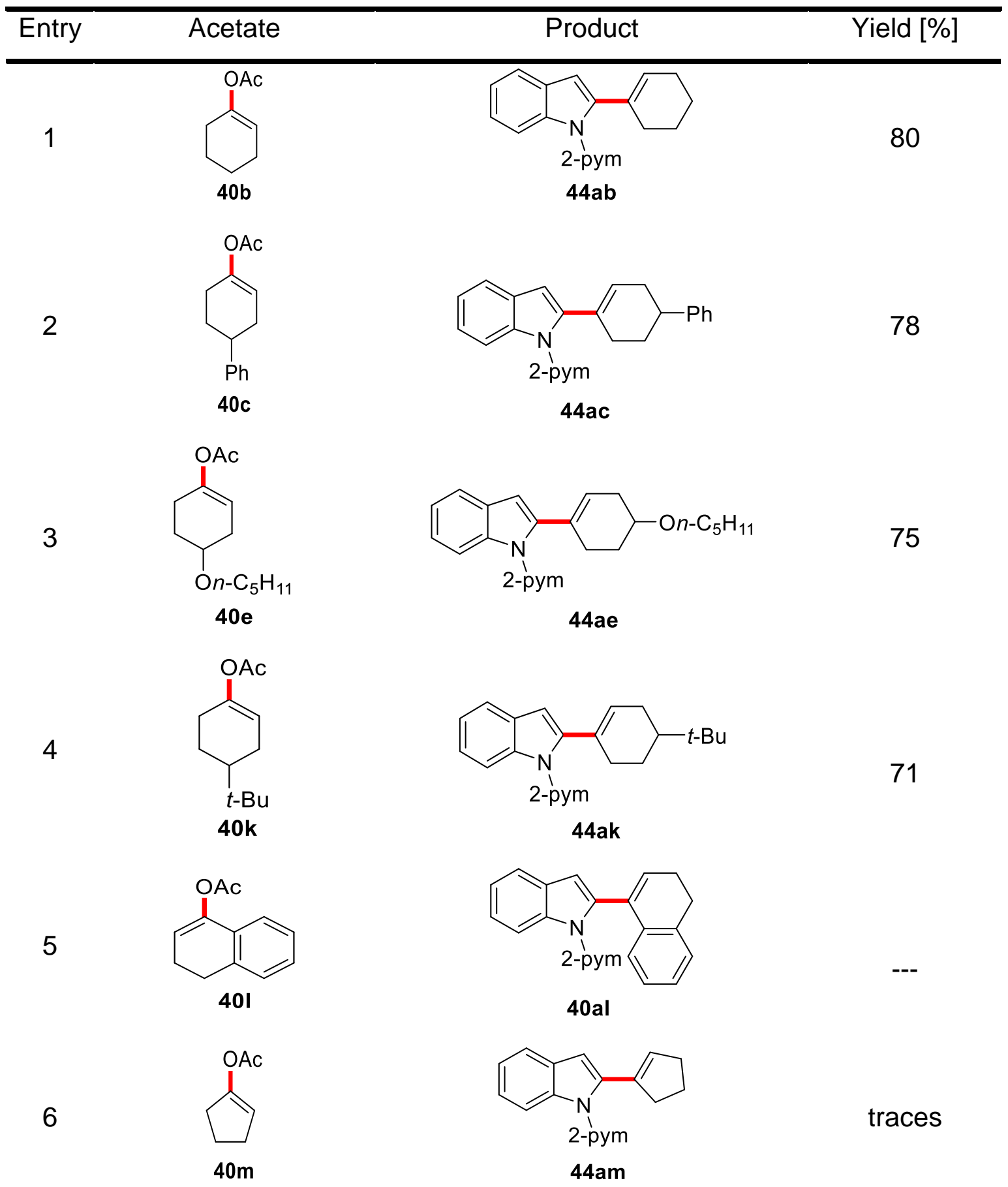


7<smiles>CC(=O)OC1=CCCCCC1</smiles>

40n

8<smiles>CC=C(OC(=O)CCCC)c1ccccc1</smiles>

$40 a$

$E / Z=24 / 76$<smiles>[Z6][R6]([H])n1c(C2=CCCCCC2)cc2ccccc21</smiles>

traces

44an<smiles>[Z20]n1c(/C(=C/P=[Pt])c2ccccc2)cc2ccccc21</smiles>

44aa

a Reaction conditions: 23a $(0.25 \mathrm{mmol}), 40$ (0.38 mmol), Col2 $(10 \mathrm{~mol} \%), 212 \mathrm{~h}(10 \mathrm{~mol} \%), \mathrm{CyMgCl}$ (0.50 mmol), DMPU (1.5 mL), $23^{\circ} \mathrm{C}, 16 \mathrm{~h}$.

Cyclohexenylacetate (40b) and its substituted analogues were smoothly converted with up to $80 \%$ yield (entries $1-4$ ). However, $\alpha$-Tetralone derived acetate $\mathbf{4 0 I}$ showed no reactivity. Smaller and larger cyclic enol acetates 40m and 40n (entries 6 and 7) were not suitable substrates, only resulting in traces of the desired products $\mathbf{4 4}$, while acyclic acetate 40a was converted with moderate yield, and again exclusively to the $E$ product.

Additionally, the scope of indoles $\mathbf{2 3}$ was investigated using cyclohexenylacetate (40b) as the standard alkenylation reagent (Table 3.7).

Table 3.7. Cobalt-catalyzed C-H alkenylation of indoles 23 .

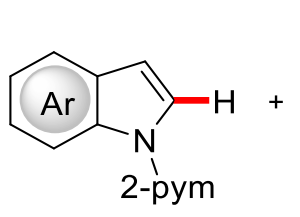

23<smiles>CC(=O)OC1=CCCCC1</smiles>

40b
$\mathrm{Col}_{2}(10 \mathrm{~mol} \%)$

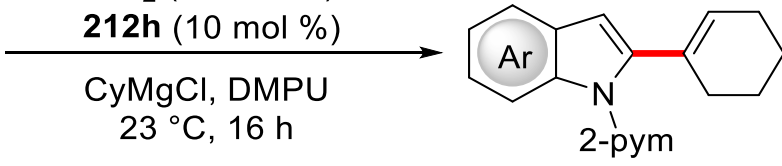

44

Entry Indole


2<smiles>[R6]n1ccc2cc(F)ccc21</smiles>

23b

3<smiles>COC(=O)c1cccc2c1ccn2[PbH2]</smiles>

23c

4<smiles>COc1ccc2c(ccn2P(O)P)c1</smiles>

23d

5<smiles>Cc1ccc2c(c1)cc(C)n2C(=O)O</smiles>

$\mathrm{F}_{3} \mathrm{C}$

6

7

8<smiles>FC(F)(F)c1ccc2c(ccn2P)c1</smiles>

$23 f$<smiles></smiles>

23g<smiles>[PH3+]n1ccc2cc(Br)ccc21</smiles>

23h<smiles>CC(=O)Nc1ccc2c(ccn2[Pb])c1</smiles>

$23 \mathbf{i}$

9

$$
\text { 2-pym }
$$<smiles>OP(O)n1c(C2=CCCCC2)cc2cc(F)ccc21</smiles>

44bb<smiles>CC(=O)c1cccc2c1cc(C1=CCCCC1)n2P(P)P</smiles>

44cb<smiles>COc1ccc2c(c1)cc(C1=CCCCC1)n2[Po+]</smiles>

44db<smiles>Cc1ccc2c(c1)cc(C1=CCCCC1)n2[PH2+]</smiles>

44eb<smiles>O=Pn1c(C2=CCCCC2)cc2cc(C(F)(F)F)ccc21</smiles>

44fb<smiles>[12CH2]n1c(C2=CCCCC2)cc2cc(Cl)ccc21</smiles>

44gb<smiles>[R6]n1c(C2=CCCCC2)cc2cc(Br)ccc21</smiles>

44hb<smiles>CC(=O)Nc1ccc2c(c1)cc(C1=CCCCC1)n2[Po+]</smiles>

44ib 
10

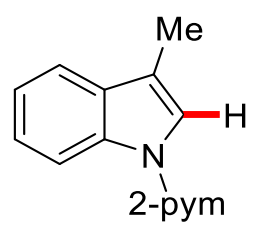

23j

11<smiles>CCc1cccc2cccn12</smiles>

23k

12<smiles>Cc1c(C2=CCCCC2)n([PbH])c2ccccc12</smiles>

44jb

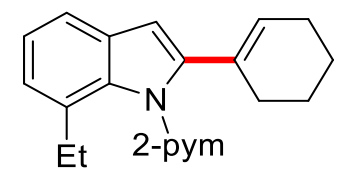

44kb

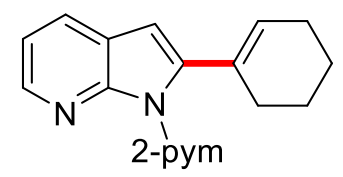

44Ib

a Reaction conditions: $23(0.25 \mathrm{mmol}), \mathbf{4 0 b}(0.38 \mathrm{mmol}), \mathrm{Col}_{2}(10 \mathrm{~mol} \%), \mathbf{2 1 2 h}(10 \mathrm{~mol} \%), \mathrm{CyMgCl}$ (0.50 mmol), DMPU (1.5 mL), $23^{\circ} \mathrm{C}, 16 \mathrm{~h} .{ }^{b} \mathrm{CyMgCl}(1.00 \mathrm{mmol})$

As shown in Table 3.7, diversely decorated indoles bearing fluoride, ester, alkyl and alkoxy substituents were amenable substrates (entries 1-6). While 5-chloroindole $\mathbf{2 3 g}$ (entry 7) was converted with moderate yield, the corresponding 5-bromoindole 23h (entry 8 ) did not show any formation of the desired product $\mathbf{4 4 h b}$. This can be attributed to the higher reactivity of bromo compounds in the cross coupling of bromoarenes and Grignard reagents, ${ }^{[181]}$ and indeed the formation of 5-cyclohexylindole was confirmed by GC-analysis. Acetanilide 23i also showed no reaction, even when more base was used to account for initial deprotonation of the $\mathrm{N}-\mathrm{H}$ bond which might occur under the reaction conditions (entry 9). Furthermore, sterically crowded indoles 23j and 23k reacted smoothly to the desired products (entries 10 and 11). Finally, 7-Azaindole derived substrate $23 \mathrm{I}$ proved not suitable, maybe due to a strong chelating coordination of the cobalt-catalyst between the pyridine and pyrimidine nitrogens.

Besides indoles 23, pyrroles 217 were also suitable substrates for this reaction (Table 3.8). 
Table 3.8 Cobalt-catalyzed C-H alkenylation of pyrroles 217.

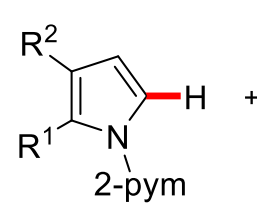

217<smiles>CC(=O)OC1=CCCCC1</smiles>

$40 \mathrm{~b}$

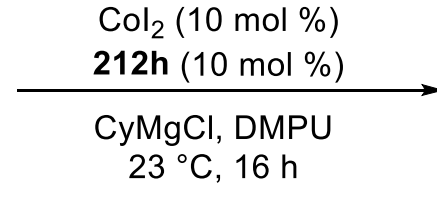

$23^{\circ} \mathrm{C}, 16 \mathrm{~h}$

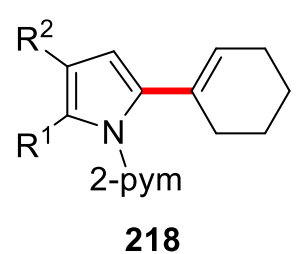

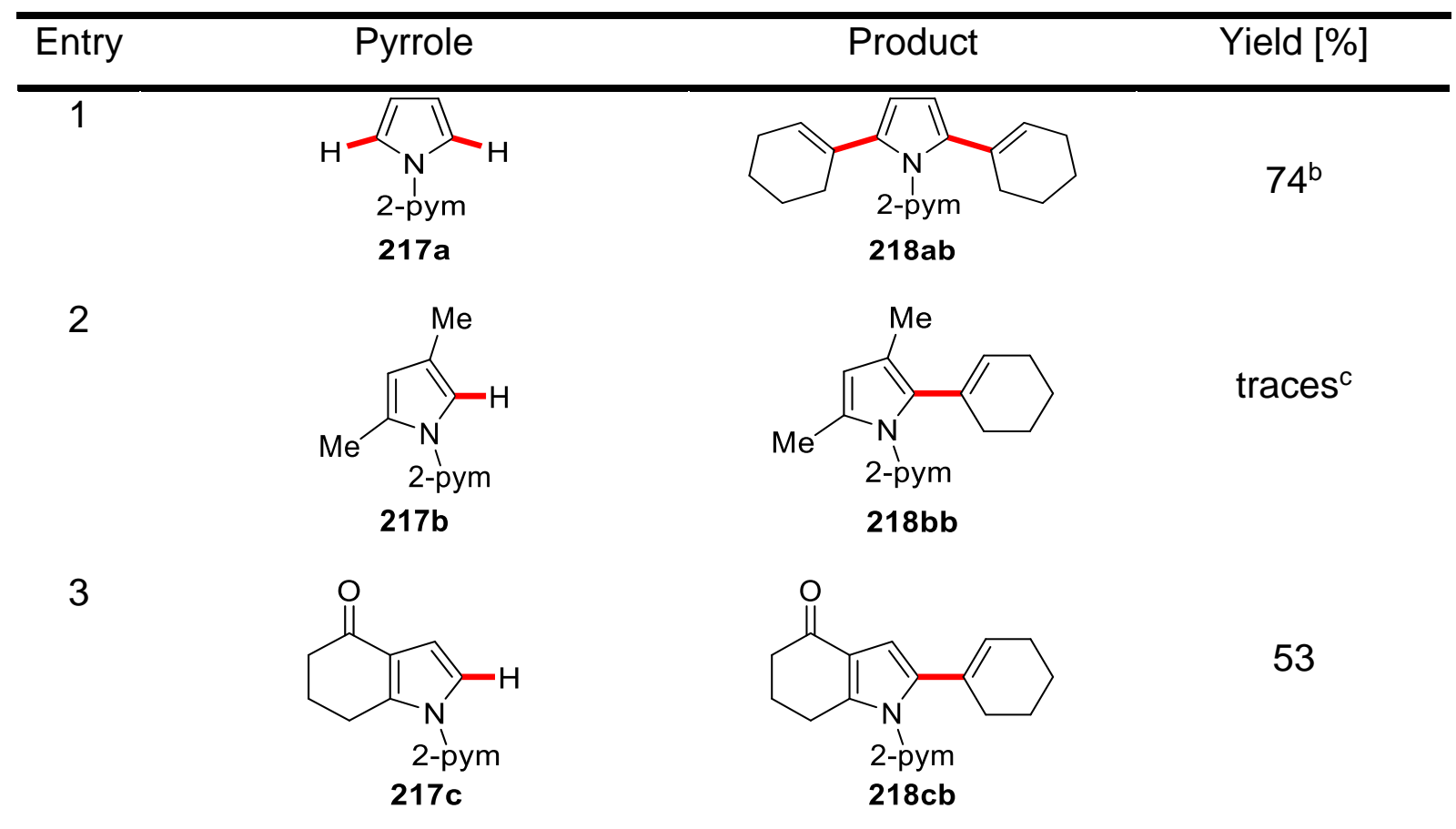

a Reaction conditions: $217(0.25 \mathrm{mmol}), \mathbf{4 0 b}(0.38 \mathrm{mmol}), \mathrm{Col}_{2}(10 \mathrm{~mol} \%), \mathbf{2 1 2 h}(10 \mathrm{~mol} \%), \mathrm{CyMgCl}$ (0.50 mmol), DMPU $(1.5 \mathrm{~mL}), 23^{\circ} \mathrm{C}, 16 \mathrm{~h}^{\mathrm{b}}{ }^{\circ} 40 \mathrm{~b}(0.75 \mathrm{mmol}){ }^{\circ} 60^{\circ} \mathrm{C}$

While simple unsubstituted 2-pyrimidylpyrrole (217a) was a very good substrate, reactions using 1.50 equivalents of the alkenyl acetate resulted in mixtures of monoand bisalkenylated products. Selective conversion to the bis-alkenylated product was achieved using 3.00 equivalents of the alkenyl acetate $40 \mathrm{~b}$ (entry 1 ). In contrast 2,4-

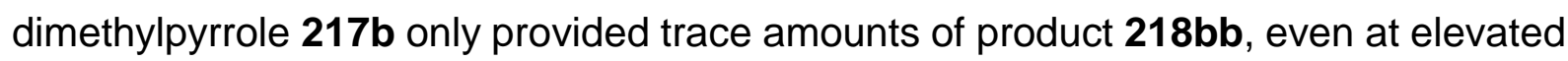
temperature (entry 2). Finally, tetrahydroindolone $217 \mathrm{c}$ was converted with a yield of $53 \%$, which is remarkable given that ketones usually undergo facile addition of Grignard reagents. (entry 3). ${ }^{[180]}$

\subsubsection{Mechanism of the Cobalt-Catalyzed Alkenylation}

The mechanism of the cobalt-catalyzed $\mathrm{C}-\mathrm{H}$ alkenylation by triazole assistance is rationalized to be similar to the previously proposed mechanism using imidazolium 
salts as preligands (Scheme 3.1). ${ }^{[56,182]}$ After generation of the active species $28, \mathrm{C}-\mathrm{H}$ activation occurs, and the enol reagent is coordinated. E/Z-isomerization takes place to give rise to the exclusively E-configured enol acetate or phosphate, followed by migratory insertion resulting in intermediate 222. Subsequent $\beta$-O elimination furnished the desired product and the active species $\mathbf{2 8}$ is regenerated upon transmetalation.

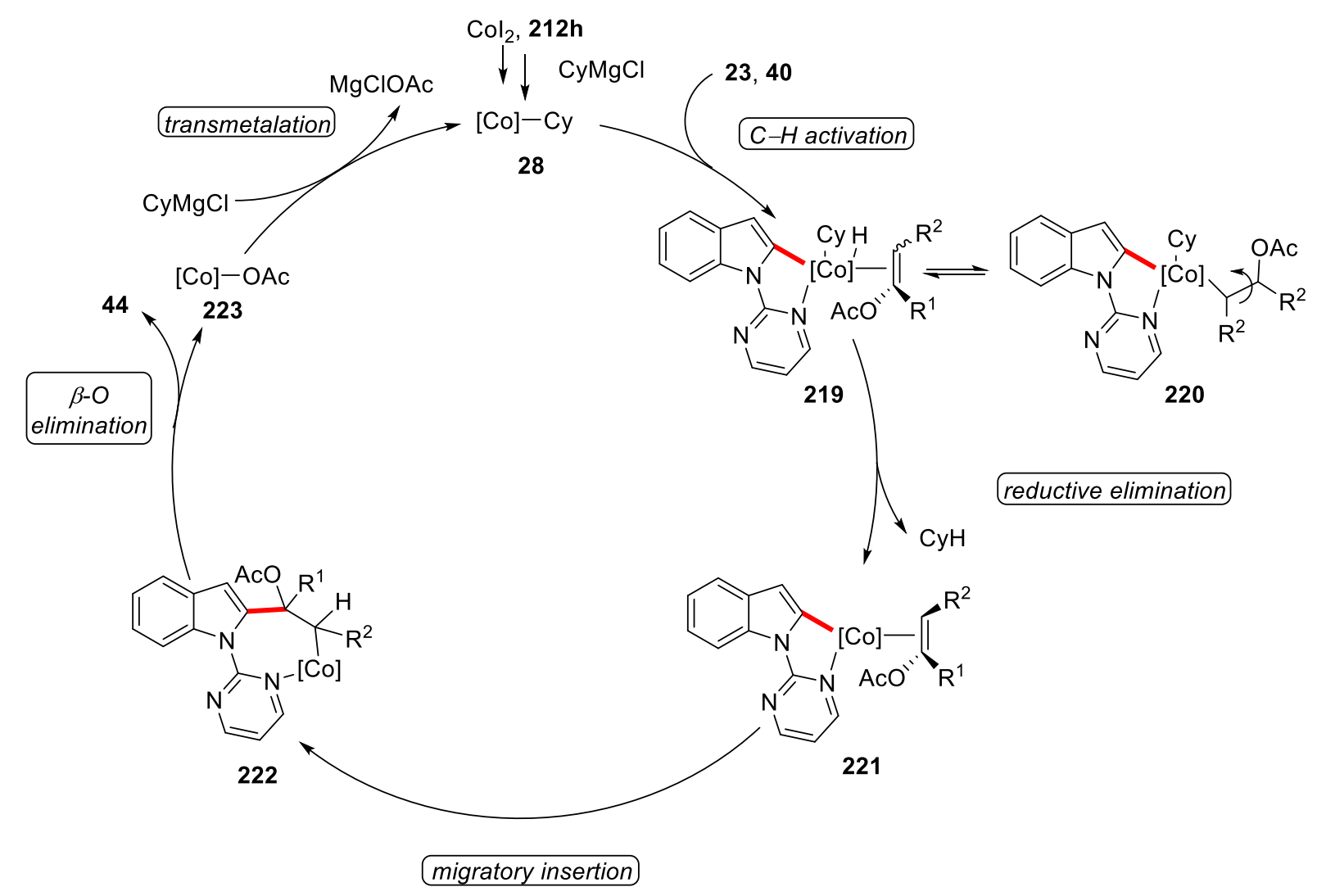

Scheme 3.1. Proposed catalytic cycle for the cobalt-catalyzed C-H alkenylation of indoles 44.

In summary, the first application of triazolylidenes in cobalt-catalyzed $\mathrm{C}-\mathrm{H}$ activation could be realized in the $\mathrm{C}-\mathrm{H}$ alkenylation of indoles 23 and pyrroles 217 using alkenyl acetates $\mathbf{4 0}$ and phosphates 41. Cyclic as well as acyclic enol acetates $\mathbf{4 0}$ and phosphates 41 were suitable coupling partners, and for acyclic compounds, a stereoconvergent reaction was observed.

\subsection{Cobalt-Catalyzed Allylation using Allyl Acetates}

While a range of $\mathrm{C}-\mathrm{H}$ functionalizations has been established with low-valent cobalt catalysis, ${ }^{[48 c, 48 d]}$ limitations exist with regard to the functional group tolerance due to 
the omnipresent Grignard reagents. In this regard, $\mathrm{Cp}{ }^{*} \mathrm{Co}(\mathrm{III})$-complexes offer a versatile alternative, which should exhibit higher compatibility towards electrophilic functional groups. ${ }^{[48 a, 69]}$

Allyl groups present versatile handles for further post-synthetic diversification, for example by olefin metathesis ${ }^{[183]}$ or allylic functionalization. ${ }^{[184]}$ Therefore, the introduction of allyl groups is an interesting research area, especially using easily accessible allyl acetate 213. Indoles are a key structural motif in many biologically active compounds, ${ }^{[185]}$ rendering them interesting substrates in $\mathrm{C}-\mathrm{H}$ activation.

\subsubsection{Optimization and Scope}

Optimization studies on the cobalt(III)-catalyzed $\mathrm{C}-\mathrm{H}$ allylation were conducted by $\mathrm{M}$. Moselage ${ }^{[182]}$ and after testing various cobalt complexes and additives, a catalytic system comprised of $\mathrm{Cp}^{*} \mathrm{Co}(\mathrm{CO}) \mathrm{I}_{2}(81)(5 \mathrm{~mol} \%), \mathrm{AgSbF}_{6}(10 \mathrm{~mol} \%)$ and KOAc (10 $\mathrm{mol} \%$ ) in DCE at $80^{\circ} \mathrm{C}$ for $16 \mathrm{~h}$ was identified as optimal. With these optimized conditions in hand, the scope of the cobalt-catalyzed $\mathrm{C}-\mathrm{H}$ allylation was explored regarding the indole moiety (Table 3.9 ).

Table 3.9 Scope of the cobalt-catalyzed allylation of indoles $23 .^{a}$

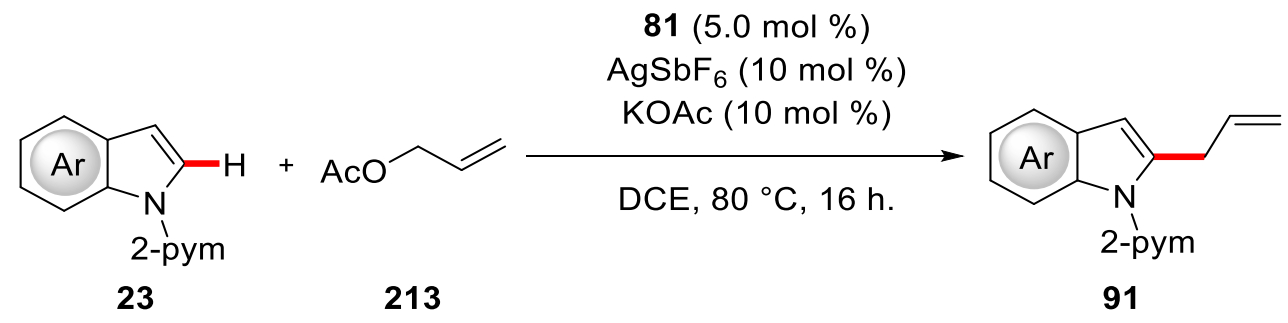

Entry


3<smiles>Cc1c(C)n(OP(=O)(O)O)c2ccccc12</smiles>

23j

4<smiles>[R6]n1ccc2cc([N+](=O)[O-])ccc21</smiles>

$23 n$

5<smiles></smiles>

23i<smiles>C=CCc1c(C)c2ccccc2n1P([O-])O</smiles>

91j<smiles>[Z20]n1c(CC=C)cc2cc([N+](=O)[O-])ccc21</smiles>

91n<smiles></smiles>
$91 i$

a Reaction conditions: 23 (0.50 mmol), $213(1.00 \mathrm{mmol}), \mathbf{8 1}(5.0 \mathrm{~mol} \%), \mathrm{AgSbF}_{6}(10 \mathrm{~mol} \%), \mathrm{KOAc}(10$ $\mathrm{mol} \%)$, DCE (1.5 mL), $80^{\circ} \mathrm{C}, 16 \mathrm{~h}$.

The scope of indoles $\mathbf{2 3}$ showed a broad applicability of the cobalt(III)-catalyzed $\mathrm{C}-\mathrm{H}$ allylation. Electron-rich as well as electron-deficient indoles $\mathbf{2 3}$ were converted (entries 1 and 2). Sterically congested indole $\mathbf{2 3 \mathbf { j }}$ (entry 3 ) was allylated with excellent yield and a nitro substituent was well tolerated (entry 4). Finally, the acetanilide containing substrate 23i proved amenable in the cobalt(III)-catalyzed C-H allylation (entry 5).

In addition, M. Moselage established several other indoles $\mathbf{2 3}$ and phenyl pyri(mi)dines 22 as viable substrates, although at reduced catalytic efficiency. ${ }^{[182]}$ Experiments with substituted allyl acetates revealed a high sensitivity towards the substitution patterns, resulting in significant loss of reactivity. After considerable optimization, J. Koeller could realize an example, in which crotonylacetate was converted with an overall yield of $63 \%$ for a mixture of isomers. ${ }^{[186]}$ Finally, mechanistic studies were conducted by $\mathrm{M}$. Moselage, ${ }^{[182]}$ and a catalytic cycle was rationalized.

Initial formation of the cationic complex 101 followed by reversible $\mathrm{C}-\mathrm{H}$ cobaltation by BIES-type mechanism ${ }^{[29]}$ delivers five-membered intermediate 219 (Scheme 3.2). Insertion of the allylic double bond into the cobalt-carbon bond generates intermediate 220, stabilized by coordination of the carbonyl group. From intermediate 225, $\beta$-O elimination regenerates the active cobalt complex 101 and furnishes the desired product 91. 


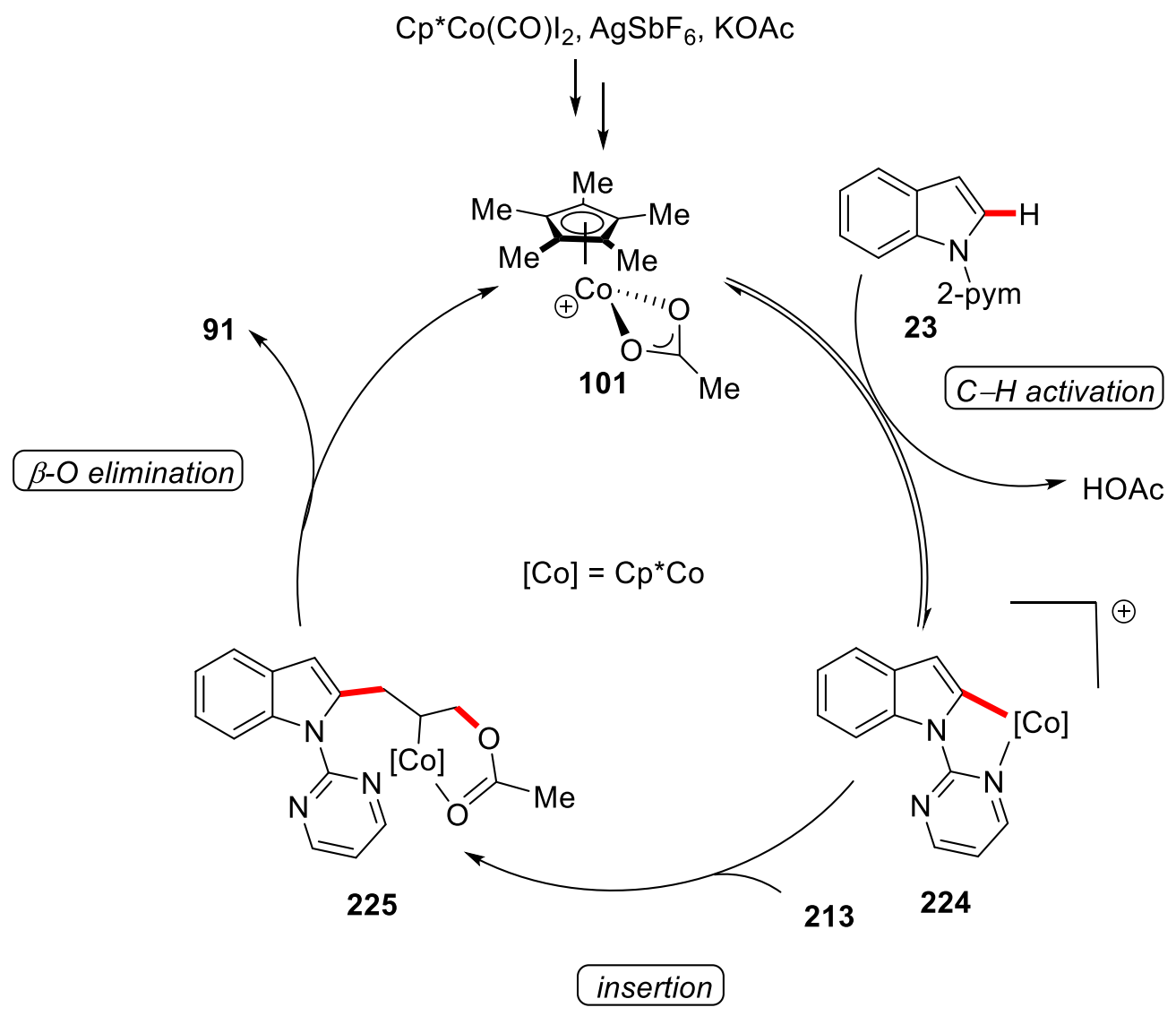

Scheme 3.2 Proposed catalytic cycle for the cobalt-catalyzed $\mathrm{C}-\mathrm{H}$ allylation by $\mathrm{C}-\mathrm{H} / \mathrm{C}-\mathrm{O}$ cleavage.

\subsection{Base Metal-Catalyzed C-H Alkynylation}

Alkynes are versatile building blocks in organic synthesis. Possible applications include selective reductions, ${ }^{[187]}$ Sonogashira-Hagihara cross-coupling ${ }^{[188]}$ and the so-called "Click-chemistry",[173c, 189] among others. Therefore, alkynes represent valuable synthetic handles for further late-stage functionalization, rendering environmentallybenign and cost-effective methods to introduce alkynes into the target molecules highly desirable.

\subsubsection{Optimization of the Cobalt-Catalyzed C-H Alkynylation}

At the outset of this study, base metal-catalyzed $\mathrm{C}-\mathrm{H}$ alkynylations were identified as a research area in need of further development. Indeed, most known methods for C-H alkynylation previously used precious and cost intensive metals, like rhodium [190] and iridium. ${ }^{[191]}$ 
During the studies presented in this thesis, Shi independently reported on a cobaltcatalyzed alkynylation under harsh conditions, that is $120^{\circ} \mathrm{C}$ and the use of a strong alcoholate base. ${ }^{[78]}$ Furthermore, the alkynylating reagent, TIPS-EBX (88) requires a three-step synthesis and is not very atom-economical. ${ }^{[192]}$ Due to the desire to realize the cobalt-catalyzed alkynylation efficiently under mild reaction conditions, easily accessible and more atom efficient bromoalkynes 132 were chosen as the alkyne coupling partner.

Therefore, the optimization of the envisioned cobalt-catalyzed $\mathrm{C}-\mathrm{H}$ alkynylation was initiated using bromoalkyne 132a, 2-pyrimidylindole (23a) and $\mathrm{Cp}^{*} \mathrm{Co}(\mathrm{CO}) \mathrm{I}_{2}(\mathbf{8 1})$ as the catalyst (Table 3.10).

Table 3.10 Optimization of the cobalt-catalyzed $\mathrm{C}-\mathrm{H}$ alknynylation using bromoalkyne $\mathbf{1 3 2 a} .^{\mathrm{a}}$

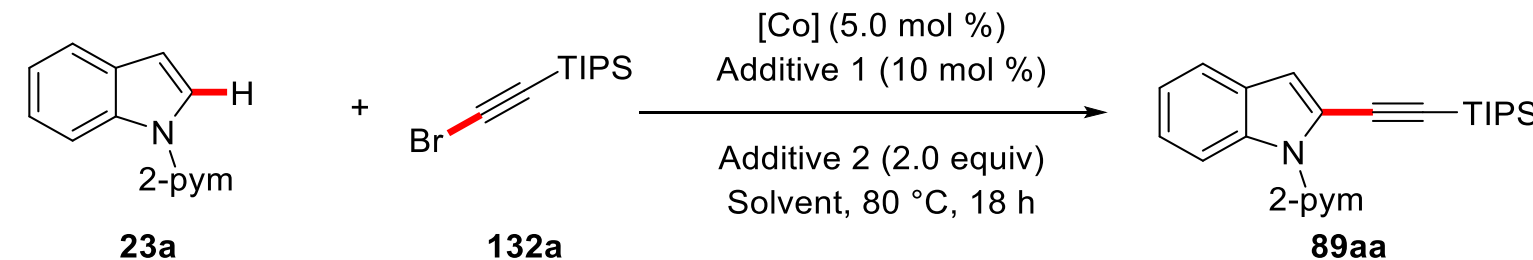

\begin{tabular}{|c|c|c|c|c|c|}
\hline Entry & [Co] & Additive 1 & Additive 2 & Solvent & $\bar{Y}$ Yield [\%] \\
\hline 1 & $\mathrm{Cp}^{*} \mathrm{Co}(\mathrm{CO}) \mathrm{I}_{2}$ & $\mathrm{AgSbF}_{6}$ & KOAc & $\mathrm{MeOH}$ & --- \\
\hline 2 & $\mathrm{Cp}^{*} \mathrm{Co}(\mathrm{CO}) \mathrm{l}_{2}$ & $\mathrm{AgSbF}_{6}$ & KOAC & DCE & 28 \\
\hline 3 & $\mathrm{Cp}^{*} \mathrm{Co}(\mathrm{CO}) \mathrm{l}_{2}$ & $\mathrm{AgSbF}_{6}$ & KOAC & TFE & 68 \\
\hline 4 & $\mathrm{Cp}^{*} \mathrm{Co}(\mathrm{CO}) \mathrm{I}_{2}$ & $\mathrm{AgSbF}_{6}$ & KOAC & HFIP & 17 \\
\hline 5 & $\mathrm{Co}(\mathrm{OAc})_{2}$ & $\mathrm{AgSbF}_{6}$ & KOAC & TFE & --- \\
\hline 6 & {$\left[\mathrm{Cp}^{*} \mathrm{Col}_{2}\right]_{2}$} & $\mathrm{AgSbF}_{6}$ & KOAC & TFE & 75 \\
\hline 7 & {$\left[\mathrm{Cp}{ }^{*} \mathrm{Co}\left(\mathrm{C}_{6} \mathrm{H}_{6}\right)\right]\left[\mathrm{PF}_{6}\right]_{2}$} & --- & KOAC & TFE & --- \\
\hline 8 & {$\left[\mathrm{Cp}^{*} \mathrm{Col}_{2}\right]_{2}$} & $\mathrm{AgBF}_{4}$ & KOAC & TFE & 66 \\
\hline 9 & {$\left[\mathrm{Cp}^{*} \mathrm{Col}_{2}\right]_{2}$} & $\mathrm{AgPF}_{6}$ & KOAC & TFE & 72 \\
\hline 10 & {$\left[\mathrm{Cp}^{*} \mathrm{Col}_{2}\right]_{2}$} & $\mathrm{AgNTf}_{2}$ & KOAC & TFE & 58 \\
\hline 11 & {$\left[\mathrm{Cp}^{*} \mathrm{Col}_{2}\right]_{2}$} & $\mathrm{Zn}(\mathrm{OTf})_{2}$ & KOAC & TFE & --- \\
\hline 12 & {$\left[\mathrm{Cp}^{*} \mathrm{Col}_{2}\right]_{2}$} & $\mathrm{KPF}_{6}$ & KOAC & TFE & --- \\
\hline 13 & {$\left[\mathrm{Cp}^{*} \mathrm{Col}_{2}\right]_{2}$} & $\mathrm{AgOTf}$ & KOAC & TFE & --- \\
\hline 14 & {$\left[\mathrm{Cp}^{*} \mathrm{Col}_{2}\right]_{2}$} & $\mathrm{AgSbF}_{6}$ & $\mathrm{PivOH}$ & TFE & $<5$ \\
\hline 15 & {$\left[\mathrm{Cp}^{*} \mathrm{Col}_{2}\right]_{2}$} & $\mathrm{AgSbF}_{6}$ & $\mathrm{~K}_{3} \mathrm{PO}_{4}$ & TFE & 52 \\
\hline 16 & {$\left[\mathrm{Cp}^{*} \mathrm{Col}_{2}\right]_{2}$} & $\mathrm{AgSbF}_{6}$ & KOTs & TFE & --- \\
\hline
\end{tabular}




$\begin{array}{lccccc}17 & {\left[\mathrm{Cp}^{*} \mathrm{Col}_{2}\right]_{2}} & \mathrm{AgSbF}_{6} & \mathrm{NaOAc} & \text { TFE } & 69 \\ 18 & {\left[\mathrm{Cp}^{*} \mathrm{Col}_{2}\right]_{2}} & \mathrm{AgSbF}_{6} & \mathrm{~K}_{2} \mathrm{CO}_{3} & \text { TFE } & 91 \\ 19 & {\left[\mathrm{Cp}^{*} \mathrm{Col}_{2}\right]_{2}} & \mathrm{AgSbF}_{6} & \mathrm{Na}_{2} \mathrm{CO}_{3} & \text { TFE } & 86 \\ 20 & --- & \mathrm{AgSbF} & \mathrm{K}_{2} \mathrm{CO}_{3} & \text { TFE } & --- \\ 21 & {\left[\mathrm{Cp}^{*} \mathrm{Col}_{2}\right]_{2}} & --- & \mathrm{K}_{2} \mathrm{CO}_{3} & \text { TFE } & --- \\ 22 & {\left[\mathrm{Cp}^{*} \mathrm{Col}_{2}\right]_{2}} & \mathrm{AgSbF}_{6} & -- & \text { TFE } & --- \\ \mathbf{2 3} & {\left[\mathrm{Cp}^{*} \mathrm{Col}_{2}\right]_{2}} & \mathbf{A g S b F} & \mathrm{K}_{2} \mathrm{CO}_{3} & \text { TFE } & \mathbf{9 6}^{\mathbf{b}}\end{array}$

a Reaction conditions: 23a $(0.50 \mathrm{mmol}), 132 \mathrm{a}(1.00 \mathrm{mmol}),[\mathrm{Co}](5.0 \mathrm{~mol} \%)$, additive 1 (10 mol \%), additive $2(1.00 \mathrm{mmol})$, solvent $(2.0 \mathrm{~mL}), 80^{\circ} \mathrm{C}, 18 \mathrm{~h} .{ }^{\mathrm{b}} 25^{\circ} \mathrm{C}, 18 \mathrm{~h}$.

While $\mathrm{MeOH}$ was not a suitable reaction medium, DCE gave a promising result (entry 2), which could be further improved by the use of 2,2,2-trifluoroethanol as the solvent (entry 3). Of the screened cobalt complexes, the dimeric species $\left[\mathrm{Cp}^{*} \mathrm{Col}_{2}\right]_{2}$ (82) proved to be the most efficient catalyst (entry 6), wile simple $\mathrm{Cp}^{*} \mathrm{Co}(\mathrm{CO}) \mathrm{I}_{2}(\mathbf{8 1})$ gave somewhat lower yields. In contrast, simple cobalt(II) acetate and cationic sandwich complex $\left[\mathrm{Cp}^{*} \mathrm{Co}\left(\mathrm{C}_{6} \mathrm{H}_{6}\right)\right]\left[\mathrm{PF}_{6}\right]_{2}$ (73) were not competent catalysts for the $\mathrm{C}-\mathrm{H}$ alkynylation (entries 5 and 7). Other silver additives with weakly coordinating counter ions ${ }^{[193]}$ showed comparable results to $\mathrm{AgSbF}_{6}$ (entries 8-10), while additives such as zinc(II) triflate and $\mathrm{KPF}_{6}$, were not suitable. Furthermore, among a representative set of additives, several beneficial effects were obtained (entries 14-19), with the highest efficacy observed with the mild base $\mathrm{K}_{2} \mathrm{CO}_{3}$ (entry 18). Several control experiments highlighted the essential nature of the cobalt catalyst, silver salt and base (entries 2022). Finally, an experiment at ambient temperature of $25^{\circ} \mathrm{C}$ confirmed the outstanding catalytic activity of this system, as nearly quantitative yield of 89aa was (entry 23).

\subsubsection{Scope of the Cobalt-Catalyzed C-H Alkynylation}

With the optimized catalytic system in hand, the robustness of the $\mathrm{C}-\mathrm{H}$ alkynylation by cobalt catalysis was evaluated towards diversely substituted indoles $\mathbf{2 3}$ and amino acids 226 (Table 3.11). 
Table 3.11 Scope of the cobalt-catalyzed C-H alkynylation of indoles 23, pyrroles 217 and amino acid 226. $^{\text {a }}$

$82(2.5 \mathrm{~mol} \%)$

$\mathrm{AgSbF}_{6}(10 \mathrm{~mol} \%)$

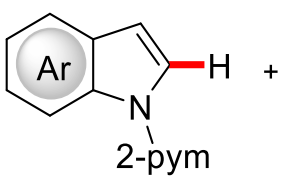

23

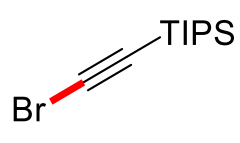

132a

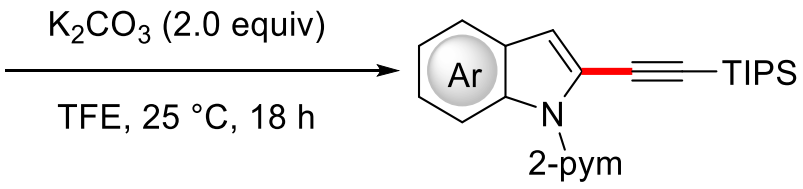

89

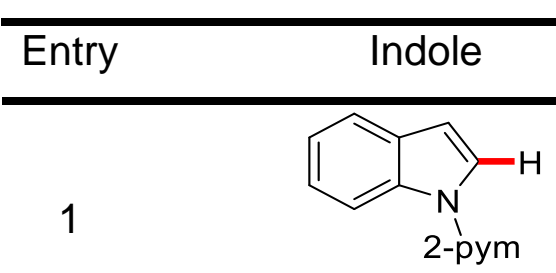

23a<smiles>CCOc1cccc2c1ccn2[Po]</smiles>

23m<smiles></smiles>

23d<smiles>[Z20]n1ccc2cc(F)ccc21</smiles>

230<smiles></smiles>

$23 h$<smiles>[R6]n1ccc2cc(I)ccc21</smiles>

$23 p$

6<smiles></smiles>

89 ma<smiles>COc1ccc2c(c1)cc(C#C[In]S)n2-c1ccccc1</smiles>

89da<smiles>[Z20]n1c(C#C[In]S)cc2cc(F)ccc21</smiles>

$890 a$<smiles></smiles>

89ha

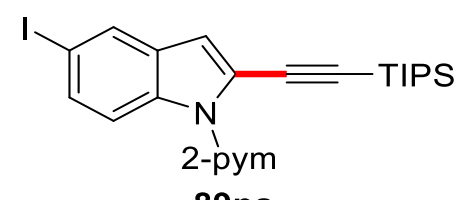

$87^{b}$

.

(n)

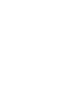


7<smiles></smiles>

23n

8<smiles>Cc1c(C)n([PbH])c2ccccc12</smiles>

23j

9<smiles>[PbH2]n1cccc1</smiles>

217a

10<smiles>O=C1CCCc2c1ccn2P([OH2+])[18OH]</smiles>

217 c

11<smiles></smiles>

89na<smiles>Cc1c(C#C[In](F)F)n([PbH])c2ccccc12</smiles>

89ja<smiles>[R6]n1c(C#C[In]C)ccc1C#C[In]S[In]</smiles>

223aa<smiles>O=C1CCCc2c1cc(C#C[In]S)n2[Po+]</smiles>

227aa 223ca<smiles>[2H]n1c(C#C[In+])c(CC(Nc2ccccc2COC(C)=O)C(=O)O)c2ccccc21</smiles><smiles>CC(=O)C(Cc1cc2ccccc2n1P)NC(=O)OCc1ccccc1</smiles>

226a

a Reaction conditions: 23 or $226(0.50 \mathrm{mmol}), \mathbf{1 3 2 a}(1.00 \mathrm{mmol}), 82(2.5 \mathrm{~mol} \%), \mathrm{AgSbF}_{6}(10 \mathrm{~mol} \%)$, $\mathrm{K}_{2} \mathrm{CO}_{3}(1.00 \mathrm{mmol})$, TFE $(2.5 \mathrm{~mL}), 25^{\circ} \mathrm{C}, 18 \mathrm{~h} .{ }^{\mathrm{b}} 80^{\circ} \mathrm{C}, 18 \mathrm{~h} .{ }^{\mathrm{c}} 132 \mathrm{a}(2.00 \mathrm{mmol})$.

The reaction generally proceeded with good to excellent yields. It is noteworthy, that electronically neutral or electron-rich substrates reacted efficiently at room temperature (entries 1-3), while electron-deficient substrates, such as halide substituted indoles 23o, 23h and $23 \mathrm{p}$ (entries 4-6) required a higher reaction temperature of $80{ }^{\circ} \mathrm{C}$. Furthermore, sterically crowded substrate 23j was converted less efficiently (entry 8), while nitro-substrate $23 \mathrm{n}$ appeared to be completely insoluble in TFE (entry 7). Simple pyrimidylpyrrole 217a was converted with excellent yield (entry 9), however only double alkynylation was achieved selectively by increasing the amount of $132 a$. Lower amounts of bromoalkyne $132 \mathrm{a}$ led to an inseperable mixture of mono- and 
bisalkynylated products. Moreover, tetrahydroindolone 217c was smoothly converted, once again highlighting the exceptional functional group tolerance of the cobalt catalysis (entry 10).

For tryptophan derived substrate 226a, no reaction was observed (entry 11). Besides indoles 23, also pyrroles 217 were investigated regarding the substrate scope

Finally, the use of different bromoalkynes 132 was tested, both regarding other silyl protecting groups as well as alkyl and aryl alkynes (Table 3.12).

Table 3.12 Scope of the cobalt-catalyzed C-H alkynylation using bromoalkynes $132 .^{\text {a }}$

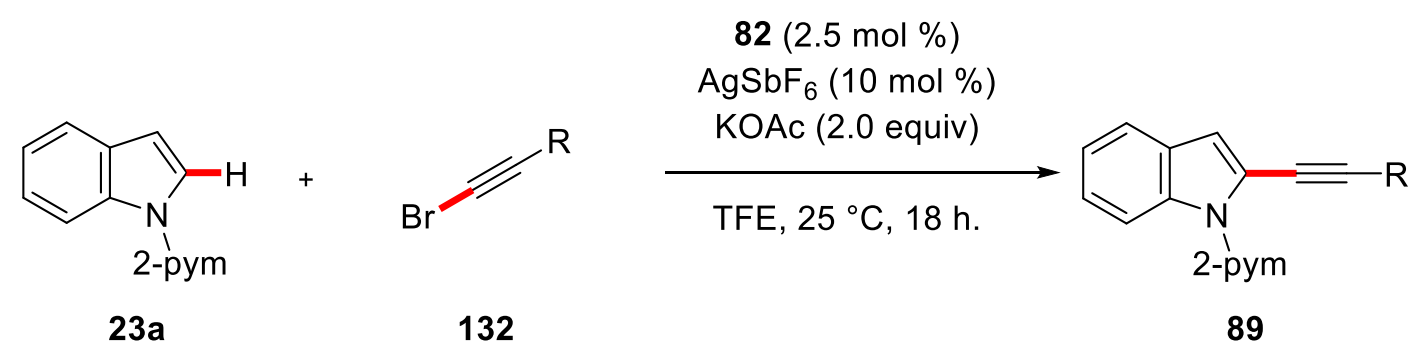

Entry


5

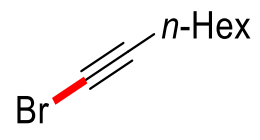

$132 \mathrm{e}$

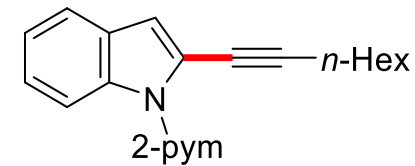

89ae

a Reaction conditions: 23a $(0.50 \mathrm{mmol}), 132(1.00 \mathrm{mmol}), 82(2.5 \mathrm{~mol} \%), \mathrm{AgSbF}_{6}(10 \mathrm{~mol} \%), \mathrm{KOAc}$ (1.00 mmol), TFE $(2.5 \mathrm{~mL}), 25{ }^{\circ} \mathrm{C}, 18 \mathrm{~h} .{ }^{b} \mathrm{~K}_{2} \mathrm{CO}_{3}(1.00 \mathrm{mmol})$.

Besides TIPS-alkyne 132a (entry 1), also DPMS- and TMS-alkynes 132b and 132c were successfully tolerated (entries 2 and 3 ), under a slight variation of the standard conditions. In contrast, aryl and alkyl substituted alkynes $132 \mathrm{~d}$ abd 132e proved to be not reactive under the reaction conditions (entries 4 and 5 ).

\subsubsection{Mechanistic Studies}

After establishing the scope of the cobalt-catalyzed $\mathrm{C}-\mathrm{H}$ alkynylation of indoles $\mathbf{2 3}$, mechanistic experiments were conducted to gain insights into its mode of action. To this end, a reaction using $\mathrm{D}_{2} \mathrm{O}$ as cosolvent was conducted in the absence of bromoalkyne 132a. Starting material 23a could be reisolated and deuterium incorporation was observed in the C-2 position with $50 \%$ deuteration. This is indicative of a reversible $\mathrm{C}-\mathrm{H}$ metalation, while no deuteration could be observed in the $\mathrm{C}-3$ or C-7 position (Scheme 3.3).<smiles>c1cnc(-n2ccc3ccccc32)nc1</smiles>

23a
$82(2.5 \mathrm{~mol} \%)$ $\mathrm{AgSbF}_{6}(10 \mathrm{~mol} \%)$

$\mathrm{K}_{2} \mathrm{CO}_{3}$ (2.0 equiv)

TFE/D $\mathrm{D}_{2} \mathrm{O}(4 / 1)$

$80^{\circ} \mathrm{C}, 18 \mathrm{~h}$

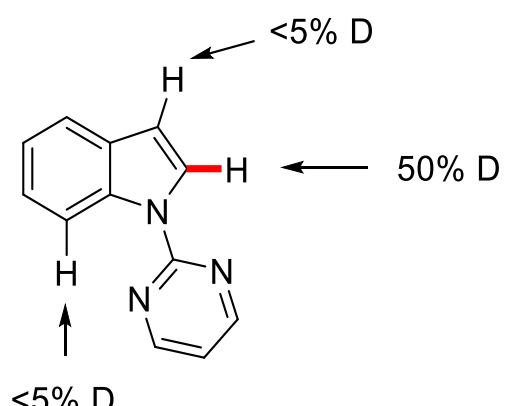

$[D]_{n}-23 a$

Scheme 3.3 H/D Exchange experiment.

Additionally, competition experiments were conducted with regard to the indole $\mathbf{2 3}$ (Scheme 3.4). 


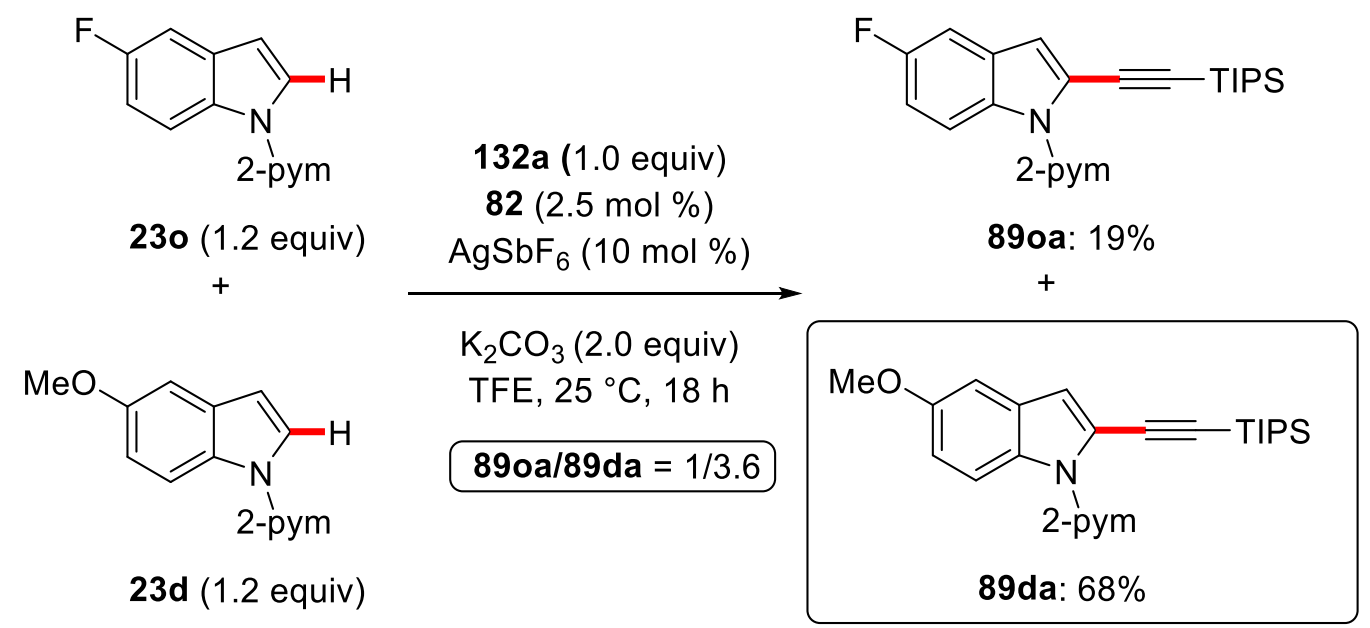

Scheme 3.4 Intermolecular competition experiment between indoles 230 and $\mathbf{2 3 d}$.

The competition experiment between electron-rich and electron-deficient arenes $\mathbf{2 3 d}$ and 230 revealed a preferential reactivity in favor of the more electron-rich substrate 23d. This is however not in line with a CMD/AMLA-type $\mathrm{C}-\mathrm{H}$ activation, ${ }^{[27-28]}$ where a preferred reaction of the electron-deficient arene is expected, due to the higher kinetic acidity of electron deficient arenes. Therefore, a BIES C-H activation seems plausible for the cobalt-catalyzed $\mathrm{C}-\mathrm{H}$ activation. ${ }^{[29]}$ Furthermore, a competition experiment between TMS-substituted alkyne 132c and TIPS substituted alkyne 132a was conducted by M. J. Gonzalez and showed a preference for the TMS-alkyne 132c under the reaction conditions. ${ }^{[194]}$ This can, for example, be rationalized by a faster rection due to steric effects of the far less bulky TMS group.

\subsubsection{Proposed Catalytic Cycle}

Based on these findings, a mechanistic scenario for the cobalt-catalyzed $\mathrm{C}-\mathrm{H}$ alkynylation of indoles $\mathbf{2 3}$ was proposed (Scheme 3.5). The active cobalt catalyst $\mathbf{2 2 9}$ is formed in situ through the cleavage of the $\left[\mathrm{Cp}^{*} \mathrm{Col}_{2}\right]_{2}$-dimer upon coordination of the base and abstraction of the iodide ligands. Coordination of substrate 23a followed by a BIES C-H metalation event ${ }^{[29]}$ generates cobaltacycle 230 . Insertion of alkyne 132a into the $\mathrm{Co}-\mathrm{C}$ bond generates seven-membered cobaltacycle intermediate 226, which can then undergo $\beta$-bromo elimination to liberate the desired product 89aa. $A$ subsequent ligand exchange regenerates the active cationic complex 229. 


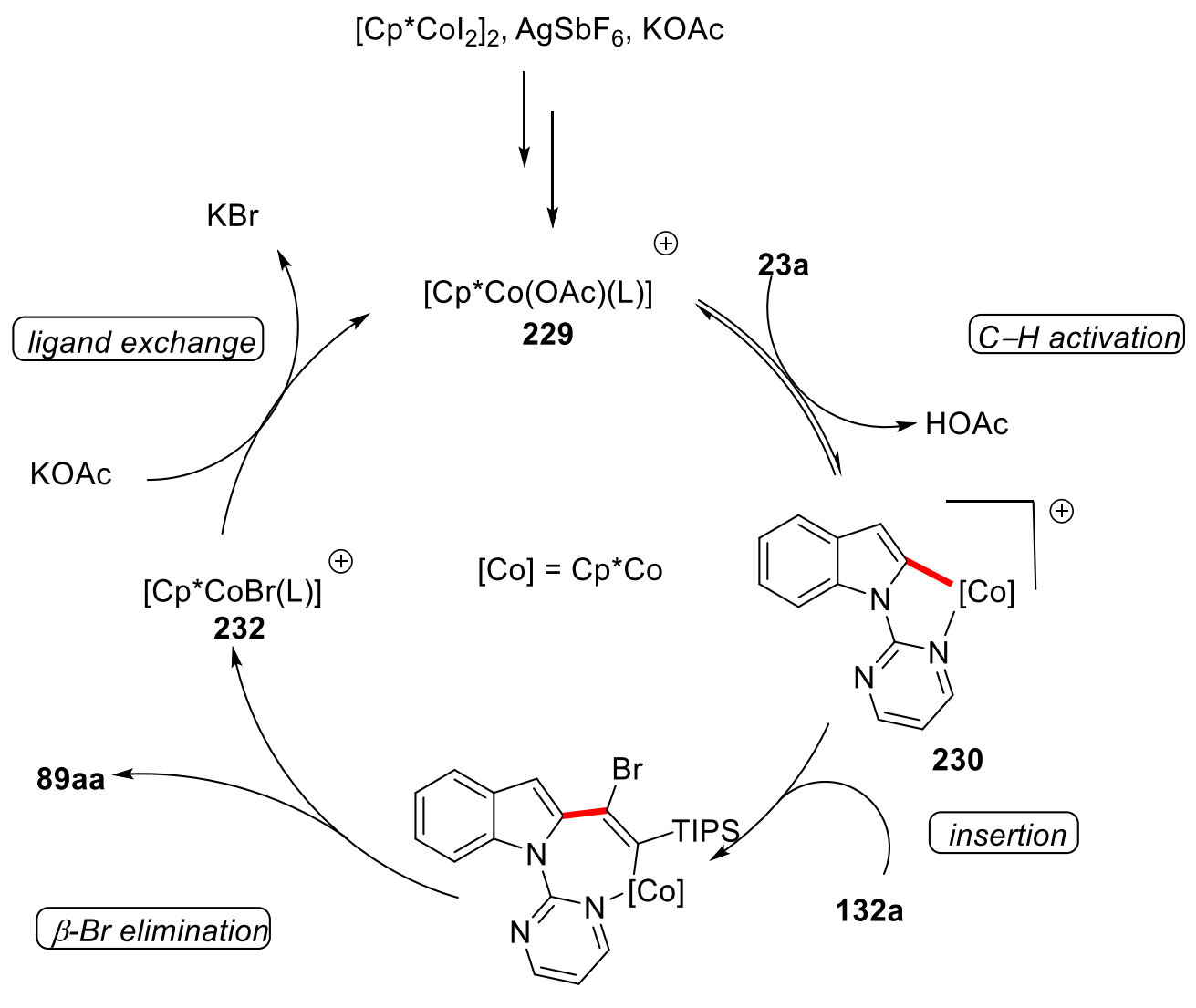

231

Scheme 3.5 Proposed catalytic cycle for the cobalt-catalyzed C-H alkynylation.

\subsubsection{Diversification of the Alkynylated Indoles}

To highlight the synthetic potential of the devised cobalt-catalyzed $\mathrm{C}-\mathrm{H}$ alkynylation, several modifications of the isolated products 89 were performed (Scheme 3.6).

First, the selective deprotection of the silyl group was achieved using TBAF.[195] The generated terminal alkyne $\mathbf{2 3 3}$ was subsequently alkylated by a simple deprotonation/alkylation sequence using methyl iodide ${ }^{[196]}$ or arylated by a Sonogashira-Hagihara coupling using $\mathrm{Pd}(\mathrm{OAc})_{2}, \mathrm{Cul}$ and $\mathrm{PPh}_{3}$ as the catalytic system. ${ }^{[197]}$ Furthermore, a deprotection of both silyl group and pyrimidyl group was achieved using $\mathrm{NaOEt}$ in a $\mathrm{DMSO} / \mathrm{MeOH}$ mixture at $60{ }^{\circ} \mathrm{C} .{ }^{\text {.79a] }}$ The generated ethynylindole $\mathbf{2 3 6}$ was then utilized in a copper-catalyzed 1,3-dipolar cycloaddition to synthesize triazole 237 (Scheme 3.6, bottom). ${ }^{[198]}$ 


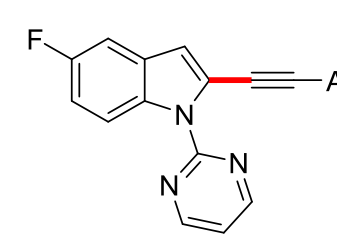

234: $78 \%$ $\mathrm{Ar}=4-\mathrm{CO}_{2} \mathrm{MeC}_{6} \mathrm{H}_{4}$

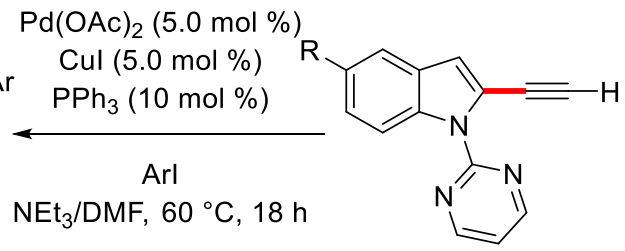

$\mathrm{R}=\mathrm{H}(\mathbf{2 3 3 a}) 81 \%$

$R=F(233 b) 81 \%$

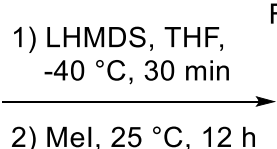

2) $\mathrm{Mel}, 25^{\circ} \mathrm{C}, 12 \mathrm{~h}$

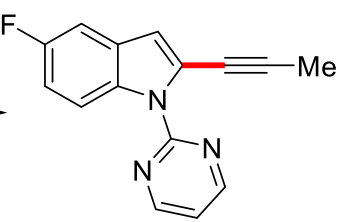

235: $92 \%$

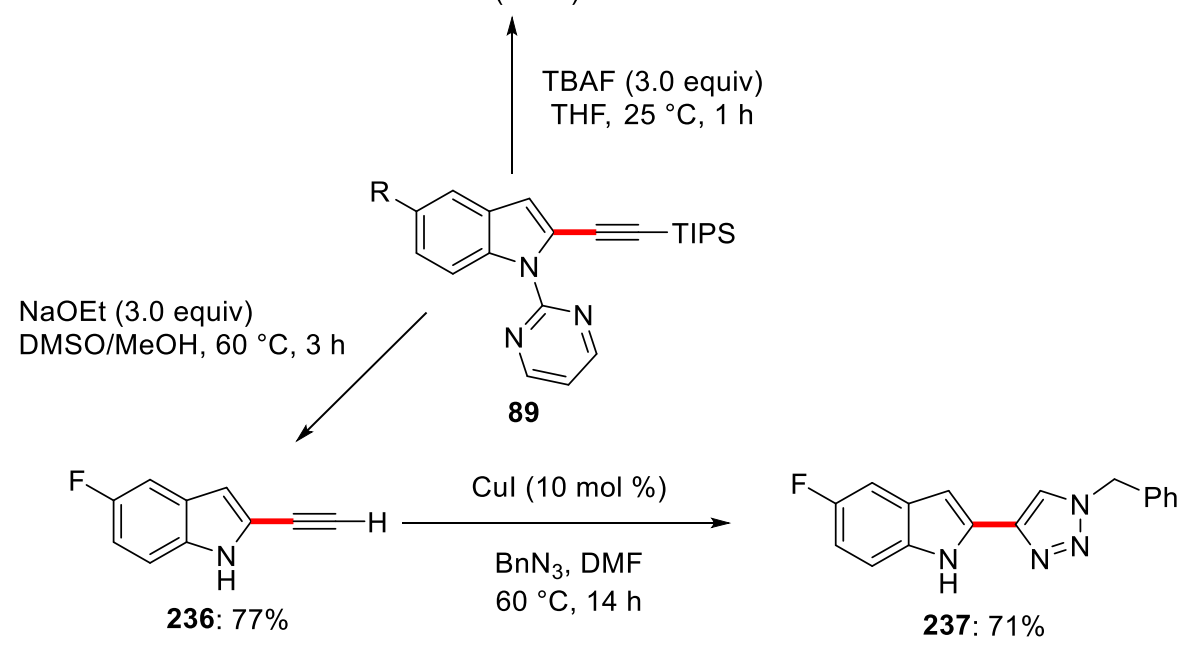

Scheme 3.6 Diversification of alkynyl indoles 89.

Overall, the synthetic value of the alkynyl group could be highlighted by these reactions, underlining the usefulness of the novel cobalt-catalyzed $\mathrm{C}-\mathrm{H}$ alkynylation at exceedingly mild conditions.

\subsubsection{Optimization of the Manganese-Catalyzed C-H Alkynylation}

In recent years, the power of manganese $(\mathrm{I})$ complexes as catalysts for $\mathrm{C}-\mathrm{H}$ activation was discovered and exploited for numerous transformations. ${ }^{[119]}$ Manganese is an important trace metal in living organisms, the third most abundant transition metal in the earth's crust and advantageous regarding toxicity and availability. ${ }^{[35]}$ So far a majority of transformations are hydrofunctionalizations of unsaturated $\mathrm{C}-\mathrm{C}$ or $\mathrm{C}-\mathrm{Het}$ multiple bonds, while substitutive transformations remained scarce. ${ }^{[119]}$ Along these lines, Z. Ruan discovered the $\mathrm{C}-\mathrm{H}$ alkynylation of indoles $\mathbf{2 3}$ using bromoalkynes 132. ${ }^{[199]}$ While the initial reaction was already convincing with an isolated yield of $93 \%$, further optimization studies were conducted to identify the ideal conditions (Table 3.13). 
Table 3.13 Optimization of the manganese(I)-catalyzed C-H alkynylation. ${ }^{a}$

\begin{tabular}{ccccccc} 
23a or 23q & & & & & & \\
\hline
\end{tabular}

a Reaction conditions: $23(0.50 \mathrm{mmol}), 132 \mathrm{a}(0.75 \mathrm{mmol}), 169(\mathrm{Y} \mathrm{mol} \%)$, Base (1.00 mmol), solvent $(1.0 \mathrm{~mL}), T, 16 \mathrm{~h} .{ }^{\mathrm{b}}$ performed by Z. Ruan. ${ }^{\mathrm{c}}$ 132a $(0.60 \mathrm{mmol})$.

It was observed that pyridyl as well as pyrimidyl directing groups were competent in the $\mathrm{C}-\mathrm{H}$ alkynylation, with the pyrimidyl group being preferred due to the easy synthesis of the pyrimidyl indoles (entries 1-4). ${ }^{[200]}$ A reduction of the catalyst loading to $5.0 \mathrm{~mol} \%$ led to a reduced yield (entry 5), whereas bases other than dicyclohexylamine were not effective (entries 6 and 7). TFE was not suitable as the reaction medium (entry 8), however DCE showed very promising results (entry 9). Again, a further reduction of the catalyst loading led to a decrease in yield (entry 10), while the temperature could be reduced to $80^{\circ} \mathrm{C}$ without a loss of reactivity (entries 11 
and 12). Below $80^{\circ} \mathrm{C}$ the transformation was not as efficient (entry 13). The amount of bromoalkyne 132a could be reduced to 1.2 equivalents (entry 14) and control experiments confirmed the essential role of the manganese catalyst 169 and the base (entries 15 and 16).

Furthermore, due to the limitations known from the cobalt-catalyzed $\mathrm{C}-\mathrm{H}$ alkynylation regarding aryl and alkyl substituted alkynes 132, further optimization studies using various Lewis-acidic additives were conducted (Table 3.14).

Table 3.14 Optimization of the manganese(I)-catalyzed C-H alkynylation using aryl alkyne $\mathbf{1 3 2 d} .^{\text {a }}$

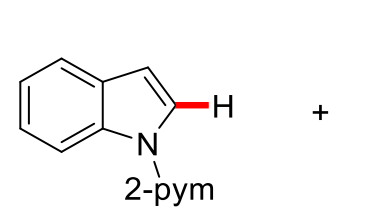

23a

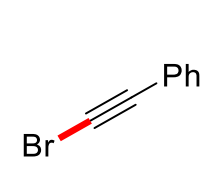

$132 d$

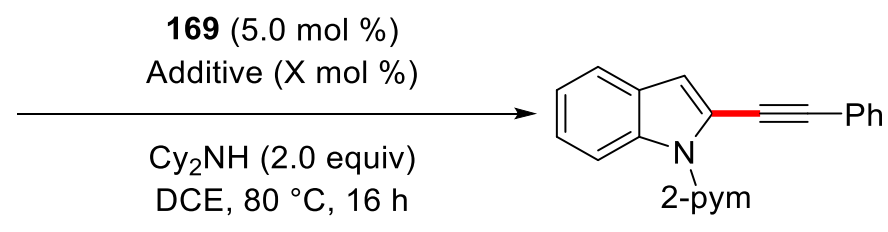

89ad

\begin{tabular}{cccc}
\hline Entry & Additive & $\mathrm{X}$ & Yield [\%] \\
\hline 1 & -- & --- & $---\mathrm{b}$ \\
2 & $\mathrm{BPh}_{3}$ & 5.0 & $61^{\mathrm{b}}$ \\
3 & $\mathrm{BPh}_{3}$ & 5.0 & $---\mathrm{b}, \mathrm{c}$ \\
4 & $\mathrm{CuBr}_{2}$ & 5.0 & --- \\
5 & $\mathrm{AlCl}_{3}$ & 5.0 & 32 \\
6 & $\mathrm{BBr}_{3}$ & 5.0 & 56 \\
7 & $\mathrm{ZnCl}_{2}$ & 5.0 & $<5$ \\
8 & $\mathrm{ZnBr}_{2}$ & 5.0 & $<5$ \\
9 & $\mathrm{Znl}_{2}$ & 5.0 & $---\mathrm{b}$ \\
10 & $\mathrm{FeCl}_{3}$ & 2.5 & $---\mathrm{b}^{\mathrm{b}}$ \\
11 & $\mathrm{MgCl}_{2}$ & 5.0 & --- \\
12 & $\mathrm{BPh}_{3}$ & 0.05 & $92^{\mathrm{b}}$ \\
13 & $\mathrm{BPh}_{3}$ & 0.05 & $95^{\mathrm{b}, \mathrm{d}}$ \\
14 & $\mathrm{BPh}_{3}$ & 0.05 & $86^{\mathrm{b}, \mathrm{e}}$ \\
\hline
\end{tabular}

a Reaction conditions: 23a $(0.50 \mathrm{mmol}), 132 \mathrm{~d}(0.60 \mathrm{mmol}), 169(5.0 \mathrm{~mol} \%), \mathrm{Cy}_{2} \mathrm{NH}(1.00 \mathrm{mmol}), \mathrm{DCE}$

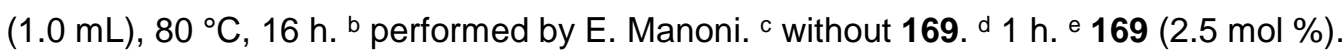

The reaction did not not proceed in the absence of the additive (entry 1), while the addition of catalytic amounts of $\mathrm{BPh}_{3}$ provided beneficial results (entry 2). A control experiment confirmed that the manganese catalyst 169 is still essential (entry 3). 
Furthermore, only additives containing group 3 elements were able to promote the catalytic activity. Simple aluminumtrichloride and borontribromide led to product formation, although at reduced efficacy (entries 5 and 6), whereas other Lewis-acidic additives, such as copper(II) bromide, zinc(II) halides and iron trichloride were not effective (entries 4, 7-11). The loading of the additive could be reduced (entries 12-14). Moreover, it was possible to lower the catalyst loading and the reaction time of the transformation (entry 13).

\subsubsection{Scope of the Manganese-Catalyzed C-H Alkynylation}

With the optimized reaction conditions being identified, the robustness of the discovered $\mathrm{C}-\mathrm{H}$ alkynylation with regard to various functional groups was evaluated. First, the scope of pyrimidyl and pyridyl indoles 23 and pyrroles 217 was investigated (Table 3.15).

Table 3.15 Manganese(I)-catalyzed C-H alkynylation of indoles 23 and pyrroles 217.

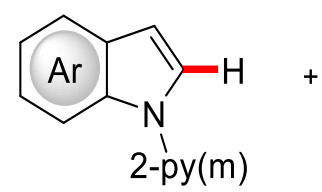

23

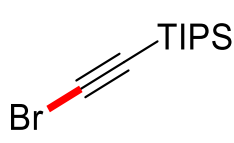

$132 a$

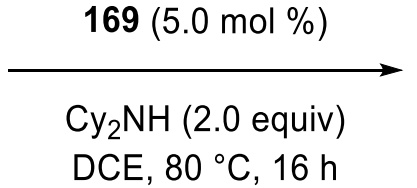

DCE, $80^{\circ} \mathrm{C}, 16 \mathrm{~h}$

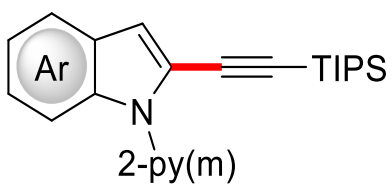

89

Entry


4<smiles>[PH3+]n1ccc2cc(Br)ccc21</smiles>

23h

5<smiles>[R6][PH2+]n1ccc2cc([N+](=O)[O-])ccc21</smiles>

$23 n$

6<smiles>[PbH2]n1cccc1</smiles>

217a

7<smiles>Cc1cc(C)n(CP)c1[Pb]</smiles>

217b<smiles>O=C1CCCc2c1ccn2[PbH2+]</smiles>

217c<smiles></smiles>

89 ha

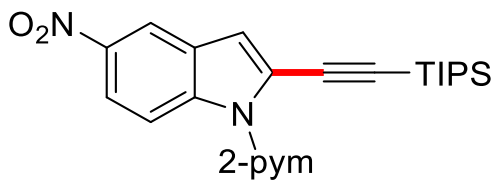

89na<smiles>CC(C)(C)n1c(C#C[In]S)ccc1C#C[In]S</smiles>

$89^{b}$<smiles>O=C1CCCc2c1cc(C#C[In]S)n2[PbH]</smiles>

223ca 2-pym

223ba<smiles>Cc1cc(C)n(C#[Pb])c1C#C[In]C(F)(F)F</smiles>

96

a Reaction conditions: 23 or $217(0.50 \mathrm{mmol}), \mathbf{1 3 2 a}(0.6 \mathrm{mmol}), 169(5.0 \mathrm{~mol} \%), \mathrm{Cy}_{2} \mathrm{NH}(1.00 \mathrm{mmol})$, DCE (1.0 mL), $80^{\circ} \mathrm{C}, 16$ h. ${ }^{b} 132 \mathrm{a}(1.20 \mathrm{mmol})$.

Besides the unsubstituted indole 23a, which was transformed with excellent yield (entries 1), electron-rich 5-methoxyindole 23d was converted with good yield (entriy 2). Further indoles 23 containing valuable electrophilic functional groups, such as fluoro, bromo and nitro, were smoothly converted (entries 3-5). Also, pyrroles were investigated regarding their use in this reaction. Simple 2-pyrimidylpyrrole (217a) was also readily alkynylated, however an excess of bromoalkyne $132 \mathrm{a}$ was necessary to ensure selective transformation to the bisalkynylated product 223aa (entry 6). Cyclic ketone 217c was converted with excellent yield, as was the sterically congested 2,4dimethylpyrolle $\mathbf{2 1 7 b}$.

The scope of silyl groups on the alkyne 132 was studied exclusively by Z. Ruan and will therefore not be shown in detail.[199] It was, however, observed that a variety of 
different silylalkynes 132 reacted all with good to excellent yields of more than $85 \%$, regardless of the steric bulk.

In addition, the scope of non-silyl substituted alkynes 132 was investigated using the optimized reaction conditions with the Lewis-acidic additive $\mathrm{BPh}_{3}$ as co-catalyst (Table 3.16).

Table 3.16 Scope of the manganese-catalyzed C-H alkynylation using bromoalkynes $132 .^{a}$

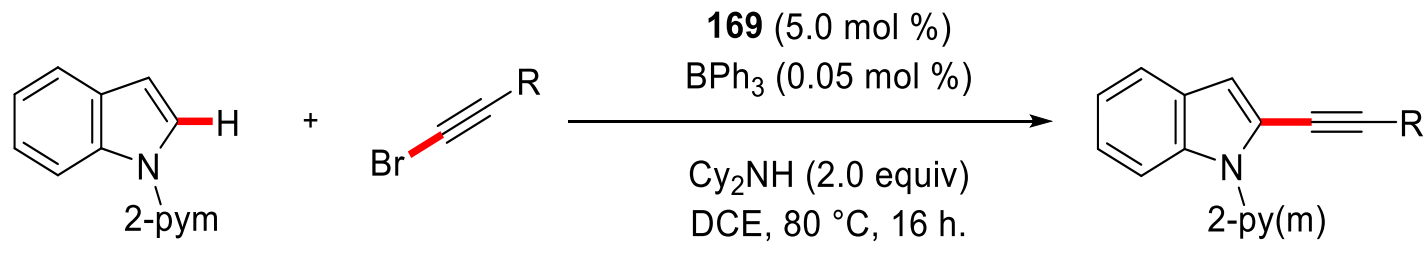

23a

132

89

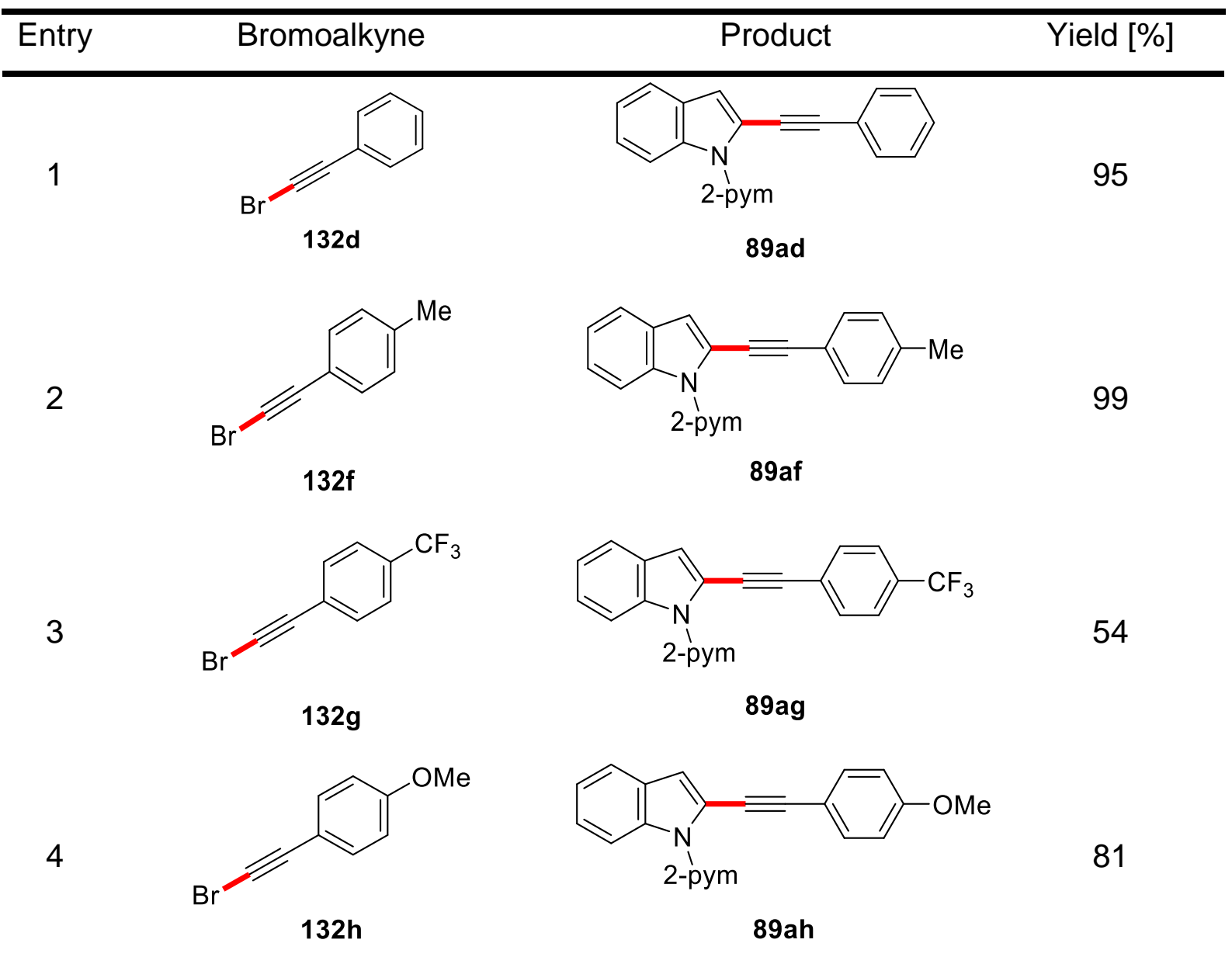

a Reaction conditions: 23a $(0.50 \mathrm{mmol}), 132(0.60 \mathrm{mmol}), 169(5.0 \mathrm{~mol} \%), \mathrm{BPh}_{3}(0.05 \mathrm{~mol} \%), \mathrm{Cy}_{2} \mathrm{NH}$ (1.00 mmol), DCE $(1.0 \mathrm{~mL}), 80^{\circ} \mathrm{C}, 16 \mathrm{~h}$.

The manganese-catalyzed C-H alkynylation proved to be amenable towards variety of aryl substituted 132 with electron-rich as well as electron-deficient substituents. While 
electronically neutral and electron-rich alkynes are converted very effictively (entries 1 , 2, 4), electron-deficient alkyne $\mathbf{1 3 2}$ (entry 3 ) was less efficient in the manganesecatalyzed $\mathrm{C}-\mathrm{H}$ alkynylation. Moreover, several other aryl as well as alkenyl and alkyl substituted bromoalkynes 132 were shown to be viable substrates by Z. Ruan and E. Manoni. ${ }^{[201]}$

Finally, the $\mathrm{C}-\mathrm{H}$ alkynylation of readily available tryptophan derivatives 221a and several oligopeptides 222 was investigated (Table 3.17).

Table 3.17 Scope of the manganese-catalyzed C-H alkynylation of peptides $221 .^{\mathrm{a}}$

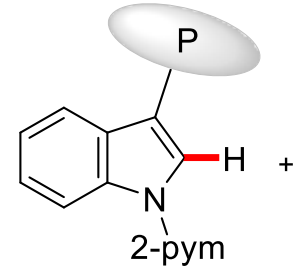

226

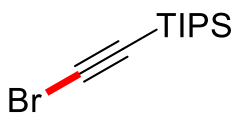

$132 \mathrm{a}$

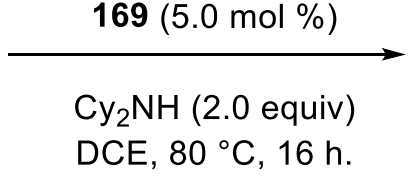

DCE, $80^{\circ} \mathrm{C}, 16 \mathrm{~h}$

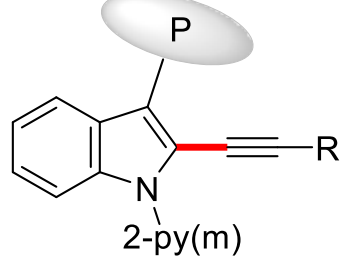

227

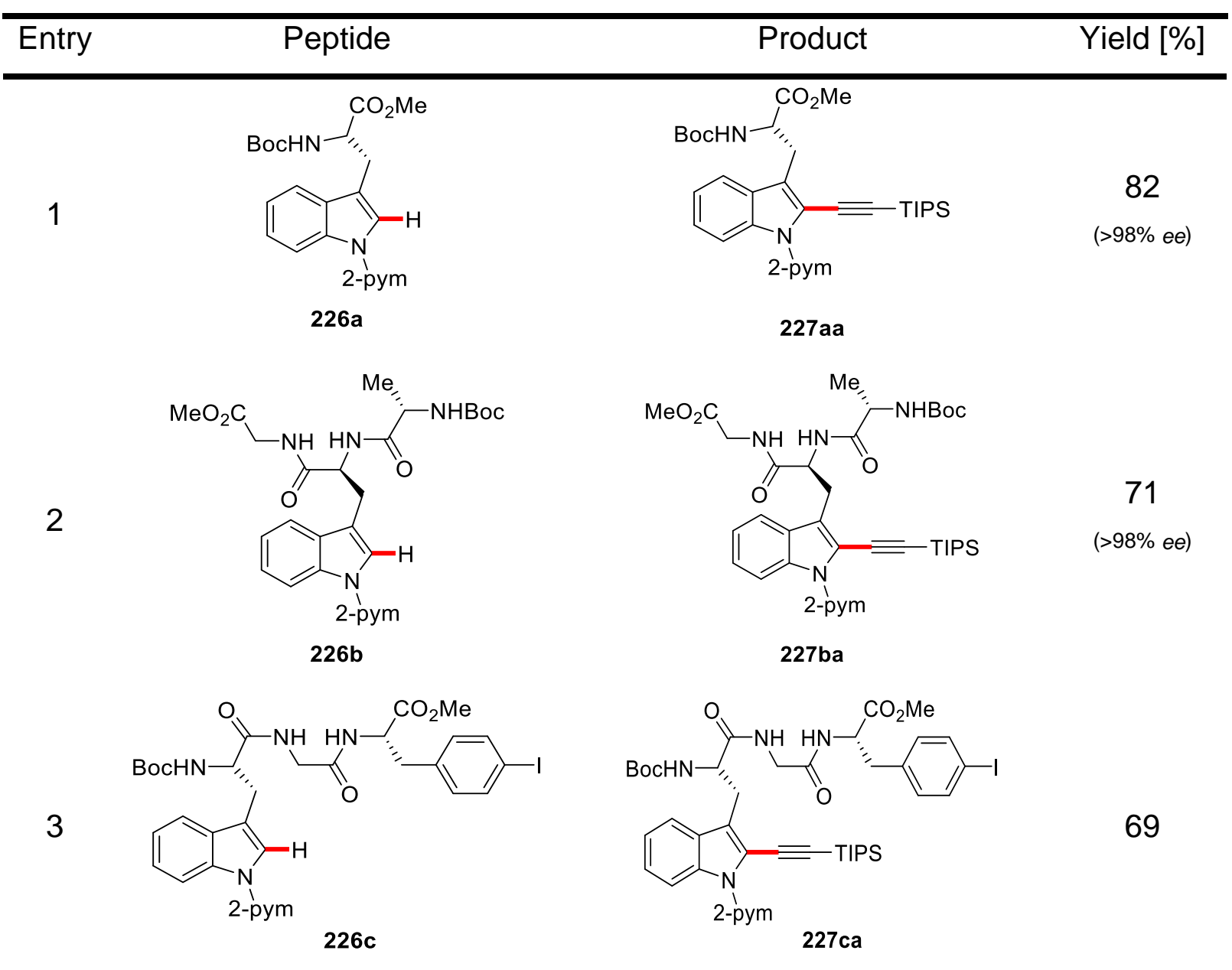

a Reaction conditions: $226(0.50 \mathrm{mmol}), \mathbf{1 3 2 a}(0.60 \mathrm{mmol}), 169(5.0 \mathrm{~mol} \%), \mathrm{Cy}_{2} \mathrm{NH}(1.00 \mathrm{mmol}), \mathrm{DCE}$ $(1.0 \mathrm{~mL}), 80^{\circ} \mathrm{C}, 16 \mathrm{~h}$. 
Simple methyl- and Boc-protected tryptophan 226a reacted readily with bromoalkyne 132a to alknynylated tryptophan 227aa (entry 1 ). Tripeptide 226b with the tryptophane moiety in the middle of the peptide chain (entry 2) and tripeptide 226c with the tryptophan in terminal position (entry 3 ) resulted both in efficient product formation. Furthermore, peptide 226c includes a handle for further ligation which was left intact during the transformation.

To ensure the retention of stereoconfiguration during the manganese catalysis, the products 227aa and 227ba were analyzed by chiral HPLC and compared to their racemic analogues, showing that no racemization occured during the manganese catalysis (Figure 3.2 and 3.3)
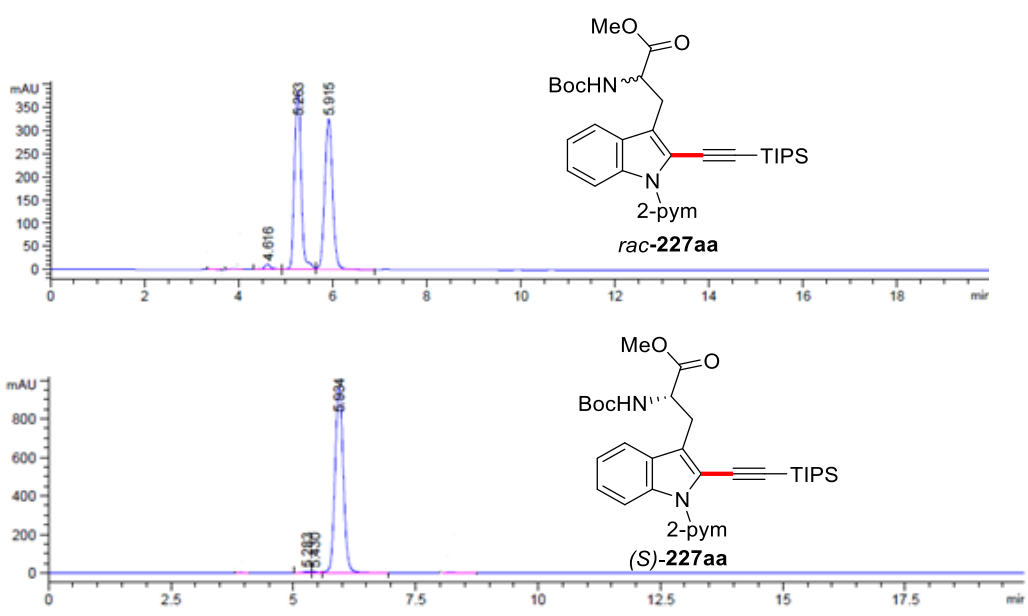

Figure 3.2 HPLC analysis of 227aa

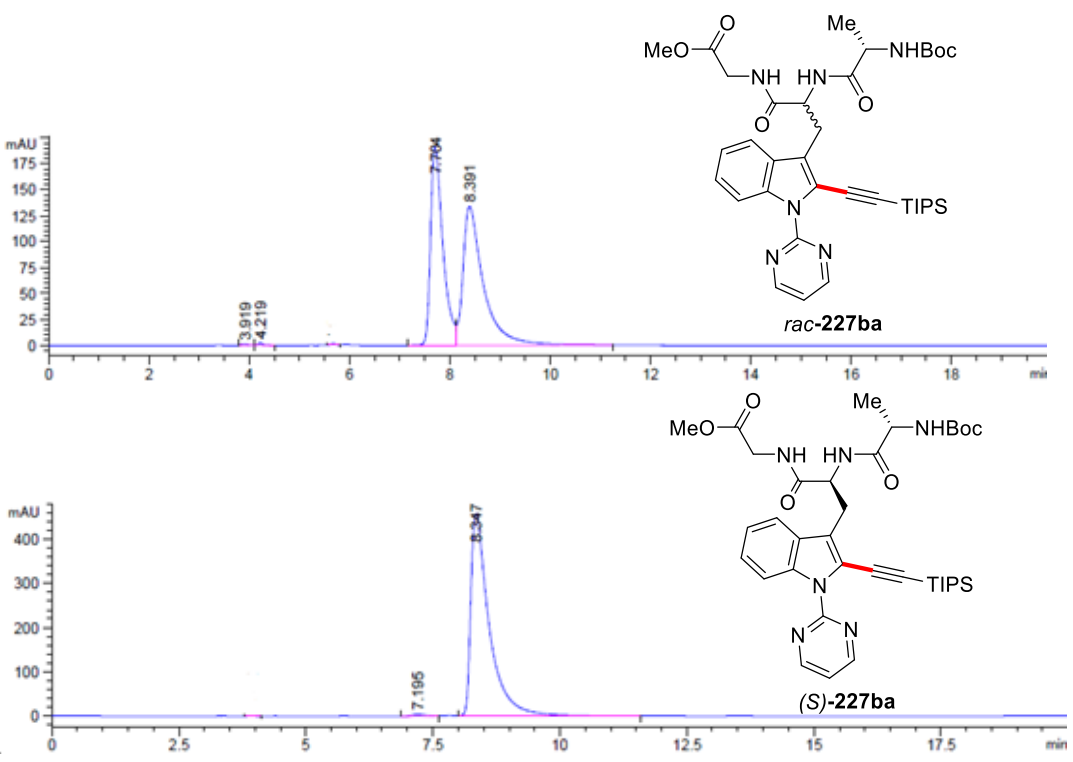

Figure 3.3 HPLC analysis of 227ba. 


\subsubsection{Mechanistic Studies for the Manganese-Catalyzed Alkynylation}

After the investigation of the scope of the manganese-catalyzed $\mathrm{C}-\mathrm{H}$ alkynylation, detailed mechanistic experiments were conducted to gain insights into its mode of action.

First, deuteration studies in the presence of $D_{2} \mathrm{O}$ were conducted by Z. Ruan, [199] revealing the incorporation of deuterium in the reisolated starting material in $\mathrm{C}-2$ position of $61 \%$ and in C-3 position of $13 \%$. Furthermore, the isolated product showed $26 \%$ deuterium incorporation in the C-3 position (Scheme 3.7).

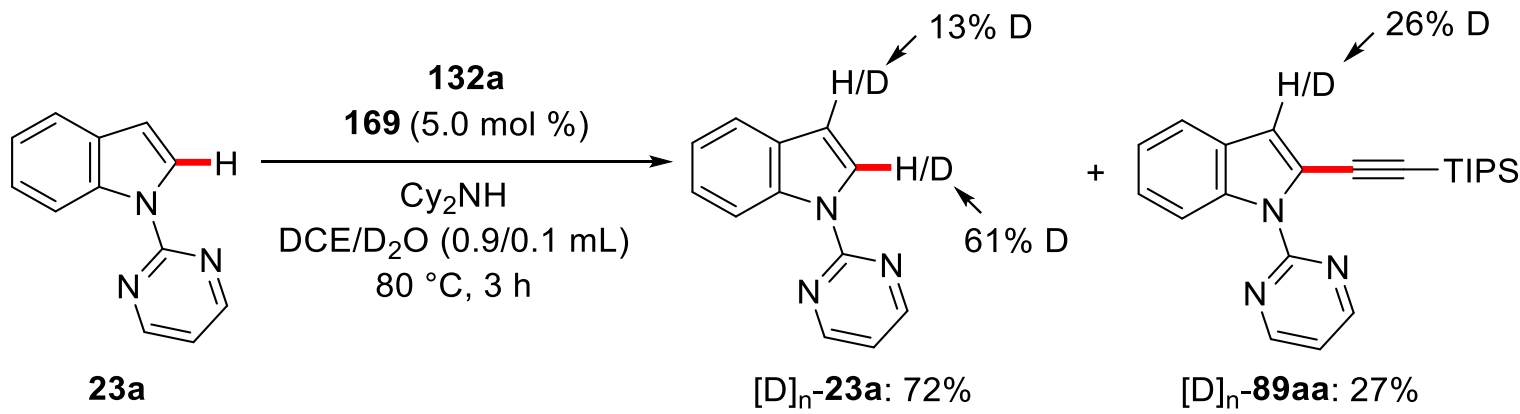

Scheme 3.7 H/D-exchange with isotopically labeled co-solvent.

These findings are indicative of a facile and reversible $\mathrm{C}-\mathrm{H}$ cleavage. To gain further insight into the $\mathrm{C}-\mathrm{H}$ cleavage, additional deuteration studies in the absence of alkyne 132a (Scheme 3.8), in the absence of $\operatorname{MnBr}(\mathrm{CO})_{5}$ (169) (Scheme 3.9) and for the product 89aa under the otherwise optimized reaction conditions (Scheme 3.10) were conducted.<smiles>c1cnc(-n2ccc3ccccc32)nc1</smiles>

$23 a$

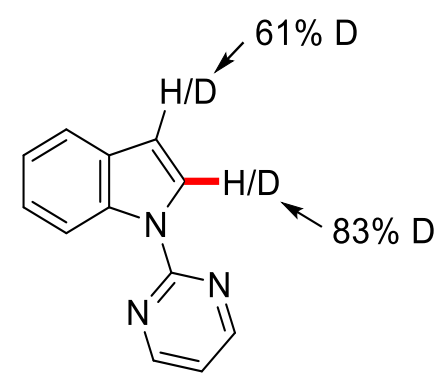

$[D]_{n}-23 a a: 96 \%$

Scheme 3.8 H/D-exchange in the absence of bromoalkyne 132a. 


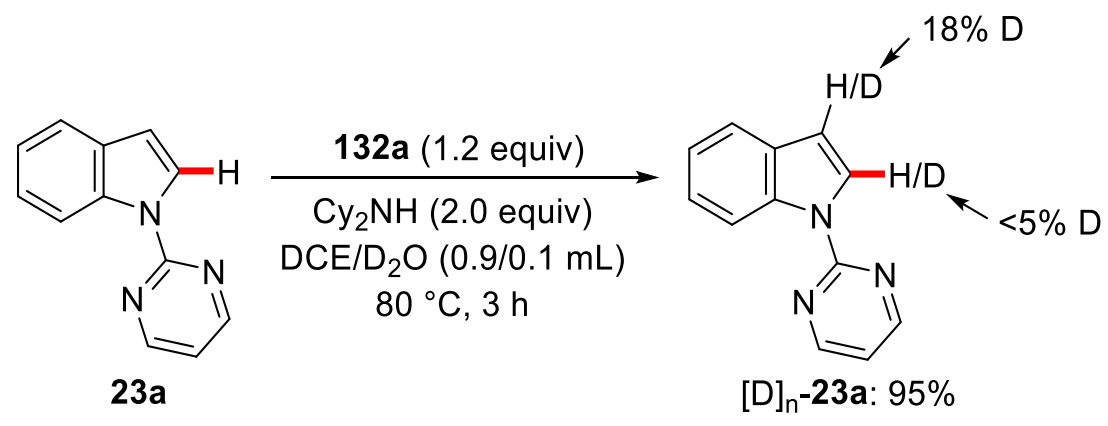

Scheme 3.9 H/D-exchange in the absence of the catalyst 169 .

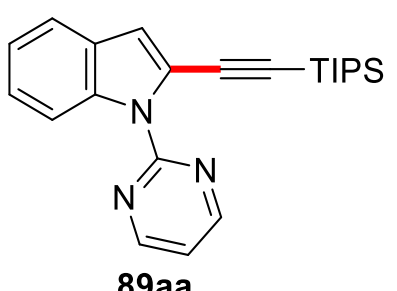

89aa

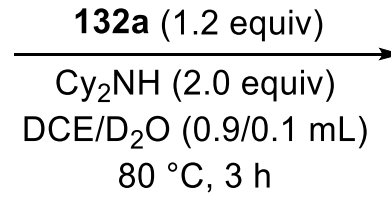

$80{ }^{\circ} \mathrm{C}, 3 \mathrm{~h}$

Scheme 3.10 H/D-exchange of the product 89aa in the absence of catalyst 169 .

The results of the deuteration experiments confirmed that the catalyst 169 is involved in the deuteration at the $\mathrm{C}-2$ position of indole 23a, while bromoalkyne 132a was not essential for the deuteration. The observed deuteration in C-3 position in the reisolated starting material 23a and product 89aa can be attributed to an electrophilic aromatic substitution pathway, ${ }^{[202]}$ that is operative also in the absence of the manganese catalyst $\mathbf{1 6 9}$, for both the starting material $\mathbf{2 3 a}$ as well as the product $\mathbf{8 9 a a}$ (Schemes 3.9 and 3.10$)$.

A KIE experiment conducted by $Z$. Ruan revealed a KIE of $k H / k D=1.0,{ }^{[199]}$ indicating that the $\mathrm{C}-\mathrm{H}$ bond cleavage is not the rate-determining step of this reaction. Further reactions also conducted by $Z$. Ruan using various radical scavengers were inconclusive, as TEMPO did shut down the reaction nearly completely, while air and BHT reduced the catalytic efficiency, with yields over $50 \%$ could still be achieved. [199] Finally, a slight preference for the more electron-deficient arene could be observed by Z. Ruan. ${ }^{[199]}$ However, the ratio of $1.1 / 1.0$ showed only a minor preferance.

A detailed analysis of the reaction order for indole 23a, alkyne 132a and manganese catalyst 169 was conducted (Figure 3.4). All orders were determined to be 1, indicating the involvement of one molecule of each component in or before the kinetically relevant steps. Furthermore, the results strongly support the hypothesis that the $\mathrm{C}-\mathrm{H}$ cleavage 
is not rate-determining, as the reaction order of alkyne 132a would have been (pseudo)-zeroth order if it enters the catalytic cycle after the rate-determining step.
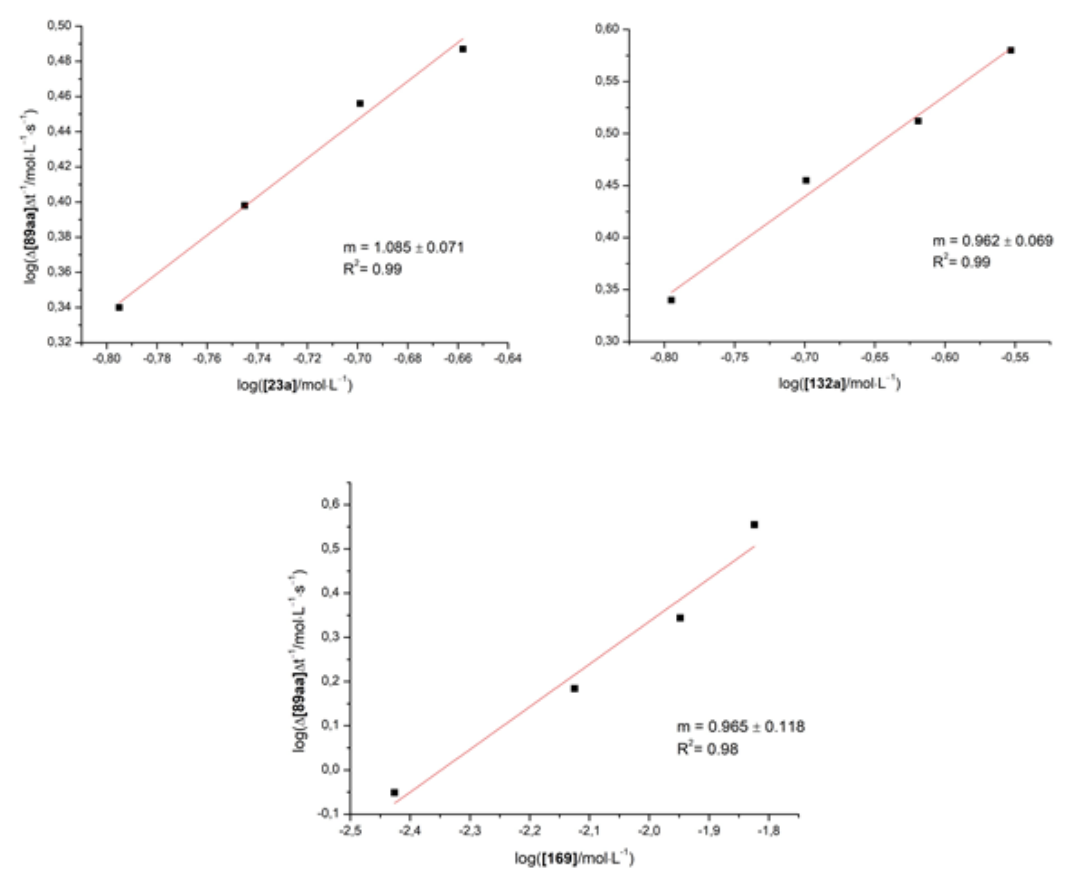

Figure 3.4 Kinetic analysis of the manganese(I)-catalyzed C-H alkynylation.

To further investigate the mechanism of the manganese $(\mathrm{I})$-catalyzed $\mathrm{C}-\mathrm{H}$ alkynylation, five-membered manganacycle $\mathbf{2 3 8}$, which is proposed to be an intermediate of the catalytic cycle, was synthesized according to a modified literature procedure ${ }^{[129]}$ and characterized (Scheme 3.11).<smiles>c1cnc(-n2ccc3ccccc32)nc1</smiles>

23a

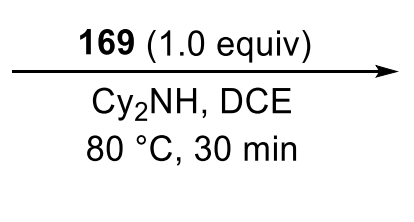

$80{ }^{\circ} \mathrm{C}, 30 \mathrm{~min}$<smiles></smiles>

238: $77 \%$

Scheme 3.11 Stoichiometric metalation of substrate $\mathbf{2 3 a}$.

The stable manganacycle $\mathbf{2 3 8}$ was formed in good yield in a reaction time of $30 \mathrm{~min}$, with comparable yield in the presence of catalytic amounts of $\mathrm{BPh}_{3}$. Upon stoichiometric reaction with bromoalkyne 132, the desired product 89 aa could be obtained in $84 \%$ yield in the absence of base after $30 \mathrm{~min}$, hinting at the role of cyclometalated complex $\mathbf{2 3 8}$ as an intermediate of the reaction (Scheme 3.12). A 
similar reaction with alkyne $132 \mathrm{~d}$ in the presence of $\mathrm{BPh}_{3}$ yielded $73 \%$ of the desired product 89ad.

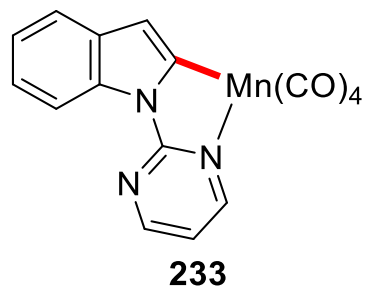

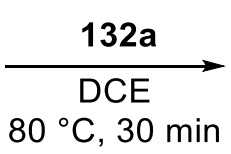

$80{ }^{\circ} \mathrm{C}, 30 \mathrm{~min}$<smiles></smiles>

89aa: $84 \%$

Scheme 3.12 Stoichiometric alkynylation of complex 233.

Finally, to support these findings, Z. Ruan conducted a reaction with $5.0 \mathrm{~mol} \%$ of complex $\mathbf{2 3 8}$ as the catalyst, confirming its applicability as the catalyst. ${ }^{[199]}$

Based on the thus obtained results, a catalytic cycle was proposed, which initiates by facile and reversible $\mathrm{C}-\mathrm{H}$ metalation, followed by insertion of bromoalkyne 132a into the manganese-carbon bond to generate seven-membered intermediate 240. From this intermediate, the catalyst is regenerated by $\beta$-bromo elimination, which furnishes the desired product 89aa (Scheme 3.13). In case of the aryl and alkyl alkynes, the Lewis acid additive is proposed to accelerate the $\beta$-bromo elimination, which is not necessary for silyl alkynes due to the stabilization by the $\beta$-silicon effect. ${ }^{[203]}$

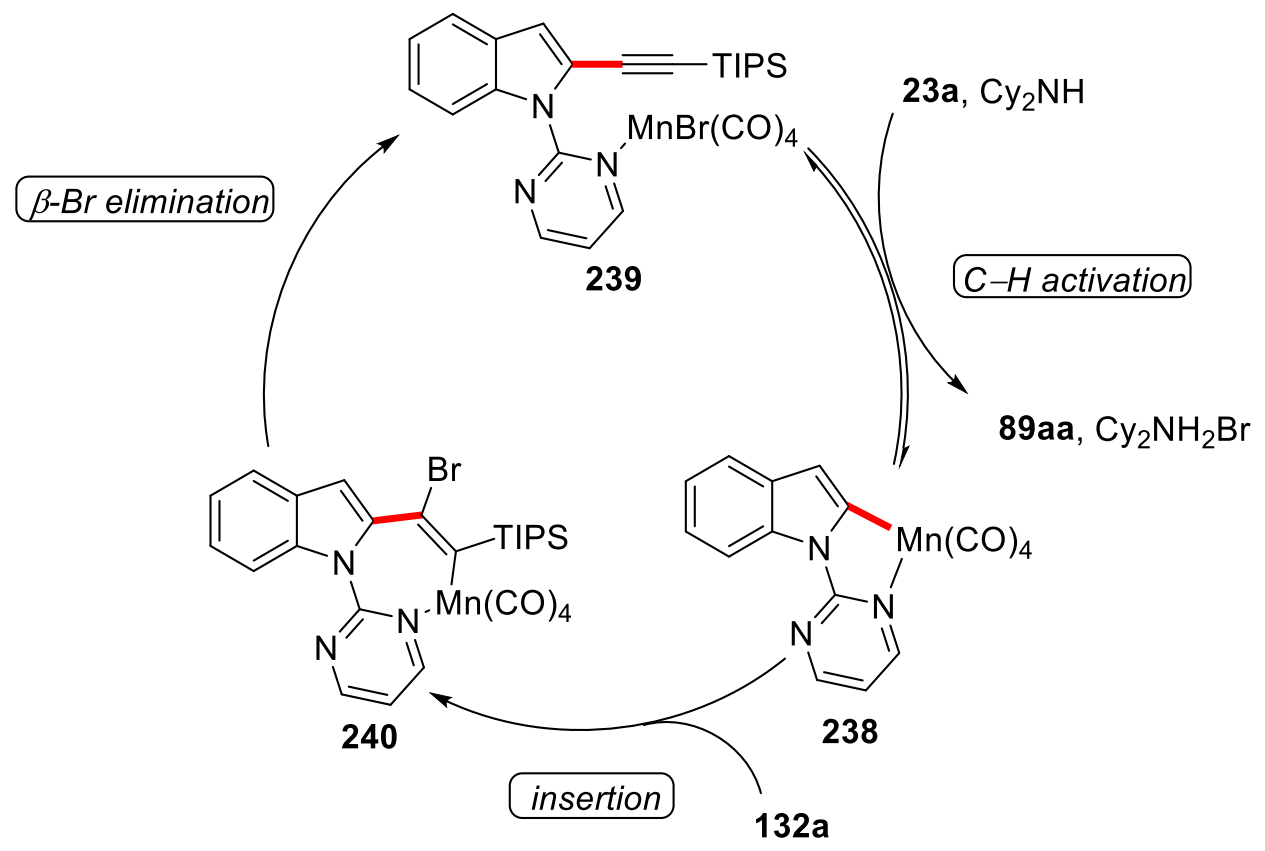

Scheme 3.13 Plausible mechanism for the manganese(I)-catalyzed $\mathrm{C}-\mathrm{H}$ alkynylation.

In summary, two powerful methods have been developed to access alkynylated indoles $\mathbf{8 9}$ using base metal catalysis under mild conditions. Both protocols showed 
good functional group tolerance and exclusive regioselectivity for the C-2 position of the indole. The mechanism of the manganese-catalyzed protocol was thoroughly investigated and analyzed. The applicability of this method to the modification of peptides highlights the potential of base metal catalysis for late-stage peptide diversification.

\subsection{Electrochemical Cobalt-Catalyzed C-H Oxygenation}

Cross-dehydrogenative transformations have greaat potential to realize $\mathrm{C}-\mathrm{H}$ activations with formally only $\mathrm{H}_{2}$ as the stoichiometric byproduct. However, this approach suffers from the need for expensive transition metal oxidants, such as copper(II) and silver(I) salts to achieve catalytic activity. ${ }^{[174]}$ Therefore, a merger of these $\mathrm{C}-\mathrm{H}$ activations and electrochemistry would be highly desirable. ${ }^{204]}$

\subsubsection{Optimization of the Cobalt-Catalyzed Electrochemical C-H Oxygentation}

For the optimization of the cobalt-catalyzed $\mathrm{C}-\mathrm{H}$ oxygenation unsubstituted benzamide 117a was chosen as the model substrate, and a constant potential of $2.0 \mathrm{~V} \mathrm{vs} \mathrm{Ag} / \mathrm{Ag}^{+}$ was applied in a divided cell using a constant potential setup. As the initial step of the optimization, the electrode material was investigated regarding its efficiency for the envisioned transformation (Table 3.18).

Table 3.18 Evaluation of electrode material. ${ }^{2}$

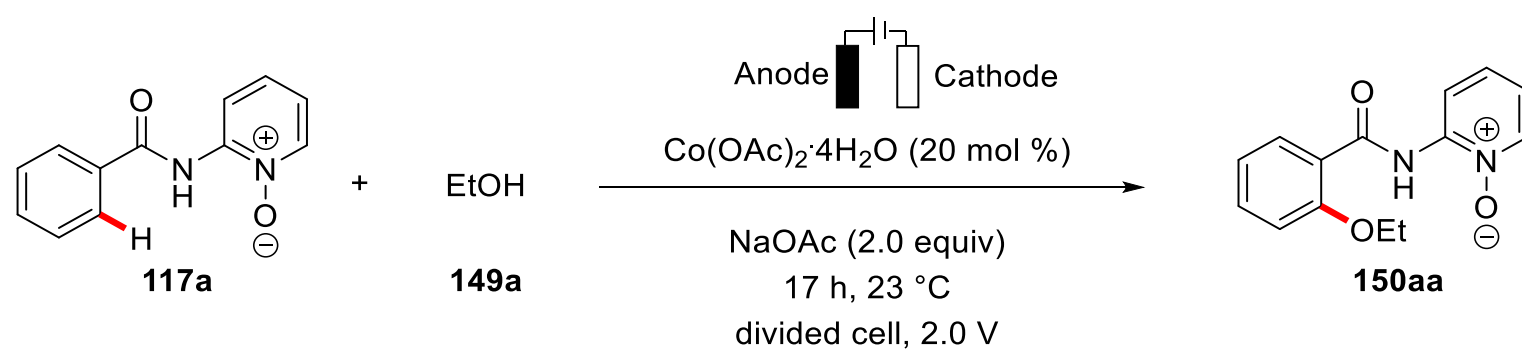

\begin{tabular}{cccc}
\hline Entry & Anode & Cathode & Yield [\%] \\
\hline 1 & $\mathrm{Pt}$ & $\mathrm{Pt}$ & $24^{\mathrm{b}}$ \\
2 & $\mathrm{Pt}$ & $\mathrm{RVC}$ & Traces $^{\mathrm{b}}$ \\
3 & $\mathrm{RVC}$ & $\mathrm{Pt}$ & 58 \\
4 & $\mathrm{RVC}$ & $\mathrm{Pt}$ & $\mathbf{6 5}^{\mathrm{c}}$ \\
\hline
\end{tabular}


a Reaction conditions: divided cell, $117(0.25 \mathrm{mmol}), \mathrm{Co}(\mathrm{OAc})_{2} \cdot 4 \mathrm{H}_{2} \mathrm{O}(20 \mathrm{~mol} \%)$, NaOAc (1.00 mmol each cell), $149 \mathrm{a}(14 \mathrm{~mL}), 23^{\circ} \mathrm{C}, 16 \mathrm{~h}, 2.0 \mathrm{~V}$. ${ }^{\mathrm{b}}$ Performed by T. H. Meyer. ${ }^{\mathrm{c}}$ Constant current $4.0 \mathrm{~mA}$.

A setup using only platinum electrodes showed promising conversion (entry 1), while the use of carbon as the cathode was not suitable (entry 2). However, a combination of a platinum cathode and a carbon anode proved to be the key for success (entry 3 ). A test reaction using constant current electrolysis (CCE) instead of constant potential revealed comparable efficacy (entry 4), thus making the constant current setup more attractive due to the much simpler equipment needed. ${ }^{[140 c]}$

For the further optimization, the reaction time was shortened to $6 \mathrm{~h}$ with the current increased accordingly. The reaction conditions were first investigated regarding the cobalt catalyst (Table 3.19).

Table 3.19 Optimization of the cobalt catalyst. ${ }^{a}$

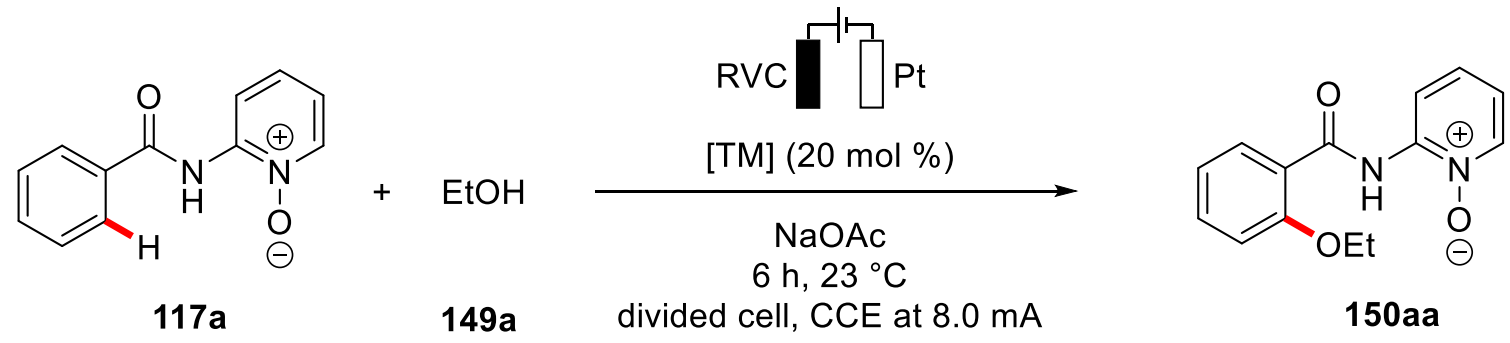

\begin{tabular}{ccc}
\hline Entry & {$[\mathrm{TM}]$} & Yield [\%] \\
\hline $\mathbf{1}$ & $\mathrm{Co}(\mathrm{OAc})_{2} \cdot 4 \mathrm{H}_{2} \mathrm{O}$ & $\mathbf{5 8}$ \\
2 & $\mathrm{Co}(\text { napht })_{2}$ & 31 \\
3 & $\mathrm{Co}(\text { oxalate })_{2}$ & 21 \\
4 & $\mathrm{Co}(\mathrm{acac})_{2}$ & 44 \\
5 & $\mathrm{Co}\left(\mathrm{NO}_{3}\right)_{2}$ & 13 \\
6 & $\mathrm{CoCl} 2$ & $64^{\mathrm{b}, \mathrm{c}}$ \\
7 & $\mathrm{CoBr} 2$ & $55^{\mathrm{b}, \mathrm{c}}$ \\
8 & $\mathrm{Co}(\mathrm{OAc})_{2} \cdot 4 \mathrm{H}_{2} \mathrm{O}$ & $26^{\mathrm{d}}$ \\
9 & $\mathrm{Cu}(\mathrm{OAc})_{2}$ & - \\
10 & - & - \\
\hline
\end{tabular}

a Reaction conditions: 117a (0.50 mmol), [TM] (20 mol \%), NaOAc (1.00 mmol) in each cell, 149a $(7.0 \mathrm{~mL}$ in each cell), constant current of $8 \mathrm{~mA}, 6 \mathrm{~h}$. ${ }^{b}$ Using NaOPiv (1.00 mmol) instead of NaOAc. ${ }^{c}$ Performed by T. H. Meyer d [TM] (10 mol \%). 
The evaluation of cobalt catalysts established that common cobalt(II) salts are all competent catalysts to some extend. Cobalt(II)acetate tetrahydrate was identified as the best choice, $\mathrm{CoCl}_{2}$ and $\mathrm{CoBr}_{2}$ gave comparable yields, although with another base, which was later also shown to be beneficial when $\mathrm{Co}(\mathrm{OAc})_{2}$ was used (see Table 3.23). Reduced catalyst loadings of $10 \mathrm{~mol} \%$ were not effective (entry 8), whereas copper(II)acetate did not promote the reaction at all (entry 9). The essential nature of the cobalt catalyst was highlighted by a control experiment in the absence of cobalt (entry 10).

Table 3.20 Optimization of bases. ${ }^{a}$

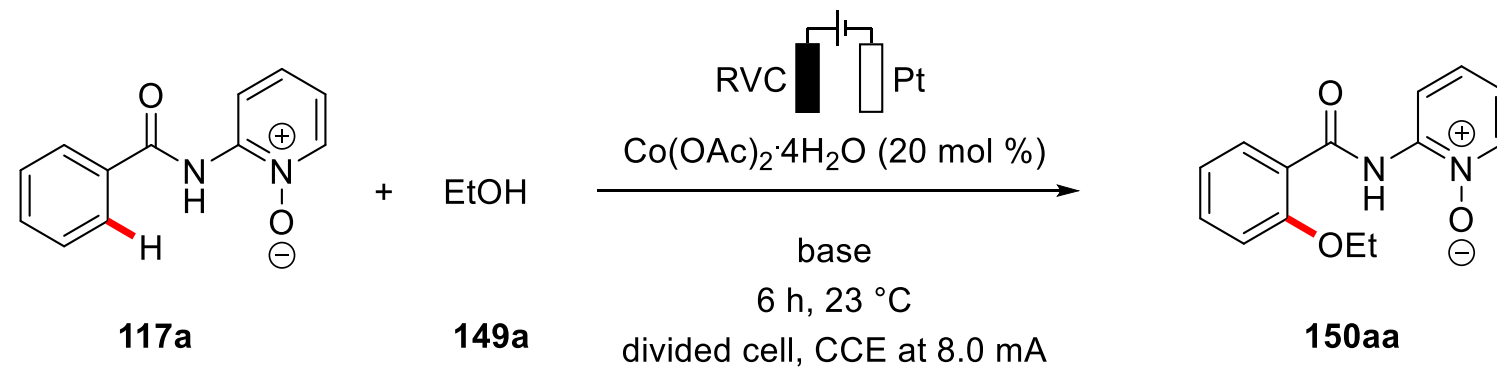

\begin{tabular}{ccc}
\hline Entry & Base & Yield [\%] \\
\hline 1 & $\mathrm{NaOAc}$ & 58 \\
2 & $\mathrm{KOAc}$ & 57 \\
3 & $\mathrm{CsOAc}$ & 55 \\
4 & $n-\mathrm{Bu} 4 \mathrm{NOAc}$ & trace \\
5 & $\mathrm{Na}_{2} \mathrm{CO}_{3}$ & $34^{\mathrm{b}}$ \\
6 & $\mathrm{NaO}_{2} \mathrm{CMes}$ & 34 \\
7 & $\mathrm{NaOPiv}$ & 75 \\
8 & - & $-\mathrm{b}$ \\
\hline
\end{tabular}

[a] Reaction conditions: 117a $(0.50 \mathrm{mmol}), \mathrm{Co}(\mathrm{OAc})_{2} \cdot 4 \mathrm{H}_{2} \mathrm{O}(20 \mathrm{~mol} \%)$, base $(1.00 \mathrm{mmol})$ in each cell,

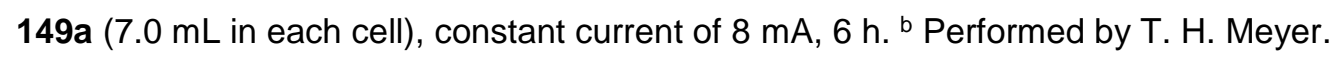

While the alkali metal cation of the base did not seem to have any significant influence (entries 1-3), carbonate and aryl carboxylate performed significantly worse (entries 5 \& 6). The ideal base was identified as sodiumpivalate, yielding $75 \%$ of the desired product (entry 7 ). The base was found to be essential here (entry 8 ), probably due to the need to deprotonate the amide to facilitate coordination to the catalyst. While the use of ethanol (149a) as the solvent has some benefits, such as good solubility of the additive, which makes the use of costly supporting electrolytes unnecessary, ${ }^{[205]}$ this is 
not true for all alcohols which might be explored in the scope. Therefore, several solvents and solvent mixtures were evaluated during the optimization as well (Table 3.21).

Table 3.21 Optimization of solvents ${ }^{a}$

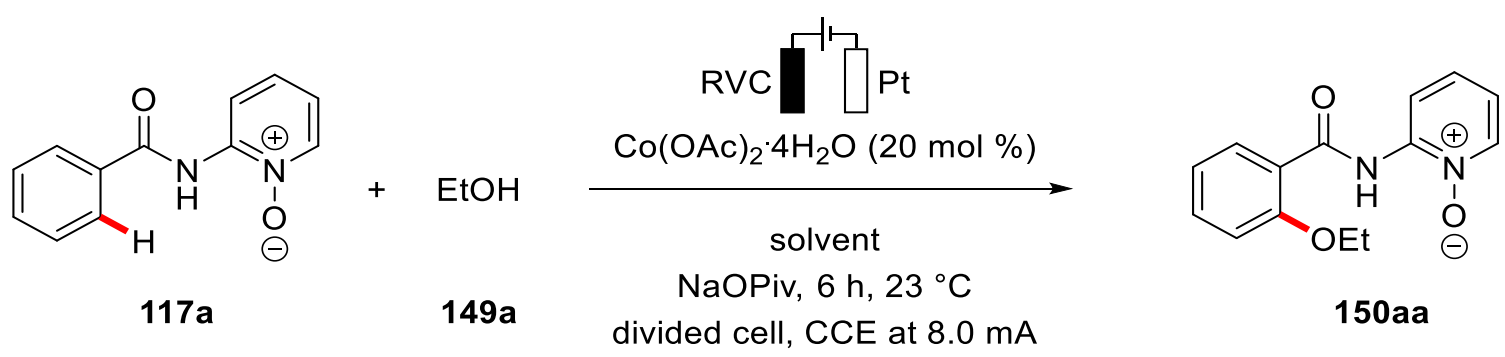

\begin{tabular}{ccc}
\hline Entry & Solvent & Yield [\%] \\
\hline 1 & EtOH & 75 \\
2 & $\mathrm{MeCN} / \mathrm{EtOH}(16 / 1)$ & $12^{\mathrm{b}}$ \\
3 & $\mathrm{MeCN} / \mathrm{EtOH}(1 / 1)$ & $19^{\mathrm{b}}$ \\
4 & $\mathrm{DMSO} / \mathrm{EtOH}(16 / 1)$ & $---\mathrm{b}$ \\
5 & $\mathrm{DMF} / \mathrm{EtOH}(16 / 1)$ & --- \\
6 & $\mathrm{DMF} / \mathrm{EtOH}(1 / 1)$ & --- \\
7 & $\mathrm{Aceton} / \mathrm{EtOH}(1 / 1)$ & 39 \\
8 & $\mathrm{THF} / \mathrm{EtOH}(1 / 1)$ & 11 \\
9 & $\mathrm{CH}_{2} \mathrm{Cl} / \mathrm{EtOH}(1 / 1)$ & $---\mathrm{b}$ \\
\hline
\end{tabular}

[a] Reaction conditions: 117a $(0.50 \mathrm{mmol}), \mathrm{Co}(\mathrm{OAc})_{2}(20 \mathrm{~mol} \%), \mathrm{NaOPiv}(1.00 \mathrm{mmol})$ in each cell,

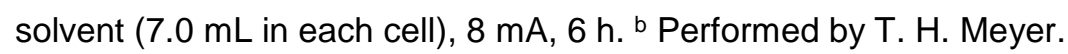

While a mixture of acetone and ethanol (149a) seemed to support catalytic turnover (entry 7), all other evaluated mixtures showed either stoichiometric conversion or no reaction at all. Therefore, EtOH (149a) was kept as the sole solvent, while for other alcohols with a lower conductivity, the addition of a supporting electrolyte was identified as the ideal solution. Moreover, also the reaction temperature and time were thereafter optimized (Tables 3.22 and 3.23). 
Table 3.22 Effect of reaction temperature. ${ }^{a}$<smiles>O=C(Nc1cccc[n+]1[O-])c1ccccc1</smiles>

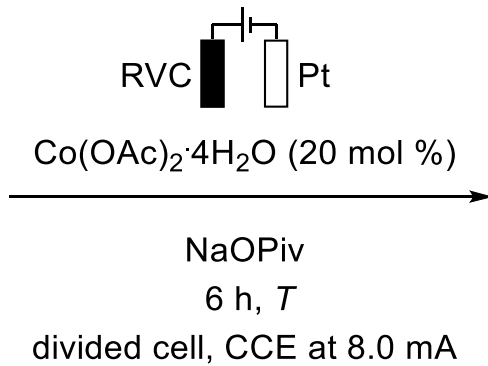<smiles>CCCCCCOc1ccccc1C(=O)Nc1cccc[n+]1[O-]</smiles>

\begin{tabular}{ccc}
\hline Entry & $\mathrm{T}\left[{ }^{\circ} \mathrm{C}\right]$ & Yield [\%] \\
\hline 1 & 0 & 17 \\
2 & 10 & 23 \\
3 & 20 & 71 \\
4 & 30 & 73 \\
5 & 40 & $68^{\mathrm{b}}$ \\
6 & 60 & $58^{\mathrm{b}}$
\end{tabular}

[a] Reaction conditions: 117a $(0.50 \mathrm{mmol}), \mathrm{Co}(\mathrm{OAc})_{2}(20 \mathrm{~mol} \%)$, NaOPiv $(1.00 \mathrm{mmol})$ in each cell, 149a

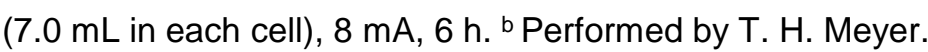

Table 3.23: Optimization of catalyst loading. ${ }^{\mathrm{a}}$<smiles>O=C(Nc1cccc[n+]1[O-])c1ccccc1</smiles>

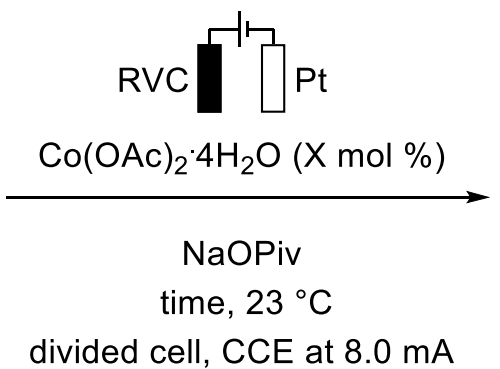<smiles></smiles>

\begin{tabular}{ccccc}
\hline Entry & $\mathrm{X}[\mathrm{mol} \%]$ & Time $[\mathrm{h}]$ & Current $[\mathrm{mA}]$ & Yield [\%] \\
\hline $\mathbf{1}$ & $\mathbf{2 0}$ & $\mathbf{6}$ & $\mathbf{8}$ & $\mathbf{7 5}$ \\
2 & 10 & 6 & 8 & 26 \\
3 & 10 & 24 & 4 & 68 \\
4 & 5 & 24 & 4 & 46
\end{tabular}

a Reaction conditions: 117a $(0.50 \mathrm{mmol}), \mathrm{Co}(\mathrm{OAc})_{2}(\mathrm{X} \mathrm{mol} \%)$, NaOPiv $(1.00 \mathrm{mmol})$ in each cell, 149a (7.0 mL in each cell), $23^{\circ} \mathrm{C}$.

Interestingly, the reaction was operative over a wide range of reaction temperatures. While the obtained yields are rather low at $0{ }^{\circ} \mathrm{C}$ and $10{ }^{\circ} \mathrm{C}$ (entries $1 \& 2$ ), the 
transformation was still ongoing, hinting at a facile $\mathrm{C}-\mathrm{H}$ cleavage. Optimal yields were observed at $20^{\circ} \mathrm{C}$ and $30^{\circ} \mathrm{C}$ (entries 3 and 4), while a slow decrease was observed at higher temperatures. As for the catalyst loading, $20 \mathrm{~mol} \%$ were ideal regarding the short reaction time. Yet, the yield for a lower catalyst loading could however be significantly increased with a longer reaction time (entries 3 and 4, Table 3.24).

\subsubsection{Scope of the Cobalt-Catalyzed Electrochemical C-H Oxygentation}

With the optimized rection conditions in hand, we became interested in exploring the scope of benzamides $\mathbf{1 1 7}$ for the electrochemical cobalt-catalyzed $\mathrm{C}-\mathrm{H}$ oxygenation. In initial test reactions, several $N$-substituents were evaluated regarding their potential to promote the envisioned $\mathrm{C}-\mathrm{H}$ transformation (Table 3.24).

Table 3.24 $\mathrm{N}$-directing group effect for the electrochemical cobalt-catalyzed $\mathrm{C}-\mathrm{H}$ oxygenation. ${ }^{\mathrm{a}}$<smiles>O=C(N[O+])c1ccccc1</smiles>

$115 a, 117 a, 241 a$, $244 a$ or $246 a$

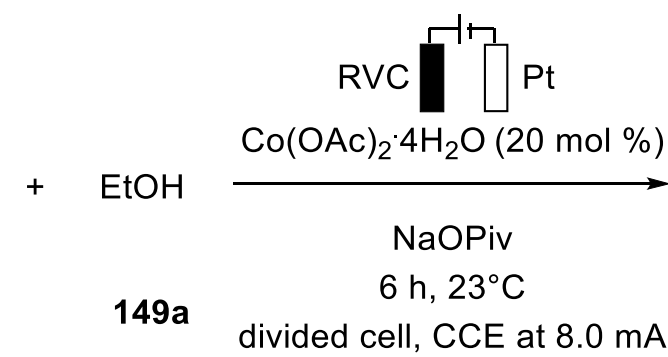

$\mathrm{NaOPi}$

divided cell, CCE at $8.0 \mathrm{~mA}$<smiles>CCOc1ccccc1C(=O)NOC(=O)[O-]</smiles>

150aa, 242aa, 243aa,

245 aa or 247 aa

Entry Benzamide Yield [\%]


3<smiles>O=C(Nc1cccc2cccnc12)c1ccccc1</smiles>

4

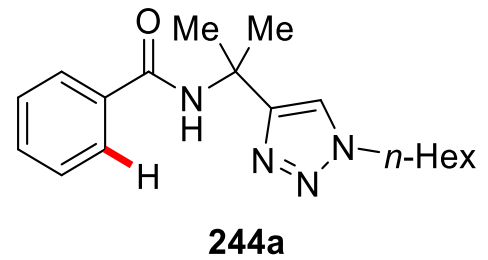

5<smiles>O=C(NC(F)(F)F)c1ccccc1</smiles>

$246 a$<smiles>CCOc1ccccc1C(=O)Nc1cccc2cccnc12</smiles>

243aa<smiles>[R16]#Cn1cc(C(C)(C)NC(=O)c2ccccc2OCC)nn1</smiles><smiles>CCOc1ccccc1C(=O)NC(F)(F)F</smiles>

247 aa

${ }^{a}$ Reaction conditions: Benzamide (0.50 mmol), $\mathrm{Co}(\mathrm{OAc}) 2$ (20 mol \%), NaOPiv (1.00 mmol in each cell), 149a $\left(7.0 \mathrm{~mL}\right.$ in each cell), $23^{\circ} \mathrm{C}, 8.0 \mathrm{~mA}$. b Performed by T. H. Meyer.

Besides pyridine- $\mathrm{N}$-oxide, 8-aminoquinoline was able to promote the electrochemical reaction with moderate yield (entry 3 ), ${ }^{[205]}$ while with other directing groups no reaction could be observed. With the best $N$-substituent identified, the functional group tolerance of the $\mathrm{C}-\mathrm{H}$ oxygenation was investigated (Table 3.25).

Table 3.25 Electrochemical cobalt-catalyzed C-H oxygenation of benzamides 117a. ${ }^{a}$<smiles>CC(C)(C)NC(=O)c1ccccc1</smiles>

$117 a$

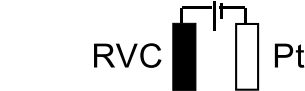

$\mathrm{Co}(\mathrm{OAc})_{2} \cdot 4 \mathrm{H}_{2} \mathrm{O}(20 \mathrm{~mol} \%)$

NaOPiv

$6 \mathrm{~h}, 23^{\circ} \mathrm{C}$

$149 a$
Product

Yield [\%]

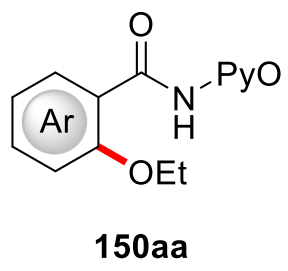

divided cell, CCE at $8.0 \mathrm{~mA}$
150 aa

\section{Benzamide}<smiles>O=C(N[Pb])c1ccccc1</smiles>

$117 a$

Entry Benzamide

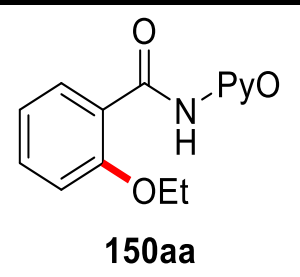


2<smiles>O=[Pb]NC(=O)c1ccc(C(F)(F)F)cc1[18F]</smiles>

3<smiles>COc1ccc(C(=O)NP(=O)(O)O)c(C)c1</smiles>

117c

4<smiles>O=C(N[Pb](=O)c1ccccc1)c1ccc(Cl)cc1</smiles>

5<smiles>Cc1cccc(C(=O)N[Pb]NC(=O)c2ccccc2)c1</smiles>

117 e

6<smiles>CCCCNC(=O)c1cc2ccccc2cc1-c1ccccc1</smiles>

7<smiles>CN(C)c1cccc(C(=O)NP(=O)(O)c2ccccc2)c1</smiles>

$117 \mathrm{~g}$<smiles>O=C(N[Pb])c1cccc(Br)c1</smiles>

$117 \mathrm{~h}$<smiles>CC(=O)c1ccc(C(=O)NP(=O)(O)c2ccccc2)c(C)c1</smiles><smiles>CCOc1cc(C(F)(F)F)ccc1C(=O)NP=O</smiles><smiles>CCOc1cc(C(C)=O)ccc1C(=O)NP(=O)(O)O</smiles> 
10<smiles>O=C(N[Pb])c1cccc2ccccc12</smiles>

117j

11<smiles>O=C(N[Pb])c1cccs1</smiles>

117k

12<smiles>O=[Pb]NC(=O)c1c([In][In])[nH]c2ccccc12</smiles>

13

$117 m$<smiles>CCOc1ccc2ccccc2c1C(=O)NP(=O)(O)OC</smiles>

$150 \mathrm{ja}$

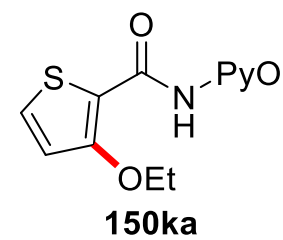<smiles>CCOc1[nH]c2ccccc2c1C(=O)N[Pb]O</smiles><smiles>CCOc1ccncc1C(=O)NP(=O)(O)OC</smiles>

a Reaction conditions: 117 (0.50 mmol), Co(OAc) 2 (20 mol \%), NaOPiv (1.00 mmol in each cell), 149a (7.0 mL in each cell), $23^{\circ} \mathrm{C}, 8.0 \mathrm{~mA}$.

Unsubstituted benzamide 117a (entry 1) was efficiently converted as substitutents in para-position to the benzamide were well tolerated, while a good yield was achieved for electron-rich 4-methoxybenzamide 117c (entry 3). Electron-deficient amide 117b (entry 2) was not transformed as efficiently and the chloro substitutent in amide $\mathbf{1 1 7} \mathbf{d}$ was left untouched (entry 4). 3-Methylbenzamide 117e and naphthylamide 117f were effectively oxygenated (entries 5 and 6). meta-Bromo arene $117 \mathrm{~h}$ was well converted with moderate yield (entry 8 ). Tertiary amine $\mathbf{1 1 7 g}$ did not reduce the catalytic efficacy (entry 7), ketone 117i was well tolerated with moderate yield (entry 9), highlighting the mild reaction conditions of the electrochemical approach. However, also for this transformation, limitations regarding the scope remain. The use of benzamide with an ortho-substituent $\mathbf{1 1 7} \mathbf{j}$ was generally not feasible, as no reaction could be observed (entry 10). This can be rationalized by steric interactions between the ortho-substitutent and the amide in the relevant transition states of the catalysis. ${ }^{[206]}$ Moreover, also heterocyclic substrates did not show any reactivity, for both electron-rich (entry 11 and 12) as well as electron-deficient heteroarenes (entry 13), as solely the remaining starting material could be observed. 
With the scope of benzamides 117 established, the use of different alcohols 149 as coupling partners was explored for the cobalt-catalyzed $\mathrm{C}-\mathrm{H}$ oxygenation under electrochemical conditions (Table 3.26).

Table 3.26 Electrochemical cobalt-catalyzed C-H oxygenation using alcohols 149 . $^{\mathrm{a}}$<smiles>O=C(NC(=O)c1ccccc1)c1ccccc1</smiles>

$117 a$
$+\mathrm{ROH}$

149

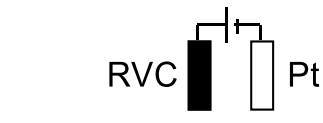

$\mathrm{Co}(\mathrm{OAc})_{2} \cdot 4 \mathrm{H}_{2} \mathrm{O}(20 \mathrm{~mol} \%)$

NaOPiv

$6 \mathrm{~h}, 23^{\circ} \mathrm{C}$

divided cell, CCE at $8.0 \mathrm{~mA}$<smiles>[R]c1ccccc1C(=O)N[Po]</smiles>

150

\begin{tabular}{|c|c|c|c|}
\hline Entry & Alcohol & Product & Yield [\%] \\
\hline 1 & $\begin{array}{l}\mathrm{MeOH} \\
(149 b)\end{array}$ & & 71 \\
\hline 2 & $\begin{array}{c}n-\mathrm{BuOH} \\
(\mathbf{1 4 9 c})\end{array}$ & & $52^{\mathrm{b}}$ \\
\hline 3 & $\begin{array}{c}\mathrm{CF}_{3} \mathrm{CH}_{2} \mathrm{OH} \\
(\mathbf{1 4 9} \mathbf{d})\end{array}$ & 3 & $62^{\mathrm{c}}$ \\
\hline 4 & $\begin{array}{c}\mathrm{ClCH}_{2} \mathrm{CH}_{2} \mathrm{OH} \\
(\mathbf{1 4 9 e})\end{array}$ & & 76 \\
\hline
\end{tabular}


5

$\mathrm{MeOCH}_{2} \mathrm{CH}_{2} \mathrm{OH}$

(149f)

6

$\mathrm{AcOCH}_{2} \mathrm{CH}_{2} \mathrm{OH}$

(149g)

$\mathrm{NCCH}_{2} \mathrm{CH}_{2} \mathrm{OH}$

(149h)

7

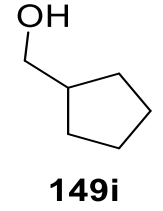

9<smiles>OCc1ccccc1</smiles>

149j

10<smiles>Cc1ccccc1CO</smiles><smiles>COCCOc1ccccc1C(=O)NP(=O)(O)OC(C)(C)C</smiles><smiles>CC(=O)OCCOc1ccccc1C(=O)NP(=O)(O)O</smiles>

150ag<smiles>N#CCCOc1ccccc1C(=O)NP(=O)(O)O</smiles>

150ah<smiles>CCCNC(=O)NC(=O)c1ccccc1OCC1CCCC1</smiles>

150ai<smiles>CC(C)(C)Cc1ccccc1COc1ccccc1C(=O)NP(=O)(O)O</smiles>

$74^{d}$<smiles>Cc1ccccc1COc1ccccc1C(=O)NP(=O)(O)O</smiles>

150ak 149k 
11<smiles>CC(C)=CCCC(C)CCO</smiles>

12<smiles>CC(C)(C)CO</smiles>

$149 m$

13 $s-\mathrm{BuOH}$

(149n)

14<smiles>OC1CCCCC1</smiles>

149 o

15

$t$-BuOH

(149p)<smiles>CC(C)=CCCC(C)CCOc1ccccc1C(=O)NC(=O)O</smiles><smiles>CC(C)(C)COc1ccccc1C(=O)NC(=O)O</smiles>

150am<smiles>CCC(C)(C)Oc1ccccc1C(=O)NP(=O)(O)c1ccccc1</smiles>
trace $^{d}$<smiles>O=C(NC(=O)c1ccccc1OC1CCCCC1)c1ccccc1</smiles>

150ao<smiles>CC(C)(C)Oc1ccccc1C(=O)NPO</smiles>

150ap

a Reaction conditions: 117a (0.50 mmol), $\mathrm{Co}(\mathrm{OAc})_{2}(20 \mathrm{~mol} \%)$, NaOPiv (1.00 mmol in each cell), 149 (7.0 mL in each cell), $23{ }^{\circ} \mathrm{C}, 8.0 \mathrm{~mA} .{ }^{\mathrm{b}} n$-Bu4NOAc $\left(1.0 \mathrm{mmol}\right.$ in each cell) ${ }^{\circ} 60^{\circ} \mathrm{C}$. ${ }^{\mathrm{d}}$ in $\mathrm{MeCN}$ and $n-\mathrm{Bu}_{4} \mathrm{NPF}_{6}(0.3 \mathrm{M})$.

Simple methanol (149b) enabled the reaction efficiently (entry 1 ), while in $n$-butanol (149c) the conductivity was low, and no conversion was observed under standard conditions. However, upon addition of $n$-Bu ${ }_{4} \mathrm{NOAc}$ in each cell as supporting electrolyte, the reaction proceeded smoothly (entriy 2). Trifluoroethanol (149d) was 
converted with moderate yield at an increased temperature of $60^{\circ} \mathrm{C}$ (entry 3), while ethanol derivatives $149 \mathrm{e}$ and $149 \mathrm{f}$ were converted under the standard conditions efficiently (entries 4 and 5). Ethanol derivates $149 \mathrm{~g}$ and $149 \mathrm{~h}$ containing valuable functional groups, such as ester and nitrile (entries 6 and 7), were smoothly oxygenated. However, the addition of acetonitrile and a supporting electrolyte were necessary to ensure a sufficient conductivity. Especially noteworthy was the $\mathrm{C}-\mathrm{H}$ oxygenation using benzylic alcohol 149j (entry 9) and its derivate 149k (entry 10), as these alcohols should be more prone to oxidation than the aliphatic alcohols. ${ }^{[206]}(S)$ Citronellol (149I) could be employed upon the addition of a supporting electrolyte without racemization of the stereogenic center, as confirmed by HPLC analysis (Figure 3.5). Finally, neopentyl alcohol (149m) (entry 13) was used, however no catalytic activity was observed. Besides primary alcohols, secondary alcohols were also evaluated towards this reaction. While $s-\mathrm{BuOH}(\mathbf{1 4 9 n})$ showed only traces of the desired product, cyclohexyl alcohol 1490 did not exhibit any reactivity (entries 13 and 14). Finally, also tertiary alcohol $t-\mathrm{BuOH}(\mathbf{1 4 9 p})$ was tested, but no reaction could be observed (entry 16).

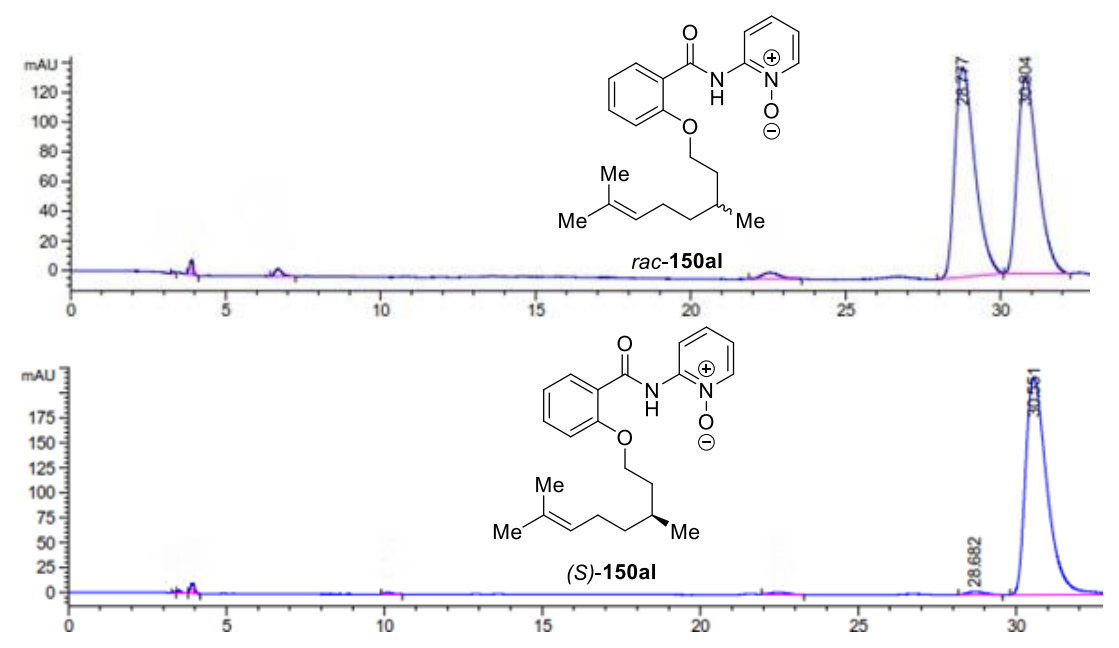

Figure 3.5: HPLC-Chromatogram of (rac)-150al and (S)-150al.

Besides the scope of benzamides 117, T. H. Meyer could also show that alkenes are viable substrates for the cobalt-catalyzed $\mathrm{C}-\mathrm{H}$ oxygenation. ${ }^{[208]}$

Finally, a gram scale reaction was performed to highlight the easy upscaling and convenient electrochemical setup. For reasons of simplicity, an undivided cell was used, as no divided cells of the necessary size were available at this point (Scheme 3.14). 


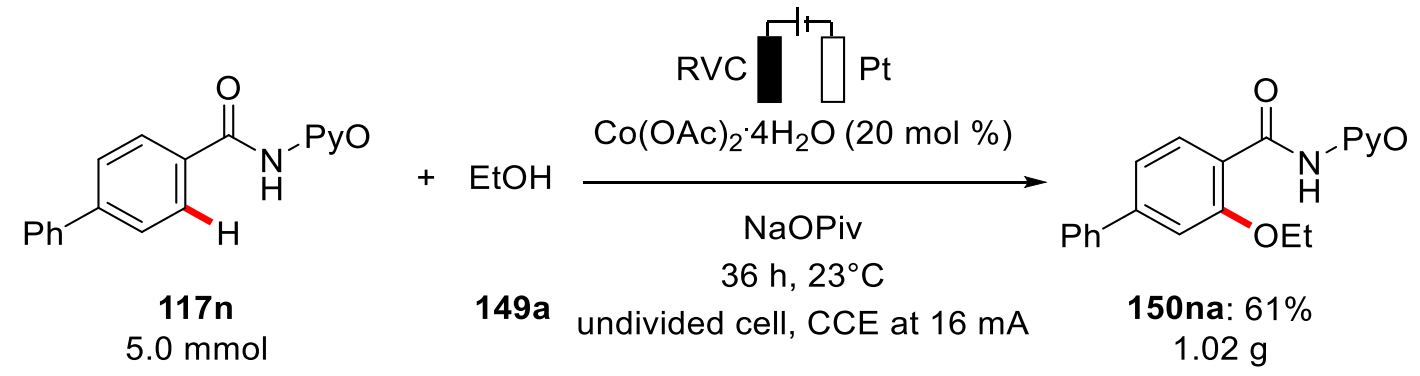

Scheme 3.14 Gram scale reaction.

\subsubsection{Mechanistic Studies and Proposed Mechanism}

To get insight into the modus operandi of the electrochemical cobalt catalyzed $\mathrm{C}-\mathrm{H}$ oxygenation, detailed mechanistic studies were conducted.

To begin with, the Faradaic efficacy of the reaction was calculated. This can be done based on the observed yield.

$$
\text { Efficacy }=\frac{n * y * z * F}{t * I}
$$

In equation (1), $n$ is the amount of starting material in mol, $y$ is the yield observed for a given reaction, $z$ the number of electrons needed to achieve turnover, $F$ is the Faraday constant, $t$ is the reaction time in seconds and I the applied current in ampere (coulomb per second). Based on equation (1), the electron efficacy was calculated for the $\mathrm{C}-\mathrm{H}$ oxygenation of benzamide 117a:

$$
\frac{0.0005 \mathrm{~mol} * 0.75 * 2 * 96485 \mathrm{C} / \mathrm{mol}}{21600 \mathrm{~s} * 0.008 \mathrm{C} / \mathrm{s}}=0.418
$$

The electron efficacy for the given reaction was thus calculated to be $42 \%$, which is corresponding to a charge of $3.58 \mathrm{~F}$ passed through the solution per each mole of substrate $117 a$.

Furthermore, deuteration studies using $[D]_{1}$-methanol ([D]1-149b) as the solvent showed no significant $\mathrm{H} / \mathrm{D}$-incorporation in either the reisolated starting material nor in the product, suggesting an irreversible $\mathrm{C}-\mathrm{H}$ activation event (Scheme 3.15). 


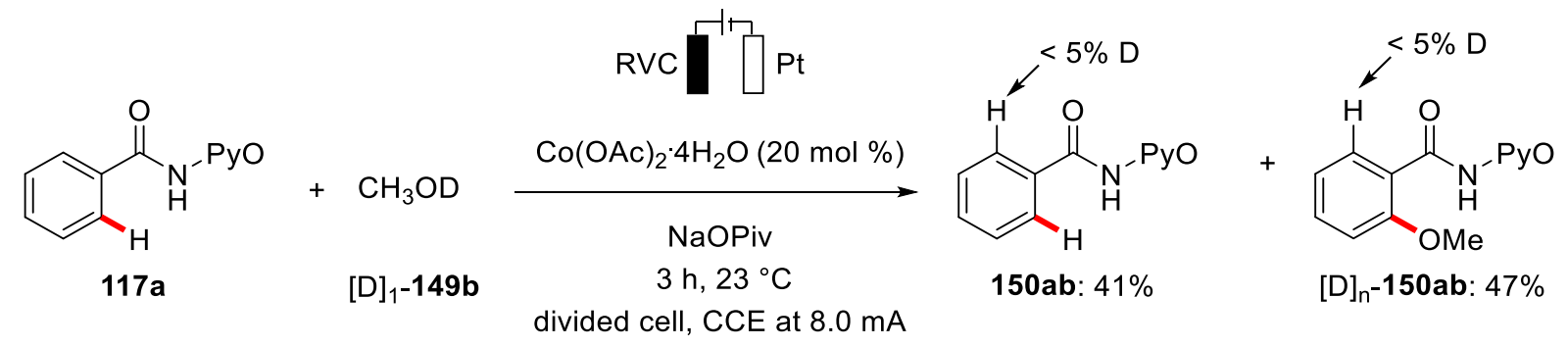

Scheme 3.15 H/D Exchange experiment.

Additionally, the kinetic isotope effect was studied by a comparison of the deuterated benzamide $[D] 5-117 a$ and the standard substrate $117 a$ in independent reactions. A minor $\mathrm{KIE}$ of $\mathrm{KH}_{\mathrm{H}} / \mathrm{K}_{\mathrm{D}} \approx 1.05$ suggests a facile $\mathrm{C}-\mathrm{H}$ activation, which is not the rate determining step of the overall transformation (Scheme 3.16).

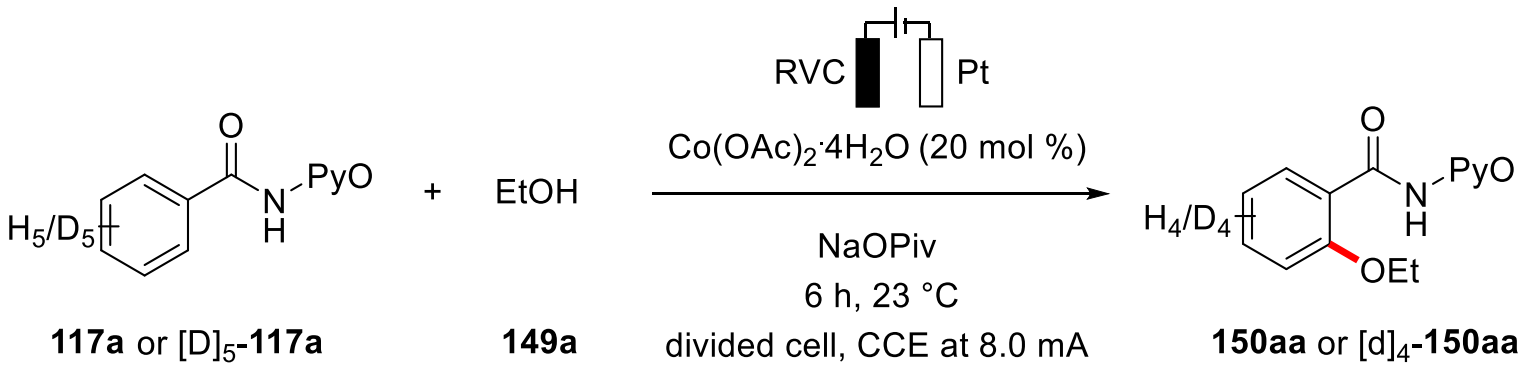

Scheme 3.16 Measurement of the kinetic isotope effect.

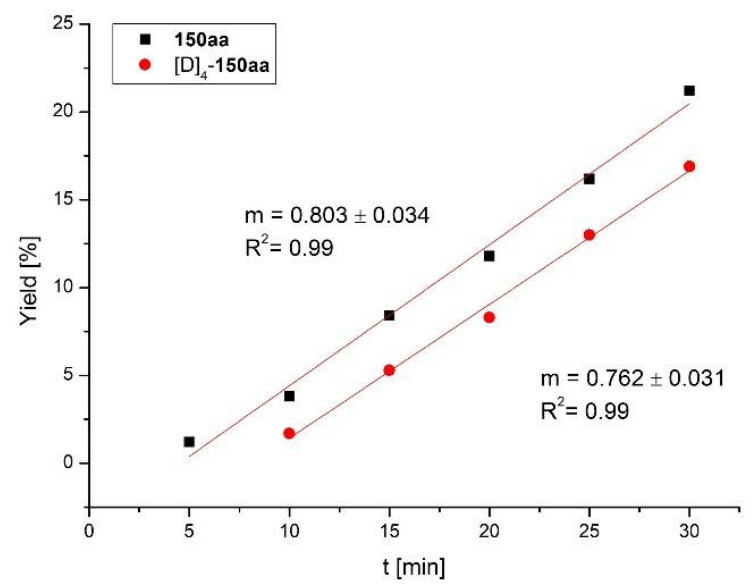

Figure 3.6 Initial rates analysis of 150aa and [ $\left.D_{4}\right]-150 \mathrm{aa}$.

To gain further insight into the reaction mechanism, competition experiments of electron-rich and electron-deficient arenes 117 as well as electron-rich and electrondeficient alcohols 149 were conducted. For benzamides 117, a competition experiment of 4-methyl benzamide $117 \mathrm{o}$ and 4-trifluoromethyl benzamide $117 \mathrm{~b}$ displayed a clear 
preference for the more electron-rich benzamide 117 with a ratio of 1.9/1 in favor of the 4-methyl substituted arene 117o (Scheme 3.17 and Figure 3.7). This finding was further substantiated by a qualitative analysis of the initial rates for both substrates, which highlighted a faster initial reaction for the electron rich substrate (Figure 3.7).

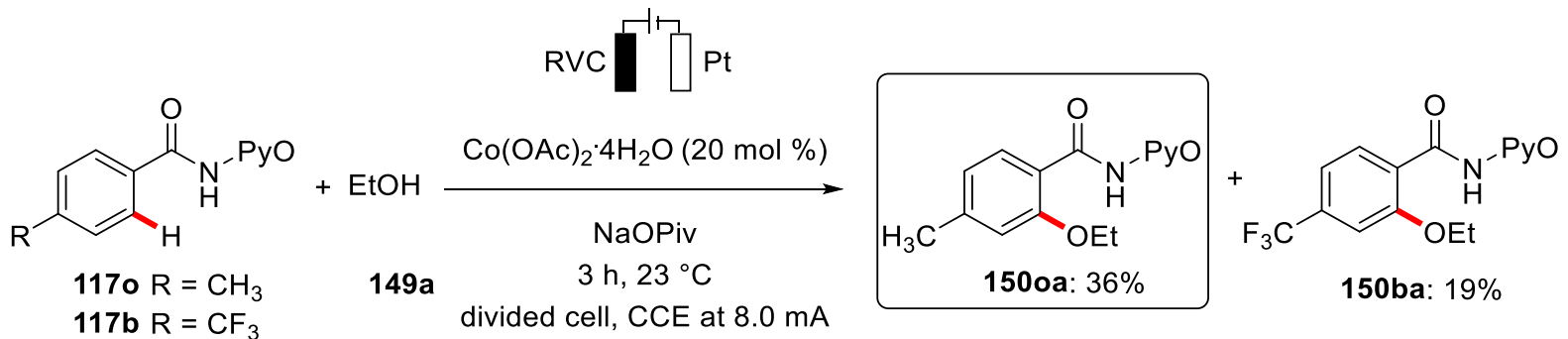

Scheme 3.17 Competition experiment of arenes 1170 and 117b.
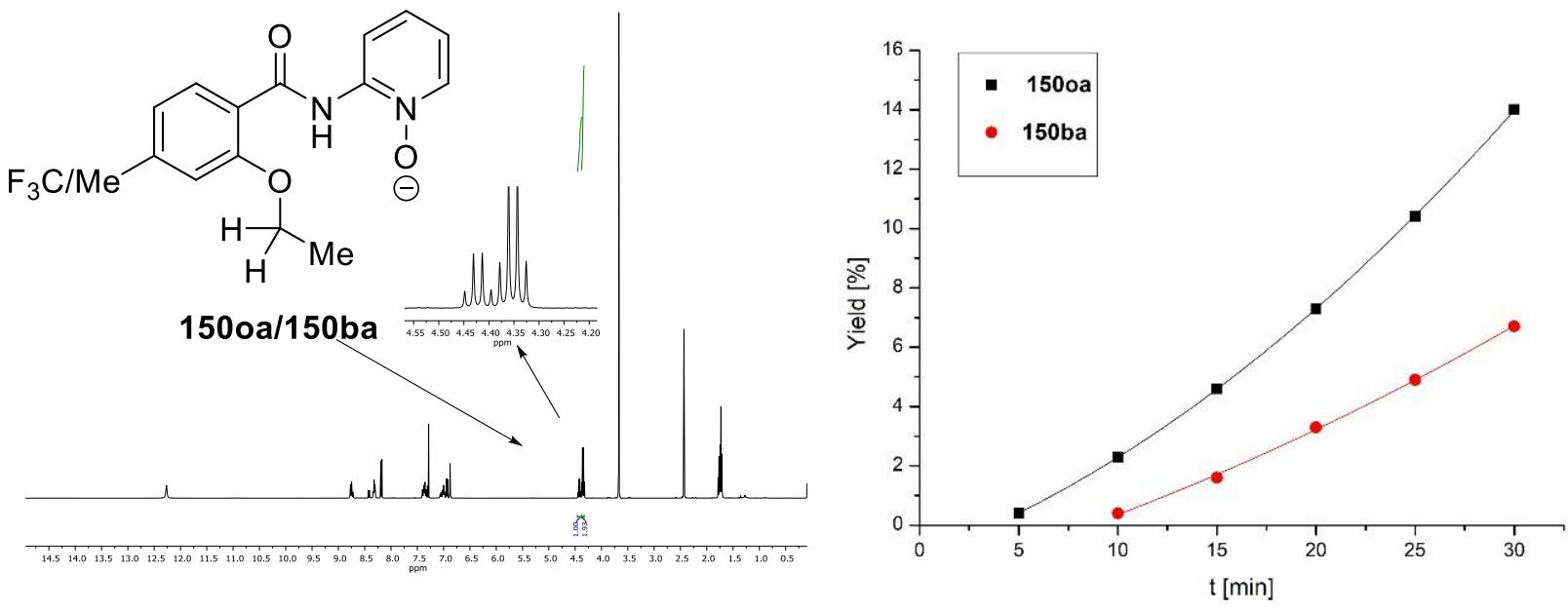

Figure 3.7. ${ }^{1} \mathrm{H}-\mathrm{NMR}$ spectra of the mixture of $150 \mathrm{oa}$ and $150 \mathrm{ba}$ and qualitative analysis of the initial rates.

For the alcohol coupling partner 149 , a similar competition experiment was conducted, showing a clear preference for electron-rich ethanol (149a) over trifluoroethanol (149c) (Scheme 3.18).

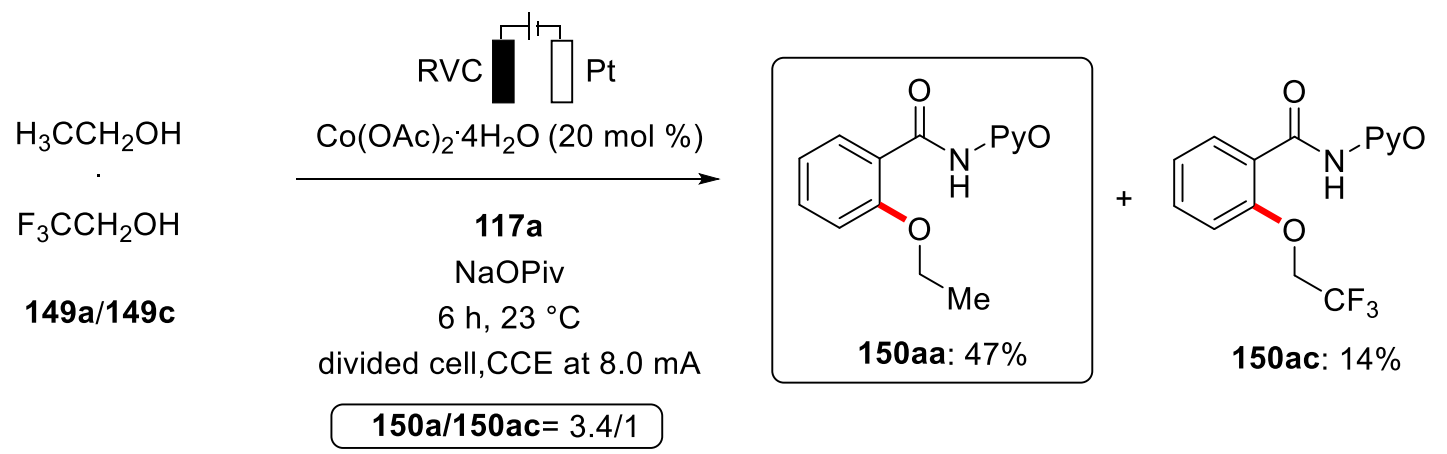

Scheme 3.18 Competition experiment of different alcohols 149 . 
Finally, a kinetic profile of the catalysis was recorded under the electrochemical conditions, as well as under the chemical conditions reported by Song and coworkers (Figure 3.8). ${ }^{[111 b]}$ As can be seen in the figure, the overall shape of the kinetic profile is somewhat similar for both reactions, slowing down after approximately $3 \mathrm{~h}$.
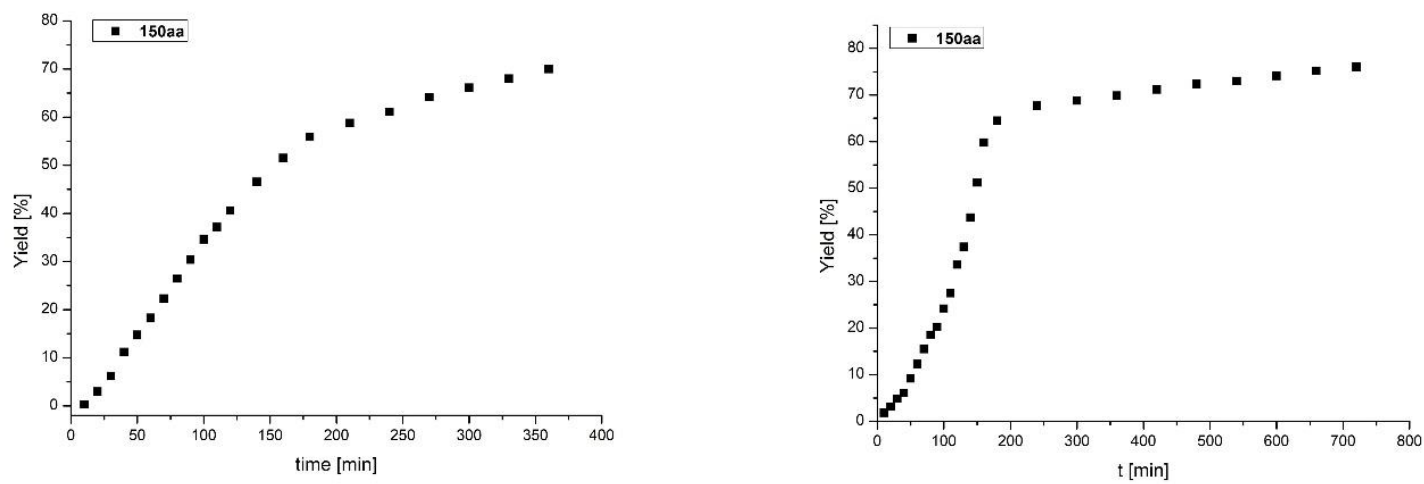

Figure 3.8 Kinetic profile for the electrochemical (left) and chemical (right) oxidation.

In addition, together with T. H. Meyer, detailed cyclovoltammetric studies were conducted in methanol as well as acetonitrile. ${ }^{[144 d]}$ In methanol (149b), the oxidation of cobalt(II) acetate in the presence of sodiumpivalate was observed in the absence or presence of the substrate at a potential of 1.19 VSCE. In contrast, the substrate 117a alone was oxidized at a much higher potential of $1.51 \mathrm{~V}_{\mathrm{SCE}}$, being suggestive of a facile initial oxidation of cobalt(II) to cobalt(III) under the reaction conditions. In acetonitrile, similar potentials were observed. Furthermore, quenching experiments indicated the formation of a cyclometalated species which reacted in the presence of ethanol (149a) but is relatively stable in its absence (Figure 3.9).
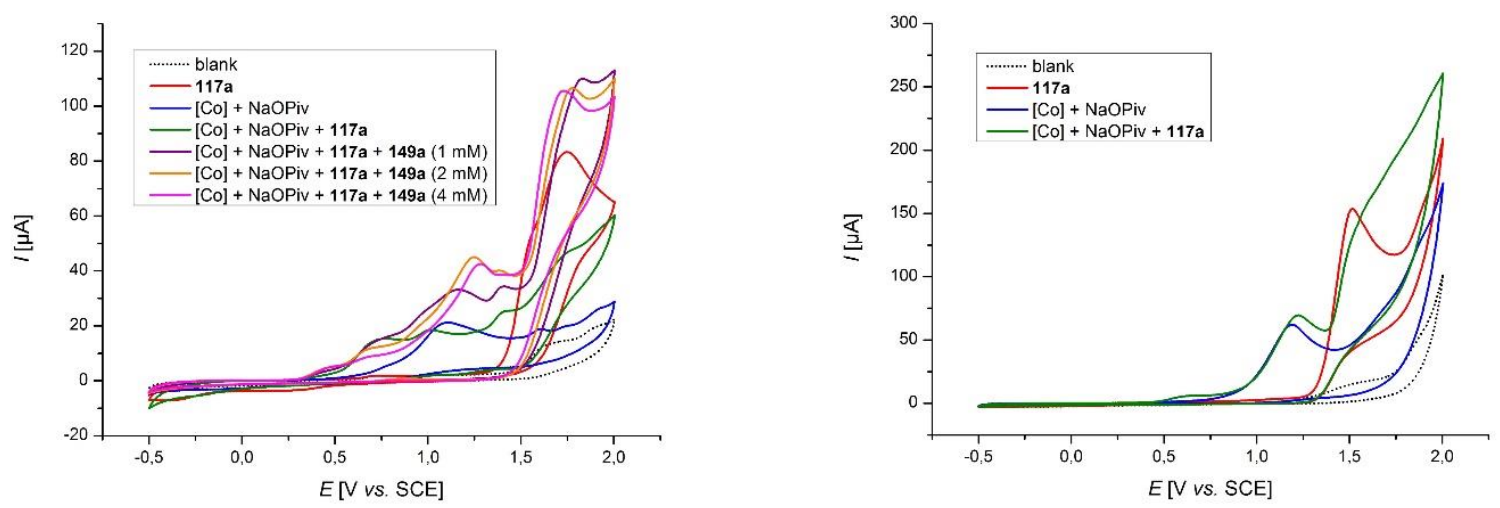

Figure 3.9 Cyclic voltammograms in $\mathrm{MeCN}$ (left) and $\mathrm{MeOH}$ (right). 
From the data obtained by the aforementioned experiments, a plausible catalytic cycle can be proposed (Scheme 3.19). The reaction is initiated by the facile formation of the active cobalt(III) species $\mathbf{2 4 8}$ by anodic oxidation. Coordination to the deprotonated substrate 117 and facile BIES ${ }^{[29]} \mathrm{C}-\mathrm{H}$ activation results in a five-membered intermediate 249. However, as shown in scheme 3.19, also one electron oxidation of 117 seems possible based on $\mathrm{CV}$ data, although $\mathrm{C}-\mathrm{H}$ activation of the radical cation would result in an open shell intermediate 249. Formation of the $\mathrm{C}-\mathrm{O}$ bond occurs presumably by reductive elimination, resulting in a cobalt $(I)$ species 250 , from which product $\mathbf{1 5 0}$ is liberated by proto-demetalation. Finally, the active species $\mathbf{2 4 8}$ is regenerated by anodic oxidation.

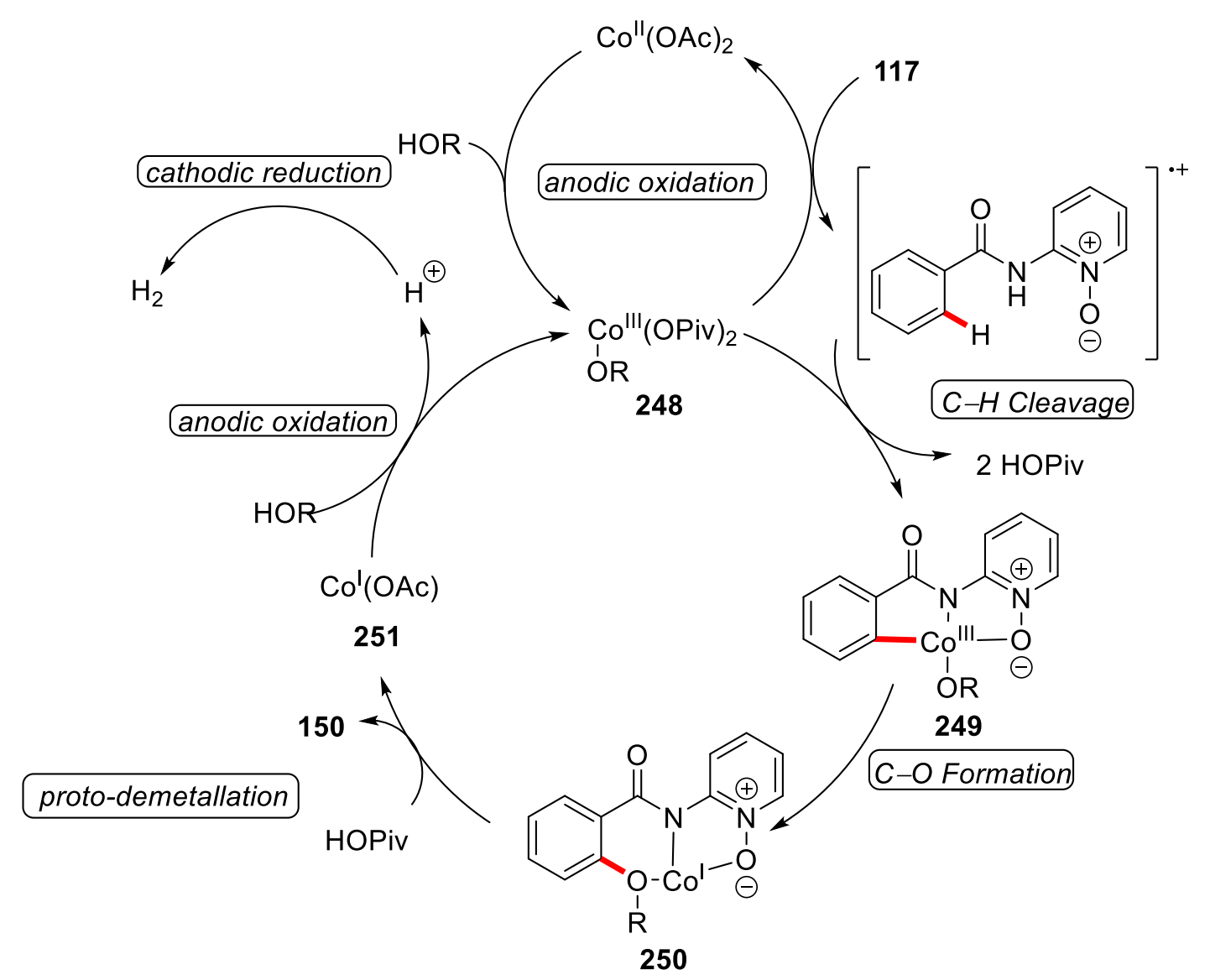

Scheme 3.19 Proposed catalytic cycle.

In summary, the first oxidative cobalt-catalyzed $\mathrm{C}-\mathrm{H}$ activation under electrochemical conditions was realized in the form of an electrocatalytic cobalt-catalyzed $\mathrm{C}-\mathrm{H}$ oxygenation of benzamides 117 . The protocol features exceedingly mild conditions, a broad and robust scope of functional groups and the possibility to perfrom an easy upscaling. Additionally, the unprecedented electrocatalytic cobalt catalysis was mechanistically investigated regarding its mode of action. 


\subsection{Electrochemical Cobalt-Catalyzed C-H Amination}

Inspired by the success of the electrochemical cobalt-catalyzed C-H oxygenations, ${ }^{[206]}$ the formation of other $\mathrm{C}-\mathrm{X}$ bonds became a next target. In the meantime, $\mathrm{C}-\mathrm{N}$ formations were realized as part of a $\mathrm{C}-\mathrm{H} / \mathrm{N}-\mathrm{H}$ annulation, ${ }^{[168]}$ making also the intermolecular direct $\mathrm{C}-\mathrm{H} / \mathrm{N}-\mathrm{H}$ cross-coupling highly desirable.

\subsubsection{Optimization of the Cobalt-Catalyzed Electrochemical C-H Amination}

Based on previous reports on cobalt-catalyzed amination, ${ }^{[110 b, 110 c]}$ initially, an undivided cell setup using cobalt(II)acetate tetrahydrate, sodium acetate, and acetonitrile with a supporting electrolyte and a temperature of $60^{\circ} \mathrm{C}$ were chosen as the starting conditions (Table 3.27).

Table 3.27 Optimization of the cobalt catalyzed amination. ${ }^{a}$<smiles>O=C(Nc1ccccc1[O-])c1ccccc1</smiles>

$117 a$<smiles>C1COCCN1</smiles>

$146 a$

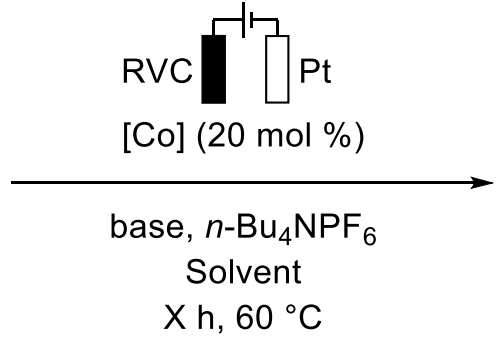

undivided cell, CCE at $Y \mathrm{~mA}$

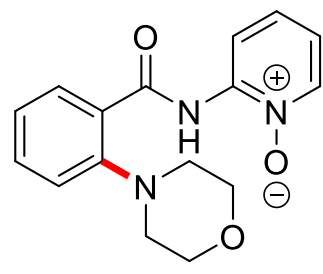

148aa

\begin{tabular}{ccccccc}
\hline Entry & {$[\mathrm{Co}]$} & $\mathrm{Base}$ & $\mathrm{X}$ & $\mathrm{Y}$ & Solvent & Yield [\%] \\
\hline 1 & $\mathrm{Co}(\mathrm{OAc})_{2} \cdot 4 \mathrm{H}_{2} \mathrm{O}$ & $\mathrm{NaOAc}$ & 4.5 & 12 & $\mathrm{MeCN}$ & 41 \\
2 & $\mathrm{Co}(\mathrm{OAc})_{2} \cdot 4 \mathrm{H}_{2} \mathrm{O}$ & $\mathrm{NaOAc}$ & 4.5 & 12 & $\mathrm{DCE}$ & 16 \\
3 & $\mathrm{Co}(\mathrm{OAc})_{2} \cdot 4 \mathrm{H}_{2} \mathrm{O}$ & $\mathrm{NaOAc}$ & 4.5 & 12 & $\mathrm{HFIP}$ & --- \\
$\mathbf{4}$ & $\mathrm{Co}(\mathrm{OAc})_{2} \cdot 4 \mathrm{H}_{2} \mathrm{O}$ & $\mathrm{NaOAc}$ & $\mathbf{1 2}$ & $\mathbf{6}$ & $\mathrm{MeCN}$ & $\mathbf{5 4}$ \\
5 & $\mathrm{Co}(\mathrm{acac})_{2}$ & $\mathrm{NaOAc}$ & 12 & 6 & $\mathrm{MeCN}$ & 21 \\
6 & $\mathrm{Co}(\mathrm{acac})_{3}$ & $\mathrm{NaOAc}$ & 12 & 6 & $\mathrm{MeCN}$ & 33 \\
7 & $\mathrm{Co}(\mathrm{ClO})_{2}$ & $\mathrm{NaOAc}$ & 12 & 6 & $\mathrm{MeCN}$ & 41 \\
8 & $\mathrm{Co}(\mathrm{oxalate})_{2}$ & $\mathrm{NaOAc}$ & 12 & 6 & $\mathrm{MeCN}$ & 12 \\
9 & $\mathrm{Col} 2$ & $\mathrm{NaOAc}$ & 12 & 6 & $\mathrm{MeCN}$ & 49 \\
10 & {$\left[\mathrm{Co}\left(\mathrm{NH}_{3}\right)_{6}\right] \mathrm{Cl}_{3}$} & $\mathrm{NaOAc}$ & 12 & 6 & $\mathrm{MeCN}$ & --- \\
11 & $\mathrm{Co}(\mathrm{OAc})_{2} \cdot 4 \mathrm{H}_{2} \mathrm{O}$ & $\mathrm{KOAc}$ & 12 & 6 & $\mathrm{MeCN}$ & 37 \\
12 & $\mathrm{Co}(\mathrm{OAc})_{2} \cdot 4 \mathrm{H}_{2} \mathrm{O}$ & $\mathrm{CsOAc}$ & 12 & 6 & $\mathrm{MeCN}$ & 29
\end{tabular}




$\begin{array}{rrlrllc}13 & \mathrm{Co}(\mathrm{OAc})_{2} \cdot 4 \mathrm{H}_{2} \mathrm{O} & \mathrm{Na}_{2} \mathrm{CO}_{3} & 12 & 6 & \mathrm{MeCN} & 31 \\ 14 & \mathrm{Co}(\mathrm{OAc})_{2} \cdot 4 \mathrm{H}_{2} \mathrm{O} & \mathrm{Na}_{3} \mathrm{PO}_{4} & 12 & 6 & \mathrm{MeCN} & 15 \\ 15 & \mathrm{Co}(\mathrm{OAc})_{2} \cdot 4 \mathrm{H}_{2} \mathrm{O} & \mathrm{NaOAc} & 12 & 6 & \mathrm{MeCN} & 30^{\mathrm{b}} \\ 16 & --- & \mathrm{NaOAc} & 12 & 6 & \mathrm{MeCN} & -\end{array}$

a Reaction conditions: $117 \mathrm{a}(0.50 \mathrm{mmol}),[\mathrm{Co}](20 \mathrm{~mol} \%)$, base $(1.50 \mathrm{mmol}), n$-Bu4NPF $(0.50 \mathrm{mmol})$ and $146 \mathrm{a}(1.00 \mathrm{mmol})$ in solvent $(2.0 \mathrm{~mL})$, time, constant current, $60^{\circ} \mathrm{C} .{ }^{\mathrm{b}}[\mathrm{Co}] 10 \mathrm{~mol} \%$.

The initial results of the chosen reaction conditions were promising (entry 1), while other solvents (entries 2 and 3) failed to deliver the desired product 148. An increase of the reaction time coupled with a decrease in applied current led to a significant improvement of the yield (entry 4). A representative set of cobalt salts were evaluated based on their catalytic ability (entries 5-10). Although several cobalt salts promoted the $\mathrm{C}-\mathrm{N}$ bond formation with comparable efficacy, $\mathrm{Co}(\mathrm{OAc})_{2} \cdot 4 \mathrm{H}_{2} \mathrm{O}$ was identified as ideal. Based on these results, the effect of different bases was tested (entries 11-14), which established NaOAc as the base of choice. Finally, a reaction using a reduced catalyst loading resulted in a reduced yield, while a control experiment without catalyst did not provide any product (entries 15 and 16).

Due to the relatively low yields observed during the optimization of the reaction in acetonitrile, it seemed improbable to find significantly improved conditions based on this solvent. Therefore, a careful evaluation of the reaction parameters, especially of the solvent was conducted again (Table 3.28). Furthermore, the reaction time was once more increased to $16 \mathrm{~h}$ and the current reduced to $4.0 \mathrm{~mA}$.

Table 3.28 Optimization of solvents. ${ }^{a}$<smiles>O=C(Nc1ccccc1[O-])c1ccccc1</smiles>

$117 a$<smiles>C1COCCN1</smiles>

$146 a$

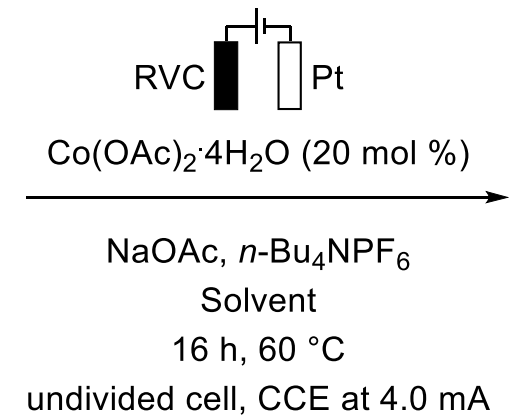

undivided cell, CCE at $4.0 \mathrm{~mA}$

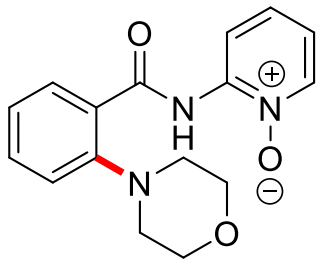

148aa

\begin{tabular}{ccc}
\hline Entry & Solvent & Yield [\%] \\
\hline 1 & MeCN & 41 \\
2 & DCE & 11 \\
3 & HFIP & ---
\end{tabular}




$\begin{array}{ccc}4 & \mathrm{DMF} & --- \\ 5 & \mathrm{DMSO} & --- \\ 6 & i-\mathrm{PrOH} / \mathrm{H}_{2} \mathrm{O} 3: 1 & 65 \\ 7 & \mathrm{GVL} & -- \\ 8 & \mathrm{GVL} / \mathrm{H}_{2} \mathrm{O} 3: 1 & -- \\ 9 & 2-\mathrm{MeTHF} & -- \\ 10 & \mathrm{H}_{2} \mathrm{O} & ---\end{array}$

a Reaction conditions: 117a $(0.50 \mathrm{mmol}), \mathrm{Co}(\mathrm{OAc})_{2} \cdot 4 \mathrm{H}_{2} \mathrm{O}(20 \mathrm{~mol} \%), \mathrm{NaOAc}(1.50 \mathrm{mmol}), n$-Bu4NPF 6 $(0.50 \mathrm{mmol})$ and $146 \mathrm{a}(1.00 \mathrm{mmol})$ in solvent $(2.0 \mathrm{~mL})$, constant current of $4.0 \mathrm{~mA}, 16 \mathrm{~h}$.

Clearly, the results for acetonitrile, DCE and HFIP are comparable to those obtained before. Polar solvents DMF and DMSO did not promote the reaction, which was also true for an $i-\mathrm{PrOH} / \mathrm{H}_{2} \mathrm{O}$ mixture (entries 4-6). Surprisingly, a significant increase in yield could be observed upon the use of $\gamma$-valerolactone as the solvent (entry 7 ), while a mixture with water was not a viable solvent (entry 8). Due to its possible synthesis from renewable biomass, ${ }^{[19,208]} \mathrm{GVL}$ as the solvent also improved the sustainability of the electrocatalysis. Further renewable biomass derived solvent 2-methyl-THF was tested as well, however, no catalytic activity was achieved in this solvent. Finally, water as the sole solvent was also not suitable for this reaction (entry 10). Based on these new information, the remaining reaction parameters were optimized again, this time with GVL as the solvent (Table 3.29).

Table 3.29 Optimization of cobalt catalyst. ${ }^{a}$

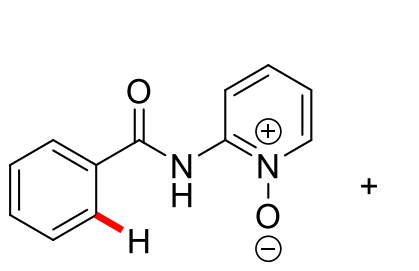

$117 a$<smiles>C1COCCN1</smiles>

$146 a$

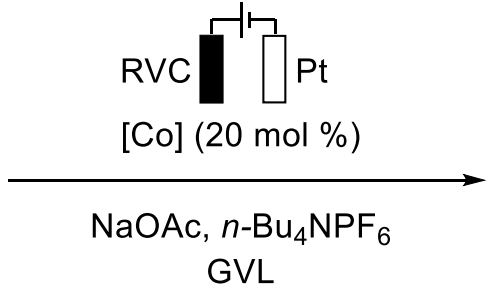

$16 \mathrm{~h}, 60^{\circ} \mathrm{C}$

undivided cell, CCE at $4.0 \mathrm{~mA}$

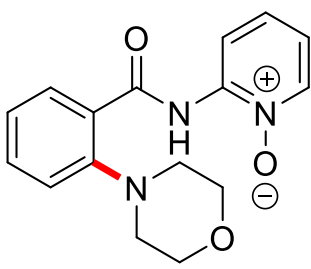

148aa

\begin{tabular}{ccc}
\hline Entry & {$[\mathrm{Co}]$} & Yield $[\%]$ \\
\hline $\mathbf{1}$ & $\mathrm{Co}(\mathrm{OAc})_{2} \cdot 4 \mathrm{H}_{2} \mathrm{O}$ & 65 \\
2 & $\mathrm{Co}\left(\mathrm{ClO}_{4}\right)_{2}$ & 58 \\
3 & $\mathrm{Co}(\mathrm{acac})_{2}$ & 19 \\
4 & $\mathrm{Co}(\mathrm{acac})_{3}$ & 35
\end{tabular}


$\left[\mathrm{Co}\left(\mathrm{NH}_{3}\right)_{6}\right] \mathrm{Cl}_{3}$

[a] Reaction conditions: 117a (0.50 mmol), [Co] $(20 \mathrm{~mol} \%), \mathrm{NaOAc}(1.50 \mathrm{mmol}), n-\mathrm{Bu}_{4} \mathrm{NPF}_{6}(0.50 \mathrm{mmol})$ and 146a $(1.00 \mathrm{mmol})$ in GVL $(2.0 \mathrm{~mL})$, constant current of $4.0 \mathrm{~mA}, 16 \mathrm{~h}$

It could be shown, that cobalt(II)acetate (entry 1) remained the best choice. However, cobalt(II)perchlorate gave a comparable yield (entry 2). The results for the other salts were comparable to those obtained in $\mathrm{MeCN}$ as the solvent (entries 3-7). Finally, a control experiment confirmed the essential nature of the cobalt catalyst for the reaction also in GVL (entry 8). With the solvent and cobalt salt being optimized, the additive was investigated again (Table 3.30).

Table 3.30 Optimization of the additive. ${ }^{\mathrm{a}}$<smiles>O=C(Nc1ccccc1)c1ccccc1</smiles>

$117 a$<smiles>C1COCCN1</smiles>

$146 a$

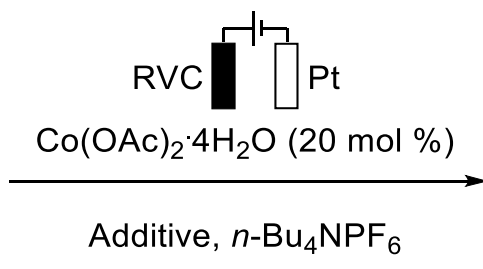

GVL

$16 \mathrm{~h}, 60^{\circ} \mathrm{C}$

undivided cell, CCE at $4.0 \mathrm{~mA}$

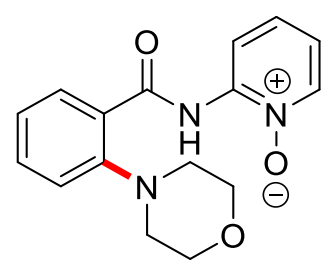

148aa

\begin{tabular}{ccc}
\hline Entry & Additive & Yield [\%] \\
\hline 1 & $\mathrm{NaOAc}$ & 65 \\
2 & $\mathrm{NaOPiv}$ & 51 \\
3 & $\mathrm{Na}_{2} \mathrm{CO}_{3}$ & 31 \\
4 & $\mathrm{KOAc}$ & 68 \\
5 & $\mathrm{~K}_{2} \mathrm{CO}_{3}$ & 30 \\
6 & $\mathrm{~K}_{3} \mathrm{PO}_{4}$ & 15 \\
7 & --- & --
\end{tabular}

[a] Reaction conditions: 117a $(0.50 \mathrm{mmol}), \mathrm{Co}(\mathrm{OAc})_{2} \cdot 4 \mathrm{H}_{2} \mathrm{O}(20 \mathrm{~mol} \%)$, additive (1.50 mmol), $n$-Bu4NPF 6 $(0.50 \mathrm{mmol})$ and $146 \mathrm{a}(1.00 \mathrm{mmol})$ in GVL $(2.0 \mathrm{~mL})$, constant current of $4.0 \mathrm{~mA}, 16 \mathrm{~h}$.

In the screening of basic additives, sodium pivalate resulted in good, although lower yields than sodium acetate (entries 1 and 2), while sodium carbonate was clearly less active. Potassium acetate (entry 4) resulted in the highest catalytic efficacy, while other 
potassium-based additives (entries 5 and 6 ) did not result in high yields. A control experiment confirmed the essential nature of the basic additive (entry 7 ).

Finally, further reaction parameters, such as time and temperature were optimized to find the ideal conditions for this transformation (Table 3.31).

Table 3.31 Optimization of further reaction parameters ${ }^{a}$

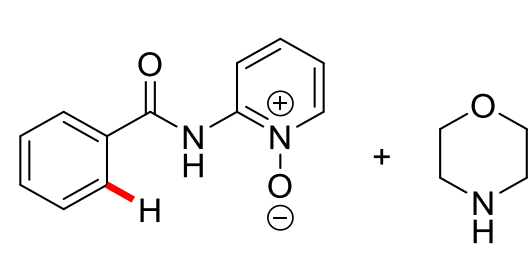

$117 a$

$146 a$

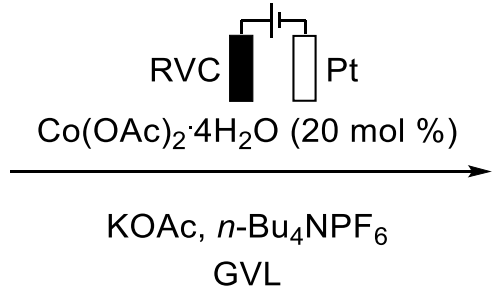

Time, $T$ undivided cell, CCE at $4.0 \mathrm{~mA}$<smiles>O=C(Nc1cccc[n+]1[O-])c1ccccc1N1CCOCC1</smiles>

148aa

\begin{tabular}{|c|c|c|c|}
\hline Entry & $T\left[{ }^{\circ} \mathrm{C}\right]$ & $t[\mathrm{~h}]$ & Yield [\%] \\
\hline$\overline{1}$ & 60 & $\overline{16}$ & 68 \\
\hline 2 & 40 & 24 & $77^{b}$ \\
\hline 3 & 20 & 24 & $23^{b}$ \\
\hline 4 & 40 & 24 & $19^{c}$ \\
\hline 5 & 40 & 24 & $77^{b, d}$ \\
\hline 6 & 40 & 24 & $\ldots--b, d, e$ \\
\hline
\end{tabular}

a Reaction conditions: $117 \mathrm{a}(0.50 \mathrm{mmol}), \mathrm{Co}(\mathrm{OAc}) 2 \cdot 4 \mathrm{H}_{2} \mathrm{O}(20 \mathrm{~mol} \%)$, additive $(1.50 \mathrm{mmol}) n$-Bu4NPF 6 $(0.50 \mathrm{mmol})$ and $146 \mathrm{a}(1.00 \mathrm{mmol})$ in GVL $(2.0 \mathrm{~mL})$, constant current of $4.0 \mathrm{~mA}, 16 \mathrm{~h} .{ }^{\mathrm{b}} \mathrm{Co}(\mathrm{OAc}) 2 \cdot 4 \mathrm{H}_{2} \mathrm{O}$ (10 mol \%), constant current of $2.5 \mathrm{~mA} .{ }^{\mathrm{c}} \mathrm{Co}(\mathrm{OAc})_{2} \cdot 4 \mathrm{H}_{2} \mathrm{O}(5.0 \mathrm{~mol} \%) .{ }^{d}$ under air. ${ }^{e}$ no current.

A longer reaction time at lower temperature of $40{ }^{\circ} \mathrm{C}$ was beneficial (entry 2), even at reduced catalyst loading of $10 \mathrm{~mol} \%$ and lower current of $2.5 \mathrm{~mA}$. A further reduction in temperature resulted in a significant loss of activity (entry 3 ), as did a further reduction in catalyst loading (entry 4). A nitrogen atmosphere was not necessary (entry 5 ), as air does not promote backround reactivity, which was confirmed by a control experiment without electric current (entry 6). Based on these results, the optimized conditions consisted of cobalt(II)acetate tetrahydrate as the catalyst, potassium acetate as the base in GVL with a supporting electrolyte at $40{ }^{\circ} \mathrm{C}$, with a current of 2.5 $\mathrm{mA}$ maintained for $24 \mathrm{~h}$. 


\subsubsection{Scope of the Electrochemical Cobalt-Catalyzed C-H Amination}

With the optimized catalytic system being identified, an initial study was conducted to confirm that indeed, pyridine- $N$-oxide was the $N$-substituent of choice (Table 3.32).

Table 3.32 $\mathrm{N}$-directing groups for the electrochemical cobalt-catalyzed $\mathrm{C}-\mathrm{H}$ oxygenation. ${ }^{\mathrm{a}}$

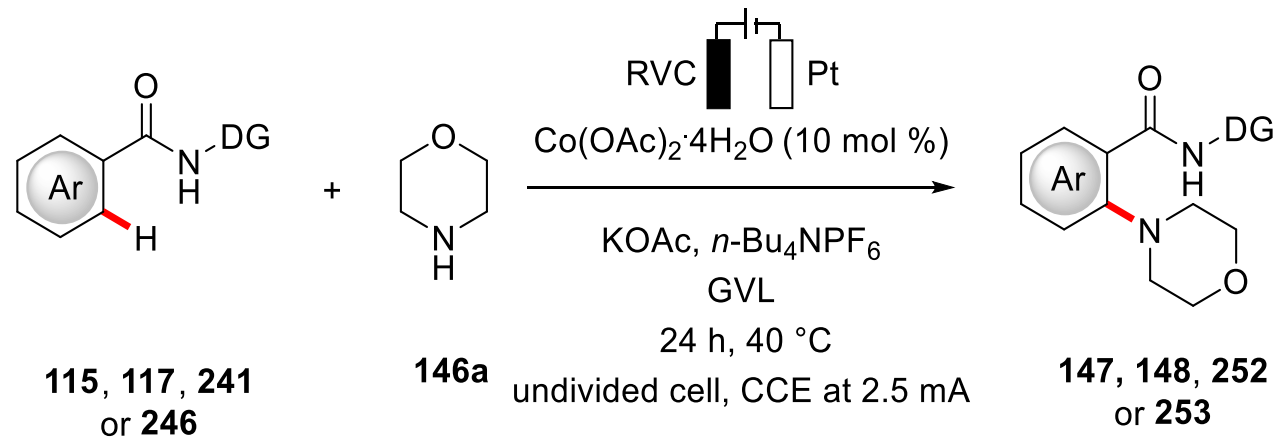

Entry Benzamide [\%]


4<smiles>O=C(NC(F)(F)F)c1ccccc1</smiles>

247a<smiles>O=C(NC(F)(F)F)c1ccccc1N1CCOCC1</smiles>

253aa

a Reaction conditions: benzamide $(0.50 \mathrm{mmol}), \mathrm{Co}(\mathrm{OAc})_{2} \cdot 4 \mathrm{H}_{2} \mathrm{O}(10 \mathrm{~mol} \%), \mathrm{KOAc}(1.50 \mathrm{mmol})$ $n$-Bu4NPF $6.50 \mathrm{mmol})$ and $146(1.00 \mathrm{mmol})$ in $\mathrm{GVL}(2.0 \mathrm{~mL}), 40^{\circ} \mathrm{C}$, constant current of $2.5 \mathrm{~mA}, 24 \mathrm{~h}$, under air.

Surprisingly, not only was pyridine- $N$-oxide the best directing group, but the only one that enabled the reaction under the optimized conditions.

With the optimal $N$-substituent identified, the scope of benzamides 117 was established regarding the functional group tolerance of different substituents on the benzamide motif (Table 3.33).

Table 3.33 Scope of the electrochemical cobalt-catalyzed amination of benzamdies $117 .^{a}$

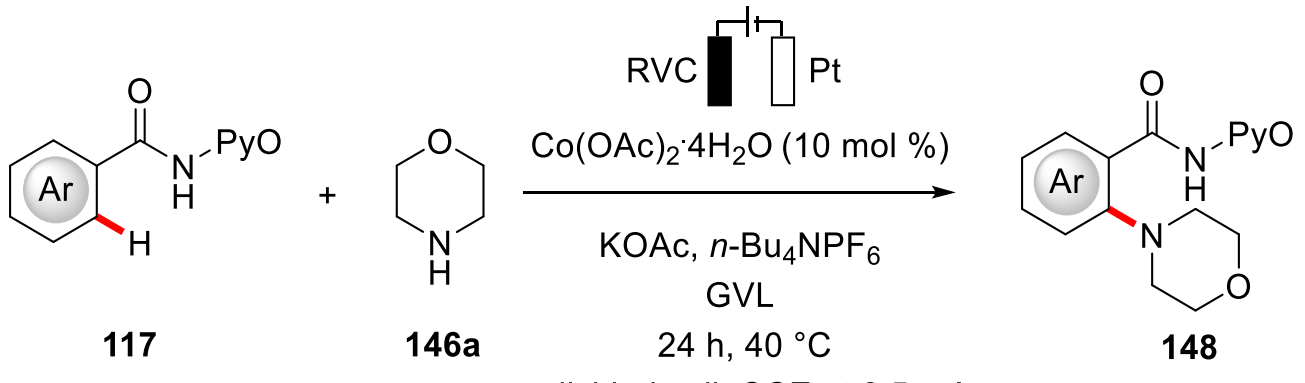

undivided cell, CCE at $2.5 \mathrm{~mA}$

Entry Benzamide


3<smiles></smiles>

4<smiles>O=C(N[Pb])c1cccc2c1Cc1ccccc1-2</smiles>

117p

5

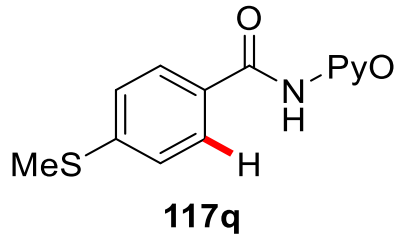

6<smiles>CC(=O)c1ccc(C(=O)NP(=O)(O)c2ccccc2)c([18F])c1</smiles>

7<smiles>O=C(N[Pb])c1cccc(I)c1</smiles>

$117 \mathrm{~h}$

8<smiles>O=C(N[Pb])c1cccs1</smiles>

9<smiles>O=C(N[18O])c1cc2ccccc2s1</smiles><smiles>O=C(NP)c1ccc(-c2ccccc2)cc1N1CCOCC1</smiles>

148na<smiles>O=C(NP)c1c(N2CCOCC2)ccc2c1Cc1ccccc1-2</smiles>

148pa<smiles>CSc1ccc(C(=O)NC(=O)OCc2ccccc2)c(N2CCOCC2)c1</smiles>

72

$$
\text { 148ha }
$$<smiles>O=C(NP)c1sccc1N1CCOCC1</smiles> 
10<smiles>O=[Te]NC(=O)c1cc2ccccc2o1</smiles>

11<smiles>O=C(NP)c1oc2ccccc2c1N1CCOCC1</smiles>

148 ta<smiles>O=C(NP)c1c(N2CCOCC2)[nH]c2ccccc12</smiles>

148la

1171

a Reaction conditions: $117(0.50 \mathrm{mmol}), \mathrm{Co}(\mathrm{OAc})_{2} \cdot 4 \mathrm{H}_{2} \mathrm{O}(10 \mathrm{~mol} \%), \mathrm{KOAc}(1.50 \mathrm{mmol}) n$-Bu $\mathrm{Bu}_{4} \mathrm{NPF}_{6}(0.50$ $\mathrm{mmol}$ ) and $246 \mathrm{a}(1.00 \mathrm{mmol})$ in GVL $(2.0 \mathrm{~mL}), 40^{\circ} \mathrm{C}$, constant current of $2.5 \mathrm{~mA}, 24 \mathrm{~h}$, under air. (siteselectivities in parentheses).

Besides the unsubstituted benzamide 117a, which was converted smoothly, various alkyl and aryl substituents were well tolerated (entries 2-4). Contrary to the electrochemical cobalt-catalyzed $\mathrm{C}-\mathrm{H}$ oxygenation, the use of ortho-substituted benzamide 117p was possible, although only moderate yield was achieved (entry 4). Additionally, sensitive but also valuable functional groups, such as thioether and ester, were well tolerated (entries 5 and 6 ). An iodo substituent in the meta position was tolerated, but a mixture of regio-isomers was isolated (entry 7 ). Finally, electron-rich heterocycles were evaluated as substrates. Thiophene 117k was efficiently converted (entry 8), which holds also true for the annulated substrates 117s and 117t (entries 9 and 10). Finally, the indole derived susbtrate 117I did not show any activity under the optimized conditions (entry 11) and was reisolated quantitatively. With a viable scope containing valuable functional groups in hand for benzamides 117, the amine coupling partner 146 was evaluated next (Table 3.34). 
Table 3.34 Electrochemical cobalt-catalyzed $\mathrm{C}-\mathrm{H}$ amination using amines $146 .{ }^{\mathrm{a}}$

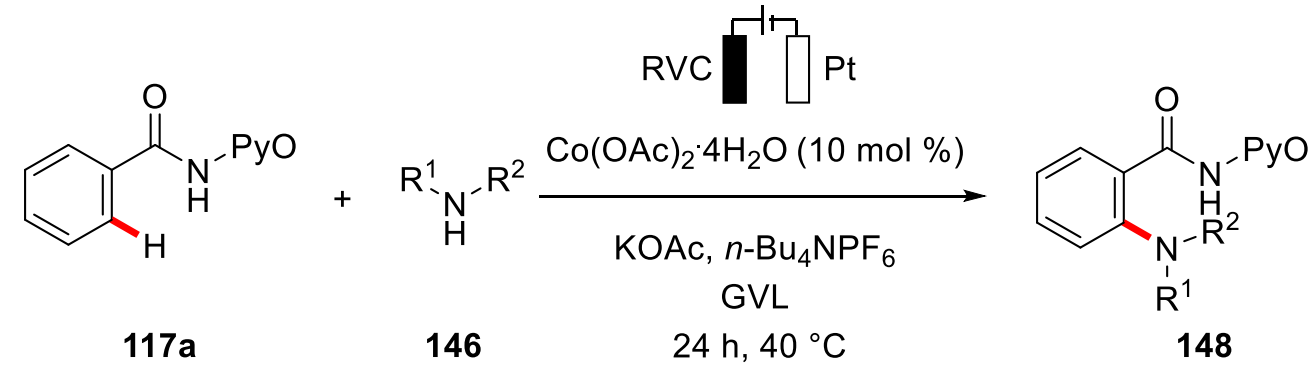

undivided cell, CCE at $2.5 \mathrm{~mA}$

Entry


6<smiles>ClC1CCNCC1</smiles>

7<smiles>CC(C)(C)ON1CCNCC1</smiles>

8<smiles>c1ccc(N2CCNCC2)cc1</smiles>

$146 \mathrm{~h}$

9<smiles>CC(C)(C)OC(=O)N1CCNCC1</smiles>
$146 i$

10<smiles>c1ccc2c(c1)CCCN2</smiles>

11<smiles>CC(C)(C)O</smiles>

12<smiles>[14CH3][Mg]</smiles><smiles>O=PNC(=O)c1ccccc1N1CCC(Cl)CC1</smiles>

148af<smiles>CN1CCN(c2ccccc2C(=O)NP(=O)(O)O)CC1</smiles>

55<smiles>O=C(NC(=O)c1ccccc1N1CCN(c2ccccc2)CC1)c1ccccc1</smiles>

148ah<smiles>O=C(N[Pb](=O)O)c1ccccc1N1CCN(C(=O)OCc2ccccc2)CC1</smiles><smiles></smiles><smiles>O=C(NC(=O)c1ccccc1N1CCCC1)Nc1ccccc1</smiles>

148ak<smiles>O=PNC(=O)c1ccccc1N1CCCCCC1</smiles>

148al

trace 
13<smiles>CN(c1ccccc1)c1ccccc1</smiles><smiles>CCCNC(=O)c1ccccc1N(C)c1ccccc1</smiles>

trace

14<smiles>c1ccc(Nc2ccccc2)cc1</smiles>

148am

4<smiles>O=C(NP)c1ccccc1N(P)c1ccccc1</smiles>

148an

15<smiles>CNCc1ccccc1</smiles><smiles>CN(Cc1ccccc1)c1ccccc1C(=O)NP(=O)(O)c1ccccc1</smiles>

16<smiles>CC(C)(C)NC(C)(C)C</smiles><smiles>CC(C)(C)N([14CH3])c1ccccc1C(=O)N[18O]</smiles>

17<smiles>CC(C)(C)N</smiles><smiles>CC(C)(C)[13C]Nc1ccccc1C(=O)NP</smiles>

18<smiles>NP(=O)(Br)c1ccccc1</smiles>

${ }^{a}$ Reaction conditions: $117 \mathrm{a}(0.50 \mathrm{mmol}), \mathrm{Co}(\mathrm{OAc})_{2} \cdot 4 \mathrm{H}_{2} \mathrm{O}(10 \mathrm{~mol} \%), \mathrm{KOAc}(1.50 \mathrm{mmol}) n$-Bu4NPF 6 $(0.50 \mathrm{mmol})$ and $146(1.00 \mathrm{mmol})$ in $\mathrm{GVL}(2.0 \mathrm{~mL}), 40^{\circ} \mathrm{C}$, constant current of $2.5 \mathrm{~mA}, 24 \mathrm{~h}$, under air.

The use of morpholine (146a) resulted in formation of the desired product 148aa in good yield (entry 1), while the thio analogue 146b (entry 2) showed slightly reduced efficacy. Unsubstituted piperidine (146c), as well as 4-methyl- and 4-phenylpiperidine 146d and 146e were converted with good yields to the desired products (entries 3-5). Remarkable is the smooth conversion of 4-chloropiperidine (146f) with moderate yield, 
which offers a potential handle for subsequent functionalization of the products (entry 6). $\mathrm{N}$-methylpiperazine (146g) was a competent substrate (entry 7), while the $\mathrm{N}$-phenyl and $\mathrm{N}$-Boc substituted analogues $146 \mathrm{~h}$ and $146 \mathrm{i}$ showed only traces of the product or no conversion, respectively (entries 8 and 9). Tetrahydroisoquinoline (146j) as well as cyclic secondary amines $\mathbf{1 4 6 k}$ and $\mathbf{1 4 6}$ with different ring sizes (entries 10-12) did not lead to any observed product formation. Acyclic amines were generally not successful in this reaction. While trace amounts of the product could be observed in two cases (entries 13 and 15), all other experiments were not successful. The low reactivity of substrates $146 p$ and 1460 was initially attributed to a possible elimination of the $\alpha$ hydrogens or an oxidation to the iminium ion. However, amines without $\alpha$-hydrogens (entries 14 and 16) showed even worse results, although especially in the case of bis$t$-butyl amine $146 p$ sterics could also play a role. Finally, primary amines $146 q$ and 146r were evaluated and found to be not suitable for the amination under these optimized conditions (entries 17 and 18).

\subsubsection{Mechanistic Studies and Proposed Mechanism}

After evaluating the robustness of the electrochemical cobalt-catalyzed $\mathrm{C}-\mathrm{H}$ amination in terms of functional group tolerance on both coupling partners, detailed mechanistic studies were conducted. Initially, the calculation of the current efficiency based on the formation of product 148aa, revealed a value of $34 \%$ (vide infra), which is slightly lower than the one determined for the cobalt-catalyzed $\mathrm{C}-\mathrm{H}$ alkoxylation.

$$
\text { Efficacy }=\frac{n * y * z * F}{t * I}=\frac{0.0005 \mathrm{~mol} * 0.77 * 2 * 96485 \mathrm{C} / \mathrm{mol}}{86400 \mathrm{~s} * 0.0025 \mathrm{C} / \mathrm{s}}=0.344
$$

Additionally, an $\mathrm{H} / \mathrm{D}$-exchange experiment was conducted in the presence of $\mathrm{D}_{2} \mathrm{O}$ as the deuterated cosolvent which showed incorporation of deuterium neither in the product 148aa nor in the reisolated starting material 146a, suggesting an irreversible $\mathrm{C}-\mathrm{H}$ metalation event (Scheme 3.20). 


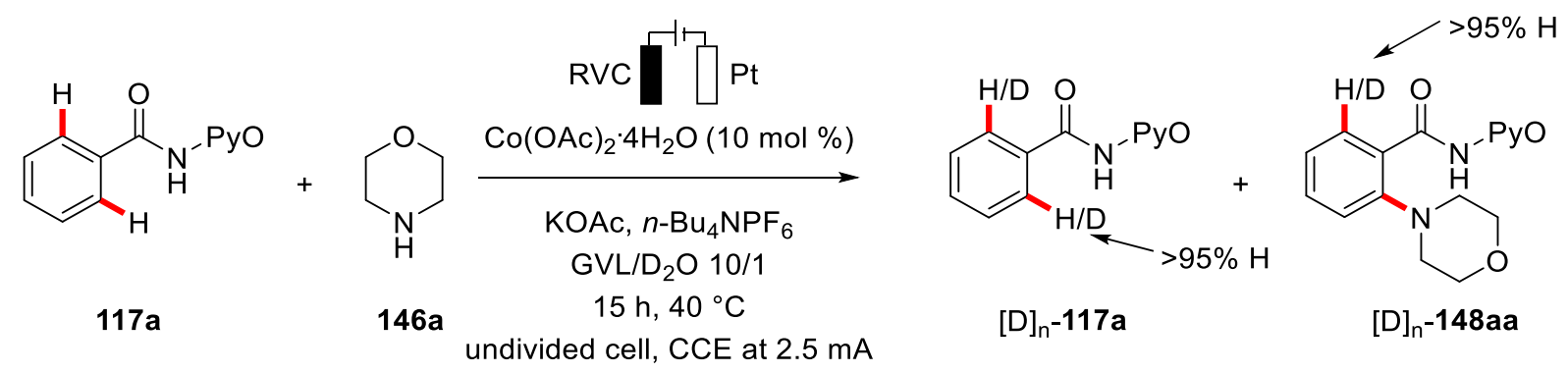

Scheme $3.20 \mathrm{H} / \mathrm{D}$-exchange experiment in the presence of $\mathrm{D}_{2} \mathrm{O}$.

To gain further insights into the catalyst's mode of action, an in-situ study using ReactIR technology was conducted, using acetonitrile as the solvent due to the strong IR bands of GVL overlaying the product signals. Initially a kinetic profile of the reaction was recorded over the complete reaction time. From the obtained surface plot, suitable peaks were identified, and the obtained values plotted against the reaction time to generate the kinetic profile (Figure 3.10).
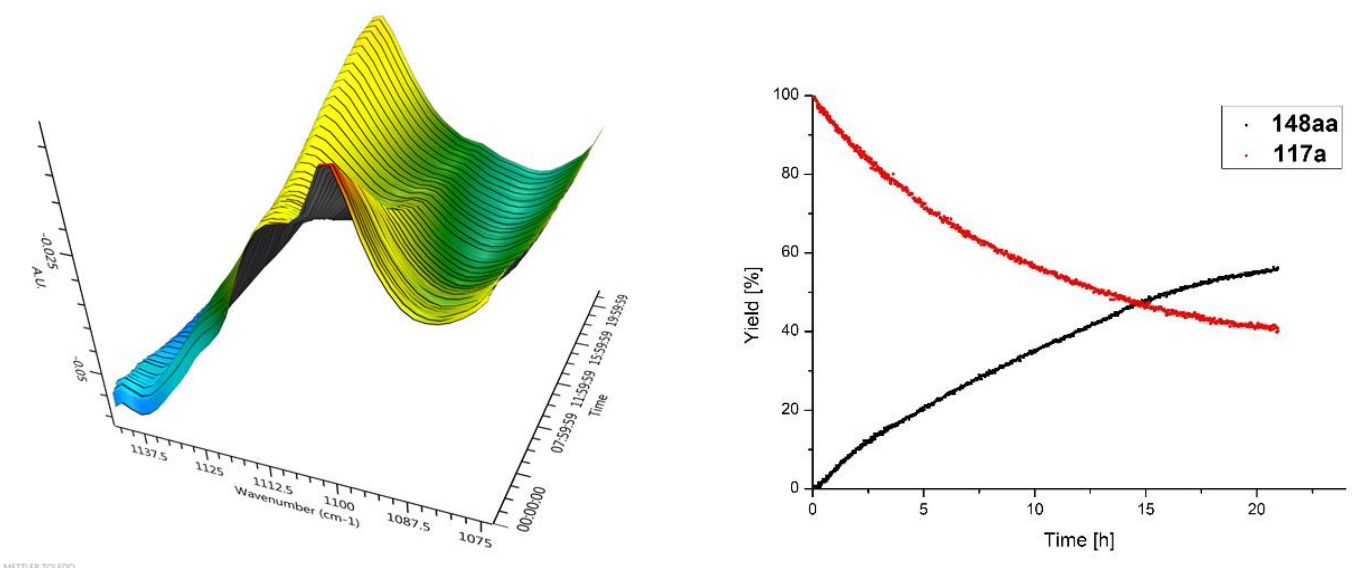

Figure 3.10 3D surface plot and kinetic profile of the electrochemical amination at $1115 \mathrm{~cm}^{-1}$ (red) and $1096 \mathrm{~cm}^{-1}$ (black).

The thus obtained data clearly showed, that an initiation period is not required, or extremely short, as the React-IR collected a measurement every minute and no initiation was observable for the cobalt catalyst. Moreover, a kinetic isotope effect (KIE) was measured using the same technique in two independent reactions for the standard substrate 117a and the penta-deuterated substrate [D]5-117a (Scheme 3.21). 
<smiles>O=C(N[Pb])c1ccc(S(=O)(=O)O[18O])cc1</smiles>

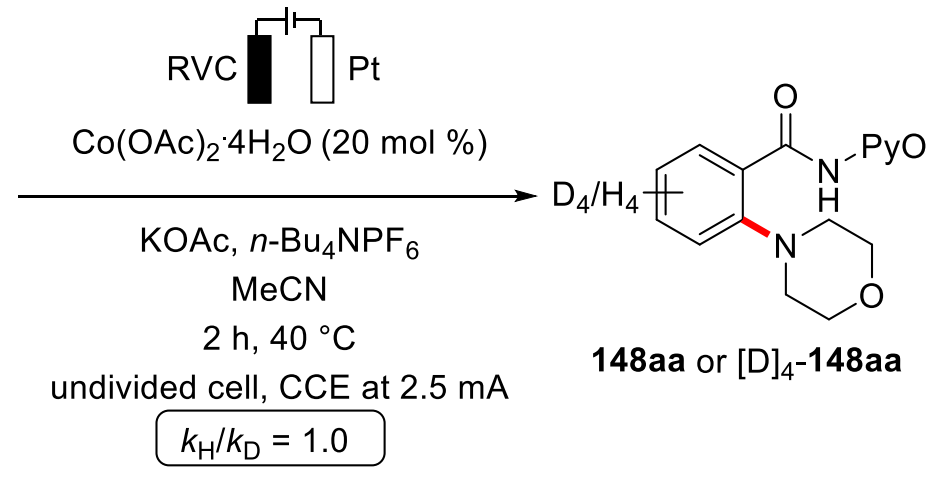

$k_{H} / k_{D}=1.0$

Scheme 3.21 KIE studies by react-IR technology.

From the data, no $\mathrm{KIE}\left(\mathrm{KH}_{\mathrm{H}} / \mathrm{KD}_{\mathrm{D}}=1.0\right)$ was observed, which indicated that the $\mathrm{C}-\mathrm{H}$ cleavage is facile and not involved in the rate, limiting step, which is in good agreement with our previous findings (Figure 3.11).
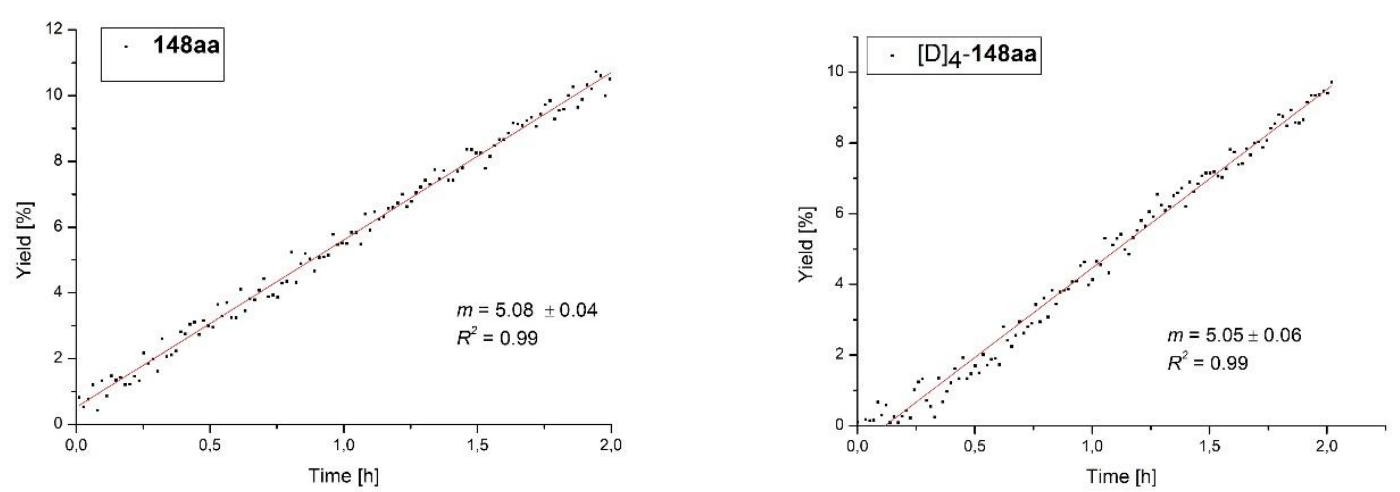

Figure 3.11 Initial rates of the electrochemical cobalt-catalyzed $\mathrm{C}-\mathrm{H}$ amination.

Finally, the oxidative, cross-dehydrogenative protocol was suggestive of the formation of $\mathrm{H}_{2}$ as the stoichiometric byproduct. Therefore, the gas phase over the reaction medium was analyzed by headspace GC technology to explore the formation of $\mathrm{H}_{2}$. The analysis qualitatively confirmed the formation of $\mathrm{H}_{2}$, which can be seen in the obtained chromatogram (Scheme 3.22). 

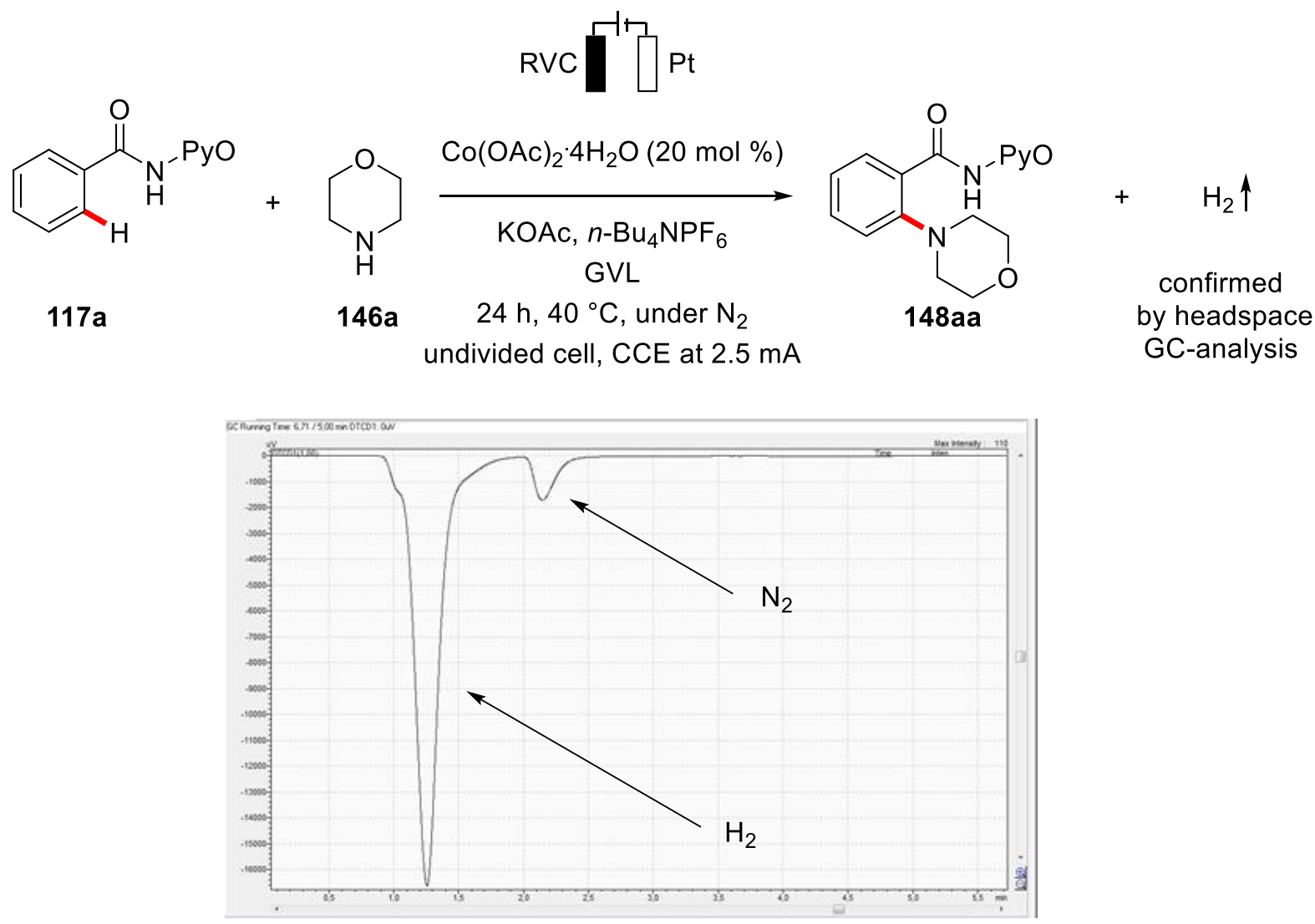

Scheme 3.22 GC headspace analysis of the reaction mixture.

In addition to these studies, the reaction was also analyzed by $\mathrm{CV}$ studies of the reaction mixture in $\mathrm{MeCN}$ (Figure 3.12). While the oxidation of $\mathrm{Co}(\mathrm{OAc})_{2}$ in the presence of KOAC was observed at a potential of $1.05 \mathrm{~V}_{\mathrm{SCE}}$, the substrate 117a was oxidized at a significantly higher potential of $1.58 \mathrm{VSCE}$. Interestingly a mixture of the cobalt salt, KOAc and 117a was shifted to significantly lower potentials with a local maximum observable at $0.73 V_{S C E}$ and several new peaks were observed. Finally, upon addition of morpholine, no quenching could be observed, however oxidation of morpholine was overlaying with most of the CV curve. Nevertheless, the oxidation of morpholine occurs at a higher potential ( $1.17 \mathrm{VSCE}_{\mathrm{SC}}$, and thus the data strongly supports a cobalt catalyzed, organometallic transformation over a radical addition pathway, which is known for electrochemical, metal-free aminations of activated oxazole heterocycles. [210] 


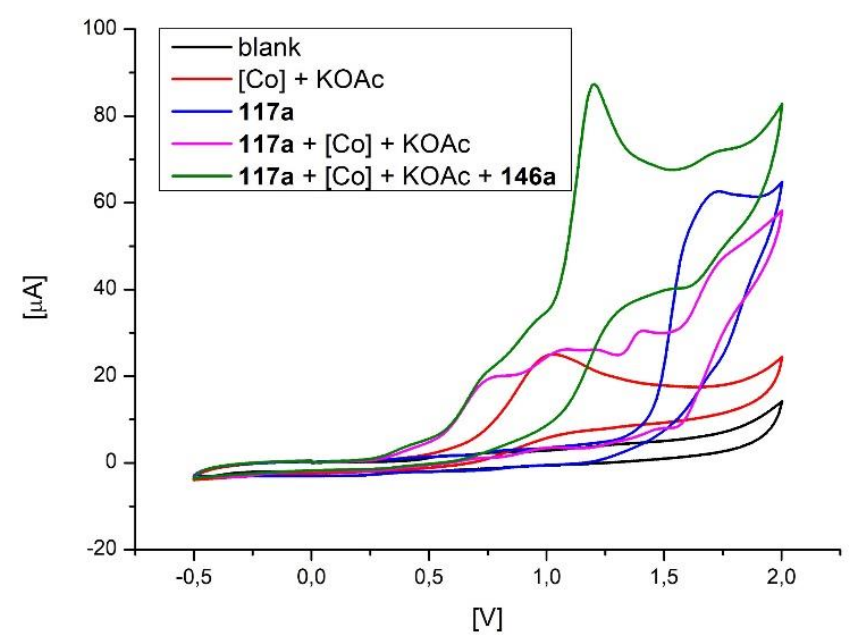

Figure 3.12 CV of the reaction mixture in $\mathrm{MeCN}$.

Based on the sum of these mechanistic experiments, a plausible catalytic cycle is proposed. After generation of the active cobalt(III) catalyst 254, the $\mathrm{C}-\mathrm{H}$ activation occurs by BIES C-H cobaltation. ${ }^{[29]}$ The thus formed cyclometalated complex 255 can undergo a ligand exchange of substrate 146a against the acetate to generate intermediate 256. Formation of the $\mathrm{C}-\mathrm{N}$ bond followed by proto-demetallation generates the desired product 148 and cobalt $(I)$ species 257 , which is oxidized at the anode to regenerate the active catalyst 254 (Scheme 3.23). 


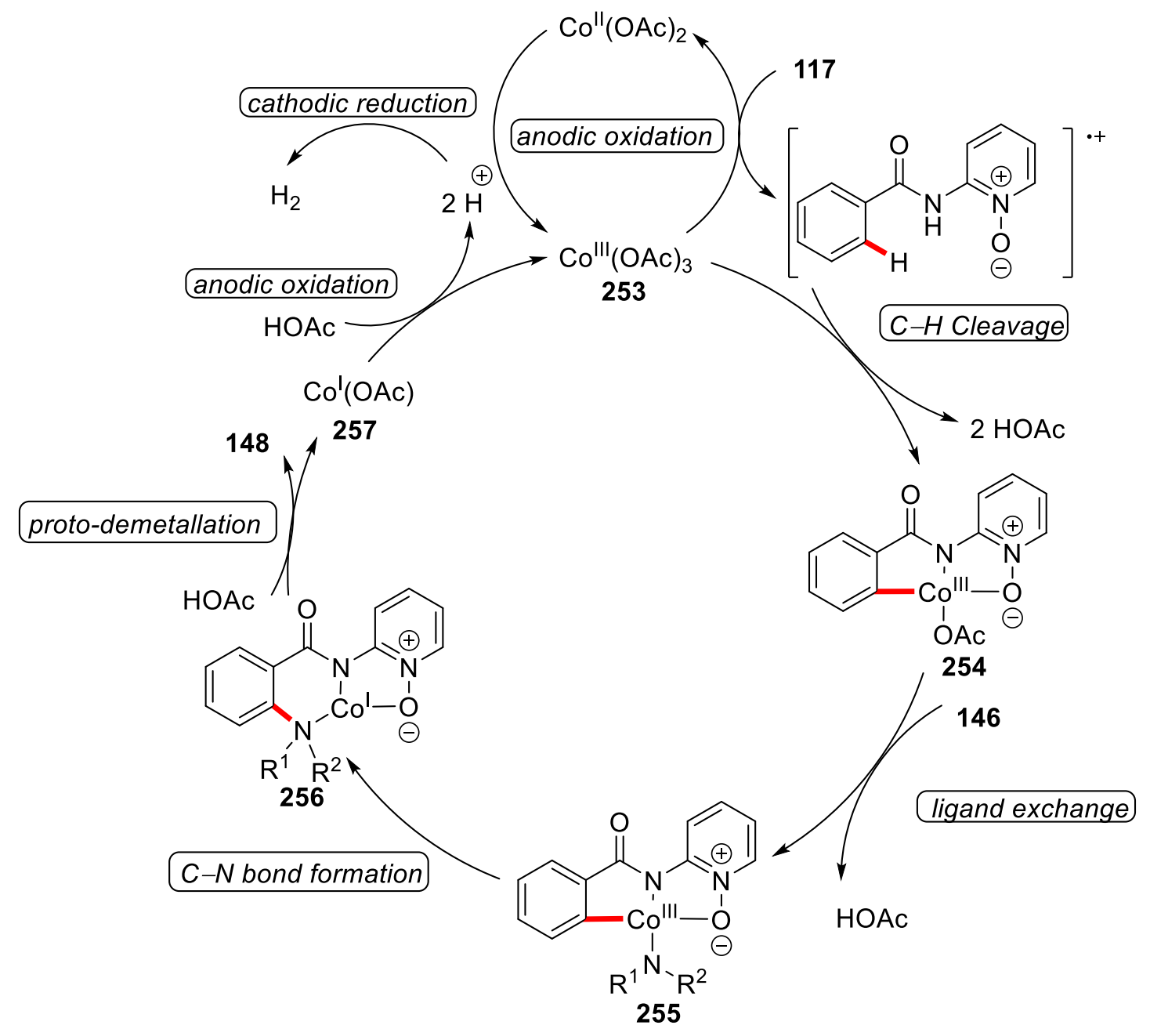

Scheme 3.23 Plausible catalytic cycle.

\subsection{Mechanistic Studies on Transititon Metal-Catalyzed Electrochemical C-H Activation.}

During the studies on the cobalt-catalyzed $\mathrm{C}-\mathrm{H}$ amination under electrochemical conditions, further electrochemical transition metal-catalyzed $\mathrm{C}-\mathrm{H}$ functionalizations were developed. The optimization and scope of these reactions was investigated by Dr. R. Mei (cobalt) ${ }^{[211]}$ and Dr. Y. Qiu, Dr. W.-J. Kong, J. Struwe and A. Scheremetjew (rhodium) $^{[212]}$ respectively, with theoretical considerations conducted by Dr. J. C. A. Oliveira and T. Rogge. Therefore, only a short overview over the general reaction will be given in the following chapter, with a detailed description of the mechanistic studies conducted in the range of this thesis. 


\subsubsection{Cobalt-Catalyzed Electrochemical Annulation of Terminal and Internal}

Alkynes using an Electrocleavable Directing Group

During his studies, R. Mei identified $N$-methyl- $N$-pyridyl benzhydrazides 215 as viable substrates for the cobalt-catalyzed electrochemical $\mathrm{C}-\mathrm{H} / \mathrm{N}-\mathrm{H}$ annulation using terminal as well as internal alkynes 8. $^{[210]}$ This is noteworthy, as previous protocols for $\mathrm{C}-\mathrm{H} / \mathrm{N}-\mathrm{H}$ annulation by electrochemical cobalt-catalysis were limited to terminal alkynes 8. ${ }^{[168-169]}$ The transformations of internal and terminal alkynes 8 were enabled under slightly different conditions, as shown below (Scheme 3.24).[211]

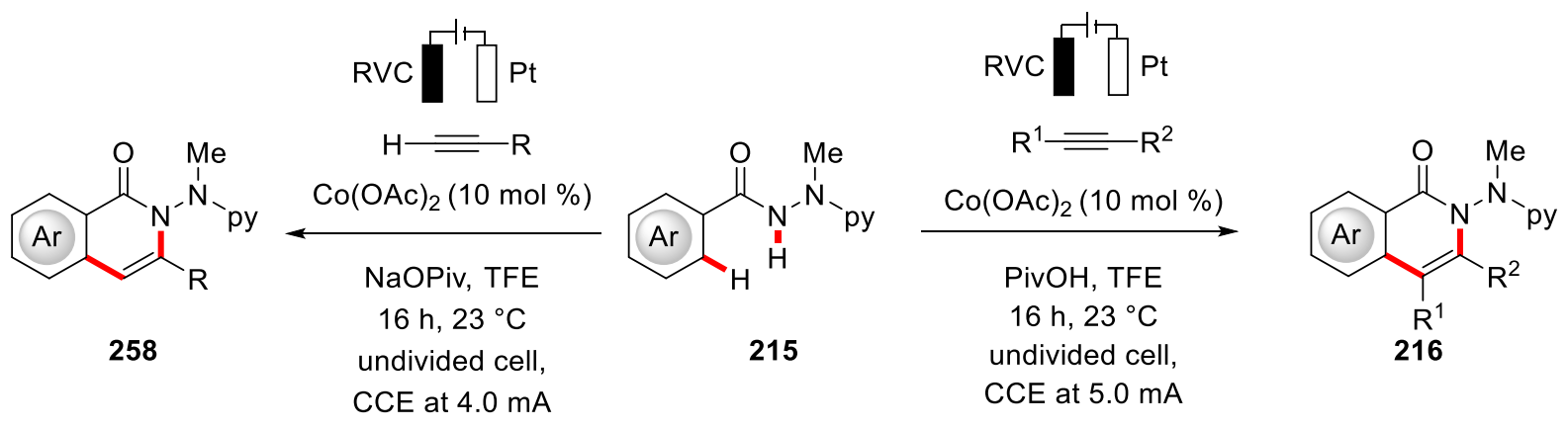

Scheme 3.24 Electrochemical cobalt-catalyzed $\mathrm{C}-\mathrm{H} / \mathrm{N}-\mathrm{H}$ annulation of alkynes 8 .

For this reaction, also the formation of hydrogen as a byproduct seems plausible. This was confirmed for the reaction of the internal alkyne $8 \mathbf{a}$ by headspace GC analysis (Scheme 3.25).<smiles>O=C(NN(c1ccccc1)c1ccccn1)c1ccccc1</smiles>

215a

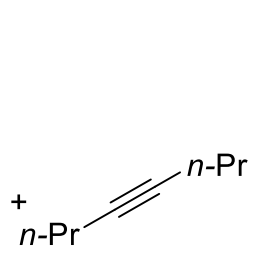

$8 \mathbf{a}$
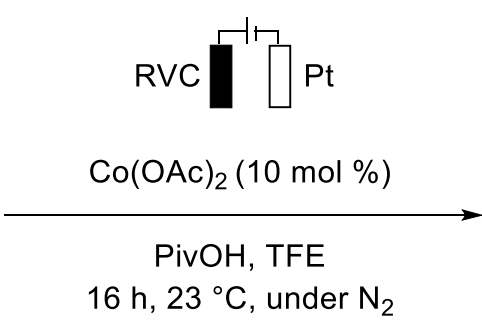

undivided cell, CCE at $5.0 \mathrm{~mA}$<smiles>[Y6]N([18F])n1c(C(C)C)c(C(C)C)c2ccccc2c1=O</smiles>

216aa

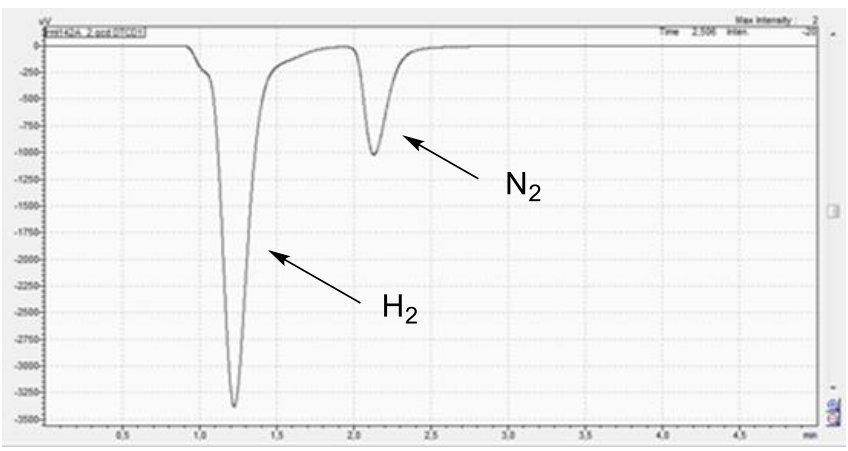

Scheme 3.25 GC headspace analysis. 
Additionally, a measurement of the kinetic profile by time-resolved UV/Vis spectroscopy was attempted. While the time-resolved spectra nicely showed several shifts in the UV/Vis region, no separated peaks could be obtained. A kinetic profile could be obtained by plotting peak intensities against time, however due to missing peak separation, this can only be a qualitative analysis not suited to calculate rate constants for the initial rates analysis (Figure 3.13).
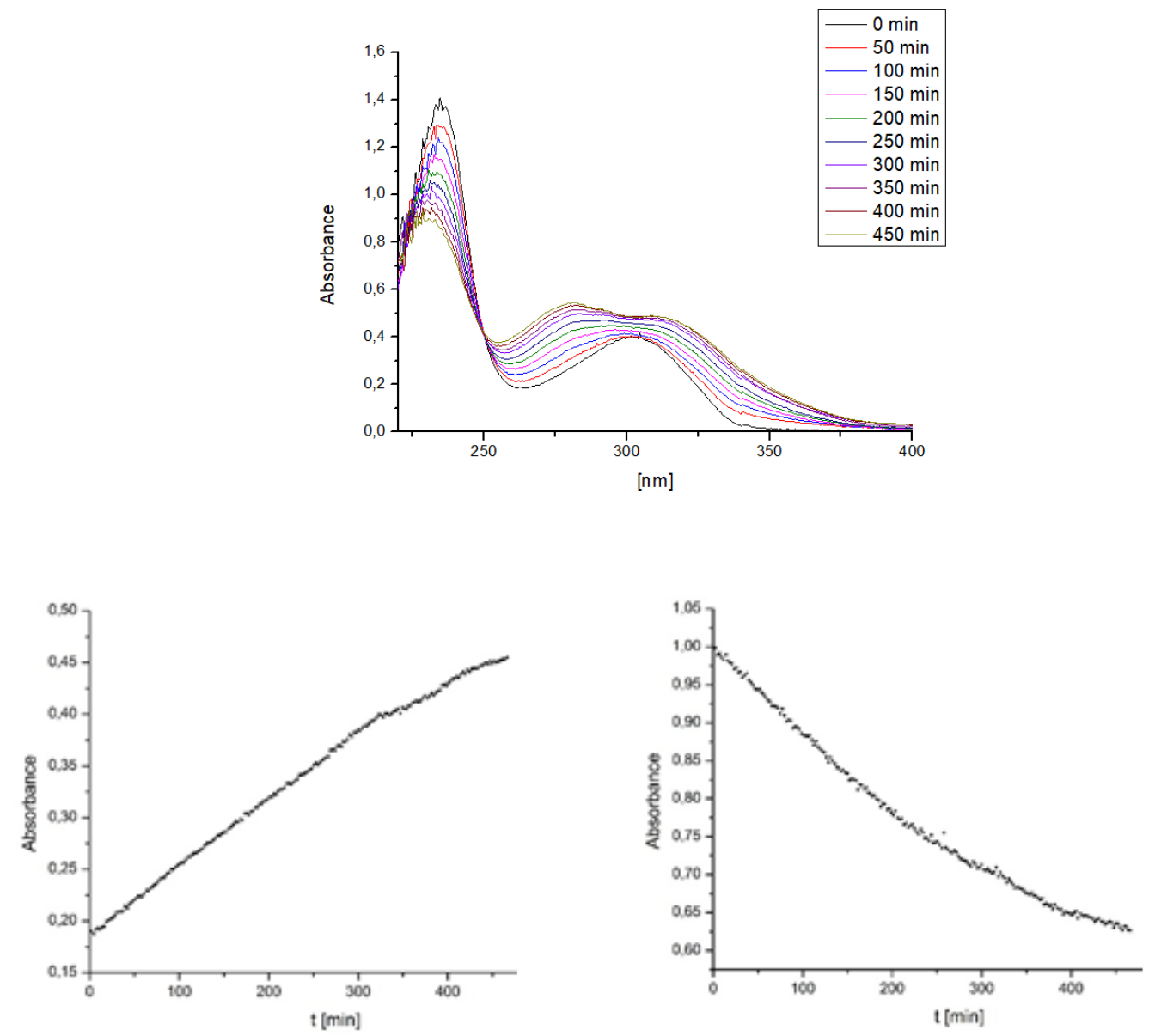

Figure 3.13 Time resolved UV/Vis spectra and kinetic profiles at $242 \mathrm{~nm}$ (left) and $266 \mathrm{~nm}$ (right).

To get further insight into possible intermediates of the reaction, the crude reaction mixture was subjected to ESI mass spectrometry. Besides several aggregates of the starting materials and products, a mass was observed, which was identified as the seven-membered cyclometalated intermediate 259 (Figure 3.14). 


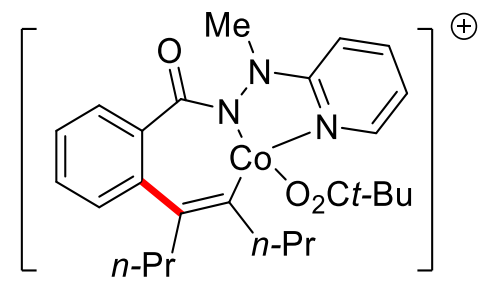

Molecular Formula: $\mathrm{C}_{26} \mathrm{H}_{34} \mathrm{CoN}_{3} \mathrm{O}_{3}$

Exact Mass: 495.1927

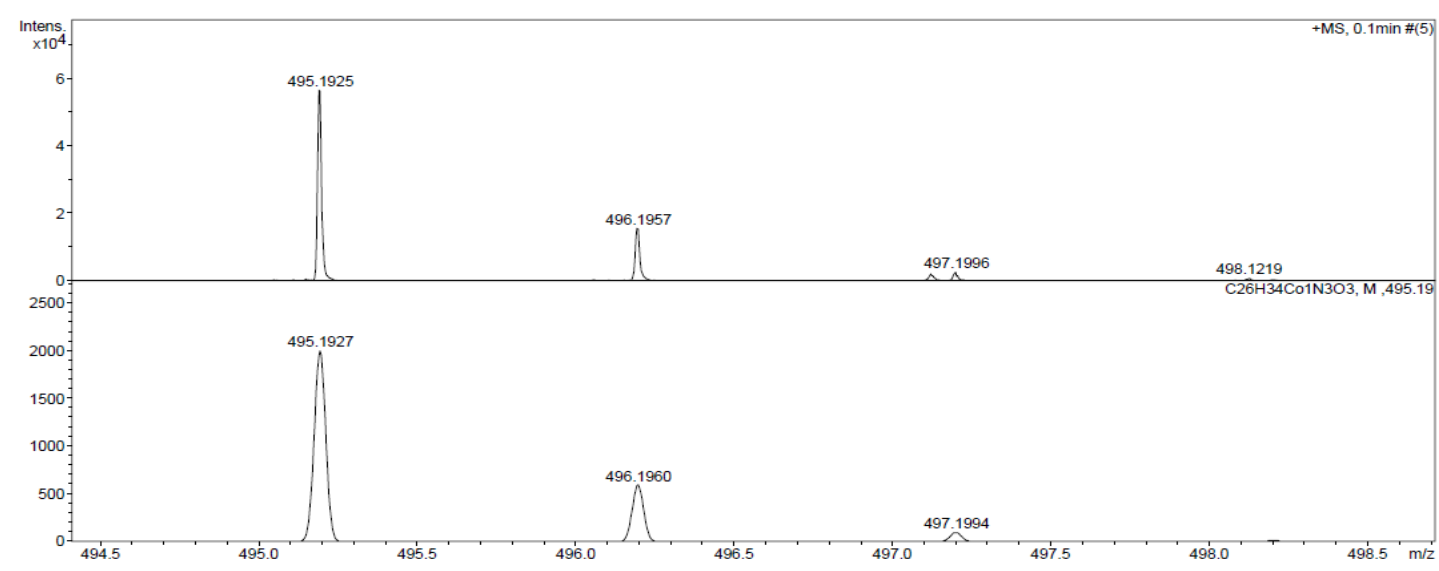

Figure 3.14 ESI-MS of the proposed intermediate 253.

Since a five-membered cyclometalated cobalt complex coordinating the alkyne (260, Figure 3.15) should have the same exact mass, this ion was isolated and analyzed by MS/MS technology. In the resulting spectra, only the loss of pivalic acid was observed, while a $\pi$-coordinated alkyne should be removed first due to its weaker coordination (Figure 3.16). Furthermore, the mass for the five membered cobaltacycle fragment 261 $(\mathrm{m} / \mathrm{z}=284)$, which would be expected in this case was not observed, supporting the proposal that the mass does indeed belong to the seven-membered species 259. Also, a complex of the product 216aa coordinated to a Co(I)-species after reductive elimination seemed unlikely, as in this case the mass of 216aa should be observable after fragmentation, which was not the case here. The same experiment was conducted using deuterated $[D] 5-215 a$, and indeed, the loss of one deuterium confirms the structure of intermediate 259. 


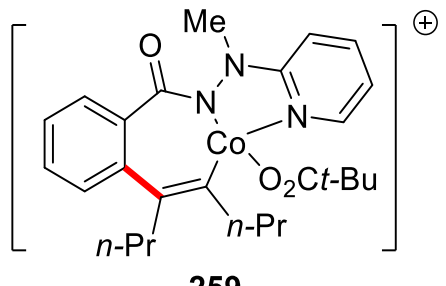

259

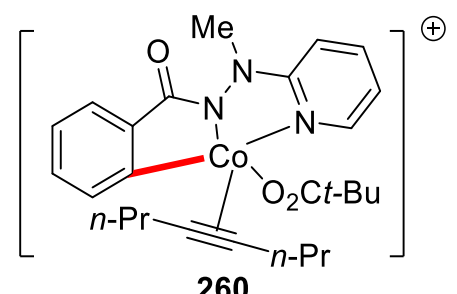

260<smiles>Cc1cccc(N(C)n2oc3ccccc3c2=O)c1</smiles>

261
Molecular Formula: $\mathrm{C}_{26} \mathrm{H}_{34} \mathrm{CoN}_{3} \mathrm{O}_{3}$ Exact Mass: 495.1927
Molecular Formula: $\mathrm{C}_{26} \mathrm{H}_{34} \mathrm{CoN}_{3} \mathrm{O}_{3}$ Molecular Formula: $\mathrm{C}_{13} \mathrm{H}_{11} \mathrm{CoN}_{3} \mathrm{O}$ Exact Mass: 495.1927
Exact Mass: 284.0229

Figure 3.15. Possible Intermediates and Fragments.

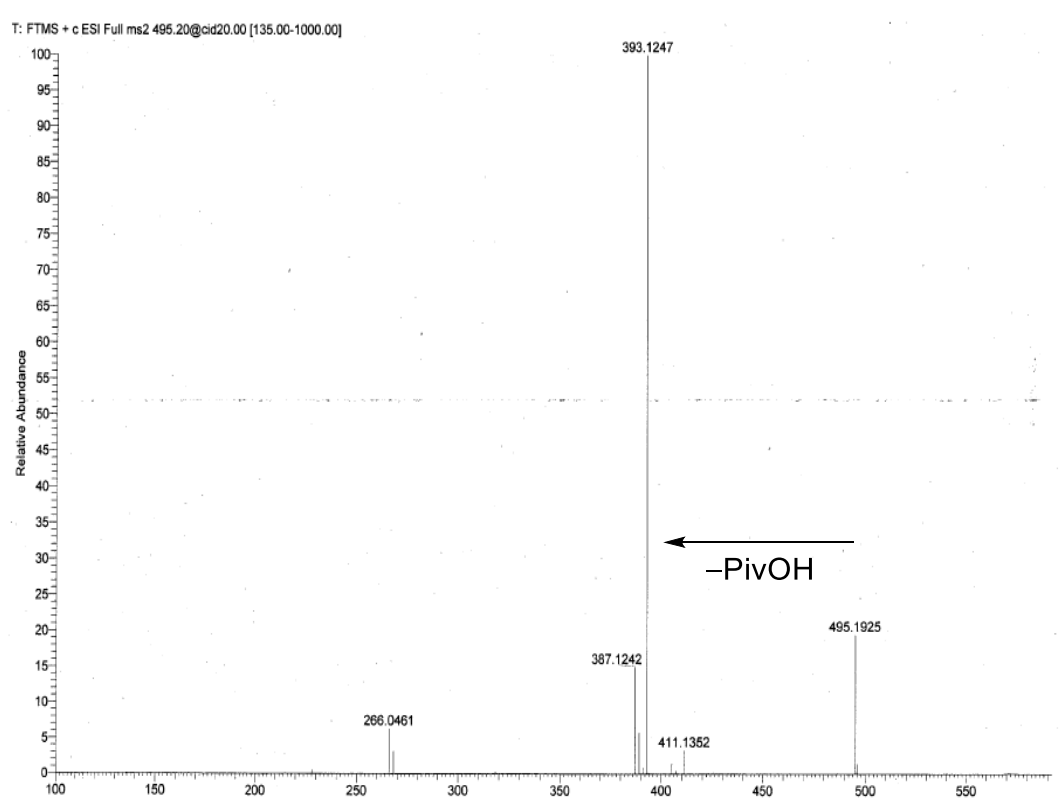

Figure 3.16 MS/MS spectra of the ion with $\mathrm{m} / \mathrm{z}$ 495.1925.

In addition to the previous experiments, CV studies were conducted on this reaction system. Initially, the reaction of internal alkyne $\mathbf{8 a}$ was studied, however the obtained spectra were inconclusive, as overlaying of the peaks occurred (Figure 3.17). In contrast, for terminal alkyne $\mathbf{8 b}$ also the use of methanol as the solvent was possible, therefore a second measurement using this system was performed, resulting in better data. While the alkyne $\mathbf{8 b}$ itself is not oxidized, the hydrazide $\mathbf{2 1 5 a}$ is easily oxidized, even at lower potential than the cobalt catalyst, which is oxidized at $1.31 \mathrm{VSCE}$. However, the complete reaction mixture is shifted to lower potential than the starting material 215a, supporting the oxidation of cobalt(II) to cobalt(III) in the presence of the starting material at much lower potential of $0.99 \mathrm{VSCE}$. 

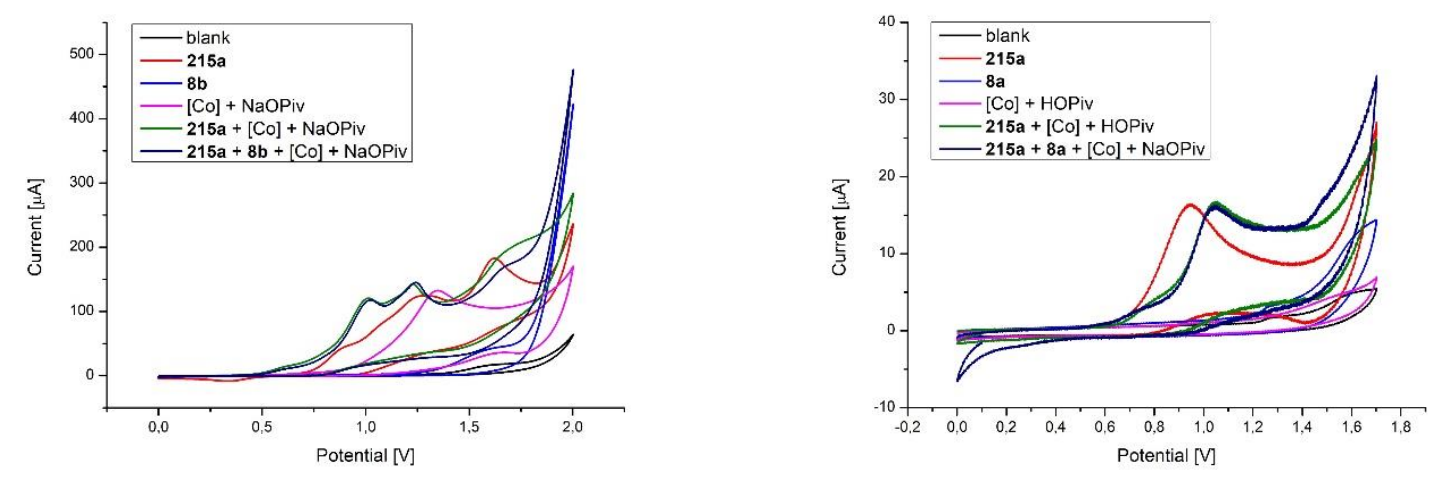

Figure $3.17 \mathrm{CV}$ spectra of the reaction mixtures in $\mathrm{MeOH}$ (left) and TFE (right).

\subsubsection{Rhodium-Catalyzed C-H/O-H Annulation of Benzoic Acids}

Rhodium is one of the most powerful metals for transition metal-catalyzed $\mathrm{C}-\mathrm{H}$ activation, ${ }^{31 \mathrm{c}, 31 \mathrm{~d}]}$ and while tremendous progress has been achieved, especially oxidative rhodium catalyzed reactions remain limited by the need for expensive stoichiometric oxidants ${ }^{[31 a, 316,32 a, 213]}$ with few exceptions utilizing hazardous $\mathrm{O}_{2}{ }^{[214]}$ as the terminal oxidant. ${ }^{[215]}$ In this regard, Dr. Y. Qiu and Dr. W.J. Kong developed a rhodium-catalyzed $\mathrm{C}-\mathrm{H} / \mathrm{O}-\mathrm{H}$ annulation of benzoic acids with acrylates under electrochemical conditions to avoid the need for costly chemical oxidants. ${ }^{[210]}$ The overall reaction equation is shown in scheme 3.26. As the optimization, scope and mechanistic studies were performed by my colleagues, only the CV studies shall be discussed here.

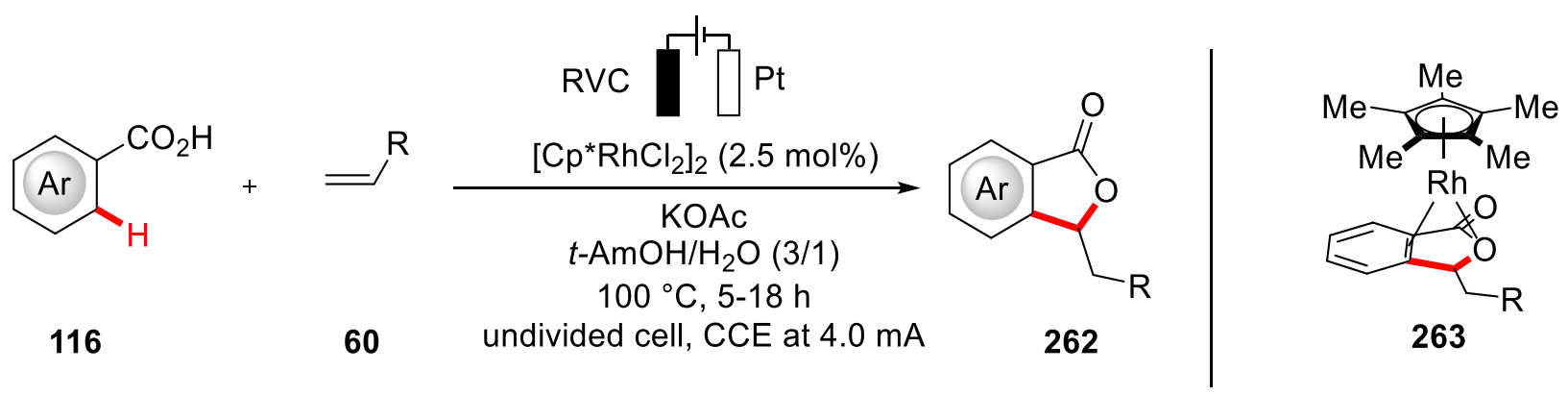

Scheme 3.26 Rhodium-catalyzed C-H/O-H annulation.

In this transformation the formation of rhodium(I) sandwich complex $\mathbf{2 6 3}$ is proposed as an intermediate. Experiments to synthesize a related complex by a known method proved to be unsuccessful.[216] Therefore, this step was studied in its microscopic 
reverse, e. g. a CV of the reductive region of $\left[\mathrm{Cp}^{*} \mathrm{RhCl}_{2}\right] 2$ in the absence and presence of the product 262 (Figure 3.18).

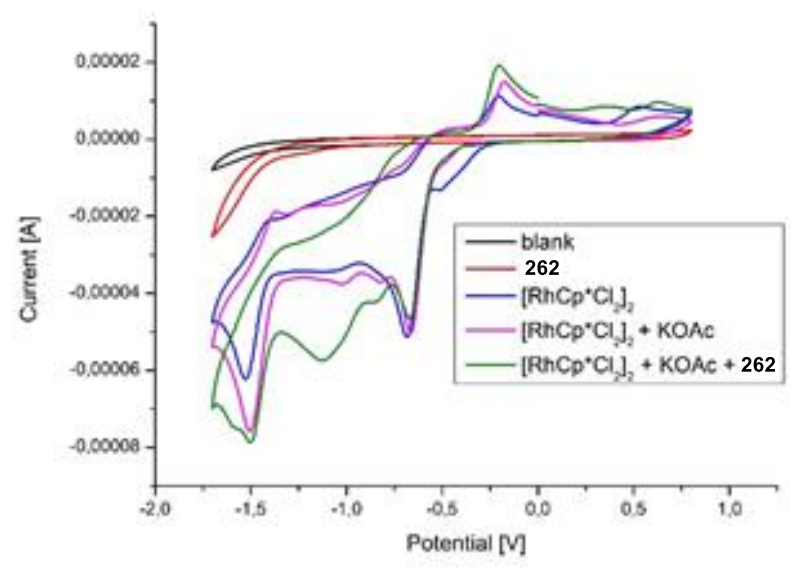

Figure 3.18 CV of $\left[\mathrm{Cp}^{*} \mathrm{RhCl}_{2}\right]_{2}$ under various conditions.

While the product 262 itself is not reduced under these conditions, $\left[\mathrm{Cp}^{*} \mathrm{RhCl}_{2}\right]_{2}$ shows clear reduction peaks, although the spectra are highly complex, and no assignment of the peaks is possible. Remarkably, no new signals upon addition of KOAc are observed, indicating that formation of the acetate complex may not occur under these conditions. Upon addition of the product however, a new peak at $-1.09 \mathrm{~V}_{\mathrm{SCE}}$ is observed.

As the generation of the acetate complex would be highly important, another measurement was conducted using HOAc as the additive instead of KOAc (Figure 3.19).

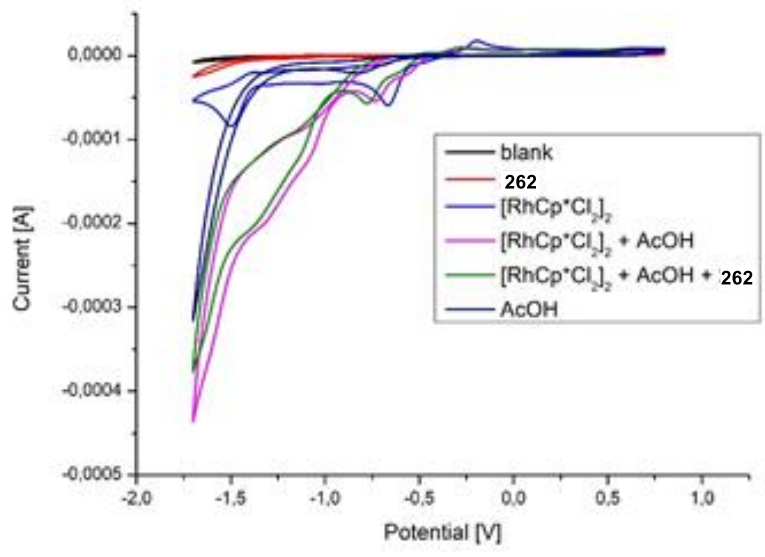

Figure $3.19 \mathrm{CV}$ spectra in the presence of HOAc. 
As can be seen in figure 3.16, there is a massive shift from the chloride dimer to a new $\mathrm{CV}$ curve after addition of $\mathrm{HOAc}$, indicating the formation of the acetate complex, as a control experiment showed no reduction of HOAc in this area. Unfortunately, this curve undergoes no significant change upon addition of the product, so that no prediction about the proposed intermediate is possible from these CV studies. 


\section{Summary and Outlook}

The sustainable and cost-efficient synthesis of key structural motifs for material sciences, medicinal chemistry and crop protection remains one of the biggest challenges in terms of declining resources and a heightened awareness of the ecological costs associated with many processes..$^{[3]}$ Therefore, $\mathrm{C}-\mathrm{H}$ activation greatly improves the tools for synthetic chemists to achieve these goals. ${ }^{[1 a}, 25 a, 25 c, 31 d, 32 c, 33 c$, 33d, 212c]

In the first project, the unprecedented use of triazolium salts 212 as preligands in cobalt-catalyzed $\mathrm{C}-\mathrm{H}$ activation, was examined based on a previously described reaction. ${ }^{[56]}$ The reaction proceeded by facile $\mathrm{C}-\mathrm{H} / \mathrm{C}-\mathrm{O}$ cleavage using easily accessible alkenyl acetates $\mathbf{4 0}$ and phosphates $\mathbf{4 1}$ (Scheme 4.1). ${ }^{217]}$

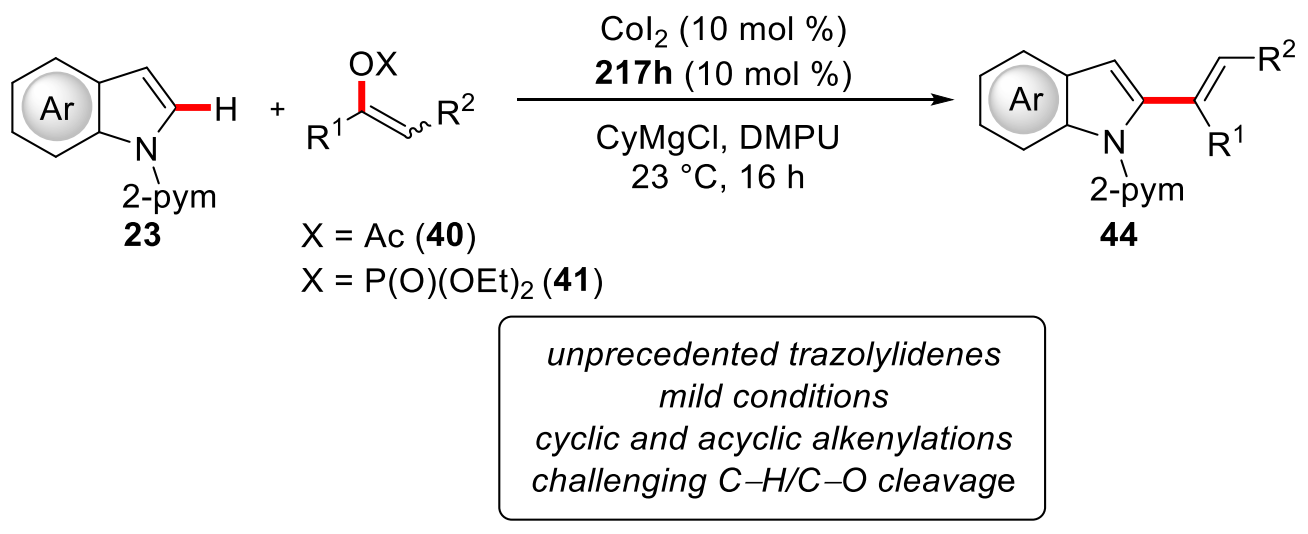

Scheme 4.1 Cobalt-catalyzed alkenylation by $\mathrm{C}-\mathrm{H} / \mathrm{O}-\mathrm{H}$ cleavage.

Compared to the known hydroarylation protocols, ${ }^{[57-61]}$ this approach allows for the use of cyclic alkenes, a structural motif that is usually not achieved using alkynes $\mathbf{8}$ due to the high ring strain. ${ }^{[176]}$ The yields achieved using triazolylidene $212 \mathrm{~h}$ are good, ${ }^{[217]}$ with excellent levels of selectivity for the $(E)$-configurated product. Although the formed products $\mathbf{4 4}$ do not contain a stereocenter, several chiral triazolylidenes are known and could prove applicable to future enantioselective processes.

In a second project, $\mathrm{Cp}{ }^{*} \mathrm{Co}$ (III) proved to be key to success for the efficient $\mathrm{C}-\mathrm{H}$ allylation of indoles 23 and pyrroles 217 (Scheme 4.2). ${ }^{\text {[79a] }}$ 


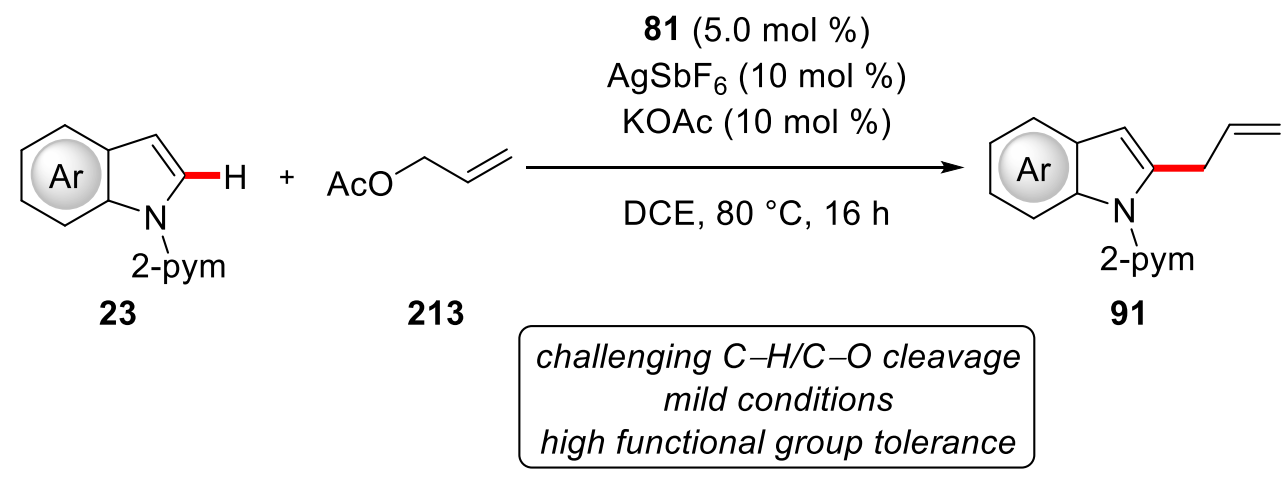

Scheme 4.2 Cobalt-catalyzed C-H allylation by $\mathrm{C}-\mathrm{H} / \mathrm{C}-\mathrm{O}$ cleavage.

Due to the high robustness of the $\mathrm{Cp}^{*} \mathrm{Co}$ (III)-catalyst, a good functional group tolerance could be established, especially in contrast to low-valent cobalt catalysis. ${ }^{[48 a]}$ Valuable functional groups, ${ }^{[79 a]}$ such as amide, nitro and halides, were well tolerated and highlighted the chemoselectivity of the $\mathrm{Cp}^{*} \mathrm{Co}(\mathrm{III})$-catalyst.

Cobalt(III)-catalysis was also used in the base metal-catalyzed $\mathrm{C}-\mathrm{H}$ alkynylation of heteroarenes 23 and 217 (Scheme 4.3). ${ }^{\text {194] }}$

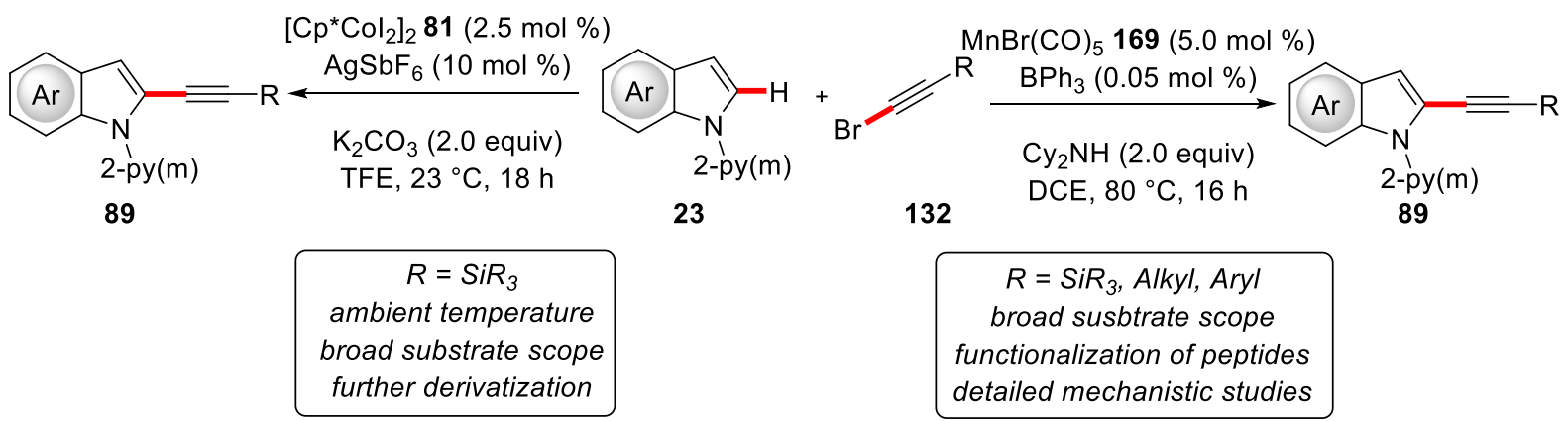

Scheme 4.3 Base metal-catalyzed C-H alkynylation of heteroarenes.

Initially, the $\mathrm{C}-\mathrm{H}$ alkynylation of indoles $\mathbf{2 3}$ and pyrroles $\mathbf{2 1 7}$ was realized using $\mathrm{Cp}^{*} \mathrm{Co}$ (III)-catalysis. The cobalt-catalyzed reaction proceeded under very mild conditions, that is at ambient temperature and a broad range of indoles and pyrroles could be functionalized. However, the reaction was limited to silyl substituted alkynes, as aryl or alkyl substituents did not provide any product. Finally, the usefulness the devised $\mathrm{C}-\mathrm{H}$ alkynylation could be highlighted by the derivatization of the synthesized products 89. Complementary to the cobalt-catalyzed $\mathrm{C}-\mathrm{H}$ alkynylation, a manganese(I)-catalyzed $\mathrm{C}-\mathrm{H}$ alkynylation with the same substrates was developed. [201] After extensive optimization, the transformation could be improved to include also alkyl and aryl alkynes 132, which were previously not suitable.[194] 
Furthermore, a broad substrate scope was established, ${ }^{[201]}$ including the functionalization of amino acids and peptides 226 without racemization (Scheme 4.4).

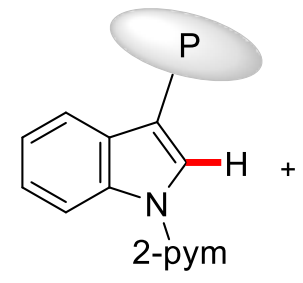

226

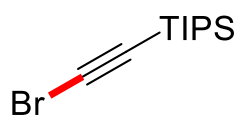

$132 a$

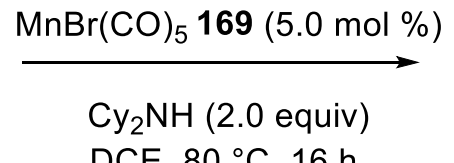

DCE, $80^{\circ} \mathrm{C}, 16 \mathrm{~h}$.

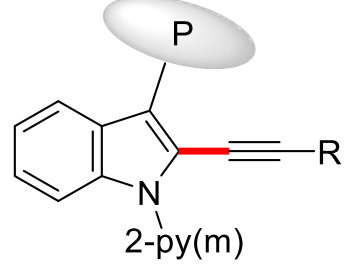

227

Scheme 4.4 Base metal-catalyzed $\mathrm{C}-\mathrm{H}$ alkynylation of peptides

Finally, detailed mechanistic studies were conducted. The reaction order for the substrates and the manganese catalyst were determined and offered support for the $\mathrm{C}-\mathrm{H}$ activation not being rate-determining. In addition, cyclometalated manganese complex $\mathbf{2 3 8}$ was isolated and identified as a competent catalyst for the reaction as well as suitable to form the product in stoichiometric reactionss suggesting that it is an on cycle intermediate.

In a fourth project, a cobalt-catalyzed $\mathrm{C}-\mathrm{H}$ oxygenation under electrochemical conditions was realized. ${ }^{[206]}$ While electrochemical $\mathrm{C}-\mathrm{H}$ activation using precious palladium catalysts is known, ${ }^{204,218]}$ this represents the first electrochemical cobaltcatalyzed C-H activation (Scheme 4.4).[206]

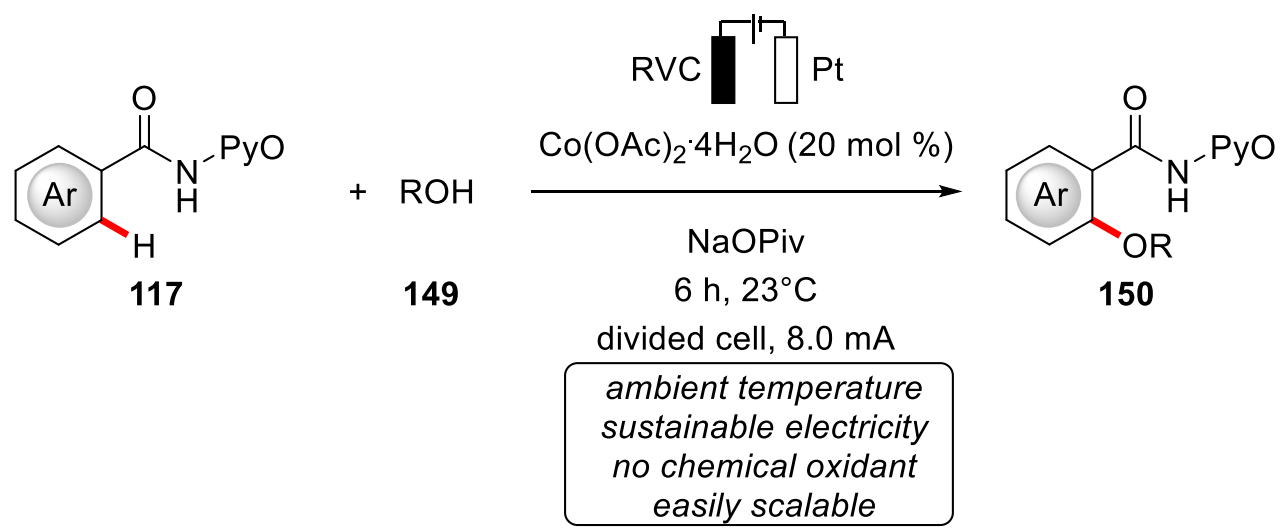

Scheme 4.4 Electrochemical cobalt-catalyzed C-H oxygenation.

The desired transformation could be realized under mild conditions, that is ambient temperature and using a mild base. The oxidative protocol was established using sustainable and cost-efficient electricity compared to previously employed stoichiometric amounts of silver(I)-salts as the terminal oxidant. The reaction was shown to tolerate various valuable functional groups, ${ }^{[206]}$ including oxidatively labile 
moieties. Additionally, several alcohols were found to be competent coupling partners. An enantiomerically pure alcohol was used and found to be stereochemically stable under the reaction conditions. Additionally, detailed mechanistic studies, including H/Dexchange experiments, KIE studies and competition experiments were conducted. Finally, the reaction was analyzed by $\mathrm{CV}$ and a plausible mechanism proposed. The synthetic significance was highlighted by the easy scaleup of the reaction and the userfriendly handling of this technique. While primary alcohols were transformed very efficiently, secondary alcohols only resulted in trace amounts of product, a venue that should allow for future optimization to realize more sophisticated substitution patterns. Moreover, the use of the alcohol as the reaction medium greatly reduces the efficacy and is also prohibitive for the use of solid alcohols, therefore the identification of a suitable inert reaction medium would be highly desirable.

Based on the $\mathrm{C}-\mathrm{H} / \mathrm{N}-\mathrm{H}$ annulation reported in the meantime, ${ }^{[168]}$ which involves an intramolecular $\mathrm{C}-\mathrm{N}$ bond formation, an intermolecular $\mathrm{C}-\mathrm{N}$ bond formation was devised (Scheme 4.5). ${ }^{[219]}$

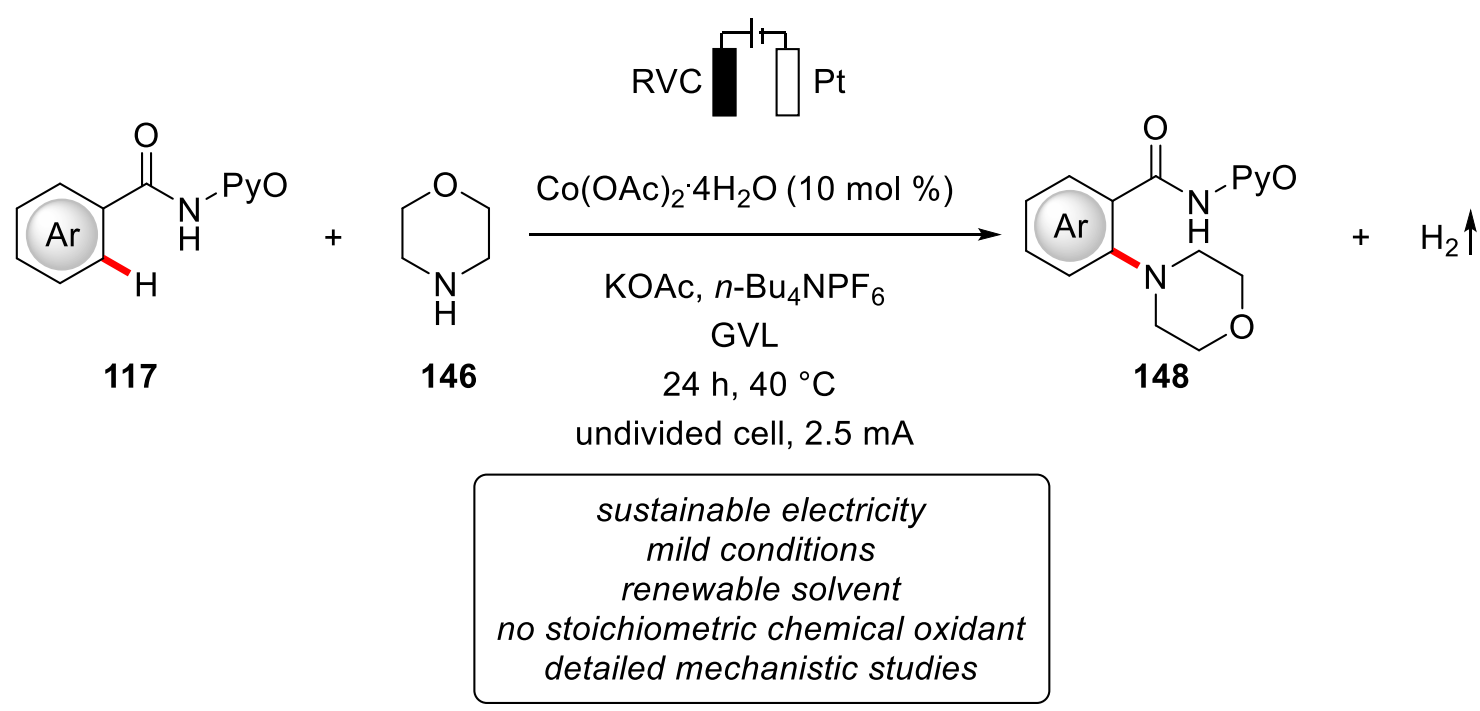

Scheme 4.5 Electrochemical cobalt-catalyzed C-H amination.

After considerable optimization, biomass-derived GV $\left[{ }^{[19,209]}\right.$ was identified as the best solvent. The reaction therefore was identified as the first electrochemical $\mathrm{C}-\mathrm{H}$ activation in a renewable solvent, highlighting the potential to further increase the sustainability of this approach. Again, mild conditions could be achieved for the reaction, ${ }^{[219]}$ including a reaction temperature of $40{ }^{\circ} \mathrm{C}$. Several substrates were smoothly converted, including important heterocyclic arenes. In operando studies by React IR were applied to electrocatalysis and showed the absence of a meaningful 
initiation period. Furthermore, a KIE measurement was performed by the same technique, in addition to standard mechanistic experiments, such as $\mathrm{H} / \mathrm{D}$ exchange. Moreover, the formation of $\mathrm{H}_{2}$ as the sole byproduct was confirmed by headspace $\mathrm{GC}$ analysis of the gas phase over the reaction mixture.

Finally, two projects from colleagues were supported with detailed CV studies under different conditions, ${ }^{[210]}$ as well as headspace analysis and extensive studies on potential intermediates by ESI-MS, ${ }^{[211]}$ and evidence for the key seven-membered intermediate 259 could be obtained. Furthermore, it could be shown that besides in situ IR technology also in situ UV/Vis was a viable method to record kinetic profiles for cobalt-catalyzed electrochemical $\mathrm{C}-\mathrm{H}$ activation, with future potential when suitable reactions are identified. 


\section{Experimental Part}

\subsection{General Remarks}

All rections involving air- and/or moisture-sensitive compounds were conducted under a nitrogen atmosphere using pre-dried glassware and standard Schlenk techniques. If not otherwise noted, yields refer to isolated compounds which were estimated to be $>95 \%$ pure based on ${ }^{1} \mathrm{H}-\mathrm{NMR}$ and/or GC analysis.

\subsubsection{Vacuum}

A Vacuubrand $R Z 6$ vacuum pump was used throughout the course of this thesis. The pressure was measured to be 0.7 mbar (uncorrected value).

\subsubsection{Chromatography}

Thin Layer Chromatography (TLC) was performed using silica gel $60 \mathrm{~F}_{254}$ on aluminum sheets from Merck and either visualized under a UV-Lamp or developed using basic $\mathrm{KMnO}_{4}$ solution or a vanillin stain upon careful heating. Purifcation of the compounds was carried out by column chromatography using Merck Geduran silica gel, grade 60 (40-63 $\mu \mathrm{m}, 70-230$ mesh).

\subsubsection{Gas Chromatography}

Monitoring of the reaction progress or kinetic analysis was conducted using a 7890 GC-system with or without mass detector 5975C (triple-axis-detector) or a 7890B GCsystem and a 5977A mass detector, both from Agilent Technologies.

Headspace analysis by GC was performed on a Shimadzu S2014 GC system using a thermal conductivity detector and a $5 \AA$ MS column. 


\subsubsection{Nuclear Magnetic Resonance}

Spectra were recorded on a Varian Unity 300, Mercury 300, Inova 500 or Bruker Avance III 300, Bruker Avance III HD 400 and Bruker Avance III HD 500 in the solvent indicated; chemical shifts $(\delta)$ are given in ppm relative to the residual solvent peak.

\begin{tabular}{c|c|c} 
& ${ }^{1} \mathrm{H}-\mathrm{NMR}$ & ${ }^{13} \mathrm{C}-\mathrm{NMR}$ \\
\hline $\mathrm{CDCl}_{3}$ & 7.26 & 77.16 \\
$\mathrm{DMSO} \mathrm{d}_{6}$ & 2.50 & 39.52
\end{tabular}

Analysis of the obtained spectra was conducted using MestreNova 10 software.

\subsubsection{Mass Spectrometry}

EI-MS-spectra were recorded on an AccuTOF from JEOL, ESI-MS- and HRMSspectra were recorded on a microTOF or maXis from Bruker Daltonic. The ratio of mass to charge $(\mathrm{m} / \mathrm{z})$ are indicated and the intensities relative to the highest peak $(I=$ $100)$ are given in parentheses.

\subsubsection{Melting Points}

Melting points were measured on a Stuart melting point apparatus SMP3, Barloworld Scientific, values are uncorrected.

\subsubsection{Infrared Spectroscopy}

IR spectra were recorded on a Bruker FT-IR Alpha device. Liquid samples were measured as a film and solid samples neat, spectra were recorded in the range of $4000-400 \mathrm{~cm}^{-1}$, absorption is given in wavenumbers $\left(\mathrm{cm}^{-1}\right)$.

In-situ IR measurements were carried out using the React-IR15 from Mettler Toledo equipped with a diamond probe. 


\subsubsection{Electrochemistry}

Platinum electrodes $\left(10 \mathrm{~mm} \times 15 \mathrm{~mm} \times 0.25 \mathrm{~mm}, 99.9 \%\right.$; obtained from ChemPur $^{\circledR}$ Karlsruhe, Germany) and RVC electrodes (10 mm $\times 15 \mathrm{~mm} \times 6 \mathrm{~mm}$, SIGRACELL ${ }^{\circledR} \mathrm{GFA}$ 6 EA, obtained from SGL Carbon, Wiesbaden, Germany) were connected using stainless steel adapters. Electrolysis was conducted using an AXIOMET AX-3003P potentiostat in constant current mode, CV studies were performed using a Metrohm Autolab PGSTAT204 workstation and Nova 2.0 software. Divided cells separated by a P4-glassfrit were obtained from Glasgerätebau Ochs Laborfachhandel e. K. (Bovenden, Germany).

\subsubsection{Solvents}

Solvents for column chromatography or reactions not sensitive to air and moisture were distilled under reduced pressure prior to use. All solvents for reactions involving air- or moisture sensitive compounds were dried, distilled and stored under inert atmosphere according to the following procedures:

Purified by solvent purification system (SPS-800, M. Braun): $\mathrm{CH}_{2} \mathrm{Cl}_{2}$, toluene, tetrahydrofuran, dimethylformamide, diethylether.

Dried and distilled over sodium/benzophenone: tert-Amylalcohol, methanol, 1,4dioxane.

Dried and distilled over $\mathrm{CaH}_{2}$ : 1,3-Dimethyltetrahydropyrimidin-2(1H)-one, 1,2Dichlorethan.

Degassed and stored over activated molecular sieves: $\gamma$-Valerolactone, acetonitrile.

\subsubsection{Chemicals}

Chemicals obtained from commercial sources with a purity $>95 \%$ were used as received without further purification. The following compounds were known from the literature and synthesized according to previously known methods:

(pyrimidine-2-yl)-indoles 23 and pyrroles 217, ${ }^{[200]}$ alkenyl acetates 40,[55a] alkenyl phosphates $41,{ }^{[55 b]}$ alkenyl carbonate $42 b$, ${ }^{[55 c]}$ alkenyl carbamate $43 b,{ }^{[55 d]}$ triazolium 
salt 212a, ${ }^{[177]} \mathrm{Cp}^{*} \mathrm{Col}_{2}(\mathrm{CO})(81),{ }^{[87]}\left[\mathrm{Cp}{ }^{*} \mathrm{Co}\left(\mathrm{C}_{6} \mathrm{H}_{6}\right)\right]\left[\mathrm{PF}_{6}\right] 2(73),{ }^{[67]}\left[\mathrm{Cp}^{*} \mathrm{Col}_{2}\right]_{2}(82),{ }^{[218]}$ bromoalkynes $132,{ }^{[221]}$ benzamides $117^{[99]}$ and alcohol 149g. ${ }^{[222]}$

The following compounds were kindly synthesized and provided by the persons listed below:

Joachim Loup: triazolium salt $\mathbf{2 1 2 d .}$

Marc Moselage: alkenyl acetates 40b, 40j and 40k.

Tjark H. Meyer: amides 117a, 117o, 117q and 117k.

Ruhuai Mei: hydrazide 215a.

Berkessel group: triazolium salts $\mathbf{2 1 2 b}, \mathbf{c}, \mathbf{e}-\mathbf{h}$.

Sier Sang: amides 117a, 117c, 117e and 117j.

Elisabetta Manoni: indoles 23k, 230 and alkyne 132d.

\subsection{General Procedures}

General Procedure A for the Cobalt-Catalzed $\mathbf{C}-\mathbf{H} / \mathbf{C}-\mathbf{O}$ Alkenylation: To a solution of 23 ( $0.25 \mathrm{mmol}, 1.00$ equiv), the enol derivative 40 or 41 (0.38 mmol, 1.50 equiv), $\mathrm{Col}_{2}(7.8 \mathrm{mg}, 25.0 \mu \mathrm{mol}, 10 \mathrm{~mol} \%)$ and triazolium salt $212 \mathrm{~h}(13.1 \mathrm{mg}$, $25.0 \mu \mathrm{mol}, 10 \mathrm{~mol} \%)$ in DMPU $(1.5 \mathrm{~mL}), \mathrm{CyMgCl}(1.7 \mathrm{M}$ in THF, $0.3 \mathrm{~mL}, 0.50 \mathrm{mmol}$, 2.00 equiv) was added dropwise. The mixture was stirred for $16 \mathrm{~h}$ at $23^{\circ} \mathrm{C}$. After completion of the reaction, saturated aq. $\mathrm{NH}_{4} \mathrm{Cl}$ solution $(10 \mathrm{~mL})$ was added and the mixture was extracted with $\mathrm{CH}_{2} \mathrm{Cl}_{2}(3 \times 5 \mathrm{~mL})$. Drying over $\mathrm{Na}_{2} \mathrm{SO}_{4}$, evaporation of the solvents and purification by column chromatography on silica gel yielded the product 44.

General Procedure B for the Cobalt-Catalyzed Allylation: To a solution of 23 (0.50 mmol, 1.00 equiv), $\left[\mathrm{Cp}^{*} \mathrm{Co}(\mathrm{CO}) \mathrm{I}_{2}\right]$ (81) $(25.0 \mu \mathrm{mol}, 5.0 \mathrm{~mol} \%), \quad \mathrm{AgSbF} 6$ $(0.05 \mathrm{mmol}, 10 \mathrm{~mol} \%)$ and KOAc $(0.05 \mathrm{mmol}, 10 \mathrm{~mol} \%)$ in DCE (1.5 mL) allyl acetate $213\left(1.00 \mathrm{mmol}, 2.00\right.$ equiv) was added. The mixture was stirred for $16 \mathrm{~h}$ at $80^{\circ} \mathrm{C}$. After completion of the reaction, saturated aq. $\mathrm{NH}_{4} \mathrm{Cl}$ solution $(5 \mathrm{~mL})$ was added at ambient temperature and the mixture was extracted with MTBE $(4 \times 5 \mathrm{~mL})$. Drying over 
$\mathrm{Na}_{2} \mathrm{SO}_{4}$, evaporation of the solvents and purification by column chromatography on silica gel or further preparative HPLC using $n$-hexane/EtOAc yielded the product 91 .

General Procedure $\mathbf{C}$ for the Cobalt-Catalyzed $\mathbf{C}-\mathbf{H}$ Alkynylation: To a solution of 23 (0.25 mmol, 1.00 equiv), [ $\left.\mathrm{Cp}^{*} \mathrm{Col}_{2}\right]_{2}$ (82) $(6.25 \mu \mathrm{mol}, 2.5 \mathrm{~mol} \%), \mathrm{AgSbF}_{6}$ $(25.0 \mu \mathrm{mol}, 10 \mathrm{~mol} \%)$ and $\mathrm{K}_{2} \mathrm{CO}_{3}(0.50 \mathrm{mmol}, 2.00$ equiv) in TFE $(1.5 \mathrm{~mL}) 132$ ( $0.30 \mathrm{mmol}, 1.20$ equiv) was added. The mixture was stirred for $18 \mathrm{~h}$ at $25^{\circ} \mathrm{C}$. After completion of the reaction saturated aq. $\mathrm{NH}_{4} \mathrm{Cl}$ solution $(5 \mathrm{~mL})$ was added and the mixture was extracted with $\mathrm{CH}_{2} \mathrm{Cl}_{2}(4 \times 5 \mathrm{~mL})$. Drying over $\mathrm{Na}_{2} \mathrm{SO}_{4}$, evaporation of the solvents and purification by column chromatography on silica gel using $n$ pentane/EtOAc yielded the product $\mathbf{8 9}$.

General Procedure D for the Manganese-Catalyzed C-H Alkynylation using Silylalkynes: To a solution of substrates 23 ( $0.50 \mathrm{mmol}, 1.00$ equiv), $\operatorname{MnBr}(\mathrm{CO})_{5}$ (169) (6.9 mg, $5.0 \mathrm{~mol} \%$ ) and $\mathrm{Cy}_{2} \mathrm{NH}$ (181 mg, $1.00 \mathrm{mmol}, 2.00$ equiv) in DCE (1.0 mL), silyl bromoalkynes 132 ( $0.60 \mathrm{mmol}, 1.20$ equiv) was added. The mixture was stirred at $80{ }^{\circ} \mathrm{C}$ for $16 \mathrm{~h}$. After completion of the reaction, $\mathrm{CH}_{2} \mathrm{Cl}_{2}(3.0 \mathrm{~mL})$ was added at ambient temperature and the volatiles were removed in vacuo. Purification by chromatography on silica gel afforded the desired product 89.

General Procedure E for the Manganese-Catalyzed C-H Alkynylation: To a solution of substrates 23 (0.50 mmol, 1.00 equiv), $\operatorname{MnBr}(\mathrm{CO})_{5}$ (169) $(6.9 \mathrm{mg}$, $5.0 \mathrm{~mol} \%$ ), Сy $2 \mathrm{NH}$ (181 mg, $1.00 \mathrm{mmol}, 2.00$ equiv) and $\mathrm{BPh}_{3}(25 \mu \mathrm{L}, 0.05 \mathrm{~mol} \%$, $0.01 \mathrm{M}$ stock solution in DCE) in DCE (1 mL), aryl or alkyl bromoalkynes 132 ( $0.60 \mathrm{mmol}, 1.20$ equiv) was added. The mixture was stirred at $80{ }^{\circ} \mathrm{C}$ for $16 \mathrm{~h}$. After completion of the reaction, $\mathrm{CH}_{2} \mathrm{Cl}_{2}(3 \mathrm{~mL})$ was added at ambient temperature and the volatiles were removed in vacuo. Purification by chromatography on silica gel afforded the desired product 89 .

General Procedure F for Electrochemical C-H Alkoxylation: The electrolysis was carried out in an $\mathrm{H}$-type divided cell (P4 sintered glass membrane), with a RVC anode $(10 \mathrm{~mm} \times 15 \mathrm{~mm} \times 6 \mathrm{~mm})$ and a platinum cathode $(10 \mathrm{~mm} \times 15 \mathrm{~mm} \times 0.25 \mathrm{~mm})$. NaOPiv (122 mg, $1.00 \mathrm{mmol}, 2.00$ equiv) was added in the cathodic chamber and dissolved in alcohol $149(7.0 \mathrm{~mL})$. The anodic chamber was charged with $\mathrm{Co}(\mathrm{OAc}) 2 \cdot 4 \mathrm{H}_{2} \mathrm{O}(25.7 \mathrm{mg}, 0.10 \mathrm{mmol}, 20 \mathrm{~mol} \%)$, NaOPiv (122 mg, $1.00 \mathrm{mmol}, 2.00$ equiv) and benzamide 117 (0.50 mmol, 1.00 equiv) and dissolved in alcohol 149 $(7.0 \mathrm{~mL})$. Electrolysis was started at ambient temperature with a constant current of 
8.0 $\mathrm{mA}$ maintained for $6 \mathrm{~h}$. Evaporation of the solvent and subsequent column chromatography on silica gel $\left(\mathrm{CH}_{2} \mathrm{Cl}_{2} /\right.$ acetone $)$ yielded the desired product 150 .

General Procedure G for Electrochemical C-H Alkoxylation: The electrolysis was carried out in an undivided cell, with a RVC anode $(10 \mathrm{~mm} \times 15 \mathrm{~mm} \times 6 \mathrm{~mm})$ and a platinum cathode $(10 \mathrm{~mm} \times 15 \mathrm{~mm} \times 0.25 \mathrm{~mm})$. A mixture of NaOPiv $(63.9 \mathrm{mg}$, $0.50 \mathrm{mmol}, 2.00$ equiv), $\mathrm{Co}(\mathrm{OAc})_{2} \cdot 4 \mathrm{H}_{2} \mathrm{O}$ (12.7 mg, $\left.0.05 \mathrm{mmol}, 20 \mathrm{~mol} \%\right)$, benzamide 117 ( $0.25 \mathrm{mmol}, 1.00$ equiv), $n$-Bu4NPF 6 (387 mg, $1.00 \mathrm{mmol}, 4.00$ equiv.) and alcohol $149(2.3 \mathrm{~mL})$ in $\mathrm{MeCN}(0.9 \mathrm{~mL})$ was added to the electrochemical cell. Electrolysis was started at ambient temperature with a constant current of $2.0 \mathrm{~mA}$ maintained for $12 \mathrm{~h}$. Evaporation of the solvent and subsequent column chromatography on silica gel $\left(\mathrm{CH}_{2} \mathrm{Cl}_{2} /\right.$ acetone) yielded the desired product 150 .

General Procedure $\mathbf{H}$ for the Electrochemical C-H Amination: The electrolysis was carried out in an undivided cell, with a RVC anode $(10 \mathrm{~mm} \times 15 \mathrm{~mm} \times 6 \mathrm{~mm})$ and a platinum cathode $(10 \mathrm{~mm} \times 15 \mathrm{~mm} \times 0.25 \mathrm{~mm}) \cdot \mathrm{Co}(\mathrm{OAc}) 2 \cdot 4 \mathrm{H}_{2} \mathrm{O}(12.7 \mathrm{mg}, 0.05 \mathrm{mmol}$, $10 \mathrm{~mol} \%$ ), KOAc (149 mg, $1.50 \mathrm{mmol}, 3.00$ equiv) and benzamide 117 (0.50 mmol, 1.00 equiv) were dissolved in GVL $(2.0 \mathrm{~mL})$ and then the amine $146(1.00 \mathrm{mmol}, 2.00$ equiv) was added. After heating to $40{ }^{\circ} \mathrm{C}$, electrolysis was started with a constant current of $2.5 \mathrm{~mA}$ which was then maintained for $24 \mathrm{~h}$. After $24 \mathrm{~h}$, the mixture was transferred to a flask and the electrodes were rinsed with acetone $(3 \times 5.0 \mathrm{~mL})$. Then the combined solvent was removed under reduced pressure, the residue diluted with EtOAc $(10 \mathrm{~mL})$ and washed with $\mathrm{NaOH}_{(\mathrm{aq})}(2 \mathrm{M}, 10 \mathrm{~mL})$ and $\mathrm{H}_{2} \mathrm{O}(2 \times 10 \mathrm{~mL})$. Drying over $\mathrm{Na}_{2} \mathrm{SO}_{4}$ and evaporation of the solvent and subsequent column chromatography on silica gel $\left(\mathrm{CH}_{2} \mathrm{Cl}_{2} /\right.$ acetone $)$ yielded the desired product 148 . 


\subsection{Cobalt-Catalyzed C-H Alkenylation under Triazole Assistance}

\subsubsection{Analytical Data and Experimental Procedures}<smiles>CCCCC=Cc1cc2ccccc2n1-c1ccccn1</smiles>

\section{(E)-2-(1-Phenylpent-1-en-1-yl)-1-(pyrimidin-2-yl)-1 H-indole (44aa)}

The general procedure A was followed using indole 23a $(49.7 \mathrm{mg}, 0.25 \mathrm{mmol}$, 1.00 equiv) and enol acetate $40 \mathrm{a}(78.5 \mathrm{mg}, 0.38 \mathrm{mmol}, 1.50$ equiv, $E / Z=24 / 76)$. Purification by column chromatography on silica gel ( $n$-pentane/EtOAc 25:1) yielded 44aa (44.7 mg, $129 \mu \mathrm{mol}, 52 \%)$ as a yellow oil. ${ }^{1} \mathrm{H}-\mathrm{NMR}\left(300 \mathrm{MHz}, \mathrm{CDCl}_{3}\right): \delta=8.55$ $(\mathrm{d}, J=5.0 \mathrm{~Hz}, 2 \mathrm{H}), 8.03-7.99(\mathrm{~m}, 1 \mathrm{H}), 7.61-7.57(\mathrm{~m}, 1 \mathrm{H}), 7.23-7.18(\mathrm{~m}, 2 \mathrm{H}), 7.11-$ $7.01(\mathrm{~m}, 5 \mathrm{H}), 6.88(\mathrm{t}, J=5.0 \mathrm{~Hz}, 1 \mathrm{H}), 6.72(\mathrm{~s}, 1 \mathrm{H}), 6.15(\mathrm{t}, J=7.0 \mathrm{~Hz}, 1 \mathrm{H}), 2.29$ (dt, $J=7.0,5.5 \mathrm{~Hz}, 2 \mathrm{H}$ ), 1.49 (tq, $J=6.2,5.5 \mathrm{~Hz}, 2 \mathrm{H}), 0.90$ (t, $J=6.2 \mathrm{~Hz}, 3 \mathrm{H}) .{ }^{13} \mathrm{C}-\mathrm{NMR}$ $\left(125 \mathrm{MHz}, \mathrm{CDCl}_{3}\right): \delta=157.9(\mathrm{CH}), 157.6\left(\mathrm{C}_{\mathrm{q}}\right), 142.8\left(\mathrm{C}_{\mathrm{q}}\right), 138.8\left(\mathrm{C}_{\mathrm{q}}\right), 137.7\left(\mathrm{C}_{\mathrm{q}}\right), 134.5$ $\left(\mathrm{C}_{\mathrm{q}}\right), 132.3(\mathrm{CH}), 129.8(\mathrm{CH}), 129.0\left(\mathrm{C}_{\mathrm{q}}\right), 127.4(\mathrm{CH}), 126.6(\mathrm{CH}), 123.3(\mathrm{CH}), 121.9$ $(\mathrm{CH}), 120.4(\mathrm{CH}), 117.0(\mathrm{CH}), 113.0(\mathrm{CH}), 108.8(\mathrm{CH}), 31.5\left(\mathrm{CH}_{2}\right), 23.4\left(\mathrm{CH}_{2}\right), 14.1$ $\left(\mathrm{CH}_{3}\right)$. IR (ATR): 2949, 2870, 1570, 1423, 1319, 1258, 1073, 852, $734 \mathrm{~cm}^{-1}$. MS (ESI) $m / z$ (relative intensity): $362(27)[\mathrm{M}+\mathrm{Na}]^{+}, 340(100)[\mathrm{M}+\mathrm{H}]^{+}, 297(30), 257$ (7), 117 (42). HR-MS (ESI) $\mathrm{m} / z$ calcd for $\mathrm{C}_{23} \mathrm{H}_{21} \mathrm{~N}_{3}[\mathrm{M}+\mathrm{H}]^{+}: 340.1808$, found: 340.1818 . The analytical data correspond with those reported in literature. ${ }^{[56]}$<smiles>C1=C(c2cc3ccccc3n2-c2ncccn2)CCCC1</smiles>

\section{2-(Cyclohex-1-en-1-yl)-1-(pyrimidin-2-yl)-1 H-indole (44ab)}

The general procedure A was followed using indole 23a $(49.5 \mathrm{mg}, 0.25 \mathrm{mmol}$, 1.00 equiv) and enol acetate $40 \mathrm{~b}(62.1 \mathrm{mg}, 0.38 \mathrm{mmol}, 1.50$ equiv). Purification by column chromatography on silica gel ( $n$-pentane/EtOAc 20:1) yielded 44ab (56.3 mg, $204 \mu \mathrm{mol}, 80 \%$ ) as a yellow oil. Alternative preparations under otherwise identical conditions using enol phosphate $41 \mathrm{~b}$ ( $88.7 \mathrm{mg}, 0.38 \mathrm{mmol}, 1.50$ equiv) yielded 44ab (58.1 mg, $211 \mu \mathrm{mol}, 84 \%$ ), using enol carbonate $42 \mathrm{~b}$ (64.7 mg, $0.38 \mathrm{mmol}, 1.50$ equiv) 
yielded 44ab (36.7 mg, $129 \mu \mathrm{mol}, 52 \%)$, using enol carbamate 43b (64.4 mg, $0.38 \mathrm{mmol}, 1.50$ equiv) yielded 44ab (52.0 mg, $188 \mu \mathrm{mol}, 75 \%)$. ${ }^{1} \mathrm{H}-\mathrm{NMR}(300 \mathrm{MHz}$, $\left.\mathrm{CDCl}_{3}\right): \delta=8.68(\mathrm{~d}, J=4.1 \mathrm{~Hz}, 2 \mathrm{H}), 8.18-8.15(\mathrm{~m}, 1 \mathrm{H}), 7.59-7.56(\mathrm{~m}, 1 \mathrm{H}), 7.27-7.18$ (m, 2H), $7.11(\mathrm{t}, J=4.1 \mathrm{~Hz}, 1 \mathrm{H}), 6.55(\mathrm{~s}, 1 \mathrm{H}), 5.88(\mathrm{~m}, 1 \mathrm{H}), 2.20-2.17(\mathrm{~m}, 2 \mathrm{H}), 2.09$ $2.05(\mathrm{~m}, 2 \mathrm{H}), 1.68-1.64(\mathrm{~m}, 4 \mathrm{H}) .{ }^{13} \mathrm{C}-\mathrm{NMR}\left(125 \mathrm{MHz}, \mathrm{CDCl}_{3}\right): \delta=158.4\left(\mathrm{C}_{\mathrm{q}}\right), 158.2$ $(\mathrm{CH}), 143.0\left(\mathrm{C}_{\mathrm{q}}\right), 137.3\left(\mathrm{C}_{\mathrm{q}}\right), 132.0\left(\mathrm{C}_{\mathrm{q}}\right), 129.1\left(\mathrm{C}_{\mathrm{q}}\right), 126.9(\mathrm{CH}), 122.7(\mathrm{CH}), 121.8$ $(\mathrm{CH}), 120.0(\mathrm{CH}), 117.5(\mathrm{CH}), 112.8(\mathrm{CH}), 106.0(\mathrm{CH}), 28.8\left(\mathrm{CH}_{2}\right), 25.4\left(\mathrm{CH}_{2}\right), 22.7$ $\left(\mathrm{CH}_{2}\right), 22.3\left(\mathrm{CH}_{2}\right)$. IR (ATR): 2931, 1555, 1450, 1344, 1322, 794, 739, 718, $619 \mathrm{~cm}^{-1}$. MS (ESI) $m / z$ (relative intensity): $298(40)[\mathrm{M}+\mathrm{Na}]^{+}, 276(100)[\mathrm{M}+\mathrm{H}]^{+}, 247(22), 219$ (8). HR-MS (ESI) $\mathrm{m} / z$ calcd for $\mathrm{C}_{18} \mathrm{H}_{17} \mathrm{~N}_{3}[\mathrm{M}+\mathrm{H}]^{+}: 276.1501$, found: 276.1497 . The analytical data correspond with those reported in literature.[5]

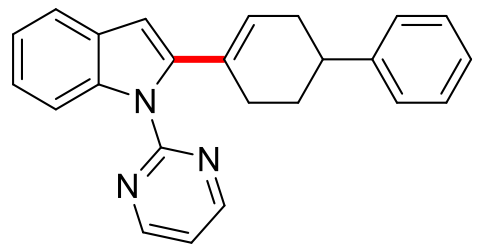

\section{1-(Pyrimidin-2-yl)-2-(1,2,3,6-tetrahydro-[1,1'-biphenyl]-4-yl)-1H-indole (44ac)}

The general procedure A was followed using indole 23a $(49.5 \mathrm{mg}, 0.25 \mathrm{mmol}$, 1.00 equiv) and enol phosphate $41 \mathrm{c}$ (106 mg, $0.38 \mathrm{mmol}, 1.50$ equiv). Purification by column chromatography on silica gel ( $n$-pentane/EtOAc $13: 1)$ yielded $44 \mathrm{ac}(71.3 \mathrm{mg}$, $202 \mu \mathrm{mol}, 81 \%)$ as a yellow solid. An alternative procedure using enol acetate 40c (82.1 mg, $0.38 \mathrm{mmol}, 1.50$ equiv) yielded 44ac (68.9 mg, $194 \mu \mathrm{mol}, 78 \%$ ) as a yellow oil.M. p. $=140-143^{\circ} \mathrm{C} .{ }^{1} \mathrm{H}-\mathrm{NMR}\left(300 \mathrm{MHz}, \mathrm{CDCl}_{3}\right): \delta=8.78(\mathrm{~d}, J=4.8 \mathrm{~Hz}, 2 \mathrm{H}), 8.17$ $(\mathrm{m}, 1 \mathrm{H}), 7.60(\mathrm{~m}, 1 \mathrm{H}), 7.34-7.20(\mathrm{~m}, 6 \mathrm{H}), 7.13(\mathrm{t}, J=4.8 \mathrm{~Hz}, 1 \mathrm{H}), 6.62(\mathrm{~s}, 1 \mathrm{H}), 5.97-$ $5.96(\mathrm{~m}, 1 \mathrm{H}), 2.97-2.89(\mathrm{~m}, 1 \mathrm{H}), 2.50-2.42(\mathrm{~m}, 1 \mathrm{H}), 2.37-2.27(\mathrm{~m}, 2 \mathrm{H}), 2.20-2.15(\mathrm{~m}$, 1H), 2.00-1.78 (m, 2H). ${ }^{13} \mathrm{C}-\mathrm{NMR}\left(125 \mathrm{MHz}, \mathrm{CDCl}_{3}\right): \delta=158.3\left(\mathrm{C}_{\mathrm{q}}\right), 158.1(\mathrm{CH}), 146.7$ $\left(\mathrm{C}_{\mathrm{q}}\right), 142.7\left(\mathrm{C}_{\mathrm{q}}\right), 137.4\left(\mathrm{C}_{\mathrm{q}}\right), 131.7\left(\mathrm{C}_{\mathrm{q}}\right), 129.2\left(\mathrm{C}_{\mathrm{q}}\right), 128.3(\mathrm{CH}), 126.8(\mathrm{CH}), 126.4$ (CH), $126.0(\mathrm{CH}), 123.0(\mathrm{CH}), 121.9(\mathrm{CH}), 120.2(\mathrm{CH}), 117.2(\mathrm{CH}), 113.1(\mathrm{CH}), 106.4$ (CH), $39.8(\mathrm{CH}), 33.8\left(\mathrm{CH}_{2}\right), 29.9\left(\mathrm{CH}_{2}\right), 29.4\left(\mathrm{CH}_{2}\right)$. IR (ATR): 2918, 2845, 2005, 1563, 1424, 1350, $1070 \mathrm{~cm}^{-1}$. MS (ESI) $\mathrm{m} / z$ (relative intensity): 374 (40) [M+Na] $]^{+}, 352$ (100) $[\mathrm{M}+\mathrm{H}]^{+}, 323$ (8), 309 (73), 269 (5), 231 (9). HR-MS (ESI) m/z calcd for $\mathrm{C}_{24} \mathrm{H}_{21} \mathrm{~N}_{3}$ $[\mathrm{M}+\mathrm{H}]^{+}: 352.1808$, found: 352.1805 . The analytical data correspond with those reported in literature. ${ }^{[56]}$ 


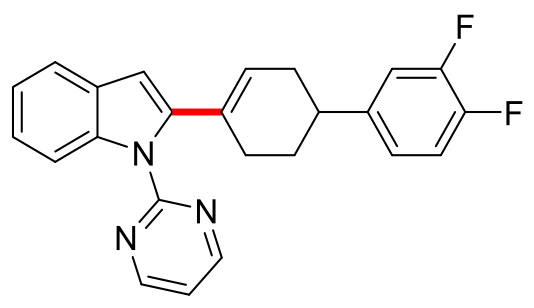

\section{2-(3',4'-Difluoro-1,2,3,6-tetrahydro-[1,1'-biphenyl]-4-yl)-1-(pyrimidin-2-yl)-1H- indole (44ad)}

The general procedure A was followed using indole 23a $(49.7 \mathrm{mg}, 0.25 \mathrm{mmol}$, 1.00 equiv) and enol phosphate $41 \mathrm{~d}$ (131 $\mathrm{mg}, 0.38 \mathrm{mmol}, 1.50$ equiv). Purification by column chromatography on silica gel ( $n$-pentane/EtOAc 14:1) yielded 44ad $(67.2 \mathrm{mg}$, $171 \mathrm{mmol}, 69 \%)$ as a yellow oil. ${ }^{1} \mathrm{H}-\mathrm{NMR}\left(300 \mathrm{MHz}, \mathrm{CDCl}_{3}\right): \delta=8.80(\mathrm{~d}, J=5.0 \mathrm{~Hz}$, $2 \mathrm{H}), 8.21(\mathrm{~d}, J=8.1 \mathrm{~Hz}, 1 \mathrm{H}), 7.56(\mathrm{~d}, J=8.1 \mathrm{~Hz}, 1 \mathrm{H}), 7.27-7.20(\mathrm{~m}, 2 \mathrm{H}), 4.12(\mathrm{t}$, $J=5.0 \mathrm{~Hz}, 1 \mathrm{H}), 7.12-7.08(\mathrm{~m}, 2 \mathrm{H}), 6.97-6.94(\mathrm{~m}, 1 \mathrm{H}), 6.60(\mathrm{~s}, 1 \mathrm{H}), 5.94-5.92(\mathrm{~m}$, $1 \mathrm{H}), 2.89-2.84(\mathrm{~m}, 1 \mathrm{H}), 2.50-2.46(\mathrm{~m}, 1 \mathrm{H}), 2.30-2.14(\mathrm{~m}, 3 \mathrm{H}), 1.97-1.92(\mathrm{~m}, 1 \mathrm{H})$, 1.82-1.77 (m, 1H). ${ }^{13} \mathrm{C}-\mathrm{NMR}\left(101 \mathrm{MHz}, \mathrm{CDCl}_{3}\right): \delta=158.3\left(\mathrm{C}_{\mathrm{q}}\right), 158.2(\mathrm{CH}), 150.2(\mathrm{dd}$, $\left.{ }^{1} \mathrm{JC}_{\mathrm{F}-\mathrm{F}}=194 \mathrm{~Hz},{ }^{2} \mathrm{JC}-\mathrm{F}=21.9 \mathrm{~Hz}, \mathrm{C}_{\mathrm{q}}\right), 148.4$ (dd, ${ }^{1} \mathrm{JC}_{\mathrm{F}}=194 \mathrm{~Hz},{ }^{2} \mathrm{JC}-\mathrm{F}=21.9 \mathrm{~Hz}, \mathrm{C}_{\mathrm{q}}$ ), 143.9 (dd, $\left.{ }^{3} \mathrm{~J}_{\mathrm{C}-\mathrm{F}}=6.2 \mathrm{~Hz},{ }^{4} \mathrm{~J}-\mathrm{F}=3.8 \mathrm{~Hz}, \mathrm{CH}\right), 142.4\left(\mathrm{C}_{\mathrm{q}}\right), 137.6\left(\mathrm{C}_{\mathrm{q}}\right), 132.0\left(\mathrm{C}_{\mathrm{q}}\right), 129.2$ $\left(\mathrm{C}_{\mathrm{q}}\right), 125.7(\mathrm{CH}), 123.2(\mathrm{CH}), 122.7\left(\mathrm{dd},{ }^{3} \mathrm{~J}_{\mathrm{C}-\mathrm{F}}=7.1 \mathrm{~Hz},{ }^{4} \mathrm{JC}_{\mathrm{C}-\mathrm{F}}=3.9 \mathrm{~Hz}, \mathrm{C}_{\mathrm{q}}\right), 121.8(\mathrm{CH})$, $120.2(\mathrm{CH}), 117.4(\mathrm{CH}), 117.0\left(\mathrm{~d},{ }^{2} \mathrm{~J}-\mathrm{F}=21.0 \mathrm{~Hz}, \mathrm{CH}\right), 115.7\left(\mathrm{~d},{ }^{2} \mathrm{~J}_{\mathrm{C}-\mathrm{F}}=20.8 \mathrm{~Hz}, \mathrm{CH}\right)$, $113.2(\mathrm{CH}), 106.6(\mathrm{CH}), 38.7(\mathrm{CH}), 33.5\left(\mathrm{CH}_{2}\right), 29.8\left(\mathrm{CH}_{2}\right), 28.9\left(\mathrm{CH}_{2}\right) .{ }^{19} \mathrm{~F}-\mathrm{NMR}(282$ $\left.\mathrm{MHz}, \mathrm{CDCl}_{3}\right): \delta-138.7,-142.5$. IR (ATR): 2958, 1685, 1423, 1273, 1162, 965, 785 $\mathrm{cm}^{-1}$. MS (ESI) $\mathrm{m} / z$ (relative intensity): 410 (8) $[\mathrm{M}+\mathrm{Na}]^{+}, 388(61)[\mathrm{M}+\mathrm{H}]^{+}, 345(15), 185$ (5). HR-MS (ESI) $m / z$ calcd for $\mathrm{C}_{24} \mathrm{H}_{19} \mathrm{~F}_{2} \mathrm{~N}_{3}[\mathrm{M}+\mathrm{Na}]^{+}: 410.1439$, found: 410.1449 . The analytical data correspond with those reported in literature.[56]<smiles>CCCCCOC1CC=C(c2cc3ccccc3n2-c2ncccn2)CC1</smiles>

\section{2-[4-(n-Pentyloxy)cyclohex-1-en-1-yl]-1-(pyrimidin-2-yl)-1 H-indole (44ae)}

The general procedure A was followed using indole 23a $(49.9 \mathrm{mg}, 0.25 \mathrm{mmol}$, 1.00 equiv) andenol phosphate $41 \mathrm{e}(93.2 \mathrm{mg}, 0.38 \mathrm{mmol}, 1.50$ equiv). Purification by column chromatography on silica gel ( $n$-pentane/EtOAc 10:1) yielded 44ae $(73.9 \mathrm{mg}$, $201 \mu \mathrm{mol}, 80 \%$ ) as a yellow oil. An alternative procedure using enol acetate $40 \mathrm{e}$ 
(87.1 mg, $0.38 \mathrm{mmol}, 1.50$ equiv) yielded 44ae (69.3 mg, $189 \mu \mathrm{mol}, 75 \%$ ) as a yellow oil. ${ }^{1} \mathrm{H}-\mathrm{NMR}\left(300 \mathrm{MHz}, \mathrm{CDCl}_{3}\right): \delta=8.75(\mathrm{~d}, J=5.3 \mathrm{~Hz}, 2 \mathrm{H}), 8.20(\mathrm{~m}, 1 \mathrm{H}), 7.56(\mathrm{~m}$, $1 \mathrm{H}), 7.22-7.19(\mathrm{~m}, 2 \mathrm{H}), 7.13(\mathrm{t}, J=5.3 \mathrm{~Hz}, 1 \mathrm{H}), 6.56(\mathrm{~s}, 1 \mathrm{H}), 5.78-5.76(\mathrm{~m}, 1 \mathrm{H}), 3.60$ $3.57(\mathrm{~m}, 1 \mathrm{H}), 3.51-3.47(\mathrm{~m}, 2 \mathrm{H}), 2.57-2.52(\mathrm{~m}, 1 \mathrm{H}), 2.23-2.09(\mathrm{~m}, 3 \mathrm{H}), 1.98-1.93(\mathrm{~m}$, $1 \mathrm{H}), 1.74-1.67(\mathrm{~m}, 1 \mathrm{H}), 1.58-1.55(\mathrm{~m}, 2 \mathrm{H}), 1.30-1.28(\mathrm{~m}, 4 \mathrm{H}), 0.88(\mathrm{t}, J=6.6 \mathrm{~Hz}, 3 \mathrm{H})$. ${ }^{13} \mathrm{C}-N M R\left(125 \mathrm{MHz}_{\mathrm{CDCl}}\right): \delta=158.2\left(\mathrm{C}_{\mathrm{q}}\right), 158.0(\mathrm{CH}), 142.3\left(\mathrm{C}_{\mathrm{q}}\right), 137.3\left(\mathrm{C}_{\mathrm{q}}\right), 131.7$ $\left(\mathrm{C}_{\mathrm{q}}\right), 129.2\left(\mathrm{C}_{\mathrm{q}}\right), 124.3(\mathrm{CH}), 123.1(\mathrm{CH}), 121.9(\mathrm{CH}), 120.2(\mathrm{CH}), 117.8(\mathrm{CH}), 113.2$ $(\mathrm{CH}), 106.5(\mathrm{CH}), 73.9(\mathrm{CH}), 68.3\left(\mathrm{CH}_{2}\right), 32.4\left(\mathrm{CH}_{2}\right), 29.9\left(\mathrm{CH}_{2}\right), 28.5\left(\mathrm{CH}_{2}\right), 28.4$ $\left(\mathrm{CH}_{2}\right), 28.0\left(\mathrm{CH}_{2}\right), 22.6\left(\mathrm{CH}_{2}\right), 14.1\left(\mathrm{CH}_{3}\right)$. IR $(\mathrm{ATR}):$ 2934, 2852, 1558, 1449, 1340, $822,746 \mathrm{~cm}^{-1}$. MS (ESI) $\mathrm{m} / z$ (relative intensity): $384(62)[\mathrm{M}+\mathrm{Na}]^{+}, 362(100)[\mathrm{M}+\mathrm{H}]^{+}$, 274 (13). HR-MS (ESI) $m / z$ calcd for $\mathrm{C}_{23} \mathrm{H}_{27} \mathrm{~N}_{3} \mathrm{O}[\mathrm{M}+\mathrm{H}]^{+}:$362.2227, found: 362.2226 . The analytical data correspond with those reported in literature. ${ }^{[56]}$<smiles>FC(F)(F)C1CC=C(c2cc3ccccc3n2-c2ncccn2)CC1</smiles>

\section{1-(Pyrimidin-2-yl)-2-[4-(trifluoromethyl)cyclohex-1-en-1-yl]-1 H-indole (44af)}

The general procedure A was followed using indole 23a $(49.8 \mathrm{mg}, 0.25 \mathrm{mmol}$, 1.00 equiv) and enol phosphate $41 \mathrm{f}$ (83.7 mg, $0.38 \mathrm{mmol}, 1.50$ equiv). Purification by column chromatography on silica gel ( $n$-pentane/EtOAc 15:1) yielded 44af (63.1 mg, $185 \mu \mathrm{mol}, 74 \%)$ as a colorless oil. ${ }^{1} \mathrm{H}-\mathrm{NMR}\left(300 \mathrm{MHz}, \mathrm{CDCl}_{3}\right) \delta=8.78(\mathrm{~d}, J=4.8 \mathrm{~Hz}$, 2H), 8.20 (dd, J=7.9, 1.2 Hz, 1H), 7.54 (dd, J = 7.9, 1.2 Hz, 1H), 7.31-7.22 (m, 2H) $7.18(\mathrm{td}, J=7.2,1.5 \mathrm{~Hz}, 1 \mathrm{H}), 7.15(\mathrm{t}, J=4.8 \mathrm{~Hz}, 1 \mathrm{H}), 6.58(\mathrm{~s}, 1 \mathrm{H}), 5.82-5.81(\mathrm{~m}, 1 \mathrm{H})$, 2.44-2.33 (m, 2H), 2.29-2.20 (m, 3H), 2.07-2.03 (m, 1H), 1.67-1.60 (m, 1H). ${ }^{13} \mathrm{C}-\mathrm{NMR}$ $\left(125 \mathrm{MHz}, \mathrm{CDCl}_{3}\right): \delta=158.3\left(\mathrm{C}_{\mathrm{q}}\right), 158.2(\mathrm{CH}), 141.8\left(\mathrm{C}_{\mathrm{q}}\right), 137.3\left(\mathrm{C}_{\mathrm{q}}\right), 132.1\left(\mathrm{C}_{\mathrm{q}}\right), 129.4$ $\left(\mathrm{C}_{\mathrm{q}}\right), 129.1$ (q, $\left.{ }^{1} \mathrm{~J}_{\mathrm{C}-\mathrm{F}}=278 \mathrm{~Hz}, \mathrm{C}_{\mathrm{q}}\right), 123.1(\mathrm{CH}), 123.4(\mathrm{CH}), 122.0(\mathrm{CH}), 120.3(\mathrm{CH})$, $117.2(\mathrm{CH}), 113.4(\mathrm{CH}), 106.9(\mathrm{CH}), 38.3\left(\mathrm{q},{ }^{2} \mathrm{~J}-\mathrm{F}=30.5 \mathrm{~Hz}, \mathrm{CH}\right), 28.3\left(\mathrm{CH}_{2}\right), 24.6(\mathrm{q}$, $\left.{ }^{3} J_{C-F}=2.6 \mathrm{~Hz}, \mathrm{CH}_{2}\right), 21.8\left(\mathrm{q},{ }^{3} \mathrm{~J}_{\mathrm{C}-\mathrm{F}}=2.6 \mathrm{~Hz}, \mathrm{CH}_{2}\right) .{ }^{19} \mathrm{~F}-\mathrm{NMR}\left(282 \mathrm{MHz}, \mathrm{CDCl}_{3}\right): \delta=$ -74.07. IR (ATR): 2931, 1565, 1418, 1353, 1269, 1162, 824, $741 \mathrm{~cm}^{-1}$. MS (ESI) $\mathrm{m} / \mathrm{z}$ (relative intensity): $344(52)[\mathrm{M}+\mathrm{H}]^{+}, 321$ (100), 258 (23), 155 (19). HR-MS (ESI) m/z calcd for $\mathrm{C}_{19} \mathrm{H}_{16} \mathrm{~F}_{3} \mathrm{~N}_{3}[\mathrm{M}+\mathrm{H}]^{+}: 344.1369$, found: 344.1367. The analytical data correspond with those reported in literature.[56] 


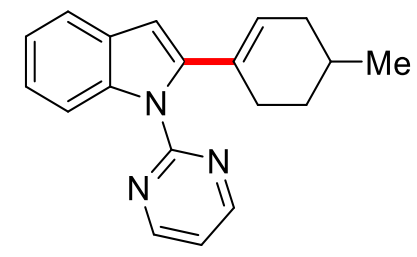

\section{2-(4-Methylcyclohex-1-en-1-yl)-1-(pyrimidin-2-yl)-1 H-indole (44ag)}

The general procedure A was followed using indole 23a $(49.7 \mathrm{mg}, 0.25 \mathrm{mmol}$, 1.00 equiv) and enol phosphate $\mathbf{4 1 \mathrm { g }}$ (85.7 $\mathrm{mg}, 0.38 \mathrm{mmol}, 1.50$ equiv). Purification by column chromatography on silica gel ( $n$-pentane/EtOAc 20:1) yielded 44ag $(52.1 \mathrm{mg}$, $177 \mu \mathrm{mol}, 71 \%)$ as a colorless oil. ${ }^{1} \mathrm{H}-\mathrm{NMR}\left(300 \mathrm{MHz}, \mathrm{CDCl}_{3}\right) \delta=8.78(\mathrm{~d}, J=4.7 \mathrm{~Hz}$, 2H), $8.13(\mathrm{dd}, J=7.4,1.2 \mathrm{~Hz}, 1 \mathrm{H}), 7.56(\mathrm{dd}, J=7.4,1.2 \mathrm{~Hz}, 1 \mathrm{H}), 7.22-7.08(\mathrm{~m}, 3 \mathrm{H})$ $6.53(\mathrm{~s}, 1 \mathrm{H}), 5.83-5.81(\mathrm{~m}, 1 \mathrm{H}), 2.29-2.06(\mathrm{~m}, 3 \mathrm{H}), 1.83-1.64(\mathrm{~m}, 3 \mathrm{H}), 1.36-1.29(\mathrm{~m}$, $1 \mathrm{H}), 0.99(\mathrm{~d}, J=8.1 \mathrm{~Hz}, 3 \mathrm{H}) .{ }^{13} \mathrm{C}-\mathrm{NMR}\left(125 \mathrm{MHz}, \mathrm{CDCl}_{3}\right): \delta=158.3\left(\mathrm{C}_{\mathrm{q}}\right), 158.0(\mathrm{CH})$, $141.8\left(\mathrm{C}_{\mathrm{q}}\right), 137.3\left(\mathrm{C}_{\mathrm{q}}\right), 131.3\left(\mathrm{C}_{\mathrm{q}}\right), 129.2\left(\mathrm{C}_{\mathrm{q}}\right), 126.5(\mathrm{CH}), 122.9(\mathrm{CH}), 121.8(\mathrm{CH})$, $120.1(\mathrm{CH}), 117.8(\mathrm{CH}), 112.9(\mathrm{CH}), 106.0(\mathrm{CH}), 34.2\left(\mathrm{CH}_{2}\right), 30.4\left(\mathrm{CH}_{2}\right), 28.8\left(\mathrm{CH}_{2}\right)$, $28.0(\mathrm{CH}) 21.8\left(\mathrm{CH}_{3}\right)$. IR (ATR): 2929, 1568, 1443, 1352, 1158, 822, 806, $738 \mathrm{~cm}^{-1}$. MS (ESI) $\mathrm{m} / z$ (relative intensity): $312(25)[\mathrm{M}+\mathrm{Na}]^{+}, 290(100)[\mathrm{M}+\mathrm{H}]^{+}, 270(18), 198$ (15), 129 (19). HR-MS (ESI) $\mathrm{m} / z$ calcd for $\mathrm{C}_{19} \mathrm{H}_{19} \mathrm{~N}_{3} \quad[\mathrm{M}+\mathrm{H}]^{+}: 290.1652$, found: 290.1648.

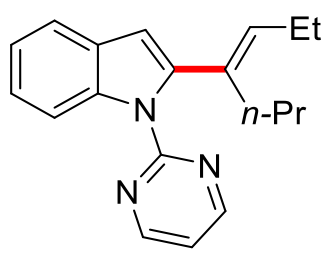

\section{(E)-2-(Hept-3-en-4-yl)-1-(pyrimidin-2-yl)-1 H-indole (44ah)}

The general procedure A was followed using indole 23a $(49.2 \mathrm{mg}, 0.25 \mathrm{mmol}$, 1.00 equiv) and enol phosphate $41 \mathrm{~h}(98.1 \mathrm{mg}, 0.38 \mathrm{mmol}, 1.50$ equiv, $E / Z=30 / 70)$. Purification by column chromatography on silica gel ( $n$-pentane/EtOAc $25: 1$ ) yielded 44ah (54.4 mg, $183 \mu \mathrm{mol}, 73 \%)$ as a colorless oil. ${ }^{1} \mathrm{H}-\mathrm{NMR}\left(300 \mathrm{MHz}, \mathrm{CDCl}_{3}\right): \delta=8.78$ (d, $J=5.8 \mathrm{~Hz}, 2 \mathrm{H}), 8.12(\mathrm{~d}, J=8.0 \mathrm{~Hz}, 1 \mathrm{H}), 7.60(\mathrm{~m}, 1 \mathrm{H}), 7.21-7.17(\mathrm{~m}, 2 \mathrm{H}), 7.13(\mathrm{t}$, $J=5.8 \mathrm{~Hz}, 1 \mathrm{H}), 6.58(\mathrm{~s}, 1 \mathrm{H}), 5.58(\mathrm{t}, J=6.9 \mathrm{~Hz}, 1 \mathrm{H}), 2.19-2.13(\mathrm{~m}, 4 \mathrm{H}), 1.38(\mathrm{dq}$, $J=6.9,6.8 \mathrm{~Hz}, 2 \mathrm{H}), 0.96(\mathrm{t}, J=6.9 \mathrm{~Hz}, 3 \mathrm{H}), 0.87(\mathrm{t}, J=6.8 \mathrm{~Hz}, 3 \mathrm{H}) .{ }^{13} \mathrm{C}-\mathrm{NMR}(101$ $\left.\mathrm{MHz}, \mathrm{CDCl}_{3}\right): \delta=158.4\left(\mathrm{C}_{\mathrm{q}}\right), 158.1(\mathrm{CH}), 143.3\left(\mathrm{C}_{\mathrm{q}}\right), 137.4\left(\mathrm{C}_{\mathrm{q}}\right), 133.1\left(\mathrm{C}_{\mathrm{q}}\right), 132.6$ $(\mathrm{CH}), 129.3\left(\mathrm{C}_{\mathrm{q}}\right), 122.8(\mathrm{CH}), 121.7(\mathrm{CH}), 120.0(\mathrm{CH}), 117.2(\mathrm{CH}), 113.0(\mathrm{CH}), 106.9$ $(\mathrm{CH}), 33.0\left(\mathrm{CH}_{2}\right), 21.8\left(\mathrm{CH}_{2}\right), 21.5\left(\mathrm{CH}_{2}\right), 14.1\left(\mathrm{CH}_{3}\right), 14.0\left(\mathrm{CH}_{3}\right)$. IR $(\mathrm{ATR}): 2950,1558$, 
1453, 1419, 1247, 822, $745 \mathrm{~cm}^{-1}$. MS (ESI) $\mathrm{m} / \mathrm{z}$ (relative intensity): $314(27)[\mathrm{M}+\mathrm{Na}]^{+}$, $292(100)[\mathrm{M}+\mathrm{H}]^{+}, 117$ (8). HR-MS (ESI) $\mathrm{m} / z$ calcd for $\mathrm{C}_{19} \mathrm{H}_{21} \mathrm{~N}_{3}[\mathrm{M}+\mathrm{H}]^{+}: 292.1808$, found: 292.1816. The analytical data correspond with those reported in literature.[56]

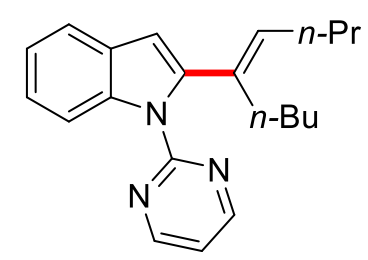

\section{(E)-2-(Non-4-en-5-yl)-1-(pyrimidin-2-yl)-1 H-indole (44ai)}

The general procedure A was followed using indole 23a $(49.8 \mathrm{mg}, 0.25 \mathrm{mmol}$, 1.00 equiv) and enol phosphate $41 \mathbf{i}(103 \mathrm{mg}, 0.38 \mathrm{mmol}, 1.50$ equiv, $E / Z=30 / 70$ ). Purification by column chromatography on silica gel ( $n$-pentane/EtOAc 20:1) yielded 44a (55.6 mg, $172 \mu \mathrm{mol}, 69 \%)$ as a colorless oil. ${ }^{1} \mathrm{H}-\mathrm{NMR}\left(300 \mathrm{MHz}, \mathrm{CDCl}_{3}\right): \delta=8.74$ (d, $J=4.5 \mathrm{~Hz}, 2 \mathrm{H}), 8.13(\mathrm{~m}, 1 \mathrm{H}), 7.58(\mathrm{~m}, 1 \mathrm{H}), 7.23-7.18(\mathrm{~m}, 2 \mathrm{H}), 7.10(\mathrm{t}, J=4.5 \mathrm{~Hz}$, $1 \mathrm{H}), 6.55(\mathrm{~s}, 1 \mathrm{H}), 5.59(\mathrm{t}, J=7.7 \mathrm{~Hz}, 1 \mathrm{H}), 2.20-2.12(\mathrm{~m}, 4 \mathrm{H}), 1.46-1.31(\mathrm{~m}, 2 \mathrm{H}), 1.28-$ $1.17(\mathrm{~m}, 4 \mathrm{H}), 0.89$ (t, $J=7.9 \mathrm{~Hz}, 3 \mathrm{H}), 0.80$ (t, $J=7.4 \mathrm{~Hz}, 3 \mathrm{H}) .{ }^{13} \mathrm{C}-\mathrm{NMR}(101 \mathrm{MHz}$, $\left.\mathrm{CDCl}_{3}\right): \delta=158.4\left(\mathrm{C}_{\mathrm{q}}\right), 158.1(\mathrm{CH}), 143.3\left(\mathrm{C}_{\mathrm{q}}\right), 137.4\left(\mathrm{C}_{\mathrm{q}}\right), 134.4\left(\mathrm{C}_{\mathrm{q}}\right), 130.7(\mathrm{CH})$, $129.3\left(\mathrm{C}_{\mathrm{q}}\right), 122.9(\mathrm{CH}), 121.8(\mathrm{CH}), 120.1(\mathrm{CH}), 117.2(\mathrm{CH}), 113.0(\mathrm{CH}), 106.9(\mathrm{CH})$, $30.9\left(\mathrm{CH}_{2}\right), 30.8\left(\mathrm{CH}_{2}\right), 30.2\left(\mathrm{CH}_{2}\right), 22.7\left(\mathrm{CH}_{2}\right), 22.6\left(\mathrm{CH}_{2}\right), 13.9\left(\mathrm{CH}_{3}\right), 13.8\left(\mathrm{CH}_{3}\right)$. IR (ATR): 2927, 1558, 1451, 1342, 1317, 1251, 1161, 797, $732 \mathrm{~cm}^{-1}$. MS (ESI) $\mathrm{m} / \mathrm{z}$ (relative intensity): $342(12)[\mathrm{M}+\mathrm{Na}]^{+}, 320(100)[\mathrm{M}+\mathrm{H}]^{+}, 290$ (10) 149 (9), 117 (60). HR-MS (ESI) $\mathrm{m} / z$ calcd for $\mathrm{C}_{21} \mathrm{H}_{25} \mathrm{~N}_{3}[\mathrm{M}+\mathrm{H}]^{+}: 320.2121$, found: 320.2129 . The analytical data corresponds with those reported in literature. ${ }^{[56]}$

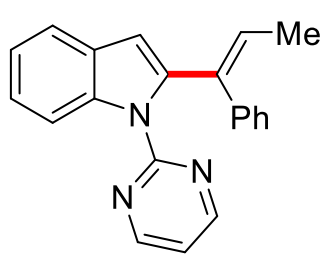

(E)-2-(1-Phenylprop-1-en-1-yl)-1-(pyrimidin-2-yl)-1H-indole (44aj)

The general procedure A was followed using indole 23a $(49.8 \mathrm{mg}, 0.25 \mathrm{mmol}$, 1.00 equiv) and enol phosphate $41 \mathrm{j}(94.2 \mathrm{mg}, 0.38 \mathrm{mmol}, 1.50$ equiv, $E / Z=25 / 75)$. Purification by column chromatography on silica gel ( $n$-pentane/EtOAc 20:1) yielded 44aj $(44.6 \mathrm{mg}, 139 \mu \mathrm{mol}, 55 \%)$ as a yellow oil. ${ }^{1} \mathrm{H}-\mathrm{NMR}\left(300 \mathrm{MHz}, \mathrm{CDCl}_{3}\right): \delta=8.53$ $(\mathrm{d}, J=4.7 \mathrm{~Hz}, 2 \mathrm{H}), 8.02(\mathrm{~d}, J=8.0 \mathrm{~Hz}, 1 \mathrm{H}), 7.65(\mathrm{~d}, J=8.0 \mathrm{~Hz}, 1 \mathrm{H}), 7.27-7.21(\mathrm{~m}$, 
2H), 7.10-7.05 (m, 4H), 6.99-6.96 (m, 1H), $6.84(\mathrm{t}, J=4.7 \mathrm{~Hz}, 1 \mathrm{H}), 6.72(\mathrm{~s}, 1 \mathrm{H}), 6.33$ (q, $J=10.4 \mathrm{~Hz}, 1 \mathrm{H}), 1.98(\mathrm{~d}, J=10.4 \mathrm{~Hz}, 3 \mathrm{H}) \cdot{ }^{13} \mathrm{C}-\mathrm{NMR}\left(101 \mathrm{MHz}, \mathrm{CDCl}_{3}\right): \delta=157.8$ $(\mathrm{CH}), 157.4\left(\mathrm{C}_{\mathrm{q}}\right), 142.6\left(\mathrm{C}_{\mathrm{q}}\right), 138.3\left(\mathrm{C}_{\mathrm{q}}\right), 137.3\left(\mathrm{C}_{\mathrm{q}}\right), 135.5\left(\mathrm{C}_{\mathrm{q}}\right), 129.8(\mathrm{CH}), 128.9\left(\mathrm{C}_{\mathrm{q}}\right)$, $127.3(\mathrm{CH}), 126.5(\mathrm{CH}), 126.1(\mathrm{CH}), 123.3(\mathrm{CH}), 121.8(\mathrm{CH}), 120.4(\mathrm{CH}), 116.8(\mathrm{CH})$, $112.9(\mathrm{CH}), 108.8(\mathrm{CH}), 15.4\left(\mathrm{CH}_{3}\right)$. IR (ATR): 2937, 2035, 1568, 1447, 1252, 1082 , 824, $793 \mathrm{~cm}^{-1}$. MS (ESI) $\mathrm{m} / z$ (relative intensity): $334(24)[\mathrm{M}+\mathrm{Na}]^{+}, 312(100)[\mathrm{M}+\mathrm{H}]^{+}$, 299 (13). HR-MS (ESI) $\mathrm{m} / z$ calcd for $\mathrm{C}_{21} \mathrm{H}_{17} \mathrm{~N}_{3}[\mathrm{M}+\mathrm{H}]^{+}: 312.1495$, found: 312.1491 . The analytical data corresponds with those reported in literature.[56]

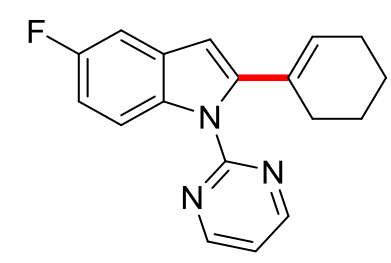

\section{2-(Cyclohex-1-en-1-yl)-5-fluoro-1-(pyrimidin-2-yl)-1H-indole (44bb)}

The general procedure A was followed using indole 23b $(53.2 \mathrm{mg}, 0.25 \mathrm{mmol}$, 1.00 equiv) and enol phosphate 41b (89 mg, $0.38 \mathrm{mmol}, 1.50$ equiv). Purification by column chromatography on silica gel ( $n$-pentane/EtOAc 15:1) yielded 44bb $(45.2 \mathrm{mg}$, $153 \mu \mathrm{mol}, 61 \%)$ as a pale yellow solid. An alternative procedure using enol acetate 40b (62.1 mg, $0.38 \mathrm{mmol}, 1.5$ equiv) yielded 44bb (51.8 mg, $175 \mu \mathrm{mol}, 70 \%)$ as a yellow solid. M. p. $=140-142{ }^{\circ} \mathrm{C} .{ }^{1} \mathrm{H}-\mathrm{NMR}\left(300 \mathrm{MHz}, \mathrm{CDCl}_{3}\right) \delta=8.72(\mathrm{~d}, J=4.8 \mathrm{~Hz}$, 2H), 8.10 (dd, $J=8.7,4.2 \mathrm{~Hz}, 1 \mathrm{H}$ ), 7.17 (dd, $J=8.7,2.8 \mathrm{~Hz}, 1 \mathrm{H}$ ), 7.15 (t, $J=4.8 \mathrm{~Hz}$, $1 \mathrm{H}), 6.91(\mathrm{td}, J=8.7,2.8 \mathrm{~Hz}, 1 \mathrm{H}), 6.50(\mathrm{~s}, 1 \mathrm{H}), 5.86-5.83(\mathrm{~m}, 1 \mathrm{H}), 2.17-2.14(\mathrm{~m}, 2 \mathrm{H})$, 2.08-2.05 (m, 2H), 1.67-1.62 (m, 4H). ${ }^{13} \mathrm{C}-\mathrm{NMR}\left(101 \mathrm{MHz}, \mathrm{CDCl}_{3}\right): \delta=159.0(\mathrm{~d}$, $\left.{ }^{1} J_{\mathrm{CF}}=244 \mathrm{~Hz}, \mathrm{C}_{\mathrm{q}}\right), 158.2(\mathrm{CH}), 145.0\left(\mathrm{C}_{\mathrm{q}}\right), 133.8\left(\mathrm{C}_{\mathrm{q}}\right), 131.8\left(\mathrm{C}_{\mathrm{q}}\right), 131.1\left(\mathrm{C}_{\mathrm{q}}\right), 130.9$ $\left(\mathrm{d},{ }^{3} \mathrm{JCF}_{\mathrm{CF}}=10.8 \mathrm{~Hz}, \mathrm{C}_{\mathrm{q}}\right), 127.5(\mathrm{CH}), 117.4(\mathrm{CH}), 114.0\left(\mathrm{~d},{ }^{3} \mathrm{JCF}=9.9 \mathrm{~Hz}, \mathrm{CH}\right), 110.7(\mathrm{~d}$, $\left.{ }^{2} \mathrm{JCF}_{\mathrm{C}} 27.0 \mathrm{~Hz}, \mathrm{CH}\right), 106.1(\mathrm{CH}), 105.4\left(\mathrm{~d},{ }^{2} \mathrm{JCF}_{2}=23.8 \mathrm{~Hz}, \mathrm{CH}\right), 29.0\left(\mathrm{CH}_{2}\right), 25.8\left(\mathrm{CH}_{2}\right)$, 23.6 $\left(\mathrm{CH}_{2}\right), 22.0\left(\mathrm{CH}_{2}\right) .{ }^{19} \mathrm{~F}-\mathrm{NMR}\left(282 \mathrm{MHz}, \mathrm{CDCl}_{3}\right): \delta=-122.52$. IR (ATR): 2931, 1568, 1420, 1270, 1214, 806, $771 \mathrm{~cm}^{-1}$. MS (ESI) $\mathrm{m} / \mathrm{z}$ (relative intensity): 316 (22) $[\mathrm{M}+\mathrm{Na}]^{+}, 294(100)[\mathrm{M}+\mathrm{H}]^{+}, 261$ (34), 221 (8), 125 (5). HR-MS (ESI) $\mathrm{m} / \mathrm{z}$ calcd for $\mathrm{C}_{18} \mathrm{H}_{16} \mathrm{FN}_{3}[\mathrm{M}+\mathrm{H}]^{+}: 294.1401$, found: 294.1404 . The analytical data correspond with those reported in literature. ${ }^{[56]}$ 
<smiles>CC(=O)c1cccc2c1cc(C1=CCCCC1)n2-c1ncccn1</smiles>

Methyl-2-(cyclohex-1-en-1-yl)-1-(pyrimidin-2-yl)-1 H-indole-4-carboxylate (44cb)

The general procedure A was followed using indole 23c $(66.1 \mathrm{mg}, 0.24 \mathrm{mmol}$, 1.00 equiv) and enol phosphate 41b (91.2 mg, $0.38 \mathrm{mmol}, 1.50$ equiv). Purification by column chromatography on silica gel ( $n$-pentane/EtOAc $7: 1)$ yielded 44cb $(55.1 \mathrm{mg}$, $163 \mu \mathrm{mol}, 65 \%)$ as a pale yellow oil. An alternative procedure using enol acetate 40b (62.3 mg, $0.38 \mathrm{mmol}, 1.5$ equiv) yielded 44cb (51.9 mg, $153 \mu \mathrm{mol}, 61 \%$ ) as a yellow oil. ${ }^{1} \mathrm{H}-\mathrm{NMR}\left(300 \mathrm{MHz}, \mathrm{CDCl}_{3}\right) \delta=8.83(\mathrm{~d}, J=5.4 \mathrm{~Hz}, 2 \mathrm{H}), 8.23(\mathrm{~d}, J=8.3 \mathrm{~Hz}, 1 \mathrm{H})$, $7.89(\mathrm{~d}, J=8.3 \mathrm{~Hz}, 1 \mathrm{H}), 7.27-7.16(\mathrm{~m}, 3 \mathrm{H}), 5.92-5.88(\mathrm{~m}, 1 \mathrm{H}), 3.98(\mathrm{~s}, 3 \mathrm{H}), 2.14-2.12$ $(\mathrm{m}, 2 \mathrm{H}), 2.05-2.04(\mathrm{~m}, 2 \mathrm{H}), 1.64-1.61(\mathrm{~m}, 4 \mathrm{H}) .{ }^{13} \mathrm{C}-\mathrm{NMR}\left(125 \mathrm{MHz} \mathrm{CDCl}_{3}\right): \delta=167.9$ $\left(\mathrm{C}_{\mathrm{q}}\right), 158.3\left(\mathrm{C}_{\mathrm{q}}\right), 158.1(\mathrm{CH}), 145.4\left(\mathrm{C}_{\mathrm{q}}\right), 138.1\left(\mathrm{C}_{\mathrm{q}}\right), 131.6\left(\mathrm{C}_{\mathrm{q}}\right), 129.2\left(\mathrm{C}_{\mathrm{q}}\right), 128.2(\mathrm{CH})$, $124.9(\mathrm{CH}), 122.2(\mathrm{CH}), 121.2\left(\mathrm{C}_{\mathrm{q}}\right), 117.8(\mathrm{CH}), 117.5(\mathrm{CH}), 106.7(\mathrm{CH}), 51.8\left(\mathrm{CH}_{3}\right)$, $28.9\left(\mathrm{CH}_{2}\right), 25.7\left(\mathrm{CH}_{2}\right), 22.8\left(\mathrm{CH}_{2}\right), 21.9\left(\mathrm{CH}_{2}\right)$. IR (ATR): 2931, 1714, 1444, 1341, 1304, 1153, 821, $727 \mathrm{~cm}^{-1}$. MS (ESI) $\mathrm{m} / z$ (relative intensity) 356 (67) $[\mathrm{M}+\mathrm{Na}]^{+}, 334$ (100) $[\mathrm{M}+\mathrm{H}]^{+}, 316$ (11), 302 (14). HR-MS (ESI) $\mathrm{m} / z$ calcd for $\mathrm{C}_{20} \mathrm{H}_{19} \mathrm{~N}_{3} \mathrm{O}_{2}$ $[\mathrm{M}+\mathrm{H}]^{+}:$334.1550, found: 334,1551.<smiles>CC(C)(C)C1CC=C(c2cc3ccccc3n2-c2ncccn2)CC1</smiles>

\section{2-[4-(tert-Butyl)cyclohex-1-en-1-yl]-1-(pyrimidin-2-yl)-1 H-indole (44ak):}

The general procedure A was followed using indole 23a $(49.5 \mathrm{mg}, 0.25 \mathrm{mmol}$, 1.00 equiv) and enol acetate 40k (77.1 mg, $0.38 \mathrm{mmol}, 1.50$ equiv). Purification by column chromatography on silica gel ( $n$-pentane/EtOAc 12:1) yielded 44ak $(57.1 \mathrm{mg}$, $176 \mu \mathrm{mol}, 71 \%)$ as a colorless oil. ${ }^{1} \mathrm{H}-\mathrm{NMR}\left(300 \mathrm{MHz}, \mathrm{CDCl}_{3}\right): \delta=8.76(\mathrm{~d}, J=5.1 \mathrm{~Hz}$, $2 \mathrm{H}$ ), 8.15 (dd, $J=8.2,1.2 \mathrm{~Hz}, 1 \mathrm{H}), 7.57(\mathrm{~d}, J=8.2 \mathrm{~Hz}, 1 \mathrm{H}), 7.26-7.14(\mathrm{~m}, 2 \mathrm{H}), 7.15$ (t, $J=5.1 \mathrm{~Hz} .1 \mathrm{H}), 6.55(\mathrm{~s}, 1 \mathrm{H}), 5.90-5.86(\mathrm{~m}, 1 \mathrm{H}), 2.21-2.09(\mathrm{~m}, 3 \mathrm{H}), 2.00-1.88(\mathrm{~m}, 1 \mathrm{H})$, 1.83-1.75 (m, 1H), $1.37(\mathrm{~m}, 1 \mathrm{H}), 1.24(\mathrm{~m}, 1 \mathrm{H}), 0.86(\mathrm{~s}, 9 \mathrm{H}) .{ }^{13} \mathrm{C}-\mathrm{NMR}(101 \mathrm{MHz}$, 
$\left.\mathrm{CDCl}_{3}\right): \delta=157.4\left(\mathrm{C}_{\mathrm{q}}\right), 157.2(\mathrm{CH}), 142.0\left(\mathrm{C}_{\mathrm{q}}\right), 136.6\left(\mathrm{C}_{\mathrm{q}}\right), 130.5\left(\mathrm{C}_{\mathrm{q}}\right), 128.3\left(\mathrm{C}_{\mathrm{q}}\right), 126.3$ $(\mathrm{CH}), 121.9(\mathrm{CH}), 120.8(\mathrm{CH}), 119.2(\mathrm{CH}), 116.3(\mathrm{CH}), 111.8(\mathrm{CH}), 105.3(\mathrm{CH}), 42.7$ (CH), $31.2\left(\mathrm{CH}_{2}\right), 29.7\left(\mathrm{CH}_{2}\right), 26.4\left(\mathrm{CH}_{2}\right), 26.1\left(\mathrm{CH}_{3}\right), 24.1\left(\mathrm{C}_{\mathrm{q}}\right)$. IR (ATR): 2958, 1561, 1454, 1340, 1262, 1116, 798, 675, $627 \mathrm{~cm}^{-1}$. MS (ESI) $\mathrm{m} / z$ (relative intensity): 354 (22) $[\mathrm{M}+\mathrm{Na}]^{+}, 332(100)[\mathrm{M}+\mathrm{H}]^{+}, 177$ (8), 149 (11). HR-MS (ESI) $\mathrm{m} / z$ calcd for $\mathrm{C}_{22} \mathrm{H}_{25} \mathrm{~N}_{3}$ $[\mathrm{M}+\mathrm{H}]^{+}: 332.2121$, found: 332.2126 . The analytical data correspond with those reported in literature.[56]

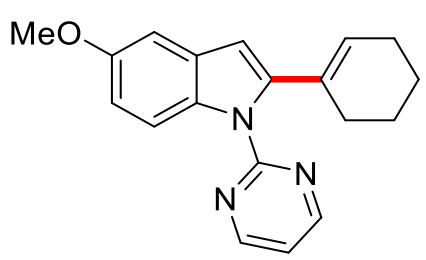

\section{2-(Cyclohex-1-en-1-yl)-1-(pyrimidin-2-yl)-5-methoxy-1 $H$-indole (44db)}

The general procedure A was followed using indole $23 \mathrm{~d}(58.7 \mathrm{mg}, 0.25 \mathrm{mmol}$, 1.00 equiv) and enol acetate $40 \mathrm{~b}(61.7 \mathrm{mg}, 0.38 \mathrm{mmol}, 1.50$ equiv). Purification by column chromatography on silica gel ( $n$-pentane/EtOAc $8: 1)$ yielded $44 \mathrm{db}(54.6 \mathrm{mg}$, $179 \mu \mathrm{mol}, 72 \%)$ as a pale yellow oil. ${ }^{1} \mathrm{H}-\mathrm{NMR}\left(300 \mathrm{MHz}, \mathrm{CDCl}_{3}\right) \delta=8.75(\mathrm{~d}, J=4.7 \mathrm{~Hz}$, 2H), 8.09 (d, $J=7.9 \mathrm{~Hz}, 1 \mathrm{H}$ ), 7.10 (t, $J=4.7 \mathrm{~Hz}, 1 \mathrm{H}), 7.02(\mathrm{~d}, J=1.0 \mathrm{~Hz}, 1 \mathrm{H}), 6.84$ (dd, $J=7.9,1.0 \mathrm{~Hz}, 1 \mathrm{H}) 6.43(\mathrm{~s}, 1 \mathrm{H}), 5.87-5.84(\mathrm{~m}, 1 \mathrm{H}), 3.84(\mathrm{~s}, 3 \mathrm{H}), 2.18-2.13(\mathrm{~m}$, 2H), 2.07-2.02 (m, 2H), 1.66-1.61 (m, 4H). ${ }^{13} \mathrm{C}-\mathrm{NMR}\left(125 \mathrm{MHz}, \mathrm{CDCl}_{3}\right): \delta=158.3$ $(\mathrm{CH}), 158.1\left(\mathrm{C}_{\mathrm{q}}\right), 155.5\left(\mathrm{C}_{\mathrm{q}}\right), 144.1\left(\mathrm{C}_{\mathrm{q}}\right), 132.4\left(\mathrm{C}_{\mathrm{q}}\right), 132.2\left(\mathrm{C}_{\mathrm{q}}\right), 130.1\left(\mathrm{C}_{\mathrm{q}}\right), 126.2(\mathrm{CH})$, $116.9(\mathrm{CH}), 114.2(\mathrm{CH}), 111.9(\mathrm{CH}) 106.2(\mathrm{CH}), 102.5(\mathrm{CH}), 55.1\left(\mathrm{CH}_{3}\right), 29.1\left(\mathrm{CH}_{2}\right)$, $25.6\left(\mathrm{CH}_{2}\right), 22.7\left(\mathrm{CH}_{2}\right), 22.1\left(\mathrm{CH}_{2}\right)$. IR (ATR): 2934, 1557, 1441, 1317, 1157, 1027, 807, $723 \mathrm{~cm}^{-1}$. MS (ESI) m/z (relative intensity): $306(100)[\mathrm{M}+\mathrm{H}]^{+}, 282$ (33), 261 (40) 219 (85). HR-MS (ESI) $\mathrm{m} / z$ calcd for $\mathrm{C}_{19} \mathrm{H}_{18} \mathrm{~N}_{3} \mathrm{O}[\mathrm{M}+\mathrm{H}]^{+}: 306.1601$, found: 306.1601 .

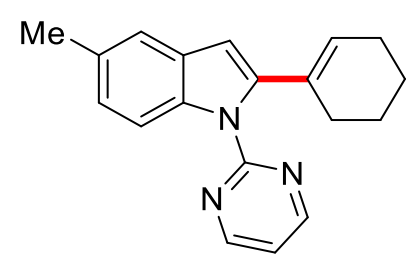

\section{2-(Cyclohex-1-en-1-yl)-1-(pyrimidin-2-yl)-5-methyl-1 H-indole (44eb)}

The general procedure A was followed using indole $23 \mathrm{e}(52.7 \mathrm{mg}, 0.25 \mathrm{mmol}$, 1.00 equiv) and enol acetate $40 \mathrm{~b}(61.7 \mathrm{mg}, 0.38 \mathrm{mmol}, 1.50$ equiv). Purification by column chromatography on silica gel ( $n$-pentane/EtOAc 14:1) yielded 44eb (58.6 mg, 
$202 \mu \mathrm{mol}, 80 \%)$ as a pale yellow oil. ${ }^{1} \mathrm{H}-\mathrm{NMR}\left(300 \mathrm{MHz}, \mathrm{CDCl}_{3}\right) \delta=8.69(\mathrm{~d}, J=4.7 \mathrm{~Hz}$, 2H), $7.89(\mathrm{~d}, J=7.9 \mathrm{~Hz}, 1 \mathrm{H}), 7.32(\mathrm{~d}, J=0.7 \mathrm{~Hz}, 1 \mathrm{H}), 7.05$ (t, $J=4.7 \mathrm{~Hz}, 1 \mathrm{H}), 6.98$ (dd, $J=7.9,0.7 \mathrm{~Hz}, 1 \mathrm{H}) 6.43(\mathrm{~s}, 1 \mathrm{H}), 5.83-5.81(\mathrm{~m}, 1 \mathrm{H}), 2.37(\mathrm{~s}, 3 \mathrm{H}), 2.14-2.08(\mathrm{~m}$, 2H), 2.02-1.95 (m, 2H), 1.66-1.61 (m, 4H). ${ }^{13} \mathrm{C}-\mathrm{NMR}\left(101 \mathrm{MHz}, \mathrm{CDCl}_{3}\right): \delta=158.4$ $(\mathrm{CH}), 158.1\left(\mathrm{C}_{\mathrm{q}}\right), 143.4\left(\mathrm{C}_{\mathrm{q}}\right), 135.8\left(\mathrm{C}_{\mathrm{q}}\right), 132.2\left(\mathrm{C}_{\mathrm{q}}\right), 131.2\left(\mathrm{C}_{\mathrm{q}}\right), 129.7\left(\mathrm{C}_{\mathrm{q}}\right), 126.5(\mathrm{CH})$, $124.5(\mathrm{CH}), 120.2(\mathrm{CH}), 116.9(\mathrm{CH}), 112.9(\mathrm{CH}), 106.2(\mathrm{CH}), 28.9\left(\mathrm{CH}_{3}\right), 25.6\left(\mathrm{CH}_{2}\right)$, $22.7\left(\mathrm{CH}_{2}\right), 22.1\left(\mathrm{CH}_{2}\right), 21.2\left(\mathrm{CH}_{2}\right)$. IR (ATR): 2934, 1552, 1371, 1312, 1256, 1127, $824 \mathrm{~cm}^{-1}$. MS (ESI) $\mathrm{m} / z$ (relative intensity): $312(21)[\mathrm{M}+\mathrm{Na}]^{+}, 290(100)[\mathrm{M}+\mathrm{H}]^{+}, 263$ (5). HR-MS (ESI) $m / z$ calcd for $\mathrm{C}_{19} \mathrm{H}_{19} \mathrm{~N}_{3}[\mathrm{M}+\mathrm{H}]^{+}: 290.1652$, found: 290.1653.

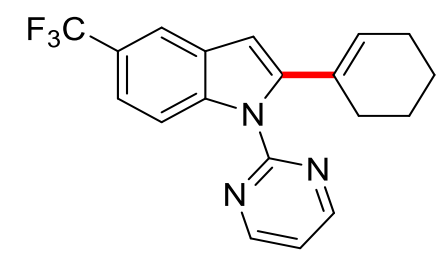

\section{2-(Cyclohex-1-en-1-yl)-1-(pyrimidin-2-yl)-5-(trifluoromethyl)-1 $H$-indole (44fb)}

The general procedure A was followed using indole $23 \mathrm{f}(68.7 \mathrm{mg}, 0.25 \mathrm{mmol}$, 1.00 equiv) and enol acetate $40 \mathrm{~b}$ (63.4 mg, $0.38 \mathrm{mmol}, 1.50$ equiv). Purification by column chromatography on silica gel ( $n$-pentane/EtOAc 15:1) yielded $\mathbf{4 4 f b}(64.9 \mathrm{mg}$, $184 \mu \mathrm{mol}, 74 \%)$ as a pale yellow oil. ${ }^{1} \mathrm{H}-\mathrm{NMR}\left(300 \mathrm{MHz}, \mathrm{CDCl}_{3}\right) \delta=8.80(\mathrm{~d}, J=4.7 \mathrm{~Hz}$, $2 \mathrm{H}$ ), 8.15 (dd, $J=7.3,0.9 \mathrm{~Hz}, 1 \mathrm{H}$ ), 7.85-7.82 (m, $1 \mathrm{H}), 7.45$ (dd, $J=7.3,1.9 \mathrm{~Hz}, 1 \mathrm{H}$ ), $7.21(\mathrm{t}, J=4.7 \mathrm{~Hz}, 1 \mathrm{H}), 6.61(\mathrm{~s}, 1 \mathrm{H}), 5.86-5.84(\mathrm{~m}, 1 \mathrm{H}), 2.17-2.15(\mathrm{~m}, 2 \mathrm{H}), 2.06-2.02$ $(\mathrm{m}, 2 \mathrm{H}), 1.67-1.61(\mathrm{~m}, 4 \mathrm{H}) .{ }^{13} \mathrm{C}-\mathrm{NMR}\left(101 \mathrm{MHz}, \mathrm{CDCl}_{3}\right): \delta=158.4(\mathrm{CH}), 158.0\left(\mathrm{C}_{\mathrm{q}}\right)$, $145.0\left(\mathrm{C}_{\mathrm{q}}\right), 138.7\left(\mathrm{C}_{\mathrm{q}}\right), 131.3\left(\mathrm{C}_{\mathrm{q}}\right), 128.8\left(\mathrm{C}_{\mathrm{q}}\right), 128.2(\mathrm{CH}), 125.1$ (q, ${ }^{1} \mathrm{~J}_{\mathrm{C}}$ $\left.\mathrm{F}=269.1 \mathrm{~Hz}, \mathrm{C}_{\mathrm{q}}\right), 124.1$ (q, $\left.{ }^{2} \mathrm{JC}_{\mathrm{C}-\mathrm{F}}=31.5 \mathrm{~Hz}, \mathrm{C}_{\mathrm{q}}\right), 119.7$ (q, $\left.{ }^{3} \mathrm{~J}_{\mathrm{C}-\mathrm{F}}=3.9 \mathrm{~Hz}, \mathrm{CH}\right) 118.0$ $(\mathrm{CH}), 117.6\left(\mathrm{q},{ }^{3} \mathrm{JC}_{\mathrm{C}-\mathrm{F}}=3.3 \mathrm{~Hz}, \mathrm{CH}\right) 113.2(\mathrm{CH}), 105.9(\mathrm{CH}), 29.2\left(\mathrm{CH}_{2}\right), 25.8\left(\mathrm{CH}_{2}\right)$, $22.7\left(\mathrm{CH}_{2}\right), 21.5\left(\mathrm{CH}_{2}\right) .{ }^{19} \mathrm{~F}-\mathrm{NMR}\left(282 \mathrm{MHz}, \mathrm{CDCl}_{3}\right): \delta=-60.74$. IR (ATR): 2933, 1557, $1441,1333,1271,1051,796 \mathrm{~cm}^{-1}$. MS (ESI) $\mathrm{m} / z$ (relative intensity): $344(100)[\mathrm{M}+\mathrm{H}]^{+}$, 321 (11), 306 (15), 261 (10), 219 (13). HR-MS (ESI) m/z calcd for $\mathrm{C}_{19} \mathrm{H}_{16} \mathrm{~F}_{3} \mathrm{~N}_{3}$ $[\mathrm{M}+\mathrm{H}]^{+}: 344.1369$ found: 344.1366 . The analytical data correspond with those reported in literature.[56] 


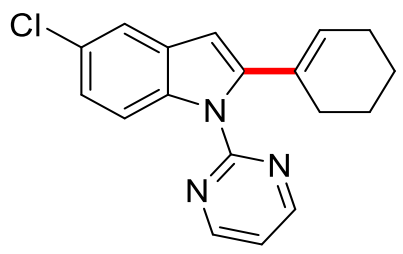

\section{2-(Cyclohex-1-en-1-yl)-1-(pyrimidin-2-yl)-5-chloro-1H-indole (44gb)}

The general procedure A was followed using indole $23 \mathrm{~g}(59.7 \mathrm{mg}, 0.25 \mathrm{mmol}$, 1.00 equiv) and enol acetate 40b (62.2 mg, $0.38 \mathrm{mmol}, 1.50$ equiv). Purification by column chromatography on silica gel (n-pentane/EtOAc 20:1) yielded 44gb $(45.6 \mathrm{mg}$, $147 \mu \mathrm{mol}, 59 \%)$ as a pale yellow oil. ${ }^{1} \mathrm{H}-\mathrm{NMR}\left(300 \mathrm{MHz}, \mathrm{CDCl}_{3}\right) \delta=8.76(\mathrm{~d}, J=4.7 \mathrm{~Hz}$, 2H), $8.05(\mathrm{~d}, J=7.7 \mathrm{~Hz}, 1 \mathrm{H}), 7.49(\mathrm{~d}, J=0.8 \mathrm{~Hz}, 1 \mathrm{H}), 7.17-7.13(\mathrm{~m}, 2 \mathrm{H}), 6.58(\mathrm{~s}, 1 \mathrm{H})$, 5.83-5.81 (m, 1H), 2.14-2.08 (m, 2H), 2.08-2.02 (m, 2H), 1.62-1.57 (m, 4H). ${ }^{13} \mathrm{C}-\mathrm{NMR}$ $\left(101 \mathrm{MHz}, \mathrm{CDCl}_{3}\right): \delta=158.2(\mathrm{CH}), 158.0\left(\mathrm{C}_{\mathrm{q}}\right), 144.7\left(\mathrm{C}_{\mathrm{q}}\right), 135.8\left(\mathrm{C}_{\mathrm{q}}\right), 131.5\left(\mathrm{C}_{\mathrm{q}}\right), 130.5$ $\left(\mathrm{C}_{\mathrm{q}}\right), 127.6(\mathrm{CH}), 127.1\left(\mathrm{C}_{\mathrm{q}}\right), 123.0(\mathrm{CH}), 119.6(\mathrm{CH}), 117.6(\mathrm{CH}), 114.2(\mathrm{CH}), 106.4$ (CH), $28.9\left(\mathrm{CH}_{2}\right), 25.6\left(\mathrm{CH}_{2}\right), 22.8\left(\mathrm{CH}_{2}\right), 21.8\left(\mathrm{CH}_{2}\right)$. IR (ATR): 2934, 1572, 1423, 1325, 1212, 1047, 802, $736 \mathrm{~cm}^{-1}$. MS (ESI) $\mathrm{m} / z$ (relative intensity): $312(24)[\mathrm{M}+\mathrm{H}]^{+}$ $\left({ }^{37} \mathrm{Cl}\right), 310(90)[\mathrm{M}+\mathrm{H}]+{ }^{+}\left({ }^{35} \mathrm{Cl}\right), 280(100), 254$ (14), 229 (11). HR-MS (ESI) $\mathrm{m} / \mathrm{z}$ calcd for $\mathrm{C}_{18} \mathrm{H}_{15} \mathrm{~N}_{3}{ }^{37} \mathrm{Cl}[\mathrm{M}]^{+}:$309.1027, found: 309.1019 .

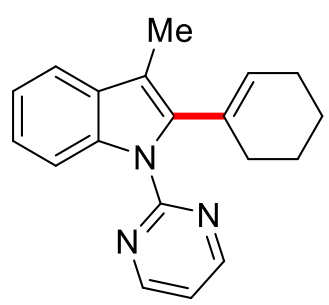

\section{2-(Cyclohex-1-en-1-yl)-3-methyl-1-(pyrimidin-2-yl)-1H-indole (44jb)}

The general procedure A was followed using indole 23j $(53.4 \mathrm{mg}, 0.25 \mathrm{mmol}$, 1.00 equiv) and enol acetate $40 \mathrm{~b}$ (62.7 $\mathrm{mg}, 0.38 \mathrm{mmol}, 1.50$ equiv). Purification by column chromatography on silica gel ( $n$-pentane/EtOAc 18:1) yielded $44 \mathbf{j b}$ as a pale yellow solid (62.2 mg, $214 \mu \mathrm{mol}, 85 \%)$. M. p. $=168-170{ }^{\circ} \mathrm{C}$. ${ }^{1} \mathrm{H}-\mathrm{NMR}(300 \mathrm{MHz}$, $\left.\mathrm{CDCl}_{3}\right): \delta=8.74(\mathrm{~d}, J=4.4 \mathrm{~Hz}, 2 \mathrm{H}), 8.30(\mathrm{~m}, 1 \mathrm{H}), 7.58-7.52(\mathrm{~m}, 1 \mathrm{H}), 7.24-7.19(\mathrm{~m}$, $2 \mathrm{H}), 7.085(\mathrm{t}, J=4.4 \mathrm{~Hz}, 1 \mathrm{H}), 5.80-5.77(\mathrm{~m}, 1 \mathrm{H}), 2.25(\mathrm{~s}, 3 \mathrm{H}), 2.24-2.20(\mathrm{~m}, 2 \mathrm{H})$, 2.04-1.99 (m, 2H), 1.69-1.67 (m, 4H). ${ }^{13} \mathrm{C}-\mathrm{NMR}\left(125 \mathrm{MHz}, \mathrm{CDCl}_{3}\right): \delta=158.1\left(\mathrm{C}_{\mathrm{q}}\right)$, $157.8(\mathrm{CH}), 138.7\left(\mathrm{C}_{\mathrm{q}}\right), 136.6\left(\mathrm{C}_{\mathrm{q}}\right), 131.5\left(\mathrm{C}_{\mathrm{q}}\right), 130.5\left(\mathrm{C}_{\mathrm{q}}\right), 128.5(\mathrm{CH}), 123.2(\mathrm{CH})$, $123.1(\mathrm{CH}), 121.6(\mathrm{CH}), 118.2(\mathrm{CH}), 116.2(\mathrm{CH}), 113.3\left(\mathrm{C}_{\mathrm{q}}\right), 29.8\left(\mathrm{CH}_{2}\right), 25.6\left(\mathrm{CH}_{2}\right)$, $23.3\left(\mathrm{CH}_{2}\right), 22.0\left(\mathrm{CH}_{2}\right), 9.6\left(\mathrm{CH}_{3}\right)$. IR (ATR): 2915, 1561, 1427, 1355, 1271, 1138, 824, 
792. $\mathrm{cm}^{-1}$. MS (ESI) $\mathrm{m} / z$ (relative intensity): $312(41)[\mathrm{M}+\mathrm{Na}]^{+}, 290(100)[\mathrm{M}+\mathrm{H}]^{+}, 263$ (9), 247 (19), 159 (11). HR-MS (ESI) $\mathrm{m} / z$ calcd for $\mathrm{C}_{19} \mathrm{H}_{19} \mathrm{~N}_{3}[\mathrm{M}+\mathrm{H}]^{+}: 290.1652$, found: 290.1652 . The analytical data correspond with those reported in literature.[56]<smiles>CCc1cccc2cc(C3=CCCCC3)n(-c3ncccn3)c12</smiles>

\section{2-(Cyclohex-1-en-1-yl)-7-ethyl-1-(pyrimidin-2-yl)-1 H-indole (44kb)}

The general procedure A was followed using indole 23k $(59.9 \mathrm{mg}, 0.25 \mathrm{mmol}$, 1.00 equiv) and enol acetate $40 \mathrm{~b}(61.8 \mathrm{mg}, 0.38 \mathrm{mmol}, 1.50$ equiv). Purification by column chromatography on silica gel ( $n$-pentane/EtOAc $20: 1$ ) yielded $44 \mathbf{k b}(56.6 \mathrm{mg}$, $185 \mu \mathrm{mol}, 74 \%)$ as a pale yellow oil. ${ }^{1} \mathrm{H}-\mathrm{NMR}\left(300 \mathrm{MHz}, \mathrm{CDCl}_{3}\right) \delta=8.82(\mathrm{~d}, J=5.1 \mathrm{~Hz}$, $2 \mathrm{H}$ ), 7.42 (d, $J=7.5 \mathrm{~Hz}, 1 \mathrm{H}$ ), 7.29 (dd, $J=7.5,7.2 \mathrm{~Hz}, 1 \mathrm{H}$ ), 7.07 (t, $J=5.1 \mathrm{~Hz}, 1 \mathrm{H}$ ), $6.98(\mathrm{~d}, J=7.2 \mathrm{~Hz}, 1 \mathrm{H}), 6.53(\mathrm{~s}, 1 \mathrm{H}), 5.63-5.61(\mathrm{~m}, 1 \mathrm{H}), 2,29(\mathrm{q}, J=6.8 \mathrm{~Hz}, 2 \mathrm{H})$, 2.14-2.03 (m, 2H), 1.98-1.91 (m, 2H), 1.62-1.46 (m, 4H), $0.89(\mathrm{t}, J=6.8 \mathrm{~Hz}, 3 \mathrm{H}) .{ }^{13} \mathrm{C}-$ $\operatorname{NMR}\left(125 \mathrm{MHz}, \mathrm{CDCl}_{3}\right): \delta=160.5\left(\mathrm{C}_{\mathrm{q}}\right), 158.0(\mathrm{CH}), 144.2\left(\mathrm{C}_{\mathrm{q}}\right), 136.3\left(\mathrm{C}_{\mathrm{q}}\right), 129.9\left(\mathrm{C}_{\mathrm{q}}\right)$, $129.5\left(\mathrm{C}_{\mathrm{q}}\right), 128.9(\mathrm{CH}), 127.9\left(\mathrm{C}_{\mathrm{q}}\right), 123.0(\mathrm{CH}), 121.2(\mathrm{CH}) 119.6(\mathrm{CH}), 118.2(\mathrm{CH})$, $103.4(\mathrm{CH}), 28.9\left(\mathrm{CH}_{2}\right), 25.7\left(\mathrm{CH}_{2}\right), 25.2\left(\mathrm{CH}_{2}\right) 22.7\left(\mathrm{CH}_{2}\right), 21.8\left(\mathrm{CH}_{2}\right), 14.4\left(\mathrm{CH}_{3}\right)$. IR (ATR): 2937, 1558, 1371, 1227, 1162. 1039, 822, $744 \mathrm{~cm}^{-1}$. MS (ESI) $\mathrm{m} / z$ (relative intensity): 304 (100) [M+H]+, 279 (18), 219 (14), 179 (11). HR-MS (ESI) m/z calcd for $\mathrm{C}_{20} \mathrm{H}_{21} \mathrm{~N}_{3}[\mathrm{M}]^{+}: 303.1808$, found: 303.1796 .

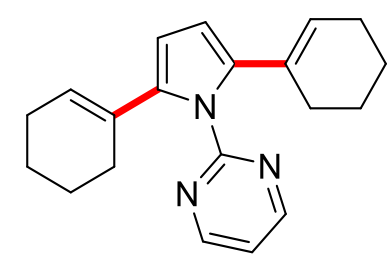

\section{2-[2,5-Bis(cyclohex-1-en-1-yl)-1H-pyrrol-1-yl]pyrimidine (218ab)}

The general procedure A was followed using pyrrole $217 \mathrm{a}(39.3 \mathrm{mg}, 0.25 \mathrm{mmol}$, 1.00 equiv) and enol acetate 40b (106 mg, $0.75 \mathrm{mmol}, 1.50$ equiv). Purification by column chromatography on silica gel ( $n$-pentane/EtOAc 18:1) yielded 218ab as a colorless oil $(58.0 \mathrm{mg}, 186 \mu \mathrm{mol}, 74 \%)$. ${ }^{1} \mathrm{H}-\mathrm{NMR}\left(300 \mathrm{MHz}, \mathrm{CDCl}_{3}\right): \delta=8.77$ (d, $J=4.6 \mathrm{~Hz}, 2 \mathrm{H}$ ), 7.21 (t, $4.6 \mathrm{~Hz}, 1 \mathrm{H}), 6.07$ (s, 2H), 5.35-5.32 (m, 2H), 1.97-1.90 (m, $8 \mathrm{H}), 1.55-1.44(\mathrm{~m}, 8 \mathrm{H}) .{ }^{13} \mathrm{C}-\mathrm{NMR}\left(125 \mathrm{MHz}, \mathrm{CDCl}_{3}\right): \delta=159.4\left(\mathrm{C}_{\mathrm{q}}\right), 158.1(\mathrm{CH}), 137.6$ 
$\left(\mathrm{C}_{\mathrm{q}}\right), 130.6\left(\mathrm{C}_{\mathrm{q}}\right), 125.9(\mathrm{CH}), 120.2(\mathrm{CH}), 108.8(\mathrm{CH}), 28.6\left(\mathrm{CH}_{2}\right), 25.5\left(\mathrm{CH}_{2}\right), 22.8$ $\left(\mathrm{CH}_{2}\right), 22.1\left(\mathrm{CH}_{2}\right)$. IR (ATR): 2927, 1578, 1512, 1327, 1024, $824 \mathrm{~cm}^{-1}$. MS (ESI) $\mathrm{m} / \mathrm{z}$ (relative intensity): $328(25)[\mathrm{M}+\mathrm{Na}]^{+} 306(100)[\mathrm{M}+\mathrm{H}]^{+}, 219$ (5), 117 (10). HR-MS (ESI) $\mathrm{m} / \mathrm{z}$ calcd for $\mathrm{C}_{20} \mathrm{H}_{23} \mathrm{~N}_{3}[\mathrm{M}+\mathrm{H}]^{+}: 306.1965$, found: 306.1976 .<smiles>O=C1CCCc2c1cc(C1=CCCCC1)n2-c1ncccn1</smiles>

\section{2-(Cyclohex-1-en-1-yl)-1-(pyrimidin-2-yl)-1,5,6,7-tetrahydro-4H-indol-4-one $(218 \mathrm{cb})$}

The general procedure $\mathbf{A}$ was followed using 1-(pyrimidin-2-yl)-1,5,6,7-tetrahydro- $4 \mathrm{H}$ indol-4-one (217c) (80.3 mg, $0.50 \mathrm{mmol}, 1.00$ equiv) and enol acetate $40 \mathrm{~b}(62.9 \mathrm{mg}$, $0.38 \mathrm{mmol}, 1.50$ equiv). Purification by column chromatography on silica gel ( $n$-pentane/EtOAc 1:2) yielded $218 \mathrm{cb}(39.3 \mathrm{mg}, 134 \mu \mathrm{mol}, 53 \%)$ as a white solid. M. p. $=112-116{ }^{\circ} \mathrm{C} .{ }^{1} \mathrm{H}-\mathrm{NMR}\left(300 \mathrm{MHz}, \mathrm{CDCl}_{3}\right): \delta=8.80(\mathrm{~d}, J=4.6 \mathrm{~Hz}, 2 \mathrm{H}), 7.31$ (t, $J=4.6 \mathrm{~Hz}, 1 \mathrm{H}), 6.49(\mathrm{~s}, 1 \mathrm{H}), 5.48-5.44(\mathrm{~m}, 1 \mathrm{H}), 2.83(\mathrm{t}, J=6.1 \mathrm{~Hz}, 2 \mathrm{H}), 2.47$ (dd, $J=7.2,5.5 \mathrm{~Hz}, 2 \mathrm{H}$ ), 2.11 (tt, $J=7.2,5.5 \mathrm{~Hz}, 2 \mathrm{H}), 2.02-1.91(\mathrm{~m}, 2 \mathrm{H}), 1.89-1.81(\mathrm{~m}$, 2H), 1.59-1.52 (m, 4H). ${ }^{13} \mathrm{C}-\mathrm{NMR}\left(125 \mathrm{MHz}, \mathrm{CDCl}_{3}\right): \delta=194.3\left(\mathrm{C}_{\mathrm{q}}\right), 158.4(\mathrm{CH}), 157.4$ $\left(\mathrm{C}_{\mathrm{q}}\right), 145.2\left(\mathrm{C}_{\mathrm{q}}\right), 138.3\left(\mathrm{C}_{\mathrm{q}}\right), 129.6\left(\mathrm{C}_{\mathrm{q}}\right), 126.9(\mathrm{CH}), 121.4\left(\mathrm{C}_{\mathrm{q}}\right), 119.3(\mathrm{CH}), 105.3$ $(\mathrm{CH}), 37.9\left(\mathrm{CH}_{2}\right), 28.7\left(\mathrm{CH}_{2}\right), 25.6\left(\mathrm{CH}_{2}\right), 23.8\left(\mathrm{CH}_{2}\right), 23.7\left(\mathrm{CH}_{2}\right), 22.7\left(\mathrm{CH}_{2}\right), 21.9$ (CH 2$)$. IR (ATR): 2930, 1658, 1573, 1410, 1218, 1178, 1017, 834, $635 \mathrm{~cm}^{-1}$. MS (ESI) $\mathrm{m} / \mathrm{z}$ (relative intensity): $332(80)[\mathrm{M}+\mathrm{K}]^{+}, 316(28)[\mathrm{M}+\mathrm{Na}]^{+}, 294(100)[\mathrm{M}+\mathrm{H}]^{+}$. HR-MS (ESI) $\mathrm{m} / z$ calcd for $\mathrm{C}_{18} \mathrm{H}_{19} \mathrm{~N}_{3} \mathrm{O}[\mathrm{M}+\mathrm{H}]^{+}: 294.1606$, found: 294.1602 . The analytical data correspond with those reported in literature. ${ }^{[56]}$ 


\subsection{Cobalt-Catalyzed Allylation of Indoles}

\subsubsection{Analytical Data and Experimental Procedures}<smiles>C=CCc1cc2c(OCC)cccc2n1-c1ncccn1</smiles>

\section{2-Allyl-4-ethoxy-1-(pyrimidin-2-yl)-1 H-indole (91m)}

The general procedure B was followed using indole $23 \mathrm{~m}(118 \mathrm{mg}, 0.50 \mathrm{mmol}$, 1.00 equiv) and allyl acetate 213 (106 mg, 1.00 mmol, 2.00 equiv). Purification by column chromatography on silica gel ( $n$-hexane/EtOAc 12:1) yielded $91 \mathrm{~m}$ (125 mg, $452 \mu \mathrm{mol}, 89 \%)$ as a colourless solid. M. p. $=125-126{ }^{\circ} \mathrm{C} .{ }^{1} \mathrm{H}-\mathrm{NMR}\left(300 \mathrm{MHz}, \mathrm{CDCl}_{3}\right)$ $\delta=8.75(\mathrm{~d}, J=4.8 \mathrm{~Hz}, 2 \mathrm{H}), 7.82(\mathrm{~d}, J=7.8 \mathrm{~Hz}, 1 \mathrm{H}), 7.13-7.09(\mathrm{~m}, 2 \mathrm{H}), 6.62-6.60(\mathrm{~m}$, 2H), 5.98 (ddt, $J=17.0,10.3,6.5 \mathrm{~Hz}, 1 \mathrm{H}$ ), 5.01 (ddt, $J=17.0,1.7 \mathrm{~Hz}, 1 \mathrm{H}$ ), 5.00 (ddt, $J=10.3,1.7 \mathrm{~Hz}, 1 \mathrm{H}), 4.16(\mathrm{q}, J=6.9 \mathrm{~Hz}, 2 \mathrm{H}) 3.92(\mathrm{dd}, J=6.5,1.2 \mathrm{~Hz}, 2 \mathrm{H}), 1.48$ (t, $J=6.9 \mathrm{~Hz}, 3 \mathrm{H}) .{ }^{13} \mathrm{C}-\mathrm{NMR}\left(125 \mathrm{MHz}, \mathrm{CDCl}_{3}\right): \delta=158.3\left(\mathrm{C}_{\mathrm{q}}\right), 158.0(\mathrm{CH}), 151.7\left(\mathrm{C}_{\mathrm{q}}\right)$ $138.4\left(\mathrm{C}_{\mathrm{q}}\right), 138.0\left(\mathrm{C}_{\mathrm{q}}\right) 135.7(\mathrm{CH}), 123.4(\mathrm{CH}), 119.8\left(\mathrm{C}_{\mathrm{q}}\right), 117.1(\mathrm{CH}), 116.3\left(\mathrm{CH}_{2}\right)$, $107.0(\mathrm{CH}), 103.5(\mathrm{CH}), 103.2(\mathrm{CH}), 63.6\left(\mathrm{CH}_{2}\right), 34.0\left(\mathrm{CH}_{2}\right), 15.0\left(\mathrm{CH}_{3}\right)$. IR (ATR): $\mathrm{n}\left(\mathrm{cm}^{-1}\right)=2973,1642,1425,1302,736,727,654 \mathrm{~cm}^{-1}$. El-MS: $m / z$ (relative intensity): 279 (91) [M] $]^{+}, 264$ (100), 250 (59), 236 (22), 222 (28) 79 (13), 43, (11). HR-MS (ESI): $m / z$ calcd for $\mathrm{C}_{17} \mathrm{H}_{17} \mathrm{~N}_{3} \mathrm{O}[\mathrm{M}]^{+}:$279.1372, found: 279.1376 .

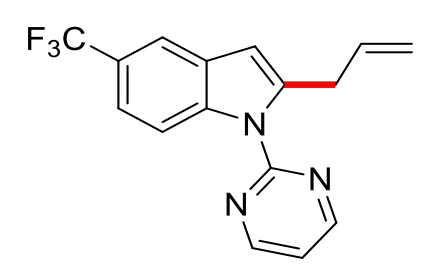

\section{2-Allyl-5-(trifluoromethyl)-1-(pyrimidin-2-yl)-1H-indole (91f)}

The general procedure B was followed using indole $23 f(132 \mathrm{mg}, 0.50 \mathrm{mmol}$, 1.00 equiv) and allyl acetate 213 (107 mg, 1.00 mmol, 2.00 equiv). Purification by HPLC ( $n$-hexane/EtOAc 80:20) yielded $91 f$ (128 mg, $421 \mu \mathrm{mol}, 84 \%$ ) as a yellow oil. ${ }^{1} \mathrm{H}-\mathrm{NMR}\left(300 \mathrm{MHz}, \mathrm{CDCl}_{3}\right) \delta=8.80(\mathrm{~d}, J=4.8 \mathrm{~Hz}, 2 \mathrm{H}), 8.29(\mathrm{~d}, J=7.9 \mathrm{~Hz}, 1 \mathrm{H}), 7.79$ (s, 1H), 7.43 (d, J=7.9, 1H), 7.19 (t, $J=4.8 \mathrm{~Hz}, 1 \mathrm{H}), 6.54$ (s, 1H), 5.94 (ddt, $J=16.8$, 10.2, $6.3 \mathrm{~Hz}, 1 \mathrm{H}$ ), 5.04 (ddt, $J=16.8,1.7,1.3 \mathrm{~Hz}, 1 \mathrm{H}$ ), 5.00 (ddt, $J=10.2,1.7 \mathrm{~Hz}$, 
$1 \mathrm{H}), 3.95(\mathrm{~d}, J=6.3 \mathrm{~Hz}, 2 \mathrm{H}) .{ }^{13} \mathrm{C}-\mathrm{NMR}\left(125 \mathrm{MHz}, \mathrm{CDCl}_{3}\right): \delta=158.2(\mathrm{CH}), 157.8\left(\mathrm{C}_{\mathrm{q}}\right)$, $141.7\left(\mathrm{C}_{\mathrm{q}}\right) 138.5\left(\mathrm{C}_{\mathrm{q}}\right), 135.0(\mathrm{CH}) 138.7\left(\mathrm{C}_{\mathrm{q}}\right), 125.1\left(\mathrm{q},{ }^{1} \mathrm{~J}_{\mathrm{CF}}=271 \mathrm{~Hz}, \mathrm{C}_{\mathrm{q}}\right), 124.0(\mathrm{q}$, $\left.{ }^{2} \mathrm{~J}_{\mathrm{CF}}=32.2 \mathrm{~Hz}, \mathrm{C}_{\mathrm{q}}\right), \quad 119.3 \quad\left(\mathrm{q}, \quad{ }^{3} \mathrm{~J}_{\mathrm{CF}}=3.8 \mathrm{~Hz}, \mathrm{CH}\right), \quad 117.7 \quad(\mathrm{CH}), \quad 117.2 \quad(\mathrm{q}$, $\left.{ }^{3} \mathrm{~J}_{\mathrm{CF}}=3.8 \mathrm{~Hz}, \mathrm{CH}\right), 116.8\left(\mathrm{CH}_{2}\right), 114.0(\mathrm{CH}), 106.5(\mathrm{CH}), 33.9\left(\mathrm{CH}_{2}\right) .{ }^{19} \mathrm{~F}-\mathrm{NMR}$ $\left(282 \mathrm{MHz}, \mathrm{CDCl}_{3}\right): d=-61.17$. IR (ATR): $\mathrm{n}\left(\mathrm{cm}^{-1}\right)=2977,1561,1426,1324,1112$, 1058, $805 \mathrm{~cm}^{-1}$. El-MS: $m / z$ (relative intensity): 303 (26) [M] ${ }^{+}, 288$ (100), 275 (9), 219 (11), 154 (8), 79, (6). HR-MS (ESI): $m / z$ calcd for $\mathrm{C}_{16} \mathrm{H}_{12} \mathrm{~N}_{3} \mathrm{~F}_{3}[\mathrm{M}+\mathrm{H}]^{+}: 304.1062$, found: 304.1056 .<smiles>C=CCc1cc2cc(NC(C)=O)ccc2n1-c1ncccn1</smiles>

\section{N-(2-Allyl-1-(pyrimidin-2-yl)-1 H-indol-5-yl)acetamide (91i)}

The general procedure B was followed using indole $23 \mathbf{i}(42.3 \mathrm{mg}, 0.17 \mathrm{mmol}$, 1.00 equiv) and allyl acetate 213 (34.0 mg, $0.34 \mathrm{mmol}, 2.00$ equiv). Purification by column chromatography on silica gel ( $n$-hexane/EtOAc 12:1) yielded $91 \mathrm{i}(38.7 \mathrm{mg}$, $132 \mu \mathrm{mol}, 78 \%)$ as a yellow oil. ${ }^{1} \mathrm{H}-\mathrm{NMR}\left(300 \mathrm{MHz}, \mathrm{CDCl}_{3}\right) \delta=8.73(\mathrm{~d}, J=5.7 \mathrm{~Hz}$, $2 \mathrm{H}$ ), 8.19 (d, $J=7.2 \mathrm{~Hz}, 1 \mathrm{H}$ ), 7.79 (d, $J=1.3 \mathrm{~Hz}, 1 \mathrm{H}$ ), 7.39 (s, $1 \mathrm{H}), 7.15$ (dd, $J=8.9$, $2.2 \mathrm{~Hz}, 1 \mathrm{H}), 7.09(\mathrm{t}, J=5.7 \mathrm{~Hz}, 1 \mathrm{H}), 6.44(\mathrm{~s}, 1 \mathrm{H}), 5.95(\mathrm{ddt}, J=17.9,10.4,5.5 \mathrm{~Hz}, 1 \mathrm{H})$, 5.03 (ddt, $J=17.9,1.4 \mathrm{~Hz}, 1 \mathrm{H}$ ), 5.00 (ddt, $J=10.4,1.4 \mathrm{~Hz}, 1 \mathrm{H}$ ), 3.93 (d, $J=5.5 \mathrm{~Hz}$, 2H) $2.15(\mathrm{~s}, 3 \mathrm{H}) .{ }^{13} \mathrm{C}-\mathrm{NMR}\left(125 \mathrm{MHz}, \mathrm{CDCl}_{3}\right): \delta=168.2\left(\mathrm{C}_{\mathrm{q}}\right), 158.1\left(\mathrm{C}_{\mathrm{q}}\right), 158.0(\mathrm{CH})$, $140.7\left(\mathrm{C}_{\mathrm{q}}\right) 135.4(\mathrm{CH}), 134.1\left(\mathrm{C}_{\mathrm{q}}\right) 132.3\left(\mathrm{C}_{\mathrm{q}}\right), 129.5\left(\mathrm{C}_{\mathrm{q}}\right), 116.9(\mathrm{CH}), 116.4\left(\mathrm{CH}_{2}\right)$, $115.8(\mathrm{CH}), 114.3(\mathrm{CH}), 111.4(\mathrm{CH}), 106.7(\mathrm{CH}), 34.2\left(\mathrm{CH}_{2}\right), 24.5\left(\mathrm{CH}_{3}\right)$. IR (ATR): $\mathrm{n}\left(\mathrm{cm}^{-1}\right)=2981,1681,1429,1302,1251,730,651 \mathrm{~cm}^{-1}$. El-MS: $\mathrm{m} / \mathrm{z}$ (relative intensity): 292 (43) [M] ${ }^{+}, 277$ (100), 249 (17), 235 (33), 79 (8), 43 (24). HR-MS (ESI): $\mathrm{m} / z$ calcd for $\mathrm{C}_{17} \mathrm{H}_{17} \mathrm{~N}_{4} \mathrm{O}[\mathrm{M}+\mathrm{H}]^{+}:$293.1402, found: 293.1398 . 


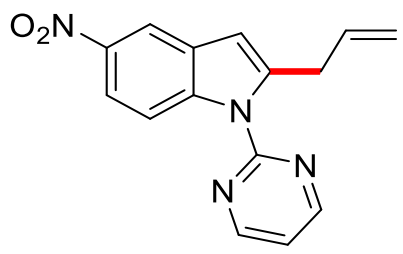

\section{2-Allyl-5-nitro-1-(pyrimidin-2-yl)-1 H-indole (91n)}

The general procedure B was followed using indole $23 \mathrm{n}(119 \mathrm{mg}, 0.50 \mathrm{mmol}$, 1.00 equiv) and allyl acetate 213 (104 mg, 1.00 mmol, 2.00 equiv). Purification by column chromatography on silica gel ( $n$-hexane/EtOAc 12:1) yielded $91 \mathrm{n}(127 \mathrm{mg}$, $455 \mu \mathrm{mol}, 91 \%)$ as a yellow solid. M. p. $=106-108{ }^{\circ} \mathrm{C} .{ }^{1} \mathrm{H}-\mathrm{NMR}\left(300 \mathrm{MHz}, \mathrm{CDCl}_{3}\right)$ $\delta=8.83(\mathrm{~d}, J=4.7 \mathrm{~Hz}, 2 \mathrm{H}), 8.43(\mathrm{~d}, J=2.3 \mathrm{~Hz}, 1 \mathrm{H}), 8.22(\mathrm{~d}, J=8.7 \mathrm{~Hz}, 1 \mathrm{H}), 8.09$ (dd, $J=8.7,2.3 \mathrm{~Hz}, 1 \mathrm{H}$ ), $7.25(\mathrm{t}, J=4.7 \mathrm{~Hz}, 1 \mathrm{H}$ ), $6.60(\mathrm{~s}, 1 \mathrm{H}), 5.93$ (ddt, $J=16.9,10.5$, $6.5 \mathrm{~Hz}, 1 \mathrm{H}$ ), 5.06 (ddt, $J=16.9,1.3 \mathrm{~Hz}, 1 \mathrm{H}$ ), 5.04 (ddt, $J=10.5,1.3 \mathrm{~Hz}, 1 \mathrm{H}$ ), 3.94 (dd, $J=6.5,1.3 \mathrm{~Hz}, 2 \mathrm{H}$ ). ${ }^{13} \mathrm{C}-\mathrm{NMR}\left(125 \mathrm{MHz}, \mathrm{CDCl}_{3}\right): \delta=158.4(\mathrm{CH}), 157.5\left(\mathrm{C}_{\mathrm{q}}\right), 143.3$ $\left(\mathrm{C}_{\mathrm{q}}\right) 143.0\left(\mathrm{C}_{\mathrm{q}}\right), 140.0\left(\mathrm{C}_{\mathrm{q}}\right) 134.5(\mathrm{CH}), 128.7\left(\mathrm{C}_{\mathrm{q}}\right), 118.3(\mathrm{CH}), 118.0(\mathrm{CH}), 117.1$ $\left(\mathrm{CH}_{2}\right), 116.3(\mathrm{CH}), 113.7(\mathrm{CH}), 107.0(\mathrm{CH}), 33.9\left(\mathrm{CH}_{2}\right)$. IR $($ ATR $): \mathrm{n}\left(\mathrm{cm}^{-1}\right)=2977$, 1610, 1570, 1421, 1071, 924, 745, $541 \mathrm{~cm}^{-1}$. El-MS: $\mathrm{m} / z$ (relative intensity): 280 (34) [M] ${ }^{+}, 265$ (100), 219 (44), 207 (18). HR-MS (ESI): $\mathrm{m} / z$ calcd for $\mathrm{C}_{15} \mathrm{H}_{12} \mathrm{~N}_{4} \mathrm{O}_{2}[\mathrm{M}]^{+}$: 280.0960, found: 280.0963 .

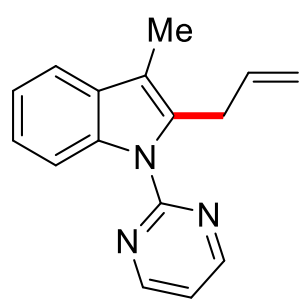

\section{2-Allyl-3-methyl-1-(pyrimidin-2-yl)-1 H-indole (91j)}

The general procedure B was followed using indole 23j $(106 \mathrm{mg}, 0.50 \mathrm{mmol}$, 1.00 equiv) and allyl acetate 213 (105 mg, $1.00 \mathrm{mmol}, 2.00$ equiv). Purification by column chromatography on silica gel ( $n$-hexane/EtOAc 15:1) yielded $91 \mathbf{j}$ (116 mg, $467 \mu \mathrm{mol}, 93 \%)$ as a colourless solid. M. p. $=79-81^{\circ} \mathrm{C} .{ }^{1} \mathrm{H}-\mathrm{NMR}\left(300 \mathrm{MHz}, \mathrm{CDCl}_{3}\right)$ $\delta=8.75(\mathrm{~d}, J=5.2 \mathrm{~Hz}, 2 \mathrm{H}), 8.23-8.21(\mathrm{~m}, 1 \mathrm{H}), 7.52-7.50(\mathrm{~m}, 1 \mathrm{H}), 7.22-7.19(\mathrm{~m}, 2 \mathrm{H})$, 7.06 (t, $J=5.2 \mathrm{~Hz}, 1 \mathrm{H}$ ), 5.90 (ddt, $J=16.7,9.9,5.9 \mathrm{~Hz}, 1 \mathrm{H}$ ), 4.87 (ddt, $J=16.7,1.9 \mathrm{~Hz}$, $1 \mathrm{H}$ ), $4.84(\mathrm{ddt}, J=9.9,1.9 \mathrm{~Hz}, 1 \mathrm{H}), 3.97(\mathrm{dd}, J=5.9,1.8 \mathrm{~Hz}, 2 \mathrm{H}), 2.29(\mathrm{~s}, 3 \mathrm{H}) .{ }^{13} \mathrm{C}-$ $\operatorname{NMR}\left(125 \mathrm{MHz}, \mathrm{CDCl}_{3}\right): \delta=158.2\left(\mathrm{C}_{\mathrm{q}}\right), 158.0(\mathrm{CH}), 136.2\left(\mathrm{C}_{\mathrm{q}}\right), 135.9(\mathrm{CH}), 134.1$ $\left(\mathrm{C}_{\mathrm{q}}\right), 130.4\left(\mathrm{C}_{\mathrm{q}}\right), 122.9(\mathrm{CH}), 121.4(\mathrm{CH}), 118.0(\mathrm{CH}), 116.7(\mathrm{CH}), 115.0\left(\mathrm{CH}_{2}\right), 113.8$ 
(C), $113.5(\mathrm{CH}), 30.4\left(\mathrm{CH}_{2}\right), 8.8\left(\mathrm{CH}_{3}\right)$. IR (ATR): $\mathrm{n}\left(\mathrm{cm}^{-1}\right)=2912,1656,1416,1197$, 809, 734, 603, $440 \mathrm{~cm}^{-1}$. El-MS: $\mathrm{m} / z$ (relative intensity): 249 (32) [M] $]^{+}, 234$ (100), 220 (20), 154 (11), 43, (18). HR-MS (ESI): $m / z$ calcd for $\mathrm{C}_{16} \mathrm{H}_{15} \mathrm{~N}_{3}$ [M] ${ }^{+}: 249.1266$, found: 249.1264. The analytical data correspond with those reported in literature.[79b]

\subsection{Base-Metal Catalyzed C-H Alkynyaltion}

\subsubsection{Analytical Data and Experimental Procedures}

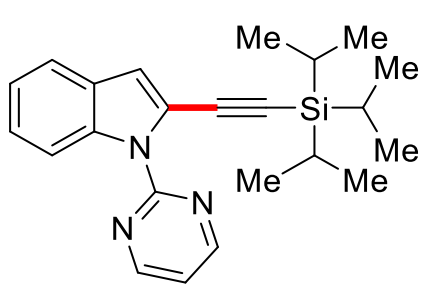

\section{1-(Pyrimidin-2-yl)-2-[(triisopropylsilyl)ethynyl]-1 H-indole (89aa)}

The general procedure C was followed using indole 23a $(48.9 \mathrm{mg}, 0.25 \mathrm{mmol}$, 1.00 equiv) and $132 \mathrm{a}(79.1 \mathrm{mg}, 0.30 \mathrm{mmol}, 1.20$ equiv). Purification by column chromatography on silica gel ( $n$-pentane/EtOAc 8:1) yielded 89aa $(90.3 \mathrm{mg}, 241 \mu \mathrm{mol}$, $96 \%)$ as a yellow oil.

The general procedure D was followed using indole 23a $(98 \mathrm{mg}, 0.50 \mathrm{mmol}$, 1.00 equiv) and $132 \mathrm{a}$ (157 mg, $0.60 \mathrm{mmol}, 1.20$ equiv). Isolation by column chromatography ( $n$-hexane/EtOAc: $9 / 1$ ) yielded 89aa (186 mg, 99\%) as a colorless liquid. ${ }^{1} \mathrm{H}-\mathrm{NMR}\left(500 \mathrm{MHz}, \mathrm{CDCl}_{3}\right) \delta=8.79(\mathrm{~d}, J=4.8 \mathrm{~Hz}, 2 \mathrm{H}$ ), 8.28 (ddd, $J=8.1,1.0$, $0.6 \mathrm{~Hz} 1 \mathrm{H}$ ), 7.57 (ddd, $J=8.1,1.0,0.6 \mathrm{~Hz} 1 \mathrm{H}$ ), 7.33 (ddd, $J=8.5,2.0,1.3 \mathrm{~Hz}, 1 \mathrm{H}$ ), 7.23 (ddd, $J=8.5,2.0,1.3 \mathrm{~Hz}, 1 \mathrm{H}$ ), $7.18(\mathrm{t}, J=4.8 \mathrm{~Hz}, 1 \mathrm{H}), 7.07(\mathrm{~d}, J=0.6 \mathrm{~Hz}, 1 \mathrm{H}$ ), 1.13-1.11 (m, 21H). ${ }^{13} \mathrm{C}-\mathrm{NMR}\left(125 \mathrm{MHz}, \mathrm{CDCl}_{3}\right): \delta=158.1(\mathrm{CH}), 157.4\left(\mathrm{C}_{\mathrm{q}}\right), 136.2$ $\left(\mathrm{C}_{\mathrm{q}}\right), 128.5\left(\mathrm{C}_{\mathrm{q}}\right), 124.8(\mathrm{CH}), 122.3(\mathrm{CH}), 120.9\left(\mathrm{C}_{\mathrm{q}}\right), 120.7(\mathrm{CH}), 117.5(\mathrm{CH}), 115.7$ $(\mathrm{CH}), 114.0(\mathrm{CH}), 98.7\left(\mathrm{C}_{\mathrm{q}}\right), 97.8\left(\mathrm{C}_{\mathrm{q}}\right), 18.7\left(\mathrm{CH}_{3}\right), 11.4(\mathrm{CH}) . \mathrm{IR}(\mathrm{ATR}):$ 2940, 2862, 2149, 1561, 1422, 1253, $715 \mathrm{~cm}^{-1}$. MS (El) $\mathrm{m} / \mathrm{z}$ (relative intensity): 375 (32), 332 (100), 304 (16), 290 (32), 262 (18), 222 (24), 138 (9), 69 (14). HR-MS (ESI) m/z calcd for $\mathrm{C}_{23} \mathrm{H}_{29} \mathrm{~N}_{3} \mathrm{Si}[\mathrm{M}]^{+}: 375.2131$, found: 375.2132 . The analytical data are in accordance with those previously reported in the literature. ${ }^{[78]}$ 


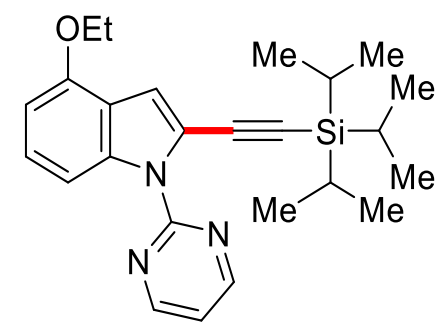

\section{4-Ethoxy-1-(pyrimidin-2-yl)-2-[(triisopropylsilyl)ethynyl]-1 H-indole (89ma)}

The general procedure C was followed using indole $23 \mathrm{~m}(60.1 \mathrm{mg}, 0.25 \mathrm{mmol}$, 1.00 equiv), and $132 \mathrm{a}$ ( $78.9 \mathrm{mg}, 0.30 \mathrm{mmol}, 1.20$ equiv). Purification by column chromatography on silica gel ( $n$-pentane/EtOAc $6: 1$ ) yielded $89 \mathrm{ma}$ (63.8 mg, $164 \mu \mathrm{mol}, 91 \%)$ as a white solid. M. p. $=112-114{ }^{\circ} \mathrm{C} .{ }^{1} \mathrm{H}-\mathrm{NMR}\left(500 \mathrm{MHz}, \mathrm{CDCl}_{3}\right)$ $\delta=8.76(\mathrm{~d}, J=5.0 \mathrm{~Hz}, 2 \mathrm{H}), 7.82$ (ddd, $J=8.1,1.6,0.7 \mathrm{~Hz}, 1 \mathrm{H}), 7.22-7.17(\mathrm{~m}, 2 \mathrm{H})$, $7.14(\mathrm{t}, J=5.0 \mathrm{~Hz}, 1 \mathrm{H}), 6.59(\mathrm{dd}, J=8.1,0.7 \mathrm{~Hz}, 1 \mathrm{H}), 4.16(\mathrm{q}, J=6.7 \mathrm{~Hz}, 2 \mathrm{H}), 1.48(\mathrm{t}$, $J=6.7 \mathrm{~Hz}, 3 \mathrm{H}), 1.11-1.09(\mathrm{~m}, 21 \mathrm{H}) .{ }^{13} \mathrm{C}-\mathrm{NMR}\left(125 \mathrm{MHz}, \mathrm{CDCl}_{3}\right): \delta=158.0(\mathrm{CH})$, $157.5\left(\mathrm{C}_{\mathrm{q}}\right), 152.1\left(\mathrm{C}_{\mathrm{q}}\right), 137.4\left(\mathrm{C}_{\mathrm{q}}\right), 125.7(\mathrm{CH}), 119.5\left(\mathrm{C}_{\mathrm{q}}\right), 119.4\left(\mathrm{C}_{\mathrm{q}}\right), 117.5(\mathrm{CH})$, 113.2 $(\mathrm{CH}), 107.0(\mathrm{CH}), 103.1(\mathrm{CH}), 99.0\left(\mathrm{C}_{\mathrm{q}}\right), 97.0\left(\mathrm{C}_{\mathrm{q}}\right), 63.6\left(\mathrm{CH}_{2}\right), 18.7\left(\mathrm{CH}_{3}\right), 14.9$ ( $\left.\mathrm{CH}_{3}\right), 11.4$ (CH). IR (ATR): 2941, 2863, 2142, 1571, 1417, 1246, 740, $727 \mathrm{~cm}^{-1} . \mathrm{MS}$ (EI) m/z (relative intensity): 419 (65), 376 (100), 348 (18), 334 (23), 304 (16). HR-MS (ESI) $\mathrm{m} / z$ calcd for $\mathrm{C}_{25} \mathrm{H}_{33} \mathrm{~N}_{3} \mathrm{OSi}[\mathrm{M}]^{+}: 419.2393$, found: 419.2395 .

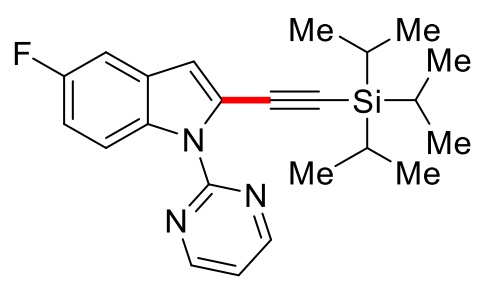

\section{5-Fluoro-1-(pyrimidin-2-yl)-2-[(triisopropylsilyl)ethynyl]-1 H-indole (89oa)}

The general procedure C was followed using indole $230(53.4 \mathrm{mg}, 0.25 \mathrm{mmol}$, 1.00 equiv) and $132 \mathrm{a}\left(78.8 \mathrm{mg}, 0.30 \mathrm{mmol}, 1.20\right.$ equiv) at $80^{\circ} \mathrm{C}$. Purification by column chromatography on silica gel ( $n$-pentane/EtOAc $8: 1)$ yielded $890 a(80.9 \mathrm{mg}$, $206 \mu \mathrm{mol}, 82 \%$ ) as a white solid.

The general procedure D was followed using indole $230(108 \mathrm{mg}, 0.50 \mathrm{mmol}$, 1.00 equiv) and 132a (155 mg, $0.60 \mathrm{mmol}, 1.20$ equiv). Isolation by column chromatography ( $n$-pentane/EtOAc: $8 / 1$ ) yielded $890 a(174 \mathrm{mg}, 88 \%$ ) as a yellow solid. M. p. $=91-93{ }^{\circ} \mathrm{C} .{ }^{1} \mathrm{H}-\mathrm{NMR}\left(500 \mathrm{MHz}, \mathrm{CDCl}_{3}\right) \delta=8.77(\mathrm{~d}, J=4.7 \mathrm{~Hz}, 2 \mathrm{H}), 8.26$ (dd, $J=9.1,4.7 \mathrm{~Hz} 1 \mathrm{H}$ ), 7.23-7.17 (m, 2H), 7.05 (ddd, $J=9.1,3.0,1.5 \mathrm{~Hz}, 1 \mathrm{H}$ ), 7.01 (s, 
1H), $1.13-1.11(\mathrm{~m}, 21 \mathrm{H}) .{ }^{13} \mathrm{C}-\mathrm{NMR}\left(125 \mathrm{MHz}, \mathrm{CDCl}_{3}\right): \delta=159.2\left(\mathrm{~d},{ }^{1} \mathrm{JCF}=238 \mathrm{~Hz}, \mathrm{Cq}_{\mathrm{q}}\right)$, $158.1(\mathrm{CH}), 157.2\left(\mathrm{C}_{\mathrm{q}}\right), 132.5\left(\mathrm{C}_{\mathrm{q}}\right), 129.2\left(\mathrm{~d},{ }^{3} \mathrm{~J}_{\mathrm{CF}}=10 \mathrm{~Hz}, \mathrm{C}_{\mathrm{q}}\right), 122.4\left(\mathrm{C}_{\mathrm{q}}\right), 117.7(\mathrm{CH})$, $115.3\left(\mathrm{~d},{ }^{3} \mathrm{~J}_{\mathrm{CF}}=12 \mathrm{~Hz}, \mathrm{CH}\right), 115.2(\mathrm{CH}), 112.8\left(\mathrm{~d},{ }^{2} \mathrm{~J}_{\mathrm{CF}}=25 \mathrm{~Hz}, \mathrm{CH}\right), 105.5(\mathrm{~d}$, $\left.{ }^{2} J_{\mathrm{CF}}=23 \mathrm{~Hz}, \mathrm{CH}\right), 98.6\left(\mathrm{C}_{\mathrm{q}}\right), 98.3\left(\mathrm{C}_{\mathrm{q}}\right), 18.6\left(\mathrm{CH}_{3}\right), 11.4(\mathrm{CH}) .{ }^{19} \mathrm{~F}-\mathrm{NMR}(282 \mathrm{MHz}$, $\mathrm{CDCl}_{3}$ ): -121.9. IR (ATR): 2940, 2862, 2143, 1573, 1556, 1419, 1253, 1211, $723 \mathrm{~cm}^{-1}$. MS (EI) m/z (relative intensity): 393 (22), 350 (100), 322 (19), 308 (30), 280 (22), 240 (28), 147 (12). HR-MS (ESI) $\mathrm{m} / z$ calcd for $\mathrm{C}_{23} \mathrm{H}_{28} \mathrm{~N}_{3} \mathrm{FSi}$ [M] ${ }^{+}: 393.2037$, found: 393.2020. The analytical data are in accordance with those previously reported in the literature. ${ }^{[78]}$

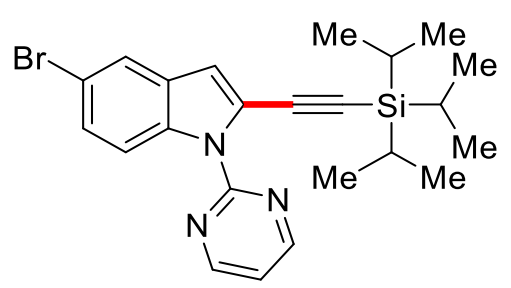

\section{5-Bromo-1-(pyrimidin-2-yl)-2-[(triisopropylsilyl)ethynyl]-1 H-indole (89ha)}

The general procedure C was followed using indole $23 \mathrm{~h}(68.1 \mathrm{mg}, 0.25 \mathrm{mmol}$, 1.00 equiv) and $132 \mathrm{a}$ ( $78.4 \mathrm{mg}, 0.30 \mathrm{mmol}, 1.20$ equiv) at $80^{\circ} \mathrm{C}$. Purification by column chromatography on silica gel ( $n$-pentane/EtOAc $8: 1$ ) yielded $89 \mathrm{ha}(104.4 \mathrm{mg}$, $231 \mu \mathrm{mol}, 92 \%)$ as a white solid.

The general procedure D was followed using indole $23 \mathrm{~h}(137 \mathrm{mg}, 0.50 \mathrm{mmol}$, 1.00 equiv) and $132 \mathrm{a}$ (159 mg, $0.60 \mathrm{mmol}, 1.20$ equiv). Isolation by column chromatography ( $n$-pentane/EtOAc: $8 / 1$ ) yielded $89 \mathrm{ha}(204 \mathrm{mg}, 91 \%$ ) as a yellow solid. M. p. $=94-96{ }^{\circ} \mathrm{C} .{ }^{1} \mathrm{H}-\mathrm{NMR}\left(500 \mathrm{MHz}, \mathrm{CDCl}_{3}\right) \delta=8.76$ (d, $\left.J=5.4 \mathrm{~Hz}, 2 \mathrm{H}\right), 8.04$ (ddd, $J=9.0,1.5,0.5 \mathrm{~Hz} 1 \mathrm{H}$ ), 7.90 (dd, $J=1.5,0.5 \mathrm{~Hz}, 1 \mathrm{H}), 7.53(\mathrm{dd}, J=8.7,1.9 \mathrm{~Hz}, 1 \mathrm{H}$ ), $7.18(\mathrm{t}, J=5.4 \mathrm{~Hz}, 1 \mathrm{H}), 6.94(\mathrm{~d}, J=0.3 \mathrm{~Hz}, 1 \mathrm{H}), 1.11-1.08(\mathrm{~m}, 21 \mathrm{H}) \cdot{ }^{13} \mathrm{C}-\mathrm{NMR}$ $\left(125 \mathrm{MHz}, \mathrm{CDCl}_{3}\right): \delta=158.1(\mathrm{CH}), 157.1\left(\mathrm{C}_{\mathrm{q}}\right), 135.3\left(\mathrm{C}_{\mathrm{q}}\right), 133.0(\mathrm{CH}), 130.9\left(\mathrm{C}_{\mathrm{q}}\right)$, $129.3(\mathrm{CH}), 121.7\left(\mathrm{C}_{\mathrm{q}}\right), 117.9(\mathrm{CH}), 116.2(\mathrm{CH}), 114.3(\mathrm{CH}), 98.8\left(\mathrm{C}_{\mathrm{q}}\right), 98.1\left(\mathrm{C}_{\mathrm{q}}\right), 86.2$ $\left(\mathrm{C}_{\mathrm{q}}\right), 18.6\left(\mathrm{CH}_{3}\right), 11.4(\mathrm{CH})$. IR (ATR): 2960, 2861, 2140,1572, 1420, 1256, 1014, 792, $657 \mathrm{~cm}^{-1}$. MS (El) m/z (relative intensity): 455 (21), 412 (100), 368 (33), 302 (24), 178 (14). HR-MS (ESI) $\mathrm{m} / z$ calcd for $\mathrm{C}_{23} \mathrm{H}_{28} \mathrm{~N}_{3} \mathrm{BrSi}[\mathrm{M}]^{+}: 453.1236$, found: 453.1229 . The analytical data are in accordance with those previously reported in the literature. ${ }^{[78]}$ 


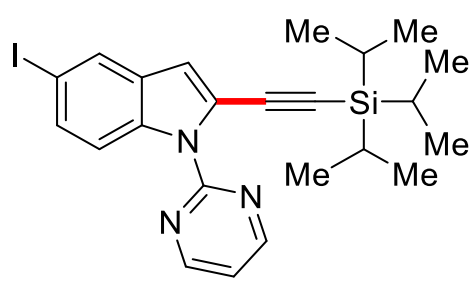

\section{5-lodo-1-(pyrimidin-2-yl)-2-[(triisopropylsilyl)ethynyl]-1 H-indole (89pa)}

The general procedure C was followed using indole $23 \mathrm{p}(80.1 \mathrm{mg}, 0.25 \mathrm{mmol}$, 1.00 equiv) and 132a (78.9 mg, $0.30 \mathrm{mmol}, 1.20$ equiv) at $80^{\circ} \mathrm{C}$. Purification by column chromatography on silica gel ( $n$-pentane/EtOAc 8:1) yielded 89pa $(109.4 \mathrm{mg}$, $217 \mu \mathrm{mol}, 87 \%)$ as a white solid. M. p. $=68-69{ }^{\circ} \mathrm{C} .{ }^{1} \mathrm{H}-\mathrm{NMR}\left(500 \mathrm{MHz}, \mathrm{CDCl}_{3}\right)$ $\delta=8.77(\mathrm{~d}, J=4.9 \mathrm{~Hz}, 2 \mathrm{H}$ ), 8.16 (ddd, $J=8.8,1.4,0.6 \mathrm{~Hz} 1 \mathrm{H}$ ), 7.67 (dd, $J=2.0$, $0.6 \mathrm{~Hz}, 1 \mathrm{H}), 7.36(\mathrm{dd}, J=8.8,2.0 \mathrm{~Hz}, 1 \mathrm{H}), 7.19(\mathrm{t}, J=4.9 \mathrm{~Hz}, 1 \mathrm{H}), 6.98(\mathrm{~d}, J=0.5 \mathrm{~Hz}$, $1 \mathrm{H}), 1.11-1.09(\mathrm{~m}, 21 \mathrm{H}) .{ }^{13} \mathrm{C}-\mathrm{NMR}\left(125 \mathrm{MHz}, \mathrm{CDCl}_{3}\right): \delta=158.1(\mathrm{CH}), 157.1\left(\mathrm{C}_{\mathrm{q}}\right)$, $134.7\left(\mathrm{C}_{\mathrm{q}}\right), 130.2\left(\mathrm{C}_{\mathrm{q}}\right), 127.5(\mathrm{CH}), 123.0(\mathrm{CH}), 122.1\left(\mathrm{C}_{\mathrm{q}}\right), 117.9(\mathrm{CH}), 115.7(\mathrm{CH})$, $115.5\left(\mathrm{C}_{\mathrm{q}}\right), 114.6(\mathrm{CH}), 98.9\left(\mathrm{C}_{\mathrm{q}}\right), 98.1\left(\mathrm{C}_{\mathrm{q}}\right), 18.6\left(\mathrm{CH}_{3}\right), 11.4(\mathrm{CH}) . \mathrm{IR}(\mathrm{ATR}): 2939$, 2860, 2149,1562, 1422, 1180, 782, $662 \mathrm{~cm}^{-1}$. MS (EI) m/z (relative intensity): 501 (32), 458 (100), 430 (16), 416 (28), 388 (15), 348 (12), 201 (11). HR-MS (ESI) $\mathrm{m} / z$ calcd for $\mathrm{C}_{23} \mathrm{H}_{28} \mathrm{~N}_{3} \mathrm{ISi}[\mathrm{M}]^{+}:$501.1097, found: 501.1104 .

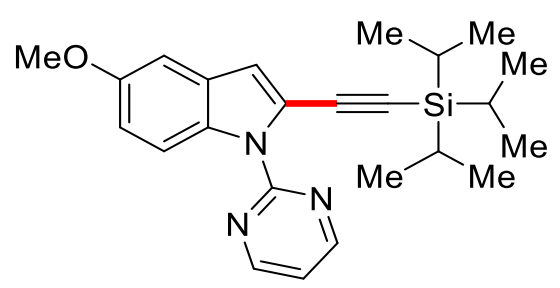

\section{5-Methoxy-1-(pyrimidin-2-yl)-2-[(triisopropylsilyl)ethynyl]-1 H-indole (89da)}

The general procedure C was followed using indole 23d $(56.4 \mathrm{mg}, 0.25 \mathrm{mmol}$, 1.00 quiv) and $132 \mathrm{a}$ (78.7 mg, $0.30 \mathrm{mmol}, 1.20$ equiv). Purification by column chromatography on silica gel ( $n$-pentane/EtOAc 5:1) yielded 89da (94.9 mg, $234 \mu \mathrm{mol}$, $94 \%)$ as a white solid.

The general procedure D was followed using indole $23(113 \mathrm{mg}, 0.50 \mathrm{mmol}$, 1.00 equiv) and 132a (157 mg, $0.60 \mathrm{mmol}, 1.20$ equiv). Isolation by column chromatography ( $n$-pentane/EtOAc: $9 / 1$ ) yielded $89 \mathrm{da}(158 \mathrm{mg}, 78 \%$ ) as a white solid. M. p. $=116-118^{\circ} \mathrm{C} .{ }^{1} \mathrm{H}-\mathrm{NMR}\left(500 \mathrm{MHz}, \mathrm{CDCl}_{3}\right) \delta=8.74(\mathrm{~d}, J=4.8 \mathrm{~Hz}, 2 \mathrm{H}), 8.21(\mathrm{~m}$, $J=9.0,1.1,0.6 \mathrm{~Hz} 1 \mathrm{H}$ ), 7.23 (ddd, $J=8.5,2.0,1.3 \mathrm{~Hz}, 1 \mathrm{H}$ ), $7.15(\mathrm{t}, J=4.8 \mathrm{~Hz}, 1 \mathrm{H}$ ), 
7.01-6.99 (m, 1H), $6.98(\mathrm{~d}, J=0.4 \mathrm{~Hz}, 1 \mathrm{H}), 3.86(\mathrm{~s}, 3 \mathrm{H}), 1.13-1.11(\mathrm{~m}, 21 \mathrm{H}) .{ }^{13} \mathrm{C}-$ $\operatorname{NMR}\left(125 \mathrm{MHz}, \mathrm{CDCl}_{3}\right): \delta=158.0(\mathrm{CH}), 157.3\left(\mathrm{C}_{\mathrm{q}}\right), 155.7\left(\mathrm{C}_{\mathrm{q}}\right), 131.1\left(\mathrm{C}_{\mathrm{q}}\right), 129.3\left(\mathrm{C}_{\mathrm{q}}\right)$, $121.3\left(\mathrm{C}_{\mathrm{q}}\right), 117.3(\mathrm{CH}), 115.6(\mathrm{CH}), 115.3(\mathrm{CH}), 114.4(\mathrm{CH}), 102.2(\mathrm{CH}), 98.9\left(\mathrm{C}_{\mathrm{q}}\right)$, $97.8\left(\mathrm{C}_{\mathrm{q}}\right), 55.6\left(\mathrm{CH}_{3}\right) 18.7\left(\mathrm{CH}_{3}\right), 11.4(\mathrm{CH})$. IR $(\mathrm{ATR}):$ 2940, 2864, 2143, 1562, 1417, 1335, 1207, 840, $741 \mathrm{~cm}^{-1}$. MS (EI) $\mathrm{m} / z$ (relative intensity): 405 (46), 362 (100), 320 (29), 292 (11), 252 (13), 153 (10). HR-MS (ESI) m/z calcd for $\mathrm{C}_{24} \mathrm{H}_{32} \mathrm{~N}_{3} \mathrm{OSi}[\mathrm{M}+\mathrm{H}]^{+}$: 406.2315, found: 406.2318 . The analytical data are in accordance with those previously reported in the literature. ${ }^{[78]}$

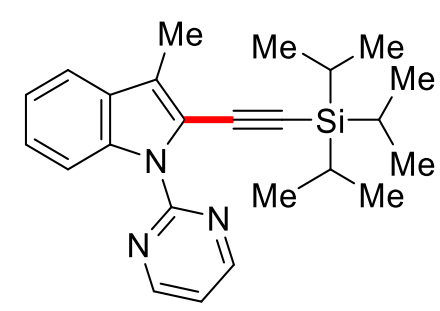

\section{3-Methyl-1-(pyrimidin-2-yl)-2-[(triisopropylsilyl)ethynyl]-1H-indole (89ja)}

The general procedure C was followed using indole 23j $(53.4 \mathrm{mg}, 0.25 \mathrm{mmol}$, 1.00 equiv) and $132 \mathrm{a}\left(79.1 \mathrm{mg}, 0.30 \mathrm{mmol}, 1.20\right.$ equiv) at $80^{\circ} \mathrm{C}$. Purification by column chromatography on silica gel ( $n$-pentane/EtOAc 20:1) yielded 89ja (63.8 mg, $164 \mu \mathrm{mol}, 66 \%)$ as a yellow oil. ${ }^{1} \mathrm{H}-\mathrm{NMR}\left(500 \mathrm{MHz}, \mathrm{CDCl}_{3}\right) \delta=8.73(\mathrm{~d}, J=4.6 \mathrm{~Hz}$, 2H), 8.32 (ddd, $J=8.5,1.2 \mathrm{~Hz}, 1 \mathrm{H}$ ), 7.53 (ddd, $J=8.5,1.2,0.8 \mathrm{~Hz}, 1 \mathrm{H}$ ), 7.31 (ddd, $J=7.4,4.2,2.0 \mathrm{~Hz}, 1 \mathrm{H}$ ), 7.21 (ddd, $J=7.4,4.2,2.0 \mathrm{~Hz}, 1 \mathrm{H}$ ), $7.10(\mathrm{t}, J=4.6 \mathrm{~Hz}, 1 \mathrm{H}$ ), $2.45(\mathrm{~s}, 3 \mathrm{H}), 1.11-1.09(\mathrm{~m}, 21 \mathrm{H}) .{ }^{13} \mathrm{C}-\mathrm{NMR}\left(125 \mathrm{MHz}, \mathrm{CDCl}_{3}\right): \delta=158.1\left(\mathrm{C}_{\mathrm{q}}\right), 157.9$ $(\mathrm{CH}), 157.5\left(\mathrm{C}_{\mathrm{q}}\right), 135.8\left(\mathrm{C}_{\mathrm{q}}\right), 129.4\left(\mathrm{C}_{\mathrm{q}}\right), 125.1\left(\mathrm{C}_{\mathrm{q}}\right), 125.0(\mathrm{CH}), 122.0(\mathrm{CH}), 119.0$ $(\mathrm{CH}), 116.7(\mathrm{CH}), 114.2(\mathrm{CH}), 100.7\left(\mathrm{C}_{\mathrm{q}}\right), 98.4\left(\mathrm{C}_{\mathrm{q}}\right), 18.7\left(\mathrm{CH}_{3}\right), 11.4(\mathrm{CH}) 9.9\left(\mathrm{CH}_{3}\right)$. IR (ATR): 2940, 2862, 2143,1561, 1426, $727 \mathrm{~cm}^{-1}$. MS (EI) $\mathrm{m} / \mathrm{z}$ (relative intensity): 389 (57), 346 (100), 330 (40), 304 (24), 236 (14). HR-MS (ESI) $m / z$ calcd for $\mathrm{C}_{23} \mathrm{H}_{32} \mathrm{~N}_{3} \mathrm{OSi}$ $[\mathrm{M}+\mathrm{H}]^{+}$: 389.2287, found: 389.2300 . 


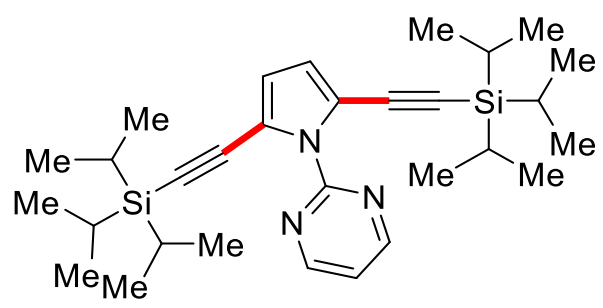

\section{2-(2,5-Bis[(triisopropylsilyl)ethynyl]-1H-pyrrol-1-yl)pyrimidine (223aa)}

The general procedure C was followed using pyrrole $217 \mathrm{a}(35.8 \mathrm{mg}, 0.25 \mathrm{mmol}$, 1.00 equiv) and $132 \mathrm{a}(79.0 \mathrm{mg}, 0.30 \mathrm{mmol}, 1.20$ equiv). Purification by column chromatography on silica gel (n-pentane/EtOAc 5:1) yielded 218aa (114.5 mg, $226 \mu \mathrm{mol}, 91 \%)$ as a white solid. M. p. $=74-76{ }^{\circ} \mathrm{C} .{ }^{1} \mathrm{H}-\mathrm{NMR}\left(500 \mathrm{MHz}, \mathrm{CDCl}_{3}\right)$ $\delta=8.76(\mathrm{~d}, J=4.3 \mathrm{~Hz}, 2 \mathrm{H}), 7.26(\mathrm{t}, J=4.3 \mathrm{~Hz}, 1 \mathrm{H}), 6.51(\mathrm{~s}, 2 \mathrm{H}), 1.00-0.97(\mathrm{~m}, 42 \mathrm{H})$. ${ }^{13} \mathrm{C}-\mathrm{NMR}\left(125 \mathrm{MHz}, \mathrm{CDCl}_{3}\right): \delta=158.3(\mathrm{CH}), 156.5\left(\mathrm{C}_{\mathrm{q}}\right), 119.4(\mathrm{CH}), 117.6(\mathrm{CH}), 117.3$ $\left(\mathrm{C}_{\mathrm{q}}\right), 97.7\left(\mathrm{C}_{\mathrm{q}}\right), 95.2\left(\mathrm{C}_{\mathrm{q}}\right), 18.5\left(\mathrm{CH}_{3}\right), 11.2(\mathrm{CH}) . \mathrm{IR}(\mathrm{ATR})$ : 2940, 2863, 2146, 1563, 1421, 918, 767, $626 \mathrm{~cm}^{-1}$. MS (EI) $\mathrm{m} / z$ (relative intensity): 505 (42), 462 (100), 420 (21). HR-MS (ESI) $m / z$ calcd for $\mathrm{C}_{30} \mathrm{H}_{47} \mathrm{~N}_{3} \mathrm{Si}_{2}[\mathrm{M}]^{+}:$505.3309, found 505.3300 .<smiles>CC(C)[Si](C#Cc1cc2c(n1-c1ncccn1)CCCC2=O)(C(C)C)C(C)C</smiles>

1-(Pyrimidin-2-yl)-2-[(triisopropylsilyl)ethynyl]-5,6,7,7a-tetrahydro-1 $\mathrm{H}$-indol$4(3 a H)$-one (218ca)

The general procedure C was followed using pyrrole 217c (53.2 mg, $0.25 \mathrm{mmol}$, 1.00 equiv) and $132 \mathrm{a}$ (78.6 $\mathrm{mg}, 0.30 \mathrm{mmol}, 1.20$ equiv). Purification by column chromatography on silica gel ( $n$-pentane/EtOAc 5:1) yielded 218ca (79.3 mg, $202 \mu \mathrm{mol}, 80 \%)$ as a white solid.

The general procedure D was followed using pyrrole 217c $(107 \mathrm{mg}, 0.50 \mathrm{mmol}$, 1.00 equiv) and 132a (157 mg, $0.60 \mathrm{mmol}, 1.20$ equiv). Isolation by column chromatography ( $n$-pentane/EtOAc: $4 / 1$ ) yielded $218 \mathrm{ca}(187 \mathrm{mg}, 96 \%)$ as a white solid. M. p. $=144-146{ }^{\circ} \mathrm{C} .{ }^{1} \mathrm{H}-\mathrm{NMR}\left(500 \mathrm{MHz}, \mathrm{CDCl}_{3}\right) \delta=8.78(\mathrm{~d}, J=4.9 \mathrm{~Hz}, 2 \mathrm{H}), 7.30(\mathrm{t}$, $J=4.9 \mathrm{~Hz}, 1 \mathrm{H}), 6.96(\mathrm{~s}, 1 \mathrm{H}), 2.96$ (dd, $J=6.4,5.2 \mathrm{~Hz}, 2 \mathrm{H}), 2.49$ (dd, $J=9.2,5.8 \mathrm{~Hz}$, $2 \mathrm{H}), 2.10$ (dddd, $J=9.2,6.4,5.8,5.2 \mathrm{~Hz}, 2 \mathrm{H}), 1.11-1.08(\mathrm{~m}, 21 \mathrm{H}) .{ }^{13} \mathrm{C}-\mathrm{NMR}$ 
(125 MHz, $\left.\mathrm{CDCl}_{3}\right): \delta=194.1\left(\mathrm{C}_{\mathrm{q}}\right), 158.4(\mathrm{CH}), 156.1\left(\mathrm{C}_{\mathrm{q}}\right), 145.4\left(\mathrm{C}_{\mathrm{q}}\right), 121.6\left(\mathrm{C}_{\mathrm{q}}\right), 119.5$ $(\mathrm{CH}), 117.3\left(\mathrm{C}_{\mathrm{q}}\right), 115.1(\mathrm{CH}), 97.2\left(\mathrm{C}_{\mathrm{q}}\right), 96.0\left(\mathrm{C}_{\mathrm{q}}\right), 37.8\left(\mathrm{CH}_{2}\right), 24.2\left(\mathrm{CH}_{2}\right), 23.6\left(\mathrm{CH}_{2}\right)$, $18.5\left(\mathrm{CH}_{3}\right), 11.2(\mathrm{CH})$. IR (ATR): 2940, 2862, 2148,1660, 1573, 1415, 1135, 808, 720 $\mathrm{cm}^{-1}$. MS (El) $\mathrm{m} / z$ (relative intensity): 393 (35), 350 (100), 322 (18), 308 (22), 280 (10), 240 (10). HR-MS (ESI) $\mathrm{m} / z$ calcd for $\mathrm{C}_{23} \mathrm{H}_{32} \mathrm{~N}_{3} \mathrm{OSI}[\mathrm{M}+\mathrm{H}]^{+}: 394.2315$, found: 394.2309 .<smiles>CS(=O)(=CC(C#Cc1cc2ccccc2n1-c1ncccn1)(c1ccccc1)c1ccccc1)c1ccccc1</smiles>

\section{2-[(Methyldiphenylsilyl)ethynyl]-1-(pyrimidin-2-yl)-1H-indole (89ab)}

The general procedure C was followed using indole 23a $(49.8 \mathrm{mg}, 0.25 \mathrm{mmol}$, 1.00 equiv) and $132 \mathrm{~b}$ ( $53.1 \mathrm{mg}, 0.30 \mathrm{mmol}, 1.20$ equiv). Purification by column chromatography on silica gel ( $n$-pentane/EtOAc 20:1) yielded 89ab $(64.6 \mathrm{mg}$, $156 \mu \mathrm{mol}, 62 \%)$ as a yellow oil. ${ }^{1} \mathrm{H}-\mathrm{NMR}\left(500 \mathrm{MHz}, \mathrm{CDCl}_{3}\right) \delta=8.66(\mathrm{~d}, J=4.8 \mathrm{~Hz}$, 2H), 8.32 (ddd, $J=8.4,2.5,0.8 \mathrm{~Hz}, 1 \mathrm{H}$ ) 7.72-7.69 (m, 4H), 7.59 (ddd, $J=7.9,1.9$, $1.0 \mathrm{~Hz}, 1 \mathrm{H}), 7.42-7.34(\mathrm{~m}, 7 \mathrm{H}), 7.23$ (ddd, $J=7.9,1.9,1.0 \mathrm{~Hz}, 1 \mathrm{H}), 7.15(\mathrm{~s}, 1 \mathrm{H}), 7.10$ (t, $J=4.8 \mathrm{~Hz}, 1 \mathrm{H}), 0.76(\mathrm{~s}, 3 \mathrm{H}) .{ }^{13} \mathrm{C}-\mathrm{NMR}\left(125 \mathrm{MHz}, \mathrm{CDCl}_{3}\right): \delta=158.0(\mathrm{CH}), 157.2$ $\left(\mathrm{C}_{\mathrm{q}}\right), 136.3\left(\mathrm{C}_{\mathrm{q}}\right), 135.3\left(\mathrm{C}_{\mathrm{q}}\right), 134.6(\mathrm{CH}), 133.9\left(\mathrm{C}_{\mathrm{q}}\right), 129.6(\mathrm{CH}), 128.4\left(\mathrm{C}_{\mathrm{q}}\right), 127.9$ $(\mathrm{CH}), 125.2(\mathrm{CH}), 122.5(\mathrm{CH}), 121.0(\mathrm{CH}), 120.3\left(\mathrm{C}_{\mathrm{q}}\right), 117.6(\mathrm{CH}), 116.3(\mathrm{CH}), 114.3$ (CH), $100.4\left(\mathrm{C}_{\mathrm{q}}\right), 97.2\left(\mathrm{C}_{\mathrm{q}}\right),-2.2\left(\mathrm{CH}_{3}\right)$. IR (ATR): 3046, 2959, 2152, 1562, 1425, 1115, 868, $792 \mathrm{~cm}^{-1}$. MS (EI) m/z (relative intensity): 414 (100), 400 (20), 338 (14), 294 (11), 108 (8). HR-MS (ESI) $\mathrm{m} / z$ calcd $\mathrm{C}_{27} \mathrm{H}_{20} \mathrm{~N}_{3} \mathrm{Si}[\mathrm{M}-\mathrm{H}]^{+}: 414.1426$, found: 414.1422.

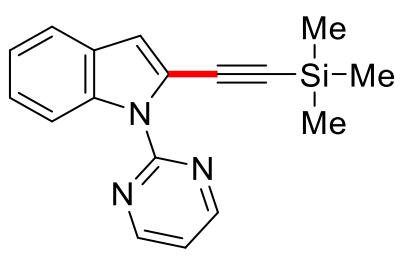

\section{1-(Pyrimidin-2-yl)-2-[(trimethylsilyl)ethynyl]-1 $H$-indole (89ac)}

The general procedure C was followed using indole 23a $(49.7 \mathrm{mg}, 0.25 \mathrm{mmol}$, 1.00 equiv) and $132 \mathrm{c}$ (53.3 $\mathrm{mg}, 0.30 \mathrm{mmol}, 1.20$ equiv). Purification by column chromatography on silica gel (n-pentane/EtOAc 80:1) yielded $89 \mathrm{ac}$ (52.9 mg, $183 \mu \mathrm{mol}, 73 \%)$ as a yellow oil. ${ }^{1} \mathrm{H}-\mathrm{NMR}\left(500 \mathrm{MHz}, \mathrm{CDCl}_{3}\right) \delta=8.78(\mathrm{~d}, J=4.7 \mathrm{~Hz}$, 
2H), 8.28 (ddd, $J=8.4,2.1,0.7 \mathrm{~Hz}, 1 \mathrm{H}$ ), 7.56 (ddd, $J=7.7,2.4,0.9 \mathrm{~Hz}, 1 \mathrm{H}$ ), 7.31 (ddd, $J=7.7,2.4,0.9 \mathrm{~Hz}, 1 \mathrm{H}), 7.23-7.16(\mathrm{~m}, 2 \mathrm{H}), 7.04(\mathrm{~s}, 1 \mathrm{H}), 0.24(\mathrm{~s}, 9 \mathrm{H}) .{ }^{13} \mathrm{C}-\mathrm{NMR}$ $\left(125 \mathrm{MHz}, \mathrm{CDCl}_{3}\right): \delta=158.0(\mathrm{CH}), 157.2\left(\mathrm{C}_{\mathrm{q}}\right), 136.2\left(\mathrm{C}_{\mathrm{q}}\right), 128.4\left(\mathrm{C}_{\mathrm{q}}\right), 124.9(\mathrm{CH})$, $122.4(\mathrm{CH}), 120.9(\mathrm{CH}), 120.6\left(\mathrm{C}_{q}\right), 117.7(\mathrm{CH}), 115.4(\mathrm{CH}), 114.0(\mathrm{CH}), 101.1\left(\mathrm{C}_{q}\right)$, $97.1\left(\mathrm{C}_{\mathrm{q}}\right), 0.2\left(\mathrm{CH}_{3}\right) . \mathrm{IR}(\mathrm{ATR}): 2957,2150,1561,1421,1248,839,746 \mathrm{~cm}^{-1} . \mathrm{MS}$ (EI) $\mathrm{m} / \mathrm{z}$ (relative intensity): 290 (100), 276 (29), 250 (8), 223 (11). HR-MS (ESI) m/z calcd $\mathrm{C}_{17} \mathrm{H}_{16} \mathrm{~N}_{3} \mathrm{Si}[\mathrm{M}-\mathrm{H}]^{+}: 290.1113$, found: 290.1121.<smiles>C#Cc1cc2ccccc2n1-c1ncccn1</smiles>

\section{2-Ethynyl-1-(pyrimidin-2-yl)-1 $H$-indole (233a)}

To a solution of $89 \mathrm{aa}(29.3 \mathrm{mg}, 0.15 \mathrm{mmol}, 1.00$ equiv) in THF (1 mL), tetra- $n$ butylammoniumfluoride trihydrate (141 mg, $0.45 \mathrm{mmol}, 3.00$ equiv) in THF ( $1 \mathrm{~mL}$ ) was added and stirred at $25^{\circ} \mathrm{C}$ for $1 \mathrm{~h} . \mathrm{H}_{2} \mathrm{O}(5 \mathrm{~mL})$ was added and the mixture was extracted with $\mathrm{CH}_{2} \mathrm{Cl}_{2}(3 \times 5 \mathrm{~mL})$. The combined organic phases were dried over $\mathrm{Na}_{2} \mathrm{SO}_{4}$ and the solvent removed at reduced pressure. Purification by column chromatography on silica gel ( $n$-pentane/EtOAc 3:1) yielded 233a (26.5 mg, $121 \mu \mathrm{mol}$, $81 \%)$ as a brown oil. ${ }^{1} \mathrm{H}-\mathrm{NMR}\left(500 \mathrm{MHz}, \mathrm{CDCl}_{3}\right): \delta=8.82(\mathrm{~d}, J=5.5 \mathrm{~Hz}, 2 \mathrm{H}), 8.29$ (ddd, $J=8.3,2.3,1.0 \mathrm{~Hz}, 1 \mathrm{H}$ ) 7.58 (ddd, $J=7.9,1.9,0.9 \mathrm{~Hz}, 1 \mathrm{H}$ ), 7.34 (ddd, $J=8.3$, 2.3, $1.0 \mathrm{~Hz}, 1 \mathrm{H}) 7.22$ (ddd, $J=7.9,1.9,0.9 \mathrm{~Hz}, 1 \mathrm{H}$ ), $7.19(\mathrm{t}, J=5.5 \mathrm{~Hz}, 1 \mathrm{H}$ ), 7.10 (s, $1 \mathrm{H}), 3.45(\mathrm{~s}, 1 \mathrm{H}) .{ }^{13} \mathrm{C}-\mathrm{NMR}\left(125 \mathrm{MHz} \mathrm{CDCl}_{3}\right): \delta=158.1(\mathrm{CH}), 157.2\left(\mathrm{C}_{\mathrm{q}}\right), 136.2\left(\mathrm{C}_{\mathrm{q}}\right)$, $128.3\left(\mathrm{C}_{\mathrm{q}}\right), 125.1(\mathrm{CH}), 122.5(\mathrm{CH}), 120.8(\mathrm{CH}), 119.5\left(\mathrm{C}_{\mathrm{q}}\right), 117.7(\mathrm{CH}), 116.2(\mathrm{CH})$, $114.2(\mathrm{CH}), 83.3(\mathrm{CH}), 76.4\left(\mathrm{C}_{\mathrm{q}}\right)$. IR (ATR): 3285, 1626, 1563, 1423, 806, $747 \mathrm{~cm}^{-1}$. MS (ESI) $m / z$ (relative intensity): 219 (100), 192 (13), 169 (8), 85 (15). HR-MS (ESI) $\mathrm{m} / z$ calcd for $\mathrm{C}_{14} \mathrm{H}_{9} \mathrm{~N}_{3}[\mathrm{M}]^{+}:$219.0796, found: 219.0788 . 


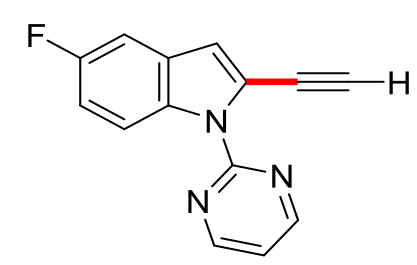

\section{2-Ethynyl-5-fluoro-1-(pyrimidin-2-yl)-1 H-indole (233b)}

To a solution of $890 a(32.0 \mathrm{mg}, 0.15 \mathrm{mmol}, 1.00$ equiv) in THF ( $1 \mathrm{~mL})$, tetra- $n$ butylammoniumfluoride trihydrate ( $141 \mathrm{mg}, 0.45 \mathrm{mmol}, 3.00$ equiv) in THF ( $1 \mathrm{~mL}$ ) was added and stirred at $25^{\circ} \mathrm{C}$ for $1 \mathrm{~h} . \mathrm{H}_{2} \mathrm{O}(5 \mathrm{~mL})$ was added $(5 \mathrm{~mL})$ and the mixture extracted with $\mathrm{CH}_{2} \mathrm{Cl}_{2}(3 \times 5 \mathrm{~mL})$. The combined organic phases were dried over $\mathrm{Na}_{2} \mathrm{SO}_{4}$ and the solvent removed at reduced pressure. Purification by column chromatography on silica gel ( $n$-pentane/EtOAc 3:1) yielded 233b $28.9 \mathrm{mg}, 122 \mu \mathrm{mol}$, $81 \%$ ) as a brown oil. ${ }^{1} \mathrm{H}-\mathrm{NMR}\left(500 \mathrm{MHz}, \mathrm{CDCl}_{3}\right): \delta=8.81(\mathrm{~d}, J=5.2 \mathrm{~Hz}, 2 \mathrm{H}$ ), 8.28 (dd, $J=9.4,2.5 \mathrm{~Hz}, 1 \mathrm{H}$ ) 7.23-7.19 (m, 2H), 7.06 (ddd, $J=8.6,2.3,1.0 \mathrm{~Hz}, 1 \mathrm{H}$ ), 7.03 (s, 1H), $3.47(\mathrm{~s}, 1 \mathrm{H}) .{ }^{13} \mathrm{C}-\mathrm{NMR}\left(125 \mathrm{MHz} \mathrm{CDCl}_{3}\right): \delta=159.0\left(\mathrm{~d},{ }^{1} \mathrm{~J}_{\mathrm{CF}}=235 \mathrm{~Hz}, \mathrm{C}_{\mathrm{q}}\right), 158.2$ $(\mathrm{CH}), 157.0\left(\mathrm{C}_{\mathrm{q}}\right), 132.6\left(\mathrm{C}_{\mathrm{q}}\right), 128.9\left(\mathrm{~d},{ }^{3} \mathrm{~J}_{\mathrm{CF}}=12 \mathrm{~Hz}, \mathrm{C}_{\mathrm{q}}\right), 121.0\left(\mathrm{C}_{\mathrm{q}}\right), 117.9(\mathrm{CH}), 115.8$ $\left(\mathrm{d},{ }^{4} \mathrm{~J}_{\mathrm{CF}}=5 \mathrm{~Hz}, \mathrm{CH}\right), 115.4\left(\mathrm{~d},{ }^{3} \mathrm{JCF}=9 \mathrm{~Hz}, \mathrm{CH}\right), 113.2\left(\mathrm{~d},{ }^{2} \mathrm{~J} \mathrm{CF}=27 \mathrm{~Hz}, \mathrm{CH}\right), 105.7(\mathrm{~d}$, $\left.{ }^{2} \mathrm{JCF}=29 \mathrm{~Hz}, \mathrm{CH}\right), 83.9(\mathrm{CH}), 76.0\left(\mathrm{C}_{\mathrm{q}}\right) .{ }^{19} \mathrm{~F}-\mathrm{NMR}\left(282 \mathrm{MHz}, \mathrm{CDCl}_{3}\right):-121.6 . \mathrm{IR}(\mathrm{ATR})$ : 3278, 1631, 1562, 1425, 1103, 868, $791 \mathrm{~cm}^{-1}$. MS (ESI) $\mathrm{m} / z$ (relative intensity): 237 (100), 210 (20), 187 (17), 157 (11). HR-MS (ESI) $\mathrm{m} / z$ calcd for $\mathrm{C}_{14} \mathrm{H}_{8} \mathrm{~N}_{3} \mathrm{~F}[\mathrm{M}]+$ : 237.0702, found: 237.0708 .

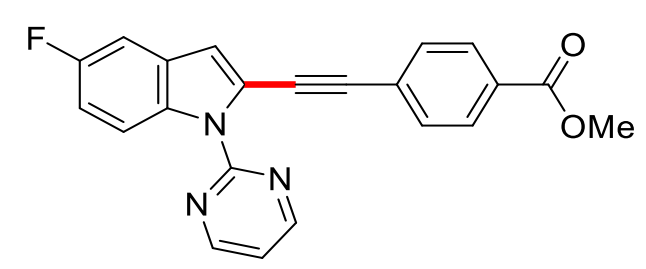

\section{Methyl-4-\{[5-fluoro-1-(pyrimidin-2-yl)-1 H-indol-2-yl]ethynyl\}benzoate (234)}

Following a published procedure, ${ }^{[197]} 233 \mathrm{~b}(32.2 \mathrm{mg}, 0.15 \mathrm{mmol}, 1.00$ equiv), $\mathrm{Pd}(\mathrm{OAc}) 2(1.7 \mathrm{mg}, 7.5 \mu \mathrm{mol}, 5 \mathrm{~mol} \%)$, Cul (1.4 mg, $7.5 \mu \mathrm{mol}, 5 \mathrm{~mol} \%), \mathrm{PPh}_{3}(3.9 \mathrm{mg}$, $15.0 \mu \mathrm{mol}, 10 \mathrm{~mol} \%$ ) and methyl-4-iodobenzoate ( $39.8 \mathrm{mg}, 0.15 \mathrm{mmol}, 1.00$ equiv) were suspended in a mixture of DMF $(0.4 \mathrm{~mL})$ and $\mathrm{NEt}_{3}(1.2 \mathrm{~mL})$ and stirred at $60{ }^{\circ} \mathrm{C}$ for $18 \mathrm{~h}$. After completion of the reaction saturated aq. $\mathrm{NH}_{4} \mathrm{Cl}$ solution $(5 \mathrm{~mL})$ was added and the mixture was extracted with EtOAc $(4 \times 5 \mathrm{~mL})$. Drying over $\mathrm{Na}_{2} \mathrm{SO}_{4}$, evaporation of the solvents and purification by column chromatography on silica gel using $n$-pentane/EtOAc (10:1) yielded the product 234 (42.3 mg, $114 \mu \mathrm{mol}, 76 \%)$ as 
an orange solid. M. p. $=152-154{ }^{\circ} \mathrm{C} .{ }^{1} \mathrm{H}-\mathrm{NMR}\left(500 \mathrm{MHz}, \mathrm{CDCl}_{3}\right): \delta=8.84(\mathrm{~d}$, $J=5.4 \mathrm{~Hz}, 2 \mathrm{H}$ ), $8.33(\mathrm{dd}, J=9.1,4.3 \mathrm{~Hz}, 1 \mathrm{H}), 8.02(\mathrm{~d}, J=8.2 \mathrm{~Hz}, 2 \mathrm{H}), 7.54(\mathrm{~d}$, $J=8.2 \mathrm{~Hz}, 2 \mathrm{H}), 7.30-7.25(\mathrm{~m}, 2 \mathrm{H}), 7.11-7.05(\mathrm{~m}, 2 \mathrm{H}), 3.92(\mathrm{~s}, 3 \mathrm{H}) .{ }^{13} \mathrm{C}-\mathrm{NMR}(125$ $\left.\mathrm{MHz} \mathrm{CDCl}_{3}\right): \delta=166.5\left(\mathrm{C}_{\mathrm{q}}\right), 159.2\left(\mathrm{~d},{ }^{1} \mathrm{~J}_{\mathrm{CF}}=251 \mathrm{~Hz}, \mathrm{C}_{\mathrm{q}}\right), 158.2(\mathrm{CH}), 157.1\left(\mathrm{C}_{\mathrm{q}}\right), 133.7$ $\left(\mathrm{d},{ }^{2} \mathrm{~J}_{\mathrm{CF}}=24 \mathrm{~Hz}, \mathrm{CH}\right), 132.9\left(\mathrm{C}_{\mathrm{q}}\right), 131.1(\mathrm{CH}), 129.6\left(\mathrm{C}_{\mathrm{q}}\right), 129.5(\mathrm{CH}), 129.3$ $\left({ }^{3} J_{C F}=9 \mathrm{~Hz}, \mathrm{C}_{q}\right), 128.4\left({ }^{3} \mathrm{~J}_{\mathrm{CF}}=9 \mathrm{~Hz}, \mathrm{CH}\right), 127.8\left(\mathrm{C}_{\mathrm{q}}\right), 121.6\left(\mathrm{C}_{\mathrm{q}}\right), 117.9(\mathrm{CH}), 115.6$ $\left({ }^{4} \mathrm{JCF}=6 \mathrm{~Hz}, \mathrm{CH}\right), 115.0\left({ }^{4} \mathrm{JCF}=5 \mathrm{~Hz}, \mathrm{CH}\right), 113.2\left({ }^{2} \mathrm{JCF}=26 \mathrm{~Hz}, \mathrm{CH}\right) 105.7(\mathrm{CH}), 94.7$ $\left(\mathrm{C}_{\mathrm{q}}\right), 85.2\left(\mathrm{C}_{\mathrm{q}}\right), 52.3\left(\mathrm{CH}_{3}\right) .{ }^{19} \mathrm{~F}-\mathrm{NMR}\left(282 \mathrm{MHz} \mathrm{CDCl}_{3}\right): \delta=-121.4$. IR (ATR): 2959, $2202,1720,1562,1424,1224,1155,787,539 \mathrm{~cm}^{-1}$. MS (EI) $\mathrm{m} / z$ (relative intensity) 370 (100), 311 (33), 277 (15), 232 (10). HR-MS (ESI) $\mathrm{m} / z$ calcd for $\mathrm{C}_{22} \mathrm{H}_{13} \mathrm{~N}_{3} \mathrm{FO}_{2}$ [M-H]+: 370.0992, found: 370.0997 .

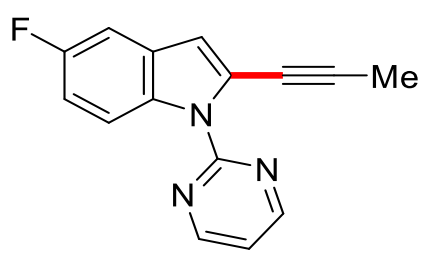

\section{5-Fluoro-2-(prop-1-yn-1-yl)-1-(pyrimidin-2-yl)-1 H-indole (235)}

In a modification of a known procedure, ${ }^{[196]}$ to a solution of $\mathbf{2 3 3 b}(32.2 \mathrm{mg}, 0.15 \mathrm{mmol}$, 1.00 equiv) in THF ( $1.5 \mathrm{~mL}$ ) lithiumbis(trimethylsilyl)amide in THF $(0.9 \mathrm{M}, 0.185 \mathrm{~mL}$, $0.17 \mathrm{mml}, 1.10$ equiv) was added at $-40^{\circ} \mathrm{C}$ and stirred for $30 \mathrm{~min}$. Then methyliodide (42.5 mg, $0.30 \mathrm{mmol}, 2.00$ equiv) was added and the mixture was slowly warmed to $25^{\circ} \mathrm{C}$ and stirred for $12 \mathrm{~h} . \mathrm{H}_{2} \mathrm{O}(5 \mathrm{~mL})$ was added and the mixture extracted with $\mathrm{CH}_{2} \mathrm{Cl}_{2}(3 \times 5 \mathrm{~mL})$. The combined organic phases were dried over $\mathrm{Na}_{2} \mathrm{SO}_{4}$ and the solvent removed at reduced pressure. Purification by column chromatography on silica gel ( $n$-pentane/EtOAc 5:1) yielded 235 (18.6 mg, $137 \mu \mathrm{mol}, 92 \%)$ as a brown oil. ${ }^{1} \mathrm{H}$ $\operatorname{NMR}\left(500 \mathrm{MHz}, \mathrm{CDCl}_{3}\right): \delta=8.82(\mathrm{~d}, J=5.2 \mathrm{~Hz}, 2 \mathrm{H}), 8.15(\mathrm{dd}, J=8.7,5.2 \mathrm{~Hz}, 1 \mathrm{H})$ 7.22-7.15 (m, 2H), 7.00 (ddd, $J=8.4,2.5,0.7 \mathrm{~Hz}, 1 \mathrm{H}$ ), $6.86(\mathrm{~s}, 1 \mathrm{H}), 2.10(\mathrm{~s}, 3 \mathrm{H}) .{ }^{13} \mathrm{C}-$ $\operatorname{NMR}\left(125 \mathrm{MHz} \mathrm{CDCl}_{3}\right): \delta=158.9\left(\mathrm{~d},{ }^{1} \mathrm{~J}_{\mathrm{CF}}=234 \mathrm{~Hz}, \mathrm{C}_{\mathrm{q}}\right), 158.1(\mathrm{CH}), 157.1\left(\mathrm{C}_{\mathrm{q}}\right), 132.3$ $\left(\mathrm{C}_{\mathrm{q}}\right), 129.3\left(\mathrm{~d},{ }^{3} \mathrm{~J}_{\mathrm{CF}}=13 \mathrm{~Hz}, \mathrm{C}_{\mathrm{q}}\right), 122.8\left(\mathrm{C}_{\mathrm{q}}\right), 117.7(\mathrm{CH}), 114.9\left(\mathrm{~d},{ }^{4} \mathrm{~J}_{\mathrm{CF}}=6 \mathrm{~Hz}, \mathrm{CH}\right)$, $113.3\left(\mathrm{~d},{ }^{4} \mathrm{~J}_{\mathrm{CF}}=4 \mathrm{~Hz}, \mathrm{CH}\right), 112.2\left(\mathrm{~d},{ }^{2} \mathrm{~J}_{\mathrm{CF}}=26 \mathrm{~Hz}, \mathrm{CH}\right), 105.4\left(\mathrm{~d},{ }^{2} \mathrm{~J}_{\mathrm{CF}}=27 \mathrm{~Hz}, \mathrm{CH}\right)$, $92.6\left(\mathrm{C}_{\mathrm{q}}\right), 72.1\left(\mathrm{C}_{\mathrm{q}}\right), 5.1\left(\mathrm{CH}_{3}\right) .{ }^{19} \mathrm{~F}-\mathrm{NMR}\left(282 \mathrm{MHz}, \mathrm{CDCl}_{3}\right): \delta=-122.1$. IR (ATR): 3023, 1562, 1422, 1193, 855, 800, $630 \mathrm{~cm}^{-1}$. MS (ESI) $\mathrm{m} / \mathrm{z}$ (relative intensity): 251 (100), 223 (22), 197 (17), 172 (10) 125 (8). HR-MS (ESI) $\mathrm{m} / z$ calcd for $\mathrm{C}_{15} \mathrm{H}_{11} \mathrm{~N}_{3} \mathrm{~F}$ $[\mathrm{M}+\mathrm{H}]^{+}$: 252.0937, found: 252.0932 . 


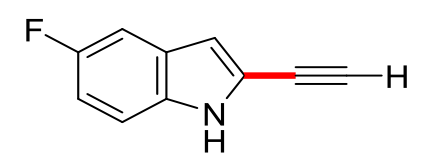

\section{2-Ethynyl-5-fluoro-1H-indole (236)}

To a solution of $890 \mathrm{oa}$ (32.0 mg, $0.15 \mathrm{mmol}, 1.00$ equiv) in DMSO $\left(1.5 \mathrm{~mL}\right.$ ) and $\mathrm{CH}_{3} \mathrm{OH}$ $(0.5 \mathrm{~mL}$ ), sodium ethanolate ( $30.6 \mathrm{mg}, 0.45 \mathrm{mmol}, 3.00$ equiv) was added and stirred at $60{ }^{\circ} \mathrm{C}$ for $3 \mathrm{~h} . \mathrm{H}_{2} \mathrm{O}(5 \mathrm{~mL})$ was added and the mixture extracted with $\mathrm{CH}_{2} \mathrm{Cl}_{2}$ $(3 \times 5 \mathrm{~mL})$. The combined organic phases were dried over $\mathrm{Na}_{2} \mathrm{SO}_{4}$ and the solvent removed at reduced pressure. Purification by column chromatography on silica gel (n-pentane/EtOAc 2:1) yielded 236 (18.6 mg, $116 \mu \mathrm{mol}, 77 \%$ ) as a brown oil. ${ }^{1} \mathrm{H}-\mathrm{NMR}$ $\left(500 \mathrm{MHz}, \mathrm{CDCl}_{3}\right): \delta=8.19(\mathrm{~s}, 1 \mathrm{H}), 7.23-7.18(\mathrm{~m}, 2 \mathrm{H}), 6.98$ (ddd, $J=8.2,3.2,2.3 \mathrm{~Hz}$, $1 \mathrm{H}), 6.75(\mathrm{~s}, 1 \mathrm{H}), 3.31(\mathrm{~s}, 1 \mathrm{H}) .{ }^{13} \mathrm{C}-\mathrm{NMR}\left(125 \mathrm{MHz} \mathrm{CDCl}_{3}\right): \delta=158.2\left(\mathrm{~d},{ }^{1} \mathrm{JCF}=247 \mathrm{~Hz}\right.$, $\left.\mathrm{C}_{\mathrm{q}}\right), 132.3\left(\mathrm{C}_{\mathrm{q}}\right), 127.6\left(\mathrm{~d},{ }^{3} \mathrm{~J}_{\mathrm{CF}}=12 \mathrm{~Hz}, \mathrm{C}_{\mathrm{q}}\right), 119.2\left(\mathrm{C}_{\mathrm{q}}\right), 112.4\left(\mathrm{~d},{ }^{2} \mathrm{~J}_{\mathrm{CF}}=28 \mathrm{~Hz}, \mathrm{CH}\right)$, $111.4\left(\mathrm{~d},{ }^{3} \mathrm{~J}_{\mathrm{CF}}=10 \mathrm{~Hz}, \mathrm{CH}\right), 109.5\left(\mathrm{~d},{ }^{4} \mathrm{~J}_{\mathrm{CF}}=6 \mathrm{~Hz}, \mathrm{CH}\right), 105.4\left(\mathrm{~d},{ }^{2} \mathrm{~J}_{\mathrm{CF}}=26 \mathrm{~Hz}, \mathrm{CH}\right)$, $81.1(\mathrm{CH}), 75.8\left(\mathrm{C}_{\mathrm{q}}\right) .{ }^{19} \mathrm{~F}-\mathrm{NMR}$ (282 MHz, $\mathrm{CDCl}_{3}$ ): -124.0. IR (ATR): 3422, 2383, 1484, 1166, 854, $597 \mathrm{~cm}^{-1}$. MS (ESI) $\mathrm{m} / z$ (relative intensity): 159 (100), 132 (32), 118 (17). HR-MS (ESI) $m / z$ calcd for $\mathrm{C}_{10} \mathrm{H}_{6} \mathrm{NF}[\mathrm{M}]^{+}:$159.0484, found: 159.0485 .<smiles>Fc1ccc2[nH]c(-c3cn(Cc4ccccc4)nn3)cc2c1</smiles>

\section{2-(1-Benzyl-1 H-1,2,3-triazol-4-yl)-5-fluoro-1 $H$-indole (237)}

Following a previously published procedure, ${ }^{[198]} 237$ (24.2 mg. $0.15 \mathrm{mmol}, 1.00$ equiv), Cul (2.9 mg, $15.0 \mu \mathrm{mol}, 10 \mathrm{~mol} \%$ ) and benzyl azide (13.7 mg, $0.15 \mathrm{mmol}, 1.00$ equiv) were dissolved in DMF $(1.5 \mathrm{~mL})$ and stirred at $60^{\circ} \mathrm{C}$ for $14 \mathrm{~h}$. After completion of the reaction saturated aq. $\mathrm{NH}_{4} \mathrm{Cl}$ solution $(5 \mathrm{~mL})$ was added and the mixture was extracted with $\mathrm{CH}_{2} \mathrm{Cl}_{2}(4 \times 5 \mathrm{~mL})$. Drying over $\mathrm{Na}_{2} \mathrm{SO}_{4}$, evaporation of the solvents and purification by column chromatography on silica gel using $n$-pentane/EtOAc (2:1) yielded the product $232(31.1 \mathrm{mg}, 107 \mu \mathrm{mol}, 71 \%)$ as a white solid. Decomposed at $240^{\circ} \mathrm{C}$. ${ }^{1} \mathrm{H}-\mathrm{NMR}(500 \mathrm{MHz}$, DMSO-d 6 ): $\delta=11.70(\mathrm{~s}, 1 \mathrm{H}), 8.53(\mathrm{~s}, 1 \mathrm{H}), 7.44-7.36(\mathrm{~m}$, $6 \mathrm{H}$ ), $7.28(\mathrm{dd}, J=9.3,2.5 \mathrm{~Hz}, 1 \mathrm{H}$ ), $6.93(\mathrm{dd}, J=7.3,4.3 \mathrm{~Hz}, 1 \mathrm{H}), 6.76(\mathrm{~s}, 1 \mathrm{H}), 5.67$ (s, 2H). ${ }^{13} \mathrm{C}-\mathrm{NMR}\left(125 \mathrm{MHz} \mathrm{CDCl}_{3}\right): \delta=157.1\left(\mathrm{~d},{ }^{1} \mathrm{~J}_{\mathrm{CF}}=229 \mathrm{~Hz}, \mathrm{C}_{\mathrm{q}}\right), 140.6\left(\mathrm{C}_{\mathrm{q}}\right), 135.8$ $\left(\mathrm{C}_{\mathrm{q}}\right), 133.1\left(\mathrm{C}_{\mathrm{q}}\right), 131.0\left(\mathrm{C}_{\mathrm{q}}\right), 128.8(\mathrm{CH}), 128.5(\mathrm{CH}), 128.4(\mathrm{CH}), 128.2\left(\mathrm{C}_{\mathrm{q}}\right), 121.6$ $(\mathrm{CH}), 112.3\left(\mathrm{~d},{ }^{3} \mathrm{~J} \mathrm{CF}=11 \mathrm{~Hz}, \mathrm{CH}\right), 109.4\left(\mathrm{~d},{ }^{2} \mathrm{~J} \mathrm{CF}=25 \mathrm{~Hz}, \mathrm{CH}\right), 104.5\left(\mathrm{~d},{ }^{2} \mathrm{JCF}=27 \mathrm{~Hz}\right.$, 
$\mathrm{CH}), 98.6\left(\mathrm{~d},{ }^{4} \mathrm{~J}_{\mathrm{CF}}=6 \mathrm{~Hz}, \mathrm{CH}\right) 53.0\left(\mathrm{CH}_{2}\right) .{ }^{19} \mathrm{~F}-\mathrm{NMR}\left(282 \mathrm{MHz}, \mathrm{DMSO}-\mathrm{d}_{6}\right): \delta=-125.2$. IR (ATR): 3288, 1624, 1419, 1216, 1013, 790, 690, $411 \mathrm{~cm}^{-1}$. MS (EI) $\mathrm{m} / z$ (relative intensity): 292 (48), 263 (100), 236 (35), 187 (22), 91 (51), 43 (44). HR-MS (ESI) m/z calcd for $\mathrm{C}_{17} \mathrm{H}_{13} \mathrm{~N}_{4} \mathrm{~F}[\mathrm{M}]^{+}: 292.1124$, found: 292.1120 .

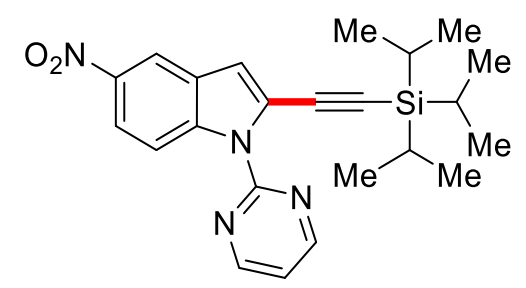

\section{5-Nitro-1-(pyrimidin-2-yl)-2-[(triisopropylsilyl)ethynyl]-1 H-indole (89na)}

The general procedure D was followed using indole $23 \mathrm{n}(121 \mathrm{mg}, 0.50 \mathrm{mmol}$, 1.00 equiv) and $132 \mathrm{a}$ (158 mg, $0.60 \mathrm{mmol}, 1.20$ equiv) at $100^{\circ} \mathrm{C}$. Isolation by column chromatography ( $n$-pentane/EtOAc: $3 / 1$ ) yielded $89 \mathrm{na}(135 \mathrm{mg}, 63 \%$ ) as a yellow solid. M.p. $=127-129^{\circ} \mathrm{C} .{ }^{1} \mathrm{H} N M R\left(400 \mathrm{MHz}, \mathrm{CDCl}_{3}\right) \delta=8.83(\mathrm{~d}, J=5.9 \mathrm{~Hz}, 2 \mathrm{H}), 8.49(\mathrm{~d}, J$ $=2.0 \mathrm{~Hz}, 1 \mathrm{H}), 8.29(\mathrm{~d}, J=9.5 \mathrm{~Hz}, 1 \mathrm{H}), 8.17(\mathrm{dd}, J=9.5,2.0 \mathrm{~Hz}, 1 \mathrm{H}), 7.28(\mathrm{t}, J=5.9$ $\mathrm{Hz}, 1 \mathrm{H}), 7.17(\mathrm{~s}, 1 \mathrm{H}), 1.11-1.09(\mathrm{~m}, 21 \mathrm{H}) .{ }^{13} \mathrm{C} \mathrm{NMR}\left(125 \mathrm{MHz}, \mathrm{CDCl}_{3}\right) \delta=158.4(\mathrm{CH})$, $156.7\left(\mathrm{C}_{\mathrm{q}}\right), 143.5\left(\mathrm{C}_{\mathrm{q}}\right), 138.8\left(\mathrm{C}_{\mathrm{q}}\right), 128.0\left(\mathrm{C}_{\mathrm{q}}\right), 124.2\left(\mathrm{C}_{\mathrm{q}}\right), 119.7(\mathrm{CH}), 118.7(\mathrm{CH})$, $117.2(\mathrm{CH}), 115.7(\mathrm{CH}), 114.2(\mathrm{CH}), 100.5\left(\mathrm{C}_{\mathrm{q}}\right), 97.1\left(\mathrm{C}_{\mathrm{q}}\right), 18.6\left(\mathrm{CH}_{3}\right), 11.3(\mathrm{CH})$. IR (neat): 2940, 2863, 2163, 1568, 1414, 1209, 676, $659 \mathrm{~cm}^{-1}$. MS (ESI) $\mathrm{m} / \mathrm{z}$ (relative intensity) 443 (100) [M+Na+], $421\left[{\left.\mathrm{M}+\mathrm{H}^{+}\right]}_{\text {(75), }} 383\right.$ (22), 301 (11), 242 (27), 182 (58). HR-MS (ESI) $\mathrm{m} / z$ calcd for $\mathrm{C}_{23} \mathrm{H}_{29} \mathrm{~N}_{4} \mathrm{O}_{2} \mathrm{Si}\left[\mathrm{M}+\mathrm{H}^{+}\right]$421.2060, found 421.2060 .

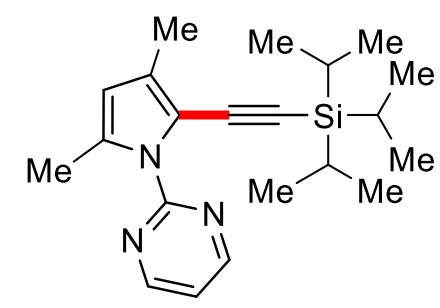

\section{2-(3,5-Dimethyl-2-[(triisopropylsilyl)ethynyl]-1 H-pyrrol-1-yl)pyrimidine (223ba)}

The general procedure $\mathbf{D}$ was followed using pyrrole $217 \mathrm{~b}(87 \mathrm{mg}, 0.50 \mathrm{mmol}$, 1.00 equiv) and 132a (154 mg, $0.60 \mathrm{mmol}, 1.20$ equiv). Isolation by column chromatography ( $n$-pentane/EtOAc:10/1) yielded 223ba (161 mg, 92\%) as white solid. M.p. $=139-141^{\circ} \mathrm{C} .{ }^{1} \mathrm{H} \mathrm{NMR}\left(400 \mathrm{MHz}, \mathrm{CDCl}_{3}\right) \delta=8.70(\mathrm{~d}, J=4.7 \mathrm{~Hz}, 2 \mathrm{H}), 7.15(\mathrm{t}, J$ $=4.7 \mathrm{~Hz}, 1 \mathrm{H}), 5.86(\mathrm{~s}, 1 \mathrm{H}), 2.34(\mathrm{~s}, 3 \mathrm{H}), 2.15(\mathrm{~s}, 3 \mathrm{H}), 1.07-1.03(\mathrm{~m}, 21 \mathrm{H}) .{ }^{13} \mathrm{C}$ NMR $\left(125 \mathrm{MHz}, \mathrm{CDCl}_{3}\right) \delta=158.0(\mathrm{CH}), 157.2\left(\mathrm{C}_{\mathrm{q}}\right), 131.8\left(\mathrm{C}_{\mathrm{q}}\right), 129.4\left(\mathrm{C}_{\mathrm{q}}\right), 118.2(\mathrm{CH}), 113.7$ 
$\left(\mathrm{C}_{\mathrm{q}}\right), 111.8(\mathrm{CH}), 98.7\left(\mathrm{C}_{\mathrm{q}}\right), 96.1\left(\mathrm{C}_{\mathrm{q}}\right), 18.3\left(\mathrm{CH}_{3}\right), 14.3\left(\mathrm{CH}_{3}\right), 11.9\left(\mathrm{CH}_{3}\right), 11.3(\mathrm{CH})$. IR (neat): 2938, 2851, 2141, 1526, 1433, 1169, 1083, 740, $669 \mathrm{~cm}^{-1}$. MS (ESI) $\mathrm{m} / \mathrm{z}$ (relative intensity) $376(100)\left[\mathrm{M}+\mathrm{Na}^{+}\right], 353\left[{\left.\mathrm{M}+\mathrm{H}^{+}\right]}\right.$(72), 312 (5). HR-MS (ESI) $\mathrm{m} / z$ calcd for $\mathrm{C}_{21} \mathrm{H}_{31} \mathrm{~N}_{3} \mathrm{SiNa}\left[\mathrm{M}+\mathrm{Na}^{+}\right] 376.2179$, found 376.2170.

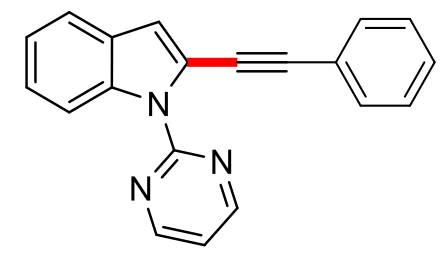

\section{2-(Phenylethynyl)-1-(pyrimidin-2-yl)-1H-indole (89ad)}

The general procedure $\mathbf{E}$ was followed using indole $23 \mathbf{a}$ ( $98 \mathrm{mg}, 0.50 \mathrm{mmol}, 1.00$ equiv) and $132 \mathrm{~d}$ (108 $\mathrm{mg}, 0.60 \mathrm{mmol}, 1.20$ equiv) for $1 \mathrm{~h}$. Isolation by column chromatography ( $n$-pentane/EtOAc: $5 / 1$ ) yielded 89 ad (141 mg, $95 \%$ ) as a colorless oil. ${ }^{1} \mathrm{H}$ NMR (500 $\left.\mathrm{MHz}, \mathrm{CDCl}_{3}\right) \delta=8.85(\mathrm{~d}, J=4.9 \mathrm{~Hz}, 2 \mathrm{H}), 8.31(\mathrm{~d}, J=8.4 \mathrm{~Hz}, 1 \mathrm{H}), 7.60(\mathrm{~d}, J=7.6 \mathrm{~Hz}$, $1 \mathrm{H}), 7.52-7.48(\mathrm{~m}, 2 \mathrm{H}), 7.35-7.31(\mathrm{~m}, 4 \mathrm{H}), 7.25-7.21(\mathrm{~m}, 1 \mathrm{H}), 7.21(\mathrm{t}, J=4.9 \mathrm{~Hz}, 1 \mathrm{H})$, $7.08(\mathrm{~s}, 1 \mathrm{H}) .{ }^{13} \mathrm{C} \mathrm{NMR}\left(125 \mathrm{MHz}, \mathrm{CDCl}_{3}\right) \delta=158.1(\mathrm{CH}), 157.4\left(\mathrm{C}_{\mathrm{q}}\right), 136.4\left(\mathrm{C}_{\mathrm{q}}\right), 131.3$ $(\mathrm{CH}), 128.8\left(\mathrm{C}_{\mathrm{q}}\right), 128.4(\mathrm{CH}), 128.3(\mathrm{CH}), 124.8(\mathrm{CH}), 123.3\left(\mathrm{C}_{\mathrm{q}}\right), 122.4(\mathrm{CH}), 120.9$ $\left(\mathrm{C}_{\mathrm{q}}\right), 120.8(\mathrm{CH}), 117.7(\mathrm{CH}), 114.6(\mathrm{CH}), 114.1(\mathrm{CH}), 95.0\left(\mathrm{C}_{\mathrm{q}}\right), 82.5\left(\mathrm{C}_{\mathrm{q}}\right)$. IR (neat): 3048, 2963, 2851, 1560, 1418, 1081, 741, 686, $521 \mathrm{~cm}^{-1}$. MS (ESI) $\mathrm{m} / z$ (relative intensity) 296 (5) [M+], 214 (11), 196 (100), 173 (20), 149 (15). HR-MS (ESI) m/z calcd for $\mathrm{C}_{20} \mathrm{H}_{14} \mathrm{~N}_{3}\left[\mathrm{M}+\mathrm{H}^{+}\right]$296.1182, found 296.1188.

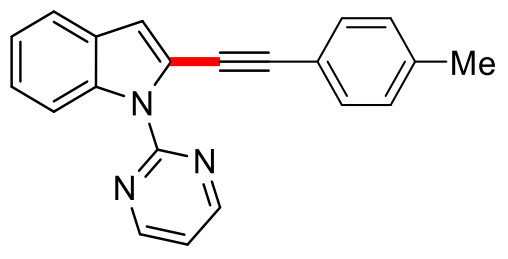

\section{1-(Pyrimidin-2-yl)-2-(p-tolylethynyl)-1H-indole (89af)}

The general procedure $\mathbf{E}$ was followed using indole $23 \mathrm{a}$ ( $98 \mathrm{mg}, 0.50 \mathrm{mmol}, 1.00$ equiv) and $132 \mathrm{f}$ (117 $\mathrm{mg}, 0.60 \mathrm{mmol}, 1.20$ equiv) for $1 \mathrm{~h}$. Isolation by column chromatography ( $n$-pentane/EtOAc: 9/1) yielded 89af $(153 \mathrm{mg}, 99 \%)$ as a colorless solid. M.p. $=100$ $102{ }^{\circ} \mathrm{C} .{ }^{1} \mathrm{H}$ NMR $\left(500 \mathrm{MHz}, \mathrm{CDCl}_{3}\right) \delta=8.84(\mathrm{~d}, J=4.8 \mathrm{~Hz}, 2 \mathrm{H}), 8.30(\mathrm{~d}, J=8.4 \mathrm{~Hz}$, $1 \mathrm{H}$ ), $7.59(\mathrm{~d}, J=7.8 \mathrm{~Hz}, 1 \mathrm{H}$ ), 7.39 (d, $J=8.0 \mathrm{~Hz}, 2 \mathrm{H}$ ), 7.32 (ddd, $J=8.3,6.9,1.0 \mathrm{~Hz}$, $1 \mathrm{H}), 7.24-7.21(\mathrm{~m}, 1 \mathrm{H}), 7.19(\mathrm{t}, J=4.8 \mathrm{~Hz}, 1 \mathrm{H}), 7.14(\mathrm{~d}, J=7.9 \mathrm{~Hz}, 2 \mathrm{H}), 7.06(\mathrm{~s}, 1 \mathrm{H})$, $2.35(\mathrm{~s}, 3 \mathrm{H}) .{ }^{13} \mathrm{C} \mathrm{NMR}\left(125 \mathrm{MHz}, \mathrm{CDCl}_{3}\right) \delta=158.1(\mathrm{CH}), 157.4\left(\mathrm{C}_{\mathrm{q}}\right), 138.5\left(\mathrm{C}_{\mathrm{q}}\right), 136.3$ 
$\left(\mathrm{C}_{\mathrm{q}}\right), 131.2(\mathrm{CH}), 129.1(\mathrm{CH}), 128.8\left(\mathrm{C}_{\mathrm{q}}\right), 124.6(\mathrm{CH}), 122.4(\mathrm{CH}), 121.0\left(\mathrm{C}_{\mathrm{q}}\right), 120.7$ $(\mathrm{CH}), 120.2\left(\mathrm{C}_{\mathrm{q}}\right), 117.7(\mathrm{CH}), 114.3(\mathrm{CH}), 114.0(\mathrm{CH}), 95.1\left(\mathrm{C}_{\mathrm{q}}\right), 81.8\left(\mathrm{C}_{\mathrm{q}}\right), 21.5\left(\mathrm{CH}_{3}\right)$. IR (neat): 3046, 2920, 2851, 1557, 1422, 800, 739, $526 \mathrm{~cm}^{-1}$. MS (EI) $\mathrm{m} / z$ (relative intensity) 309 (100) $\left[\mathrm{M}^{+}\right], 294$ (15). HR-MS (ESI) $\mathrm{m} / z$ calcd for $\mathrm{C}_{21} \mathrm{H}_{16} \mathrm{~N}_{3}\left[\mathrm{M}^{+} \mathrm{H}^{+}\right]$ 310.1344 , found 310.1339 .

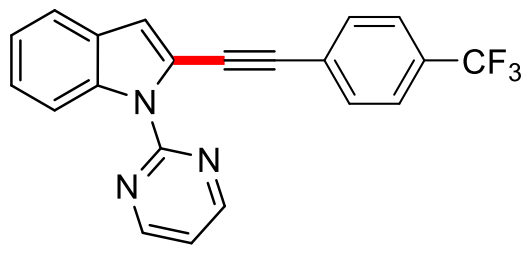

\section{2-[(4-Trifluoromethylphenyl)ethynyl]-1-(pyrimidin-2-yl)-1H-indole (89ag)}

The general procedure $\mathbf{E}$ was followed using indole $23 \mathbf{a}(98 \mathrm{mg}, 0.50 \mathrm{mmol}, 1.00$ equiv) and $132 \mathrm{~g}$ (148 $\mathrm{mg}, 0.60 \mathrm{mmol}, 1.20$ equiv). Isolation by column chromatography ( $n$ pentane/EtOAc: $7 / 1$ ) yielded $89 \mathrm{ag}$ (96 mg, $54 \%)$ as a colorless oil. ${ }^{1} \mathrm{H} \mathrm{NMR}(500 \mathrm{MHz}$, $\left.\mathrm{CDCl}_{3}\right) \delta=8.84(\mathrm{~d}, J=4.5 \mathrm{~Hz}, 2 \mathrm{H}), 8.35(\mathrm{~d}, J=8.2 \mathrm{~Hz}, 1 \mathrm{H}), 7.63-7.59(\mathrm{~m}, 5 \mathrm{H}), 7.36$ (dd, $J=8.2,2.3 \mathrm{~Hz}, 1 \mathrm{H}), 7.24-7.20(\mathrm{~m}, 2 \mathrm{H}), 7.13(\mathrm{~s}, 1 \mathrm{H}) .{ }^{13} \mathrm{C} \mathrm{NMR}\left(125 \mathrm{MHz}, \mathrm{CDCl}_{3}\right)$ $\delta=157.9(\mathrm{CH}), 157.2\left(\mathrm{C}_{\mathrm{q}}\right), 156.5\left(\mathrm{C}_{\mathrm{q}}\right), 131.3(\mathrm{CH}), 129.8\left(\mathrm{q},{ }^{2} \mathrm{~J}_{\mathrm{CF}}=32.0 \mathrm{~Hz}, \mathrm{C}_{\mathrm{q}}\right) 128.6$ $\left(\mathrm{C}_{\mathrm{q}}\right), 127.1\left(\mathrm{C}_{\mathrm{q}}\right), 125.2\left(\mathrm{q},{ }^{3} \mathrm{~J}_{\mathrm{CF}}=12.0 \mathrm{~Hz}, \mathrm{CH}\right), 125.1(\mathrm{CH}), 123.8\left(\mathrm{q},{ }^{1} \mathrm{~J}_{\mathrm{CF}}=265.0 \mathrm{~Hz}\right.$, $\left.\mathrm{C}_{\mathrm{q}}\right), 122.6(\mathrm{CH}), 120.9(\mathrm{CH}), 120.0\left(\mathrm{C}_{\mathrm{q}}\right), 117.7(\mathrm{CH}), 115.6(\mathrm{CH}), 114.3(\mathrm{CH}), 93.5\left(\mathrm{C}_{\mathrm{q}}\right)$, $85.1\left(\mathrm{C}_{\mathrm{q}}\right) .{ }^{19} \mathrm{~F} \mathrm{NMR}\left(282 \mathrm{MHz}, \mathrm{CDCl}_{3}\right) \delta=-62.8$. IR (neat): 3041, 2960, 1562, 1449, 1424, 805, 747, $690 \mathrm{~cm}^{-1}$. MS (EI) $\mathrm{m} / z$ (relative intensity) $363\left[\mathrm{M}^{+}\right]$(100), $344\left[\mathrm{M}-\mathrm{F}^{+}\right]$ (10), 293 (12), 214 (10), 147 (15), 43 (18). HR-MS (ESI) m/z calcd for $\mathrm{C}_{21} \mathrm{H}_{13} \mathrm{~N}_{3} \mathrm{~F}_{3}$ $\left[\mathrm{M}+\mathrm{H}^{+}\right]$364.1056, found 364.1059.<smiles>COc1ccc(C#Cc2cc3ccccc3n2-c2ncccn2)cc1</smiles>

\section{2-[(4-Methoxyphenyl)ethynyl]-1-(pyrimidin-2-yl)-1H-indole (89ah)}

The general procedure $\mathbf{E}$ was followed using indole $23 \mathrm{a}(98 \mathrm{mg}, 0.50 \mathrm{mmol}$, 1.00 equiv), $132 \mathrm{~h}$ (128 mg, $0.60 \mathrm{mmol}, 1.20$ equiv) and $\mathrm{MnBr}(\mathrm{CO})_{5}$ (3.4 mg, $2.5 \mathrm{~mol}$ $\%$ ). Isolation by column chromatography ( $n$-pentane/EtOAc: $4 / 1$ ) yielded 89ah (132 $\mathrm{mg}, 81 \%)$ as a colorless oil. ${ }^{1} \mathrm{H} \mathrm{NMR}\left(500 \mathrm{MHz}, \mathrm{CDCl}_{3}\right) \delta=8.85(\mathrm{~d}, J=4.6 \mathrm{~Hz}, 2 \mathrm{H})$, $8.29(\mathrm{~d}, J=7.6 \mathrm{~Hz}, 1 \mathrm{H}), 7.59$ (d, $J=7.6 \mathrm{~Hz}, 1 \mathrm{H}), 7.43(\mathrm{~d}, J=9.4 \mathrm{~Hz}, 2 \mathrm{H}), 7.31$ (dd, $J$ 
$=7.6,1.8 \mathrm{~Hz}, 1 \mathrm{H}) 7.23-7.21(\mathrm{~m}, 1 \mathrm{H}), 7.20(\mathrm{t}, J=4.6 \mathrm{~Hz}, 1 \mathrm{H}), 7.03(\mathrm{~s}, 1 \mathrm{H}), 6.86(\mathrm{~d}, J$ $=9.4 \mathrm{~Hz}, 2 \mathrm{H}), 3.81(\mathrm{~s}, 3 \mathrm{H}) \cdot{ }^{13} \mathrm{C} \mathrm{NMR}\left(125 \mathrm{MHz}, \mathrm{CDCl}_{3}\right) \delta=159.7\left(\mathrm{C}_{\mathrm{q}}\right), 158.1(\mathrm{CH})$, $157.4\left(\mathrm{C}_{\mathrm{q}}\right), 136.3\left(\mathrm{C}_{\mathrm{q}}\right), 132.8(\mathrm{CH}), 128.8\left(\mathrm{C}_{\mathrm{q}}\right), 124.6(\mathrm{CH}), 122.4(\mathrm{CH}), 121.2\left(\mathrm{C}_{\mathrm{q}}\right)$, $120.7(\mathrm{CH}), 117.7(\mathrm{CH}), 115.4\left(\mathrm{C}_{\mathrm{q}}\right), 114.1(\mathrm{CH}), 114.0(\mathrm{CH}), 113.9(\mathrm{CH}), 95.0\left(\mathrm{C}_{\mathrm{q}}\right)$, $81.2\left(\mathrm{C}_{\mathrm{q}}\right), 55.3\left(\mathrm{CH}_{3}\right) . \mathrm{IR}$ (neat): 3041, 2931, 2835 1604, 1561, 1420, 1204, 801, 746, $521 \mathrm{~cm}^{-1}$. MS (ESI) $\mathrm{m} / z$ (relative intensity). $348\left[\mathrm{M}+\mathrm{Na}^{+}\right]$(95), $326\left[\mathrm{M}^{+} \mathrm{H}^{+}\right]$(100), 288 (7), 198 (11), 149 (8). HR-MS (ESI) $m / z$ calcd for $\mathrm{C}_{21} \mathrm{H}_{15} \mathrm{~N}_{3} \mathrm{ONa}\left[\mathrm{M}+\mathrm{Na}^{+}\right] 348.1107$, found 348.1117 .

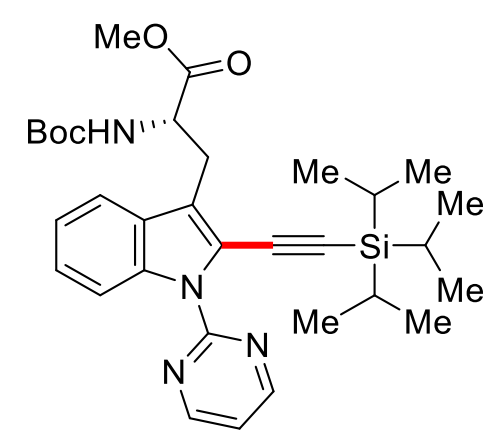

Methyl-(S)-2-[(tert-butoxycarbonyl)amino]-3-\{1-(pyrimidin-2-yl)-2[(triisopropylsilyl)ethynyl]-1 H-indol-3-yl\}propanoate (227aa)

The general procedure $\mathbf{D}$ was followed using substrate 226a $(198 \mathrm{mg}, 0.50 \mathrm{mmol}$, 1.00 equiv) and 132a (154 mg, $0.60 \mathrm{mmol}, 1.20$ equiv). Isolation by column chromatography ( $n$-pentane/EtOAc: $2 / 1$ ) yielded 227aa (237 mg, $82 \%$ ) as white solid. M.p. $=111-113^{\circ} \mathrm{C}^{1} \mathrm{H} \mathrm{NMR}\left(400 \mathrm{MHz}, \mathrm{CDCl}_{3}\right) \delta=8.75(\mathrm{~d}, J=5.0 \mathrm{~Hz}, 2 \mathrm{H}), 8.32(\mathrm{~d}, J$ $=9.0 \mathrm{~Hz}, 1 \mathrm{H}), 7.60(\mathrm{~d}, J=7.3 \mathrm{~Hz}, 1 \mathrm{H}), 7.32(\mathrm{dd}, J=7.3,2.2 \mathrm{~Hz}, 1 \mathrm{H}), 7.23(\mathrm{dd}, J=9.0$, $2.2 \mathrm{~Hz}, 1 \mathrm{H}$ ), 7.14 (t, $J=5.0 \mathrm{~Hz}, 1 \mathrm{H}), 5.24(\mathrm{~d}, J=7.6 \mathrm{~Hz}, 1 \mathrm{H}), 4.55(\mathrm{dd}, J=8.2,7.6 \mathrm{~Hz}$, $1 \mathrm{H}), 3.67(\mathrm{~s}, 3 \mathrm{H}), 3.41-3.31(\mathrm{~m}, 2 \mathrm{H}), 1.33(\mathrm{~s}, 9 \mathrm{H}), 1.15-1.13(\mathrm{~m}, 21 \mathrm{H}) .{ }^{13} \mathrm{C}$ NMR $(125$ $\left.\mathrm{MHz}, \mathrm{CDCl}_{3}\right) \delta=172.8\left(\mathrm{C}_{\mathrm{q}}\right), 158.0(\mathrm{CH}), 157.2\left(\mathrm{C}_{\mathrm{q}}\right), 155.3\left(\mathrm{C}_{\mathrm{q}}\right), 135.9\left(\mathrm{C}_{\mathrm{q}}\right), 128.3\left(\mathrm{C}_{\mathrm{q}}\right)$, $125.4(\mathrm{CH}), 123.2\left(\mathrm{C}_{\mathrm{q}}\right), 122.4(\mathrm{CH}), 120.0\left(\mathrm{C}_{\mathrm{q}}\right), 119.0(\mathrm{CH}), 117.4(\mathrm{CH}), 114.4(\mathrm{CH})$, $101.6\left(\mathrm{C}_{\mathrm{q}}\right), 97.8\left(\mathrm{C}_{\mathrm{q}}\right), 79.6\left(\mathrm{C}_{\mathrm{q}}\right), 54.3(\mathrm{CH}), 52.2\left(\mathrm{CH}_{3}\right), 28.2\left(\mathrm{CH}_{3}\right), 28.0\left(\mathrm{CH}_{2}\right), 18.7$ $\left(\mathrm{CH}_{3}\right), 11.4(\mathrm{CH})$. IR (neat): 2960, 2864, 2138, 1738, 1420, 1257, 996, 747, $675 \mathrm{~cm}^{-1}$. MS (ESI) $\mathrm{m} / z$ (relative intensity): $1175\left[2 \mathrm{M}+\mathrm{Na}^{+}\right](100), 599\left[\mathrm{M}+\mathrm{Na}^{+}\right](77), 577\left[\mathrm{M}+\mathrm{H}^{+}\right]$ (23), 512 (11), 389 (13), 208 (5). HR-MS (ESI) $m / z$ calcd for $\mathrm{C}_{32} \mathrm{H}_{44} \mathrm{~N}_{4} \mathrm{O}_{4} \mathrm{SiNa}\left[\mathrm{M}+\mathrm{Na}^{+}\right]$ 599.3024 , found 599.3024 . The enantiomeric excess was determined to be $>98 \%$ by HPLC analysis of compound (S)-227aa and a racemic sample ( \pm )-227aa. 


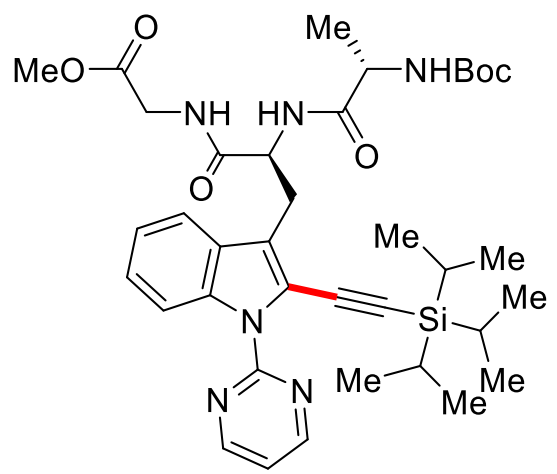

Methyl-\{(S)-2-\{(S)-2-[(tert-butoxycarbonyl)amino]propanamido\}-3-\{1-(pyrimidin2-yl)-2-[(triisopropylsilyl)ethynyl]-1 H-indol-3-yl\}propanoyl\}glycinate (227ba)

The general procedure $\mathbf{D}$ was followed using substrate $226 \mathrm{~b}(132 \mathrm{mg}, 0.25 \mathrm{mmol}$, 1.00 equiv) and $132 \mathrm{a}$ (78 mg, $0.30 \mathrm{mmol}, 1.20$ equiv). Isolation by column chromatography ( $n$-pentane/EtOAc: $1 / 2$ ) yielded 227 ba $(124 \mathrm{mg}, 71 \%$ ) as a yellow solid. M.p. $=64-66{ }^{\circ} \mathrm{C}^{1} \mathrm{H}$ NMR $\left(400 \mathrm{MHz}, \mathrm{CDCl}_{3}\right) \delta=8.75(\mathrm{~d}, J=5.4 \mathrm{~Hz}, 2 \mathrm{H}), 8.30$ $(\mathrm{d}, J=8.8 \mathrm{~Hz}, 1 \mathrm{H}), 7.74(\mathrm{~d}, J=8.6 \mathrm{~Hz}, 1 \mathrm{H}), 7.33(\mathrm{dd}, J=8.8,2.7 \mathrm{~Hz}, 1 \mathrm{H}), 7.23(\mathrm{dd}, J$ $=8.6,2.7 \mathrm{~Hz}, 1 \mathrm{H}), 7.15(\mathrm{t}, J=5.4 \mathrm{~Hz}, 1 \mathrm{H}), 6.67(\mathrm{~d}, J=6.7 \mathrm{~Hz}, 1 \mathrm{H}), 6.50(\mathrm{~s}, 1 \mathrm{H}), 4.93$ (s, 1H), 4.80 (dd, $J=7.0,4.5 \mathrm{~Hz}, 1 \mathrm{H}$ ), $4.03(\mathrm{dd}, J=6.8,3.3 \mathrm{~Hz}, 1 \mathrm{H}$ ), 3.97 (dd, $J=10.2$, $5.6 \mathrm{~Hz}, 1 \mathrm{H}), 3.86(\mathrm{dd}, J=10.2,5.6 \mathrm{~Hz}, 1 \mathrm{H}), 3.60(\mathrm{~s}, 3 \mathrm{H}), 3.47-3.41(\mathrm{~m}, 2 \mathrm{H}), 1.33(\mathrm{~s}$, $9 \mathrm{H}), 1.22(\mathrm{~d}, J=7.0 \mathrm{~Hz}, 3 \mathrm{H}), 1.15-1.13(\mathrm{~m}, 21 \mathrm{H}) .{ }^{13} \mathrm{C} \mathrm{NMR}\left(125 \mathrm{MHz}, \mathrm{CDCl}_{3}\right) \delta=$ $172.5\left(\mathrm{C}_{\mathrm{q}}\right), 170.8\left(\mathrm{C}_{\mathrm{q}}\right), 169.4\left(\mathrm{C}_{\mathrm{q}}\right), 158.0(\mathrm{CH}), 157.3\left(\mathrm{C}_{\mathrm{q}}\right), 155.5\left(\mathrm{C}_{\mathrm{q}}\right), 136.0\left(\mathrm{C}_{\mathrm{q}}\right), 128.0$ $\left(\mathrm{C}_{\mathrm{q}}\right), 125.6(\mathrm{CH}), 123.2\left(\mathrm{C}_{\mathrm{q}}\right), 122.7(\mathrm{CH}), 120.1\left(\mathrm{C}_{\mathrm{q}}\right), 119.5(\mathrm{CH}), 117.5(\mathrm{CH}), 114.4$ $(\mathrm{CH}), 101.6\left(\mathrm{C}_{\mathrm{q}}\right), 97.8\left(\mathrm{C}_{\mathrm{q}}\right), 80.2\left(\mathrm{C}_{\mathrm{q}}\right), 53.0(\mathrm{CH}), 52.1\left(\mathrm{CH}_{3}\right), 50.9(\mathrm{CH}), 41.5\left(\mathrm{CH}_{2}\right)$, $28.2\left(\mathrm{CH}_{3}\right), 28.0\left(\mathrm{CH}_{2}\right), 18.7\left(\mathrm{CH}_{3}\right), 18.3\left(\mathrm{CH}_{3}\right), 11.4(\mathrm{CH})$. IR (neat): 2926, 2861, 2144, 1747, 1657, 1423, 1205, $710 \mathrm{~cm}^{-1}$. MS (ESI) $\mathrm{m} / z$ (relative intensity): 1431 [2M+Na+]

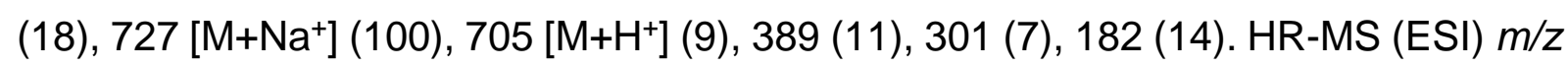
calcd for $\mathrm{C}_{37} \mathrm{H}_{53} \mathrm{~N}_{6} \mathrm{O}_{6} \mathrm{Si}\left[\mathrm{M}+\mathrm{H}^{+}\right] 705.3790$, found 705.3789 . The enantiomeric excess was determined to be $>98 \%$ by HPLC analysis of compound 227 ba and a racemic control sample.

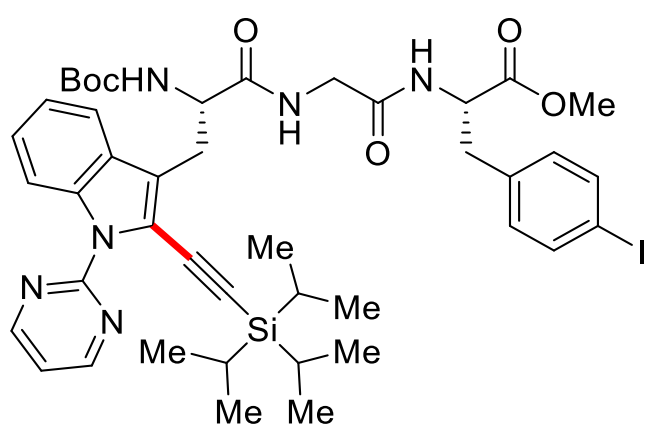


Methyl-(6S,12S)-12-(4-iodobenzyl)-2,2-dimethyl-4,7,10-trioxo-6-\{[1-(pyrimidin-2yl)-2-[(triisopropylsilyl)ethynyl]-1 $H$-indol-3-yl]methyl\}-3-oxa-5,8,11-triazatridecan-13-oate (227ca)

The general procedure $\mathbf{D}$ was followed using substrate $226 \mathrm{c}$ (183 $\mathrm{mg}, 0.25 \mathrm{mmol}$, 1.00 equiv) and $132 \mathrm{a}$ (78 mg, $0.30 \mathrm{mmol}, 1.20$ equiv). Isolation by column chromatography ( $n$-pentane/EtOAc: $1 / 4$ ) yielded $227 \mathrm{ca}(154 \mathrm{mg}, 69 \%)$ as a colorless oil. ${ }^{1} \mathrm{H}$ NMR $\left(400 \mathrm{MHz}, \mathrm{CDCl}_{3}\right) \delta=8.76(\mathrm{~d}, J=4.6 \mathrm{~Hz}, 2 \mathrm{H}), 8.31(\mathrm{~d}, J=7.7 \mathrm{~Hz}, 1 \mathrm{H})$, $7.61(\mathrm{~d}, J=8.5 \mathrm{~Hz}, 1 \mathrm{H}), 7.57(\mathrm{~d}, J=8.7 \mathrm{~Hz}, 2 \mathrm{H}), 7.31$ (dd, $J=8.5,1.7 \mathrm{~Hz}, 1 \mathrm{H}), 7.21$ (dd, $J=7.7,1.7 \mathrm{~Hz}, 1 \mathrm{H}), 7.16(\mathrm{t}, J=4.6 \mathrm{~Hz}, 1 \mathrm{H}), 6.86(\mathrm{~d}, J=8.7 \mathrm{~Hz}, 2 \mathrm{H}), 6.46(\mathrm{dd}, J$ $=6.4,6.4 \mathrm{~Hz}, 1 \mathrm{H}$ ), $5.38(\mathrm{~s}, 1 \mathrm{H}), 4.70(\mathrm{dd}, J=6.2,4.4 \mathrm{~Hz}, 1 \mathrm{H}$ ), $4.38(\mathrm{dd}, J=6.8,3.9$ $\mathrm{Hz}, 1 \mathrm{H}), 3.83-3.73(\mathrm{~m}, 2 \mathrm{H}), 3.64(\mathrm{~s}, 3 \mathrm{H}), 3.47-3.34(\mathrm{~m}, 2 \mathrm{H}), 3.04(\mathrm{dd}, J=11.0,6.6 \mathrm{~Hz}$, $1 \mathrm{H}), 2.93(\mathrm{dd}, J=11.0,6.6 \mathrm{~Hz}, 1 \mathrm{H}), 1.33(\mathrm{~s}, 9 \mathrm{H}), 1.18-1.14(\mathrm{~m}, 21 \mathrm{H}) .{ }^{13} \mathrm{C}$ NMR $(101$ $\left.\mathrm{MHz}, \mathrm{CDCl}_{3}\right) \delta=172.1\left(\mathrm{C}_{\mathrm{q}}\right), 171.2\left(\mathrm{C}_{\mathrm{q}}\right), 168.4\left(\mathrm{C}_{\mathrm{q}}\right), 158.0(\mathrm{CH}), 157.9\left(\mathrm{C}_{\mathrm{q}}\right), 157.1\left(\mathrm{C}_{\mathrm{q}}\right)$, $155.8\left(\mathrm{C}_{\mathrm{q}}\right), 137.5(\mathrm{CH}), 135.8\left(\mathrm{C}_{\mathrm{q}}\right), 131.2(\mathrm{CH}), 128.1\left(\mathrm{C}_{\mathrm{q}}\right), 125.6(\mathrm{CH}), 123.2\left(\mathrm{C}_{\mathrm{q}}\right)$, $122.6(\mathrm{CH}), 119.9\left(\mathrm{C}_{\mathrm{q}}\right), 119.3(\mathrm{CH}), 117.6(\mathrm{CH}), 114.3(\mathrm{CH}), 102.1\left(\mathrm{C}_{\mathrm{q}}\right), 97.7\left(\mathrm{C}_{\mathrm{q}}\right), 92.5$ $\left(\mathrm{C}_{\mathrm{q}}\right) 80.5\left(\mathrm{C}_{\mathrm{q}}\right), 58.8\left(\mathrm{CH}_{2}\right), 56.1(\mathrm{CH}), 53.3(\mathrm{CH}), 52.2\left(\mathrm{CH}_{3}\right), 43.1\left(\mathrm{CH}_{2}\right), 37.2\left(\mathrm{CH}_{2}\right)$, $28.2\left(\mathrm{CH}_{3}\right), 18.7\left(\mathrm{CH}_{3}\right), 11.3(\mathrm{CH})$. IR (neat): 2941, 2863, 2142, 1733, 1656, 1436, 1339, 1163, $725 \mathrm{~cm}^{-1}$. MS (ESI) $\mathrm{m} / z$ (relative intensity): 1836 [2M+Na+] (27), 929 $\left[\mathrm{M}+N a^{+}\right]$(100), 907 [M+H+] (9), 389 (12). HR-MS (ESI) $m / z$ calcd for $\mathrm{C}_{43} \mathrm{H}_{55} \mathrm{~N}_{6} \mathrm{O}_{6} \mathrm{ISiNa}$ $\left[\mathrm{M}+\mathrm{Na}^{+}\right]$705.3790, found 705.3789.

\subsubsection{Mechanistic Experiments for the Cobalt Catalysis}

\section{Competition Experiments:}

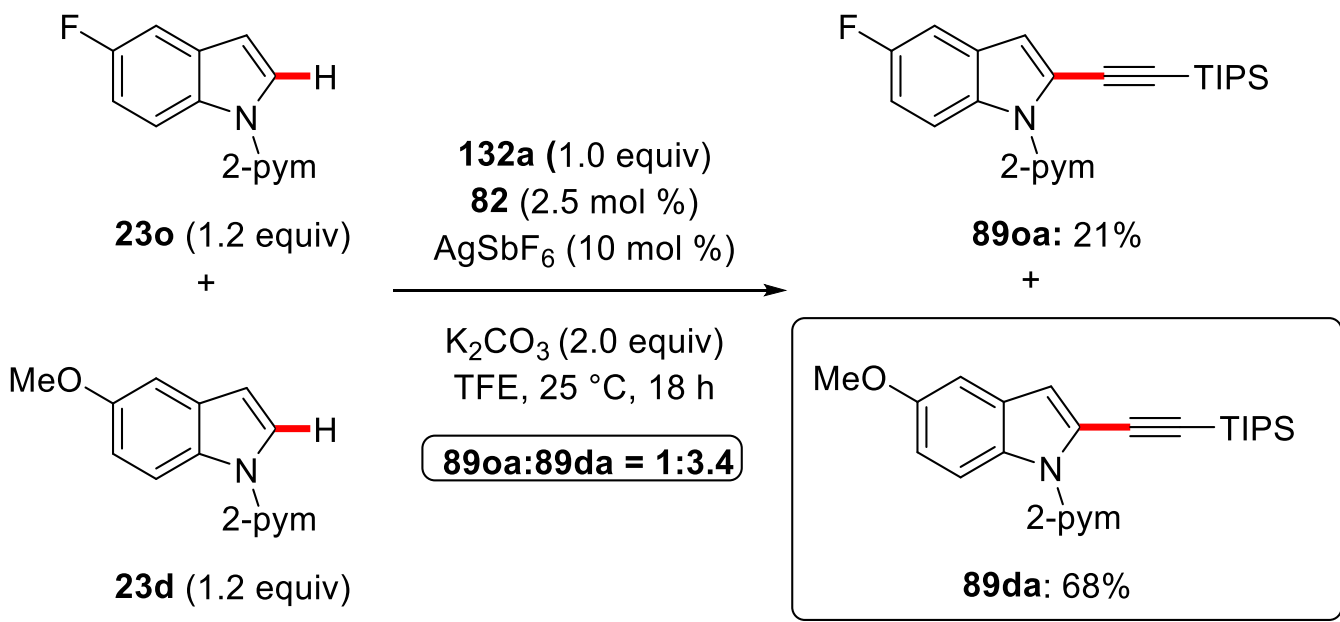

Scheme 5.1. Intermolecular competition experiment between indoles $\mathbf{2 3 0}$ and $\mathbf{2 3 d}$. 
To a solution of 5-fluoro-1-(pyrimidin-2-yl)- $1 H$-indole (23o) $(63.8 \mathrm{mg}, 0.30 \mathrm{mmol}, 1.20$ equiv), 5-methoxy-1-(pyrimidin-2-yl)-1H-indole $\quad$ (23d) $\quad(65.9 \mathrm{mg}, \quad 0.30 \mathrm{mmol}$, 1.20 equiv), [ $\left.\mathrm{Cp}^{*} \mathrm{Col}_{2}\right]_{2}$ (82) (5.6 mg, $\left.6.25 \mu \mathrm{mol}, 2.5 \mathrm{~mol} \%\right), \mathrm{AgSbF}_{6} \quad(8.8 \mathrm{mg}$, $25.0 \mu \mathrm{mol}, 10 \mathrm{~mol} \%$ ) and $\mathrm{K}_{2} \mathrm{CO}_{3}(69.8 \mathrm{mg}, 0.50 \mathrm{mmol}, 2.00$ equiv) in TFE (1.5 mL), 132a ( $65.7 \mathrm{mg}, 0.25 \mathrm{mmol}, 1.0$ equiv) was added. The mixture was stirred for $18 \mathrm{~h}$ at $25^{\circ} \mathrm{C}$. The crude mixture was analyzed by GC using tridecane as an internal standart.

\section{H/D-Exchange Experiment}

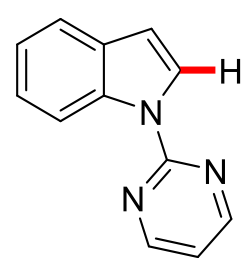

23a

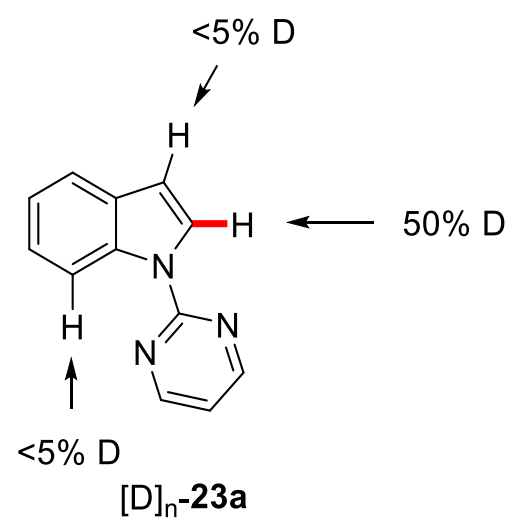

Scheme 5.2. H/D-Exchange experiment.

A solution of (pyrimidin-2-yl)-1H-indole (23a) $(49.5 \mathrm{mg}, 0.25 \mathrm{mmol}, 1.00$ equiv), [Cp* ${ }^{*} \mathrm{Col}_{2}{ }_{2}$ (82) (5.6 mg, $\left.6.25 \mu \mathrm{mol}, 2.5 \mathrm{~mol} \%\right), \mathrm{AgSbF}_{6}(8.8 \mathrm{mg}, 25.0 \mu \mathrm{mol}, 10 \mathrm{~mol} \%$ ) and KOAc (50.1 mg, $0.50 \mathrm{mmol}, 2.00$ equiv) in TFE $(1.6 \mathrm{~mL})$ and $\mathrm{D}_{2} \mathrm{O}(0.4 \mathrm{~mL})$ was stirred at $80^{\circ} \mathrm{C}$ for $18 \mathrm{~h}$. After completion of the reaction, the solvent was removed at reduced pressure and the mixture purified by column chromatography using $n$ pentane/EtOAc 5:1. The amount of deuterium incorporation was determined by ${ }^{1} \mathrm{H}$ NMR. 

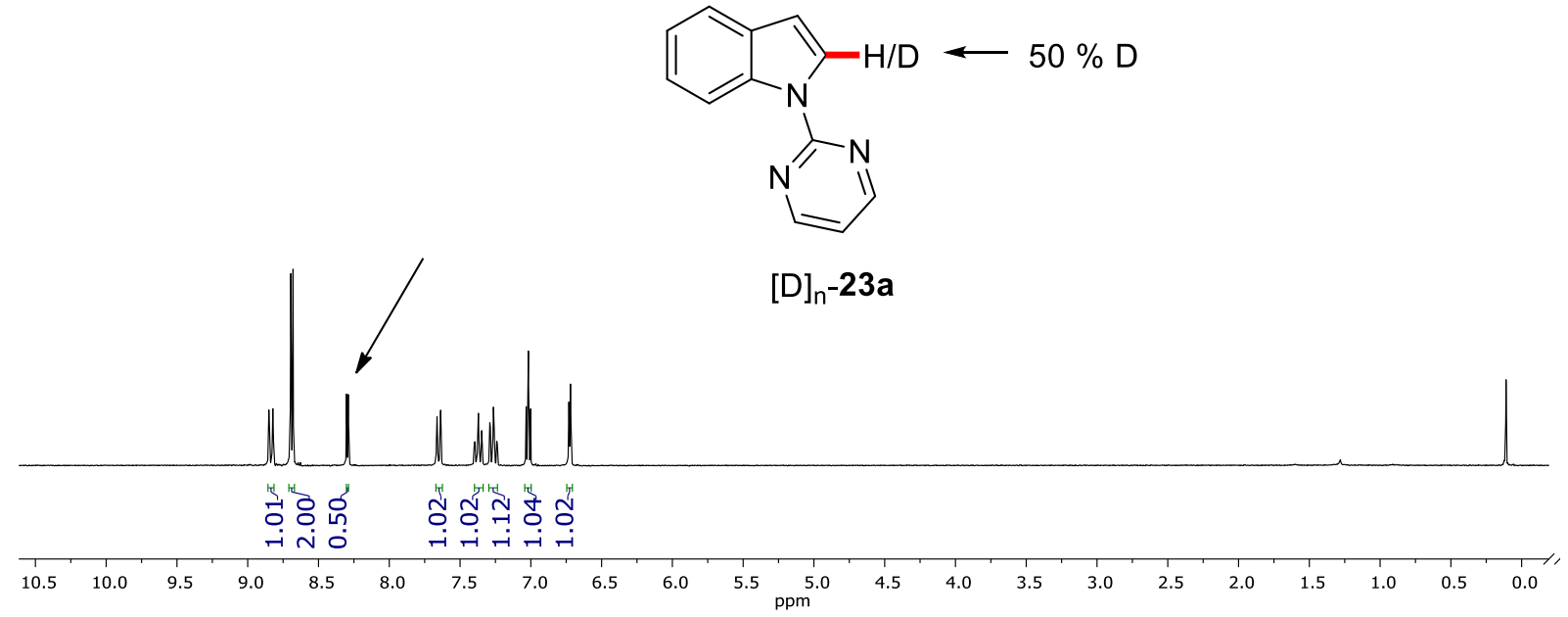

Figure 5.1. ${ }^{1} \mathrm{H}-\mathrm{NMR}$ spectra of the $\mathrm{H} / \mathrm{D}$-exchage experiment.

\subsubsection{Mechanistic Experiments for the Manganese Catalysis}

\section{Studies on a potential racemization of $L$ - and $D$-peptides}

In order to confirm that no racemization occurred within the peptides during the manganese-catalyzed $\mathrm{C}-\mathrm{H}$ alkynylation, we prepared the racemic substrates methyl $\mathrm{N}$-(tert-butoxycarbonyl)-1-(pyrimidin-2-yl)tryptophanate (rac-226a) and methyl $\mathrm{N}$-[(tertbutoxycarbonyl)alanyl]-1-(pyrimidin-2-yl)tryptophylglycinate (rac-226b). Alkynylation reactions were carried out under the optimized reaction conditions. The manganesecatalyzed alkynylation of rac-226a and rac-226b yielded racemic products rac-227aa and rac-227ba, respectively. Chiral HPLC analysis showed that no racemization after the manganese-catalyzed $\mathrm{C}-\mathrm{H}$ alkynylation process. HPLC chromatograms were recorded on an Agilent 1290 Infinity using the column CHIRALPAK® IC-3 and $n$ hexane/ $\mathrm{PrOH}(90: 10,1 \mathrm{~mL} / \mathrm{min}$, detection at $274 \mathrm{~nm})$. 

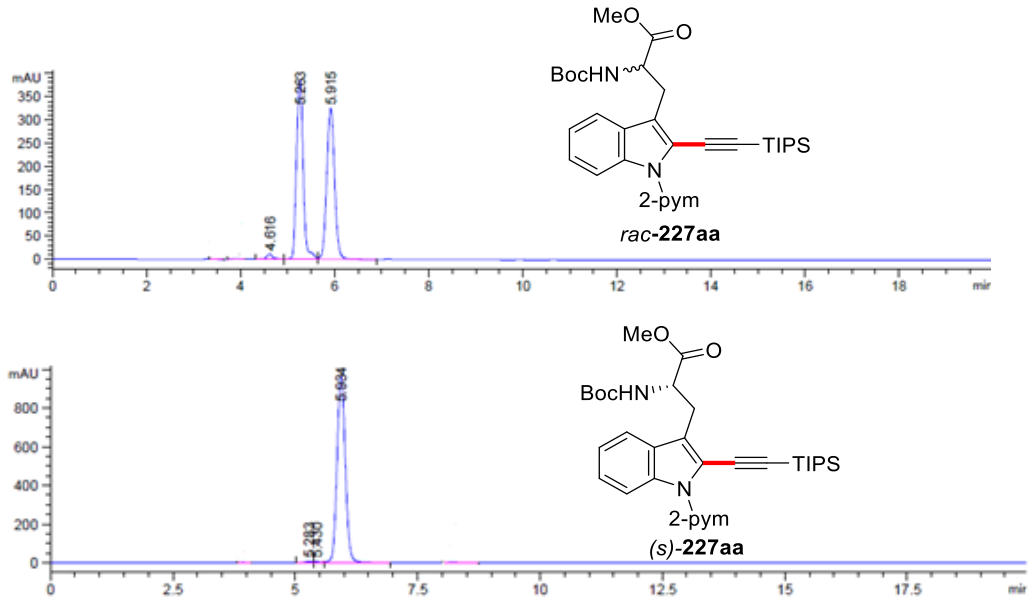

Figure 5.2. HPLC Chromatograms of rac-227aa and (S)-227aa.

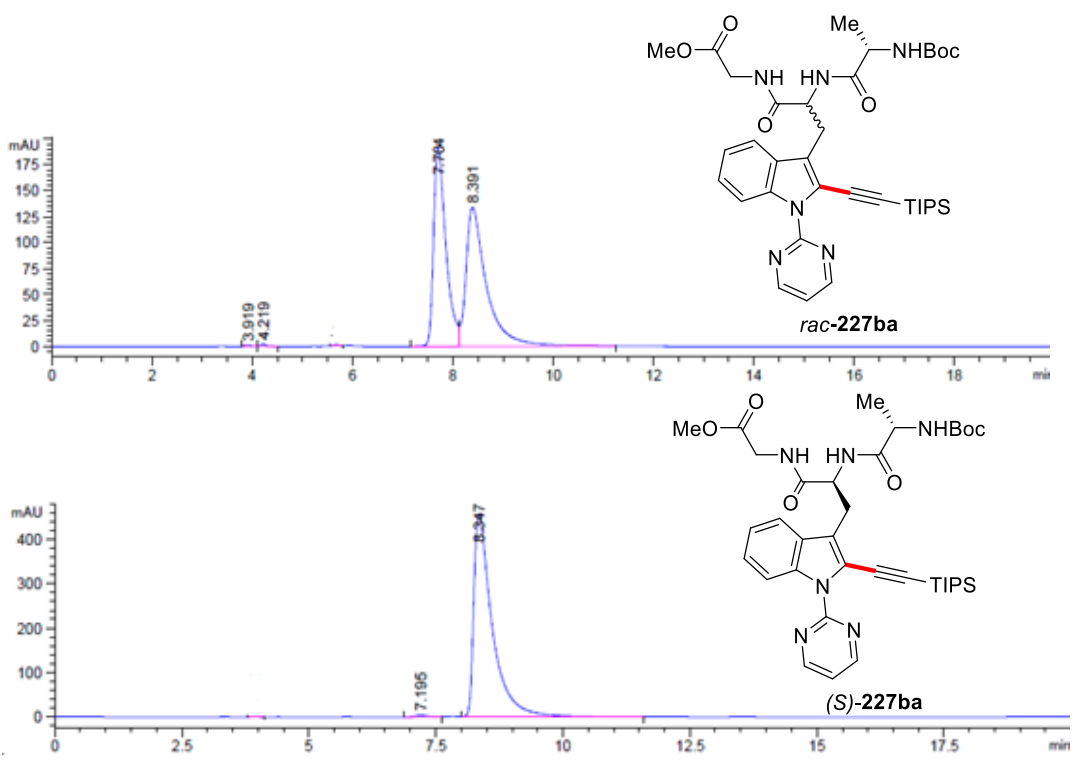

Figure 5.3. HPLC Chromatogram of rac-227ba and (S)-227ba.

\section{Manganese-Catalyzed H/D Exchange Experiments}

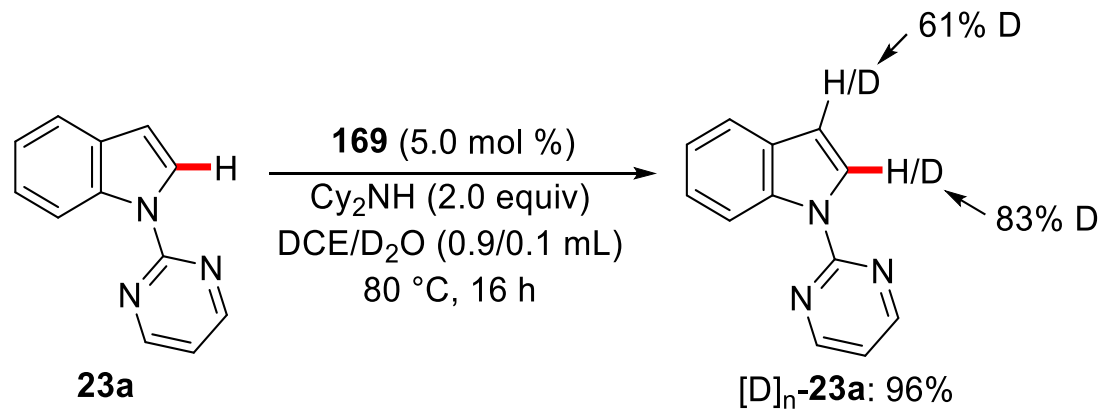

Scheme 5.3. H/D exchange in the absence of bromoalkyne 132a. 
1-(Pyrimidin-2-yl)-1H-indole (23a) (98.2 mg, 0.50 mmol, 1.00 equiv), $\operatorname{MnBr}(\mathrm{CO})_{5}$ (169) (6.9 mg, $5.0 \mathrm{~mol} \%$ ), Cy2 $\mathrm{NH}$ (181 mg, $1.00 \mathrm{mmol}, 2.00$ equiv), DCE $\left(0.9 \mathrm{~mL}\right.$ ) and $\mathrm{D}_{2} \mathrm{O}$ $(0.1 \mathrm{~mL})$ were placed in a $25 \mathrm{~mL}$ Schlenk tube under $\mathrm{N}_{2}$ and were then stirred at $80^{\circ} \mathrm{C}$ for $16 \mathrm{~h}$. At ambient temperature, the reaction mixture was diluted with $\mathrm{H}_{2} \mathrm{O}(10 \mathrm{~mL})$ and extracted with EtOAc $(3 \times 15 \mathrm{~mL})$. The combined organic layer was dried with $\mathrm{Na}_{2} \mathrm{SO}_{4}$ and concentrated under reduced pressure. Purification by flash column chromatography on silica gel (n-hexane/EtOAc: 10/1) yielded [D]n-23a $(94.6 \mathrm{mg}$, $0.25 \mathrm{mmol}, 96 \%)$. The $\mathrm{D}$ incorporation was determined by ${ }^{1} \mathrm{H}$-NMR spectroscopy.

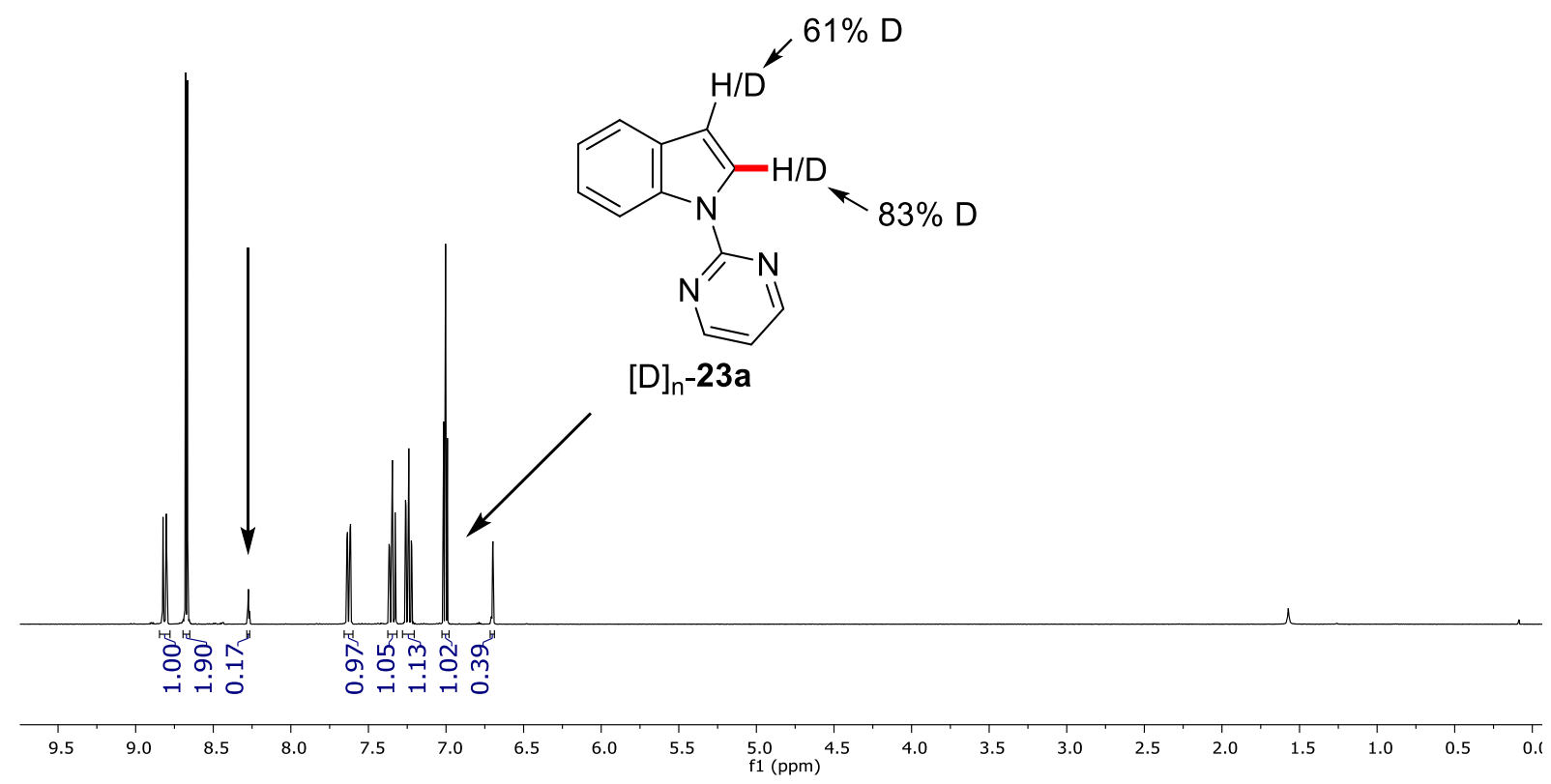

Figure 5.4. ${ }^{1} \mathrm{H}-\mathrm{NMR}$ spectra of the $\mathrm{H} / \mathrm{D}$-exchage experiment in absence of bromoalkyne 132a.

$\mathrm{H} / \mathrm{D}$ Exchange Experiments in the Absence of $\mathrm{MnBr}(\mathrm{CO})_{5}$

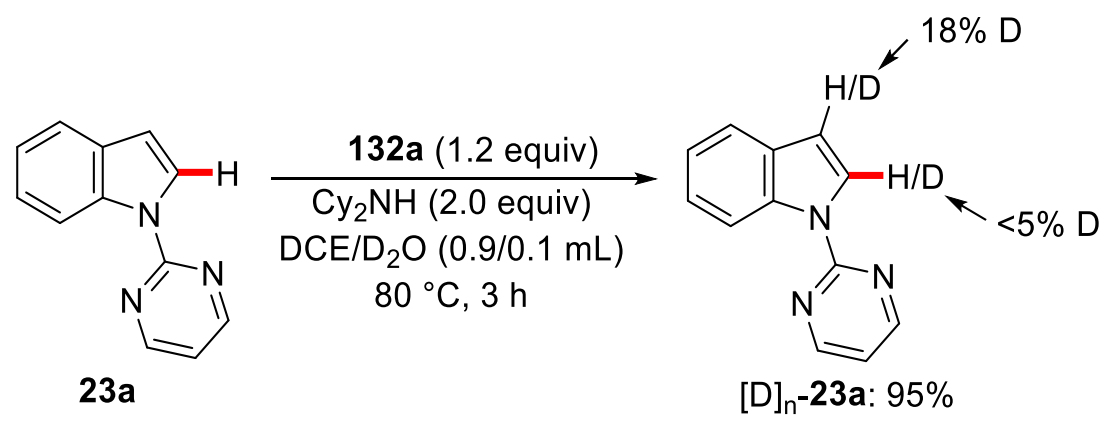


Scheme 5.4. H/D-exchage experiment in the absence of catalyst 169.

1-(Pyrimidin-2-yl)-1 $H$-indole (23a) (49.0 mg, $0.25 \mathrm{mmol}, 1.00$ equiv), \%), bromoalkyne 132a (77.5 mg, $0.30 \mathrm{mmol}, 1.20$ equiv), Cy2 $\mathrm{NH}$ (93.2 mg, $0.50 \mathrm{mmol}, 2.00$ equiv), DCE $(0.9 \mathrm{~mL})$ and $\mathrm{D}_{2} \mathrm{O}(0.1 \mathrm{~mL})$ were placed in a $25 \mathrm{~mL}$ Schlenk tube under $\mathrm{N}_{2}$ and were then stirred at $80^{\circ} \mathrm{C}$ for $3 \mathrm{~h}$. At ambient temperature, the reaction mixture was diluted with $\mathrm{H}_{2} \mathrm{O}(10 \mathrm{~mL})$ and extracted with EtOAc $(3 \times 15 \mathrm{~mL})$. The combined organic layer was dried with $\mathrm{Na}_{2} \mathrm{SO}_{4}$ and concentrated under reduced pressure. Purification by flash column chromatography on silica gel ( $n$-hexane/EtOAc: $10 / 1)$ yielded [D]n-23a $(47.3$ $\mathrm{mg}, 0.24 \mathrm{mmol}, 95 \%)$. The $\mathrm{D}$ incorporation was determined by ${ }^{1} \mathrm{H}-\mathrm{NMR}$ spectroscopy.
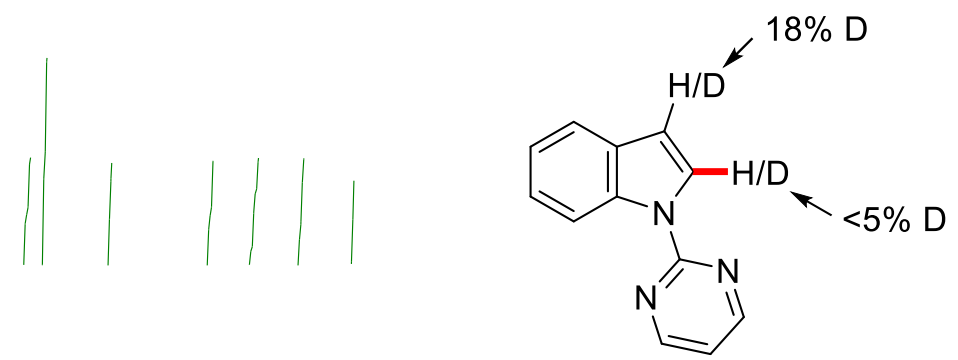

$[D]_{n}-23 a$

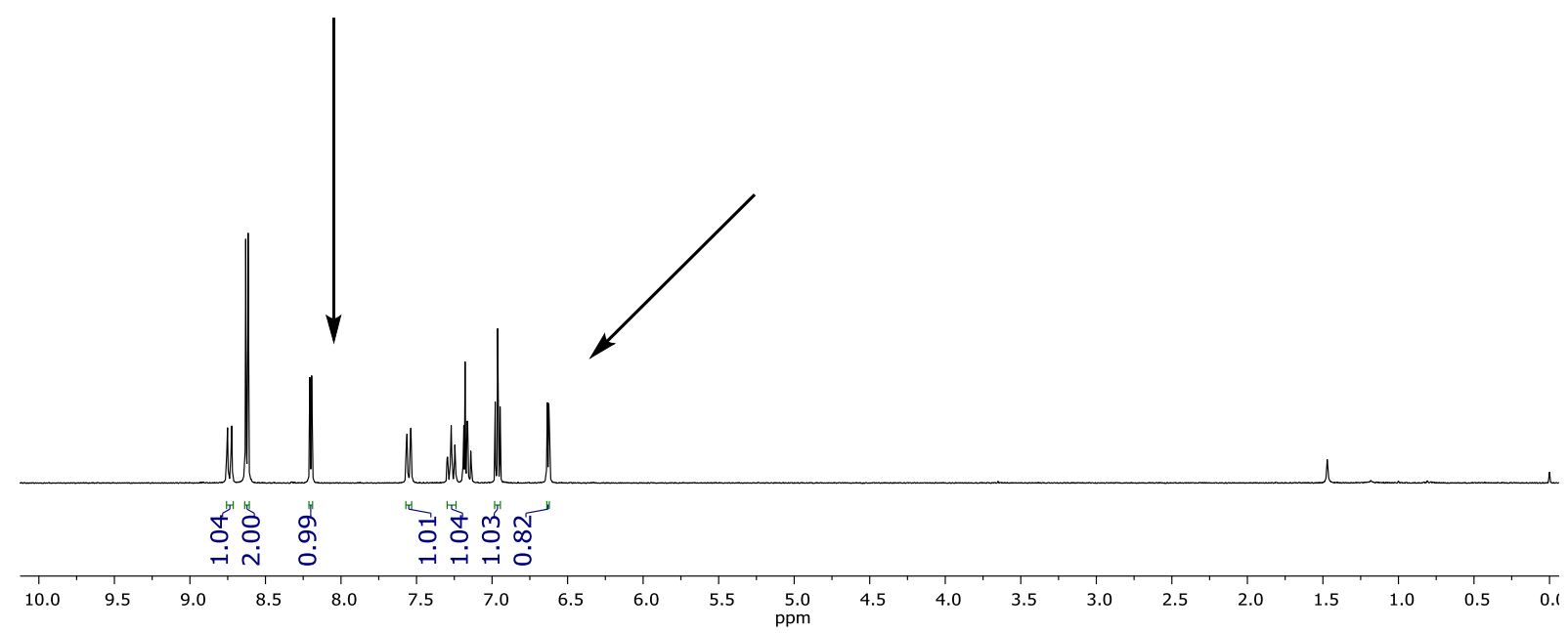

Figure 5.5. ${ }^{1} \mathrm{H}-\mathrm{NMR}$ spectra of the $\mathrm{H} / \mathrm{D}$-exchage experiment in the absence of catalyst 169 . 


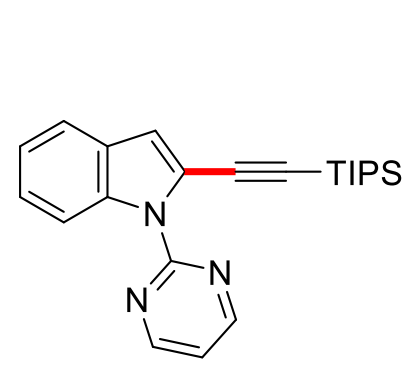

89 aa

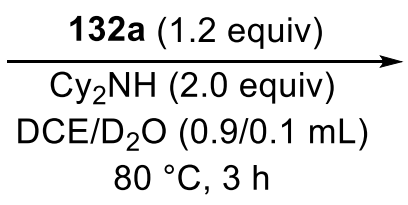

$80^{\circ} \mathrm{C}, 3 \mathrm{~h}$

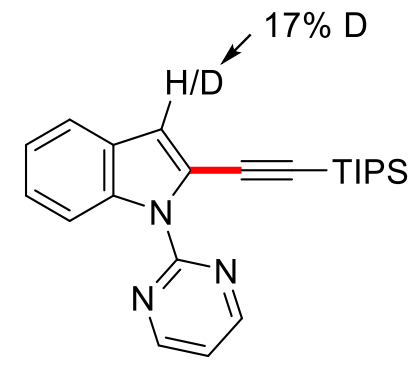

[D] $]_{n}-89 a a: 97 \%$

Scheme 5.5. H/D-exchage experiment of product 89aa.

1-(Pyrimidin-2-yl)-2-[(triisopropylsilyl)ethynyl]-1 $H$-indole (89aa) $(95.3 \mathrm{mg}, 0.25 \mathrm{mmol}$, 1.00 equiv), bromoalkyne 132a ( $75.2 \mathrm{mg}, 0.30 \mathrm{mmol}, 1.20$ equiv), Су $2 \mathrm{NH}$ (190 mg, $0.50 \mathrm{mmol})$, DCE $(0.9 \mathrm{~mL})$ and $\mathrm{D}_{2} \mathrm{O}(0.1 \mathrm{~mL})$ were placed in a $25 \mathrm{~mL}$ Schlenk tube under $\mathrm{N}_{2}$ and were then stirred at $80^{\circ} \mathrm{C}$ for $3 \mathrm{~h}$. At ambient temperature, the reaction mixture was diluted with $\mathrm{H}_{2} \mathrm{O}(10 \mathrm{~mL})$ and extracted with EtOAc $(3 \times 15 \mathrm{~mL})$. The combined organic layer was dried with $\mathrm{Na}_{2} \mathrm{SO}_{4}$ and concentrated under reduced pressure. Purification by flash column chromatography on silica gel ( $n$-hexane/EtOAc: 10/1) yielded [D]n-89aa $(91.2 \mathrm{mg}, 0.25 \mathrm{mmol}, 97 \%)$. The $D$ incorporation was determined by ${ }^{1} \mathrm{H}-\mathrm{NMR}$ spectroscopy.
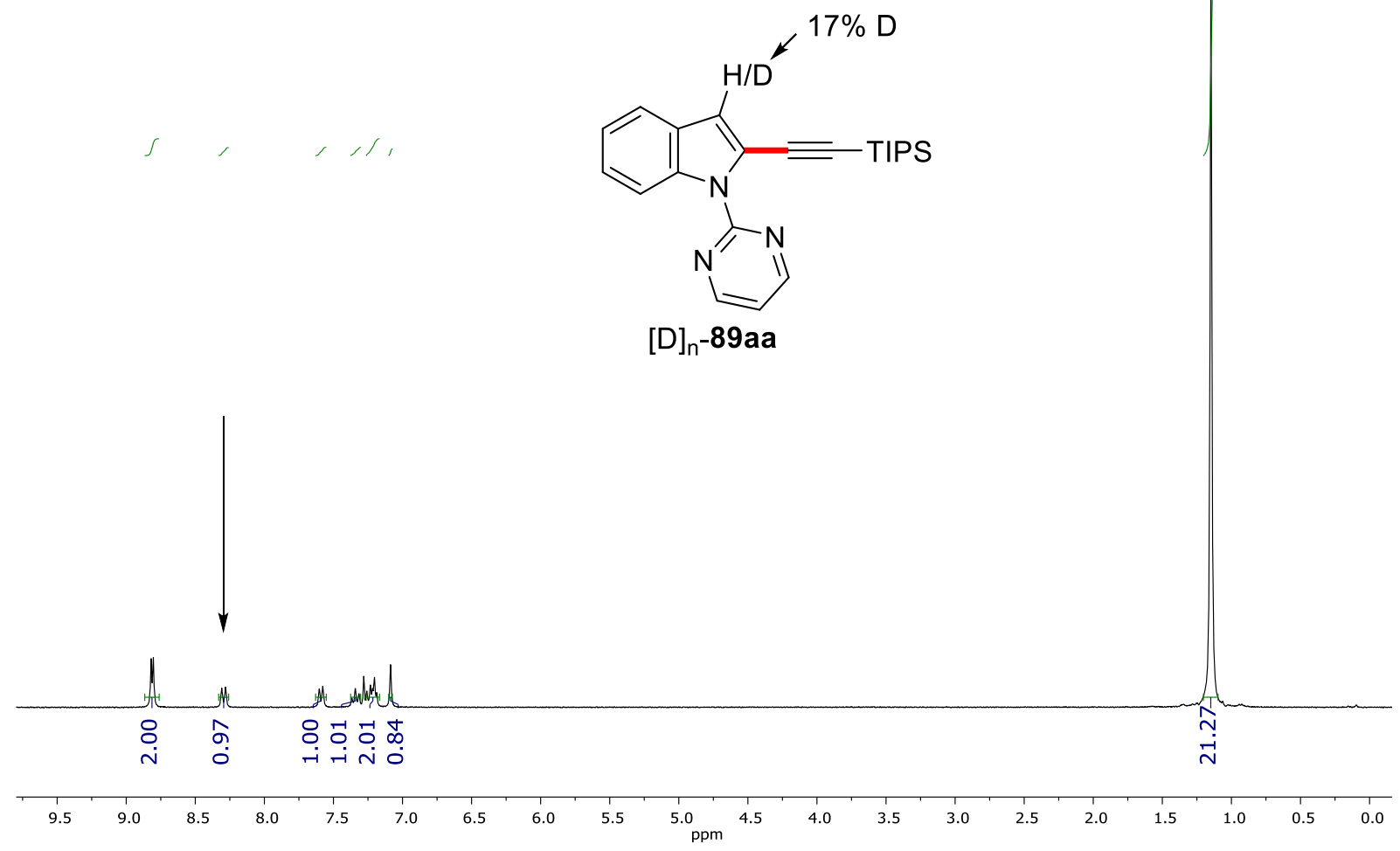

Figure 5.6. ${ }^{1} \mathrm{H}-\mathrm{NMR}$ spectra of the $\mathrm{H} / \mathrm{D}$-exchage experiment of product 169 . 


\section{Kinetic Analysis}<smiles>c1cnc(-n2ccc3ccccc32)nc1</smiles>

23

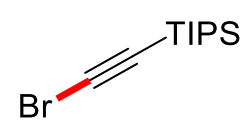

$132 a$

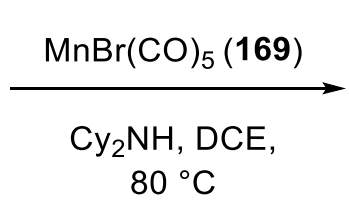

$80{ }^{\circ} \mathrm{C}$

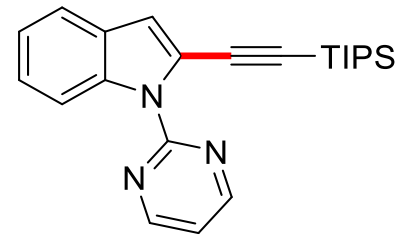

89aа

Scheme 5.6. Determination of the reaction order in indole 23a.

The reaction order with respect to indole 23a was examined using the initial rate method. ${ }^{[223]}$ A Schlenk-flask was charged with indole 23a $(0.80,0.90,1.00$, 1.10 equiv.), 132a (209 mg, $0.80 \mathrm{mmol}), \operatorname{MnBr}(\mathrm{CO})_{5}(169)(11 \mathrm{mg}, 5.0 \mathrm{~mol} \%)$ and $n-$ tridecane $(80 \mu \mathrm{L})$. DCE $(4.0 \mathrm{~mL})$ was added and the mixture was divided into four preheated Schlenk-tubes and stirred at $80^{\circ} \mathrm{C}$. After one minute the first reaction was opened and a sample removed by syringe, diluted with EtOAc, filtered through a short plug of silica gel and $\mathrm{Na}_{2} \mathrm{SO}_{4}$ and analyzed by gas chromatography. This was repeated for all reactions with a time difference of one minute between each sample.

\begin{tabular}{cccc}
\hline Equiv 23q & $\Delta\left[\right.$ 89aa] $\Delta t^{1} / \mathrm{mol} \mathrm{L}^{-1} \mathrm{~s}^{-1}$ & $\log \left(c / \mathrm{mol} \mathrm{L}^{-1}\right)$ & $\log \left(\Delta[\mathbf{8 9 a a}] \Delta t^{-1} / \mathrm{mol} \mathrm{L}^{-1} \mathrm{~s}^{-1}\right)$ \\
\hline 0.8 & 2.188 & -0.795 & 0.340 \\
0.9 & 2.500 & -0.745 & 0.398 \\
1.0 & 2.858 & -0.699 & 0.456 \\
1.1 & 3.069 & -0.658 & 0.487 \\
\hline
\end{tabular}




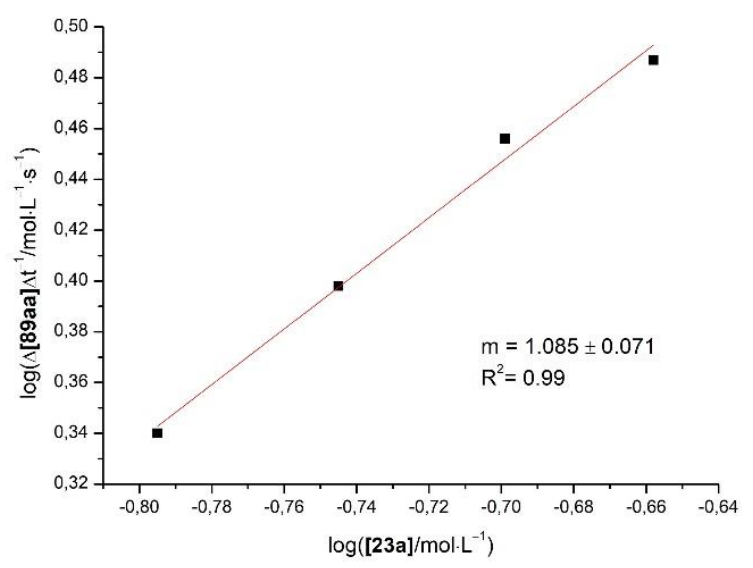

Figure 5.7. Reaction order in indole 23a.<smiles>c1cnc(-n2ccc3ccccc32)nc1</smiles>

$23 a$<smiles>S=[In]C#CBr</smiles>

$132 a$

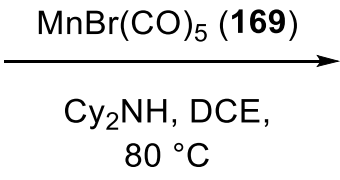

$80{ }^{\circ} \mathrm{C}$<smiles>S[InH]C#Cc1cc2ccccc2n1-c1ncccn1</smiles>

89aa

Scheme 5.7. Determination of the reaction order in bromoalkyne 132a.

The reaction order with respect to alkyne 132a was examined using the initial rate method. ${ }^{[223]}$ A Schlenk-flask was charged with indole 23a $(156 \mathrm{mg}, 0.80 \mathrm{mmol}$, 1.00 equiv.), 132a (0.80, 1.00, 1.20, 1.40 equiv), $\operatorname{MnBr}(\mathrm{CO})_{5}(\mathbf{1 6 9})(11 \mathrm{mg}, 5.0 \mathrm{~mol} \%)$ and $n$-tridecane $(80 \mu \mathrm{L})$. DCE $(4.0 \mathrm{~mL})$ was added and the mixture was divided into four pre-heated Schlenk-tubes and stirred at $80^{\circ} \mathrm{C}$. After one minute the first reaction was opened and a sample removed by syringe, diluted with EtOAc, filtered through a short plug of silica gel and $\mathrm{Na}_{2} \mathrm{SO}_{4}$ and analyzed by gas chromatography. This was repeated for all reactions with a time difference of one minute between each sample.

\begin{tabular}{cccc}
\hline Equiv 132a & $\Delta\left[\right.$ 89aa] $\Delta t^{-1} / \mathrm{mol} \mathrm{L}^{-1} \mathrm{~s}^{-1}$ & $\log \left(c / \mathrm{mol} \mathrm{L}^{-1}\right)$ & $\log \left(\Delta[89 \mathrm{aa}] \Delta t^{-1} / \mathrm{mol} \mathrm{L}^{-1} \mathrm{~s}^{-1}\right)$ \\
\hline 0.8 & 2.187 & -0.795 & 0.340 \\
1.0 & 2.853 & -0.699 & 0.455 \\
1.2 & 3.250 & -0.619 & 0.512 \\
1.4 & 3.802 & -0.553 & 0.580
\end{tabular}




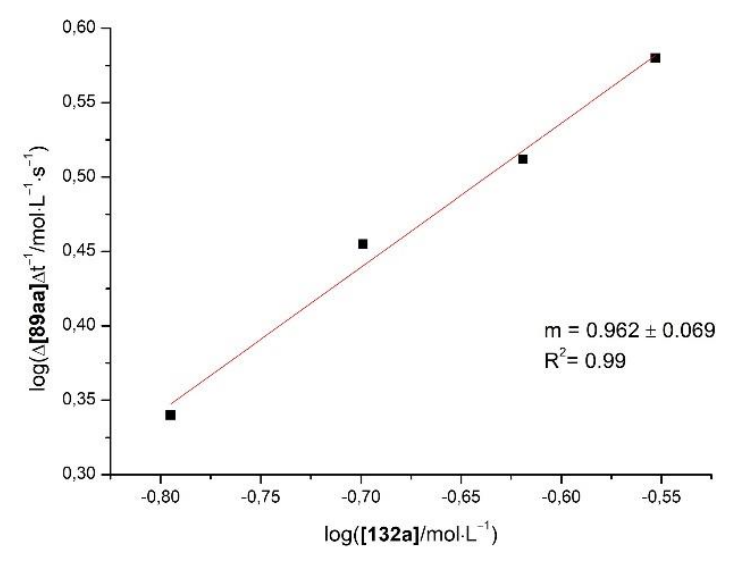

Figure 5.8. Reaction order in bromoalkyne 132a.

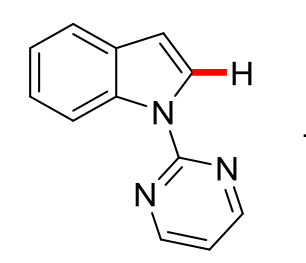

23a

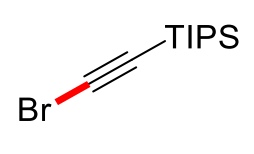

$132 \mathrm{a}$

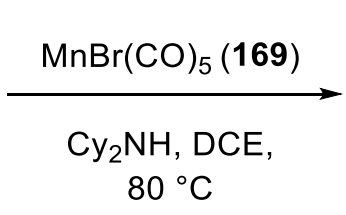

$80{ }^{\circ} \mathrm{C}$

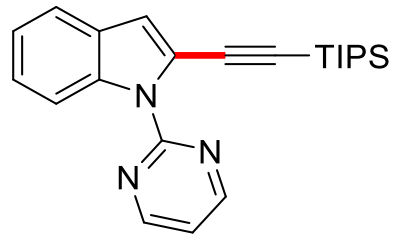

89aa

Scheme 5.8. Determination of the reaction order in catalyst 169 .

The reaction order with respect to the catalyst 169 was examined using the initial rate method. ${ }^{[223]}$ A Schlenk-flask was charged with indole 23a $(117 \mathrm{mg}, 0.60 \mathrm{mmol}$, 1.00 equiv.), $132 \mathrm{a}$ (188 mg, $0.72 \mathrm{mmol}, 1.20$ equiv), $\operatorname{MnBr}(\mathrm{CO})_{5}$ (2.5, 5.0, 7.5, $10 \mathrm{~mol} \%)$ and $n$-tridecane $(80 \mu \mathrm{L})$. DCE $(4.0 \mathrm{~mL})$ was added and the mixture was divided into four pre-heated Schlenk-tubes and stirred at $80^{\circ} \mathrm{C}$. After one minute the first reaction was opened and a sample removed by syringe, diluted with EtOAc, filtered through a short plug of silica gel and $\mathrm{Na}_{2} \mathrm{SO}_{4}$ and analyzed by gas chromatography. This was repeated for all reactions with a time difference of one minute between each sample.

\begin{tabular}{cccc}
\hline Mol \% catalyst & $\Delta[89 \mathrm{aa}] \Delta t^{1} / 10^{-8} \mathrm{~mol} \mathrm{~L}^{-1} \mathrm{~s}^{-1}$ & $\log \left(c / \mathrm{mol} \mathrm{L}^{-1}\right)$ & $\log \left(\Delta[89 \mathrm{aa}] \Delta t^{-1} / \mathrm{mol} \mathrm{L}^{-1} \mathrm{~s}^{-1}\right)$ \\
\hline 3.5 & 0.889 & -2.426 & -0.051 \\
5.0 & 1.528 & -2.125 & 0.184 \\
7.5 & 2.208 & -1.948 & 0.344
\end{tabular}




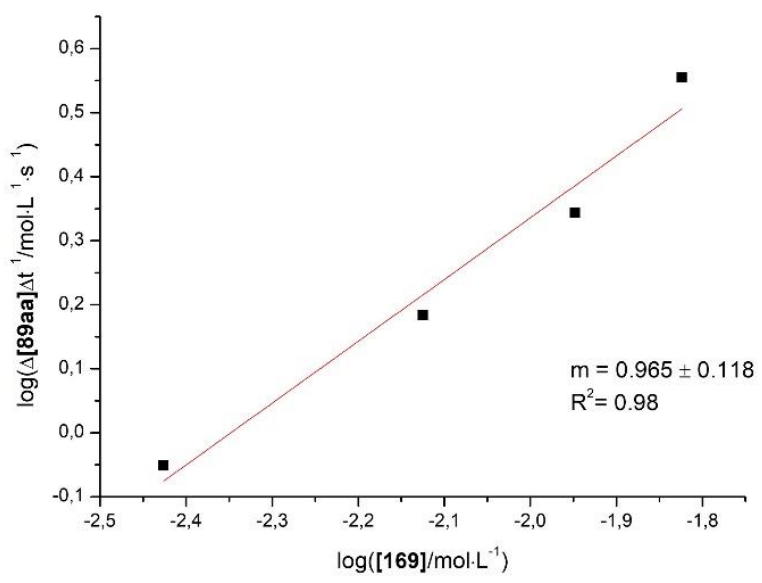

Figure 5.9. Reaction order in catalyst 169.

\section{C-H Alkynylations with Cyclometalated Complex 238}<smiles>c1cnc(-n2ccc3ccccc32)nc1</smiles>

23

$$
\begin{gathered}
\underset{\mathrm{MnBr}(\mathrm{CO})_{5}(169)(1.0 \text { equiv })}{\stackrel{\mathrm{Cy}_{2} \mathrm{NH}, \mathrm{DCE}}{\longrightarrow}} \\
80^{\circ} \mathrm{C}, 30 \mathrm{~min}
\end{gathered}
$$<smiles>CC(=O)Nc1cc2ccccc2n1-c1ccccn1</smiles>

238: $77 \%$

Scheme 5.10. Synthesis of manganacycle 238.

Following a modification of a reported procedure, ${ }^{[129]} 1$-(pyrimidin-2-yl)-1 $H$-indole (23) (195 mg, 1.00 mmol, 1.00 equiv), $\operatorname{MnBr}(\mathrm{CO})_{5}$ (169) (274 mg, $1.00 \mathrm{mmol}, 1.00$ equiv), Cy $2 \mathrm{NH}$ (362 mg, $2.00 \mathrm{mmol}, 2.00$ equiv) and DCE (2.0 mL) were placed in a $25 \mathrm{~mL}$ Schlenk tube under $\mathrm{N}_{2}$ and then stirred at $80^{\circ} \mathrm{C}$ for $30 \mathrm{~min}$. At ambient temperature, the mixture was diluted with EtOAc $(20 \mathrm{ml})$ and filtered through a short pad of celite. The solvent was removed by rotary evaporation and the residue was purified by flash column chromatography on silica gel (n-hexane/EtOAc: 20/1) afforded 238 (279 mg, $0.77 \mathrm{mmol}, 77 \%$ ) as a yellow solid. An alternative preparation with catalytic amounts of $\mathrm{BPh}_{3}(0.05 \mathrm{~mol} \%, 0.01 \mathrm{M}$ stock solution in DCE) under otherwise identical conditions afforded the same product (268 mg, $0.74 \mathrm{mmol}, 74 \%)$. M.p. $=150-151^{\circ} \mathrm{C}$. ${ }^{1} \mathrm{H}$ NMR $\left(300 \mathrm{MHz}, \mathrm{CDCl}_{3}\right) \delta=8.69(\mathrm{dd}, J=4.8,2.4 \mathrm{~Hz}, 1 \mathrm{H}), 8.57(\mathrm{dd}, J=5.6,2.4 \mathrm{~Hz}$, $1 \mathrm{H}), 8.50(\mathrm{~d}, J=8.0 \mathrm{~Hz}, 1 \mathrm{H}), 7.44(\mathrm{~d}, J=7.5 \mathrm{~Hz}, 1 \mathrm{H}), 7.20(\mathrm{dd}, J=7.5,7.3 \mathrm{~Hz}, 1 \mathrm{H})$, 
$7.12(\mathrm{dd}, J=7.5,7.2,1 \mathrm{H}), 6.85(\mathrm{t}, J=5.2 \mathrm{~Hz}, 1 \mathrm{H}), 6.79(\mathrm{~s}, 1 \mathrm{H}) .{ }^{13} \mathrm{C}$ NMR $(125 \mathrm{MHz}$, $\left.\mathrm{CDCl}_{3}\right) \delta=218.4\left(\mathrm{C}_{\mathrm{q}}\right), 213.1\left(\mathrm{C}_{\mathrm{q}}\right), 210.7(\mathrm{Cq}), 162.2(\mathrm{CH}), 161.3\left(\mathrm{C}_{\mathrm{q}}\right), 160.9\left(\mathrm{C}_{\mathrm{q}}\right), 160.1$ $(\mathrm{CH}), 138.5\left(\mathrm{C}_{\mathrm{q}}\right), 136.0\left(\mathrm{C}_{\mathrm{q}}\right), 122.9(\mathrm{CH}), 120.7(\mathrm{CH}), 119.3(\mathrm{CH}), 117.5(\mathrm{CH}), 114.1$ (CH), 113.6 (CH). IR (neat): 2078, 1974, 1937, 1920, 1575, 1491, 1380, 787, $639 \mathrm{~cm}^{-}$ 1. MS (EI) $m / z$ (relative intensity): 360 [M+] (5), 249 (35), 195 (100). HR-MS (EI) $\mathrm{m} / z$ calcd for $\mathrm{C}_{16} \mathrm{H}_{8} \mathrm{MnN}_{3} \mathrm{O}_{4}\left[\mathrm{M}^{+}\right] 360.9895$, found 360.9880 .
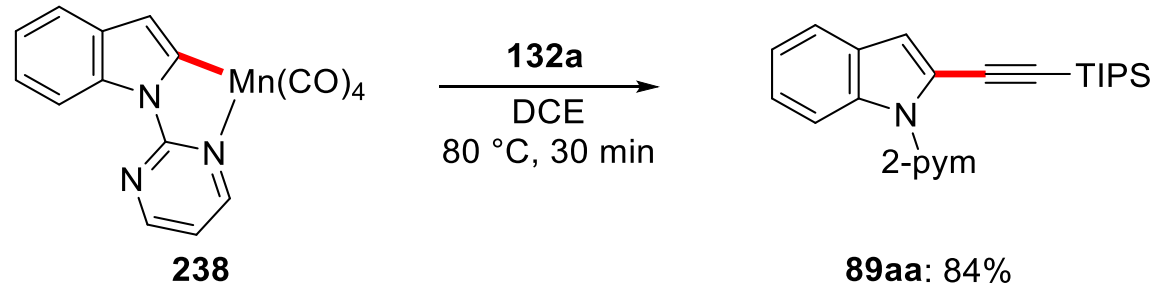

Scheme 5.11. Stoichiometric C-H alkynylation using bromoalkyne 132a.

Complex 238 (72.8 mg, 0.20 mmol, 1.00 equiv), bromoalkyne 132a (62.3 mg, 0.24 mmol, 1.20 equiv), and DCE $(0.5 \mathrm{~mL})$ were placed in a $25 \mathrm{~mL}$ Schlenk tube under $\mathrm{N}_{2}$ and were then stirred at $80^{\circ} \mathrm{C}$ for $30 \mathrm{~min}$. At ambient temperature, $\mathrm{CH}_{2} \mathrm{Cl}_{2}(2 \mathrm{~mL})$ was added, and the reaction mixture was transferred into a round bottom flask with $\mathrm{CH}_{2} \mathrm{Cl}_{2}$ and concentrated under reduced pressure. Purification by flash column chromatography on silica gel (n-hexane/EtOAc: 10/1) afforded 89aa (64.3 mg, $0.17 \mathrm{mmol}, 84 \%)$.

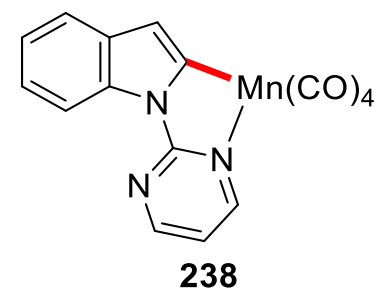

238

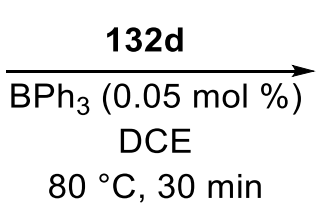

$80^{\circ} \mathrm{C}, 30 \mathrm{~min}$

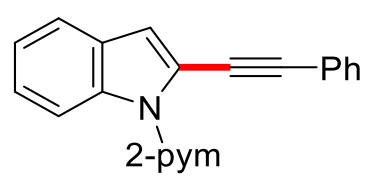

89ad: $73 \%$

Scheme 5.12. Stoichiometric C-H alkynylation 132d.

Complex 238 (72 mg, 0.20 mmol, 1.00 equiv), bromoalkyne 132d (43.4 mg, 0.24 mmol, 1.20 equiv), $\mathrm{BPh}_{3}(10 \mu \mathrm{L}, 0.05 \mathrm{~mol} \%, 0.01 \mathrm{M}$ stock solution in DCE) and DCE (0.5 $\mathrm{mL}$ ) were placed in a $25 \mathrm{~mL}$ Schlenk tube under $\mathrm{N}_{2}$ and were then stirred at $80^{\circ} \mathrm{C}$ for 30 min. At ambient temperature, $\mathrm{CH}_{2} \mathrm{Cl}_{2}(2 \mathrm{~mL})$ was added, and the reaction mixture was transferred into a round bottom flask with $\mathrm{CH}_{2} \mathrm{Cl}_{2}$ and concentrated under reduced pressure. Purification by flash column chromatography on silica gel ( $n$-hexane/EtOAc: 8/1) afforded 89ad (43.2 mg, $0.15 \mathrm{mmol}, 73 \%$ ). 


\subsection{Electrochemical Cobalt-Catalyzed C-H Oxygenation}

\subsubsection{Analytical Data and Experimental Procedures}<smiles></smiles>

\section{2-(2-Ethoxybenzamido)pyridine-1-oxide (150aa)}

The general procedure $\mathbf{F}$ was followed using benzamide $117 \mathrm{a}(107 \mathrm{mg}, 0.50 \mathrm{mmol}$, 1.00 equiv) and ethanol (149a) $(2 \times 7.0 \mathrm{~mL})$. Purification by column chromatography on silica gel $\left(\mathrm{CH}_{2} \mathrm{Cl}_{2} /\right.$ acetone 3:1) yielded 150aa $(97.5 \mathrm{mg}, 376 \mu \mathrm{mol}, 75 \%)$ as a white solid. M. p.: $141-143{ }^{\circ} \mathrm{C} .{ }^{1} \mathrm{H}-\mathrm{NMR}\left(500 \mathrm{MHz}, \mathrm{CDCl}_{3}\right): \delta=12.29$ (s, 1H), 8.72 (dd, $J=8.6,1.9 \mathrm{~Hz}, 1 \mathrm{H}$ ), 8.30-8.23 (m, 2H), 7.50 (ddd, $J=8.4,2.1,0.7 \mathrm{~Hz} 1 \mathrm{H}$ ), 7.32 (dd, $J=8.6,1.9 \mathrm{~Hz}, 1 \mathrm{H}), 7.11-7.01(\mathrm{~m}, 2 \mathrm{H}), 6.97(\mathrm{dd}, J=8.4,2.1 \mathrm{~Hz}, 1 \mathrm{H}), 4.29(\mathrm{q}$, $J=6.7 \mathrm{~Hz}, 2 \mathrm{H}), 1.69(\mathrm{t}, J=6.7 \mathrm{~Hz}, 3 \mathrm{H}) .{ }^{13} \mathrm{C}-\mathrm{NMR}\left(125 \mathrm{MHz}, \mathrm{CDCl}_{3}\right): \delta=163.8\left(\mathrm{C}_{\mathrm{q}}\right)$, $157.3\left(\mathrm{C}_{\mathrm{q}}\right), 145.3\left(\mathrm{C}_{\mathrm{q}}\right), 137.2(\mathrm{CH}), 134.2(\mathrm{CH}), 132.5(\mathrm{CH}), 127.7(\mathrm{CH}), 121.0(\mathrm{CH})$, $120.5\left(\mathrm{C}_{q}\right), 118.3(\mathrm{CH}), 115.7(\mathrm{CH}), 112.3(\mathrm{CH}), 65.3\left(\mathrm{CH}_{2}\right), 14.8\left(\mathrm{CH}_{3}\right)$. IR $(\mathrm{ATR})$ : 3178, 3060, 1658, 1507, 1278, 1241, 1029, $737 \mathrm{~cm}^{-1}$. MS (El) $\mathrm{m} / \mathrm{z}$ (relative intensity): 258 (10) [M]+, 241 (12), 197 (34), 149 (55), 121 (100), 93 (22). HR-MS (EI) m/z calcd for $\mathrm{C}_{14} \mathrm{H}_{14} \mathrm{~N}_{2} \mathrm{O}_{3}[\mathrm{M}]^{+}:$258.1004, found: 258.1009. The analytical data correspond with those reported in the literature. ${ }^{[111 b]}$<smiles>CCOc1cc(C(F)(F)F)ccc1C(=O)Nc1cccc[n+]1[O-]</smiles>

\section{2-(2-Ethoxy-4-(trifluoromethyl)benzamido)pyridine-1-oxide (150ba)}

The general procedure $\mathbf{F}$ was followed using benzamide 117b $(141 \mathrm{mg}, 0.50 \mathrm{mmol}$, 1.00 equiv) and ethanol (149a) $(2 \times 7.0 \mathrm{~mL})$. Purification by column chromatography on silica gel $\left(\mathrm{CH}_{2} \mathrm{Cl}_{2} /\right.$ acetone 3:1) yielded 150ba (85.3 mg, $\left.262 \mu \mathrm{mol}, 52 \%\right)$ as a white solid. M. p.: $186-189{ }^{\circ} \mathrm{C}$. ${ }^{1} \mathrm{H}-\mathrm{NMR}\left(400 \mathrm{MHz}, \mathrm{CDCl}_{3}\right): \delta=12.26$ (s, 1H), 8.68 (dd, $J=8.4,1.7 \mathrm{~Hz}, 1 \mathrm{H}), 8.37(\mathrm{~d}, J=8.0 \mathrm{~Hz}, 1 \mathrm{H}), 8.28(\mathrm{dd}, J=6.7,1.4 \mathrm{~Hz}, 1 \mathrm{H}), 7.39-7.30$ (m, 2H), $7.28(\mathrm{~s}, 1 \mathrm{H}), 7.00$ (ddd, $J=8.4,6.4,1.7 \mathrm{~Hz}, 1 \mathrm{H}), 4.39$ (q, J = 7.0 Hz, 2H), 1.73 (t, $J=7.0 \mathrm{~Hz}, 3 \mathrm{H}) .{ }^{13} \mathrm{C}-\mathrm{NMR}\left(125 \mathrm{MHz}, \mathrm{CDCl}_{3}\right): \delta=162.7\left(\mathrm{C}_{\mathrm{q}}\right), 157.4\left(\mathrm{C}_{\mathrm{q}}\right), 145.0\left(\mathrm{C}_{\mathrm{q}}\right)$, $137.3(\mathrm{CH}), 135.6\left(\mathrm{q},{ }^{2} \mathrm{~J}_{\mathrm{C}-\mathrm{F}}=33.3 \mathrm{~Hz}, \mathrm{C}_{\mathrm{q}}\right), 133.5(\mathrm{CH}), 127.8(\mathrm{CH}), 123.5\left(\mathrm{C}_{\mathrm{q}}\right), 123.4$ 
$\left(\mathrm{q},{ }^{1} \mathrm{JC}_{\mathrm{C}-\mathrm{F}}=280 \mathrm{~Hz}, \mathrm{C}\right.$ ) $), 118.9(\mathrm{CH}), 117.6\left(\mathrm{q},{ }^{3} \mathrm{JC}-\mathrm{F}=3.8 \mathrm{~Hz}, \mathrm{CH}\right), 116.0\left(\mathrm{q},{ }^{3} \mathrm{JC}-\mathrm{F}=4.0\right.$ $\mathrm{Hz}, \mathrm{CH}), 109.5(\mathrm{CH}), 66.1\left(\mathrm{CH}_{2}\right), 14.6\left(\mathrm{CH}_{3}\right) .{ }^{19} \mathrm{~F}-\mathrm{NMR}\left(282 \mathrm{MHz}, \mathrm{CDCl}_{3}\right): d=-63.19$. IR (ATR): 3180, 3061, 1654, 1501, 1268, 1071, 760, $744 \mathrm{~cm}^{-1}$. MS (EI) $\mathrm{m} / z$ (relative intensity): 326 (10) [M]+, 209 (19), 265 (31), 217 (40), 189 (100), 161 (28), 113 (10). HR-MS (EI) $\mathrm{m} / z$ calcd for $\mathrm{C}_{15} \mathrm{H}_{13} \mathrm{~F}_{3} \mathrm{~N}_{2} \mathrm{O}_{3}[\mathrm{M}]^{+}: 326.0878$, found: 326.0876 .<smiles>CCOc1cc(OC)ccc1C(=O)Nc1cccc[n+]1[O-]</smiles>

\section{2-(2-Ethoxy-4-methoxybenzamido)pyridine-1-oxide (150ca)}

The general procedure $\mathbf{F}$ was followed using benzamide $117 \mathrm{c}(123 \mathrm{mg}, 0.50 \mathrm{mmol}$, 1.00 equiv) and ethanol (149a) $(2 \times 7.0 \mathrm{~mL})$. Purification by column chromatography on silica gel $\left(\mathrm{CH}_{2} \mathrm{Cl}_{2} /\right.$ acetone $\left.2: 1\right)$ yielded $150 \mathrm{ca}(106.3 \mathrm{mg}, 369 \mu \mathrm{mol}, 74 \%)$ as a white solid. M. p.: $191-193{ }^{\circ} \mathrm{C}$. ${ }^{1} \mathrm{H}-\mathrm{NMR}\left(300 \mathrm{MHz}, \mathrm{CDCl}_{3}\right): \delta=12.13(\mathrm{~s}, 1 \mathrm{H}), 8.72(\mathrm{~d}$, $J=7.9 \mathrm{~Hz}, 1 \mathrm{H}$ ), $8.28(\mathrm{~d}, J=2.1 \mathrm{~Hz}, 1 \mathrm{H}), 8.22(\mathrm{~d}, J=9.3 \mathrm{~Hz}, 1 \mathrm{H}), 7.29(\mathrm{~d}, J=7.9$, $2.1 \mathrm{~Hz}, 1 \mathrm{H}$ ), $6.96(\mathrm{dd}, J=7.4,7.1 \mathrm{~Hz}, 1 \mathrm{H}), 6.60(\mathrm{dd}, J=9.3,2.5 \mathrm{~Hz}, 1 \mathrm{H}), 6.53(\mathrm{~d}$, $J=2.5 \mathrm{~Hz}, 1 \mathrm{H}$ ), 4.27 (q, $J=7.0 \mathrm{~Hz}, 2 \mathrm{H}), 3.84(\mathrm{~s}, 3 \mathrm{H}), 1.64(\mathrm{t}, J=7.0 \mathrm{~Hz}, 3 \mathrm{H}) .{ }^{13} \mathrm{C}-$ $\operatorname{NMR}\left(125 \mathrm{MHz}, \mathrm{CDCl}_{3}\right): \delta=164.5\left(\mathrm{C}_{\mathrm{q}}\right), 163.6\left(\mathrm{C}_{\mathrm{q}}\right), 158.8\left(\mathrm{C}_{\mathrm{q}}\right), 145.7\left(\mathrm{C}_{\mathrm{q}}\right), 137.3(\mathrm{CH})$, $134.3(\mathrm{CH}), 127.8(\mathrm{CH}), 117.7(\mathrm{CH}), 115.6(\mathrm{CH}), 113.6\left(\mathrm{C}_{\mathrm{q}}\right), 105.7(\mathrm{CH}), 99.1(\mathrm{CH})$, $65.4\left(\mathrm{CH}_{2}\right), 55.6\left(\mathrm{CH}_{3}\right), 14.7\left(\mathrm{CH}_{3}\right)$. IR (ATR): 3193, 3057, 2203, 2120, 1658, 1504, 1030, 727, $516 \mathrm{~cm}^{-1}$. MS (EI) $\mathrm{m} / \mathrm{z}$ (relative intensity): 288 (12) [M] ${ }^{+}, 227$ (10), 179 (100), 151 (82), 95 (15). HR-MS (EI) $m / z$ calcd for $\mathrm{C}_{15} \mathrm{H}_{16} \mathrm{~N}_{2} \mathrm{O}_{4} \quad$ [M] : 288.1110, found: 288.1120 . The analytical data correspond with those reported in the literature. ${ }^{[111 \mathrm{~b}]}$<smiles></smiles>

\section{2-(4-Chloro-2-ethoxybenzamido)pyridine-1-oxide (150da)}

The general procedure $\mathbf{F}$ was followed using benzamide $117 \mathrm{~d}(125 \mathrm{mg}, 0.50 \mathrm{mmol}$, 1.00 equiv) and ethanol (149a) $(2 \times 7.0 \mathrm{~mL})$. Purification by column chromatography on silica gel $\left(\mathrm{CH}_{2} \mathrm{Cl}_{2} /\right.$ acetone $\left.3: 1\right)$ yielded $150 \mathrm{da}(72.4 \mathrm{mg}, 292 \mu \mathrm{mol}, 58 \%)$ as a white solid. M. p.: $196-199{ }^{\circ} \mathrm{C} .{ }^{1} \mathrm{H}-\mathrm{NMR}\left(300 \mathrm{MHz}, \mathrm{CDCl}_{3}\right): \delta=12.14(\mathrm{~s}, 1 \mathrm{H}), 8.68$ (dd, $J=7.9,1.8 \mathrm{~Hz}, 1 \mathrm{H}$ ), 8.31 (dd, $J=7.0,2.1 \mathrm{~Hz}, 1 \mathrm{H}), 8.17(\mathrm{~d}, J=7.6 \mathrm{~Hz}, 1 \mathrm{H}), 7.34$ (dd, $J=7.9,7.5,2.1 \mathrm{~Hz} 1 \mathrm{H}), 7.09-7.01(\mathrm{~m}, 2 \mathrm{H}), 6.99(\mathrm{dd}, J=7.5,7.0,1.8 \mathrm{~Hz}, 1 \mathrm{H}), 4.31$ (q, 
$J=7.2 \mathrm{~Hz}, 2 \mathrm{H}), 1.68(\mathrm{t}, J=7.2 \mathrm{~Hz}, 3 \mathrm{H}) .{ }^{13} \mathrm{C}-\mathrm{NMR}\left(125 \mathrm{MHz}, \mathrm{CDCl}_{3}\right): \delta=162.8\left(\mathrm{C}_{\mathrm{q}}\right)$, $157.7\left(\mathrm{C}_{\mathrm{q}}\right), 145.1\left(\mathrm{C}_{\mathrm{q}}\right), 140.1\left(\mathrm{C}_{\mathrm{q}}\right), 137.3(\mathrm{CH}), 133.7(\mathrm{CH}), 128.0(\mathrm{CH}), 121.4(\mathrm{CH})$, $119.1\left(\mathrm{C}_{\mathrm{q}}\right), 118.5(\mathrm{CH}), 115.8(\mathrm{CH}), 113.0(\mathrm{CH}), 65.0\left(\mathrm{CH}_{2}\right), 14.6\left(\mathrm{CH}_{3}\right)$. IR (ATR): 3184, 3054, 1653, 1502, 1268, 760, $744 \mathrm{~cm}^{-1}$. MS (EI) $\mathrm{m} / \mathrm{z}$ (relative intensity): 294 (4) [ $\left.{ }^{37} \mathrm{Cl}-\mathrm{M}\right]^{+}, 292$ (12) [ $\left.\left.{ }^{35} \mathrm{Cl}-\mathrm{M}\right]\right]^{+}, 277$ (5), 275 (15), 185 (23), 183 (75), 157 (33), 155 (100), 127 (19), 99 (15). HR-MS (EI) $\mathrm{m} / \mathrm{z}$ calcd for $\mathrm{C}_{14} \mathrm{H}_{13} \mathrm{~N}_{2} \mathrm{O}_{3}{ }^{35} \mathrm{Cl} \quad[\mathrm{M}]^{+}: 292.0615$, found: 292.0617 . The analytical data correspond with those reported in the literature. ${ }^{[111 b]}$<smiles></smiles>

\section{2-(2-Ethoxy-5-methylbenzamido)pyridine-1-oxide (150ea)}

The general procedure $F$ was followed using benzamide $117 \mathrm{e}(114 \mathrm{mg}, 0.50 \mathrm{mmol}$, 1.00 equiv) and ethanol (149a) $(2 \times 7.0 \mathrm{~mL})$. Purification by column chromatography on silica gel $\left(\mathrm{CH}_{2} \mathrm{Cl}_{2} /\right.$ acetone $\left.3: 1\right)$ yielded $150 \mathrm{ea}(106 \mathrm{mg}, 389 \mu \mathrm{mol}, 78 \%)$ as a white solid. M. p.: ${ }^{183-186}{ }^{\circ} \mathrm{C} .{ }^{1} \mathrm{H}-\mathrm{NMR}\left(300 \mathrm{MHz}, \mathrm{CDCl}_{3}\right): \delta=12.27$ (s, $\left.1 \mathrm{H}\right), 8.70$ (dd, $J=8.7,2.3 \mathrm{~Hz}, 1 \mathrm{H}$ ), 8.27 (dd, $J=7.2,1.8 \mathrm{~Hz}, 1 \mathrm{H}), 8.05(\mathrm{~d}, J=2.0 \mathrm{~Hz}, 1 \mathrm{H}), 7.35-7.26$ (m, 2H), 7.00-6.97 (m, 2H), 4.29 (q, $J=6.9 \mathrm{~Hz}, 2 \mathrm{H}), 2.33(\mathrm{~s}, 3 \mathrm{H}), 1.67(\mathrm{t}, J=6.9 \mathrm{~Hz}$, 3H). ${ }^{13} \mathrm{C}-N M R\left(125 \mathrm{MHz}, \mathrm{CDCl}_{3}\right): \delta=164.0\left(\mathrm{C}_{\mathrm{q}}\right), 155.3\left(\mathrm{C}_{\mathrm{q}}\right), 145.4\left(\mathrm{C}_{\mathrm{q}}\right), 137.3(\mathrm{CH})$, $134.7(\mathrm{CH}), 132.6(\mathrm{CH}), 130.3(\mathrm{CH}), 127.7\left(\mathrm{C}_{\mathrm{q}}\right), 120.0\left(\mathrm{C}_{\mathrm{q}}\right), 118.2(\mathrm{CH}), 115.7(\mathrm{CH})$, $112.3(\mathrm{CH}), 65.3\left(\mathrm{CH}_{2}\right), 20.4\left(\mathrm{CH}_{3}\right), 14.8\left(\mathrm{CH}_{3}\right)$. IR (ATR): 3176, 2918, 1657, 1508, 1278, 795, $511 \mathrm{~cm}^{-1}$. MS (EI) $\mathrm{m} / z$ (relative intensity): 272 (19) [M] ${ }^{+}, 255$ (23), 163 (87), 135 (100), 107 (26), 77 (21). HR-MS (EI) $\mathrm{m} / z$ calcd for $\mathrm{C}_{15} \mathrm{H}_{16} \mathrm{~N}_{2} \mathrm{O}_{3}[\mathrm{M}]^{+}:$272.1161, found: 272.1165 . The analytical data correspond with those reported in the literature.[111b]<smiles></smiles>

\section{2-(3-Ethoxy-2-naphthamido)pyridine-1-oxide (150fa)}

The general procedure $\mathbf{F}$ was followed using benzamide $117 \mathrm{f}(132 \mathrm{mg}, 0.50 \mathrm{mmol}$, 1.00 equiv) and ethanol (149a) $(2 \times 7.0 \mathrm{~mL})$. Purification by column chromatography on silica gel $\left(\mathrm{CH}_{2} \mathrm{Cl}_{2} /\right.$ acetone $\left.3: 1\right)$ yielded $150 \mathrm{fa}(108 \mathrm{mg}, 351 \mu \mathrm{mol}, 70 \%)$ as a white solid. M. p.: $191-193{ }^{\circ} \mathrm{C} .{ }^{1} \mathrm{H}-\mathrm{NMR}\left(400 \mathrm{MHz}, \mathrm{CDCl}_{3}\right): \delta=12.39(\mathrm{~s}, 1 \mathrm{H}), 8.94(\mathrm{~s}, 1 \mathrm{H})$, 8.76 (dd, $J=8.9,1.5 \mathrm{~Hz}, 1 \mathrm{H}$ ), 8.30 (dd, $J=6.8,2.3 \mathrm{~Hz}, 1 \mathrm{H}$ ), 7.91 (dd, $J=8.0,0.9 \mathrm{~Hz}$, 
$1 \mathrm{H}), 7.74(\mathrm{dd}, J=9.2,1.0 \mathrm{~Hz}, 1 \mathrm{H}), 7.54(\mathrm{dd}, J=8.9,6.9,2.3 \mathrm{~Hz}, 1 \mathrm{H}), 7.39(\mathrm{dd}, J=8.0$, 7.7, $1.0 \mathrm{~Hz}, 1 \mathrm{H}$ ), $7.36(\mathrm{dd}, J=6.9,6.8,1.5 \mathrm{~Hz}, 1 \mathrm{H}$ ), $7.28(\mathrm{~s}, 1 \mathrm{H}$ ), 7.00 (dd, $J=9.2,7.7$, $0.9 \mathrm{~Hz}, 1 \mathrm{H}), 4.43(\mathrm{q}, J=7.1 \mathrm{~Hz}, 2 \mathrm{H}), 1.80(\mathrm{t}, J=7.1 \mathrm{~Hz}, 3 \mathrm{H}) .{ }^{13} \mathrm{C}-\mathrm{NMR}(101 \mathrm{MHz}$, $\left.\mathrm{CDCl}_{3}\right): \delta=163.9\left(\mathrm{C}_{\mathrm{q}}\right), 154.1\left(\mathrm{C}_{\mathrm{q}}\right), 145.4\left(\mathrm{C}_{\mathrm{q}}\right), 137.5(\mathrm{CH}), 136.5(\mathrm{CH}), 134.9(\mathrm{CH})$, $129.3(\mathrm{CH}), 128.9(\mathrm{CH}), 127.9(\mathrm{CH}), 126.3\left(\mathrm{C}_{\mathrm{q}}\right), 124.7(\mathrm{CH}), 121.5(\mathrm{CH}), 118.6\left(\mathrm{C}_{\mathrm{q}}\right)$, $116.0(\mathrm{CH}), 107.5(\mathrm{CH}), 65.4\left(\mathrm{CH}_{2}\right), 14.7\left(\mathrm{CH}_{3}\right)$. IR (ATR): 3189, 2918, 1652, 1507, 1278, 1200, 1038, $725 \mathrm{~cm}^{-1}$. MS (EI) $\mathrm{m} / z$ (relative intensity): 308 (13) [M] $]^{+}, 291$ (15), 247 (30), 199 (89), 171 (100), 155 (22), 127 (19), 115 (41). HR-MS (ESI) m/z calcd for $\mathrm{C}_{18} \mathrm{H}_{16} \mathrm{~N}_{2} \mathrm{O}_{3}[\mathrm{M}]^{+}:$308.1161, found: 308.1158 .<smiles>CCOc1ccc(N(C)C)cc1C(=O)Nc1cccc[n+]1[O-]</smiles>

\section{2-[5-(Dimethylamino)-2-ethoxybenzamido]pyridine-1-oxide (150ga)}

The general procedure $\mathbf{F}$ was followed using benzamide $\mathbf{1 1 7 g}(128 \mathrm{mg}, 0.50 \mathrm{mmol}$, 1.00 equiv) and ethanol (149a) $(2 \times 7.0 \mathrm{~mL})$. Purification by column chromatography on silica gel $\left(\mathrm{CH}_{2} \mathrm{Cl}_{2} /\right.$ acetone $\left.3: 1\right)$ yielded $150 \mathrm{ga}(97.9 \mathrm{mg}, 294 \mu \mathrm{mol}, 59 \%)$ as a yellow solid. M. p.: ${ }^{183-186}{ }^{\circ} \mathrm{C} .{ }^{1} \mathrm{H}-\mathrm{NMR}\left(400 \mathrm{MHz}, \mathrm{CDCl}_{3}\right): \delta=12.35$ (s, $1 \mathrm{H}$ ), 8.67 (dd, $J=8.5,2.3 \mathrm{~Hz}, 1 \mathrm{H}$ ), $8.22(\mathrm{dd}, J=8.0,1.9 \mathrm{~Hz}, 1 \mathrm{H}), 7.60(\mathrm{~d}, J=2.3 \mathrm{~Hz}, 1 \mathrm{H}), 7.27$ (dd, $J=8.0,6.8,2.3 \mathrm{~Hz}, 1 \mathrm{H}), 6.94-6.86(\mathrm{~m}, 3 \mathrm{H}), 4.21(\mathrm{q}, J=7.4 \mathrm{~Hz}, 2 \mathrm{H}), 2.87(\mathrm{~s}, 6 \mathrm{H}), 1.59$ (t, $J=7.4 \mathrm{~Hz}, 3 \mathrm{H}) .{ }^{13} \mathrm{C}-\mathrm{NMR}\left(125 \mathrm{MHz}, \mathrm{CDCl}_{3}\right): \delta=164.4\left(\mathrm{C}_{\mathrm{q}}\right), 149.6\left(\mathrm{C}_{\mathrm{q}}\right), 145.7\left(\mathrm{C}_{\mathrm{q}}\right)$, $145.4\left(\mathrm{C}_{\mathrm{q}}\right), 137.5(\mathrm{CH}), 127.8(\mathrm{CH}), 120.5\left(\mathrm{C}_{\mathrm{q}}\right), 119.3(\mathrm{CH}), 118.2(\mathrm{CH}), 116.2(\mathrm{CH})$, $115.7(\mathrm{CH}), 113.8(\mathrm{CH}), 65.6\left(\mathrm{CH}_{2}\right), 41.3\left(\mathrm{CH}_{3}\right), 14.8\left(\mathrm{CH}_{3}\right)$. IR (ATR): 3196, 3057, 2931, 1657, 1502, 1426, 1204, $725 \mathrm{~cm}^{-1}$. MS (ESI) $\mathrm{m} / z$ (relative intensity): 324 (19) $[\mathrm{M}+\mathrm{Na}]^{+}, 302(100),[\mathrm{M}+\mathrm{H}]^{+}, 288$ (7), 209 (25), 192 (47). HR-MS (ESI) m/z calcd for $\mathrm{C}_{16} \mathrm{H}_{19} \mathrm{~N}_{3} \mathrm{O}_{3}[\mathrm{M}+\mathrm{H}]^{+}: 302.1499$, found: 302.1497 . The analytical data correspond with those reported in the literature..$^{[111 b]}$<smiles></smiles>

\section{2-(5-Bromo-2-ethoxybenzamido)pyridine-1-oxide (150ha)}

The general procedure $\mathbf{F}$ was followed using benzamide $117 \mathrm{~h}$ (146 $\mathrm{mg}, 0.50 \mathrm{mmol}$, 1.00 equiv) and ethanol (149a) $(2 \times 7.0 \mathrm{~mL})$. Purification by column chromatography 
on silica gel $\left(\mathrm{CH}_{2} \mathrm{Cl}_{2} /\right.$ acetone $\left.3: 1\right)$ yielded 150ha $(96.3 \mathrm{mg}, 286 \mu \mathrm{mol}, 57 \%)$ as a white solid. M. p.: $224-226{ }^{\circ} \mathrm{C}$. $1 \mathrm{H}-\mathrm{NMR}\left(300 \mathrm{MHz}, \mathrm{CDCl}_{3}\right): \delta=12.22$ (s, 1H), 8.67 (dd, $J=$ 8.1, $2.5 \mathrm{~Hz}, 1 \mathrm{H}$ ), 8.37 (d, J=3.0 Hz, 1H), 8.27 (dd, J = 7.5, 2.3 Hz, 1H), 7.58 (dd, $J=$ 8.1, 3.0 Hz, 1H), 7.34 (ddd, $J=8.1,6.8,2.3 \mathrm{~Hz}, 1 \mathrm{H}$ ), 7.00 (ddd, $J=7.5,6.8,2.5 \mathrm{~Hz}$, $1 \mathrm{H}), 6.93(\mathrm{~d}, J=8.1 \mathrm{~Hz}, 1 \mathrm{H}), 4.23(\mathrm{q}, J=7.2 \mathrm{~Hz}, 2 \mathrm{H}), 1.68(\mathrm{t}, J=7.2 \mathrm{~Hz}, 3 \mathrm{H}) .13 \mathrm{C}-$ NMR (125 MHz, CDCl3): $\delta=162.4\left(\mathrm{C}_{\mathrm{q}}\right), 156.3\left(\mathrm{C}_{\mathrm{q}}\right), 145.1\left(\mathrm{C}_{\mathrm{q}}\right), 137.2(\mathrm{CH}), 136.7$ $(\mathrm{CH}), 135.1(\mathrm{CH}), 127.7(\mathrm{CH}), 122.2\left(\mathrm{C}_{\mathrm{q}}\right), 118.7(\mathrm{CH}), 115.8(\mathrm{CH}), 114.3(\mathrm{CH}), 113.5$ $\left(\mathrm{C}_{\mathrm{q}}\right), 65.9\left(\mathrm{CH}_{2}\right), 14.7\left(\mathrm{CH}_{3}\right)$. IR (ATR): 3163, 2924, 1656, 1562, 1508, 1238, 1028, 747 $\mathrm{cm}^{-1}$. MS (ESI) m/z (relative intensity): 361 (29) [ $\left.{ }^{81} \mathrm{Br}-\mathrm{M}+\mathrm{Na}\right]^{+}, 359$ (31) $\left[{ }^{79} \mathrm{Br}-\mathrm{M}+\mathrm{Na}\right]^{+}$, 339 (39) [ $\left.{ }^{81} \mathrm{Br}-\mathrm{M}+\mathrm{H}\right]^{+}, 337$ (29) $\left[{ }^{79} \mathrm{Br}-\mathrm{M}+\mathrm{H}\right]^{+}, 242$ (100), 227 (10). HR-MS (ESI) m/z calcd for $\mathrm{C}_{14} \mathrm{H}_{13} \mathrm{~N}_{2} \mathrm{O}_{3}{ }^{79} \mathrm{Br}\left[{ }^{79} \mathrm{Br}-\mathrm{M}+\mathrm{H}\right]^{+}:$337.0182, found: 337.0184 .<smiles></smiles>

\section{2-(4-Acetyl-2-ethoxybenzamido)pyridine-1-oxide (150ia)}

The general procedure $\mathbf{F}$ was followed using benzamide 117i (129 mg, $0.50 \mathrm{mmol}$, 1.00 equiv) and ethanol (149a) $(2 \times 7.0 \mathrm{~mL})$. Purification by column chromatography on silica gel $\left(\mathrm{CH}_{2} \mathrm{Cl}_{2} /\right.$ acetone 3:1) yielded 150ia (92.1 mg, $\left.307 \mu \mathrm{mol}, 61 \%\right)$ as a white solid. M. p.: $131-133{ }^{\circ} \mathrm{C}$. ${ }^{1} \mathrm{H}-\mathrm{NMR}\left(300 \mathrm{MHz}, \mathrm{CDCl}_{3}\right): \delta=12.27$ (s, $\left.1 \mathrm{H}\right), 8.70$ (dd, $J=8.7,2.1 \mathrm{~Hz}, 1 \mathrm{H}), 8.34(\mathrm{~d}, J=8.8 \mathrm{~Hz}, 1 \mathrm{H}), 8.30(\mathrm{dd}, J=8.0,2.3 \mathrm{~Hz}, 1 \mathrm{H}), 7.63$ (d, $J=1.4 \mathrm{~Hz}, 1 \mathrm{H}), 7.52(\mathrm{dd}, J=8.8,1.4 \mathrm{~Hz}, 1 \mathrm{H}), 7.32(\mathrm{dd}, J=8.7,7.7,2.3 \mathrm{~Hz}, 1 \mathrm{H}), 7.01$ (dd, $J=8.0,7.7,2.1 \mathrm{~Hz}, 1 \mathrm{H}), 4.40(\mathrm{q}, J=6.8 \mathrm{~Hz}, 2 \mathrm{H}), 2.62(\mathrm{~s}, 3 \mathrm{H}), 1.71(\mathrm{t}, J=6.8 \mathrm{~Hz}$, 3H). ${ }^{13} \mathrm{C}-N M R\left(125 \mathrm{MHz}, \mathrm{CDCl}_{3}\right): \delta=197.2\left(\mathrm{C}_{\mathrm{q}}\right), 162.9\left(\mathrm{C}_{\mathrm{q}}\right), 157.4\left(\mathrm{C}_{\mathrm{q}}\right), 145.3\left(\mathrm{C}_{\mathrm{q}}\right)$, $141.4\left(\mathrm{C}_{\mathrm{q}}\right), 137.5(\mathrm{CH}), 133.1(\mathrm{CH}), 127.9(\mathrm{CH}), 124.2\left(\mathrm{C}_{\mathrm{q}}\right), 121.0(\mathrm{CH}), 118.7(\mathrm{CH})$, $115.8(\mathrm{CH}), 111.4(\mathrm{CH}), 65.8\left(\mathrm{CH}_{2}\right), 26.8\left(\mathrm{CH}_{3}\right), 14.6\left(\mathrm{CH}_{3}\right)$. IR (ATR): 3183, 2924, 1683, 1608, 1503, 1428, 1207, $756 \mathrm{~cm}^{-1}$. MS (El) $\mathrm{m} / \mathrm{z}$ (relative intensity): 300 (15) [M] ${ }^{+}$, 283 (23), 256 (21), 191 (93), 163 (100), 147 (85), 119 (249, 91 (20), 43 (57). HR-MS (El) $\mathrm{m} / \mathrm{z}$ calcd for $\mathrm{C}_{16} \mathrm{H}_{16} \mathrm{~N}_{2} \mathrm{O}_{4}[\mathrm{M}]^{+}: 300.1110$, found: 300.1111 . The analytical data correspond with those reported in the literature.[111b] 
<smiles></smiles>

\section{2-(2-Methoxybenzamido)pyridine-1-oxide (150ab)}

The general procedure $\mathbf{F}$ was followed using benzamide $117 \mathrm{a}(107 \mathrm{mg}, 0.50 \mathrm{mmol}$, 1.00 equiv) and methanol (150b) $(2 \times 7.0 \mathrm{~mL})$. Purification by column chromatography on silica gel $\left(\mathrm{CH}_{2} \mathrm{Cl}_{2} /\right.$ acetone $\left.2: 1\right)$ yielded 150ab (86.8 mg, $\left.256 \mu \mathrm{mol}, 71 \%\right)$ as a white solid. M. p.: $121-124{ }^{\circ} \mathrm{C}$. ${ }^{1} \mathrm{H}-\mathrm{NMR}\left(400 \mathrm{MHz}, \mathrm{CDCl}_{3}\right): \delta=12.41$ (s, 1H), 8.67 (dd, $J=8.3,1.7 \mathrm{~Hz}, 1 \mathrm{H}), 8.28-8.25(\mathrm{~m}, 2 \mathrm{H}), 7.53$ (ddd, $J=7.9,7.0,1.7 \mathrm{~Hz}, 1 \mathrm{H}), 7.35$ (ddd, $J=8.3,7.0,1.4 \mathrm{~Hz}, 1 \mathrm{H}$ ), 7.10 (ddd, $J=8.5,7.5,2.1 \mathrm{~Hz}, 1 \mathrm{H}$ ), 7.05 (dd, $J=8.5,1.0 \mathrm{~Hz}$, $1 \mathrm{H}), 6.97$ (ddd, $J=8.0,7.5,1.0 \mathrm{~Hz}, 1 \mathrm{H}), 4.13(\mathrm{~s}, 3 \mathrm{H}) .{ }^{13} \mathrm{C}-\mathrm{NMR}(101 \mathrm{MHz}, \mathrm{CDCl}): \delta$ $=163.5\left(\mathrm{C}_{\mathrm{q}}\right), 157.9\left(\mathrm{C}_{\mathrm{q}}\right), 145.4\left(\mathrm{C}_{\mathrm{q}}\right), 137.3(\mathrm{CH}), 134.3(\mathrm{CH}), 132.4(\mathrm{CH}), 128.3(\mathrm{CH})$, $121.3(\mathrm{CH}), 120.4\left(\mathrm{C}_{\mathrm{q}}\right), 118.3(\mathrm{CH}), 115.5(\mathrm{CH}), 111.6(\mathrm{CH}), 56.3\left(\mathrm{CH}_{3}\right)$. IR $(\mathrm{ATR})$ : $3175,1671,1564,1479,1238,1043,744 \mathrm{~cm}^{-1}$. MS (El) $\mathrm{m} / z$ (relative intensity): 244 (18) [M]+, 227 (11), 197 (10), 135 (100), 110 (15), 92 (22), 77 (25). HR-MS (ESI) m/z calcd for $\mathrm{C}_{14} \mathrm{H}_{13} \mathrm{~N}_{2} \mathrm{O}_{3}{ }^{79} \mathrm{Br}[\mathrm{M}]^{+}: 244.0848$, found 244.0851 . The analytical data correspond with those reported in the literature. ${ }^{[111 b]}$<smiles></smiles>

\section{2-(2-n-Butoxybenzamido)pyridine-1-oxide (150ac)}

The general procedure $\mathbf{F}$ was followed using benzamide 117a $(107 \mathrm{mg}, 0.50 \mathrm{mmol}$, 1.00 equiv), tetra- $n$-butylammonium acetate $(150 \mathrm{mg}, 0.50 \mathrm{mmol}, 1.00$ equiv in each cell) and $n$-butanol (149c) $(2 \times 7.0 \mathrm{~mL})$. Purification by column chromatography on silica gel $\left(\mathrm{CH}_{2} \mathrm{Cl}_{2} /\right.$ acetone $\left.4: 1\right)$ yielded 150ac $(74.8 \mathrm{mg}, 262 \mu \mathrm{mol}, 52 \%)$ as a white solid. M. p.: $73-75^{\circ} \mathrm{C} .{ }^{1} \mathrm{H}-\mathrm{NMR}\left(400 \mathrm{MHz}, \mathrm{CDCl}_{3}\right): \delta=12.41$ (s, $\left.1 \mathrm{H}\right), 8.84$ (dd, $J=9.3$, $1.6 \mathrm{~Hz}, 1 \mathrm{H}$ ), 8.41 (dd, $J=7.4,2.3 \mathrm{~Hz}, 1 \mathrm{H}$ ), 8.33 (dd, $J=7.7,2.1 \mathrm{~Hz}, 1 \mathrm{H}$ ), 7.55 (ddd, $J=9.3,8.0,2.3 \mathrm{~Hz}, 1 \mathrm{H}$ ), 7.29 (ddd, $J=8.0,7.4,1.6 \mathrm{~Hz}, 1 \mathrm{H}), 7.17-7.07(\mathrm{~m}, 2 \mathrm{H}), 7.00$ (ddd, $J=7.7,7.5,1.8 \mathrm{~Hz}, 1 \mathrm{H}$ ), 4.35 (t, $J=7.4 \mathrm{~Hz}, 2 \mathrm{H}), 2.19-2.09$ (m, 2H), 1.65-1.55 $(\mathrm{m}, 2 \mathrm{H}), 1.06(\mathrm{q}, J=7.2 \mathrm{~Hz}, 3 \mathrm{H}) .{ }^{13} \mathrm{C}-\mathrm{NMR}\left(101 \mathrm{MHz}, \mathrm{CDCl}_{3}\right): \delta=164.0\left(\mathrm{C}_{\mathrm{q}}\right), 157.6$ 
$\left(\mathrm{C}_{\mathrm{q}}\right), 138.1\left(\mathrm{C}_{\mathrm{q}}\right), 134.2(\mathrm{CH}), 132.6(\mathrm{CH}), 129.0(\mathrm{CH}), 128.1(\mathrm{CH}), 121.0(\mathrm{CH}), 120.6$ $\left(\mathrm{C}_{\mathrm{q}}\right), 118.0(\mathrm{CH}), 115.4(\mathrm{CH}), 112.5(\mathrm{CH}), 69.6\left(\mathrm{CH}_{2}\right), 30.5\left(\mathrm{CH}_{2}\right), 19.2\left(\mathrm{CH}_{2}\right), 13.7$ $\left(\mathrm{CH}_{3}\right)$. IR (ATR): $3164,1673,1561,1502,1204,796,741 \mathrm{~cm}^{-1}$. MS (ESI) $\mathrm{m} / z$ (relative intensity): 309 (21) [M+Na] $]^{+}, 287(100)[\mathrm{M}+\mathrm{H}]^{+}, 237$ (19), 215 (13), 177 (45), 121 (19). HR-MS (ESI) $\mathrm{m} / z$ calcd for $\mathrm{C}_{16} \mathrm{H}_{18} \mathrm{~N}_{2} \mathrm{O}_{3}[\mathrm{M}+\mathrm{H}]^{+}: 287.1390$, found: 287.1389 . The analytical data correspond with those reported in the literature.[111b]<smiles></smiles>

\section{2-[2-(2,2,2-Trifluoroethoxy)benzamido]pyridine-1-oxide (150ad)}

The general procedure $\mathbf{F}$ was followed using benzamide $117 \mathrm{a}(107 \mathrm{mg}, 0.50 \mathrm{mmol}$, 1.00 equiv) and trifluoroethanol (149d) $(2 \times 7.0 \mathrm{~mL})$ at $60^{\circ} \mathrm{C}$. Purification by column chromatography on silica gel $\left(\mathrm{CH}_{2} \mathrm{Cl}_{2} /\right.$ acetone $\left.4: 1\right)$ yielded 150ad $(97.6 \mathrm{mg}, 312 \mu \mathrm{mol}$, $62 \%)$ as a white solid. M. p.: $152-154{ }^{\circ} \mathrm{C} .{ }^{1} \mathrm{H}-\mathrm{NMR}\left(300 \mathrm{MHz}, \mathrm{CDCl}_{3}\right): \delta=11.93$ (s, $1 \mathrm{H}$ ), 8.68 (dd, $J=7.8,2.2 \mathrm{~Hz}, 1 \mathrm{H}$ ), 8.33 (dd, $J=6.6,1.2 \mathrm{~Hz}, 1 \mathrm{H}$ ), 8.27 (dd, $J=7.9$, $1.6 \mathrm{~Hz}, 1 \mathrm{H}$ ), 7.59 (ddd, $J=7.9,7.8,2.2 \mathrm{~Hz}, 1 \mathrm{H}$ ), 7.38 (ddd, $J=8.1,6.6,1.7 \mathrm{~Hz}, 1 \mathrm{H}$ ), 7.29 (ddd, $J=8.1,6.6,1.2 \mathrm{~Hz}, 1 \mathrm{H}$ ), 7.12 (dd, $J=8.1,1.7 \mathrm{~Hz}, 1 \mathrm{H}$ ), 7.03 (ddd, $J=7.9$, 7.8, $1.6 \mathrm{~Hz}, 1 \mathrm{H}), 4.76$ (t, $J=8.6 \mathrm{~Hz}, 2 \mathrm{H}) .{ }^{13} \mathrm{C}-\mathrm{NMR}\left(125 \mathrm{MHz}, \mathrm{CDCl}_{3}\right): \delta=163.0\left(\mathrm{C}_{\mathrm{q}}\right)$, $155.6\left(\mathrm{C}_{\mathrm{q}}\right), 144.9\left(\mathrm{C}_{\mathrm{q}}\right), 137.2(\mathrm{CH}), 134.1(\mathrm{CH}), 132.8(\mathrm{CH}), 127.6(\mathrm{CH}), 123.3(\mathrm{CH})$, $123.0\left(\mathrm{q},{ }^{1} \mathrm{~J}_{\mathrm{CF}}=258 \mathrm{~Hz}, \mathrm{C}_{\mathrm{q}}\right), 122.3\left(\mathrm{C}_{\mathrm{q}}\right), 118.7(\mathrm{CH}), 115.5(\mathrm{CH}), 113.5(\mathrm{CH}), 66.5(\mathrm{q}$, $\left.{ }^{2} \mathrm{JCF}=34.5 \mathrm{~Hz}, \mathrm{CH}_{2}\right) .{ }^{19} \mathrm{~F}-\mathrm{NMR}\left(282 \mathrm{MHz}, \mathrm{CDCl}_{3}\right): d=-72.81 . \mathrm{IR}$ (ATR): 3172, 1669, 1563, 1504, 1452, 1092, $670 \mathrm{~cm}^{-1}$. MS (EI) $\mathrm{m} / z$ (relative intensity): 312 (16) [M], 203 (100), 197 (35), 183 (10) 155 (5), 120 (6), 92 (12). HR-MS (ESI) m/z calcd for $\mathrm{C}_{14} \mathrm{H}_{12} \mathrm{~F}_{3} \mathrm{~N}_{2} \mathrm{O}_{3}[\mathrm{M}+\mathrm{H}]^{+}:$313.0795, found: 313.0791 . 
<smiles></smiles>

\section{2-[2-(2-Chloroethoxy)benzamido]pyridine-1-oxide (150ae)}

The general procedure $\mathbf{F}$ was followed using benzamide 117a $(107 \mathrm{mg}, 0.50 \mathrm{mmol}$, 1.00 equiv) and 2-chloroethanol $(149 \mathrm{e})(2 \times 7.0 \mathrm{~mL})$. Purification by column chromatography on silica gel $\left(\mathrm{CH}_{2} \mathrm{Cl}_{2} /\right.$ acetone $\left.4: 1\right)$ yielded 150ae $(111 \mathrm{mg}, 381 \mu \mathrm{mol}$, $76 \%)$ as a white solid. M. p.: $142-144{ }^{\circ} \mathrm{C} .{ }^{1} \mathrm{H}-\mathrm{NMR}\left(400 \mathrm{MHz}, \mathrm{CDCl}_{3}\right): \delta=12.18$ (s, $1 \mathrm{H}$ ), 8.69 (dd, $J=8.0,2.0 \mathrm{~Hz}, 1 \mathrm{H}$ ), 8.29-8.25 (m, 2H), 7.53 (ddd, $J=7.2,6.8,2.0 \mathrm{~Hz}$, $1 \mathrm{H}$ ), 7.33 (ddd, $J=8.0,6.8,1.7 \mathrm{~Hz}, 1 \mathrm{H}$ ), 7.14 (ddd, $J=7.7,7.0,1.9 \mathrm{~Hz}, 1 \mathrm{H}$ ), 7.06$6.94(\mathrm{~m}, 2 \mathrm{H}), 4.49$ (t, J=7.9 Hz, 2H), 4.17 (t, $J=7.9 \mathrm{~Hz}, 2 \mathrm{H}) .{ }^{13} \mathrm{C}-\mathrm{NMR}(125 \mathrm{MHz}$, $\left.\mathrm{CDCl}_{3}\right): \delta=163.3\left(\mathrm{C}_{\mathrm{q}}\right), 156.5\left(\mathrm{C}_{\mathrm{q}}\right), 145.2\left(\mathrm{C}_{\mathrm{q}}\right), 137.2(\mathrm{CH}), 134.3(\mathrm{CH}), 132.7(\mathrm{CH})$, $128.9\left(\mathrm{C}_{\mathrm{q}}\right), 127.7(\mathrm{CH}), 121.9(\mathrm{CH}), 120.6\left(\mathrm{C}_{\mathrm{q}}\right), 118.5(\mathrm{CH}), 115.6(\mathrm{CH}), 112.6(\mathrm{CH})$, $69.5\left(\mathrm{CH}_{2}\right), 41.2\left(\mathrm{CH}_{2}\right)$. IR (ATR): 3168, 1565, 1508, 1178, 1021, $741 \mathrm{~cm}^{-1} . \mathrm{MS}(\mathrm{ESI})$ $\mathrm{m} / \mathrm{z}$ (relative intensity): $317(30)\left[{ }^{37} \mathrm{Cl}-\mathrm{M}+\mathrm{Na}\right]^{+}, 315(94)\left[{ }^{35} \mathrm{Cl}-\mathrm{M}+\mathrm{Na}\right]^{+}, 295(35)\left[{ }^{37} \mathrm{Cl}-\right.$ $\mathrm{M}+\mathrm{H}]^{+}, 293(100)\left[{ }^{35} \mathrm{Cl}-\mathrm{M}+\mathrm{H}\right]^{+}, 242$ (5), 183 (56), 121 (12). HR-MS (ESI) m/z calcd for $\mathrm{C}_{14} \mathrm{H}_{13} \mathrm{~N}_{2} \mathrm{O}_{3}{ }^{35} \mathrm{Cl}\left[{ }^{35} \mathrm{Cl}-\mathrm{M}+\mathrm{H}\right]^{+}:$293.0687, found: 293.0687.<smiles></smiles>

\section{2-(2-(2-Methoxyethoxy)benzamido)pyridine-1-oxide (150af)}

The general procedure $\mathbf{F}$ was followed using benzamide 117a $(107 \mathrm{mg}, 0.50 \mathrm{mmol}$, 1.00 equiv) and 2-methoxyethanol (149f) $(2 \times 7.0 \mathrm{~mL})$. Purification by column chromatography on silica gel $\left(\mathrm{CH}_{2} \mathrm{Cl}_{2} /\right.$ acetone $\left.2: 1\right)$ yielded 150af $(92.3 \mathrm{mg}, 320 \mu \mathrm{mol}$, $64 \%)$ as a white solid. M. p.: $107-109{ }^{\circ} \mathrm{C} .{ }^{1} \mathrm{H}-\mathrm{NMR}\left(300 \mathrm{MHz}, \mathrm{CDCl}_{3}\right): \delta=12.21$ (s, $1 \mathrm{H}$ ), 8.70 (dd, $J=7.9,1.3 \mathrm{~Hz}, 1 \mathrm{H}$ ), 8.29-8.23 (m, 2H), 7.51 (ddd, $J=8.3,7.2,1.3 \mathrm{~Hz}$, 1H), 7.31 (ddd, $J=7.9,7.2,2.0 \mathrm{~Hz}, 1 \mathrm{H}$ ), 7.14-7.07 (m, 2H), 6.97 (ddd, $J=8.0,6.5$, $2.3 \mathrm{~Hz}, 1 \mathrm{H}$ ), $4.41(\mathrm{t}, J=5.1 \mathrm{~Hz}, 2 \mathrm{H}), 4.06(\mathrm{t}, J=5.1 \mathrm{~Hz}, 2 \mathrm{H}), 3.45(\mathrm{~s}, 3 \mathrm{H}) .{ }^{13} \mathrm{C}-\mathrm{NMR}$ 
(125 MHz, $\left.\mathrm{CDCl}_{3}\right): \delta=163.8\left(\mathrm{C}_{\mathrm{q}}\right), 157.4\left(\mathrm{C}_{\mathrm{q}}\right), 145.4\left(\mathrm{C}_{\mathrm{q}}\right), 137.3(\mathrm{CH}), 134.3(\mathrm{CH})$, $132.6(\mathrm{CH}), 127.7(\mathrm{CH}), 124.5(\mathrm{CH}), 120.8\left(\mathrm{C}_{\mathrm{q}}\right), 118.4(\mathrm{CH}), 115.7(\mathrm{CH}), 112.8(\mathrm{CH})$, $70.4\left(\mathrm{CH}_{2}\right), 69.0\left(\mathrm{CH}_{2}\right), 59.0\left(\mathrm{CH}_{3}\right)$. IR (ATR): 3171, 1656, 1560, 1422, 1251, 904 , $747 \mathrm{~cm}^{-1}$. MS (ESI) $\mathrm{m} / z$ (relative intensity): 311 (62) [M+Na] $]^{+}, 289(100)[\mathrm{M}+\mathrm{H}]^{+}, 179$ (37), 147 (6), 123 (9). HR-MS (ESI) $\mathrm{m} / z$ calcd for $\mathrm{C}_{15} \mathrm{H}_{16} \mathrm{~N}_{2} \mathrm{O}_{4}[\mathrm{M}+\mathrm{H}]^{+}:$289.1183, found: 289.1184 . The analytical data correspond with those reported in the literature. ${ }^{[111 b]}$<smiles></smiles>

\section{2-[2-(2-Acetoxyethoxy)benzamido]pyridine-1-oxide (150ag)}

The general procedure $\mathrm{G}$ was followed using benzamide $117 \mathrm{a}(53.5 \mathrm{mg}, 0.25 \mathrm{mmol}$, 1.00 equiv) and 2-hydroxyethylacetate (149g) (2.3 mL) in MeCN (0.9 mL). Purification by column chromatography on silica gel $\left(\mathrm{CH}_{2} \mathrm{Cl}_{2} /\right.$ acetone $\left.3: 1\right)$ yielded $150 \mathrm{ag}(42.5 \mathrm{mg}$, $136 \mu \mathrm{mol}, 54 \%)$ as a white solid. M. p.: $125-127^{\circ} \mathrm{C} .{ }^{1} \mathrm{H}-\mathrm{NMR}\left(300 \mathrm{MHz}, \mathrm{CDCl}_{3}\right): \delta=$ $12.11(\mathrm{~s}, 1 \mathrm{H}$ ), 8.67 (dd, $J=7.4,2.2 \mathrm{~Hz}, 1 \mathrm{H}$ ), 8.27-8.22 (m, 2H), 7.51 (ddd, $J=8.2,7.4$, $2.0 \mathrm{~Hz}, 1 \mathrm{H}$ ), 7.32 (ddd, $J=8.2,7.4,2.2 \mathrm{~Hz}, 1 \mathrm{H}$ ), $7.13(\mathrm{dd}, J=8.2,2.0 \mathrm{~Hz}, 1 \mathrm{H}), 7.04$ (dd, $J=8.4,1.3 \mathrm{~Hz}, 1 \mathrm{H}$ ), 6.96 (ddd, $J=8.2,8.0,1.3 \mathrm{~Hz}, 1 \mathrm{H}$ ), $4.71(\mathrm{t}, J=5.6 \mathrm{~Hz}, 2 \mathrm{H}$ ), $4.45(\mathrm{t}, J=5.6 \mathrm{~Hz}, 2 \mathrm{H}), 2.01$ (s, 3H). ${ }^{13} \mathrm{C}-\mathrm{NMR}\left(125 \mathrm{MHz}, \mathrm{CDCl}_{3}\right): \delta=170.9\left(\mathrm{C}_{\mathrm{q}}\right), 163.4$ $\left(\mathrm{C}_{\mathrm{q}}\right), 156.8\left(\mathrm{C}_{\mathrm{q}}\right), 145.1\left(\mathrm{C}_{\mathrm{q}}\right), 137.1(\mathrm{CH}), 134.1(\mathrm{CH}), 132.6(\mathrm{CH}), 127.4(\mathrm{CH}), 121.7$ $(\mathrm{CH}), 121.0\left(\mathrm{C}_{\mathrm{q}}\right), 118.4(\mathrm{CH}), 115.5(\mathrm{CH}), 112.7(\mathrm{CH}), 67.6\left(\mathrm{CH}_{2}\right), 62.4\left(\mathrm{CH}_{2}\right), 20.9$ (CH3). IR (ATR): 3241, 2924, 1730, 1671, 1599, 1505, 1222, 1046, 860, $721 \mathrm{~cm}^{-1}$. MS (EI) $\mathrm{m} / z$ (relative intensity): 316 (5) [M] ${ }^{+}, 230$ (41), 197 (53), 165 (100), 121 (81), 87 (45) 43 (67). HR-MS (ESI) $\mathrm{m} / z$ calcd for $\mathrm{C}_{16} \mathrm{H}_{16} \mathrm{~N}_{2} \mathrm{O}_{5} \quad[\mathrm{M}+\mathrm{H}]^{+}: 317.1132$, found: 317.1140 . 
<smiles></smiles>

\section{2-[2-(2-Cyanoethoxy)benzamido]pyridine-1-oxide (150ah)}

The general procedure $\mathbf{G}$ was followed using benzamide $117 \mathrm{a}(53.5 \mathrm{mg}, 0.25 \mathrm{mmol}$, 1.00 equiv) and 3-hydroxypropionitrile (149h) (2.3 mL) in $\operatorname{MeCN}(0.9 \mathrm{~mL})$. Purification by column chromatography on silica gel $\left(\mathrm{CH}_{2} \mathrm{Cl}_{2} /\right.$ acetone $\left.2: 1\right)$ yielded 150ah $(43.5 \mathrm{mg}$, $153 \mu \mathrm{mol}, 61 \%)$ as a white solid. M. p.: $183-185^{\circ} \mathrm{C} .{ }^{1} \mathrm{H}-\mathrm{NMR}\left(300 \mathrm{MHz}, \mathrm{CDCl}_{3}\right): \delta=$ 12.07 (s, $1 \mathrm{H}$ ), 8.70 (dd, $J=8.4,1.8 \mathrm{~Hz}, 1 \mathrm{H}$ ), 8.32-8.25 (m, 2H), 7.57 (ddd, $J=8.4,7.9$, $2.1 \mathrm{~Hz}, 1 \mathrm{H}$ ), 7.32 (ddd, $J=8.2,7.4,2.2 \mathrm{~Hz}, 1 \mathrm{H}), 7.13$ (dd, $J=8.2,2.0 \mathrm{~Hz}, 1 \mathrm{H}), 7.04$ (dd, $J=8.4,1.3 \mathrm{~Hz}, 1 \mathrm{H}$ ), 7.04-6.99 (m, 2H), 4.71 (t, $J=5.6 \mathrm{~Hz}, 2 \mathrm{H}), 4.45$ (t, J = 5.6 Hz, 2H), $2.01(\mathrm{~s}, 3 \mathrm{H}) .{ }^{13} \mathrm{C}-\mathrm{NMR}\left(75 \mathrm{MHz}, \mathrm{CDCl}_{3}\right): \delta=163.1\left(\mathrm{C}_{\mathrm{q}}\right), 151.1\left(\mathrm{C}_{\mathrm{q}}\right), 145.1\left(\mathrm{C}_{\mathrm{q}}\right)$, $137.2(\mathrm{CH}), 134.5(\mathrm{CH}), 132.9(\mathrm{CH}), 128.0(\mathrm{CH}), 122.4(\mathrm{CH}), 120.9\left(\mathrm{C}_{\mathrm{q}}\right), 118.7(\mathrm{CH})$, $117.1\left(\mathrm{C}_{\mathrm{q}}\right), 115.6(\mathrm{CH}), 112.4(\mathrm{CH}), 64.3\left(\mathrm{CH}_{2}\right), 18.4\left(\mathrm{CH}_{2}\right)$. IR (ATR): 3191, 2930, 2257, 1662, 1599, 1428, 1267, 1205, $741 \mathrm{~cm}^{-1}$. MS (El) $\mathrm{m} / \mathrm{z}$ (relative intensity): 283 (13) [M]+, 264 (8), 230 (44), 214 (17), 174 (69), 121 (100), 110 (53), 93 (27), 65 (25). HR-MS (ESI) $m / z$ calcd for $\mathrm{C}_{15} \mathrm{H}_{13} \mathrm{~N}_{3} \mathrm{O}_{3}[\mathrm{M}]^{+}:$: 284.1030, found: 284.1036 .<smiles></smiles>

\section{2-[2-(Cyclopentylmethoxy)benzamido]pyridine-1-oxide (150ai)}

The general procedure G was followed using benzamide $117 \mathrm{a}(53.7 \mathrm{mg}, 0.25 \mathrm{mmol}$, 1.00 equiv) and cyclopentylmethanol (149i) (2.3 mL) in MeCN (0.9 mL). Purification by column chromatography on silica gel $\left(\mathrm{CH}_{2} \mathrm{Cl}_{2} /\right.$ acetone $\left.4: 1\right)$ yielded 150ai $(61.3 \mathrm{mg}$, $196 \mu \mathrm{mol}, 78 \%)$ as a white solid. M. p.: $124-126^{\circ} \mathrm{C} .{ }^{1} \mathrm{H}-\mathrm{NMR}\left(400 \mathrm{MHz}, \mathrm{CDCl}_{3}\right): \delta=$ $12.17(\mathrm{~s}, 1 \mathrm{H}), 8.71$ (dd, $J=7.7,1.9 \mathrm{~Hz}, 1 \mathrm{H}), 8.33-8.27(\mathrm{~m}, 2 \mathrm{H}), 7.50$ (ddd, $J=8.0,7.6$, $1.9 \mathrm{~Hz}, 1 \mathrm{H}$ ), 7.32 (dd, $J=8.0,2.2 \mathrm{~Hz}, 1 \mathrm{H}), 7.10-7.03(\mathrm{~m}, 2 \mathrm{H}), 6.97$ (ddd, $J=8.0,6.5$, 
$2.2 \mathrm{~Hz}, 1 \mathrm{H}), 4.13(\mathrm{~d}, J=8.0 \mathrm{~Hz}, 2 \mathrm{H}), 2.82-2.74(\mathrm{~m}, 1 \mathrm{H}), 2.00-1.92(\mathrm{~m}, 2 \mathrm{H}), 1.66-1.54$ (m, 4H), 1.40-1.31 (m, 2H). ${ }^{13} \mathrm{C}-\mathrm{NMR}\left(125 \mathrm{MHz}, \mathrm{CDCl}_{3}\right): \delta=164.1\left(\mathrm{C}_{\mathrm{q}}\right), 157.6\left(\mathrm{C}_{\mathrm{q}}\right)$, $145.4\left(\mathrm{C}_{\mathrm{q}}\right), 137.4(\mathrm{CH}), 134.2(\mathrm{CH}), 132.6(\mathrm{CH}), 127.5(\mathrm{CH}), 121.0(\mathrm{CH}), 120.6\left(\mathrm{C}_{\mathrm{q}}\right)$, $118.4(\mathrm{CH}), 115.8(\mathrm{CH}), 112.6(\mathrm{CH}), 74.3\left(\mathrm{CH}_{2}\right), 38.3(\mathrm{CH}), 29.8\left(\mathrm{CH}_{2}\right), 24.4\left(\mathrm{CH}_{2}\right)$. IR (ATR): $3170,2955,1662,1500,1264,1206,1047,746 \mathrm{~cm}^{-1}$. MS (EI) $\mathrm{m} / \mathrm{z}$ (relative intensity): 312 (4) [M] $]^{+}, 295$ (10), 230 (37), 203 819), 197 (44), 121 (100), 110 (15). HR-MS (ESI) $m / z$ calcd for $\mathrm{C}_{18} \mathrm{H}_{21} \mathrm{~N}_{2} \mathrm{O}_{3}[\mathrm{M}+\mathrm{H}]^{+}: 313.1547$, found: 313.1543 .<smiles>O=C(Nc1ccccc1OCc1ccccc1)c1ccccc1[O-]</smiles>

\section{2-[2-(Benzyloxy)benzamido]pyridine-1-oxide (150aj)}

The general procedure $G$ was followed using benzamide $117 \mathrm{a}(53.9 \mathrm{mg}, 0.25 \mathrm{mmol}$, 1.00 equiv) and benzylalcohol (149j) $(2.3 \mathrm{~mL})$ in $\mathrm{MeCN}(0.9 \mathrm{~mL})$. Purification by column chromatography on silica gel $\left(\mathrm{CH}_{2} \mathrm{Cl}_{2} /\right.$ acetone $\left.6: 1\right)$ yielded 150aj $(58.9 \mathrm{mg}$, $184 \mu \mathrm{mol}, 74 \%)$ as a white solid. M. p.: $121-122{ }^{\circ} \mathrm{C} .{ }^{1} \mathrm{H}-\mathrm{NMR}\left(400 \mathrm{MHz}, \mathrm{CDCl}_{3}\right): \delta=$ 12.59 (s, $1 \mathrm{H}$ ), 8.79 (dd, $J=7.9,1.7 \mathrm{~Hz}, 1 \mathrm{H}$ ), 8.28 (dd, $J=8.2,1.3 \mathrm{~Hz}, 1 \mathrm{H}$ ), 8.22 (dd, $J=8.5,2.0 \mathrm{~Hz}, 1 \mathrm{H}$ ), 7.49 (d, $J=7.9 \mathrm{~Hz}, 2 \mathrm{H}$ ), 7.41-7.32 (m, 4H), 7.26 (ddd, $J=8.2$, 7.9, $1.7 \mathrm{~Hz}, 1 \mathrm{H}$ ), 7.06 (ddd, $J=8.2,7.9,1.3 \mathrm{~Hz}, 1 \mathrm{H}), 7.01-6.98(\mathrm{~m}, 2 \mathrm{H}), 5.53(\mathrm{~s}, 2 \mathrm{H})$. ${ }^{13} \mathrm{C}-N M R\left(125 \mathrm{MHz}, \mathrm{CDCl}_{3}\right): \delta=163.7\left(\mathrm{C}_{\mathrm{q}}\right), 156.6\left(\mathrm{C}_{\mathrm{q}}\right), 145.4\left(\mathrm{C}_{\mathrm{q}}\right), 137.3(\mathrm{CH}), 135.8$ $\left(\mathrm{C}_{\mathrm{q}}\right), 134.0(\mathrm{CH}), 132.4(\mathrm{CH}), 128.7(\mathrm{CH}), 128.1(\mathrm{CH}), 128.0(\mathrm{CH}), 127.2(\mathrm{CH}), 121.4$ $(\mathrm{CH}), 121.2\left(\mathrm{C}_{\mathrm{q}}\right), 118.4(\mathrm{CH}), 115.6(\mathrm{CH}), 113.7(\mathrm{CH}), 71.2\left(\mathrm{CH}_{2}\right)$. IR (ATR): 3135, $1671,1599,1504,1422,1196,999,732,684 \mathrm{~cm}^{-1}$. MS (ESI) $\mathrm{m} / \mathrm{z}$ (relative intensity): 320 (8) [M] ${ }^{+}, 303$ (15), 211 (27), 197 (20), 183 (33), 121 (11), 91 (100), 65 (17). HRMS (ESI) $\mathrm{m} / z$ calcd for $\mathrm{C}_{19} \mathrm{H}_{16} \mathrm{~N}_{2} \mathrm{O}_{3}[\mathrm{M}]^{+}: 320.1161$, found: 320.1162 . The analytical data correspond with those reported in the literature. ${ }^{[111 b]}$ 
<smiles></smiles>

\section{2-\{2-[(2-Methylbenzyl)oxy]benzamido\}pyridine-1-oxide (150ak)}

The general procedure $\mathbf{G}$ was followed using benzamide $117 \mathrm{a}(53.2 \mathrm{mg}, 0.25 \mathrm{mmol}$, 1.00 equiv) and 2-methylbenzylalcohol (149k) (2.3 mL) in $\operatorname{MeCN}(0.9 \mathrm{~mL})$. Purification by column chromatography on silica gel $\left(\mathrm{CH}_{2} \mathrm{Cl}_{2} /\right.$ acetone $\left.3: 1\right)$ yielded 150ak $(58.9 \mathrm{mg}$, $184 \mu \mathrm{mol}, 68 \%)$ as a white solid. M. p.: $161-162{ }^{\circ} \mathrm{C} .{ }^{1} \mathrm{H}-\mathrm{NMR}\left(400 \mathrm{MHz}, \mathrm{CDCl}_{3}\right): \delta=$ 12.50 (s, 1H), 8.69 (dd, $J=7.6,1.5 \mathrm{~Hz}, 1 \mathrm{H}$ ), 8.24 (dd, $J=8.2,1.9 \mathrm{~Hz}, 2 \mathrm{H}$ ), 8.41-8.36 (m, 2H), 8.33 (ddd, $J=8.0,7.6,2.1 \mathrm{~Hz}, 1 \mathrm{H}), 7.21-7.14(\mathrm{~m}, 3 \mathrm{H}), 7.08$ (ddd, $J=7.6,6.8$, $2.2 \mathrm{~Hz}, 1 \mathrm{H}$ ), 6.98 (ddd, $J=8.0,7.6,1.5 \mathrm{~Hz}, 1 \mathrm{H}), 6.91$ (dd, $J=7.9,1.7 \mathrm{~Hz}, 1 \mathrm{H}), 5.53$ (s, 2H), $2.42(\mathrm{~s}, 3 \mathrm{H}) .{ }^{13} \mathrm{C}-\mathrm{NMR}\left(125 \mathrm{MHz}, \mathrm{CDCl}_{3}\right): \delta=163.7\left(\mathrm{C}_{\mathrm{q}}\right), 156.0\left(\mathrm{C}_{\mathrm{q}}\right), 145.4$ $\left(\mathrm{C}_{\mathrm{q}}\right), 137.3(\mathrm{CH}), 135.4\left(\mathrm{C}_{\mathrm{q}}\right), 134.0(\mathrm{CH}), 133.8\left(\mathrm{C}_{\mathrm{q}}\right), 132.4(\mathrm{CH}), 130.4(\mathrm{CH}), 127.9$ $(\mathrm{CH}), 127.6(\mathrm{CH}), 127.1(\mathrm{CH}), 126.1(\mathrm{CH}), 121.6(\mathrm{CH}), 121.1\left(\mathrm{C}_{\mathrm{q}}\right), 118.3(\mathrm{CH}), 115.5$ $(\mathrm{CH}), 113.7(\mathrm{CH}), 70.0\left(\mathrm{CH}_{2}\right) 19.1\left(\mathrm{CH}_{3}\right)$. IR (ATR): 3173, 2952, 1662, 1561, 1469, 1236, 841, 748, $601 \mathrm{~cm}^{-1}$. MS (ESI) $m / z$ (relative intensity): 334 (11) [M] $]^{+}, 317$ (7), 230 (20), 197 (26), 121 (15), 105 (100), 79 (16). HR-MS (EI) m/z calcd for $\mathrm{C}_{20} \mathrm{H}_{18} \mathrm{~N}_{2} \mathrm{O}_{3}$ $[\mathrm{M}]^{+}:$334.1317, found: 334.1325.<smiles>CC(C)=CCCC(C)CCOc1ccccc1C(=O)Nc1cccc[n+]1[O-]</smiles>

(S)-2-\{2-[(3,7-Dimethyloct-6-en-1-yl)oxy]benzamido\}pyridine-1-oxide (150al)

The general procedure $\mathbf{G}$ was followed using benzamide $117 \mathrm{a}(53.5 \mathrm{mg}, 0.25 \mathrm{mmol}$, 1.00 equiv) and (S)-citronellol (149I) (2.3 mL) in MeCN (0.9 mL). Purification by column chromatography on silica gel $\left(\mathrm{CH}_{2} \mathrm{Cl}_{2} /\right.$ acetone $\left.8: 1\right)$ yielded $150 \mathrm{al}$ (48.9 mg, $133 \mu \mathrm{mol}$, $52 \%)$ as a yellow oil. ${ }^{1} \mathrm{H}-\mathrm{NMR}\left(400 \mathrm{MHz}, \mathrm{CDCl}_{3}\right): \delta=12.22(\mathrm{~s}, 1 \mathrm{H}), 8.69(\mathrm{dd}, J=7.8$, $2.2 \mathrm{~Hz}, 1 \mathrm{H}$ ), 8.29-8.22 (m, 2H), 7.50 (ddd, $J=8.0,7.8,2.2 \mathrm{~Hz}, 1 \mathrm{H}$ ), 7.32 (ddd, $J=8.0$, 
7.8, 1.7 Hz, 1H), 7.09-7.04 (m, 2H), 6.96 (ddd, $J=7.9,6.9,2.0 \mathrm{~Hz}, 1 \mathrm{H}), 5.07-5.04(\mathrm{~m}$, $1 \mathrm{H}), 4.35-4.24(\mathrm{~m}, 2 \mathrm{H}), 2.17-2.11(\mathrm{~m}, 1 \mathrm{H}), 2.03-1.90(\mathrm{~m}, 2 \mathrm{H}), 1.72-1.65(\mathrm{~m}, 2 \mathrm{H}), 1.62$ (s, 3H), $1.55(\mathrm{~s}, 3 \mathrm{H}), 1.41-1.33(\mathrm{~m}, 1 \mathrm{H}), 1.27-1.20(\mathrm{~m}, 1 \mathrm{H}), 0.98(\mathrm{~d}, J=7.9 \mathrm{~Hz}, 3 \mathrm{H})$. ${ }^{13} \mathrm{C}-N M R\left(125 \mathrm{MHz}, \mathrm{CDCl}_{3}\right): \delta=163.9\left(\mathrm{C}_{\mathrm{q}}\right), 157.4\left(\mathrm{C}_{\mathrm{q}}\right), 145.3\left(\mathrm{C}_{\mathrm{q}}\right), 137.2(\mathrm{CH}), 135.1$ $(\mathrm{CH}), 132.1(\mathrm{CH}), 131.2\left(\mathrm{C}_{\mathrm{q}}\right), 127.4(\mathrm{CH}), 124.6(\mathrm{CH}), 120.9(\mathrm{CH}), 120.6\left(\mathrm{C}_{\mathrm{q}}\right), 118.3$ $(\mathrm{CH}), 115.7(\mathrm{CH}), 112.5(\mathrm{CH}), 68.3\left(\mathrm{CH}_{2}\right), 37.3\left(\mathrm{CH}_{2}\right), 35.5\left(\mathrm{CH}_{2}\right), 29.9\left(\mathrm{CH}_{3}\right), 25.7$ $\left(\mathrm{CH}_{3}\right), 25.5\left(\mathrm{CH}_{2}\right), 19.5(\mathrm{CH}), 17.7\left(\mathrm{CH}_{3}\right)$. IR (ATR): 3168, 2917, 1669, 1600, 1505, 1426, 1207, $687 \mathrm{~cm}^{-1}$. MS (ESI) $\mathrm{m} / \mathrm{z}$ (relative intensity): 368 (23) [M] $]^{+}, 351$ (11), 299 (10), 230 (21), 214 (19) 197 (16), 147 (12), 121 (100), 110 (25), 95 (28), 81 (33), 69 (53), 55 (33), 41 (44). HR-MS (EI) $\mathrm{m} / z$ calcd for $\mathrm{C}_{22} \mathrm{H}_{28} \mathrm{~N}_{2} \mathrm{O}_{3}[\mathrm{M}]^{+}: 368.2100$, found: 368.2099 .

\section{Gram-Scale Synthesis of 150 na}

In a three-neck flask fitted with a Pt-plate electrode $(2.5 \mathrm{~cm} \times 5 \mathrm{~cm} \times 0.25 \mathrm{~mm})$ and a RVC electrode $(2.5 \mathrm{~cm} \times 5 \mathrm{~cm} \times 0.6 \mathrm{~cm}), \mathrm{Co}(\mathrm{OAc})_{2} \cdot 4 \mathrm{H}_{2} \mathrm{O}(257 \mathrm{mg}, 1.00 \mathrm{mmol}$, $20 \mathrm{~mol} \%)$, NaOPiv (2.41 g, $20.0 \mathrm{mmol}, 4.00$ equiv) and benzamide $117 \mathrm{n}(1.45 \mathrm{~g}$, $5.00 \mathrm{mmol}, 1.00$ equiv) were dissolved in ethanol (149a) $(70 \mathrm{~mL})$ under $\mathrm{N}_{2}$ atmosphere. Electrolysis was started at ambient temperature and a constant current of $16 \mathrm{~mA}$ maintained for $36 \mathrm{~h}$. Evaporation of the solvent and subsequent column chromatography using $\mathrm{CH}_{2} \mathrm{Cl}_{2} /$ Acetone $(3: 1 \rightarrow 1: 1)$ yielded 150na $(1.02 \mathrm{~g}, 3.12 \mathrm{mmol}$, $61 \%)$.

\subsubsection{Mechanistic Studies}

\section{Studies on the Potential Racemization of 150al}

A racemic sample of 150 al was synthesized following general procedure $B$ using racCitronellol. Analysis by chiral HPLC showed that no racemization took place. HPLC chromatograms were recorded on an Agilent 1290 Infinity instrument using CHIRALPAK $®$ IA- 1 column and $n$-hexane $/ i-\mathrm{PrOH}(95: 5,0.5 \mathrm{~mL} / \mathrm{min}$, detection at 250 $\mathrm{nm})$. 

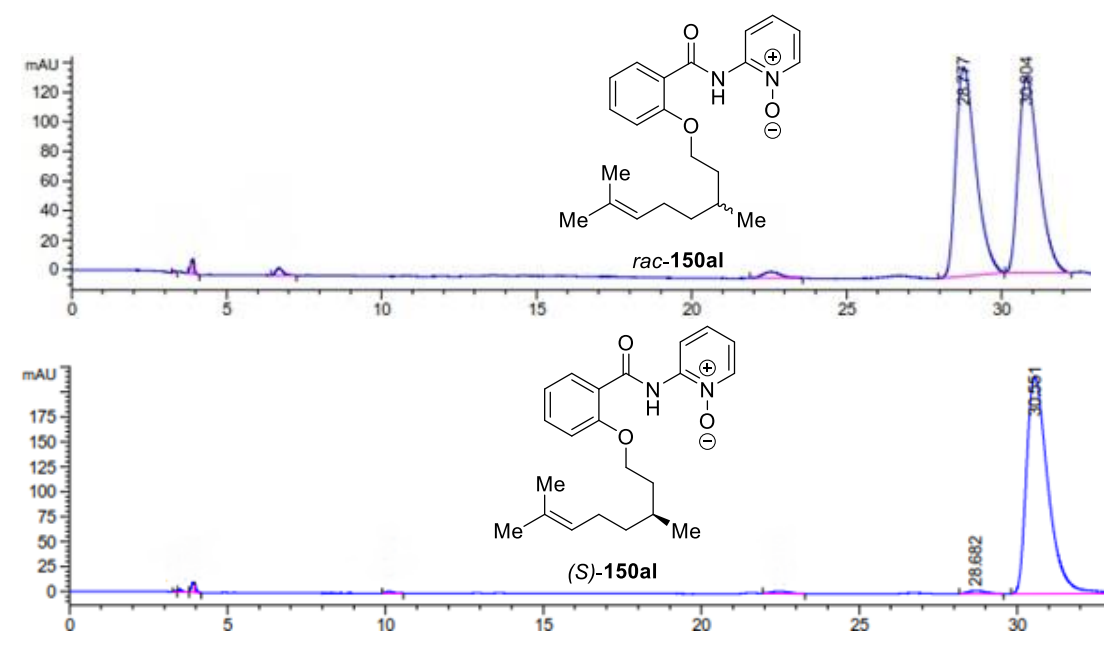

Figure 5.9. HPLC Chromatograms of rac-150al and (2)-150al.

\section{H/D Exchange Experiment}

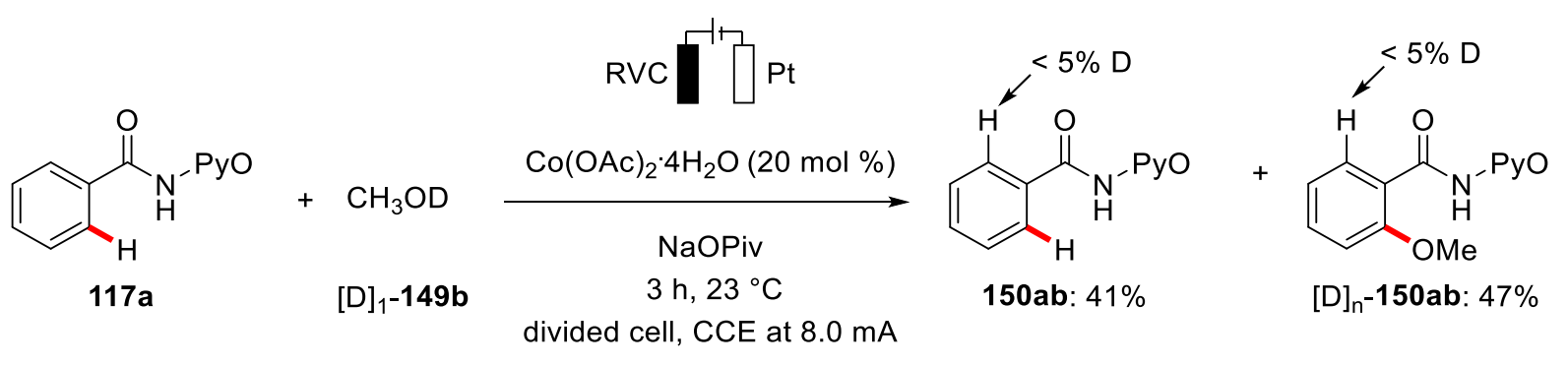

Scheme 5.13. $H / D$ exchange in the presence of $[D]_{1}-149 b$.

In a divided cell with $\mathrm{P} 4$ sintered glass membrane, NaOPiv (122 mg, $1.00 \mathrm{mmol}$ ) was added in one cell, fitted with a Pt-plate electrode and dissolved in $\mathrm{CH}_{3} \mathrm{OD}(7.0 \mathrm{~mL})$. In the other half cell $\mathrm{Co}(\mathrm{OAc})_{2} \cdot 4 \mathrm{H}_{2} \mathrm{O}(25.7 \mathrm{mg}, 0.10 \mathrm{mmol}, 20 \mathrm{~mol} \%$ ), NaOPiv (122 mg, $1.00 \mathrm{mmol}$ ) and benzamide 117aa $\left(107 \mathrm{mg}, 0.50 \mathrm{mmol}\right.$ ) were dissolved in $\mathrm{CH}_{3} \mathrm{OD}$ $(7.0 \mathrm{~mL})$ and fitted with a RVC electrode. Electrolysis was performed at ambient temperature and a constant current of $8 \mathrm{~mA}$ maintained for $3 \mathrm{~h}$. Evaporation of the solvent and subsequent column chromatography $\left(\mathrm{CH}_{2} \mathrm{Cl}_{2} /\right.$ acetone 2:1) yielded the desired product ( $57.8 \mathrm{mg}, 235 \mu \mathrm{mol}, 47 \%$ ) as a white solid and the reisolated starting material $(43.9 \mathrm{mg}, 206 \mu \mathrm{mol}, 41 \%)$ as a white solid. No deuteration could be detected in either compound by ${ }^{1} \mathrm{H}$-NMR spectroscopy and MS spectrometry. 


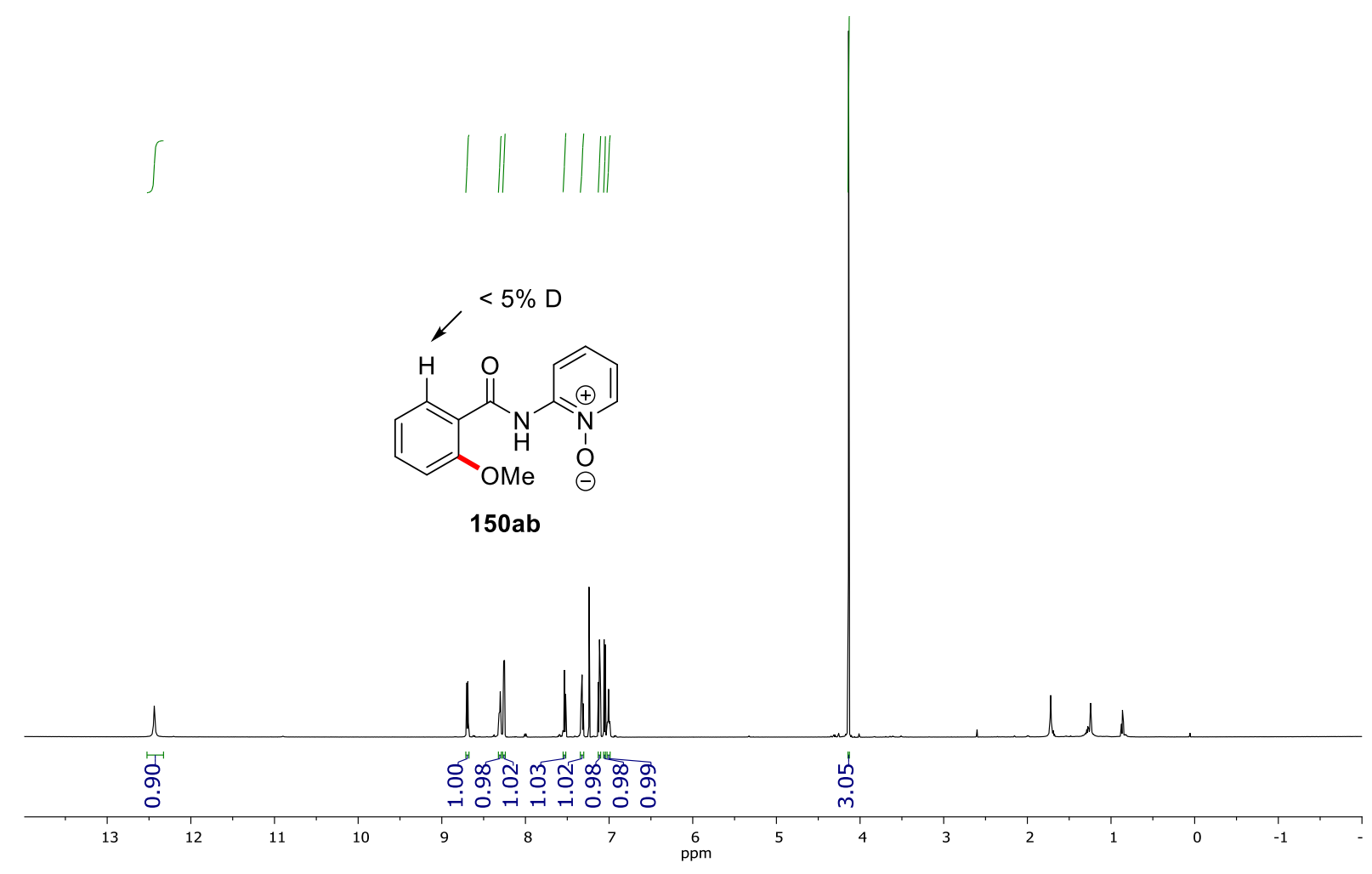

Figure 5.10. ${ }^{1} \mathrm{H}-\mathrm{NMR}$ of $150 \mathrm{ab}$ from the $\mathrm{H} / \mathrm{D}$ exchange experiment.
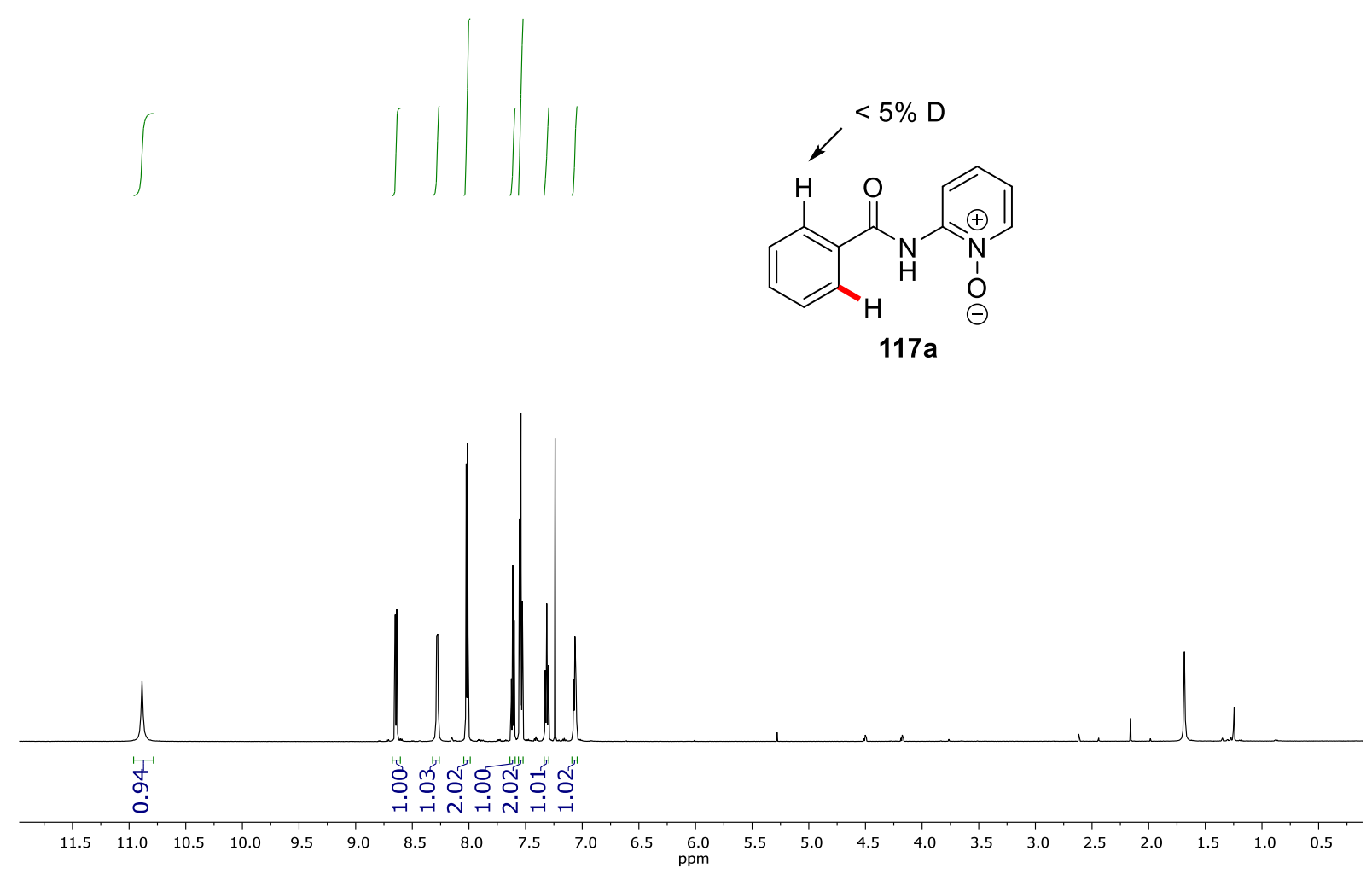

Figure 5.11. ${ }^{1} \mathrm{H}-\mathrm{NMR}$ of $117 \mathrm{a}$ from the $\mathrm{H} / \mathrm{D}$ exchange experiment. 


\section{Competition Experiments}

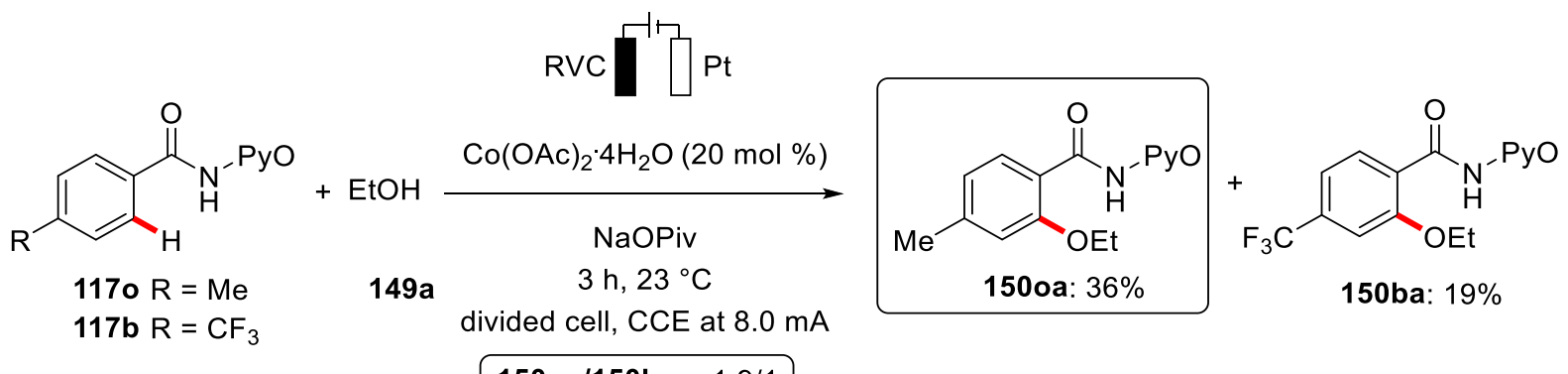

Scheme 5.14. Competition experiment between arenes 1170 and $117 \mathrm{~b}$.

In a divided cell with $\mathrm{P} 4$ sintered glass membrane, NaOPiv (122 mg, $1.00 \mathrm{mmol}, 4.00$ equiv) was added in one cell, fitted with a Pt-plate electrode and dissolved in alcohol 149a $(7.0 \mathrm{~mL})$. In the other half cell $\mathrm{Co}(\mathrm{OAc})_{2} \cdot 4 \mathrm{H}_{2} \mathrm{O}(25.7 \mathrm{mg}, 0.10 \mathrm{mmol}, 20 \mathrm{~mol} \%)$, NaOPiv (123 mg, $1.00 \mathrm{mmol}, 4.00$ equiv), benzamide $117 \mathrm{o}(57.3 \mathrm{mg}, 0.25 \mathrm{mmol}, 1.00$ equiv) and benzamide $117 \mathrm{~b}$ (70.5 mg, $0.25 \mathrm{mmol}, 1.00$ equiv) were dissolved in ethanol (149a) $(7.0 \mathrm{~mL})$ and fitted with a RVC electrode. Electrolysis was started at ambient temperature and a constant current of $8 \mathrm{~mA}$ maintained for $3 \mathrm{~h}$. Evaporation of the solvent and subsequent column chromatography using $\mathrm{CH}_{2} \mathrm{Cl}_{2}$ /acetone 3:1 yielded a mixture of products. Analysis by ${ }^{1} \mathrm{H}-\mathrm{NMR}$ using $\mathrm{CH}_{2} \mathrm{Br}_{2}$ as the internal standard showed a product distribution of 1.9:1 in favor of $\mathbf{1 5 0 0 a}$. 


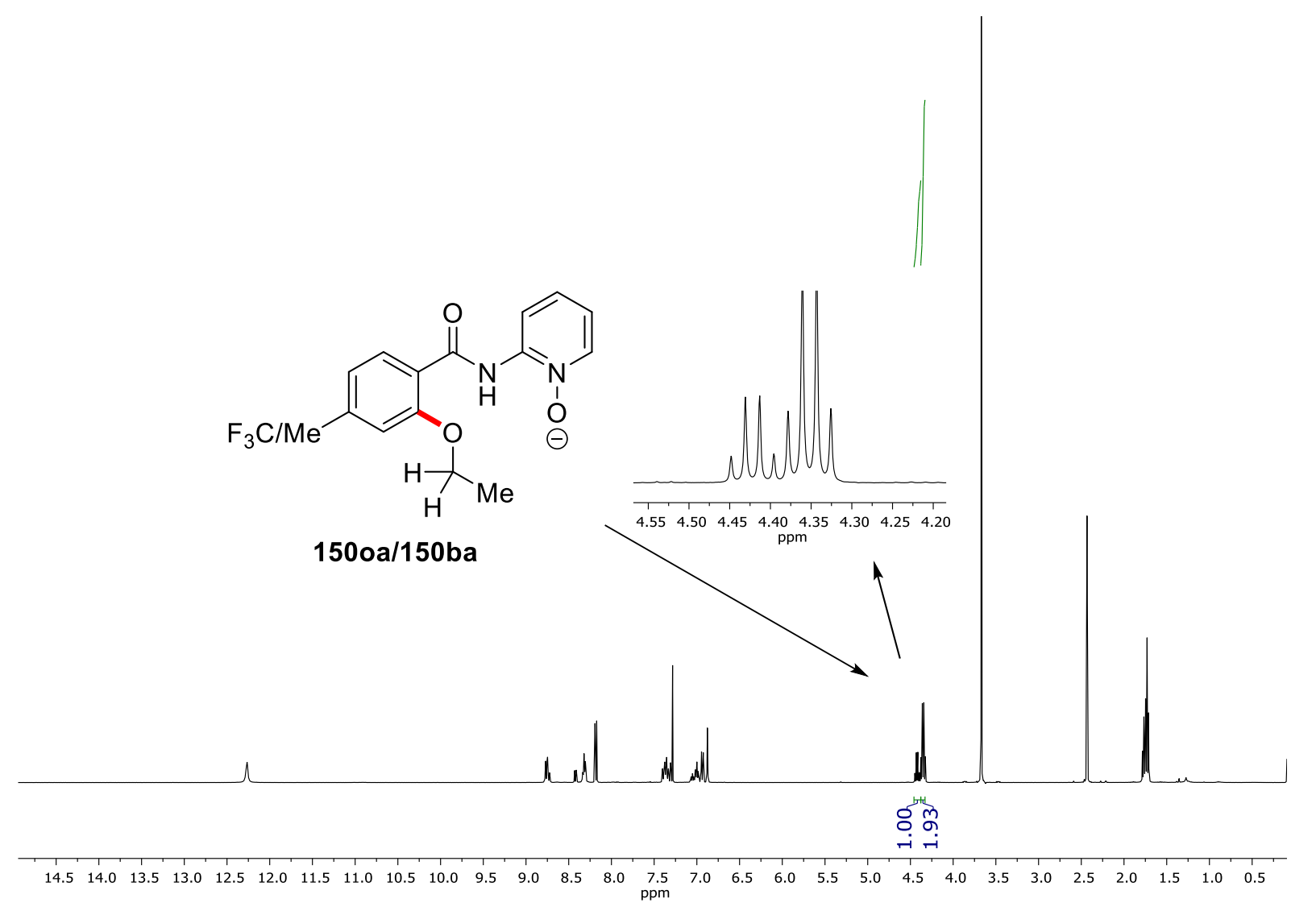

Figure 5.12. ${ }^{1} \mathrm{H}-\mathrm{NMR}$ of the isolated mixture of $150 \mathrm{oa}$ and $150 \mathrm{ba}$.

The relative kinetic studies were conducted with $150 \mathrm{oa}$ and $150 \mathrm{ba}$ using LC-MS measurements with an internal standard. Two independent reactions under standard conditions were carried out using substrates $117 \mathrm{o}$ and $117 \mathrm{~b}(0.50 \mathrm{mmol}$ each). After 10 minutes to reach a stable constant current of $8 \mathrm{~mA}$ aliquots of $0.3 \mathrm{~mL}$ were removed from the anodic chamber every five minutes. The mixture was diluted using MeCN (1.5 $\mathrm{mL})$ and filtered. After addition of a stock solution $(60 \mu \mathrm{L})$ of 1,3,5-trimethoxybenzene (84.1 $\mathrm{mg}, 0.5 \mathrm{mmol})$ in MeCN (10 mL) each sample was analyzed by RP-LCMS using $\mathrm{H}_{2} \mathrm{O} / \mathrm{MeCN} 1: 1$ as the eluent.

\begin{tabular}{|l|l|l|l|l|l|l|}
\hline Time [min] & 5 & 10 & 15 & 20 & 25 & 30 \\
\hline 150oa [\%] & 0.4 & 2.3 & 4.6 & 7.3 & 10.4 & 14.0 \\
\hline 150ba [\%] & - & 0.4 & 1.6 & 3.3 & 4.7 & 6.7 \\
\hline
\end{tabular}




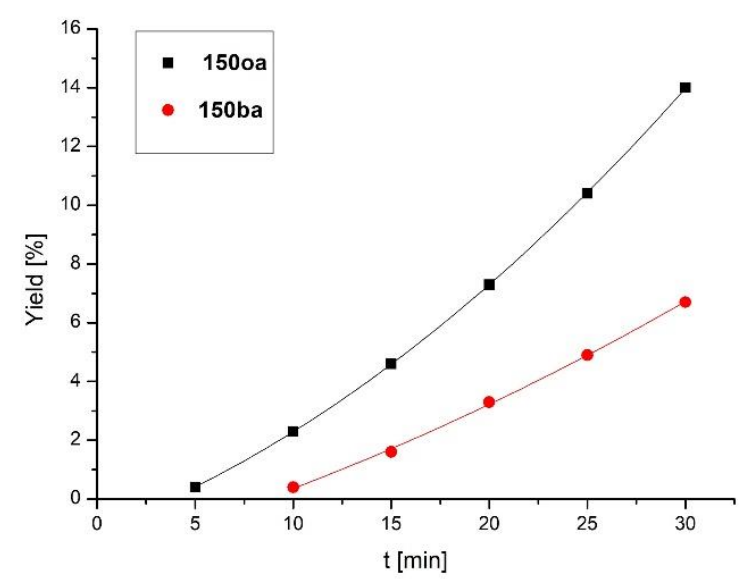

Figure 5.13. Realtive initial rates of 150 oa and $150 \mathrm{ba}$.
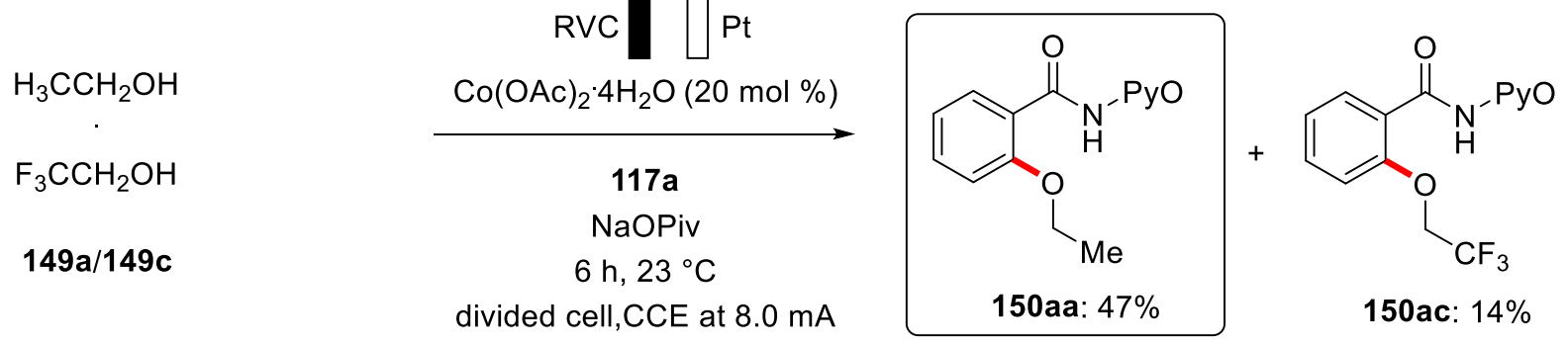

$150 \mathrm{aa} / 150 \mathrm{ac}=3.4 / 1$

Scheme 5.15. Competition experiment between alcohols 149a and 149c.

In a divided cell with P4 sintered glass membrane, NaOPiv (124 mg, $1.00 \mathrm{mmol}$, 2.00 equiv) was added in one cell, fitted with a Pt-plate electrode and dissolved in a mixture of TFE/ethanol $(1: 1,7.0 \mathrm{~mL})$. In the other half cell $\mathrm{Co}(\mathrm{OAc})_{2} \cdot 4 \mathrm{H}_{2} \mathrm{O}(25.6 \mathrm{mg}$, $0.10 \mathrm{mmol}, 20 \mathrm{~mol} \%$ ), NaOPiv (122 mg, $1.00 \mathrm{mmol}, 12.00$ equiv), benzamide 117a (107 mg, $0.50 \mathrm{mmol}, 1.00$ equiv) were fitted with a RVC electrode and dissolved in a mixture of TFE 149c/ethanol (149a) $(1: 1,7.0 \mathrm{~mL})$. Electrolysis was started at ambient temperature and a constant current of $8 \mathrm{~mA}$ maintained for $6 \mathrm{~h}$. Evaporation of the solvent and subsequent column chromatography using $\mathrm{CH}_{2} \mathrm{Cl}_{2} /$ acetone 3:1 yielded 150aa (60.4 mg, $236 \mu \mathrm{mol}, 47 \%$ ) and 150ac (21.9 mg, $71.2 \mu \mathrm{mol}, 14 \%)$. 


\section{KIE studies}

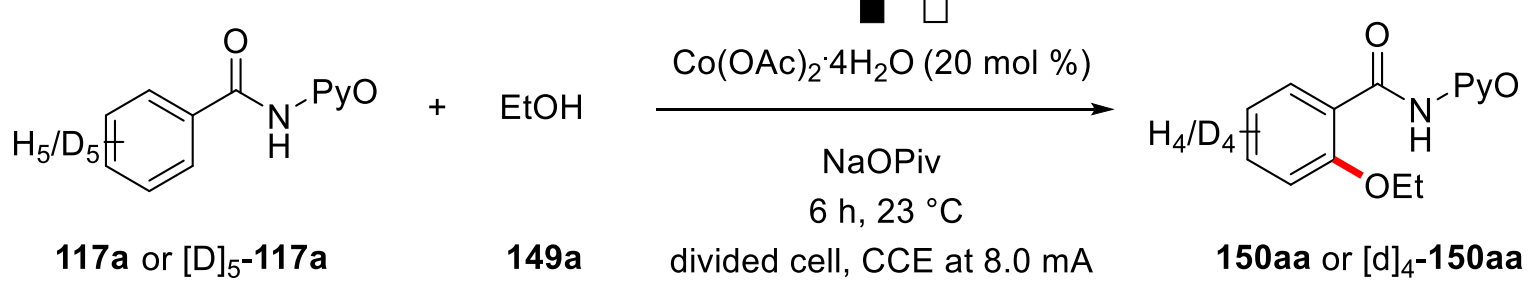

Scheme 5.16. KIE study of the cobalt-catalyzed C-H oxygenation.

Two independent reactions under standard conditions were carried out using substrates $117 \mathrm{a}$ and $\left[\mathrm{D}_{5}\right]-117 \mathrm{a}(0.50 \mathrm{mmol}$ each). After 10 minutes to reach a stable constant current of $8 \mathrm{~mA}$ aliquots of $0.3 \mathrm{~mL}$ were removed from the anodic chamber every five minutes. The mixture was diluted using $\operatorname{MeCN}(1.5 \mathrm{~mL})$ and filtered. After addition of a stock solution ( $60 \mu \mathrm{L}$ ) of 1,3,5-trimethoxybenzene ( $84.1 \mathrm{mg}, 0.5 \mathrm{mmol}$ ) in MeCN (10 mL) each sample was analyzed by RP-LCMS using $\mathrm{H}_{2} \mathrm{O} / \mathrm{MeCN} 1: 1$ as the eluent.

\begin{tabular}{|l|l|l|l|l|l|l|}
\hline Time [min] & 5 & 10 & 15 & 20 & 25 & 30 \\
\hline 150aa [\%] & 1.2 & 3.8 & 8.4 & 11.8 & 16.2 & 21.2 \\
\hline [D5]-150aa [\%] & - & 1.7 & 5.3 & 8.3 & 13.0 & 16.9 \\
\hline
\end{tabular}

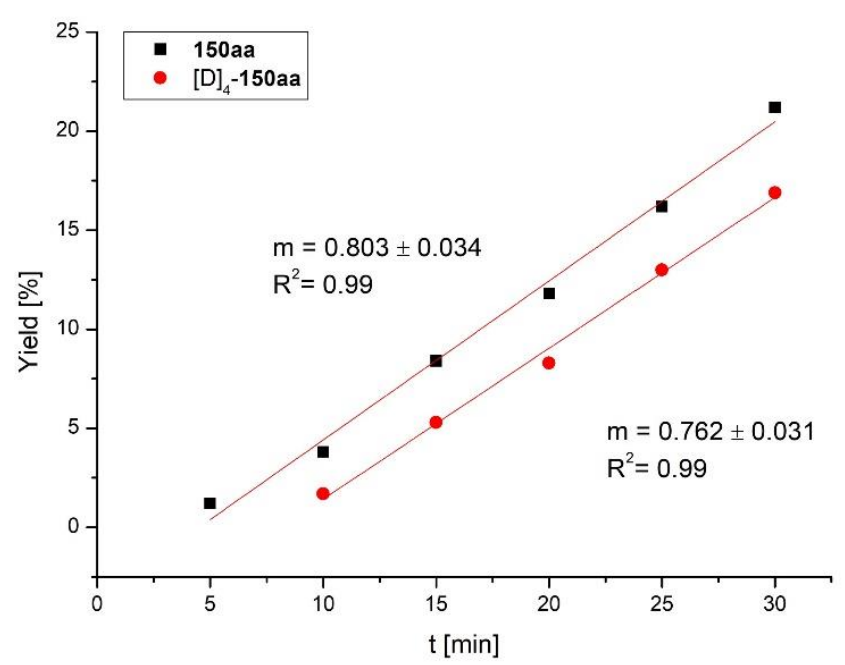

Figure 5.14. Initial rates of 150aa and [D]4-150aa. 


\section{Kinetic Profile (Electrochemical Oxidation)}

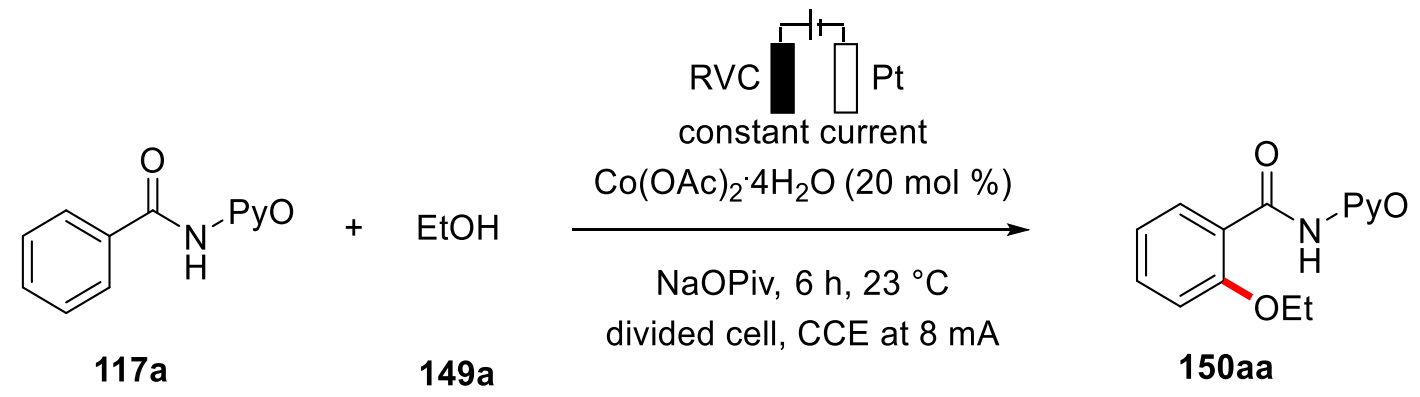

Scheme 5.17. C-H oxygenation under electrochemical conditions.

The general procedure $F$ was followed using $117 a$ and $149 a$. After 10 minutes to reach a stable constant current of $8 \mathrm{~mA}$ aliquots of $0.1 \mathrm{~mL}$ were removed from the anodic chamber every 10 minutes (first $3 \mathrm{~h}$ ) and every $30 \mathrm{~min}$ (last $3 \mathrm{~h}$ ). The mixture was diluted using MeCN (1.5 mL) and filtered. After addition of a stock solution $(60 \mu \mathrm{L})$ of 1,3,5-trimethoxybenzene $(84.1 \mathrm{mg}, 0.5 \mathrm{mmol})$ in $\mathrm{MeCN}$ (10 mL) each sample was analyzed by RP-LCMS using $\mathrm{H}_{2} \mathrm{O} / \mathrm{MeCN} 1: 1$ as the eluent.

\begin{tabular}{|l|l|l|l|l|l|l|l|l|l|l|l|}
\hline Time [min] & 10 & 20 & 30 & 40 & 50 & 60 & 70 & 80 & 90 & 100 & 110 \\
\hline 150aa [\%] & 0.3 & 3.0 & 6.2 & 11.2 & 14.8 & 18.3 & 22.3 & 26.5 & 30.4 & 34.6 & 37.2 \\
\hline Time [min] & 120 & 140 & 160 & 180 & 210 & 240 & 270 & 300 & 330 & 360 & \\
\hline 150aa [\%] & 40.6 & 46.6 & 51.5 & 55.9 & 58.8 & 61.1 & 64.2 & 66.1 & 68.0 & 70.1 & \\
\hline
\end{tabular}

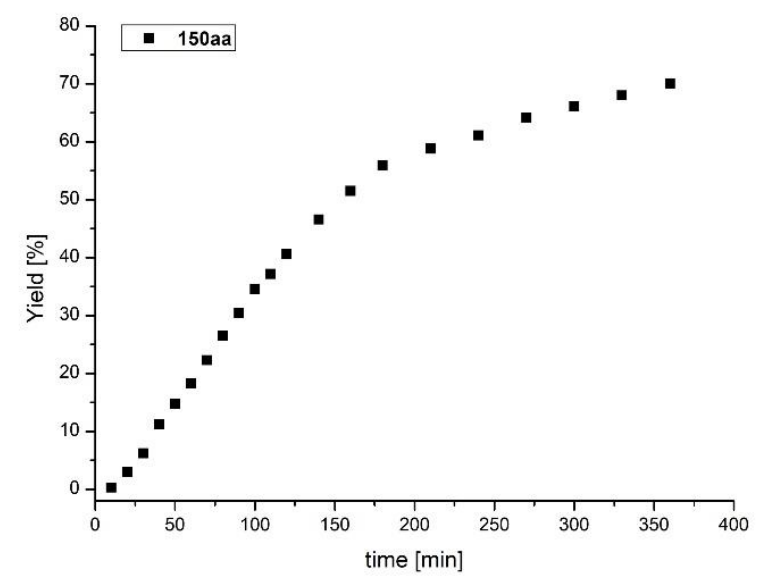

Figure 5.15. Lifetime of the catalyst under electrochemical oxidation. 


\section{Kinetic Profile (Chemical Oxidation)}

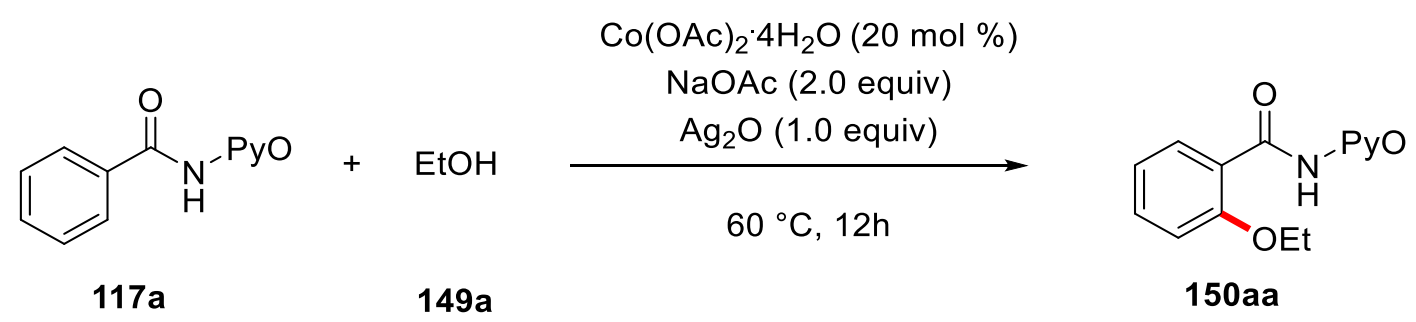

Scheme 5.18. C-H oxygenation under chemical conditions.

A reaction was carried out using substrate $117 \mathrm{a}$ (107 $\mathrm{mg}, 0.50 \mathrm{mmol}, 1.00$ equiv), $\mathrm{Co}(\mathrm{OAc}) 2 \cdot 4 \mathrm{H}_{2} \mathrm{O}$ (25.6 mg, $0.10 \mathrm{mmol}, 20 \mathrm{~mol} \%$ ), NaOAc (82.2 mg, $1.00 \mathrm{mmol}, 2.00$ equiv), $\mathrm{Ag}_{2} \mathrm{O}$ (232 mg, $1.00 \mathrm{mmol}, 1.00$ equiv) and ethanol (149a) (4.0 mL). Aliquots of $0.1 \mathrm{~mL}$ were removed from the reaction mixture every 10 minutes (first $160 \mathrm{~min}$ ) and every hour (last $9 \mathrm{~h}$ ). The mixture was diluted using $\mathrm{MeCN}$ (1.5 mL) and filtered. After addition of a stock solution ( $60 \mu \mathrm{L}$ ) of 1,3,5-trimethoxybenzene ( $84.1 \mathrm{mg}, 0.5 \mathrm{mmol}$ ) in MeCN (10 mL) each sample was analyzed by RP-LCMS using $\mathrm{H}_{2} \mathrm{O} / \mathrm{MeCN} 1: 1$ as the eluent.

\begin{tabular}{|l|l|l|l|l|l|l|l|l|l|l|l|}
\hline Time [min] & 10 & 20 & 30 & 40 & 50 & 60 & 70 & 80 & 90 & 100 & 110 \\
\hline 150aa [\%] & 0.3 & 3.1 & 4.8 & 6.1 & 9.2 & 12.3 & 15.5 & 18.5 & 20.2 & 24.2 & 27.5 \\
\hline Time [min] & 120 & 130 & 140 & 150 & 160 & 180 & 240 & 300 & 360 & 420 & 480 \\
\hline 150aa [\%] & 33.6 & 37.4 & 43.7 & 51.2 & 59.8 & 64.2 & 67.4 & 68.8 & 69.9 & 71.4 & 72.4 \\
\hline Time [min] & 540 & 600 & 660 & 720 & & & & & & & \\
\hline 150aa [\%] & 73.0 & 74.1 & 75.2 & 76.0 & & & & & & & \\
\hline
\end{tabular}




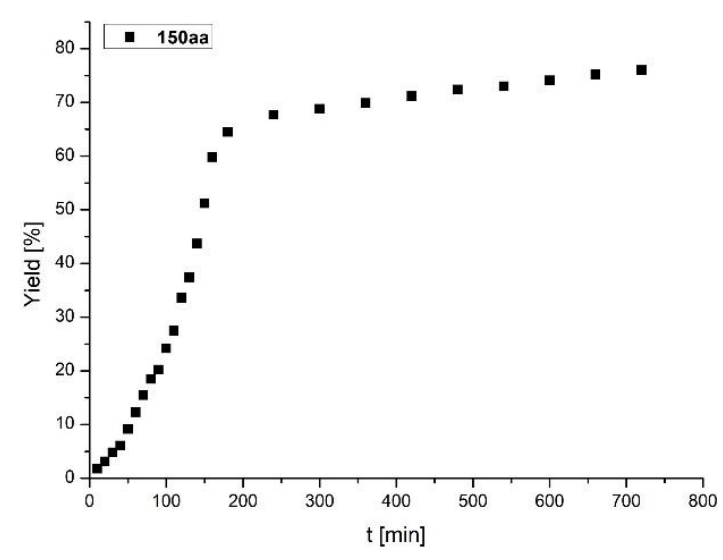

Figure 5.16. Lifetime of the catalyst under electrochemical oxidation.

\section{Cyclic Voltammetry}

The cyclic voltammetry was carried out with a Metrohm Autolab PGSTAT204 workstation and following analysis was performed with Nova 2.0 software. A glassycarbon electrode (3 $\mathrm{mm}$-diameter, disc-electrode) was used as the working electrode, a Pt wire as auxiliary electrode and a SCE electrode was used as the reference. The measurements were carried out at a scan rate of $100 \mathrm{mVs}^{-1}$

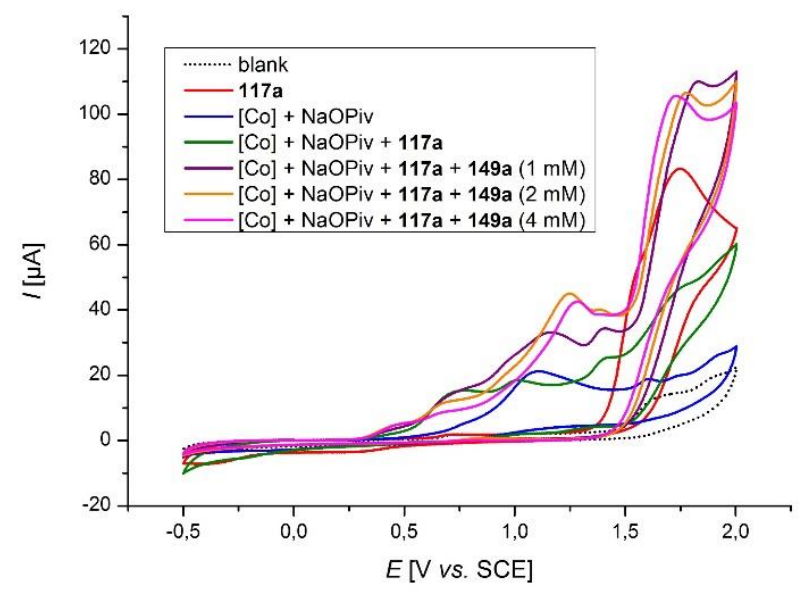

Figure 5.17. Cyclic voltammograms at $100 \mathrm{mVs}^{-1}: n-\mathrm{Bu}_{4} \mathrm{NPF}_{6}(1 \mathrm{M}$ in $\mathrm{MeCN})$, concentration of substrates $1 \mathrm{~mm}$ (NaOPiv $4 \mathrm{mM}$ ). (black) blank; (red) substrate 117a; (blue) $\mathrm{Co}(\mathrm{OAc})_{2} \cdot 4 \mathrm{H}_{2} \mathrm{O}$ and NaOPiv; (green) $\mathrm{Co}(\mathrm{OAc})_{2} \cdot 4 \mathrm{H}_{2} \mathrm{O}$, NaOPiv and 117a; (purple) $\mathrm{Co}(\mathrm{OAc})_{2} \cdot 4 \mathrm{H}_{2} \mathrm{O}, \mathrm{NaOPiv}, 117 \mathrm{a}$ and EtOH (1 mM); (orange) $\mathrm{Co}(\mathrm{OAc})_{2} \cdot 4 \mathrm{H}_{2} \mathrm{O}, \mathrm{NaOPiv}$ and 117a and $\mathrm{EtOH}(2 \mathrm{~mm})$; (magenta) $\mathrm{Co}(\mathrm{OAc})_{2} \cdot 4 \mathrm{H}_{2} \mathrm{O}$, $\mathrm{NaOPiv}$ and $1 \mathrm{a}$ and $\mathrm{EtOH}(4 \mathrm{~mm})$. 


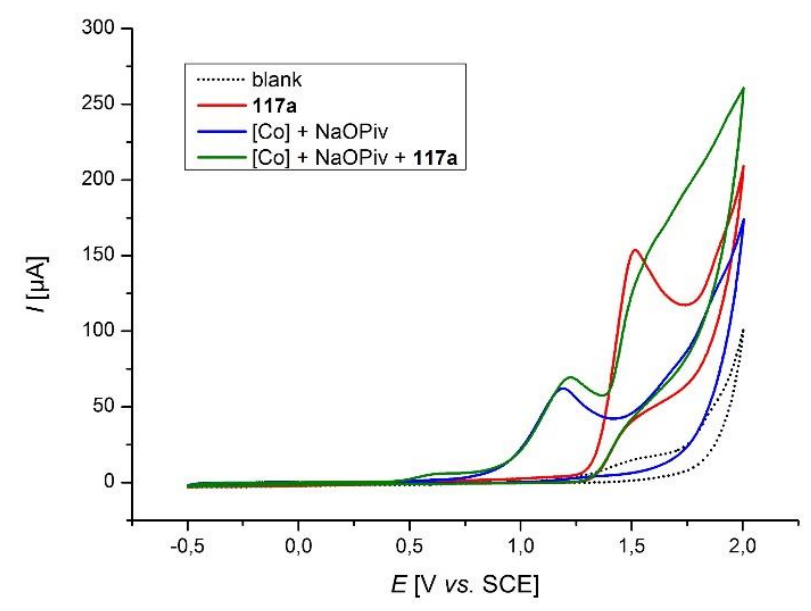

Figure 5.18. Cyclic voltammograms at $100 \mathrm{mVs}^{-1}: n-\mathrm{Bu}_{4} \mathrm{NPF}_{6}(1 \mathrm{M}$ in $\mathrm{MeOH})$, concentration of substrates $1 \mathrm{~mm}$ (NaOPiv $4 \mathrm{~mm}$ ). (black) blank; (red) substrate 117a; (blue) $\mathrm{Co}(\mathrm{OAc})_{2} \cdot 4 \mathrm{H}_{2} \mathrm{O}$ and NaOPiv; (green) $\mathrm{Co}(\mathrm{OAc})_{2} \cdot 4 \mathrm{H}_{2} \mathrm{O}, \mathrm{NaOPiv}$ and 117a.

\subsection{Electrochemical Cobalt-catalyzed C-H Amination}

\subsubsection{Analytical Data and Experimental Procedures}<smiles>O=C(Nc1cccc[n+]1[O-])c1ccccc1N1CCOCC1</smiles>

\section{2-(2-Morpholinobenzamido)pyridine-1-oxide (148aa)}

The general procedure $\mathbf{H}$ was followed using benzamide 117a $(107 \mathrm{mg}, 0.50 \mathrm{mmol}$, 1.00 equiv) and morpholine (146a) (87.0 mg, $1.00 \mathrm{mmol}, 2.00$ equiv). Purification by column chromatography on silica gel $\left(\mathrm{CH}_{2} \mathrm{Cl}_{2} /\right.$ acetone $\left.3: 1 \rightarrow 1: 1\right)$ yielded 148aa (115 mg, $384 \mu \mathrm{mol}, 77 \%)$ as a white solid. M. p.: $153-155^{\circ} \mathrm{C} .{ }^{1} \mathrm{H}-\mathrm{NMR}(500 \mathrm{MHz}$, $\left.\mathrm{CDCl}_{3}\right): \delta=13.62(\mathrm{~s}, 1 \mathrm{H}), 8.75(\mathrm{dd}, J=8.4,1.8 \mathrm{~Hz}, 1 \mathrm{H}), 8.26(\mathrm{dd}, J=6.4,2.0 \mathrm{~Hz}, 1 \mathrm{H})$, 8.19 (dd, $J=7.7,1.8 \mathrm{~Hz}, 1 \mathrm{H}$ ), 7.54 (ddd, $J=8.4,2.0,1.8 \mathrm{~Hz} 1 \mathrm{H}), 7.35-7.23(\mathrm{~m}, 3 \mathrm{H})$, 6.99 (ddd, $J=6.4,2.0,1.8 \mathrm{~Hz}, 1 \mathrm{H}), 4.08-4.05(\mathrm{~m}, 4 \mathrm{H}), 3.05-3.02$ (m, 4H). ${ }^{13} \mathrm{C}-\mathrm{NMR}$ (125 MHz, $\left.\mathrm{CDCl}_{3}\right): \delta=166.3\left(\mathrm{C}_{\mathrm{q}}\right), 151.9\left(\mathrm{C}_{\mathrm{q}}\right), 145.3\left(\mathrm{C}_{\mathrm{q}}\right), 137.5(\mathrm{CH}), 133.5(\mathrm{CH})$, $132.2(\mathrm{CH}), 127.5(\mathrm{CH}), 127.2\left(\mathrm{C}_{\mathrm{q}}\right), 125.1(\mathrm{CH}), 120.8(\mathrm{CH}), 118.6(\mathrm{CH}), 116.0(\mathrm{CH})$, $66.1\left(\mathrm{CH}_{2}\right), 54.1\left(\mathrm{CH}_{2}\right)$. IR (ATR): 2833, 1667, 1502, 1281, 1109, $764 \mathrm{~cm}^{-1}$. MS (ESI) 
$\mathrm{m} / \mathrm{z}$ (relative intensity): $322(88)[\mathrm{M}+\mathrm{Na}]^{+}, 300\left(100[\mathrm{M}+\mathrm{H}]^{+}, 242(62), 205(14), 190\right.$ (15), 169 (5). HR-MS (ESI) $m / z$ calcd for $\mathrm{C}_{16} \mathrm{H}_{17} \mathrm{~N}_{3} \mathrm{O}_{3} \quad[\mathrm{M}+\mathrm{H}]^{+}: 300.1343$, found: 300.1348 . The analytical data correspond with those reported in the literature.[110b]<smiles></smiles>

\section{2-(4-Methyl-2-morpholinobenzamido)pyridine-1-oxide (1480a)}

The general procedure $\mathbf{H}$ was followed using benzamide $1170(114 \mathrm{mg}, 0.50 \mathrm{mmol}$, 1.00 equiv) and morpholine (146a) $(87.2 \mathrm{mg}, 1.00 \mathrm{mmol}, 2.00$ equiv). Purification by column chromatography on silica gel $\left(\mathrm{CH}_{2} \mathrm{Cl}_{2} /\right.$ acetone $\left.3: 1 \rightarrow 1: 1\right)$ yielded 1480a (129 mg, $416 \mu \mathrm{mol}, 83 \%)$ as a white solid. M. p.: $197-199{ }^{\circ} \mathrm{C}$. ${ }^{1} \mathrm{H}-\mathrm{NMR}(500 \mathrm{MHz}$, $\left.\mathrm{CDCl}_{3}\right): \delta=13.54(\mathrm{~s}, 1 \mathrm{H}), 8.72(\mathrm{dd}, J=8.0,2.1 \mathrm{~Hz}, 1 \mathrm{H}), 8.24(\mathrm{dd}, J=7.4,1.9 \mathrm{~Hz}, 1 \mathrm{H})$, $8.08(\mathrm{~d}, J=7.7 \mathrm{~Hz}, 1 \mathrm{H}$ ), 7.34 (ddd, $J=8.0,2.1,1.9 \mathrm{~Hz}, 1 \mathrm{H}), 7.11(\mathrm{~d}, J=1.0 \mathrm{~Hz}, 1 \mathrm{H}$ ), 7.07 (dd, $J=7.7,1.0 \mathrm{~Hz}, 1 \mathrm{H}$ ), 6.95 (ddd, $J=7.4,2.1,1.9 \mathrm{~Hz}, 1 \mathrm{H}$ ), 4.10-4.05 (m, 4H), 3.05-3.00 (m, 4H), $2.38(\mathrm{~s}, 3 \mathrm{H}) .{ }^{13} \mathrm{C}-\mathrm{NMR}\left(100 \mathrm{MHz}, \mathrm{CDCl}_{3}\right): \delta=165.3\left(\mathrm{C}_{\mathrm{q}}\right), 152.0$ $\left(\mathrm{C}_{\mathrm{q}}\right), 145.4\left(\mathrm{C}_{\mathrm{q}}\right), 144.4\left(\mathrm{C}_{\mathrm{q}}\right), 137.5(\mathrm{CH}), 132.2(\mathrm{CH}), 127.4(\mathrm{CH}), 126.0(\mathrm{CH}), 124.5$ $\left(\mathrm{C}_{\mathrm{q}}\right), 121.6(\mathrm{CH}), 118.5(\mathrm{CH}), 116.1(\mathrm{CH}), 66.2\left(\mathrm{CH}_{2}\right), 54.2\left(\mathrm{CH}_{2}\right), 21.7\left(\mathrm{CH}_{3}\right)$. IR (ATR): 2832, 16665, 1558, 1502, 1311, 1210, 1115, 847, $755 \mathrm{~cm}^{-1}$. MS (ESI) $\mathrm{m} / z$ (relative intensity): 334 (87) [M+Na] , 314 (100) [M+H] $]^{+}, 296$ (5), 242 (44), 204 (76), 174 (11). HR-MS (El) $\mathrm{m} / \mathrm{z}$ calcd for $\mathrm{C}_{17} \mathrm{H}_{19} \mathrm{~N}_{3} \mathrm{O}_{3}[\mathrm{M}+\mathrm{H}]^{+}: 314.1499$, found: 314.1489 . The analytical data correspond with those reported in the literature.[110b]<smiles>O=C(Nc1ccccc1N1CCOCC1)c1ccc(-c2ccccc2)cc1[O-]</smiles>

\section{2-[3-Morpholino-(1,1'-biphenyl)-4-carboxamido]pyridine-1-oxide (148na)}

The general procedure $\mathbf{H}$ was followed using benzamide $117 \mathrm{n}$ (146 mg, $0.50 \mathrm{mmol}$, 1.00 equiv) and morpholine (146a) (86.4 mg, $1.00 \mathrm{mmol}, 2.00$ equiv). Purification by column chromatography on silica gel $\left(\mathrm{CH}_{2} \mathrm{Cl}_{2} /\right.$ acetone $\left.5: 1 \rightarrow 2: 1\right)$ yielded 148na (117.5 mg, $313 \mu \mathrm{mol}, 62 \%)$ as a white solid. M. p.: $183-185^{\circ} \mathrm{C} .{ }^{1} \mathrm{H}-\mathrm{NMR}(400 \mathrm{MHz}$, $\left.\mathrm{CDCl}_{3}\right): \delta=13.72(\mathrm{~s}, 1 \mathrm{H}), 8.70(\mathrm{dd}, J=8.2,2.0 \mathrm{~Hz}, 1 \mathrm{H}), 8.33-8.27(\mathrm{~m}, 2 \mathrm{H}), 7.68-7.62$ 
(m, 2H), 7.57-7.28 (m, 6H), 7.03 (ddd, $J=7.4,2.3,2.0 \mathrm{~Hz}, 1 \mathrm{H}), 4.20-4.12(\mathrm{~m}, 4 \mathrm{H})$, 3.17-3.12 (m, 4H). ${ }^{13} \mathrm{C}-\mathrm{NMR}\left(101 \mathrm{MHz}, \mathrm{CDCl}_{3}\right): \delta=166.1\left(\mathrm{C}_{\mathrm{q}}\right), 152.1\left(\mathrm{C}_{\mathrm{q}}\right), 146.5\left(\mathrm{C}_{\mathrm{q}}\right)$, $145.3\left(\mathrm{C}_{\mathrm{q}}\right), 139.7\left(\mathrm{C}_{\mathrm{q}}\right), 137.5(\mathrm{CH}), 132.8(\mathrm{CH}), 129.0(\mathrm{CH}), 128.4(\mathrm{CH}), 127.9(\mathrm{CH})$, $127.6(\mathrm{CH}), 125.1\left(\mathrm{C}_{\mathrm{q}}\right), 123.8(\mathrm{CH}), 119.6(\mathrm{CH}), 118.7(\mathrm{CH}), 116.1(\mathrm{CH}), 66.2\left(\mathrm{CH}_{2}\right)$, $54.1\left(\mathrm{CH}_{2}\right)$. IR (ATR): 2833, 1669, 1560, 1505, 1260, 1111, 759, $700 \mathrm{~cm}^{-1}$. MS (EI) $\mathrm{m} / \mathrm{z}$ (relative intensity): $398(100)\left[\mathrm{M}+\mathrm{Na}^{+}, 381(70), 376(45)[\mathrm{M}+\mathrm{H}]^{+}, 336(10) . \mathrm{HR}-\right.$ MS (EI) $\mathrm{m} / z$ calcd for $\mathrm{C}_{22} \mathrm{H}_{21} \mathrm{~N}_{3} \mathrm{O}_{3}[\mathrm{M}+\mathrm{H}]^{+}: 367.1656$, found: 367.1657 . The analytical data correspond with those reported in the literature. ${ }^{[110 b]}$

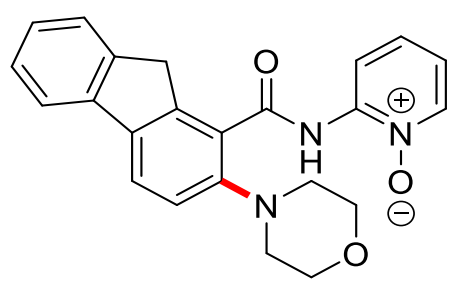

\section{2-(2-Morpholino-9H-fluorene-1-carboxamido)pyridine-1-oxide (148pa)}

The general procedure $\mathbf{H}$ was followed using benzamide $117 \mathrm{p}(151 \mathrm{mg}, 0.50 \mathrm{mmol}$, 1.00 equiv) and morpholine (146a) $(86.0 \mathrm{mg}, 1.00 \mathrm{mmol}, 2.00$ equiv). Purification by column chromatography on silica gel $\left(\mathrm{CH}_{2} \mathrm{Cl}_{2} /\right.$ acetone $\left.3: 1 \rightarrow 1: 1\right)$ yielded 148pa (97.2 mg, $254 \mu \mathrm{mol}, 51 \%)$ as a white solid. M. p.: $163-165^{\circ} \mathrm{C}$. ${ }^{1} \mathrm{H}-\mathrm{NMR}(400 \mathrm{MHz}$, $\left.\mathrm{CDCl}_{3}\right): \delta=13.13(\mathrm{~s}, 1 \mathrm{H}), 8.63(\mathrm{dd}, J=8.1,2.3 \mathrm{~Hz}, 1 \mathrm{H}), 8.26(\mathrm{dd}, J=8.4,2.0 \mathrm{~Hz}, 1 \mathrm{H})$, $7.79(\mathrm{~d}, J=8.9 \mathrm{~Hz}, 1 \mathrm{H}$ ), 7.63 (dd, $J=8.9,2.3 \mathrm{~Hz}, 1 \mathrm{H}$ ), 7.47 (ddd, $J=8.1,2.3,2.0 \mathrm{~Hz}$, $1 \mathrm{H}), 7.25-7.15(\mathrm{~m}, 4 \mathrm{H}), 6.88$ (ddd, $J=8.4,2.3,2.0 \mathrm{~Hz}, 1 \mathrm{H}), 4.19(\mathrm{~s}, 2 \mathrm{H}), 3.98-3.90$ $(\mathrm{m}, 4 \mathrm{H}), 2.97-2.88(\mathrm{~m}, 4 \mathrm{H}) .{ }^{13} \mathrm{C}-\mathrm{NMR}\left(100 \mathrm{MHz}, \mathrm{CDCl}_{3}\right): \delta=166.0\left(\mathrm{C}_{\mathrm{q}}\right), 150.5\left(\mathrm{C}_{\mathrm{q}}\right)$, $147.7\left(\mathrm{C}_{\mathrm{q}}\right), 145.3\left(\mathrm{C}_{\mathrm{q}}\right), 143.5\left(\mathrm{C}_{\mathrm{q}}\right), 140.2\left(\mathrm{C}_{\mathrm{q}}\right), 139.7\left(\mathrm{C}_{\mathrm{q}}\right), 137.5(\mathrm{CH}), 127.6(\mathrm{CH})$, $127.0(\mathrm{CH}), 126.7(\mathrm{CH}), 124.8(\mathrm{CH}), 124.4(\mathrm{C}), 123.6(\mathrm{CH}), 119.6(\mathrm{CH}), 119.1(\mathrm{CH})$, $118.5(\mathrm{CH}), 115.6(\mathrm{CH}), 66.2\left(\mathrm{CH}_{2}\right), 54.4\left(\mathrm{CH}_{2}\right), 39.4\left(\mathrm{CH}_{2}\right)$. IR (ATR): 2831, 1665, 1559, 1503, 1264, 1107, 846, 753, $701 \mathrm{~cm}^{-1}$. MS (ESI) $\mathrm{m} / z$ (relative intensity): 410 (100) [M+Na] $]^{+}, 388(87)[\mathrm{M}+\mathrm{H}]^{+}, 339$ (18), 276 (9), 244 (68), 222 (23). HR-MS (ESI) $\mathrm{m} / \mathrm{z}$ calcd for $\mathrm{C}_{23} \mathrm{H}_{21} \mathrm{~N}_{3} \mathrm{O}_{3}[\mathrm{M}+\mathrm{H}]^{+}: 3888.1656$, found: 388.1661 . 
<smiles>COc1ccc(C(=O)Nc2cccc[n+]2[O-])c(N2CCOCC2)c1</smiles>

\section{2-[4-(Methylthio)-2-morpholinobenzamido]pyridine-1-oxide (148qa)}

The general procedure $\mathbf{H}$ was followed using benzamide $117 q$ (176 mg, $0.50 \mathrm{mmol}$, 1.00 equiv) and morpholine (146a) (87.2 mg, 1.00 mmol, 2.00 equiv). Purification by column chromatography on silica gel $\left(\mathrm{CH}_{2} \mathrm{Cl}_{2} /\right.$ acetone $\left.3: 1 \rightarrow 1: 1\right)$ yielded 148qa (124 mg, $358 \mu \mathrm{mol}, 72 \%)$ as a white solid. M. p.: 229-237 ${ }^{\circ} \mathrm{C} .{ }^{1} \mathrm{H}-\mathrm{NMR}(400 \mathrm{MHz}$, $\left.\mathrm{CDCl}_{3}\right): \delta=13.51(\mathrm{~s}, 1 \mathrm{H}), 8.74(\mathrm{dd}, J=8.2,2.2 \mathrm{~Hz}, 1 \mathrm{H}), 8.31(\mathrm{dd}, J=8.0,1.5 \mathrm{~Hz}, 1 \mathrm{H})$, 8.15 (dd, $J=8.5 \mathrm{~Hz}, 1 \mathrm{H}$ ), 7.36 (ddd, $J=8.2,2.2,1.5 \mathrm{~Hz}, 1 \mathrm{H}$ ), 7.17 (d, $J=0.7 \mathrm{~Hz}, 1 \mathrm{H}$ ), 7.11 (dd, $J=8.5,0.7 \mathrm{~Hz}, 1 \mathrm{H}$ ), 7.02 (ddd, $J=8.0,2.2,1.5 \mathrm{~Hz}, 1 \mathrm{H}) 4.15-4.08(\mathrm{~m}, 4 \mathrm{H})$, 3.02-2.97 (m, 4H), $2.57(\mathrm{~s}, 3 \mathrm{H}) .{ }^{13} \mathrm{C}-\mathrm{NMR}\left(100 \mathrm{MHz}, \mathrm{CDCl}_{3}\right): \delta=164.9\left(\mathrm{C}_{\mathrm{q}}\right), 152.5$ $\left(\mathrm{C}_{\mathrm{q}}\right), 146.2\left(\mathrm{C}_{\mathrm{q}}\right), 145.3\left(\mathrm{C}_{\mathrm{q}}\right), 137.5(\mathrm{CH}), 132.5(\mathrm{CH}), 127.6(\mathrm{CH}), 123.4\left(\mathrm{C}_{\mathrm{q}}\right), 121.4$ $(\mathrm{CH}), 118.6(\mathrm{CH}), 117.8(\mathrm{CH}), 116.0(\mathrm{CH}), 66.1\left(\mathrm{CH}_{2}\right), 54.1\left(\mathrm{CH}_{2}\right), 14.9\left(\mathrm{CH}_{3}\right) . \mathrm{IR}$ (ATR):2826, 1663, 1560, 1503, 1260, 1106, 890, $724 \mathrm{~cm}^{-1}$. MS (ESI) m/z (relative intensity): 368 (83) [M+Na] ${ }^{+}, 346(100)[\mathrm{M}+\mathrm{H}]^{+}, 324$ (28), 242 (73), 210 (55), 188 (44). HR-MS (ESI) $m / z$ calcd for $\mathrm{C}_{17} \mathrm{H}_{19} \mathrm{~N}_{3} \mathrm{O}_{3} \mathrm{~S}[\mathrm{M}]^{+}:$346.1220, found: 346.1211 .<smiles>CC(=O)c1ccc(C(=O)Nc2cccc[n+]2[O-])c(N2CCOCC2)c1</smiles>

\section{2-[4-(Methoxycarbonyl)-2-morpholinobenzamido]pyridine-1-oxide (148ra)}

The general procedure $\mathbf{H}$ was followed using benzamide 117r (135 mg, $0.50 \mathrm{mmol}$, 1.00 equiv) and morpholine (146a) (87.8 mg, 1.00 mmol, 2.00 equiv). Purification by column chromatography on silica gel $\left(\mathrm{CH}_{2} \mathrm{Cl}_{2} /\right.$ acetone $\left.3: 1 \rightarrow 1: 1\right)$ yielded 148ra (116.1 mg, $325 \mu \mathrm{mol}, 65 \%)$ as a white solid. M. p.: $173-175^{\circ} \mathrm{C} .{ }^{1} \mathrm{H}-\mathrm{NMR}(400 \mathrm{MHz}$, $\left.\mathrm{CDCl}_{3}\right): \delta=13.50(\mathrm{~s}, 1 \mathrm{H}), 8.71(\mathrm{dd}, J=8.1,1.7 \mathrm{~Hz}, 1 \mathrm{H}), 8.32(\mathrm{dd}, J=8.0,1.6 \mathrm{~Hz}, 1 \mathrm{H})$, $8.15(\mathrm{~d}, J=8.1 \mathrm{~Hz}, 1 \mathrm{H}), 8.16(\mathrm{dd}, J=8.1,0.8 \mathrm{~Hz}, 1 \mathrm{H}), 8.0(\mathrm{~d}, J=0.8 \mathrm{~Hz}, 1 \mathrm{H}), 7.99$ (dd, $J=8.1,0.8 \mathrm{~Hz}, 1 \mathrm{H}$ ), 7.33 (ddd, $J=8.0,2.2,1.5 \mathrm{~Hz}, 1 \mathrm{H}$ ), 7.01 (ddd, $J=8.0,2.2$, $1.5 \mathrm{~Hz}, 1 \mathrm{H}), 4.06-4.04(\mathrm{~m}, 4 \mathrm{H}), 3.91(\mathrm{~s}, 3 \mathrm{H}), 3.12-3.08(\mathrm{~m}, 4 \mathrm{H}) .{ }^{13} \mathrm{C}-\mathrm{NMR}(101 \mathrm{MHz}$, $\left.\mathrm{CDCl}_{3}\right): \delta=166.0\left(\mathrm{C}_{\mathrm{q}}\right), 164.5\left(\mathrm{C}_{\mathrm{q}}\right), 151.9\left(\mathrm{C}_{\mathrm{q}}\right), 145.0\left(\mathrm{C}_{\mathrm{q}}\right), 137.5(\mathrm{CH}), 134.5(\mathrm{CH})$, $132.4(\mathrm{CH}), 131.0(\mathrm{CH}), 130.8\left(\mathrm{C}_{\mathrm{q}}\right), 127.5\left(\mathrm{C}_{\mathrm{q}}\right), 125.7(\mathrm{CH}), 119.0(\mathrm{CH}), 116.1(\mathrm{CH})$, 
$66.0\left(\mathrm{CH}_{2}\right), 54.1\left(\mathrm{CH}_{2}\right), 52.6\left(\mathrm{CH}_{3}\right)$. IR (ATR): 2954, 2833, 1722, 1671, 1504, 1278, $1110,757 \mathrm{~cm}^{-1}$. MS (ESI) $\mathrm{m} / z$ (relative intensity): $380(100)[\mathrm{M}+\mathrm{Na}]^{+}, 358(49)[\mathrm{M}+\mathrm{H}]^{+}$, 305 (17), 248 (27), 214 (5). HR-MS (ESI) $\mathrm{m} / z$ calcd for $\mathrm{C}_{18} \mathrm{H}_{13} \mathrm{~N}_{3} \mathrm{O}_{5}[\mathrm{M}+\mathrm{H}]^{+}: 358.1397$, found: 358.1398 .<smiles></smiles><smiles></smiles>

\section{2-(5-lodo-2-morpholinobenzamido)pyridine-1-oxide (148ha)}

\section{2-(3-Iodo-2-morpholinobenzamido)pyridine-1-oxide (148ha')}

The general procedure $\mathbf{H}$ was followed using benzamide $117 \mathrm{~h}(176 \mathrm{mg}, 0.50 \mathrm{mmol}$, 1.00 equiv) and morpholine (146a) $(87.0 \mathrm{mg}, 1.00 \mathrm{mmol}, 2.00$ equiv). Purification by column chromatography on silica gel $\left(\mathrm{CH}_{2} \mathrm{Cl}_{2}\right.$ /acetone $\left.3: 1 \rightarrow 1: 1\right)$ yielded 148ha (124 mg, $293 \mu \mathrm{mol}, 59 \%$ ) as a white solid, the ratio of 148ha and 148ha' (81:19) was determined by ${ }^{1} \mathrm{H}-\mathrm{NMR}$, in the following are the analytical data for 148ha. M. p.: 200 $204^{\circ} \mathrm{C} .{ }^{1} \mathrm{H}-\mathrm{NMR}\left(400 \mathrm{MHz}, \mathrm{CDCl}_{3}\right): \delta=13.39(\mathrm{~s}, 1 \mathrm{H}), 8.72(\mathrm{dd}, J=7.6,2.0 \mathrm{~Hz}, 1 \mathrm{H})$, 8.51 (d, $J=0.9 \mathrm{~Hz}, 1 \mathrm{H}$ ), 8.31 (dd, $J=8.2,2.0 \mathrm{~Hz}, 1 \mathrm{H}$ ), 7.85 (dd, $J=8.8,0.9 \mathrm{~Hz}, 1 \mathrm{H}$ ), 7.38 (ddd, $J=7.6,2.0,2.0 \mathrm{~Hz}, 1 \mathrm{H}$ ), 7.10 (d, $J=8.8 \mathrm{~Hz}, 1 \mathrm{H}$ ), 7.05 (ddd, $J=8.2,2.0$, $2.0 \mathrm{~Hz}, 1 \mathrm{H}) 4.19-4.12(\mathrm{~m}, 4 \mathrm{H}), 3.06-3.03(\mathrm{~m}, 4 \mathrm{H}) .{ }^{13} \mathrm{C}-\mathrm{NMR}\left(100 \mathrm{MHz}, \mathrm{CDCl}_{3}\right): \delta=$ $163.7\left(\mathrm{C}_{\mathrm{q}}\right), 151.6\left(\mathrm{C}_{\mathrm{q}}\right), 145.3\left(\mathrm{C}_{\mathrm{q}}\right), 142.2(\mathrm{CH}), 140.9(\mathrm{CH}), 137.5(\mathrm{CH}), 127.7(\mathrm{CH})$, $125.1\left(\mathrm{C}_{\mathrm{q}}\right), 122.6(\mathrm{CH}), 118.6(\mathrm{CH}), 116.1(\mathrm{CH}), 88.9\left(\mathrm{C}_{\mathrm{q}}\right), 66.0\left(\mathrm{CH}_{2}\right), 54.0\left(\mathrm{CH}_{2}\right)$. IR (ATR): $2843,1669,1562,1504,1258,1110,925,759 \mathrm{~cm}^{-1}$. MS (ESI) $\mathrm{m} / z$ (relative intensity): $448(100)[\mathrm{M}+\mathrm{Na}]^{+}, 426(55)[\mathrm{M}+\mathrm{H}]^{+}, 397$ (24), 322 (55), 300 (9), 188 (22) 170 (5). HR-MS (ESI) $m / z$ calcd for $\mathrm{C}_{16} \mathrm{H}_{16} \mathrm{~N}_{3} \mathrm{O}_{3} \mathrm{l}[\mathrm{M}+\mathrm{H}]^{+}: 426.0309$, found: 426.0315. The analytical data correspond with those reported in the literature. ${ }^{[110 \mathrm{~b}]}$ 


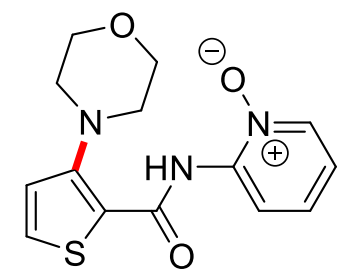

\section{2-(3-Morpholinothiophene-2-carboxamido)pyridine-1-oxide (148ka)}

The general procedure $\mathbf{H}$ was followed using benzamide $117 \mathrm{k}(110 \mathrm{mg}, 0.50 \mathrm{mmol}$, 1.00 equiv) and morpholine (146a) $(87.2 \mathrm{mg}, 1.00 \mathrm{mmol}, 2.00$ equiv). Purification by column chromatography on silica gel $\left(\mathrm{CH}_{2} \mathrm{Cl}_{2} /\right.$ acetone $\left.3: 1 \rightarrow 1: 1\right)$ yielded 148ka (104 mg, $336 \mu \mathrm{mol}, 67 \%$ ) as a white solid. M. p.: $212-214{ }^{\circ} \mathrm{C}$. ${ }^{1} \mathrm{H}-\mathrm{NMR}(400 \mathrm{MHz}$, $\left.\mathrm{CDCl}_{3}\right): \delta=12.99(\mathrm{~s}, 1 \mathrm{H}), 8.56(\mathrm{dd}, J=8.3,1.7 \mathrm{~Hz}, 1 \mathrm{H}), 8.12(\mathrm{dd}, J=7.9,2.1 \mathrm{~Hz}, 1 \mathrm{H}$ ), 7.45 (d, $J=5.5 \mathrm{~Hz}, 1 \mathrm{H}$ ), 7.21 (ddd, $J=8.3,2.1,1.7 \mathrm{~Hz}, 1 \mathrm{H}), 7.09$ (d, $J=5.5 \mathrm{~Hz}, 1 \mathrm{H}$ ), 6.88 (ddd, $J=7.9,2.1,1.7 \mathrm{~Hz}, 1 \mathrm{H}), 4.01-3.95(\mathrm{~m}, 4 \mathrm{H}), 2.92-2.88(\mathrm{~m}, 4 \mathrm{H}) .{ }^{13} \mathrm{C}-N M R$ $\left(100 \mathrm{MHz}, \mathrm{CDCl}_{3}\right): \delta=160.3\left(\mathrm{C}_{\mathrm{q}}\right), 153.5\left(\mathrm{C}_{\mathrm{q}}\right), 145.0\left(\mathrm{C}_{\mathrm{q}}\right), 137.5(\mathrm{CH}), 131.7(\mathrm{CH})$, $128.8\left(\mathrm{C}_{\mathrm{q}}\right), 127.6(\mathrm{CH}), 122.7(\mathrm{CH}), 118.6(\mathrm{CH}), 115.9(\mathrm{CH}), 66.7\left(\mathrm{CH}_{2}\right), 54.3\left(\mathrm{CH}_{2}\right)$. IR (ATR): 2837, 1661, 1606, 1517, 1433, 1102, 920, 769, $671 \mathrm{~cm}^{-1}$. MS (ESI) $\mathrm{m} / \mathrm{z}$ (relative intensity): $328(100)[\mathrm{M}+\mathrm{Na}]^{+}, 306(15)[\mathrm{M}+\mathrm{H}]^{+}, 237$ (17), 159 (24). HR-MS (ESI) $\mathrm{m} / z$ calcd for $\mathrm{C}_{14} \mathrm{H}_{15} \mathrm{~N}_{3} \mathrm{O}_{3} \mathrm{~S}[\mathrm{M}+\mathrm{H}]^{+}: 306.0907$, found: 306.0911 . The analytical data correspond with those reported in the literature.[110b]

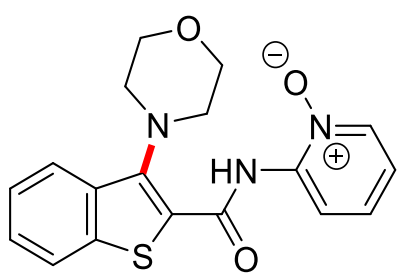

\section{2-(3-Morpholinobenzo[b]thiophene-2-carboxamido)pyridine-1-oxide (148sa)}

The general procedure $\mathbf{H}$ was followed using benzamide $117 \mathrm{~s}(135 \mathrm{mg}, 0.50 \mathrm{mmol}$, 1.00 equiv) and morpholine (146a) $(87.0 \mathrm{mg}, 1.00 \mathrm{mmol}, 2.00$ equiv). Purification by column chromatography on silica gel $\left(\mathrm{CH}_{2} \mathrm{Cl}_{2}\right.$ /acetone $\left.3: 1 \rightarrow 1: 1\right)$ yielded 148sa (108 mg, $310 \mu \mathrm{mol}, 62 \%$ ) as a white solid. M. p.: decomposed at $234{ }^{\circ} \mathrm{C} .{ }^{1} \mathrm{H}-\mathrm{NMR}$ $\left(400 \mathrm{MHz}, \mathrm{CDCl}_{3}\right): \delta=12.88(\mathrm{~s}, 1 \mathrm{H}$ ), 8.71 (dd, $J=8.3,1.7 \mathrm{~Hz}, 1 \mathrm{H}$ ), 8.28 (dd, $J=7.4$, $2.2 \mathrm{~Hz}, 1 \mathrm{H}$ ), 7.87 (dd, $J=8.2,2.1 \mathrm{~Hz}, 1 \mathrm{H}$ ), 7.61 (dd, $J=7.4,1.6 \mathrm{~Hz}, 1 \mathrm{H}$ ), 7.45 (ddd, $J=7.4,2.1,1.3 \mathrm{~Hz}, 1 \mathrm{H}$ ), 7.37-7.27 (m, 2H), 7.01 (ddd, $J=7.4,2.2,1.7 \mathrm{~Hz}, 1 \mathrm{H}$ ), 4.16$4.08(\mathrm{~m}, 4 \mathrm{H}), 3.42-3.34(\mathrm{~m}, 4 \mathrm{H}) .{ }^{13} \mathrm{C}-\mathrm{NMR}\left(100 \mathrm{MHz}, \mathrm{CDCl}_{3}\right): \delta=157.4\left(\mathrm{C}_{\mathrm{q}}\right), 154.5$ $\left(\mathrm{C}_{\mathrm{q}}\right), 144.9\left(\mathrm{C}_{\mathrm{q}}\right), 139.7\left(\mathrm{C}_{\mathrm{q}}\right), 137.6(\mathrm{CH}), 132.0\left(\mathrm{C}_{\mathrm{q}}\right), 127.9(\mathrm{CH}), 127.8(\mathrm{CH}), 124.1$ 
$\left(\mathrm{C}_{\mathrm{q}}\right), 123.5(\mathrm{CH}), 122.5(\mathrm{CH}), 118.8(\mathrm{CH}), 115.8(\mathrm{CH}), 113.4(\mathrm{CH}), 67.0\left(\mathrm{CH}_{2}\right), 52.7$ ( $\mathrm{CH}_{2}$ ). IR (ATR): 2854, 1622, 1501, 1433, 1114, 961, 846, $752 \mathrm{~cm}^{-1}$. MS (ESI) $\mathrm{m} / \mathrm{z}$ (relative intensity): $378(100)[\mathrm{M}+\mathrm{Na}]^{+}, 356(82)[\mathrm{M}+\mathrm{H}]^{+}, 300$ (13), 210 (34), 188 (15). HR-MS (ESI) $m / z$ calcd for $\mathrm{C}_{18} \mathrm{H}_{17} \mathrm{~N}_{3} \mathrm{O}_{3} \mathrm{~S}[\mathrm{M}+\mathrm{H}]^{+}: 356.1053$, found: 356.1063 .<smiles>O=C(Nc1cccc[n+]1[O-])c1oc2ccccc2c1N1CCOCC1</smiles>

\section{2-(3-Morpholinobenzofuran-2-carboxamido)pyridine-1-oxide (148ta)}

The general procedure $\mathbf{H}$ was followed using benzamide $117 \mathrm{t}(127 \mathrm{mg}, 0.50 \mathrm{mmol}$, 1.00 equiv) and morpholine (146a) $(86.2 \mathrm{mg}, 1.00 \mathrm{mmol}, 2.00$ equiv). Purification by column chromatography on silica gel $\left(\mathrm{CH}_{2} \mathrm{Cl}_{2} /\right.$ acetone $\left.3: 1 \rightarrow 1: 1\right)$ yielded 148ta (94 mg, $282 \mu \mathrm{mol}, 57 \%)$ as a white solid. M. p.: decomposed at $225{ }^{\circ} \mathrm{C}$. ${ }^{1} \mathrm{H}-\mathrm{NMR}(400 \mathrm{MHz}$, $\left.\mathrm{CDCl}_{3}\right): \delta=13.50(\mathrm{~s}, 1 \mathrm{H}), 8.72(\mathrm{dd}, J=8.3,1.7 \mathrm{~Hz}, 1 \mathrm{H}$ ), $8.30(\mathrm{dd}, J=7.4,2.2 \mathrm{~Hz}, 1 \mathrm{H}$ ), $8.22(\mathrm{dd}, J=8.0,2.1 \mathrm{~Hz}, 1 \mathrm{H}), 7.87(\mathrm{dd}, J=7.9,1.4 \mathrm{~Hz}, 1 \mathrm{H}), 7.47-7.36(\mathrm{~m}, 2 \mathrm{H}), 7.33$ (ddd, $J=8.3,2.2,1.7 \mathrm{~Hz}, 1 \mathrm{H}$ ), 7.00 (ddd, $J=7.4,2.2,1.7 \mathrm{~Hz}, 1 \mathrm{H}), 4.28-4.13(\mathrm{~m}, 4 \mathrm{H}$ ), 3.52-3.56 (m, 4H). ${ }^{13} \mathrm{C}-\mathrm{NMR}\left(100 \mathrm{MHz}, \mathrm{CDCl}_{3}\right): \delta=161.1\left(\mathrm{C}_{\mathrm{q}}\right), 145.6\left(\mathrm{C}_{\mathrm{q}}\right), 144.9\left(\mathrm{C}_{\mathrm{q}}\right)$, $139.8\left(\mathrm{C}_{\mathrm{q}}\right), 137.6(\mathrm{CH}), 135.6(\mathrm{CH}), 133.0\left(\mathrm{C}_{\mathrm{q}}\right), 127.6(\mathrm{CH}), 126.7(\mathrm{CH}), 124.9(\mathrm{CH})$, $124.3(\mathrm{CH}), 124.1\left(\mathrm{C}_{\mathrm{q}}\right), 119.1(\mathrm{CH}), 116.3(\mathrm{CH}), 66.8\left(\mathrm{CH}_{2}\right), 51.4\left(\mathrm{CH}_{2}\right)$. IR (ATR): $2847,1631,1501,1427,1261,1109,1025,752 \mathrm{~cm}^{-1}$. MS (ESI) $\mathrm{m} / z$ (relative intensity): $362(100)[\mathrm{M}+\mathrm{Na}]^{+}, 340(75)[\mathrm{M}+\mathrm{H}]^{+}, 301$ (8), 242 (14), 188 (15). HR-MS (ESI) m/z calcd for $\mathrm{C}_{18} \mathrm{H}_{17} \mathrm{~N}_{3} \mathrm{O}_{4}[\mathrm{M}+\mathrm{H}]^{+}$: 340.1297, found: 340.1294 .<smiles></smiles>

\section{2-(2-Thiomorpholinobenzamido)pyridine-1-oxide (148ab)}

The general procedure $\mathbf{H}$ was followed using benzamide $117 \mathrm{a}(107 \mathrm{mg}, 0.50 \mathrm{mmol}$, 1.00 equiv) and thiomorpholine (146b) (100 mg, $1.00 \mathrm{mmol}, 2.00$ equiv). Purification by column chromatography on silica gel $\left(\mathrm{CH}_{2} \mathrm{Cl}_{2} /\right.$ acetone $\left.3: 1 \rightarrow 1: 1\right)$ yielded 148ab (96.5 mg, $307 \mu \mathrm{mol}, 61 \%)$ as a white solid. M. p.: $123-124^{\circ} \mathrm{C} .{ }^{1} \mathrm{H}-\mathrm{NMR}(400 \mathrm{MHz}$, $\left.\mathrm{CDCl}_{3}\right): \delta=13.68(\mathrm{~s}, 1 \mathrm{H}), 8.69(\mathrm{dd}, J=8.3,2.0 \mathrm{~Hz}, 1 \mathrm{H}), 8.28(\mathrm{dd}, J=7.7,2.1 \mathrm{~Hz}, 1 \mathrm{H})$, 
$8.21(\mathrm{dd}, J=7.5,1.8 \mathrm{~Hz}, 1 \mathrm{H}), 7.50$ (ddd, $J=8.3,2.1,2.0 \mathrm{~Hz} 1 \mathrm{H}$ ), 7.35-7.23 (m, 3H), 6.97 (ddd, $J=7.7,2.1,2.0 \mathrm{~Hz}, 1 \mathrm{H}), 3.27-3.25(\mathrm{~m}, 4 \mathrm{H}), 3.06-3.01(\mathrm{~m}, 4 \mathrm{H}) .{ }^{13} \mathrm{C}-\mathrm{NMR}$ $\left(101 \mathrm{MHz}, \mathrm{CDCl}_{3}\right): \delta=166.1\left(\mathrm{C}_{\mathrm{q}}\right), 153.1\left(\mathrm{C}_{\mathrm{q}}\right), 145.3\left(\mathrm{C}_{\mathrm{q}}\right), 137.6(\mathrm{CH}), 133.5(\mathrm{CH})$, $132.1(\mathrm{CH}), 127.3(\mathrm{CH}), 127.2\left(\mathrm{C}_{\mathrm{q}}\right), 125.4(\mathrm{CH}), 121.8(\mathrm{CH}), 118.6(\mathrm{CH}), 116.1(\mathrm{CH})$, $56.3\left(\mathrm{CH}_{2}\right), 27.3\left(\mathrm{CH}_{2}\right)$. IR (ATR): 2832, 1665, 1695, 1500, 1382, 1209, 1115, 845, 746 $\mathrm{cm}^{-1}$. MS (El) m/z (relative intensity): 315 (8) [M] ${ }^{+}, 298$ (100), 242 (21). 204 (100), 176 (27), 158 (52), 146 (68), 132 (87), 95 (63). HR-MS (ESI) m/z calcd for $\mathrm{C}_{16} \mathrm{H}_{17} \mathrm{~N}_{3} \mathrm{O}_{2} \mathrm{~S}$ $[\mathrm{M}+\mathrm{H}]^{+}: 316.1114$, found: 316.1109 . The analytical data correspond with those reported in the literature..$^{[100]}$<smiles>O=C(Nc1ccccc1N1CCCCC1)c1ccccc1[O-]</smiles>

\section{2-[2-(Piperidin-1-yl)benzamido]pyridine-1-oxide (148ac)}

The general procedure $\mathbf{H}$ was followed using benzamide $117 \mathrm{a}(107 \mathrm{mg}, 0.50 \mathrm{mmol}$, 1.00 equiv) and piperidine (146c) (78.2 mg, $1.00 \mathrm{mmol}, 2.00$ equiv). Purification by column chromatography on silica gel $\left(\mathrm{CH}_{2} \mathrm{Cl}_{2} /\right.$ acetone $\left.10: 1 \rightarrow 8: 1\right)$ yielded 148ac (109 mg, $370 \mu \mathrm{mol}, 74 \%)$ as a white solid. M. p.: $140-142{ }^{\circ} \mathrm{C}$. ${ }^{1} \mathrm{H}-\mathrm{NMR}(500 \mathrm{MHz}$, $\left.\mathrm{CDCl}_{3}\right): \delta=13.63(\mathrm{~s}, 1 \mathrm{H}), 8.74(\mathrm{dd}, J=7.9,2.0 \mathrm{~Hz}, 1 \mathrm{H}), 8.25(\mathrm{dd}, J=7.8,1.9 \mathrm{~Hz}, 1 \mathrm{H})$, 8.15 (dd, $J=7.0,2.0 \mathrm{~Hz}, 1 \mathrm{H}$ ), 7.49 (ddd, $J=7.9,2.0,1.9 \mathrm{~Hz} 1 \mathrm{H}$ ), 7.32-7.29 (m, 2H), 7.20 (ddd, $J=7.0,2.5,1.9 \mathrm{~Hz} 1 \mathrm{H}$ ), 6.95 (ddd, $J=7.7,2.1,2.0 \mathrm{~Hz}, 1 \mathrm{H}$ ), 2.98-2.94 (m, $4 \mathrm{H}), 1.94-1.90(\mathrm{~m}, 4 \mathrm{H}), 1.66-1.63(\mathrm{~m}, 2 \mathrm{H}) .{ }^{13} \mathrm{C}-\mathrm{NMR}\left(125 \mathrm{MHz}, \mathrm{CDCl}_{3}\right): \delta=166.8$ $\left(\mathrm{C}_{\mathrm{q}}\right), 153.6\left(\mathrm{C}_{\mathrm{q}}\right), 145.4\left(\mathrm{C}_{\mathrm{q}}\right), 137.6(\mathrm{CH}), 133.2(\mathrm{CH}), 131.9(\mathrm{CH}), 127.3(\mathrm{CH}), 127.0$ $\left(\mathrm{C}_{\mathrm{q}}\right), 124.3(\mathrm{CH}), 120.7(\mathrm{CH}), 118.5(\mathrm{CH}), 116.2(\mathrm{CH}), 55.6\left(\mathrm{CH}_{2}\right), 25.3\left(\mathrm{CH}_{2}\right), 24.1$ ( $\mathrm{CH}_{2}$ ). IR (ATR): 2941, 2799, 1666, 1501, 1284, 1207, 1098, $753 \mathrm{~cm}^{-1}$. MS (ESI) $\mathrm{m} / \mathrm{z}$ (relative intensity): $320(70)[\mathrm{M}+\mathrm{Na}]^{+}, 298(100)[\mathrm{M}+\mathrm{H}]^{+}, 242$ (15), 204 (12), 188 (21). HR-MS (El) $m / z$ calcd for $\mathrm{C}_{17} \mathrm{H}_{19} \mathrm{~N}_{3} \mathrm{O}_{2}[\mathrm{M}+\mathrm{H}]^{+}: 298.1550$, found: 298.1555 . The analytical data correspond with those reported in the literature. ${ }^{[110 b]}$ 


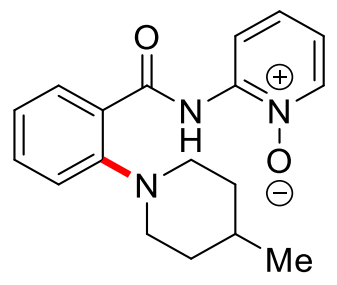

\section{2-[2-(4-Methylpiperidin-1-yl)benzamido]pyridine-1-oxide (148ad)}

The general procedure $\mathbf{H}$ was followed using benzamide $117 \mathrm{a}(107 \mathrm{mg}, 0.50 \mathrm{mmol}$, 1.00 equiv) and 4-methylpiperidine (146d) (93.1 $\mathrm{mg}, 1.00 \mathrm{mmol}, 2.00$ equiv). Purification by column chromatography on silica gel $\left(\mathrm{CH}_{2} \mathrm{Cl}_{2} /\right.$ acetone $\left.12: 1 \rightarrow 8: 1\right)$ yielded 148ad (111 mg, $355 \mu \mathrm{mol}, 71 \%$ ) as a white solid. M. p.: $179-181^{\circ} \mathrm{C} .{ }^{1} \mathrm{H}-\mathrm{NMR}$ $\left(400 \mathrm{MHz}_{\mathrm{CDCl}}\right): \delta=13.53(\mathrm{~s}, 1 \mathrm{H}), 8.71$ (dd, $\left.J=8.0,2.4 \mathrm{~Hz}, 1 \mathrm{H}\right), 8.30$ (dd, $J=7.2$, $1.9 \mathrm{~Hz}, 1 \mathrm{H}$ ), 8.14 (dd, J=7.1, $1.9 \mathrm{~Hz}, 1 \mathrm{H}$ ), 7.47 (ddd, J=8.0, 2.4, $1.9 \mathrm{~Hz} 1 \mathrm{H}$ ), 7.32$7.28(\mathrm{~m}, 2 \mathrm{H}), 7.17$ (ddd, $J=7.1,2.0,1.9 \mathrm{~Hz} 1 \mathrm{H}), 6.98$ (ddd, $J=7.2,2.4,2.0 \mathrm{~Hz}, 1 \mathrm{H}$ ), 3.21-3.17 (m, 2H), 2.83-2.75 (m, 2H), 1.91-1.81 (m, 2H), 1.71-1.64 (m, 2H), 1.55$1.43(\mathrm{~m}, 1 \mathrm{H}), 1.01(\mathrm{~d}, J=8.8 \mathrm{~Hz}, 3 \mathrm{H}) .{ }^{13} \mathrm{C}-\mathrm{NMR}\left(101 \mathrm{MHz}, \mathrm{CDCl}_{3}\right): \delta=166.8\left(\mathrm{C}_{\mathrm{q}}\right)$, $153.3\left(\mathrm{C}_{\mathrm{q}}\right), 145.4\left(\mathrm{C}_{\mathrm{q}}\right), 137.5(\mathrm{CH}), 133.1(\mathrm{CH}), 131.8(\mathrm{CH}), 127.1\left(\mathrm{C}_{\mathrm{q}}\right), 126.9(\mathrm{CH})$, $124.1(\mathrm{CH}), 120.5(\mathrm{CH}), 118.4(\mathrm{CH}), 116.0(\mathrm{CH}), 54.9\left(\mathrm{CH}_{2}\right), 33.3\left(\mathrm{CH}_{2}\right), 30.4(\mathrm{CH})$, $21.6\left(\mathrm{CH}_{3}\right)$. IR (ATR): 3049, 2832, 1664, 1593, 1505, 1269, 1122, 866, $759 \mathrm{~cm}^{-1}$. MS (ESI) $m / z$ (relative intensity): $334(52)[\mathrm{M}+\mathrm{Na}]^{+}, 312(100)[\mathrm{M}+\mathrm{H}]^{+}, 241(8), 218(18)$, 202 (22). HR-MS (EI) $m / z$ calcd for $\mathrm{C}_{18} \mathrm{H}_{21} \mathrm{~N}_{3} \mathrm{O}_{2}[\mathrm{M}+\mathrm{H}]^{+}:$312.1707, found: 312.1709 .

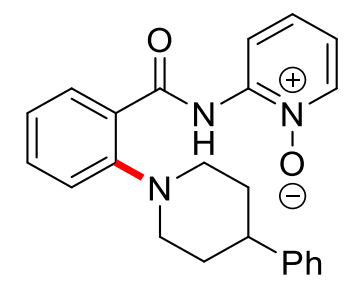

\section{2-[2-(4-Phenylpiperidin-1-yl]benzamido)pyridine-1-oxide (148ae)}

The general procedure $\mathbf{H}$ was followed using benzamide 117a (107 mg, $0.50 \mathrm{mmol}$, 1.00 equiv) and 4-phenylpiperidine (146d) (164 mg, $1.00 \mathrm{mmol}, 2.00$ equiv). Purification by column chromatography on silica gel $\left(\mathrm{CH}_{2} \mathrm{Cl}_{2} /\right.$ acetone $\left.12: 1 \rightarrow 8: 1\right)$ yielded 148ad (124 mg, $342 \mu \mathrm{mol}, 69 \%$ ) as a white solid. M. p.: $194-196{ }^{\circ} \mathrm{C} .{ }^{1} \mathrm{H}-\mathrm{NMR}$ $\left(600 \mathrm{MHz} \mathrm{CDCl}_{3}\right): \delta=13.64(\mathrm{~s}, 1 \mathrm{H}), 8.78$ (dd, $\left.J=7.8,2.2 \mathrm{~Hz}, 1 \mathrm{H}\right), 8.30$ (dd, $J=7.9$, $1.6 \mathrm{~Hz}, 1 \mathrm{H}$ ), 8.16 (dd, J=7.5, 2.2 Hz, 1H), 7.51 (ddd, J=7.8, 2.2, $1.6 \mathrm{~Hz} 1 \mathrm{H}$ ), 7.48$7.46(\mathrm{~m}, 2 \mathrm{H}), 7.34-7.28(\mathrm{~m}, 4 \mathrm{H}), 7.24-7.19(\mathrm{~m}, 2 \mathrm{H}), 6.97$ (ddd, J = 7.9, 2.2, $1.6 \mathrm{~Hz}$, $1 \mathrm{H}), 3.37-3.32(\mathrm{~m}, 2 \mathrm{H}), 2.95-2.91(\mathrm{~m}, 2 \mathrm{H}), 2.64-2.58(\mathrm{~m}, 1 \mathrm{H}), 2.55-2.47(\mathrm{~m}, 2 \mathrm{H})$, 
1.86-1.82 (m, 1H). ${ }^{13} \mathrm{C}-\mathrm{NMR}\left(125 \mathrm{MHz}, \mathrm{CDCl}_{3}\right): \delta=166.6\left(\mathrm{C}_{\mathrm{q}}\right), 152.9\left(\mathrm{C}_{\mathrm{q}}\right), 146.3\left(\mathrm{C}_{\mathrm{q}}\right)$, $145.3\left(\mathrm{C}_{\mathrm{q}}\right), 137.1(\mathrm{CH}), 133.1(\mathrm{CH}), 131.9(\mathrm{CH}), 128.3(\mathrm{CH}), 127.3(\mathrm{CH}), 127.1\left(\mathrm{C}_{\mathrm{q}}\right)$, $126.9(\mathrm{CH}), 126.0(\mathrm{CH}), 124.2(\mathrm{CH}), 120.3(\mathrm{CH}), 118.4(\mathrm{CH}), 115.9(\mathrm{CH}), 55.4\left(\mathrm{CH}_{2}\right)$, $42.9(\mathrm{CH}), 32.8\left(\mathrm{CH}_{2}\right)$. IR (ATR): 2917, 2932, 1666, 1501, 1282, 1212, 1108, 756, $699 \mathrm{~cm}^{-1}$. MS (ESI) $\mathrm{m} / z$ (relative intensity): $396(33)[\mathrm{M}+\mathrm{Na}]^{+}, 374(100)[\mathrm{M}+\mathrm{H}]^{+}, 358$ (8), 264 (12), 242 (23), 123 (10). HR-MS (El) m/z calcd for $\mathrm{C}_{23} \mathrm{H}_{23} \mathrm{~N}_{3} \mathrm{O}_{2}$ $[\mathrm{M}+\mathrm{H}]^{+}: 374.1863$, found: 374.1864 .<smiles></smiles>

\section{2-[2-(4-Chloropiperidin-1-yl]benzamido)pyridine-1-oxide (148af)}

The general procedure $\mathbf{H}$ was followed using benzamide $117 \mathrm{a}(107 \mathrm{mg}, 0.50 \mathrm{mmol}$, 1.00 equiv) and 4-chloropiperidine (146f) (110 mg, $1.00 \mathrm{mmol}, 2.00$ equiv). Purification by column chromatography on silica gel $\left(\mathrm{CH}_{2} \mathrm{Cl}_{2} /\right.$ acetone 12:1 $\left.\rightarrow 8: 1\right)$ yielded 148af (89.0 mg, $269 \mu \mathrm{mol}, 54 \%)$ as a white solid. M. p.: $132-134{ }^{\circ} \mathrm{C} .{ }^{1} \mathrm{H}-\mathrm{NMR}(300 \mathrm{MHz}$, $\mathrm{CDCl}_{3}$ ): $\delta=13.75(\mathrm{~s}, 1 \mathrm{H}), 8.87(\mathrm{dd}, J=7.8,2.0 \mathrm{~Hz}, 1 \mathrm{H}$ ), 8.35-8.27 (m, 2H), 8.16 (dd, $J=7.5,2.2 \mathrm{~Hz}, 1 \mathrm{H}$ ), 7.57 (ddd, $J=7.8,2.1,2.0 \mathrm{~Hz} 1 \mathrm{H}$ ), 7.45-7.29 (m, 3H), 7.01 (ddd, $J=7.6,2.1,2.0 \mathrm{~Hz}, 1 \mathrm{H}), 4.60-4.48(\mathrm{~m}, 2 \mathrm{H}), 3.40-3.29(\mathrm{~m}, 2 \mathrm{H}), 3.06-2.96(\mathrm{~m}, 2 \mathrm{H})$, 2.77-2.61 (m, 2H), 2.23-2.10 (m, 1H). ${ }^{13} \mathrm{C}-\mathrm{NMR}\left(75 \mathrm{MHz}, \mathrm{CDCl}_{3}\right): \delta=166.4\left(\mathrm{C}_{\mathrm{q}}\right)$, $152.6\left(\mathrm{C}_{\mathrm{q}}\right), 146.4\left(\mathrm{C}_{\mathrm{q}}\right), 137.6(\mathrm{CH}), 133.5(\mathrm{CH}), 132.1(\mathrm{CH}), 127.6\left(\mathrm{C}_{\mathrm{q}}\right), 127.0(\mathrm{CH})$, $125.0(\mathrm{CH}), 121.2(\mathrm{CH}), 118.6(\mathrm{CH}), 116.2(\mathrm{CH}), 57.2\left(\mathrm{CH}_{2}\right), 50.2(\mathrm{CH}), 33.8\left(\mathrm{CH}_{2}\right) . \mathrm{IR}$ (ATR): 2835, 1667, 1560, 1500, 1424, 1209, 1112, 757, $723 \mathrm{~cm}^{-1}$. MS (ESI) $\mathrm{m} / \mathrm{z}$ (relative intensity): $354(100)[\mathrm{M}+\mathrm{Na}]^{+}, 332(84)[\mathrm{M}+\mathrm{H}]^{+}, 305$ (15), 242 (71), 222 (55), 165 (34). HR-MS (EI) $\mathrm{m} / \mathrm{z}$ calcd for $\mathrm{C}_{17} \mathrm{H}_{18} \mathrm{~N}_{3} \mathrm{O}_{2} \mathrm{Cl} \quad\left[{ }^{35} \mathrm{Cl}-\mathrm{M}+\mathrm{H}\right]^{+}: 332.1160$, found: 332.1164 . 
<smiles></smiles>

\section{2-[2-(4-Methylpiperazin-1-yl)benzamido]pyridine-1-oxide (148ag)}

The general procedure $\mathbf{H}$ was followed using benzamide $117 \mathrm{a}(107 \mathrm{mg}, 0.50 \mathrm{mmol}$, 1.00 equiv) and 4-methylpiperazine (146f) (94.7 mg, $1.00 \mathrm{mmol}, 2.00$ equiv). Purification by column chromatography on silica gel $\left(\mathrm{CH}_{2} \mathrm{Cl}_{2} /\right.$ acetone $\left.1: 1 \rightarrow 0: 1\right)$ yielded 148ag (85.9 mg, $276 \mu \mathrm{mol}, 55 \%$ ) as a white solid. M. p.: $185-186^{\circ} \mathrm{C}$. ${ }^{1} \mathrm{H}-\mathrm{NMR}$ $\left(500 \mathrm{MHz}_{\mathrm{CDCl}}\right): \delta=13.47(\mathrm{~s}, 1 \mathrm{H}), 8.74(\mathrm{dd}, J=8.2,2.4 \mathrm{~Hz}, 1 \mathrm{H}), 8.27(\mathrm{dd}, J=7.7$, $1.8 \mathrm{~Hz}, 1 \mathrm{H}$ ), 8.14 (dd, $J=7.2,2.1 \mathrm{~Hz}, 1 \mathrm{H}$ ), 7.57 (ddd, $J=8.2,2.4,1.8 \mathrm{~Hz} 1 \mathrm{H}$ ), 7.34$7.28(\mathrm{~m}, 2 \mathrm{H}), 7.26-7.22(\mathrm{~m}, 1 \mathrm{H}), 6.97$ (ddd, $J=7.7,2.4,1.8 \mathrm{~Hz}, 1 \mathrm{H}), 3.13-3.05(\mathrm{~m}$, $4 \mathrm{H}), 2.88-2.79(\mathrm{~m}, 4 \mathrm{H}), 2.41(\mathrm{~s}, 3 \mathrm{H}) .{ }^{13} \mathrm{C}-\mathrm{NMR}\left(125 \mathrm{MHz}, \mathrm{CDCl}_{3}\right): \delta=166.5\left(\mathrm{C}_{\mathrm{q}}\right), 152.2$ $\left(\mathrm{C}_{\mathrm{q}}\right), 145.3\left(\mathrm{C}_{\mathrm{q}}\right), 137.5(\mathrm{CH}), 133.4(\mathrm{CH}), 132.0(\mathrm{CH}), 127.6\left(\mathrm{C}_{\mathrm{q}}\right), 127.2(\mathrm{CH}), 124.8$ $(\mathrm{CH}), 120.7(\mathrm{CH}), 118.5(\mathrm{CH}), 116.1(\mathrm{CH}), 53.9\left(\mathrm{CH}_{2}\right), 53.9\left(\mathrm{CH}_{2}\right), 45.9\left(\mathrm{CH}_{3}\right) . \mathrm{IR}$ (ATR):2841, 1667, 1559, 1500, 1425, 1264, 1108, 758, $724 \mathrm{~cm}^{-1}$. MS (El) m/z (relative intensity): 335 (10) [M+Na] $]^{+}, 313(100)[\mathrm{M}+\mathrm{H}]^{+}, 219$ (8), 203 (21). HR-MS (El) m/zcalcd for $\mathrm{C}_{17} \mathrm{H}_{20} \mathrm{~N}_{4} \mathrm{O}_{2}[\mathrm{M}+\mathrm{H}]^{+}:$313.1659, found: 313.1661.

\subsubsection{Mechanistic Studies}

\section{Deuteration Experiment}

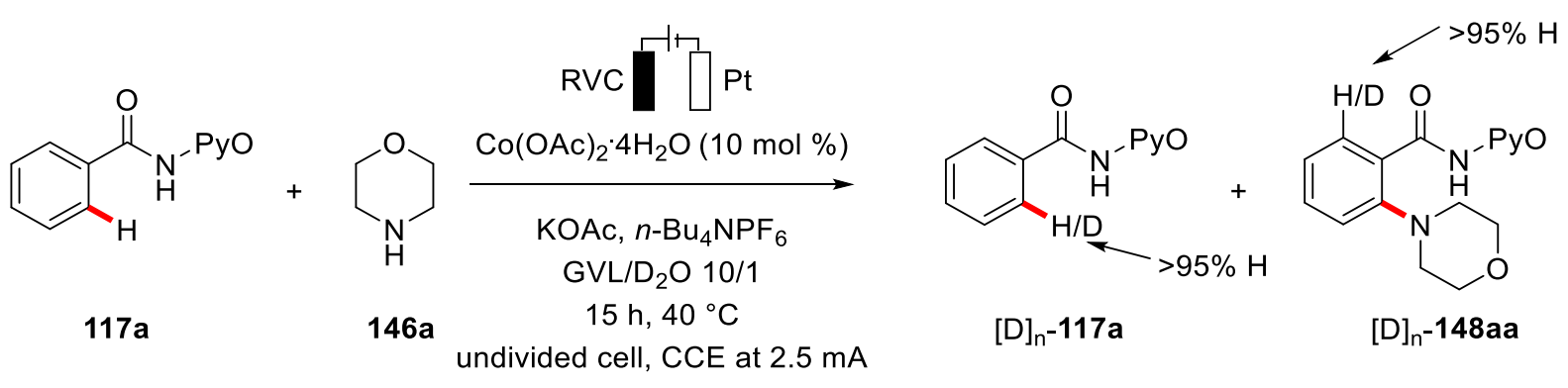

Scheme 5.19. $\mathrm{H} / \mathrm{D}$ exchange experiment using $\mathrm{D}_{2} \mathrm{O}$ as the co-solvent.

The general procedure $\mathbf{H}$ was followed using benzamide 117a (107 mg, $0.50 \mathrm{mmol}$, 1.00 equiv) and morpholine (146a) $(82.7 \mathrm{mg}, 1.00 \mathrm{mmol}, 2.00$ equiv) using a mixture of $\mathrm{GVL}$ and $\mathrm{D}_{2} \mathrm{O}(10 / 1,2.2 \mathrm{~mL})$ as solvent. Electrolysis was performed at $40{ }^{\circ} \mathrm{C}$ and a constant current of $2.5 \mathrm{~mA}$ was maintained for $15 \mathrm{~h}$. Column chromatography $\left(\mathrm{CH}_{2} \mathrm{Cl}_{2} /\right.$ acetone $\left.2: 1\right)$ yielded the desired product [D] $]_{\mathrm{n}}$ 148aa $(83.8 \mathrm{mg}, 275 \mu \mathrm{mol}$, 
$55 \%)$ as a white solid and the reisolated starting material [D]n-117a $(40.9 \mathrm{mg}$, $191 \mu \mathrm{mol}, 38 \%)$ as a white solid. Deuteration could not be detected in neither of the two compounds $117 \mathrm{a}$ and $148 \mathrm{aa}$ as determined by ${ }^{1} \mathrm{H}-\mathrm{NMR}$ spectroscopy.

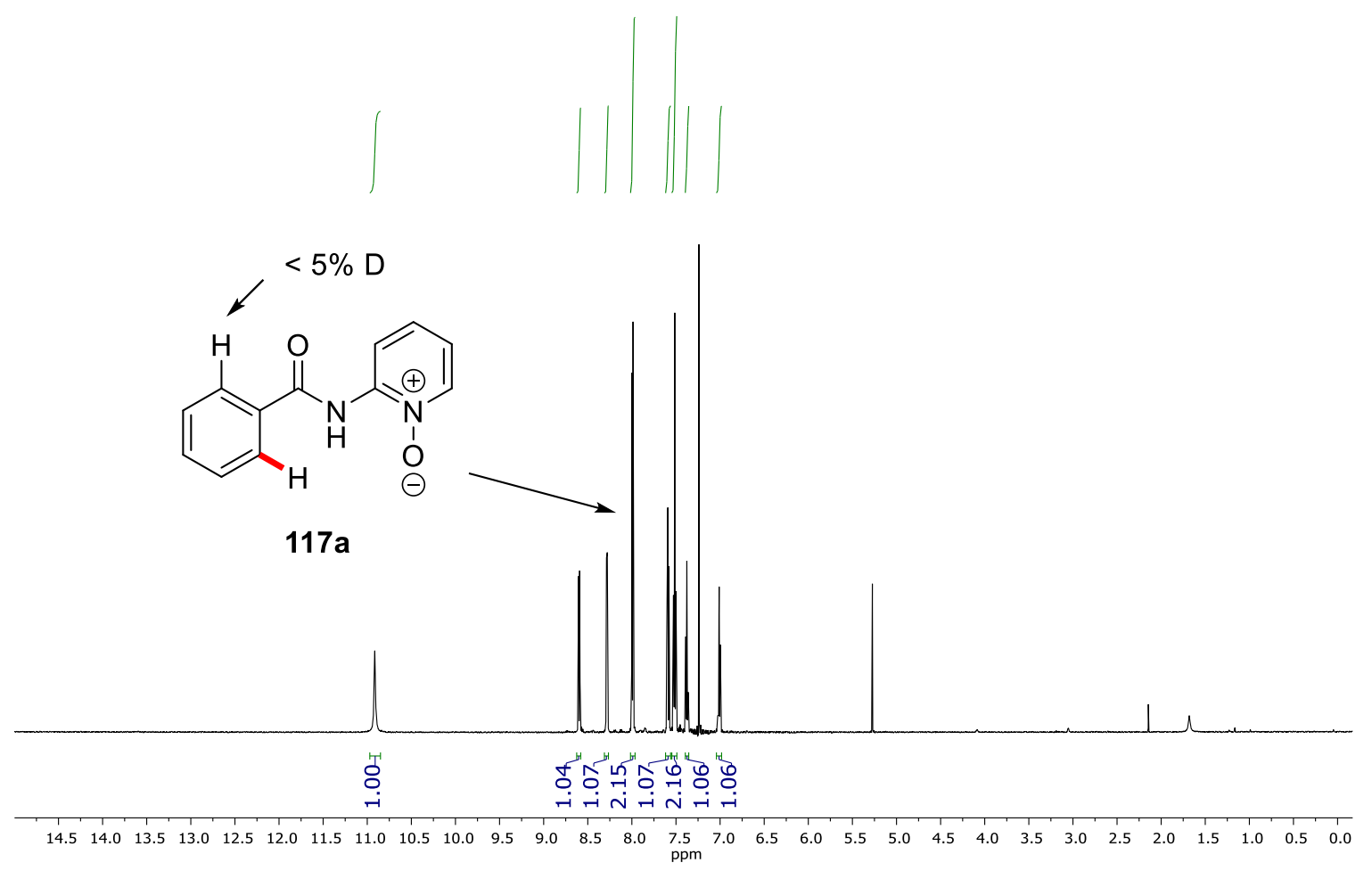

Figure 5.19. ${ }^{1} \mathrm{H}-\mathrm{NMR}$ sepctra of $117 \mathrm{a}$ from the $\mathrm{H} / \mathrm{D}$ exchange experiment. 


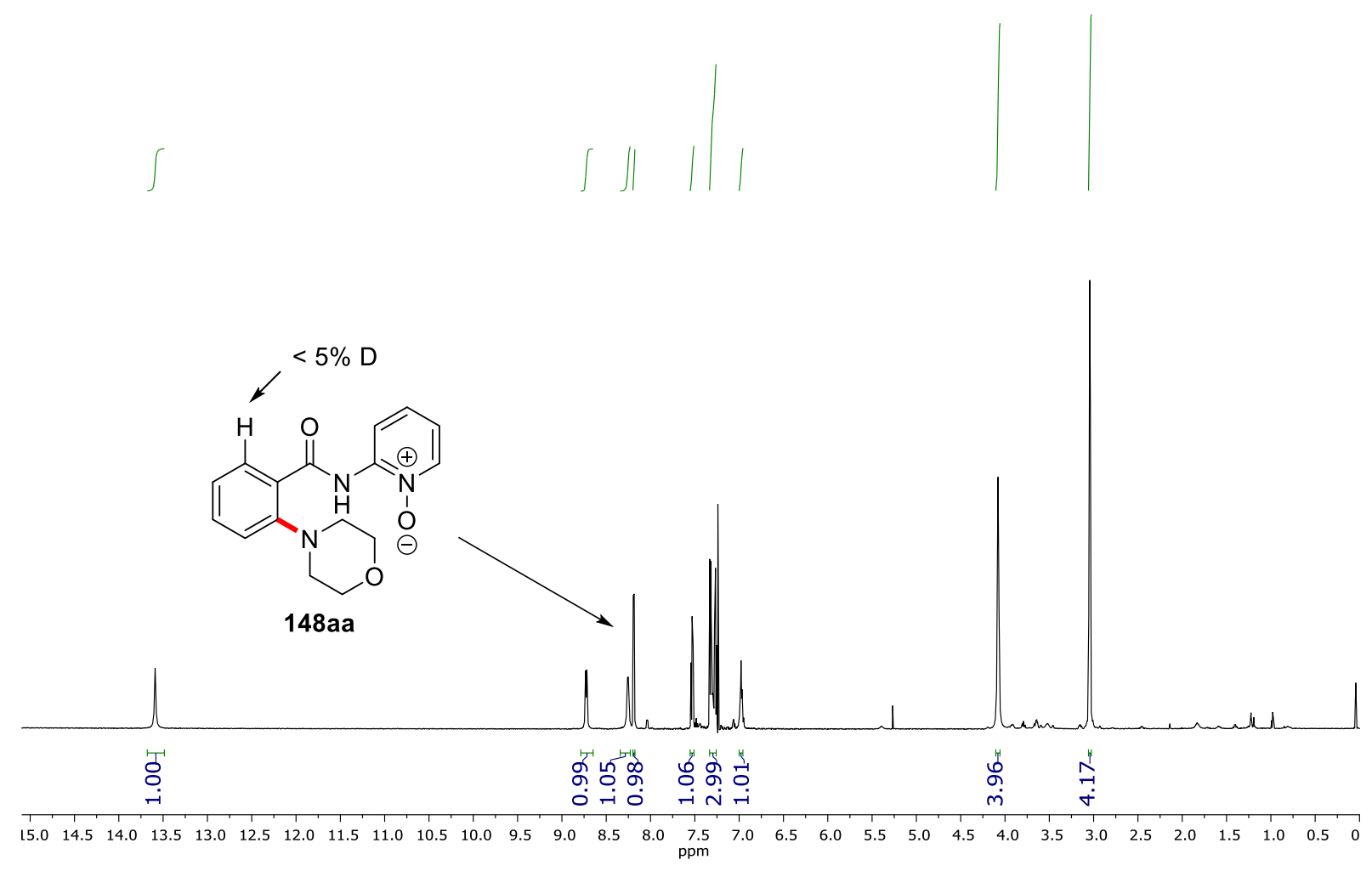

Figure 5.20. ${ }^{1} \mathrm{H}-\mathrm{NMR}$ sepctra of $150 \mathrm{aa}$ from the $\mathrm{H} / \mathrm{D}$ exchange experiment.

\section{Reaction Profile}<smiles>O=C(Nc1ccccc1)c1ccccc1</smiles>

$117 a$

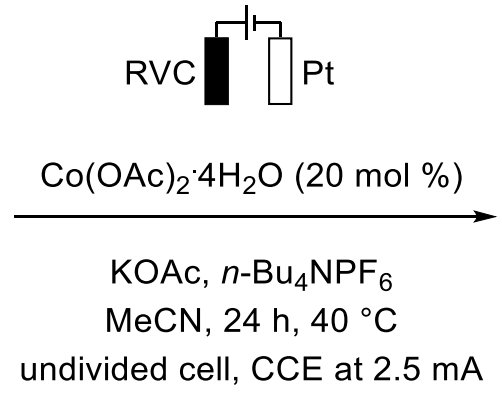

$146 a$<smiles>C1COCCN1</smiles><smiles></smiles>

148aa

Scheme 5.20. Cobalt-catalyzed $\mathrm{C}-\mathrm{H}$ amination.

A solution of benzamide $117 \mathrm{a}\left(214 \mathrm{mg}, 1.00 \mathrm{mmol}, 1.00\right.$ equiv), $\mathrm{Co}(\mathrm{OAc}) 2 \cdot 4 \mathrm{H}_{2} \mathrm{O}(51.4$ $\mathrm{mg}, 20 \mathrm{~mol} \%$ ), KOAc (301 mg, $1.50 \mathrm{mmol}, 1.50$ equiv), $n-\mathrm{Bu}_{4} \mathrm{NPF}_{6}$ (386 mg, 0.50 mmol, 0.50 equiv) and morpholine (146a) (176 mg, $2.00 \mathrm{mmol}, 2.00$ equiv) in MeCN $(20 \mathrm{~mL})$ was fitted with a carbon mesh electrode, a platinum electrode and a diamond probe connected to a Mettler Toledo ReactIR and heated for 20 min to $40^{\circ} \mathrm{C}$ to achieve a stable temperature. Then, electrolysis was started using a constant current of 5.0 $\mathrm{mA}$. Every minute (first $4 \mathrm{~h}$ ) and every 2 minutes (next $20 \mathrm{~h}$ ) an IR spectrum was 
recorded. Peaks at $1096 \mathrm{~cm}^{-1}$ and $1115 \mathrm{~cm}^{-1}$ were identified to belong to the starting material and the product, respectively. After $24 \mathrm{~h}, 148 \mathrm{aa}(82.0 \mathrm{mg}, 274 \mu \mathrm{mol}, 55 \%)$ and $117 \mathrm{a}(44.3 \mathrm{mg}, 207 \mu \mathrm{mol} 41 \%$ ) were isolated to scale the peak intensities.

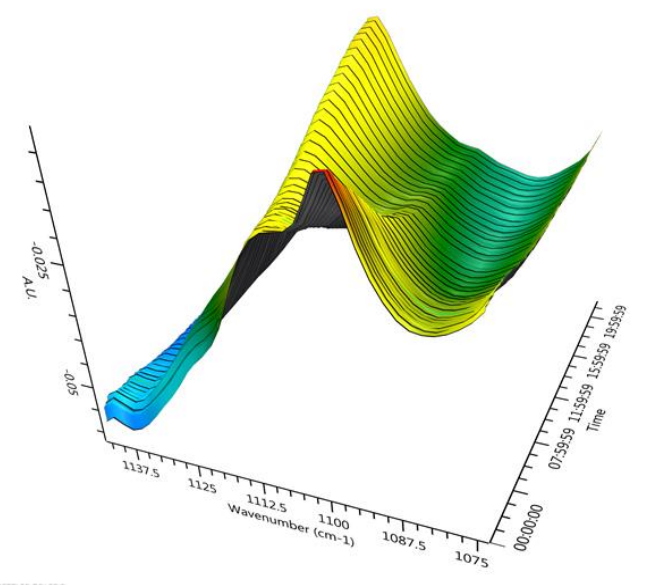

Figure 5.21. 3D-Surface plot of the observed vibrations at $1115 \mathrm{~cm}^{-1}$ and $1096 \mathrm{~cm}^{-1}$.

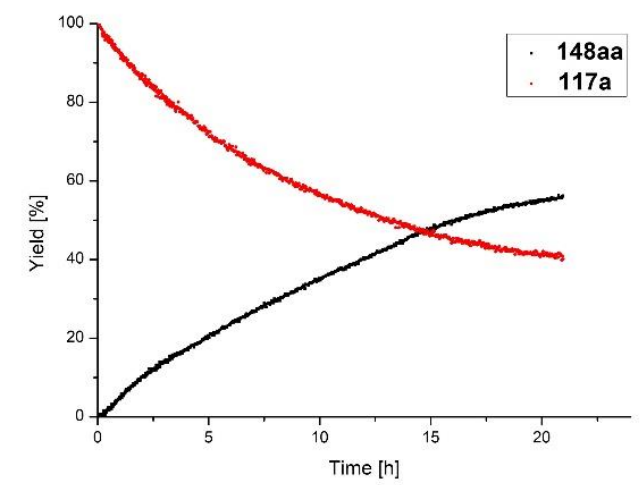

Figure 5.22. Plot of the observed vibrations over time. 


\section{KIE Studies}<smiles>O=C(N[Pb])c1ccc(S)cc1</smiles>

$117 \mathrm{a}$ or $[\mathrm{D}]_{5}-117 \mathrm{a}$<smiles>C1COCCN1</smiles>

$146 a$

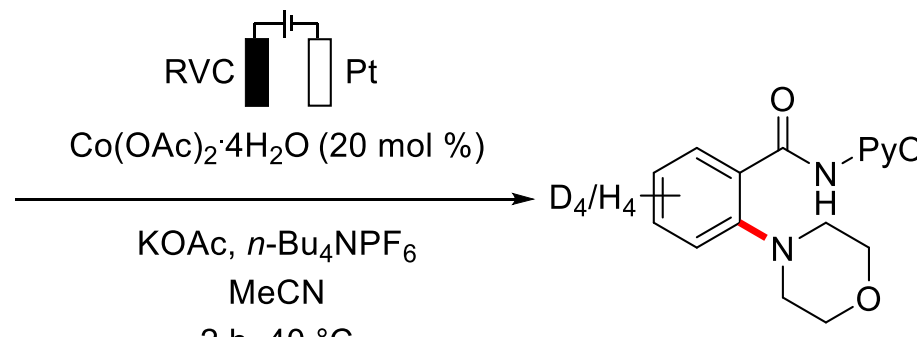

$2 \mathrm{~h}, 40^{\circ} \mathrm{C}$

undivided cell, $\mathrm{CCE}$ at $2.5 \mathrm{~mA}$

$k_{\mathrm{H}} / k_{\mathrm{D}}=1.0$

Scheme 5.21. KIE studies for the cobalt-catalyzed C-H amination.

Two independent reactions were carried out following the above procedure for the ReactIR studies using substrates $117 \mathrm{aa}(1.00 \mathrm{mmol})$ and $[\mathrm{D}]_{5}-117 \mathrm{aa}(1.00 \mathrm{mmol})$. For the first $4 \mathrm{~h}$ every minute an IR spectrum was recorded, then every 2 min for the following $18 \mathrm{~h}$. The KIE was determined by measuring the initial rates from the increase of the peak at $1115 \mathrm{~cm}^{-1}$. After the reaction, the products 148aa and [D]4-148aa were isolated to correlate the peak intensity. Then, the measured yields for the first $2 \mathrm{~h}$ were plotted to analyze the initial rates of the reaction and a linear fit revealed a KIE of $k_{H} / k_{D}$ $\approx 1.0$ (See Figures S-5 and S-6).
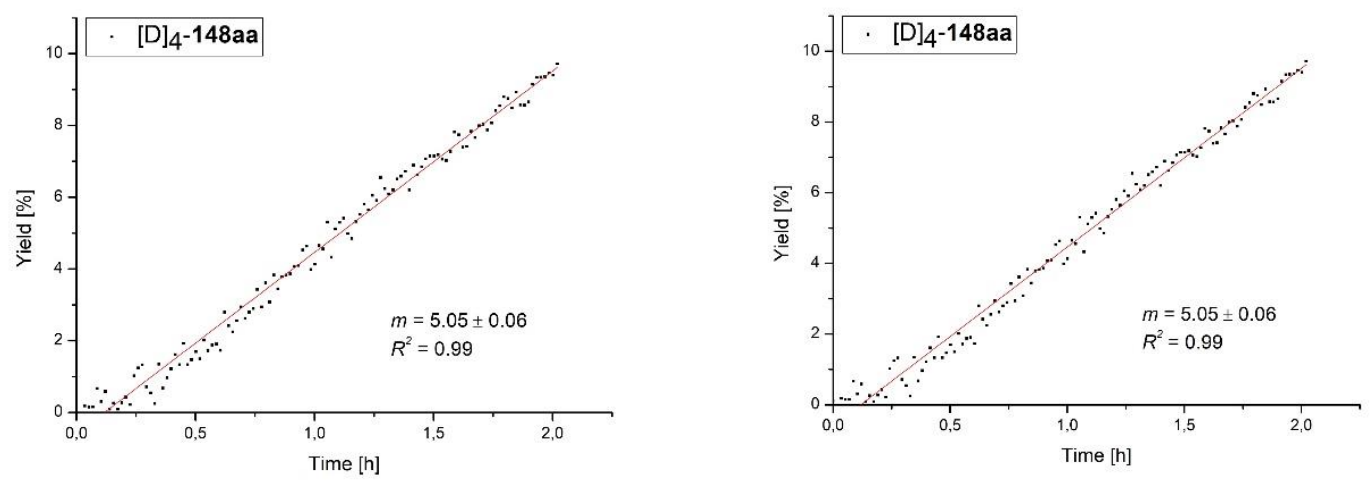

Figure 5.23. Initial rates of 148aa and [D]4-148aa. 


\section{Headspace Analysis}

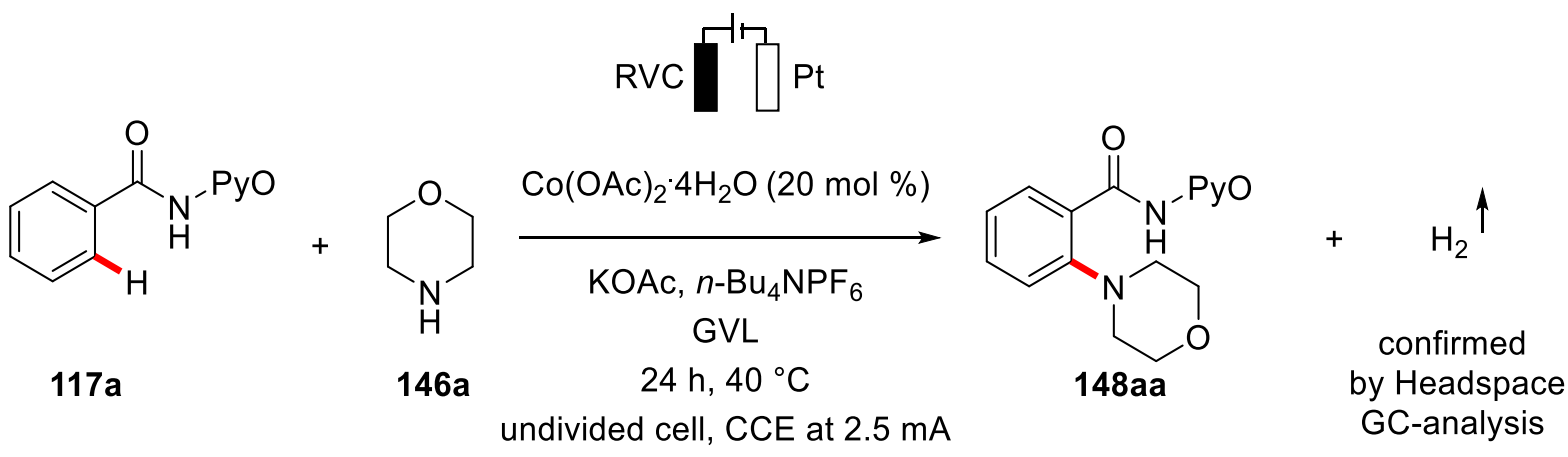

Scheme 5.22. Headspace analysisof the reaction mixture.

Following the general procedure $\mathbf{H}$, a reaction was performed under $\mathrm{N}_{2}$ in a two-neck flask, tightly sealed with two septa. After $24 \mathrm{~h}$, the gas-phase above the solution was analyzed by headspace GC analysis using a Shimadzu S 2014 gaschromatograph equipped with a $5 \AA$ MS column (column length: $2 \mathrm{~m}$, column width: $2 \mathrm{~mm}$, column temp. $100^{\circ} \mathrm{C}$ ), carrier gas Argon, $25 \mathrm{~mL} / \mathrm{min}, 1 \mathrm{~mL}$ volume was injected. The sample was analyzed by a temperature conductivity detector at $110^{\circ} \mathrm{C}$.

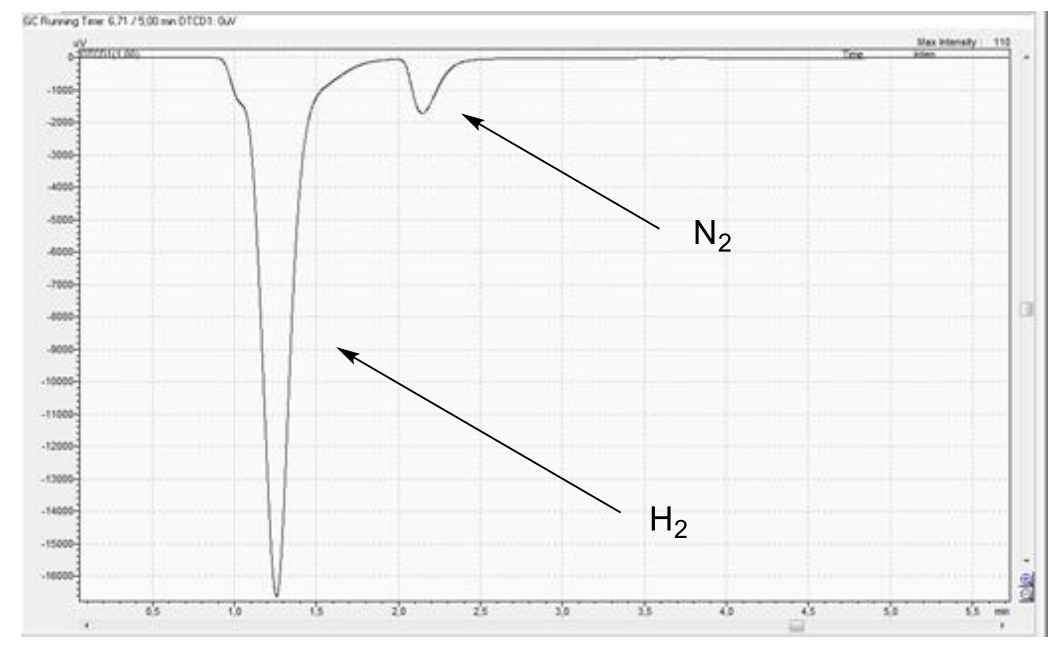

Figure 5.24. Chromatogram of the gasphase of the reaction mixture.

\section{Cyclic Voltammetry}

The cyclic voltammetry was carried out with a Metrohm Autolab PGSTAT204 workstation and following analysis was performed with Nova 2.0 software. A glassycarbon electrode ( $3 \mathrm{~mm}$-diameter, disc-electrode) was used as the working electrode, a Pt wire as auxiliary electrode and a SCE electrode was used as the reference. The measurements were carried out at a scan rate of $100 \mathrm{mVs}^{-1}$. 


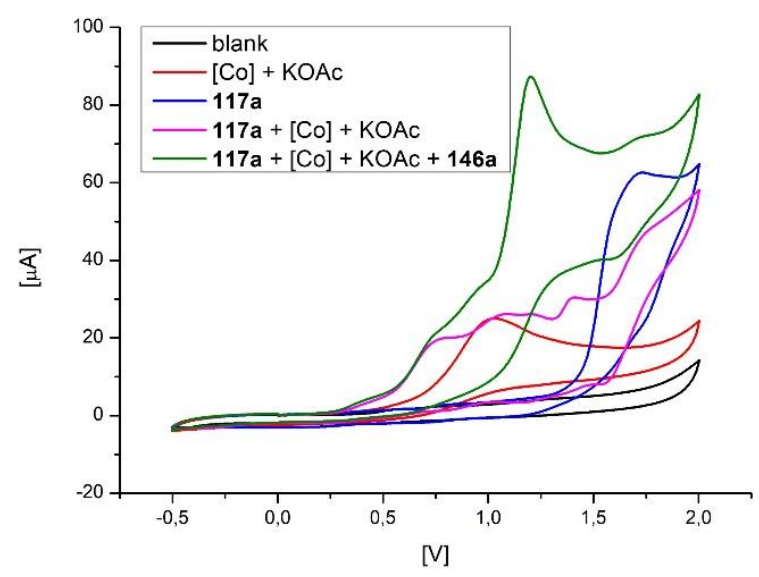

Figure 5.25. Cyclic voltammograms at $100 \mathrm{mVs}^{-1}: n-\mathrm{Bu}_{4} \mathrm{NPF}_{6}(0.1 \mathrm{M}$ in $\mathrm{MeCN})$, concentration of substrates $1 \mathrm{mM}$ (KOAc $4 \mathrm{~mm}$ ). (black) blank; (blue) substrate 117a; (red) $\mathrm{Co}(\mathrm{OAc})_{2} \cdot 4 \mathrm{H}_{2} \mathrm{O}$ and $\mathrm{KOAc}$; (purple) $\mathrm{Co}(\mathrm{OAc})_{2} \cdot 4 \mathrm{H}_{2} \mathrm{O}, \mathrm{KOAc}$ and 117a; (green) $\mathrm{Co}(\mathrm{OAc})_{2} \cdot 4 \mathrm{H}_{2} \mathrm{O}, \mathrm{KOAc}, 117 \mathrm{a}$ and 146a.

\subsection{Mechanistic Experiments for Electrochemical C-H Activation}

\section{Time-resolved UV/Vis measurements}

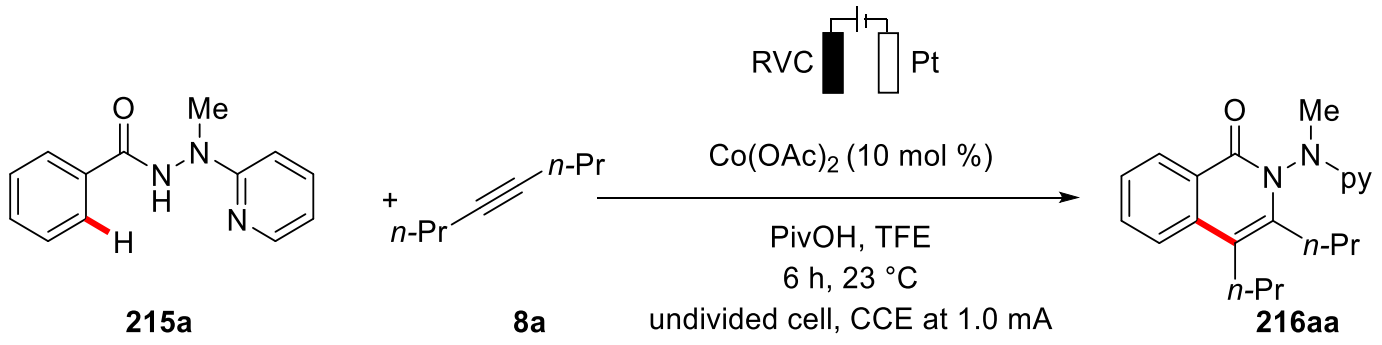

Scheme 5.23. Time resolved UV/Vis measurements.

In a $5 \mathrm{~mL}$ vial, hydrazide 215a (113 mg, $0.50 \mathrm{mmol}, 1.00$ equiv), 8 a $(66.7 \mathrm{mg}$, $0.60 \mathrm{mmol}, 1.20$ equiv), $\mathrm{Co}(\mathrm{OAc})_{2}(7.8 \mathrm{mg}, 0.05 \mathrm{mmol}, 10 \mathrm{~mol} \%)$ and PivOH (101 mg, $1.00 \mathrm{mmol}, 2.00$ equiv) were dissolved in TFE (2 mL), and stirred for $5 \mathrm{~min}$. Then, 0.2 $\mathrm{mL}$ of the prepared solution were transferred to a three-neck flask fitted with the UV/Vis probe and Pt $(5.0 \times 2.5 \mathrm{~cm})$ and $\mathrm{RVC}(5.0 \times 2.5 \mathrm{~cm})$ electrodes containing $\mathrm{PiVOH}$ (2.04 g, $20 \mathrm{mmol}, 20$ equiv) in TFE (200 mL). After start of the electrolysis, spectra were obtained every $2 \mathrm{~min}$ for $6 \mathrm{~h}$ in a range of 220 to $800 \mathrm{~nm}$. 


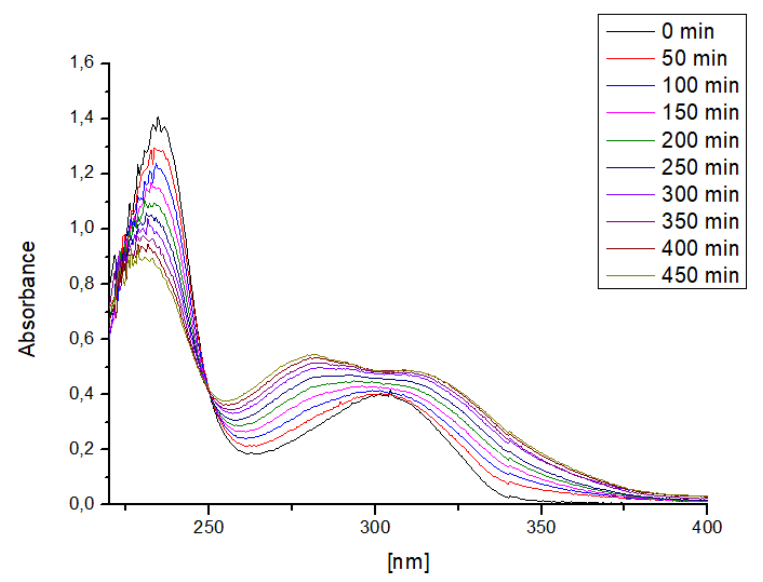

Figure 5.26. Time-resolved UV/Vis spectra for the cobalt-catalyzed annulation (region from 400-800 nm omitted for clarity.

\section{Headspace Analysis}

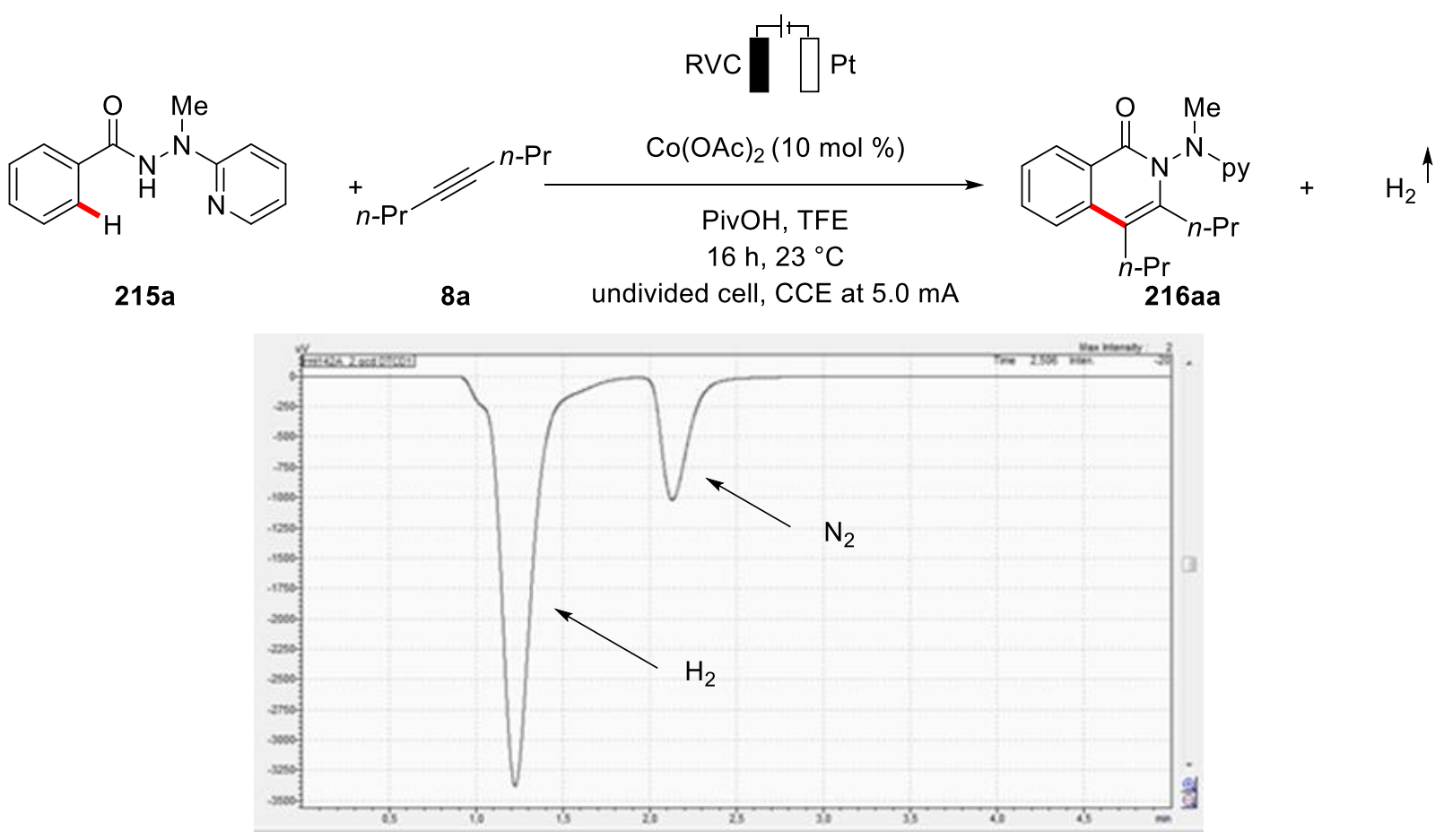

Scheme 5.24. Headspace analysis for the cobalt-catalyzed $\mathrm{C}-\mathrm{H} / \mathrm{N}-\mathrm{H}$ annulation.

A reaction was performed under nitrogen in tightly sealed flask using hydrazide $215 \mathrm{a}$ (113 mg, $0.50 \mathrm{mmol}, 1.00$ equiv), $8 \mathrm{a}$ (66.9 mg, $0.60 \mathrm{mmol}, 1.20$ equiv), $\mathrm{Co}(\mathrm{OAc})_{2}$ (7.8 $\mathrm{mg}, 0.05 \mathrm{mmol}, 10 \mathrm{~mol} \%$ ) and PivOH (101 mg, $1.00 \mathrm{mmol}, 2.00$ equiv) in TFE $(3.0 \mathrm{~mL})$. Electrolysis was carried out at a constant current of $5.0 \mathrm{~mA}$. After $16 \mathrm{~h}$, the gas-phase above the solution was analyzed by headspace GC analysis using a Shimadzu S 2014 gaschromatograph equipped with a $5 \AA$ MS column (column length: 
$2 \mathrm{~m}$, column width: $2 \mathrm{~mm}$, column temp. $100^{\circ} \mathrm{C}$ ), carrier gas Argon, $25 \mathrm{~mL} / \mathrm{min}, 1 \mathrm{~mL}$ volume was injected. The sample was analyzed by a temperature conductivity detector at $110^{\circ} \mathrm{C}$.

\section{ESI-MS studies on reaction intermediates}

\section{ESI-MS of the reaction mixture}<smiles>CN(NC(=O)c1ccccc1)c1ccccn1</smiles>

215a

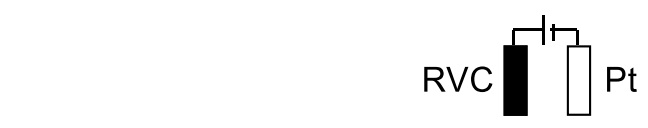<smiles>C#CPCCP</smiles>

$8 a$

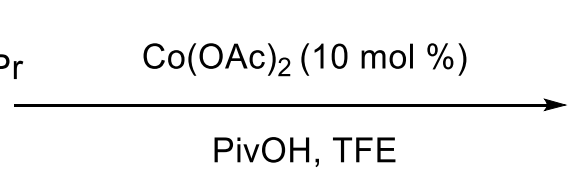

$3 \mathrm{~h}, 23^{\circ} \mathrm{C}$

undivided cell, CCE at $5.0 \mathrm{~mA}$<smiles>CCCc1c(N(C)C)n(N(C)C)c(=O)c2ccccc12</smiles>

216aa

Scheme 5.25. Reaction mixture for ESI-MS analysis.

A reaction was conducted using $215 a$ ( $56.8 \mathrm{mg}, 0.25 \mathrm{mmol}, 1.00$ equiv), 8 a (45.7 $\mathrm{mg}$, $0.28 \mathrm{mmol}, 1.10$ equiv), $\mathrm{Co}(\mathrm{Oac}) 2(8.9 \mathrm{mg}, 20 \mathrm{~mol} \%)$ and $\mathrm{PivOH}(51.0 \mathrm{mg}, 0.50 \mathrm{mmol}$, 2.00 equiv) in TFE ( $3 \mathrm{~mL})$ at $5.0 \mathrm{~mA}$ for $3 \mathrm{~h}$. Then $0.1 \mathrm{~mL}$ of the solution was removed and analyzed by ESI-MS. Furthermore, the ion observed at $m / z 495.1$ was isolated and fragmented by MS/MS.

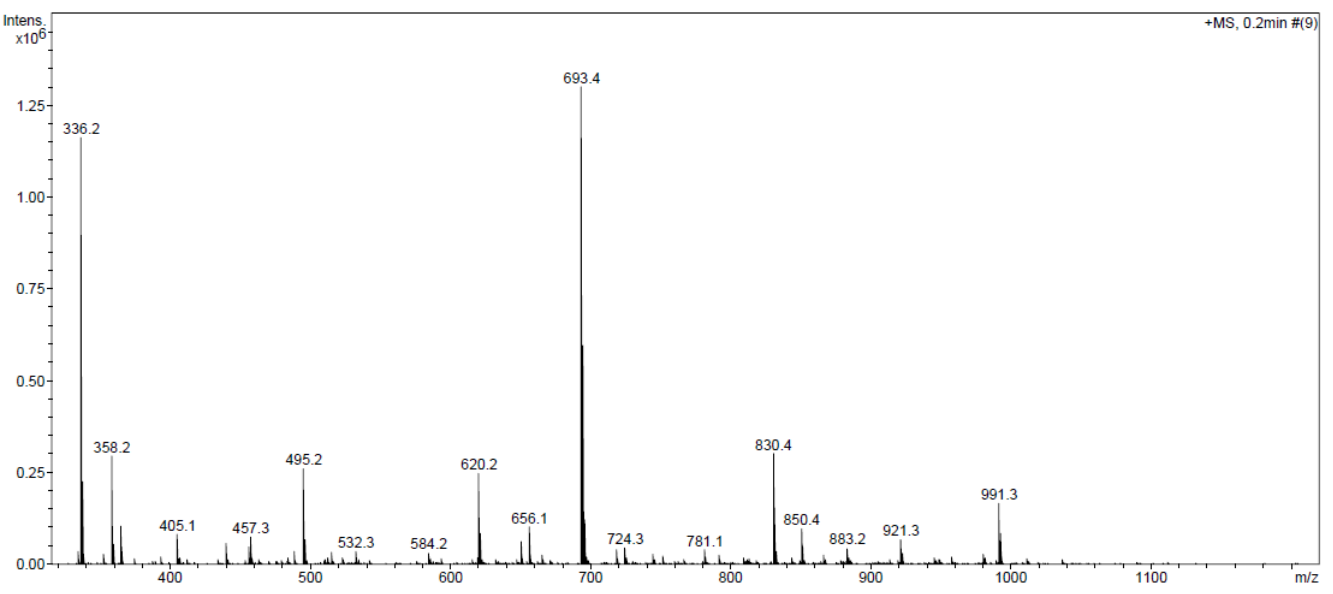

Figure 5.27. ESI-MS spectra of the reaction mixture. 


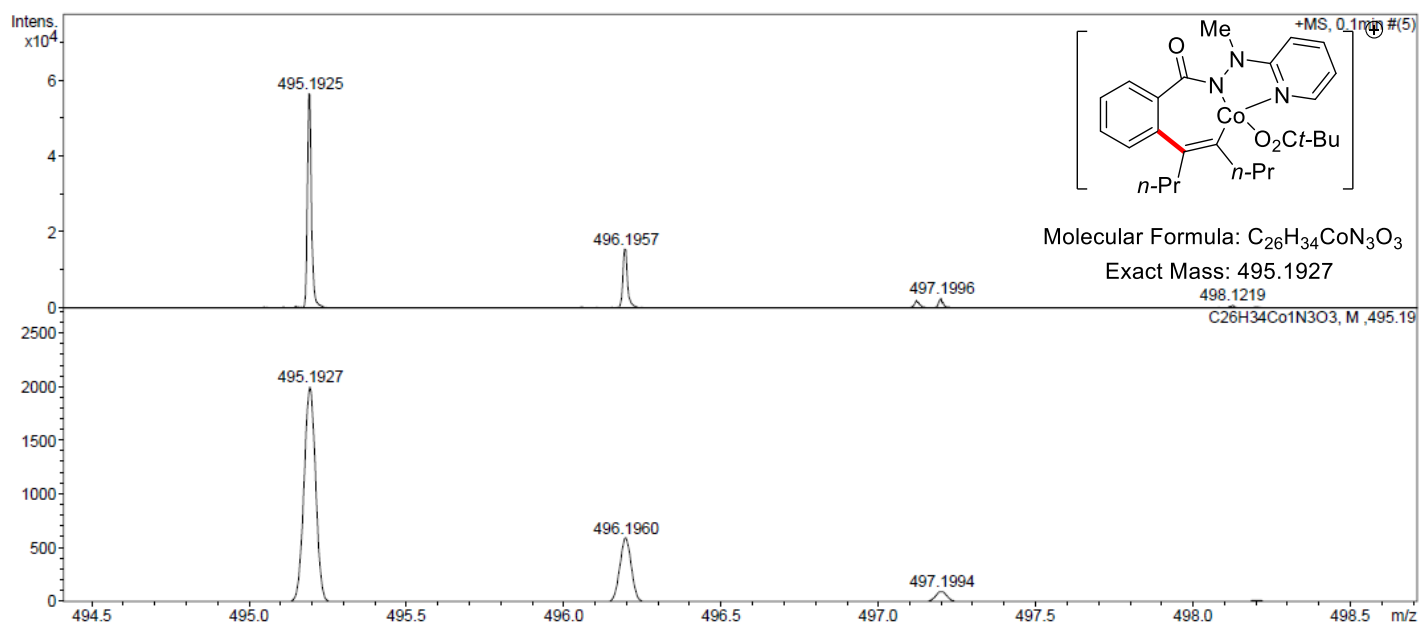

Figure 5.28. ESI-HRMS of the Peak at $\mathrm{m} / \mathrm{z}$ 495.2.

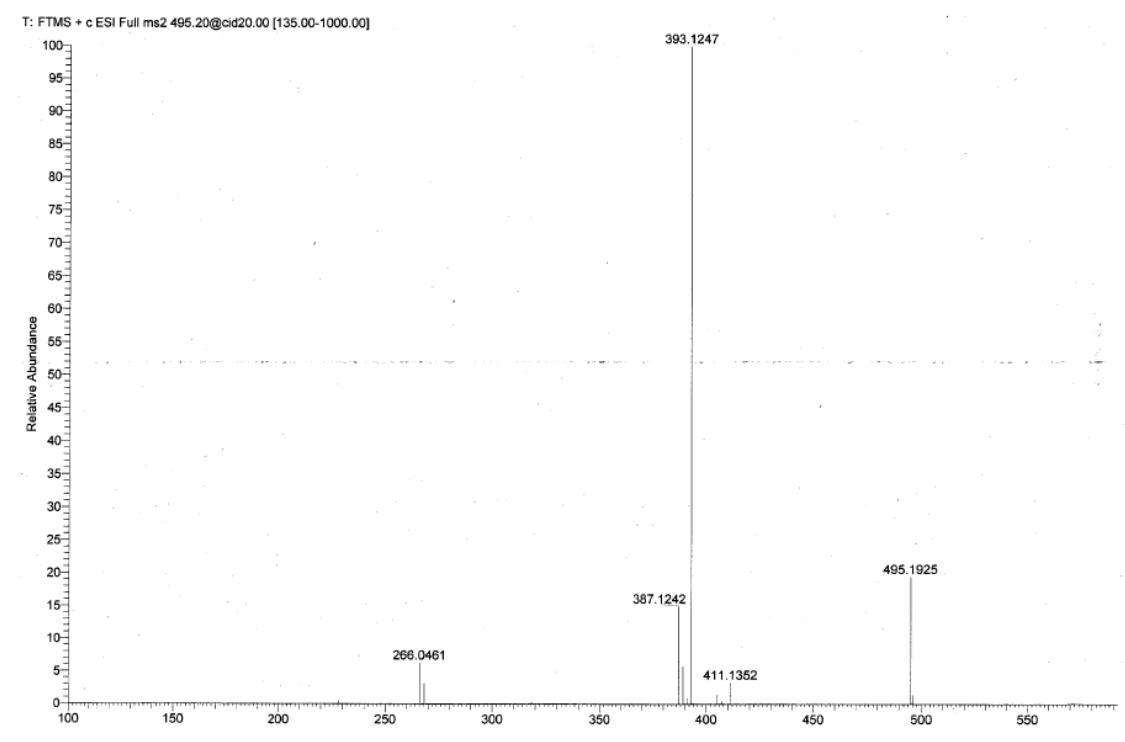

Figure 5.29. MS/MS spectra of the lon observed at $m / z$ 495.1925. 
<smiles>CN(NC(=O)c1ccccc1)c1ccccn1</smiles>

$215 a$<smiles>[R19]C1C=CC1[Y]</smiles>

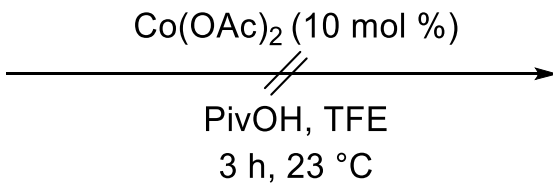

undivided cell, $\mathrm{CCE}$ at $5.0 \mathrm{~mA}$<smiles>CCCCc1c(OCC)n(N(C)[O])c(=O)c2ccccc12</smiles>

216aa

Scheme 5.26. Reaction mixture for ESI-MS analysis in the absence of alkyne $\mathbf{8 a}$.

A reaction was conducted using $215 \mathrm{a}(56.9 \mathrm{mg}, 0.25 \mathrm{mmol}, 1.00$ equiv), Co(Oac)2 (8.9 $\mathrm{mg}, 20 \mathrm{~mol} \%$ ) and PivOH (50.3 mg, $0.50 \mathrm{mmol}, 2.00$ equiv) in TFE (3 mL) at $5.0 \mathrm{~mA}$ for $3 \mathrm{~h}$. Then $0.1 \mathrm{~mL}$ of the solution was removed and analyzed by ESI-MS.

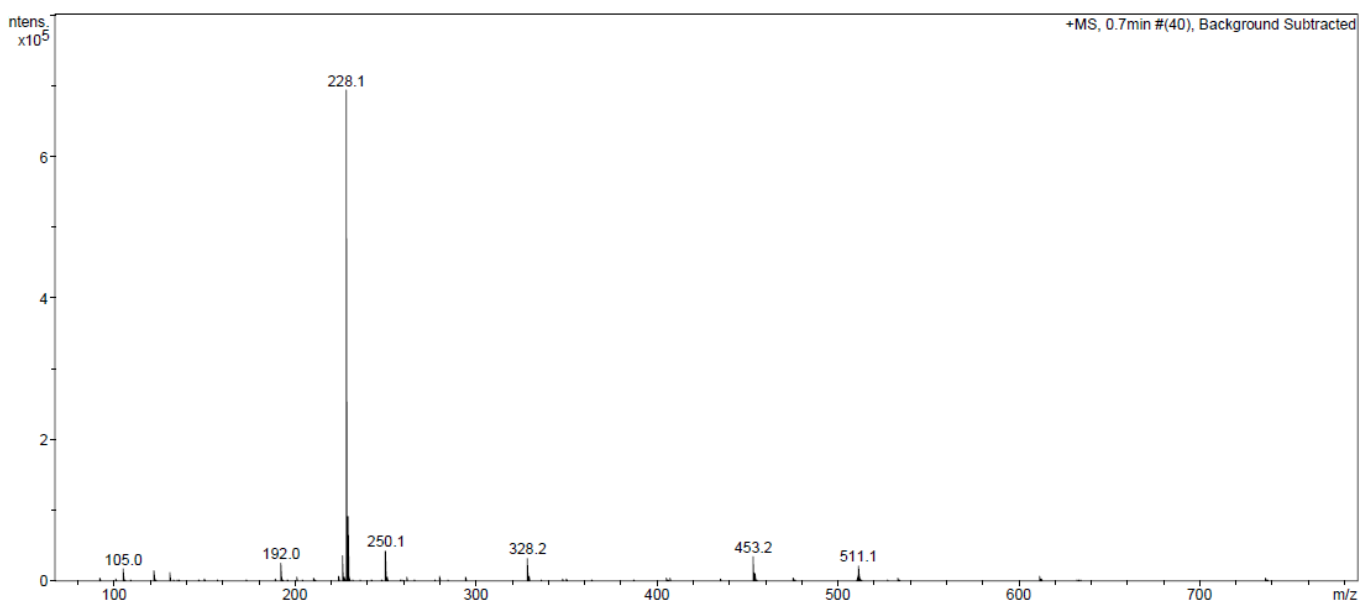

Figure 5.30. ESI-MS spectra of the reaction mixture.

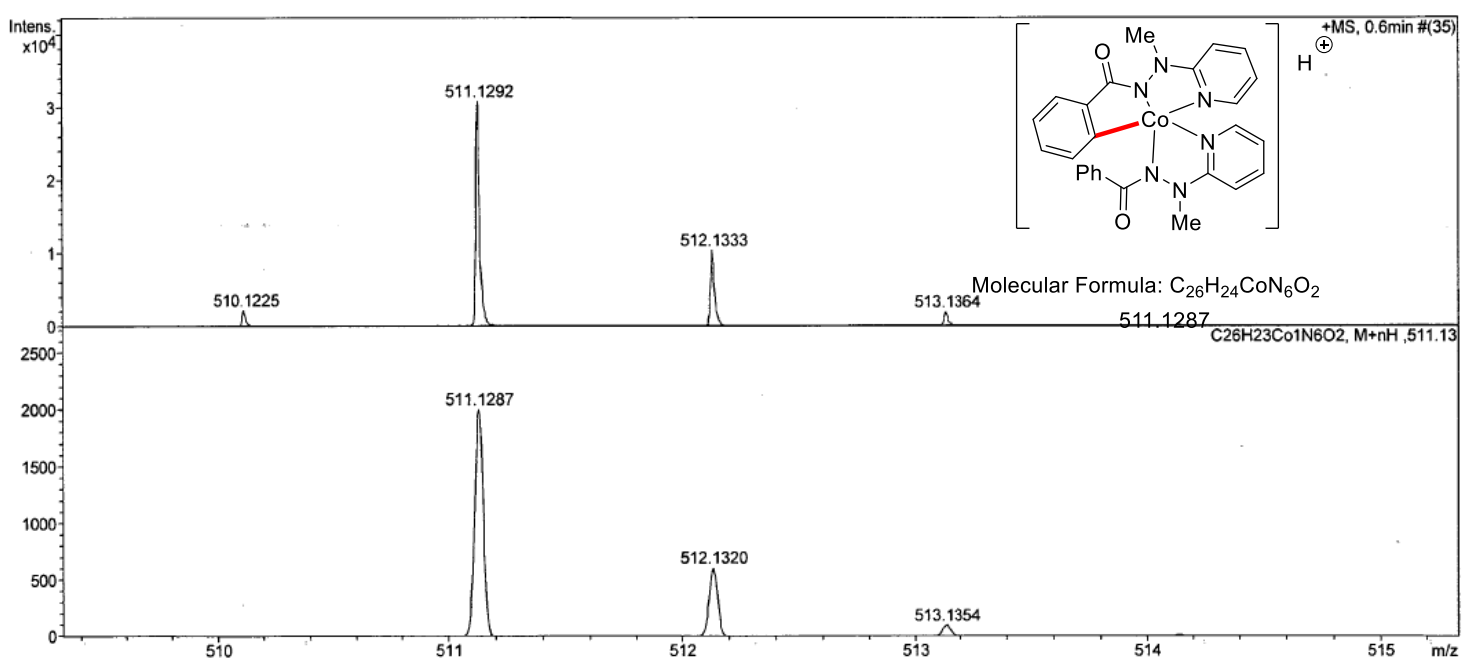

Figure 5.31. ESI-HRMS of the Peak at $\mathrm{m} / \mathrm{z}$ 511.1. 


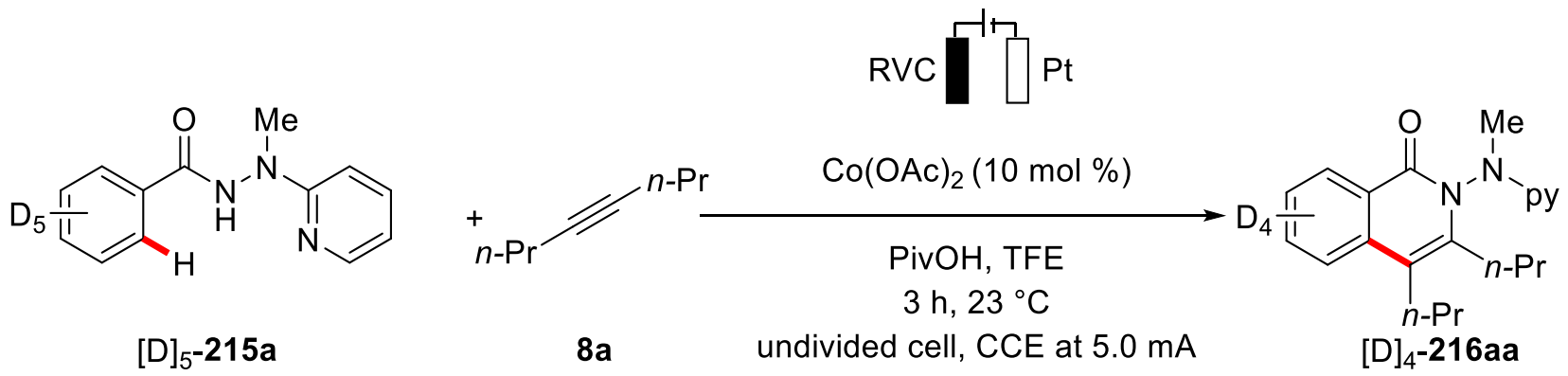

Scheme 5.27. Reaction mixture for ESI-MS analysis of the reaction using [D]5-215a.

A reaction was conducted using [D]5-1a (57.2 mg, $0.25 \mathrm{mmol}, 1.00$ equiv), $8 \mathrm{a}(46.0 \mathrm{mg}$, $0.28 \mathrm{mmol}, 1.10$ equiv), $\mathrm{Co}(\mathrm{Oac}) 2$ ( $8.9 \mathrm{mg}, 20 \mathrm{~mol} \%$ ) and PivOH (50.3 mg, $0.50 \mathrm{mmol}$, 2.00 equiv) in TFE $(3 \mathrm{~mL})$ at $5.0 \mathrm{~mA}$ for $3 \mathrm{~h}$. Then $0.1 \mathrm{~mL}$ of the solution was removed and analyzed by ESI-MS.

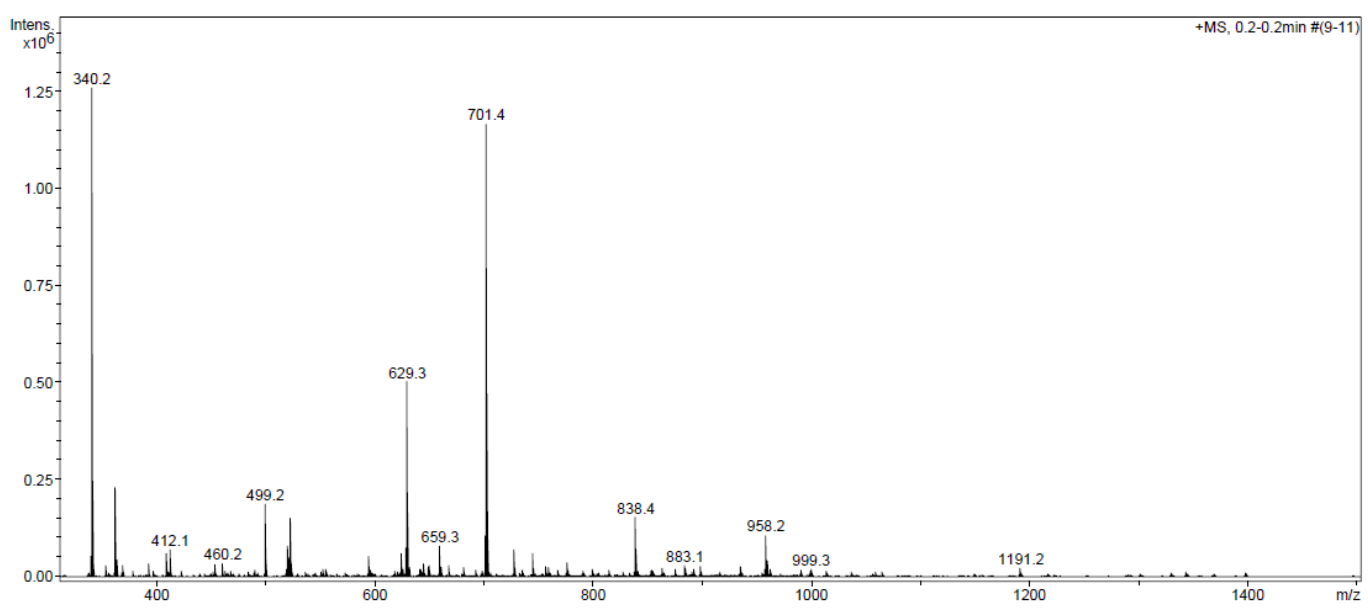

Figure 5.32. ESI-MS spectra of the reaction mixture.

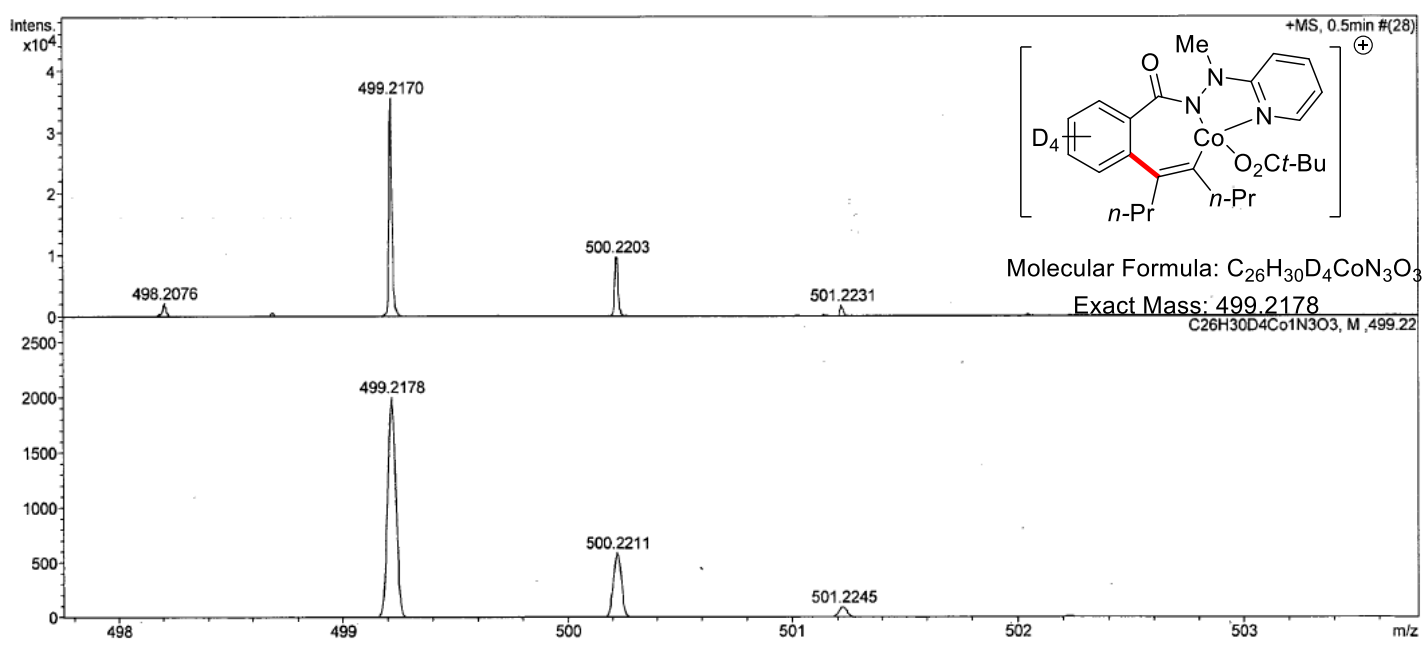

Figure 5.33. ESI-HRMS of the Peak at $\mathrm{m} / \mathrm{z}$ 499.2. 


\section{Cyclic Voltammetry}

The cyclic voltammetry was carried out with a Metrohm Autolab PGSTAT204 workstation and following analysis was performed with Nova 2.0 software. A glassycarbon electrode ( $3 \mathrm{~mm}$-diameter, disc-electrode) was used as the working electrode, a Pt wire as auxiliary electrode and a SCE electrode was used as the reference. The measurements were carried out at a scan rate of $100 \mathrm{mVs}^{-1}$.

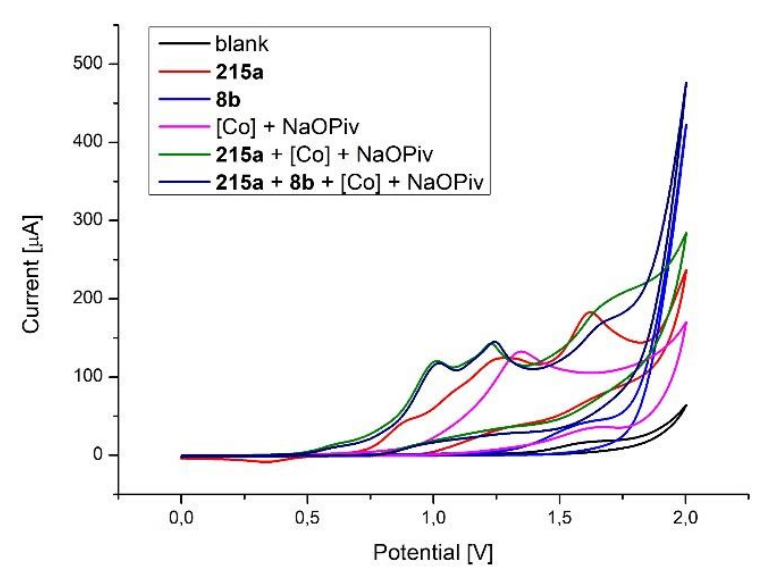

Figure 5.34. Cyclic voltammograms at $100 \mathrm{mVs}^{-1}: n-\mathrm{Bu}_{4} \mathrm{NPF}_{6}(0.1 \mathrm{M}$ in $\mathrm{MeOH})$, concentration of substrates $1 \mathrm{~mm}$ (NaOPiv $4 \mathrm{~mm}$ ). (black) blank; (blue) substrate 8a; (red) substrate 215a; (purple) $\mathrm{Co}(\mathrm{OAc})_{2}$ and NaOPiv; (green) $\mathrm{Co}(\mathrm{OAc})_{2}$, 215a and NaOPiv; (dark blue) $\mathrm{Co}(\mathrm{OAc})_{2}, 215 \mathbf{a}, \mathbf{8 a}$ and NaOPiv.

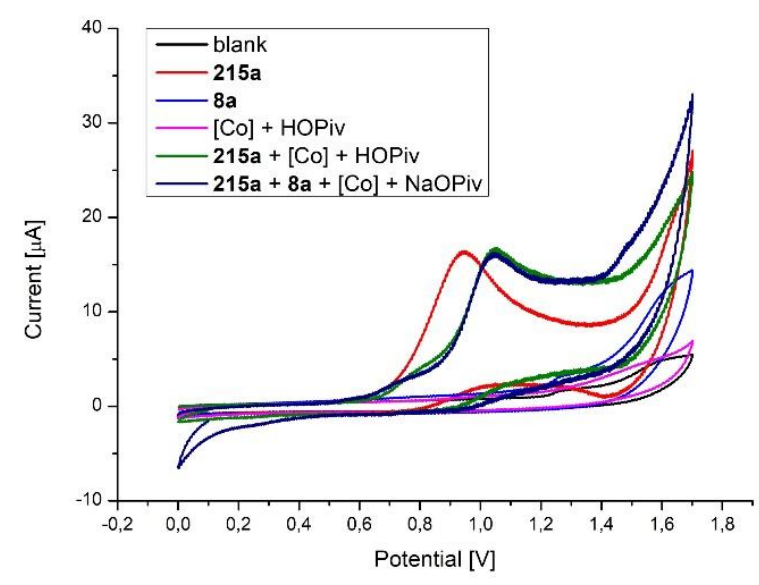

Figure 5.35. Cyclic voltammograms at $100 \mathrm{mVs}^{-1}: n-\mathrm{Bu}_{4} \mathrm{NPF}_{6}(0.1 \mathrm{M}$ in TFE), concentration of substrates $1 \mathrm{~mm}$ (NaOPiv $4 \mathrm{~mm}$ ). (black) blank; (blue) substrate 8a; (red) substrate 215a; (purple) $\mathrm{Co}(\mathrm{OAc})_{2}$ and NaOPiv; (green) $\mathrm{Co}(\mathrm{OAc})_{2}$, 215a and NaOPiv; (dark blue) $\mathrm{Co}(\mathrm{OAc})_{2}, 215 \mathbf{a}, 8 \mathbf{a}$ and NaOPiv. 


\section{Cyclic Voltammetry}

The cyclic voltammetry was carried out with a Metrohm Autolab PGSTAT204 workstation and following analysis was performed with Nova 2.0 software. A glassycarbon electrode ( $3 \mathrm{~mm}$-diameter, disc-electrode) was used as the working electrode, a Pt wire as auxiliary electrode and a SCE electrode was used as the reference. The measurements were carried out at a scan rate of $100 \mathrm{mVs}^{-1}$.

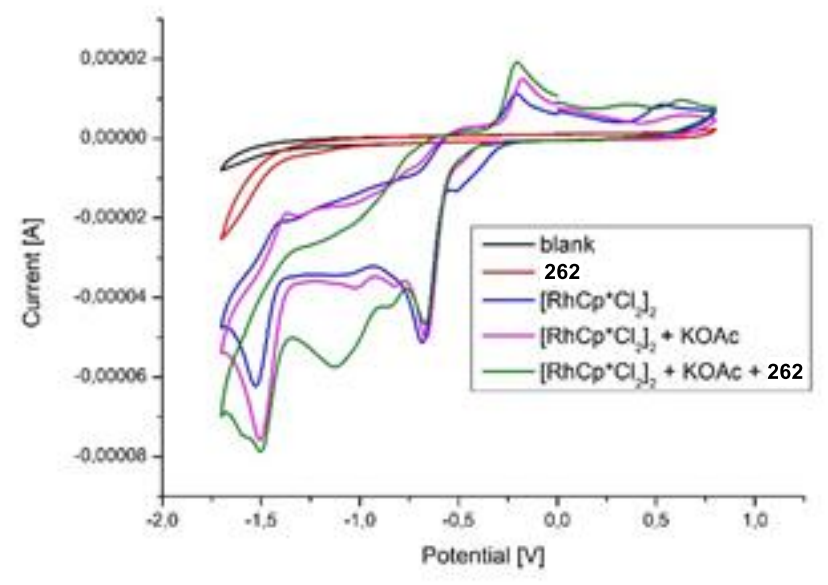

Figure 5.36. Cyclic voltammograms at $100 \mathrm{mV} / \mathrm{s}$ in $\mathrm{MeCN}: n-\mathrm{Bu}_{4} \mathrm{NPF}_{6}(0.1 \mathrm{M}$ in MeCN), concentration of substrates $1 \mathrm{mM}$ (KOAc $4 \mathrm{mM}$ ). (black) blank; (red) 262; (blue) $\left[\mathrm{RhCp}^{*} \mathrm{Cl}_{2}\right]_{2}$; (pink) $\left[\mathrm{RhCp}^{*} \mathrm{Cl}_{2}\right]_{2}+$ $\mathrm{KOAc}$; (green) $\left[\mathrm{RhCp}^{*} \mathrm{Cl}_{2}\right]_{2}+\mathrm{KOAc}+262$.

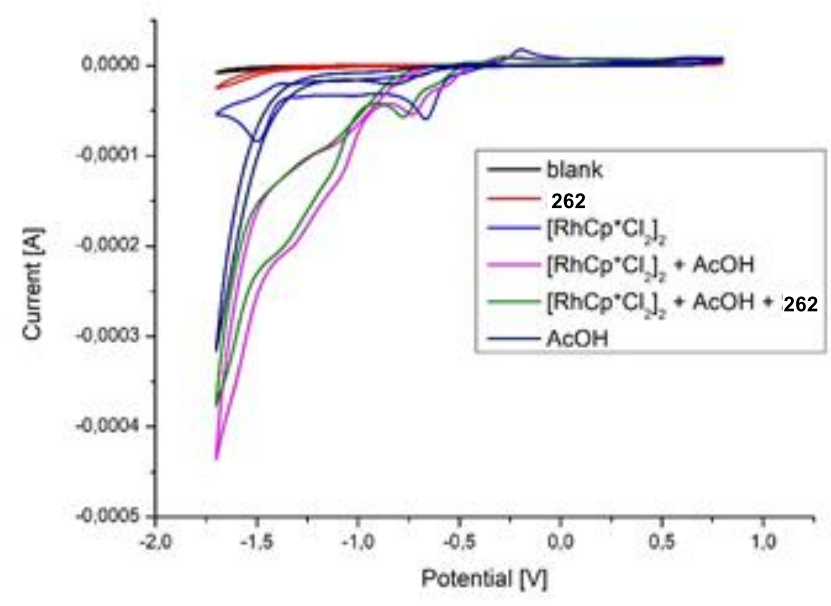

Figure 5.37. Cyclic voltammograms at $100 \mathrm{mV} / \mathrm{s}$ in $\mathrm{MeCN}$. N-Bu4NPF6 $(0.1 \mathrm{M}$ in MeCN), concentration of substrates $1 \mathrm{mM}$ (HOAc $4 \mathrm{mM}$ ). (black) blank; (red) 262; (blue) $\left[\mathrm{RhCp}^{*} \mathrm{Cl}_{2}\right]_{2}$; (pink) $\left[\mathrm{RhCp}^{*} \mathrm{Cl}_{2}\right]_{2}+$ $\mathrm{HOAc}$; (green) $\left[\mathrm{RhCp}^{*} \mathrm{Cl}_{2}\right]_{2}+\mathrm{HOAc}+262$; (dark blue) $\mathrm{HOAc}$ ). 


\section{References}

[1] a) P. Ruiz-Castillo, S. L. Buchwald, Chem. Rev. 2016, 116, 12564-12649; b) S. D. Roughley, A. M. Jordan, J. Med. Chem. 2011, 54, 3451-3479; c) S. Tasler, J. Mies, M. Lang, Adv. Synth. Catal. 2007, 349, 2286-2300; d) J.-P. Corbet, G. Mignani, Chem. Rev. 2006, 106, 2651-2710.

[2] a) E. B. Pinxterhuis, M. Giannerini, V. Hornillos, B. L. Feringa, Nat. Commun. 2016, 7, 11698; b) B. H. Lipshutz, N. A. Isley, J. C. Fennewald, E. D. Slack, Angew. Chem. Int. Ed. 2013, 52, 1095210958; c) B. H. Lipshutz, A. R. Abela, Ž. V. Bošković, T. Nishikata, C. Duplais, A. Krasovskiy, Top. Catal. 2010, 53, 985-990.

[3] Green Chemistry, Theory and Practice (Eds.: P. T. Anastas, J. C. Warner), Oxford Universal Press, Oxford, 1998.

[4] Modern Arylation Methods (Ed.: L. Ackermann), Wiley VCH, Weinheim, 2009.

[5] C. Glaser, Ber. Dtsch. Chem. Ges. 1869, 2, 422-424.

[6] F. Ullmann, J. Bielecki, Ber. Dtsch. Chem. Ges. 1901, 34, 2174-2185.

[7] a) C. C. C. Johansson Seechurn, M. O. Kitching, T. J. Colacot, V. Snieckus, Angew. Chem. Int. Ed. 2012, 51, 5062-5085; b) K. C. Nicolaou, P. G. Bulger, D. Sarlah, Angew. Chem. Int. Ed. 2005, 44, 4442-4489.

[8] a) N. Miyaura, A. Suzuki, Chem. Rev. 1995, 95, 2457-2483; b) N. Miyaura, K. Yamada, A. Suzuki, Tetrahedron Lett. 1979, 20, 3437-3440; c) N. Miyaura, A. Suzuki, J. Chem. Soc. Chem. Comm. $1979,866-867$.

[9] A. O. King, N. Okukado, E.-i. Negishi, J. Chem. Soc. Chem. Comm. 1977, 683-684.

[10] a) K. Tamao, K. Sumitani, M. Kumada, J. Am. Chem. Soc. 1972, 94, 4374-4376; b) R. J. P. Corriu, J. P. Masse, J. Chem. Soc. Chem. Comm. 1972, 144a.

[11] Y. Hatanaka, T. Hiyama, J. Org. Chem. 1988, 53, 918-920.

[12] a) J. K. Stille, Angew. Chem. Int. Ed. 1986, 25, 508-524; b) D. Milstein, J. K. Stille, J. Am. Chem. Soc. 1978, 100, 3636-3638.

[13] a) K. Sonogashira, J. Organomet. Chem. 2002, 653, 46-49; b) K. Sonogashira, Y. Tohda, N. Hagihara, Tetrahedron Lett. 1975, 16, 4467-4470.

[14] a) R. F. Heck, J. P. Nolley, J. Org. Chem. 1972, 37, 2320-2322; b) M. Tsutomu, M. Kunio, O. Atsumu, Bull. Chem. Soc. Jap. 1971, 44, 581-581.

[15] a) F. Paul, J. Patt, J. F. Hartwig, J. Am. Chem. Soc. 1994, 116, 5969-5970; b) A. S. Guram, S. L. Buchwald, J. Am. Chem. Soc. 1994, 116, 7901-7902.

[16] The Nobel prize in Chemistry 2010 - Press Release https://www.nobelprize.org/nobel_prizes/chemistry/laureates/2010/press.html accessed 20.04.2018.

[17] a) T. L. Mako, J. A. Byers, Inorg. Chem. Front. 2016, 3, 766-790; b) W. M. Czaplik, M. Mayer, J. Cvengroš, A. Jacobi von Wangelin, ChemSusChem 2009, 2, 396-417; c) J. K. Kochi, M. Tamura, J. Am. Chem. Soc. 1971, 93, 1485-1487.

[18] a) J. Yamaguchi, K. Muto, K. Itami, Eur. J. Org. Chem. 2013, 2013, 19-30; b) B. M. Rosen, K. W. Quasdorf, D. A. Wilson, N. Zhang, A.-M. Resmerita, N. K. Garg, V. Percec, Chem. Rev. 2011, 111, 1346-1416; c) D. G. Morrell, J. K. Kochi, J. Am. Chem. Soc. 1975, 97, 7262-7270.

[19] S. Santoro, F. Ferlin, L. Luciani, L. Ackermann, L. Vaccaro, Green. Chem. 2017, 19, 1601-1612.

[20] L. Ackermann, A. R. Kapdi, H. K. Potukuchi, S. I. Kozhushkov, in Handbook of Green chemistry (Ed.: C.-J. Li), Wiley-VCH, Weinheim, 2012, 259-305.

[21] a) S. I. Kozhushkov, H. K. Potukuchi, L. Ackermann, Catal. Sci. Technol. 2013, 3, 562-571; b) L. Ackermann, Chem. Commun. 2010, 46, 4866-4877.

[22] F. Kakiuchi, S. Murai, in Activation of Unreactive Bonds and Organic Synthesis (Eds.: S. Murai, H. Alper, R. A. Gossage, V. V. Grushin, M. Hidai, Y. Ito, W. D. Jones, F. Kakiuchi, G. van Koten, Y. S. Lin, Y. Mizobe, S. Murai, M. Murakami, T. G. Richmond, A. Sen, M. Suginome, A. Yamamoto), Springer Berlin, Heidelberg, 1999, 47-79.

[23] L. Ackermann, in Directed Metallation (Ed.: N. Chatani), Springer Berlin, Heidelberg, 2007, 3560. 
[24] P. Gandeepan, L. Ackermann, Chem 2018, 4, 199-222.

[25] a) L. Ackermann, Chem. Rev. 2011, 111, 1315-1345; b) D. Balcells, E. Clot, O. Eisenstein, Chem. Rev. 2010, 110, 749-823; c) J. A. Labinger, J. E. Bercaw, Nature 2002, 417, 507.

[26] J. Oxgaard, W. J. Tenn, R. J. Nielsen, R. A. Periana, W. A. Goddard, Organometallics 2007, 26, 1565-1567.

[27] a) S. I. Gorelsky, D. Lapointe, K. Fagnou, J. Am. Chem. Soc. 2008, 130, 10848-10849; b) D. García-Cuadrado, A. A. C. Braga, F. Maseras, A. M. Echavarren, J. Am. Chem. Soc. 2006, 128, 1066-1067; c) L.-C. Campeau, M. Parisien, A. Jean, K. Fagnou, J. Am. Chem. Soc. 2006, 128, 581-590; d) L.-C. Campeau, M. Parisien, M. Leblanc, K. Fagnou, J. Am. Chem. Soc. 2004, 126, 9186-9187.

[28] a) Y. Boutadla, D. L. Davies, S. A. Macgregor, A. I. Poblador-Bahamonde, Dalton Trans. 2009, 5820-5831; b) Y. Boutadla, D. L. Davies, S. A. Macgregor, A. I. Poblador-Bahamonde, Dalton Trans. 2009, 5887-5893.

[29] a) E. Tan, O. Quinonero, M. E. de Orbe, A. M. Echavarren, ACS Catal. 2018, 8, 2166-2172; b) D. Zell, M. Bursch, V. Müller, S. Grimme, L. Ackermann, Angew. Chem. Int. Ed. 2017, 56, 1037810382; c) H. Wang, M. Moselage, M. J. González, L. Ackermann, ACS Catal. 2016, 6, 2705-2709; d) D. Santrač, S. Cella, W. Wang, L. Ackermann, Eur. J. Org. Chem. 2016, 2016, 5429-5436; e) R. Mei, J. Loup, L. Ackermann, ACS Catal. 2016, 6, 793-797; f) W. Ma, R. Mei, G. Tenti, L. Ackermann, Chem. Eur. J. 2014, 20, 15248-15251.

[30] a) T. G. Saint-Denis, R.-Y. Zhu, G. Chen, Q.-F. Wu, J.-Q. Yu, Science 2018, 359; b) W. Ma, P. Gandeepan, J. Li, L. Ackermann, Org. Chem. Front 2017, 4, 1435-1467; c) Y. Segawa, T. Maekawa, K. Itami, Angew. Chem. Int. Ed. 2015, 54, 66-81; d) J. Wencel-Delord, F. Glorius, Nat. Chem. 2013, 5, 369; e) L. McMurray, F. O'Hara, M. J. Gaunt, Chem. Soc. Rev. 2011, 40, 18851898; f) O. Baudoin, Chem. Soc. Rev. 2011, 40, 4902-4911; g) R. G. Bergman, Nature 2007, 446, 391.

[31] a) K. Shin, H. Kim, S. Chang, Acc. Chem. Res. 2015, 48, 1040-1052; b) N. Kuhl, N. Schröder, F. Glorius, Adv. Synth. Catal. 2014, 356, 1443-1460; c) D. A. Colby, A. S. Tsai, R. G. Bergman, J. A. Ellman, Acc. Chem. Res. 2012, 45, 814-825; d) D. A. Colby, R. G. Bergman, J. A. Ellman, Chem. Rev. 2010, 110, 624-655.

[32] a) T. Sperger, I. A. Sanhueza, I. Kalvet, F. Schoenebeck, Chem. Rev. 2015, 115, 9532-9586; b) S. Pan, T. Shibata, ACS Catal. 2013, 3, 704-712; c) I. A. I. Mkhalid, J. H. Barnard, T. B. Marder, J. M. Murphy, J. F. Hartwig, Chem. Rev. 2010, 110, 890-931.

[33] a) J. He, M. Wasa, K. S. L. Chan, Q. Shao, J. Q. Yu, Chem. Rev. 2017, 117, 8754-8786; b) A. Dey, S. Agasti, D. Maiti, Org. Biomol. Chem. 2016, 14, 5440-5453; c) T. W. Lyons, M. S. Sanford, Chem. Rev. 2010, 110, 1147-1169; d) X. Chen, K. M. Engle, D. H. Wang, J. Q. Yu, Angew. Chem. Int. Ed. 2009, 48, 5094-5115.

[34] a) J. A. Leitch, C. G. Frost, Chem. Soc. Rev. 2017, 46, 7145-7153; b) D. J. Burns, S. I. Kozhushkov, L. Ackermann, in Catalytic Hydroarylation of Carbon-Carbon Multiple Bonds (Eds.: L. G. Habgood, T. B. Gunnoe, L. Ackermann), Wiley VCH, Weinheim, 2017; c) L. Ackermann, Acc. Chem. Res. 2014, 47, 281-295; d) P. B. Arockiam, C. Bruneau, P. H. Dixneuf, Chem. Rev. 2012, 112, 5879-5918; e) L. Ackermann, R. Vicente, in C-H Activation (Eds.: J.-Q. Yu, Z. Shi), Springer Berlin Heidelberg, Berlin, Heidelberg, 2010, 211-229.

[35] CRC Handbook of Chemistry and Physics (Ed.: D. R. Lide), CRC Press/Taylor and Francis, Boca Raton, 2010.

[36] www.infomine.com/investment/ accessed on 20.04.2018.

[37] M. Beller, B. Cornils, C. D. Frohning, C. W. Kohlpaintner, J. Mol. Catal. A 1995, 104, 17-85.

[38] a) H. Bönnemann, Angew. Chem. 1978, 90, 517-526; b) W. Reppe, N. V. Kutepow, A. Margin, Angew. Chem. 1969, 81, 717-723.

[39] a) I. U. Khand, G. R. Knox, P. L. Pauson, W. E. Watts, M. I. Foreman, J. Chem. Soc. Perkin Trans. 1973, 977-981; b) I. U. Khand, G. R. Knox, P. L. Pauson, W. E. Watts, J. Chem. Soc. Perkin Trans. 1973, 975-977.

[40] M. Tokunaga, J. F. Larrow, F. Kakiuchi, E. N. Jacobsen, Science 1997, 277, 936-938. 
[41] M. S. Kharasch, E. K. Fields, J. Am. Chem. Soc. 1941, 63, 2316-2320.

[42] a) S. Murahashi, S. Horiie, J. Am. Chem. Soc. 1956, 78, 4816-4817; b) S. Murahashi, J. Am. Chem. Soc. 1955, 77, 6403-6404.

[43] a) S. Camadanli, R. Beck, U. Florke, H.-F. Klein, Dalton Trans. 2008, 5701-5704; b) R. Beck, H. Sun, X. Li, S. Camadanli, H.-F. Klein, Eur. J. Inorg. Chem. 2008, 2008, 3253-3257; c) H.-F. Klein, S. Camadanli, R. Beck, D. Leukel, U. Flörke, Angew. Chem. Int. Ed. 2005, 44, 975-977; d) H.-F. Klein, R. Beck, U. Flörke, H.-J. Haupt, Eur. J. Inorg. Chem. 2003, 2003, 1380-1387; e) H.-F. Klein, S. Schneider, M. He, U. Flörke, H.-J. Haupt, Eur. J. Inorg. Chem. 2000, 2295-2301; f) H.-F. Klein, M. Hellwig, U. Koch, U. Flörke, H.-J. Haupt, Z. Naturforsch. B 1993, 48, 778-784.

[44] C. P. Lenges, M. Brookhart, B. E. Grant, J. Organomet. Chem. 1997, 528, 199-203.

[45] G. Halbritter, F. Knoch, A. Wolski, H. Kisch, Angew. Chem. Int. Ed. 1994, 33, 1603-1605.

[46] a) B. J. Fallon, E. Derat, M. Amatore, C. Aubert, F. Chemla, F. Ferreira, A. Perez-Luna, M. Petit, Org. Lett. 2016, 18, 2292-2295; b) B. J. Fallon, J.-B. Garsi, E. Derat, M. Amatore, C. Aubert, M. Petit, ACS Catal. 2015, 5, 7493-7497; c) B. J. Fallon, E. Derat, M. Amatore, C. Aubert, F. Chemla, F. Ferreira, A. Perez-Luna, M. Petit, J. Am. Chem. Soc. 2015, 137, 2448-2451.

[47] L. Ilies, Q. Chen, X. Zeng, E. Nakamura, J. Am. Chem. Soc. 2011, 133, 5221-5223.

[48] a) M. Moselage, J. Li, L. Ackermann, ACS Catal. 2016, 6, 498-525; b) Y. Naohiko, Bull. Chem. Soc. Jap. 2014, 87, 843-857; c) K. Gao, N. Yoshikai, Acc. Chem. Res. 2014, 47, 1208-1219; d) L. Ackermann, J. Org. Chem. 2014, 79, 8948-8954.

[49] B. Punji, W. Song, G. A. Shevchenko, L. Ackermann, Chem. Eur. J. 2013, 19, 10605-10610.

[50] K. Gao, N. Yoshikai, J. Am. Chem. Soc. 2013, 135, 9279-9282.

[51] Prices of chlorocyclohexane $(17.26 € / \mathrm{mol})$ and bromo-2,2-dimethylpropane $(936,41 € / \mathrm{mol})$ calculated based on the largest available unit from sigma aldrich, prices obtained on 16.05.2018.

[52] W. Song, L. Ackermann, Angew. Chem. Int. Ed. 2012, 51, 8251-8254.

[53] J. Li, L. Ackermann, Chem. Eur. J. 2015, 21, 5718-5722.

[54] R. Mei, L. Ackermann, Adv. Synth. Catal. 2016, 358, 2443-2448.

[55] a) Y. Onishi, Y. Yoneda, Y. Nishimoto, M. Yasuda, A. Baba, Org. Lett. 2012, 14, 5788-5791; b) Y. Ding, W. Wang, Z. Liu, Phosphorous Sulfur Relat. Elem. 1996, 118, 113-116; c) M. G. Silvestri, M. P. Hanson, J. G. Pavlovich, L. F. Studen, M. S. DeClue, M. R. DeGraffenreid, C. D. Amos, J. Org. Chem. 1999, 64, 6597-6602; d) M. Boultadakis-Arapinis, M. N. Hopkinson, F. Glorius, Org. Lett. 2014, 16, 1630-1633.

[56] M. Moselage, N. Sauermann, S. C. Richter, L. Ackermann, Angew. Chem. Int. Ed. 2015, 54, 6352-6355.

[57] K. Gao, P.-S. Lee, T. Fujita, N. Yoshikai, J. Am. Chem. Soc. 2010, 132, 12249-12251.

[58] Z. Ding, N. Yoshikai, Angew. Chem. Int. Ed. 2012, 51, 4698-4701.

[59] P.-S. Lee, T. Fujita, N. Yoshikai, J. Am. Chem. Soc. 2011, 133, 17283-17295.

[60] T. Yamakawa, N. Yoshikai, Org. Lett. 2013, 15, 196-199.

[61] a) Z. Ding, N. Yoshikai, Synthesis 2011, 2561-2566; b) Z. Ding, N. Yoshikai, Org. Lett. 2010, 12, 4180-4183.

[62] K. Gao, N. Yoshikai, J. Am. Chem. Soc. 2011, 133, 400-402.

[63] K. Gao, N. Yoshikai, Angew. Chem. Int. Ed. 2011, 50, 6888-6892.

[64] P.-S. Lee, N. Yoshikai, Org. Lett. 2015, 17, 22-25.

[65] a) W. Xu, J. H. Pek, N. Yoshikai, Adv. Synth. Catal. 2016, 358, 2564-2568; b) J. Yang, N. Yoshikai, J. Am. Chem. Soc. 2014, 136, 16748-16751.

[66] U. Koelle, B. Fuss, M. V. Rajasekharan, B. L. Ramakrishna, J. H. Ammeter, M. C. Boehm, J. Am. Chem. Soc. 1984, 106, 4152-4160.

[67] T. Yoshino, H. Ikemoto, S. Matsunaga, M. Kanai, Angew. Chem. Int. Ed. 2013, 52, 2207-2211.

[68] T. Yoshino, H. Ikemoto, S. Matsunaga, M. Kanai, Chem. Eur. J. 2013, 19, 9142-9146.

[69] T. Yoshino, S. Matsunaga, in Advances in Organometallic Chemistry, Vol. 68 (Ed.: P. J. Pérez), Academic Press, 2017, 197-247. 
[70] H. Ikemoto, T. Yoshino, K. Sakata, S. Matsunaga, M. Kanai, J. Am. Chem. Soc. 2014, 136, 54245431.

[71] H. Ikemoto, R. Tanaka, K. Sakata, M. Kanai, T. Yoshino, S. Matsunaga, Angew. Chem. Int. Ed. 2017, 56, 7156-7160.

[72] R. Tanaka, H. Ikemoto, M. Kanai, T. Yoshino, S. Matsunaga, Org. Lett. 2016, 18, 5732-5735.

[73] S. Nakanowatari, R. Mei, M. Feldt, L. Ackermann, ACS Catal. 2017, 7, 2511-2515.

[74] Z. Zhang, S. Han, M. Tang, L. Ackermann, J. Li, Org. Lett. 2017, 19, 3315-3318.

[75] J. R. Hummel, J. A. Ellman, J. Am. Chem. Soc. 2015, 137, 490-498.

[76] a) J. Li, M. Tang, L. Zang, X. Zhang, Z. Zhang, L. Ackermann, Org. Lett. 2016, 18, 2742-2745; b) H. Wang, J. Koeller, W. Liu, L. Ackermann, Chem. Eur. J. 2015, 21, 15525-15528; c) B. Sun, T. Yoshino, M. Kanai, S. Matsunaga, Angew. Chem. Int. Ed. 2015, 54, 12968-12972; d) M. Sen, D. Kalsi, B. Sundararaju, Chem. Eur. J. 2015, 21, 15529-15533.

[77] H. Wang, M. M. Lorion, L. Ackermann, Angew. Chem. Int. Ed. 2016, 55, 10386-10390.

[78] Z.-Z. Zhang, B. Liu, C.-Y. Wang, B.-F. Shi, Org. Lett. 2015, 17, 4094-4097.

[79] a) M. Moselage, N. Sauermann, J. Koeller, W. Liu, D. Gelman, L. Ackermann, Synlett 2015, 26, 1596-1600; b) D.-G. Yu, T. Gensch, F. de Azambuja, S. Vásquez-Céspedes, F. Glorius, J. Am. Chem. Soc. 2014, 136, 17722-17725.

[80] a) M. R. Sk, S. S. Bera, M. S. Maji, Org. Lett. 2018, 20, 134-137; b) K. Ramachandran, P. Anbarasan, Eur. J. Org. Chem. 2017, 2017, 3965-3968; c) L. Kong, S. Yu, G. Tang, H. Wang, X. Zhou, X. Li, Org. Lett. 2016, 18, 3802-3805.

[81] H. Wang, M. M. Lorion, L. Ackermann, ACS Catal. 2017, 7, 3430-3433.

[82] a) Y. Bunno, N. Murakami, Y. Suzuki, M. Kanai, T. Yoshino, S. Matsunaga, Org. Lett. 2016, 18, 2216-2219; b) Y. Suzuki, B. Sun, K. Sakata, T. Yoshino, S. Matsunaga, M. Kanai, Angew. Chem. Int. Ed. 2015, 54, 9944-9947.

[83] T. Gensch, S. Vásquez-Céspedes, D.-G. Yu, F. Glorius, Org. Lett. 2015, 17, 3714-3717.

[84] J. Li, L. Ackermann, Angew. Chem. Int. Ed. 2015, 54, 3635-3638.

[85] A. B. Pawar, S. Chang, Org. Lett. 2015, 17, 660-663.

[86] A. B. Pawar, D. M. Lade, Org. Biomol. Chem. 2016, 14, 3275-3283.

[87] B. Sun, T. Yoshino, S. Matsunaga, M. Kanai, Adv. Synth. Catal. 2014, 356, 1491-1495.

[88] Y. Liang, Y.-F. Liang, C. Tang, Y. Yuan, N. Jiao, Chem. Eur. J. 2015, 21, 16395-16399.

[89] P. Patel, S. Chang, ACS Catal. 2015, 5, 853-858.

[90] V. G. Zaitsev, D. Shabashov, O. Daugulis, J. Am. Chem. Soc. 2005, 127, 13154-13155.

[91] Q. Gu, H. Al Mamari Hamad, K. Graczyk, E. Diers, L. Ackermann, Angew. Chem. Int. Ed. 2014, 53, 3868-3871.

[92] F.-J. Chen, S. Zhao, F. Hu, K. Chen, Q. Zhang, S.-Q. Zhang, B.-F. Shi, Chem. Sci. 2013, 4, 41874192.

[93] X.-Q. Hao, L.-J. Chen, B. Ren, L.-Y. Li, X.-Y. Yang, J.-F. Gong, J.-L. Niu, M.-P. Song, Org. Lett. 2014, $16,1104-1107$.

[94] L. Grigorjeva, O. Daugulis, Angew. Chem. Int. Ed. 2014, 53, 10209-10212.

[95] L. Grigorjeva, O. Daugulis, Org. Lett. 2014, 16, 4684-4687.

[96] T. T. Nguyen, L. Grigorjeva, O. Daugulis, ACS Catal. 2015, 6, 551-554.

[97] T. T. Nguyen, L. Grigorjeva, O. Daugulis, Angew. Chem. Int. Ed. 2018, 57, 1688-1691.

[98] W. Ma, L. Ackermann, ACS Catal. 2015, 5, 2822-2825.

[99] R. Mei, H. Wang, S. Warratz, S. A. Macgregor, L. Ackermann, Chem. Eur. J. 2016, 22, 67596763.

[100] N. Thrimurtulu, A. Dey, D. Maiti, C. M. R. Volla, Angew. Chem. Int. Ed. 2016, 55, 12361-12365.

[101] a) D. Kalsi, B. Sundararaju, Org. Lett. 2015, 17, 6118-6121; b) O. Planas, C. J. Whiteoak, A. Company, X. Ribas, Adv. Synth. Catal. 2015, 357, 4003-4012.

[102] L. Grigorjeva, O. Daugulis, Org. Lett. 2014, 16, 4688-4690.

[103] V. G. Landge, G. Jaiswal, E. Balaraman, Org. Lett. 2016, 18, 812-815.

[104] Q. Li, Y. Li, W. Hu, R. Hu, G. Li, H. Lu, Chem. Eur. J. 2016, 22, 12286-2289.

[105] T. Yamaguchi, Y. Kommagalla, Y. Aihara, N. Chatani, Chem. Commun. 2016, 52, 10129-10132. 
[106] L. Grigorjeva, O. Daugulis, Org. Lett. 2015, 17, 1204-1207.

[107] C. Du, P. X. Li, X. Zhu, J. F. Suo, J. L. Niu, M. P. Song, Angew. Chem. Int. Ed. 2016, 55, 1357113575.

[108] a) G. Tan, S. He, X. Huang, X. Liao, Y. Cheng, J. You, Angew. Chem. Int. Ed. 2016, 55, 1041410418; b) L. Hu, Q. Gui, X. Chen, Z. Tan, G. Zhu, Org. Biomol. Chem. 2016, 14, 11070-11075.

[109] X. Zhu, J. H. Su, C. Du, Z. L. Wang, C. J. Ren, J. L. Niu, M. P. Song, Org. Lett. 2017, 19, 596-599.

[110] a) C. Du, P.-X. Li, X. Zhu, J.-N. Han, J.-L. Niu, M.-P. Song, ACS Catal. 2017, 7, 2810-2814; b) L. B. Zhang, S. K. Zhang, D. Wei, X. Zhu, X. Q. Hao, J. H. Su, J. L. Niu, M. P. Song, Org. Lett. 2016, 18, 1318-1321; c) Q. Yan, T. Xiao, Z. Liu, Y. Zhang, Adv. Synth. Catal. 2016, 358, 2707-2711.

[111] a) R. Ueno, S. Natsui, N. Chatani, Org. Lett. 2018, 20, 1062-1065; b) L. B. Zhang, X. Q. Hao, S. K. Zhang, Z. J. Liu, X. X. Zheng, J. F. Gong, J. L. Niu, M. P. Song, Angew. Chem. Int. Ed. 2015, 54, 272-275.

[112] Y. Kommagalla, K. Yamazaki, T. Yamaguchi, N. Chatani, Chem. Commun. 2018, 54, 1359-1362.

[113] X. Wu, K. Yang, Y. Zhao, H. Sun, G. Li, H. Ge, Nat. Commun. 2015, 6, 6462.

[114] J. Zhang, H. Chen, C. Lin, Z. Liu, C. Wang, Y. Zhang, J. Am. Chem. Soc. 2015, 137, 12990-12996.

[115] a) L. Zeng, S. Tang, D. Wang, Y. Deng, J. L. Chen, J. F. Lee, A. Lei, Org. Lett. 2017, 19, 2170-2173;

b) P. Williamson, A. Galvan, M. J. Gaunt, Chem. Sci. 2017, 8, 2588-2591; c) N. Barsu, S. K. Bolli, B. Sundararaju, Chem. Sci. 2017, 8, 2431-2435.

[116] a) D. S. Avila, R. L. Puntel, M. Aschner, in Interrelations between Essential Metal lons and Human Diseases (Eds.: A. Sigel, H. Sigel, R. K. O. Sigel), Springer Netherlands, Dordrecht, 2013, 199-227; b) P. B. Tchounwou, C. G. Yedjou, A. K. Patlolla, D. J. Sutton, in Molecular, Clinical and Environmental Toxicology: Volume 3: Environmental Toxicology (Ed.: A. Luch), Springer Basel, Basel, 2012, 133-164; c) N. A. Law, M. T. Caudle, V. L. Pecoraro, in Advances in Inorganic Chemistry, Vol. 46 (Ed.: A. G. Sykes), Academic Press, 1998, 305-440.

[117] a) A. S. Borovik, Chem. Soc. Rev. 2011, 40, 1870-1874; b) A. Gunay, K. H. Theopold, Chem. Rev. 2010, 110, 1060-1081.

[118] a) S. M. Paradine, J. R. Griffin, J. Zhao, A. L. Petronico, S. M. Miller, M. C. White, Nat. Chem. 2015, 7, 987-994; b) X. Huang, T. M. Bergsten, J. T. Groves, J. Am. Chem. Soc. 2015, 137, 53005303; c) D. Shen, C. Miao, S. Wang, C. Xia, W. Sun, Org. Lett. 2014, 16, 1108-1111; d) X. Huang, W. Liu, H. Ren, R. Neelamegam, J. M. Hooker, J. T. Groves, J. Am. Chem. Soc. 2014, 136, 68426845; e) W. Liu, J. T. Groves, Angew. Chem. Int. Ed. 2013, 52, 6024-6027; f) R. V. Ottenbacher, D. G. Samsonenko, E. P. Talsi, K. P. Bryliakov, Org. Lett. 2012, 14, 4310-4313; g) W. Liu, X. Huang, M.-J. Cheng, R. J. Nielsen, W. A. Goddard, J. T. Groves, Science 2012, 337, 1322-1325; h) W. Liu, J. T. Groves, J. Am. Chem. Soc. 2010, 132, 12847-12849; i) S. Das, C. D. Incarvito, R. H. Crabtree, G. W. Brudvig, Science 2006, 312, 1941-1943; j) R. Breslow, X. Zhang, Y. Huang, J. Am. Chem. Soc. 1997, 119, 4535-4536.

[119] a) Y. Hu, B. Zhou, C. Wang, Acc. Chem. Res. 2018, 51, 816-827; b) W. Liu, L. Ackermann, ACS Catal. 2016, 6, 3743-3752.

[120] a) C. Zhu, J. C. A. Oliveira, Z. Shen, H. Huang, L. Ackermann, ACS Catal. 2018, 8, 4402-4407; b) T. Sato, T. Yoshida, H. H. Al Mamari, L. Ilies, E. Nakamura, Org. Lett. 2017, 19, 5458-5461; c) W. Liu, G. Cera, J. C. A. Oliveira, Z. Shen, L. Ackermann, Chem. Eur. J. 2017, 23, 11524-11528.

[121] M. I. Bruce, M. Z. Iqbal, F. G. A. Stone, J. Chem. Soc. A. 1970, 3204-3209.

[122] R. F. Heck, J. Am. Chem. Soc. 1968, 90, 313-317.

[123] a) G. J. Depree, L. Main, B. K. Nicholson, N. P. Robinson, G. B. Jameson, J. Organomet. Chem. 2006, 691, 667-679; b) J. Albert, J. M. Cadena, J. Granell, X. Solans, M. Font-Bardia, J. Organomet. Chem. 2004, 689, 4889-4896; c) M. A. Leeson, B. K. Nicholson, M. R. Olsen, J. Organomet. Chem. 1999, 579, 243-251; d) J.-P. Djukic, A. Maisse, M. Pfeffer, J. Organomet. Chem. 1998, 567, 65-74; e) J.-P. Djukic, A. Maisse, M. Pfeffer, A. de Cian, J. Fischer, Organometallics 1997, 16, 657-667; f) J. M. Cooney, L. H. P. Gommans, L. Main, B. K. Nicholson, J. Organomet. Chem. 1988, 349, 197-207; g) M. I. Bruce, B. L. Goodall, M. Z. Iqbal, F. G. A. Stone, R. J. Doedens, R. G. Little, J. Chem. Soc. D. 1971, 1595-1596.

[124] Y. Kuninobu, Y. Nishina, T. Takeuchi, K. Takai, Angew. Chem. Int. Ed. 2007, 46, 6518-6520. 
[125] a) B. Zhou, Y. Hu, T. Liu, C. Wang, Nat. Commun. 2017, 8, 1169; b) B. Zhou, Y. Hu, C. Wang, Angew. Chem. Int. Ed. 2015, 54, 13659-13663; c) B. Zhou, P. Ma, H. Chen, C. Wang, Chem. Commun. 2014, 50, 14558-14561; d) B. Zhou, H. Chen, C. Wang, J. Am. Chem. Soc. 2013, 135, 1264-1267.

[126] a) Y. F. Liang, L. Massignan, L. Ackermann, ChemCatChem 2018, DOI: 10.1002/cctc.201800144; b) H. Wang, F. Pesciaioli, J. C. A. Oliveira, S. Warratz, L. Ackermann, Angew. Chem. Int. Ed. 2017, 56, 15063-15067; c) W. Liu, D. Zell, M. John, L. Ackermann, Angew. Chem. Int. Ed. 2015, 54, 4092-4096; d) W. Liu, J. Bang, Y. Zhang, L. Ackermann, Angew. Chem. Int. Ed. 2015, 54, 1413714140; e) H. Wang, M. M. Lorion, L. Ackermann, Angew. Chem. Int. Ed. 2017, 56, 6339-6342; f) T. H. Meyer, W. Liu, M. Feldt, A. Wuttke, R. A. Mata, L. Ackermann, Chem. Eur. J. 2017, 23, 5443-5447.

[127] a) C. Wang, A. Wang, M. Rueping, Angew. Chem. Int. Ed. 2017, 56, 9935-9938; b) S. Y. Chen, Q. Li, H. Wang, J. Org. Chem. 2017, 82, 11173-11181; c) S. Y. Chen, X. L. Han, J. Q. Wu, Q. Li, Y. Chen, H. Wang, Angew. Chem. Int. Ed. 2017, 56, 9939-9943; d) L. Shi, X. Zhong, H. She, Z. Lei, F. Li, Chem. Commun. 2015, 51, 7136-7139; e) Q. Lu, F. J. R. Klauck, F. Glorius, Chem. Sci. 2017, 8, 3379-3383.

[128] a) Y. F. Liang, R. Steinbock, A. Münch, D. Stalke, L. Ackermann, Angew. Chem. Int. Ed. 2018, 57, 5384-5388. b) Q. Lu, S. Gressies, S. Cembellin, F. J. R. Klauck, C. G. Daniliuc, F. Glorius, Angew. Chem. Int. Ed. 2017, 56, 12778-12782; c) Y. F. Liang, V. Muller, W. Liu, A. Munch, D. Stalke, L. Ackermann, Angew. Chem. Int. Ed. 2017, 56, 9415-9419; d) S. Y. Chen, Q. Li, X. G. Liu, J. Q. Wu, S. S. Zhang, H. Wang, ChemSusChem 2017, 10, 2360-2364; e) S. Sueki, Z. Wang, Y. Kuninobu, Org. Lett. 2016, 18, 304-307.

[129] W. Liu, S. C. Richter, Y. Zhang, L. Ackermann, Angew. Chem. Int. Ed. 2016, 55, 7747-7750.

[130] W. Liu, S. C. Richter, R. Mei, M. Feldt, L. Ackermann, Chem. Eur. J. 2016, 22, 17958-17961.

[131] Q. Lu, S. Gressies, F. J. R. Klauck, F. Glorius, Angew. Chem. Int. Ed. 2017, 56, 6660-6664.

[132] a) H. Amii, K. Uneyama, Chem. Rev. 2009, 109, 2119-2183; b) J. L. Kiplinger, T. G. Richmond, C. E. Osterberg, Chem. Rev. 1994, 94, 373-431.

[133] D. Zell, U. Dhawa, V. Müller, M. Bursch, S. Grimme, L. Ackermann, ACS Catal. 2017, 7, 42094213.

[134] S. H. Cai, L. Ye, D. X. Wang, Y. Q. Wang, L. J. Lai, C. Zhu, C. Feng, T. P. Loh, Chem. Commun. 2017, 53, 8731-8734.

[135] www.bmwi/Redaktion/EN/Dossier/renewable-energy.html accessed on 30.03.2018.

[136] a) J. Collins, G. Gourdin, D. Qu, in Green. Chem., Elsevier, 2018, 771-860; b) W. Leitner, E. A. Quadrelli, R. Schlogl, Green. Chem. 2017, 19, 2307-2308.

[137] Average prices calculated on the prices for the largest unit available at abcr, sigma-aldrich and fisher scientific, obtained on 20.04.2018.

[138] a) H. Kolbe, Liebigs. Ann. Chem. 1849, 69, 257-294; b) H. Kolbe, Liebigs. Ann. Chem. 1848, 68, 339-341; c) M. Faraday, Phil. Trans. R. Soc. Lond. 1832, 122, 125-162; d) A. Volta, Phil. Trans. R. Soc. Lond. 1800, 90, 403-431.

[139] a) P. Alfonso-Súarez, A. V. Kolliopoulos, J. P. Smith, C. E. Banks, A. M. Jones, Tetrahedron Lett. 2015, 56, 6863-6867; b) A. M. Jones, C. E. Banks, Beilstein J. Org. Chem. 2014, 10, 3056-3072.

[140] a) S. Möhle, M. Zirbes, E. Rodrigo, T. Gieshoff, A. Wiebe, S. R. Waldvogel, Angew. Chem. Int. Ed. 2018, 57, 6018-6041; b) A. Wiebe, T. Gieshoff, S. Möhle, E. Rodrigo, M. Zirbes, S. R. Waldvogel, Angew. Chem. Int. Ed. 2018, 57, 5594-5619; c) M. Yan, Y. Kawamata, P. S. Baran, Angew. Chem. Int. Ed. 2017, 57, 4149-4155; d) E. J. Horn, B. R. Rosen, P. S. Baran, ACS Central Science 2016, 2, 302-308; e) R. Francke, R. D. Little, Chem. Soc. Rev. 2014, 43, 2492-2521; f) J.-i. Yoshida, K. Kataoka, R. Horcajada, A. Nagaki, Chem. Rev. 2008, 108, 2265-2299.

[141] a) A. Wiebe, S. Lips, D. Schollmeyer, R. Franke, S. R. Waldvogel, Angew. Chem. Int. Ed. 2017, 56, 14727-14731; b) L. Schulz, M. Enders, B. Elsler, D. Schollmeyer, K. M. Dyballa, R. Franke, S. R. Waldvogel, Angew. Chem. Int. Ed. 2017, 56, 4877-4881; c) T. Gieshoff, A. Kehl, D. Schollmeyer, K. D. Moeller, S. R. Waldvogel, J. Am. Chem. Soc. 2017, 139, 12317-12324; d) A. Wiebe, D. Schollmeyer, K. M. Dyballa, R. Franke, S. R. Waldvogel, Angew. Chem. Int. Ed. 2016, 
55, 11801-11805; e) B. Elsler, D. Schollmeyer, K. M. Dyballa, R. Franke, S. R. Waldvogel, Angew. Chem. Int. Ed. 2014, 53, 5210-5213.

[142] a) C. Li, Y. Kawamata, H. Nakamura, J. C. Vantourout, Z. Liu, Q. Hou, D. Bao, J. T. Starr, J. Chen, M. Yan, P. S. Baran, Angew. Chem. Int. Ed. 2017, 56, 13088-13093; b) Y. Kawamata, M. Yan, Z. Liu, D.-H. Bao, J. Chen, J. T. Starr, P. S. Baran, J. Am. Chem. Soc. 2017, 139, 7448-7451; c) E. J. Horn, B. R. Rosen, Y. Chen, J. Tang, K. Chen, M. D. Eastgate, P. S. Baran, Nature 2016, 533, 77; d) B. R. Rosen, E. W. Werner, A. G. O'Brien, P. S. Baran, J. Am. Chem. Soc. 2014, 136, 55715574; e) A. G. O'Brien, A. Maruyama, Y. Inokuma, M. Fujita, P. S. Baran, D. G. Blackmond, Angew. Chem. Int. Ed. 2014, 53, 11868-11871.

[143] a) R. Hayashi, A. Shimizu, J.-i. Yoshida, J. Am. Chem. Soc. 2016, 138, 8400-8403; b) T. Morofuji, A. Shimizu, J.-i. Yoshida, J. Am. Chem. Soc. 2015, 137, 9816-9819; c) T. Morofuji, A. Shimizu, J.i. Yoshida, J. Am. Chem. Soc. 2014, 136, 4496-4499; d) T. Morofuji, A. Shimizu, J.-i. Yoshida, J. Am. Chem. Soc. 2013, 135, 5000-5003; e) Y. Ashikari, A. Shimizu, T. Nokami, J.-i. Yoshida, J. Am. Chem. Soc. 2013, 135, 16070-16073; f) T. Morofuji, A. Shimizu, J. i. Yoshida, Angew. Chem. Int. Ed. 2012, 51, 7259-7262.

[144] a) P. Xiong, H.-H. Xu, J. Song, H.-C. Xu, J. Am. Chem. Soc. 2018, 140, 2460-2464; b) H. B. Zhao, Z. J. Liu, J. Song, H. C. Xu, Angew. Chem. Int. Ed. 2017, 56, 12732-12735; c) P. Xiong, H.-H. Xu, H.-C. Xu, J. Am. Chem. Soc. 2017, 139, 2956-2959; d) Z. W. Hou, Z. Y. Mao, Y. Y. Melcamu, X. Lu, H. C. Xu, Angew. Chem. Int. Ed. 2017, 57, 1636-1639; e) L. Zhu, P. Xiong, Z. Y. Mao, Y. H. Wang, X. Yan, X. Lu, H. C. Xu, Angew. Chem. Int. Ed. 2016, 55, 2226-2229; f) H. B. Zhao, Z. W. Hou, Z. J. Liu, Z. F. Zhou, J. Song, H. C. Xu, Angew. Chem. Int. Ed. 2016, 56, 587-590; g) Z. W. Hou, Z. Y. Mao, H. B. Zhao, Y. Y. Melcamu, X. Lu, J. Song, H. C. Xu, Angew. Chem. Int. Ed. 2016, $55,9168-9172$.

[145] a) K.-Y. Ye, G. Pombar, N. Fu, G. S. Sauer, I. Keresztes, S. Lin, J. Am. Chem. Soc. 2018, 140, 24382441; b) P. Wang, S. Tang, P. Huang, A. Lei, Angew. Chem. Int. Ed. 2017, 56, 3009-3013; c) O. Koleda, T. Broese, J. Noetzel, M. Roemelt, E. Suna, R. Francke, J. Org. Chem. 2017, 82, 1166911681; d) N. Fu, G. S. Sauer, A. Saha, A. Loo, S. Lin, Science 2017, 357, 575-579; e) N. Fu, G. S. Sauer, S. Lin, J. Am. Chem. Soc. 2017, 139, 15548-15553; f) M. J. Llorente, B. H. Nguyen, C. P. Kubiak, K. D. Moeller, J. Am. Chem. Soc. 2016, 138, 15110-15113; g) L.-S. Kang, M.-H. Luo, C. M. Lam, L.-M. Hu, R. D. Little, C.-C. Zeng, Green. Chem. 2016, 18, 3767-3774; h) J. Chen, W.-Q. Yan, C. M. Lam, C.-C. Zeng, L.-M. Hu, R. D. Little, Org. Lett. 2015, 17, 986-989; i) H.-C. Xu, J. M. Campbell, K. D. Moeller, J. Org. Chem. 2014, 79, 379-391; j) W. C. Li, C. C. Zeng, L. M. Hu, H. Y. Tian, R. D. Little, Adv. Synth. Catal. 2013, 355, 2884-2890.

[146] M. S. Freund, J. A. Labinger, N. S. Lewis, J. E. Bercaw, J. Mol. Catal. 1994, 87, L11-L15.

[147] M. Khenkin Alexander, M. Somekh, R. Carmieli, R. Neumann, Angew. Chem. Int. Ed. 2018, 57, 4503-4507.

[148] C. Amatore, C. Cammoun, A. Jutand, Adv. Synth. Catal. 2007, 349, 292-296.

[149] a) Y. Fujiwara, I. Moritani, S. Danno, R. Asano, S. Teranishi, J. Am. Chem. Soc. 1969, 91, 71667169; b) Y. Fujiwara, I. Moritani, M. Matsuda, S. Teranishi, Tetrahedron Lett. 1968, 9, 633-636; c) I. Moritanl, Y. Fujiwara, Tetrahedron Lett. 1967, 8, 1119-1122.

[150] F. Kakiuchi, T. Kochi, H. Mutsutani, N. Kobayashi, S. Urano, M. Sato, S. Nishiyama, T. Tanabe, J. Am. Chem. Soc. 2009, 131, 11310-11311.

[151] H. Aiso, T. Kochi, H. Mutsutani, T. Tanabe, S. Nishiyama, F. Kakiuchi, J. Org. Chem. 2012, 77, 7718-7724.

[152] A. E. Proctor, L. A. Thompson, C. L. O’Bryant, Ann. Pharmacother. 2014, 48, 99-106.

[153] M. Konishi, K. Tsuchida, K. Sano, T. Kochi, F. Kakiuchi, J. Org. Chem. 2017, 82, 8716-8724.

[154] F. Saito, H. Aiso, T. Kochi, F. Kakiuchi, Organometallics 2014, 33, 6704-6707.

[155] Y. B. Dudkina, D. Y. Mikhaylov, T. V. Gryaznova, A. I. Tufatullin, O. N. Kataeva, D. A. Vicic, Y. H. Budnikova, Organometallics 2013, 32, 4785-4792.

[156] a) T. V. Grayaznova, Y. B. Dudkina, D. R. Islamov, O. N. Kataeva, O. G. Sinyashin, D. A. Vicic, Y. H. Budnikova, J. Organomet. Chem. 2015, 785, 68-71; b) T. Gryaznova, Y. Dudkina, M. 
Khrizanforov, O. Sinyashin, O. Kataeva, Y. Budnikova, J. Solid State. Electr. 2015, 19, 26652672.

[157] a) M. Khrizanforov, S. Strekalova, V. Khrizanforova, V. Grinenko, K. Kholin, M. Kadirov, T. Burganov, A. Gubaidullin, T. Gryaznova, O. Sinyashin, L. Xu, D. A. Vicic, Y. Budnikova, Dalton Trans. 2015, 44, 19674-19681; b) D. Mikhaylov, T. Gryaznova, Y. Dudkina, M. Khrizanphorov, S. Latypov, O. Kataeva, D. A. Vicic, O. G. Sinyashin, Y. Budnikova, Dalton Trans. 2012, 41, 165172; c) Y. B. Dudkina, D. Y. Mikhaylov, T. V. Gryaznova, O. G. Sinyashin, D. A. Vicic, Y. H. Budnikova, Eur. J. Org. Chem. 2012, 2012, 2114-2117.

[158] a) M. N. Khrizanforov, S. O. Strekalova, V. V. Grinenko, V. V. Khrizanforova, T. V. Gryaznova, Y. H. Budnikova, Russ. Chem. Bull. 2017, 66, 1446-1449; b) M. N. Khrizanforov, S. V. Fedorenko, S. O. Strekalova, K. V. Kholin, A. R. Mustafina, M. Y. Zhilkin, V. V. Khrizanforova, Y. N. Osin, V. V. Salnikov, T. V. Gryaznova, Y. H. Budnikova, Dalton Trans. 2016, 45, 11976-11982; c) Y. B. Dudkina, D. Y. Mikhailov, T. V. Gryaznova, S. G. Fattakhov, Y. G. Budnikova, O. G. Sinyashin, Russ. Chem. Bull. 2013, 62, 2362-2366.

[159] Q.-L. Yang, Y.-Q. Li, C. Ma, P. Fang, X.-J. Zhang, T.-S. Mei, J. Am. Chem. Soc. 2017, 139, 32933298.

[160] Y.-Q. Li, Q.-L. Yang, P. Fang, T.-S. Mei, D. Zhang, Org. Lett. 2017, 19, 2905-2908.

[161] A. Shrestha, M. Lee, A. L. Dunn, M. S. Sanford, Org. Lett. 2018, 20, 204-207.

[162] C. Ma, C.-Q. Zhao, Y.-Q. Li, L.-P. Zhang, X.-T. Xu, K. Zhang, T.-S. Mei, Chem. Commun. 2017, 53, 12189-12192.

[163] L. Ackermann, A. V. Lygin, Org. Lett. 2012, 14, 764-767.

[164] F. Xu, Y.-J. Li, C. Huang, H.-C. Xu, ACS Catal. 2018, 3820-3824.

[165] Y. Qiu, C. Tian, L. Massignan, T. Rogge, L. Ackermann, Angew. Chem. Int. Ed. 2018, 57, 58185822.

[166] S. De Sarkar, W. Liu, S. I. Kozhushkov, L. Ackermann, Adv. Synth. Catal. 2014, 356, 1461-1479.

[167] a) P. Gomes, C. Gosmini, J. Périchon, J. Org. Chem. 2003, 68, 1142-1145; b) P. Gomes, C. Gosmini, J. Périchon, Tetrahedron 2003, 59, 2999-3002; c) P. Gomes, C. Gosmini, J.-Y. Nédélec, J. Périchon, Tetrahedron Lett. 2002, 43, 5901-5903; d) E. Le Gall, C. Gosmini, J.-Y. Nédélec, J. Périchon, Tetrahedron Lett. 2001, 42, 267-269; e) H. Fillon, C. Gosmini, J.-Y. Nédélec, J. Périchon, Tetrahedron Lett. 2001, 42, 3843-3846; f) C. Gosmini, Y. Rollin, J. Y. Nédélec, J. Périchon, J. Org. Chem. 2000, 65, 6024-6026; g) P. Gomes, C. Gosmini, J.-Y. Nédélec, J. Périchon, Tetrahedron Lett. 2000, 41, 3385-3388.

[168] C. Tian, L. Massignan, T. H. Meyer, L. Ackermann, Angew. Chem. Int. Ed. 2018, 57, 2383-2387.

[169] S. Tang, D. Wang, Y. Liu, L. Zeng, A. Lei, Nat. Commun. 2018, 9, DOI:10.1038/s41467-4101803246-41464.

[170] G. Cera, L. Ackermann, Top. Curr. Chem. 2016, 374, 57-91.

[171] Y. Kommagalla, N. Chatani, Coord. Chem. Rev. 2017, 350, 117-135.

[172] a) D. M. Flanigan, F. Romanov-Michailidis, N. A. White, T. Rovis, Chem. Rev. 2015, 115, 93079387; b) O. Schuster, L. Yang, H. G. Raubenheimer, M. Albrecht, Chem. Rev. 2009, 109, 34453478.

[173] a) L. Raibaut, N. Ollivier, O. Melnyk, Chem. Soc. Rev. 2012, 41, 7001-7015; b) P. Tam James, J. $\mathrm{Xu}$, D. Eom Khee, Peptide Science 2004, 60, 194-205; c) C. W. Tornøe, C. Christensen, M. Meldal, J. Org. Chem. 2002, 67, 3057-3064.

[174] C.-J. Li, Acc. Chem. Res. 2009, 42, 335-344.

[175] K. Gao, P.-S. Lee, C. Long, N. Yoshikai, Org. Lett. 2012, 14, 4234-4237.

[176] a) G. Wittig, A. Krebs, Chem. Ber. 1961, 94, 3260-3275; b) G. Wittig, A. Krebs, R. Pohlke, Angew. Chem. 1960, 72, 324-324.

[177] V. R. Yatham, W. Harnying, D. Kootz, J.-M. Neudörfl, N. E. Schlörer, A. Berkessel, J. Am. Chem. Soc. 2016, 138, 2670-2677.

[178] a) X. Bugaut, F. Glorius, Chem. Soc. Rev. 2012, 41, 3511-3522; b) D. Enders, O. Niemeier, A. Henseler, Chem. Rev. 2007, 107, 5606-5655. 
[179] a) J. P. Wagner, P. R. Schreiner, Angew. Chem. Int. Ed. 2015, 54, 12274-12296; b) L. Schweighauser, M. A. Strauss, S. Bellotto, H. A. Wegner, Angew. Chem. Int. Ed. 2015, 54, 13436-13439; c) S. Grimme, P. R. Schreiner, Angew. Chem. Int. Ed. 2011, 50, 12639-12642; d) S. Grimme, R. Huenerbein, S. Ehrlich, ChemPhysChem 2011, 12, 1258-1261.

[180] Strategic Applications of Named Reactions in Organic synthesis, Elsevier Academic Press, London, 2005.

[181] G. Cahiez, A. Moyeux, Chem. Rev. 2010, 110, 1435-1462.

[182] C-H and C-C Activation by Cobalt and Ruthenium Catalysis, M. Moselage, PhD Thesis, GeorgAugust-Universität Göttingen (Göttingen), 2017.

[183] a) A. H. Hoveyda, A. R. Zhugralin, Nature 2007, 450, 243; b) A. K. Chatterjee, T.-L. Choi, D. P. Sanders, R. H. Grubbs, J. Am. Chem. Soc. 2003, 125, 11360-11370; c) A. Fürstner, Angew. Chem. Int. Ed. 2000, 39, 3012-3043.

[184] a) N. A. Butt, W. Zhang, Chem. Soc. Rev. 2015, 44, 7929-7967; b) B. M. Trost, M. L. Crawley, Chem. Rev. 2003, 103, 2921-2944.

[185] Modern Heterocyclic Chemistry, Wiley-VCH, Weinheim, 2011.

[186] Cobalt(III)-Catalyzed Allylation and Alkyne Annulation, J. Koeller, Master Thesis, Georg August Universität Göttingen (Göttingen), 2015.

[187] J. F. Daeuble, C. McGettigan, J. M. Stryker, Tetrahedron Lett. 1990, 31, 2397-2400.

[188] a) R. Chinchilla, C. Najera, Chem. Soc. Rev. 2011, 40, 5084-5121; b) R. Chinchilla, C. Nájera, Chem. Rev. 2007, 107, 874-922.

[189] H. C. Kolb, M. G. Finn, K. B. Sharpless, Angew. Chem. Int. Ed. 2001, 40, 2004-2021.

[190] a) N. Jin, C. Pan, H. Zhang, P. Xu, Y. Cheng, C. Zhu, Adv. Synth. Catal. 2015, 357, 1149-1153; b) C. Feng, T. P. Loh, Angew. Chem. Int. Ed. 2014, 53, 2722-2726; c) C. Feng, D. Feng, T.-P. Loh, Chem. Commun. 2014, 50, 9865-9868.

[191] Y. Wu, Y. Yang, B. Zhou, Y. Li, J. Org. Chem. 2015, 80, 1946-1951.

[192] a) J. Kaschel, D. B. Werz, Angew. Chem. Int. Ed. 2015, 54, 8876-8878; b) D. Fernández González, J. P. Brand, R. Mondière, J. Waser, Adv. Synth. Catal. 2013, 355, 1631-1639; c) P. Brand Jonathan, J. Charpentier, J. Waser, Angew. Chem. Int. Ed. 2009, 48, 9346-9349.

[193] I. Krossing, I. Raabe, Angew. Chem. Int. Ed. 2004, 43, 2066-2090.

[194] N. Sauermann, M. J. González, L. Ackermann, Org. Lett. 2015, 17, 5316-5319.

[195] H. K. Grover, T. P. Lebold, M. A. Kerr, Org. Lett. 2011, 13, 220-223.

[196] D. R. Stuart, M. Bertrand-Laperle, K. M. N. Burgess, K. Fagnou, J. Am. Chem. Soc. 2008, 130, 16474-16475.

[197] N. Okamoto, K. Takeda, R. Yanada, Org. Synth. 2014, 91, 27-38.

[198] L. Ackermann, H. K. Potukuchi, D. Landsberg, R. Vicente, Org. Lett. 2008, 10, 3081-3084.

[199] C-H Alkylations and Alkynylations Using Ruthenium, Nickel and Manganese Complexes, Z. Ruan, PhD Thesis, Georg-August-Universität Göttingen (Göttingen), 2017.

[200] L. Ackermann, A. V. Lygin, Org. Lett. 2011, 13, 3332-3335.

[201] Z. Ruan, N. Sauermann, E. Manoni, L. Ackermann, Angew. Chem. Int. Ed. 2017, 56, 3172-3176.

[202] R. J. Sundberg, in Heterocyclic Scaffolds II: Reactions and Applications of Indoles (Ed.: G. W. Gribble), Springer Berlin Heidelberg, Berlin, Heidelberg, 2010, 47-115.

[203] a) J. B. Lambert, Y. Zhao, R. W. Emblidge, L. A. Salvador, X. Liu, J.-H. So, E. C. Chelius, Acc. Chem. Res. 1999, 32, 183-190. b) J. B. Lambert, G. T. Wang, R. B. Finzel, D. H. Teramura, J. Am. chem. Soc. 1987, 109, 7838-7845. c) S. G. Wierschke, J. Chandrasekhar, W. L. Jorgensen, J. Am. Chem. Soc. 1985, 107, 1496-1500.

[204] N. Sauermann, T. H. Meyer, Y. Qiu, L. Ackermann, ACS Catal. 2018, submitted.

[205] C. Stang, F. Harnisch, ChemSusChem 2015, 9, 50-60.

[206] N. Sauermann, T. H. Meyer, C. Tian, L. Ackermann, J. Am. Chem. Soc. 2017, 139, 18452-18455;

[207] a) C.-C. Chang, L.-C. Chen, S.-J. Liu, Chang, J. Phys. Chem. B 2006, 110, 19426-19432; b) O. R. Brown, S. Chandra, J. A. Harrison, J. Electroanal. Chem. Interfacial Electrochem. 1972, 38, 185190.

[208] T. H. Meyer, ongoing PhD Thesis, Georg-August-Universität (Göttingen), 2017. 
[209] S. Santoro, A. Marrocchi, D. Lanari, L. Ackermann, L. Vaccaro, Chem. Eur. J. 2018, 20, DOI: 10.1039/C8G01115J.

[210] W.-J. Gao, W.-C. Li, C.-C. Zeng, H.-Y. Tian, L.-M. Hu, R. D. Little, J. Org. Chem. 2014, 79, $9613-$ 9618.

[211] R. Mei, N. Sauermann, J. C. A. Oliveira, L. Ackermann, J. Am. Chem. Soc. 2018, 140, DOI: 10.1021/jacs.8b03521.

[212] Y. Qiu, W. J. Kong, J. Struwe, N. Sauermann, T. Rogge, A. Scheremetjew, L. Ackermann, Angew. Chem. Int. Ed. 2018, 5828-5832.

[213] a) G. Song, X. Li, Acc. Chem. Res. 2015, 48, 1007-1020; b) T. Satoh, M. Miura, Chem. Eur. J. 2010, 16, 11212-11222; c) K. Fagnou, M. Lautens, Chem. Rev. 2003, 103, 169-196.

[214] a) T. J. Hansen, D. A. Crowl, Process Saf. Prog. 2010, 209-215; b) T. H. Pratt, Process Saf. Prog. 1993, 12, 203-205.

[215] a) Y. Lu, H.-W. Wang, J. E. Spangler, K. Chen, P.-P. Cui, Y. Zhao, W.-Y. Sun, J.-Q. Yu, Chem. Sci. 2015, 6, 1923-1927; b) A. Archambeau, T. Rovis, Angew. Chem. Int. Ed. 2015, 54, 1333713340; c) G. Zhang, H. Yu, G. Qin, H. Huang, Chem. Commun. 2014, 50, 4331-4334; d) G. Zhang, L. Yang, Y. Wang, Y. Xie, H. Huang, J. Am. Chem. Soc. 2013, 135, 8850-8853; e) D.-G. Yu, M. Suri, F. Glorius, J. Am. Chem. Soc. 2013, 135, 8802-8805; f) D. R. Stuart, P. Alsabeh, M. Kuhn, K. Fagnou, J. Am. Chem. Soc. 2010, 132, 18326-18339.

[216] E. Kudo, Y. Shibata, M. Yamazaki, K. Masutomi, Y. Miyauchi, M. Fukui, H. Sugiyama, H. Uekusa, T. Satoh, M. Miura, K. Tanaka, Chem. Eur. J. 2016, 22, 14190-14194.

[217] N. Sauermann, J. Loup, D. Kootz, V. R. Yatham, A. Berkessel, L. Ackermann, Synthesis 2017, 49, 3476-3484.

[218] Q. L. Yang, P. Fang, T. S. Mei, Chinese Journal of Chemistry 2018, 36, 338-352.

[219] N. Sauermann, R. Mei, L. Ackermann, Angew. Chem. Int. Ed. 2018, 57, 5090-5094.

[220] B. Sun, T. Yoshino, S. Matsunaga, M. Kanai, Chem. Commun. 2015, 51, 4659-4661.

[221] X. Y. Chen, L. Wang, M. Frings, C. Bolm, Org. Lett. 2014, 16, 3796-3799.

[222] S. Petrova, E. Jager, R. Konefal, A. Jager, C. G. Venturini, J. Spevacek, E. Pavlova, P. Stepanek, Polym. Chem. 2014, 5, 3884-3893.

[223] Chemical Kinetics and Reaction Mechanisms, 2nd ed. (Ed.: J. H. Espenson), McGraw-Hill, New York, 1995. 


\section{Erklärung}

Ich versichere, dass ich die vorliegende Dissertation im Zeitraum von November 2014 bis Juni 2018 am Institut für organische und biomolekulare Chemie der GeorgAugust-Universität Göttingen

Auf Anregung und unter Anleitung von

Prof. Dr. Lutz Ackermann

Selbstständig durchgeführt und keine anderen als die aangegebenen Hilfsmittel und Quellen verwendet habe.

Göttingen, den 